\title{
Microalgas y macroalgas bentónicas en un sistema costero Antártico (caleta Potter, islas Shetland del Sur): Efectos de la radiación ultravioleta y el pastoreo sobre la colonización y sucesión
}

Trabajo de tesis para optar por el grado de Doctor en Ciencias Naturales

\section{Gabriela Laura Campana}

Directora: Dra. Martha E. Ferrario

Codirectora: Dra. M. Liliana Quartino

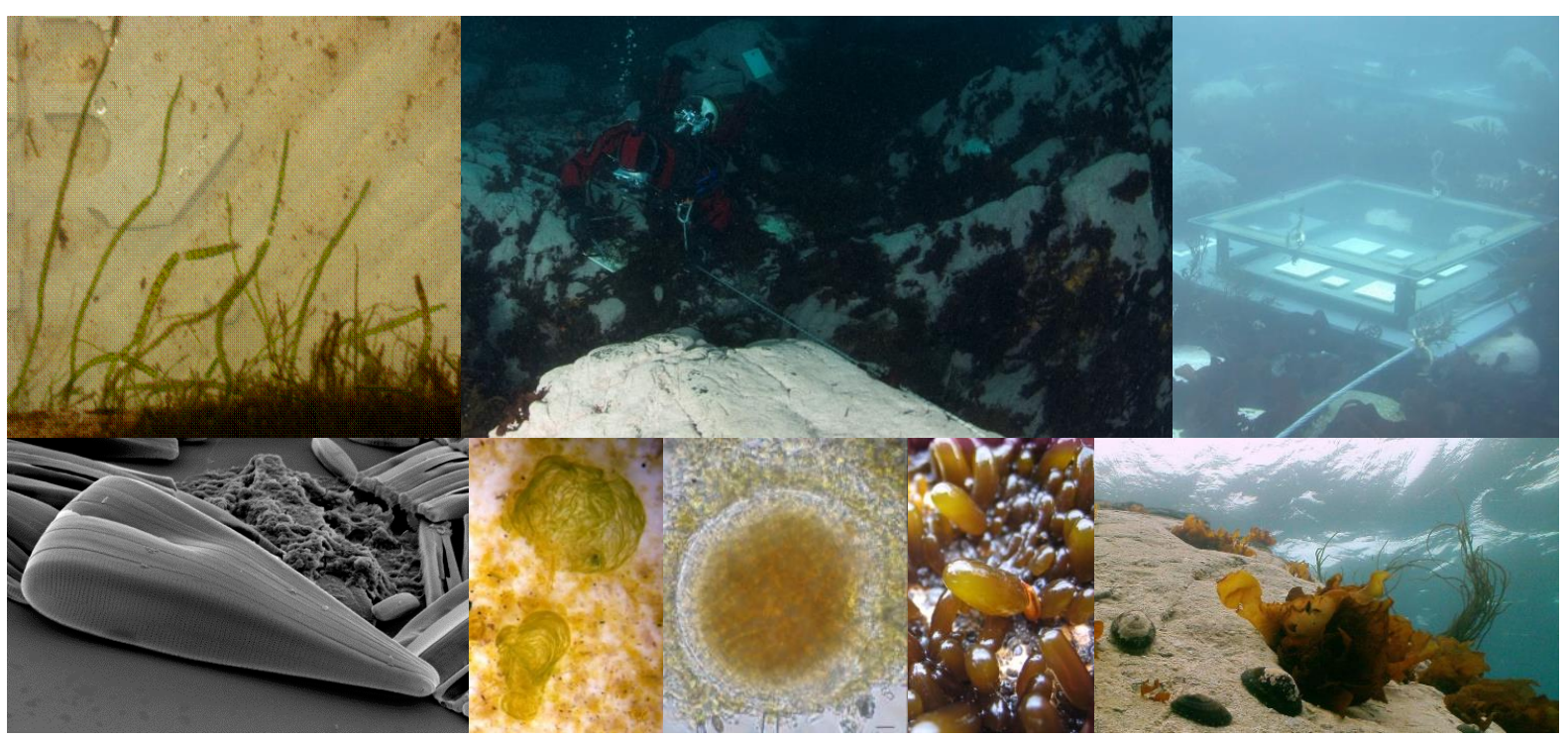


A mi familia

A los días más felices 


\section{Agradecimientos}

Me siento muy afortunada de haber llegado hasta aquí y ver que puedo dar gracias a tantas personas que me acompañaron y ayudaron en este camino:

A mis directoras de Tesis,

Martha Ferrario, por su generosidad y profundo compromiso con esta Tesis. Por brindarme su tiempo con tanto cariño, apoyarme en todo momento y enseñarme con tanta paciencia y humildad.

Lili Quartino, por su acompañamiento a cada paso y desde mi primera campaña. Por su entusiasmo y orientación permanentes y por brindarme generosamente sus conocimientos sobre las macroalgas antárticas y la vida en ese continente. Por las oportunidades que me dio y por creer en mí.

A mis directores de Beca de Postgrado de CONICET, Gustavo Ferreyra y Fernando Momo. Ambos me acompañaron y guiaron con la generosidad de los grandes.

A Fernando, especialmente gracias por su acompañamiento desde siempre, por enseñarme tanto de ecología y de la vida y por fomentar la confianza en mí misma.

A Gustavo, por su paciencia, por contagiarme entusiasmo con cada desafío y por ayudarme a pensar y cuestionarme.

Al Dr. Christian Wiencke del Alfred Wegener Institute de Alemania, por su apoyo y ayuda incondicionales.

A la Dra. Katharina Zacher, por compartir estos bellos años de amistad y cooperación.

A la Dra. Angela Wulff de la Universidad de Göteborg (Suecia) quien me permitió realizar estadías en su laboratorio y adentrarme en el conocimiento del microfitobentos antártico.

A la Dra. Irene Schloss, quien proveyó datos ambientales que emplee en esta Tesis, pero sobre todo, por creer en mí y abrirme las puertas del trabajo en la Antártida.

Al Dr. Edgardo Hernández, por ayudarme en el campo y en la toma de datos ambientales.

A la Dra. Patricia Gantes, quien me aconsejó con visión crítica y cariñosa.

Al Dr. Adrián Cefarelli por la generosidad con que me enseñó y muchas veces, acompañó a hacer innumerables preparados fijos.

A Oscar González, quien fue "faro" en cada campaña, por ayudarme siempre, por las charlas, los mates gloriosos, el acompañamiento en los muestreos en el bote, en los traslados, en las cuestiones logísticas inesperadas. Te quiero tanto, Nonino.

A los buzos que hicieron posible este trabajo. Gracias por el profesionalismo, la buena predisposición, la ayuda y las ideas para solucionar las cuestiones logísticas en un ambiente tan extremo.

A todos los científicos invernantes de la Base Carlini y a los científicos que tomaron datos o analizaron muestras cuando no pude estar: Dolores Deregibus, Laura Rigacci, al querido Augusto Thibaut, Gastón Aguirre, Gustavo Latorre (dos veces!), Maximiliano García, Juan 
Manuel Piscicelli, Alejandro Fernández Ajó, Ariel Morettini. A los integrantes de todas las dotaciones de la Base Carlini (Jubany, en los primeros años), gracias por los aereadores y bombas reparados, los traslados, los artilugios construidos; por lo grande y lo pequeño que hace que un proyecto se lleve a cabo en la Antártida.

A mis amigos y compañeros antárticos, por todas las campañas que forjaron amistades y las ganas de ayudar, dar lo mejor de cada uno y ser mi familia en la Antártida. Gracias especiales a Mecha, Mariana, Luciana, Eugenia, Oscar, Ale, Javi, Pete, Edy y Gastón con quienes compartí mis primeras campañas enfocadas en esta tesis.

A mis queridos compañeros del Instituto Antártico Argentino, quienes me acompañan en la cotidianeidad, por ayudarme siempre, por la alegría, la fuerza y el temple. A Tamara Czalbowski, a las chicas del grupo Macroalgas, Dolores Deregibus y Carolina Matula, a Silvia Rodríguez por estar siempre, siempre, siempre!, a Leo Cantoni, Willy Mercuri, a Alejandro Ulrich y Oscar González, y a Gaby Tossonotto, Marta Sierra y Edu Ruiz. A Oscar Zambrano, quien me ayudó en la confección de mapas. A todos los demás queridos compañeros que me preguntaron cariñosamente cómo iba esa Tesis.

A mis queridos amigos y compañeros del Laboratorio de Ecología de la Universidad Nacional de Luján. Gracias por estar, apoyarme y hacerme sentir tan querida. Por suplantarme en mis ausencias durante las campañas y estadías afuera. Por los árboles genealógicos, los almuerzos que estimularon mi pensamiento desde que me integré como estudiante y por hacerme sentir parte de una familia.

A los integrantes del Laboratorio de Ficología del Museo de La Plata, por recibirme tan afectuosamente, atender mis consultas y ayudarme para hacer eficiente mi tiempo allí. Mil gracias. A Patricia Sarmiento del Servicio de Microscopía Electrónica, por su predisposición y ayuda en la toma de las fotografías.

A las autoridades del Instituto Antártico Argentino y de la Dirección Nacional del Antártico a lo largo de estos años. A todos los logísticos y administrativos que colaboraron en los traslados y la llegada de muestras.

Al CONICET, al Alfred Wegener Institute, a la Universidad Nacional de La Plata, al Swedish Institute y la International Phycological Society por el apoyo financiero a través de subsidios o becas.

A la Universidad Nacional de Luján, en particular a Liliana Falco, Carlos Coviella y Jorge Mufato por apoyar mi trabajo y la inclusión de trabajos antárticos en la UNLu.

A mi familia amorosa e incondicional, a mi mamá Gemma y mi hermana Vanina, a mis tíos y mis primos. A mi tía Stella, la más generosa en el mundo. A mi papá, siempre conmigo. A mi hermana del alma Vero, a Osvi y mis sobris Moira y Tiago. Son todo.

A mis amigas y amigos de la vida, aquí y allá. Gracias por estar siempre presentes, aún en mis largas ausencias físicas. A Alicia por su guía, comprensión y apoyo en los momentos difíciles. A Santiago Doyle, por las charlas sobre ciencia y vida. A Laura Rigacci, por su generosidad y sabiduría.

A los creadores de la música que me acompañó en días y noches de trabajo, especialmente a Mariano Esain y Flopa Lestani. 
Parte de los resultados presentados en este trabajo de Tesis han sido publicados bajo los siguientes títulos:

Campana G.L., Momo, F., Quartino M.L. \& Ferreyra, G. 2008. Effects of UVR and grazing on biomass and primary production of subtidal benthic algae in Antarctica. Reports on Polar and Marine Research 571: 278-286. ISSN 1618-3193.

Zacher K. \& Campana G.L. 2008. UV and consumer effects on an intertidal and subtidal macroalgal assemblage: a comparative study. Reports on Polar and Marine Research 571: 287-294. ISSN 1618-3193.

Campana G.L., Zacher K., Fricke A., Molis M., Wulff A., Quartino M. L., Wiencke C. 2011. Drivers of colonization and succession in Polar benthic macro- and microalgal communities. (Capítulo 14, 399-320). En: C. Wiencke (ed.) Biology of Polar Benthic Algae. Walter de Gruyter GmbH \& Co, Berlín, Nueva York. 355 pp. ISBN 978-3-11022970-7.

Campana G.L., Zacher, K., Deregibus, D., Momo, F., Wiencke, C. \& Quartino M.L. 2017. Succession of Antarctic benthic algae (Potter Cove, South Shetland Islands): structural patterns and glacial impact over a four year period. Polar Biology. doi: 10.1007/s00300017-2197-x).

Otros artículos vinculados a esta Tesis:

Campana G.L., Quartino M.L., Yousif A. \& Wulff A. 2008. Effects of UV radiation and grazing on the structure of a subtidal benthic diatom assemblage in Antarctica. Reports on Polar and Marine Research 571: 302-310. ISSN 1618 - 3193.

Roleda, M., Zacher, K., Campana, G.L., Wulff, A., Hanelt, D., Quartino, M. L. \& Wiencke, C. 2008. Photosynthetic performance and impact of ultraviolet radiation on the reproductive cells of Antarctic macroalgae. Reports on Polar and Marine Research 571: 254-262. ISSN 1618-3193.

Roleda M., Campana, G.L., Wiencke, C., Hanelt, D., Quartino, M.L. \& Wulff, A. 2009. Sensitivity of Antarctic Urospora penicilliformis (Codiolales, Chlorophyta) to ultraviolet radiation is life stage dependent. Journal of Phycology 45: 600-609. doi: 10.1111/j.1529-8817.2009.00691.x

Becker S., Quartino M.L., Campana G.L., Bucolo P., Wiencke C. \& Bischof K. 2011. The biology of an Antarctic rhodophyte, Palmaria decipiens: recent advances. Antarctic Science 23: 419-430. doi: 10.1017/S0954102011000575.

\section{MARCO INSTITUCIONAL}

Los estudios desarrollados en esta Tesis se encuentran enmarcados dentro del Convenio de Cooperación Argentino-Alemán entre el Instituto Antártico Argentino (IAA) y el Alfred Wegener Institute for Polar and Marine Research (AWI). Parte de las actividades realizadas se realizaron en el marco de las Beca de Posgrado Tipo I (duración total: cinco años)(CONICET-DNA) y Beca Guest Scholarship Programme (Swedish Institute). Asimismo, se contó con las siguientes fuentes de financiamiento: Subsidio para Tesistas (FCNyM, UNLP, Exp. 347/05), DNA-IAA (PICTA 5/20012007, DNA-IAA (PICTA 7/2008-2011), ANPCyT-DNA (PICTO 0116/2012-2016), MINCyT- BMBF 2011 e IMCONet FP7-PEOPLE-2012-IRSES. 


\section{Índice}

RESUMEN

ABSTRACT

CAPÍTULO 1. INTRODUCCIÓN

1.1. Las algas marinas bentónicas en el ambiente antártico 2

1.2. Colonización y sucesión en ambientes bentónicos antárticos 6

1.3. Efectos de la UV sobre las comunidades de algas marinas bentónicas antárticas $\quad 7$

1.4. Efectos del pastoreo sobre las comunidades de algas marinas bentónicas 11 antárticas

1.5. Consideraciones para la formulación de los objetivos e hipótesis 12

Objetivos e hipótesis 13

$\begin{array}{ll}\text { Estructura general de la Tesis } & 14\end{array}$

Capítulo 2. Área de estudio y enfoque metodológico 15

2.1. Área de estudio 16

2.2. Enfoque metodológico 20

CAPÍTULO 3. FLORA BENTÓNICA

3.1 Introducción 22

3.2. Materiales y métodos 23

3.2.1. Flora diatomológica 23

3.2.2. Macroalgas 25

3.3. Resultados y discusión $\quad 26$

3.3.1. Microalgas 26

3.3.2. Macroalgas 93

$\begin{array}{ll}\text { 3.3.3. Consideraciones finales } & 111\end{array}$

$\begin{array}{ll}\text { 3.3.3.1. Diatomeas } & 111\end{array}$

$\begin{array}{ll}\text { 3.3.3.2. Macroalgas } & 115\end{array}$

CAPÍtUlo 4. PATRONES SUCESIONALES DE ALGAS MARINAS BENTÓNICAS A LARGO PLAZO 116

4.1. Introducción 117

$\begin{array}{ll}\text { 4.2. Materiales y métodos } & 120\end{array}$

$\begin{array}{ll}\text { Monitoreo de variables ambientales } & 120\end{array}$

Diseño y muestreo de las comunidades 121

$\begin{array}{ll}\text { Análisis estadísticos } & 125\end{array}$ 
$\begin{array}{ll}\text { 4.3. Resultados } & 126\end{array}$

$\begin{array}{ll}\text { Monitoreo de variables ambientales } & 126\end{array}$

Patrones generales de la composición de especies 131

$\begin{array}{ll}\text { Cobertura de algas e índices ecológicos } & 135\end{array}$

$\begin{array}{ll}\text { Cambios en la composición de taxa en el tiempo } & 136\end{array}$

4.4. Discusión 138

$\begin{array}{lr}\text { Patrones estructurales en la sucesión de algas submareales } & 139\end{array}$

Consideraciones acerca del clímax en comunidades de algas marinas bentónicas 142 en Antártida

CAPÍTULO 5. EFECTOS DE LA RADIACIÓN ULTRAVIOLETA Y EL PASTOREO SOBRE LA COLONIZACIÓN Y SUCESIÓN DE MICROALGAS Y MACROALGAS BENTÓNICAS

5.1. Introducción

$\begin{array}{ll}\text { 5.2. Materiales y métodos } & 149\end{array}$

$\begin{array}{ll}\text { Diseño experimental } & 149\end{array}$

$\begin{array}{lr}\text { Tratamientos } & 149\end{array}$

$\begin{array}{ll}\text { Mediciones de radiación solar } & 152\end{array}$

$\begin{array}{ll}\text { Análisis de laboratorio } & 152\end{array}$

Diversidad, riqueza y equitatividad 153

Análisis estadísticos 154

5.3. Resultados 155

$\begin{array}{ll}\text { Radiación atmosférica y subacuática } & 155\end{array}$

$\begin{array}{ll}\text { Presencia de consumidores } & 156\end{array}$

$\begin{array}{ll}\text { Biomasa y cobertura macroscópica } & 158\end{array}$

$\begin{array}{ll}\text { Cobertura microscópica } & 164\end{array}$

$\begin{array}{ll}\text { Índices ecológicos y composición } & 169\end{array}$

$\begin{array}{ll}\text { Ensambles de diatomeas } & 173\end{array}$

$\begin{array}{ll}\text { Densidad de diatomeas } & 173\end{array}$

$\begin{array}{ll}\text { Composición taxonómica } & 174\end{array}$

Índices ecológicos y composición 178

5.4. Discusión 183

$\begin{array}{ll}\text { Patrones generales de la colonización y sucesión } & 184\end{array}$ Efectos de la UV y el pastoreo sobre la biomasa y composición taxonómica a
nivel macroscópico 
Efectos de la UV y el pastoreo sobre la cobertura, la diversidad y la composición de las comunidades a nivel microscópico

Efectos de la UV y el pastoreo sobre los ensambles de diatomeas

Efectos combinados de la UV y el pastoreo

Efectos de la UV y el pastoreo en el tiempo

Corolario 195

CAPÍtulo 6. Conclusiones

Aspectos florísticos 198

Patrones generales de la colonización y etapas siguientes de la sucesión 198

Efectos de la UV y el pastoreo: factores que controlan la colonización y sucesión en etapas tempranas

Consideraciones metodológicas

Consideraciones finales y perspectivas futuras 


\section{Resumen}

Las algas marinas bentónicas comprenden los grupos de microalgas y macroalgas asociadas al fondo marino y cumplen un papel fundamental en el ecosistema costero antártico. Son importantes productores primarios que constituyen fuente de alimento para organismos asociados al bentos y en particular las macroalgas, son hábitat y refugio, sustrato para el desarrollo de epífitas, y representan un aporte significativo en materia orgánica particulada y disuelta para la red trófica costera. Entre las microalgas bentónicas, las diatomeas son el grupo dominante, y su ecología y taxonomía han sido aún poco estudiadas. En esta Tesis se identificaron los patrones sucesionales de algas marinas bentónicas en un ambiente submareal costero antártico, con especial énfasis en los efectos de la radiación ultravioleta (UV, $280-400 \mathrm{~nm}$ ) y el pastoreo sobre etapas tempranas de la sucesión, llevando a cabo una caracterización taxonómica detallada de las diatomeas y macroalgas bentónicas que integran estas comunidades en el curso de la colonización y etapas siguientes de la sucesión. Los objetivos específicos fueron i) identificar y caracterizar taxonómicamente la flora de microalgas y macroalgas marinas bentónicas en procesos de colonización y sucesión, ii) describir parámetros estructurales de la comunidad de algas marinas bentónicas en el curso de la sucesión y, iii) evaluar el efecto de la radiación ultravioleta y el pastoreo sobre atributos estructurales de una comunidad de microalgas y macroalgas bentónicas en etapas tempranas de la sucesión. El área elegida para este estudio fue caleta Potter, islas Shetland del Sur, Antártida.

Se llevó a cabo un análisis taxonómico detallado de las diatomeas mediante microscopia óptica y electrónica, y de las macroalgas, en particular sobre los pequeños estadios iniciales, mediante microscopía estereoscópica y óptica. Se identificaron 40 taxa de diatomeas y 13 taxa de macroalgas, citándose ocho registros de diatomeas y dos registros de macroalgas nuevos para ambientes bentónicos de caleta Potter.

Para el estudio del proceso sucesional, se emplazaron sustratos artificiales en el submareal a $3 \mathrm{~m}$ de profundidad y se determinó su composición específica mediante un experimento de cuatro años de duración. Se realizaron muestreos fotográficos mensuales y análisis detallados en el laboratorio, durante primavera y verano. Las comunidades estuvieron dominadas por algas bentónicas, determinándose un cambio interanual en los ensambles. Se identificaron a las macroalgas Palmaria decipiens y Monostroma hariotii en etapas tempranas y a Phaeurus antarcticus, Iridaea cordata y algas rojas crustosas (Corallinaceae) en las etapas más avanzadas. La especie Adenocystis utricularis presentó una gran abundancia y probablemente tenga una elevada capacidad competitiva siendo capaz de inhibir el reclutamiento de otras especies. Las comunidades procedieron hacia mayores valores de diversidad en el tiempo, aunque una vez alcanzada la máxima cobertura y complejidad tridimensional, interacciones competitivas pudieron haber causado liberación de espacio y la colonización por otras especies. Luego de cuatro años, los ensambles fueron similares a las comunidades circundantes que probablemente se encuentren sostenidas en etapas tempranas de la sucesión, a bajas profundidades. 
Se estudiaron experimentalmente los efectos de la UV ambiental y el pastoreo sobre comunidades de algas marinas bentónicas en etapas tempranas de la sucesión mediante la realización de un experimento de 73 días de duración. Se emplazaron 32 unidades experimentales a una profundidad promedio de $2 \mathrm{~m}$ en el submareal superior. Cada unidad experimental consistió en una estructura de base cuadrada, de $50 \mathrm{~cm}$ de lado y $10 \mathrm{~cm}$ de alto. Cada una de ellas contenía ocho placas de cerámico levemente rugoso: cuatro de $100 \mathrm{~cm}^{2}$ y cuatro de $25 \mathrm{~cm}^{2}$ que actuaron como sustratos para la colonización. Para evaluar el efecto de la UV, las unidades experimentales fueron cubiertas por diferentes tipos de filtros ópticos, incluyendo los siguientes tratamientos: PAR (radiación fotosintéticamente activa), PAR + UV-A y PAR + UV-A + UV-B. Para analizar el efecto del pastoreo, se emplearon unidades experimentales sin clausura (pastoreadas), en las que se permitió el libre acceso de los herbívoros a través de los laterales de las unidades experimentales y con clausura (no pastoreadas), en las que la entrada de los herbívoros se limitó mediante la clausura lateral utilizando una red de $1 \mathrm{~mm}$ de malla. Se trabajó con cuatro réplicas por tratamiento, incluyendo dos tratamientos control. Se determinó la biomasa, la composición taxonómica algal y la riqueza, diversidad y equitatividad de las comunidades empleando los sustratos de $100 \mathrm{~cm}^{2}$. Con el objeto de obtener un análisis detallado de los ensambles de diatomeas, se realizaron conteos celulares a partir de las muestras obtenidas de los sustratos de $25 \mathrm{~cm}^{2}$, determinándose la composición taxonómica, la riqueza, equitatividad y diversidad de los ensambles. El pastoreo se evidenció como el principal factor estructurante de las comunidades en etapas tempranas de la sucesión, compuestas por diatomeas, algas verdes filamentosas y estadios iniciales de algas rojas. El pastoreo redujo la biomasa y cobertura macroscópica de las comunidades, e introdujo cambios en su composición taxonómica. En particular, causó cambios en la fisonomía de los ensambles, por consumo de grupos de diatomeas filamentosas y pedunculadas. La radiación ultravioleta afectó el establecimiento de algas verdes filamentosas y de propágulos de algas rojas, mientras que las diatomeas no fueron afectadas. Por otro lado, el pastoreo sobre las diatomeas puede disminuir la competencia por la luz (y/o el espacio) y por lo tanto, favorecer el establecimiento y crecimiento de ciertas algas rojas. Se observaron efectos más intensos del pastoreo en los tratamientos en los que la UV o la UV-B estuvieron ausentes. Una disminución en la palatabilidad algal o un efecto negativo directo sobre los herbívoros, que disminuyen su densidad o su actividad en estas condiciones podrían ser explicaciones para estas tendencias. Los efectos de la UV y el pastoreo dependieron del grado de desarrollo de las comunidades, siendo más intensos durante la primera mitad del experimento. Las etapas tempranas de la sucesión demostraron ser particularmente vulnerables a la UV y el pastoreo.

En este ambiente antártico severamente afectado por los fenómenos asociados al cambio global, los patrones sucesionales de las algas bentónicas pueden entonces modificarse debido a la susceptibilidad de las especies a factores de estrés ambiental o en las interacciones biológicas, lo cual podría introducir modificaciones en los flujos de materia y energía en la red trófica costera. 


\begin{abstract}
Marine benthic algae consist of the groups of microalgae and macroalgae living on the marine benthos. Playing a key role on coastal Antarctic ecosystems, they are central primary producers that constitute and important food source for benthic organisms. In particular, macroalgae provide habitat and shelter, act as a substrate for epiphytic communities and are also a significant source of particulate and dissolved organic matter for the coastal food web. Diatoms are the dominant group in benthic microalgae assemblages, being their ecology and taxonomy not fully studied yet.

In this Thesis, the successional patterns of benthic algal communities were identified for a rocky subtidal Antarctic coastal area, with special emphasis on the effects of ultraviolet radiation and grazing on early successional stages. Additionally, a thorough taxonomic characterization of diatoms and macroalgae was carried out. The specific objectives of this study were: i) to identify and characterize taxonomically the benthic microalgae and macroalgae flora in the process of colonization and succession, ii) to describe structural attributes of the community of benthic algal communities over the process of succession and, iii) to evaluate the effects of ultraviolet radiation (UV-A and UV-B) and grazing on structural attributes of these communities at early stages of succession. This study was carried out in Potter Cove, South Shetland Islands, Antarctica.

A detailed taxonomic analysis was performed using optical and electronical microscopy for diatoms identification and using optic and stereoscopic microscopy for macroalgae adults and small initial stages. A total of 40 diatom taxa and 13 macroalgae taxa were identified, with eight diatom taxa and two macroalgae taxa as new records for the benthic habitats of Potter Cove.

To study the successional process, artificial substrates were installed in the subtidal at $3 \mathrm{~m}$ depth. The species composition was then assessed over a period of four years. Tiles were analysed in spring and summer, in the laboratory and by year-round photographic monitoring. Benthic algae dominated the communities, which exhibited an inter-annual change in composition. Palmaria decipiens and Monostroma hariotii were identified at early stages whereas Phaeurus antarcticus, Iridaea cordata and red crustose algae (Corallinaceae) were more characteristic of later stages. Adenocystis utricularis proved to be dominant, likely displaying a high competitive capacity, and it may impede the recruitment of other species. Communities showed a tendency to a higher diversity over time, but once highest cover and tri-dimensional complexity were achieved, competitive interactions may have released space, allowing the colonization by other species. After four years, assemblages resembled the surrounding communities, which are probably sustained at early successional stages at this low depth range.

The combined effects of ambient UV and grazing on early successional stages of benthic algal communities were studied experimentally. Thirty-two experimental units bearing artificial substrates were placed at $2 \mathrm{~m}$ depth in an upper subtidal site. Experimental units consisted of a squared based structure ( $50 \mathrm{~cm}$ side, $10 \mathrm{~cm}$ height) bearing eight ceramic tiles: four $100 \mathrm{~cm}^{2}$ and four $25 \mathrm{~cm}^{2}$ surface area. Cut-off filters were used for the irradiance treatments, including the following treatments: PAR (photosynthetically active radiation), PAR + UV-A and PAR + UV-A + UV-B. Grazing treatments
\end{abstract}


consisted on open (grazed treatments) and closed (ungrazed treatments) experimental units. Two control treatments were included; every treatment comprised four replicates. Biomass, taxonomic composition, richness, equitability and diversity was analysed using the $100 \mathrm{~cm}^{2}$ tiles. A detailed analysis of diatom assemblages was performed using the $25 \mathrm{~cm}^{2}$ tiles, by means of cell counting, taxonomic composition, richness, equitabiliy and diversity. Grazing was identified as the main structuring force of the benthic algal communities in early stages of succession. These communities are composed by diatoms, green algal filaments and red algal germlings. Grazers reduced biomass and the macroscopic cover causing changes in the taxonomic composition. In particular, grazers exerted a change in the physiognomy of the assemblages by consuming filamentous and pedunculated diatoms. UV radiation affected the establishment of green algal filaments and propagules of red macroalgae, whereas diatoms were unaffected. Furthermore, grazing on diatoms can reduce competition for light (and/or space) and favour the establishment and growth of certain red macroalgae. Some of the observed grazing effects were more intense when UV (or UV-B) was absent. It can be hypothesized that a reduction in algal palatability or a direct negative UV effect on grazers, which reduce their density or activity under these conditions, could be explanations for the observed trends. UV and grazing effects depended on the community developmental stage, being more intense during the first half of the experimental period. In general, early stages of succession were shown to be highly vulnerable to UV radiation and grazing.

This Antarctic coastal area is severely affected by global change phenomena. As a result, patterns of succession may change due to species specific susceptibilities to environmental stress factors and changes in biotic interactions, which may cause modifications of the energy and matter flows through the coastal food web. 
CAPÍTULO 1

\section{Introducción}




\subsection{Las algas marinas bentónicas en el ambiente antártico}

Las algas marinas bentónicas comprenden los grupos de microalgas y macroalgas asociadas al fondo marino y cumplen un papel fundamental en el ecosistema costero antártico. Son importantes productores primarios (Mc Minn et al. 2010, Wiencke \& Amsler 2012) que constituyen fuente de alimento para organismos asociados al bentos (Brêthes et al. 1994, Blazewicz-Paszkowycz \& Ligowski 2002, Iken et al. 1997, 1998, Iken 1999, Amsler et al. 2005) y en particular las macroalgas, representan un aporte significativo en materia orgánica particulada y disuelta para la red trófica costera (Reichardt \& Dieckmann 1985, Fischer \& Wiencke 1992, Marina et al. 2018).

La estructura y funcionamiento de estas comunidades está en gran parte determinada por las características climáticas, físicas y ambientales que diferencian a la Antártida del resto de los continentes. La Antártida es un continente rodeado por la Corriente Circumpolar Antártica (CCA) que circula en sentido ciclónico impulsada por los vientos preponderantes del oeste (Mann \& Lazier 1991). Hacia el norte, el Frente Polar Antártico o Convergencia Antártica constituye el límite que separa a las aguas frías antárticas de los océanos Atlántico, Pacífico e Índico (Mann \& Lazier, 1991, Orsi et al. 1995). La historia geológica y climática de esta región y las antes mencionadas particulares condiciones oceanográficas han influido en la composición de la flora marina bentónica antártica, que se caracteriza por un elevado nivel de endemismo entre las macroalgas (Clayton 1994, Wulff et al. 2011, Zacher et al. 2011).

La región antártica no sólo se caracteriza por las bajas temperaturas medias sino por una marcada estacionalidad en las condiciones de luz, presentando variaciones extremas de irradiancia y cambios de la longitud del día a lo largo del año. Las algas marinas bentónicas, por lo tanto, están expuestas a extensos periodos de oscuridad total o condiciones de luz muy bajas, que pueden acentuarse por la presencia de hielo marino y nieve (Kirst \& Wiencke 1995, Wiencke et al. 2007, Zacher et al. 2011). Estas condiciones cambian drásticamente en los meses de primavera -particularmente luego de la ruptura de la cobertura de hielo marino- en los que las aguas se caracterizan por una elevada transparencia para luego, en los meses de verano, disminuir debido a la existencia de blooms de fitoplancton y el ingreso de sedimento de origen terrestre proveniente del agua de deshielo (Gómez et al. 2011, Zacher et al. 2011). Las algas que habitan el bentos antártico están adaptadas a condiciones de baja luminosidad y, además, deben tolerar condiciones de luz elevada tanto de radiación fotosintéticamente activa (PAR, 400-700nm) como de radiación ultravioleta (UV, $280-400 \mathrm{~nm}$ ) particularmente durante la primavera y principios del verano (Karsten et al. 2011, Gómez et al. 2011). En el caso de las macroalgas, se ha 
establecido que su grado de adaptación a la baja luminosidad determina su límite inferior de distribución vertical (Kirst \& Wiencke 1995), mientras que el límite superior está parcialmente

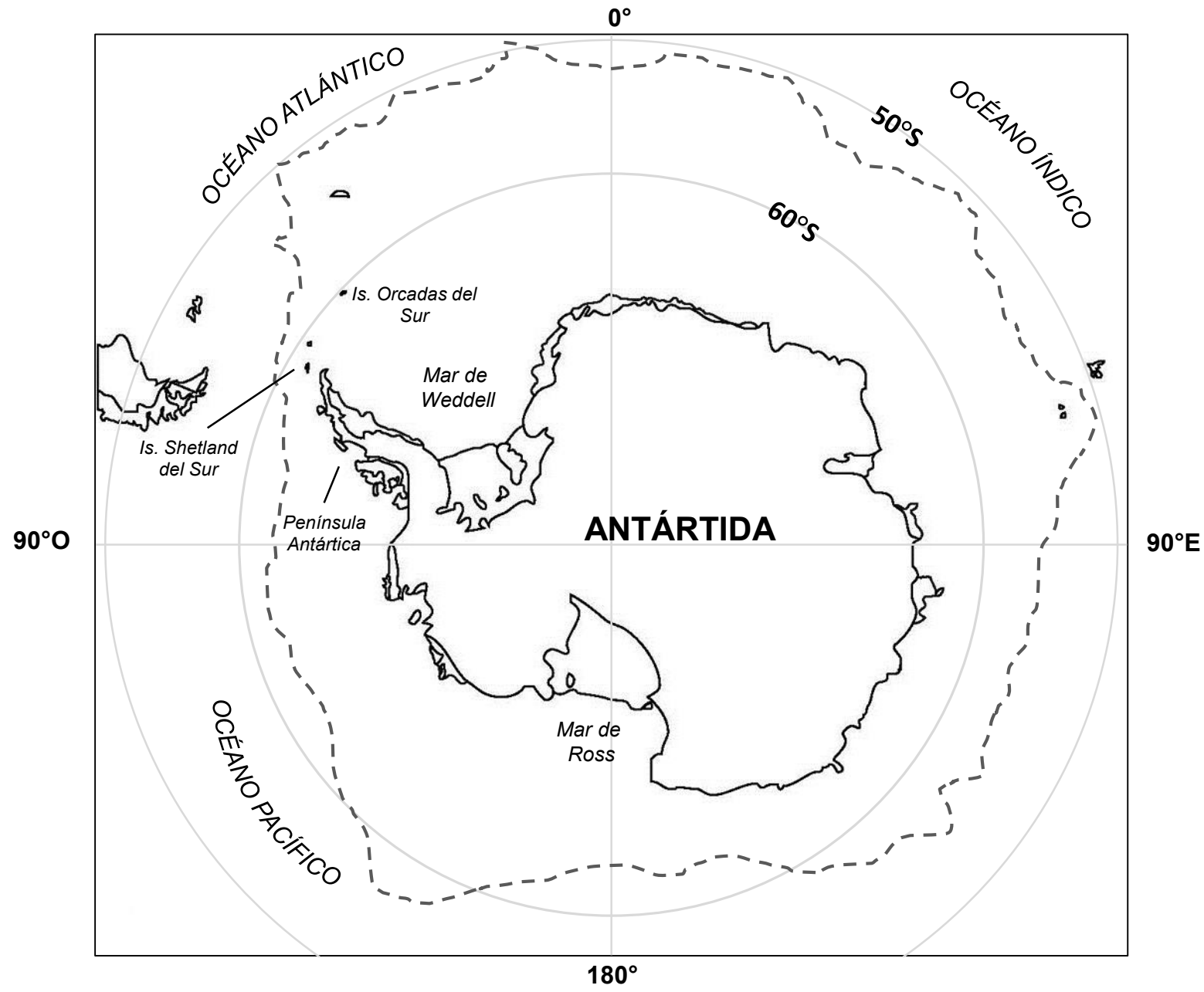

Fig. 1.1. Antártida. Se indica la ubicación de la Península Antártica y otros sitios mencionados en esta Tesis. Se señala la localización del Frente Polar (línea discontinua). Adaptado de Aguirre (2015).

determinado por su capacidad para tolerar el estrés provocado por el exceso de luz (Hanelt et al. 1997, Wiencke \& Clayton 2002). Entre las microalgas, las diatomeas bentónicas poseen una gran capacidad de aclimatación tanto a condiciones de baja como de elevada irradiancia (compilado en Gómez et al. 2011).

Asimismo, las comunidades bentónicas antárticas están expuestas a factores de disturbio tales como la abrasión por hielo y la turbulencia producida por las mareas y el oleaje (Barnes \& Conlan 2007, Campana et al. 2011, Zacher et al. 2011). En particular, los ambientes intermareales son además afectados por marcados cambios de salinidad, temperatura e irradiancia, entre otros, por lo que las comunidades de macroalgas se desarrollan principalmente en el submareal, donde estos cambios son menos pronunciados (Wiencke et al. 2007). Las áreas afectadas por la abrasión por hielo son colonizadas repetidamente (Barnes \& Conlan 2007, Zacher et al. 2011) y se postula que la influencia de este factor disminuye al aumentar la profundidad, determinando en gran parte la estructura y 
complejidad de los ensambles de macroalgas (Kim 2001, Quartino et al. 2005, Wulff et al. 2011).

\section{Microalgas}

En los ambientes costeros marinos antárticos, las microalgas integran tres fuentes principales de producción primaria: el fitoplancton, las microalgas asociadas al hielo y el microfitobentos (Gilbert 1991a,b). De todas ellas, el microfitobentos en sustratos rocosos marinos ha sido el menos estudiado (Brêthes et al. 1994, Zacher et al. 2007b).

El fitoplancton es la comunidad que ha recibido la mayor atención y por ello el más conocido. Desde mitad del siglo XIX (Hooker 1847), numerosos trabajos han abordado su estudio en aguas abiertas y costeras antárticas. Una de las primeras revisiones sobre la distribución, productividad y ecología del fitoplancton ha sido realizada por El-Sayed (1968), siendo intensamente estudiado hasta la actualidad (Horner 1984, Priddle 1990, Helbling et al. 1994, Garibotti et al. 2003, 2005, Olguín \& Alder 2011, Schloss et al. 2012, 2014, entre otros).

Los estudios referidos a las microalgas del hielo han demostrado que estas pueden contribuir significativamente a la producción primaria en ambientes costeros (Palmisano \& Sullivan 1983, Mc Minn et al. 2010). Asimismo, pueden crear un inóculo potencial para la flora algal marina cercana al borde del hielo (Everitt \& Thomas 1986, Wulff et al. 2011) y podrían contribuir a la biomasa del microfitobentos (Mc Minn et al. 2004). En los últimos años se abordó también el posible efecto de los témpanos sobre las comunidades planctónicas adyacentes (Cefarelli et al. 2011, 2016, Vernet et al. 2011, Ferrario et al 2012).

El conocimiento del microfitobentos antártico es escaso, particularmente comparado con la información que se dispone respecto a las comunidades de macroalgas (Wulff et al. 2011). Las microalgas bentónicas habitan fondos blandos, rocosos o viven como epifitas sobre macroalgas. Los trabajos sistemáticos y ecológicos son relativamente limitados y se han enfocado principalmente en ambientes de fondos blandos, ocupándose de la producción primaria y de la estacionalidad de la biomasa (Dayton et al. 1986, Gilbert 1991a, b, Knox 1994, Mc Minn et al. 2004, 2010, Al Handal \& Wulff 2008a, Atencio et al. 2008, entre otros), puntualizando en ellos la dominancia de diatomeas (Wulff et al. 2011). Cabe destacar que, en ausencia de hielo marino, el microfitobentos puede aportar hasta el $90 \%$ de la producción primaria microalgal (Mc Minn et al. 2010). Asimismo, las diatomeas bentónicas representan una fuente de alimento para consumidores pelágicos y bentónicos, particularmente cuando son resuspendidas por procesos de mezcla vertical causados por el viento (Ahn et al. 1997, Blazewicz-Paszkowycz \& Ligowski 2002).

En los fondos rocosos, particularmente dominados por macroalgas, el microfitobentos ha sido poco estudiado (Brêthes et al. 1994, Klöser 1998). Se señala su 
importancia como fuente de alimento para gasterópodos (Brêthes et al. 1994, Kim 2001), y en estos ambientes, las diatomeas epífitas sobre macroalgas han sido investigadas con mayor detalle (Thomas \& Jiang 1986, Al Handal \& Wulff 2008b, Majewska et al. 2013a,b, 2015, 2016, Majewska \& De Stefano 2015).

A pesar de la importancia que las diatomeas bentónicas revisten en los ecosistemas costeros antárticos, su taxonomía, distribución, biodiversidad y ecología, permanecen aún poco conocidas (Wulff et al. 2011, Majewska et al. 2016).

\section{Macroalgas}

Particularmente en el oeste de la Península Antártica las zonas costeras rocosas se encuentran colonizadas por macroalgas que alcanzan elevada biomasa y cobertura (Wiencke \& Clayton 2002). Además de revestir una gran importancia como fuente de alimento directa e indirecta, constituyen el hábitat de varios grupos de organismos bentónicos tales como anfípodos (Takeuchi \& Watanabe 2002, Huang et al. 2007, Aumack et al. 2011) y gasterópodos (Amsler et al. 2015) e incluso pueden proveer refugios químicos contra predadores (Amsler et al. 1999). Asimismo, las macroalgas son sustratos biológicos sobre los que se desarrollan comunidades de diatomeas epífitas (Majewska et al. 2016). En este sentido pueden ser consideradas especies fundacionales en este sistema (foundation species sensu Dayton 1972).

Las macroalgas antárticas han estado aisladas de otras regiones biogeográficas y esto se ha señalado como causa de un relativamente elevado nivel de endemismo en este grupo (Clayton 1994, Hurd et al. 2014). La riqueza de especies es mayor en la Antártida Occidental, particularmente en la Península Antártica, las Islas Shetland del Sur y las Islas Orcadas del Sur (Wiencke \& Clayton 2002), el número de especies disminuye hacia Antártida Oriental, y es mínimo a elevadas latitudes, con una distribución que se extiende hasta el sur del Mar de Ross, a aproximadamente $77^{\circ} \mathrm{S}$ (Wiencke \& Clayton 2002, Wiencke \& Amsler 2012).

Un rasgo característico de los ambientes submareales antárticos es la ausencia de bosques de Laminariales (Moe \& Silva 1977). Este orden es reemplazado ecológicamente por grandes algas pardas del orden Desmarestiales, que se considera se han originado en la Antártida y radiado hacia el Hemisferio Norte (Clayton 1994, Wulff et al. 2011). En particular, las especies de este orden Himantothallus grandifolius, Desmarestia anceps y $D$. menziesii dominan el sustrato rocoso debajo de la zona más afectada por la abrasión por hielo y pueden aportar hasta el $80 \%$ de la biomasa algal en zonas costeras del oeste de la Península Antártica (Wiencke \& Clayton 2002, Quartino \& Boraso de Zaixso 2008). 


\subsection{Colonización y sucesión en ambientes bentónicos antárticos}

Los estudios iniciales de las comunidades de algas bentónicas antárticas consistieron en descripciones de su distribución geográfica y zonación vertical (detallado en Wulff et al. 2011). La información sobre los procesos y factores que determinan estos patrones fueron menos explorados, particularmente para el caso del microfitobentos (Cunningham \& Mc Minn 2004, Cunningham et al. 2005). La gran mayoría de los estudios ecológicos se centraron en el macrozoobentos (Barnes \& Conlan 2007, Dayton et al. 2016 y referencias) y particularmente, el efecto de la abrasión por hielo sobre la estructura y diversidad de estas comunidades han sido el foco de atención (Gutt 2001, Piepenburg 2005, Teixidó et al. 2007).

Los estudios sobre las comunidades de macroalgas bentónicas en fondos rocosos han sido principalmente de naturaleza observacional, correlacionando patrones de diversidad con los factores potenciales que los determinarían, tales como las características del sustrato, la irradiancia y los nutrientes (Amsler et al. 1995, Brouwer et al. 1995, Quartino et al. 2001, 2005) así como la presencia de cobertura de hielo marino (Johnston et al. 2007), entre otros. Para el caso del microfitobentos en sustratos rocosos, la escasa información proviene del estudio de variaciones temporales de la biomasa de microalgas (Brêthes et al. 1994) y de la distribución de diatomeas bentónicas en diferentes hábitats (Klöser 1998).

Los estudios sobre patrones sucesionales en el bentos son mucho más escasos y se enfocaron principalmente en los ensambles de invertebrados sésiles, mediante el clareo de áreas submareales o la instalación de sustratos artificiales seguidos de observaciones directas o análisis de fotografías subacuáticas (compilados en Barnes \& Conlan 2007, Lagger et al. 2017). Estos estudios señalan la prevalencia de procesos lentos de colonización del bentos antártico, aunque se han registrado eventos de colonización masiva (Barnes \& Conlan 2007).

En ambientes dominados por macroalgas, la identidad y abundancia relativa de las especies registradas en ambientes con distinto grado de disturbio se han utilizado para realizar inferencias acerca de los estadios sucesionales de las comunidades (Klöser et al. 1996, Quartino et al. 2005). Por ejemplo, en caleta Potter, la presencia del alga verde Monostroma hariotii junto a diatomeas coloniales en ambientes severamente afectados por el hielo indicarían etapas tempranas de la sucesión (Klöser et al. 1996). A su vez, la coexistencia de parches en diferentes estadios sucesionales -mediados por la abrasión por hielo- ha sido postulada como la causa de una elevada diversidad a profundidades intermedias (5 a 10 m) (Quartino et al. 2005). Sin embargo, no existe información acerca de los patrones de sucesión de las algas marinas bentónicas a partir de la generación de espacio nuevo en el ambiente submareal. 


\section{Etapas tempranas de la sucesión}

Las bacterias, las algas unicelulares y los propágulos de macroalgas son colonizadores tempranos en los ambientes marinos rocosos (Connell 1987, Wahl 1989). Algunos de estos colonizadores iniciales pueden afectar positiva o negativamente el reclutamiento 0 establecimiento de la macrobiota (Wahl 2009). En particular, las diatomeas pueden interactuar con los propágulos de macroalgas favoreciendo o inhibiendo su crecimiento (Huang \& Boney 1985, Noël et al. 2009). Por lo tanto, para lograr un conocimiento completo del proceso de sucesión a largo plazo, la composición del microfitobentos del sustrato rocoso debe ser analizada conjuntamente, en particular durante los estadios menos avanzados, en los que este grupo puede ser dominante (Wahl et al. 2004, Fricke et al. 2008).

En particular, las esporas y estadios iniciales de macroalgas son particularmente sensibles a factores de estrés ambiental, tales como la UV (Coehlo et al. 2000, Karsten et al. 2011). Asimismo, las comunidades de algas bentónicas en etapas tempranas pueden ser particularmente vulnerables al pastoreo, que puede actuar acelerando o retardando los procesos sucesionales (Farrel et al. 1991, Sousa \& Connell 1992), por lo que se espera que su efecto sea más intenso en etapas tempranas de la sucesión. Como hemos mencionado, en la Antártida, la abrasión por hielo causa frecuentes eventos de recolonización (Campana et al. 2011, Wulff et al. 2011). Sin embargo, hasta el momento, no se ha evaluado el efecto simultaneo de factores ambientales y biológicos sobre la colonización y etapas tempranas de la sucesión para el ambiente submareal (Zacher et al. 2007a,b).

\subsection{Efectos de la radiación ultravioleta sobre las comunidades de algas marinas bentónicas antárticas}

Antártida es una de las regiones más afectadas por la disminución estacional de la concentración del ozono estratosférico que ocurre particularmente sobre las regiones polares (Whitehead et al. 2000) y que ha incrementado la radiación ultravioleta B (UV-B, 280-315 nm) que alcanza la superficie terrestre. El adelgazamiento de la capa de ozono sobre esta región se conoce comúnmente como "agujero de ozono" debido a su marcada y localizada depleción (Karentz \& Boch 2001 y referencias, Hegglin et al. 2015). Este fenómeno se produce desde finales del invierno o principios de la primavera y se extiende hasta finales de la primavera o comienzos del verano, y su área se define por el contorno de 220 UD (unidades Dobson) en los mapas de ozono (Hegglin et al. 2014) (Fig. 1). En las últimas dos décadas aproximadamente, se ha observado un proceso de recuperación del ozono estratosférico mundial, relacionado con la disminución en la estratósfera de sustancias de cloro y bromo originadas de la degradación de compuestos que agotan la 
capa de ozono (ODS, ozone depleting substances, por sus siglas en inglés ${ }^{1}$ ), lo que ha apoyado la efectividad de la aplicación del Protocolo de Montreal de 1987 (WMO 2014).

Para la región Antártica, muy recientemente se ha relacionado la disminución en la concentración de compuestos reactivos de cloro con una reducción en la destrucción de ozono (Strahan \& Douglass 2018). Las observaciones satelitales dan indicios de que las pérdidas de ozono han disminuido desde fines de los años 1990s (Nash et al. 2016, Newman et al. 2017). Sin embargo, el agujero de ozono continúa ocurriendo cada primavera sobre la Antártida, un hecho esperable considerando que los niveles de ODSs, son aún bastante elevados (WMO 2014, Stammerjohn 2016). Los modelos químico-climáticos proyectan que la recuperación del ozono a los niveles del año 1980 no ocurrirá hasta después de la mitad de este siglo, más tarde que en cualquier otra región del mundo (WMO 2014, Hegglin et al. 2015). Sin embargo, el tamaño y la intensidad de la pérdida de ozono dentro del vórtice Antártico son variables y dependen de la meteorología y la dinámica atmosférica de cada invierno, entre otros factores (Weber et al. 2017). En los últimos años se han producido fluctuaciones en la cobertura y persistencia del agujero de ozono, por ejemplo, en 2015, el agujero de ozono sobre Antártida estuvo entre los de mayor extensión y duración, asociado a un vórtice polar estratosférico más frío y fuerte que el normal (Stammerjohn 2016).

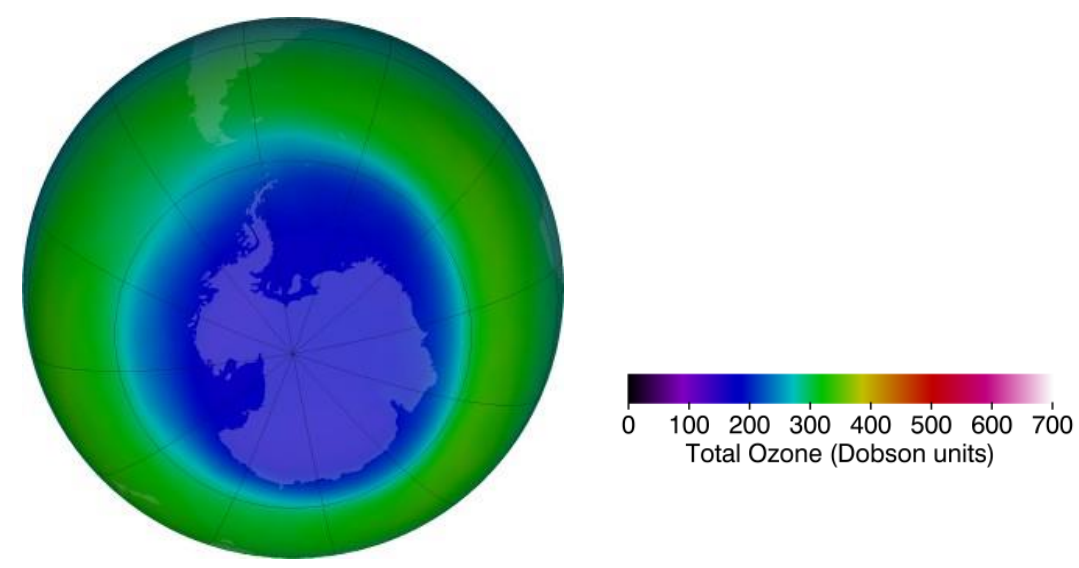

Figura 1.1. Mapa en falso color que muestra la concentración de ozono media mensual sobre la Antártida (Septiembre de 2015). Los datos fueron obtenidos por el satélite Aura, con el instrumento OMI (KNMI/NASA, Holanda/Estados Unidos), OMTO3d, Global Ozone Data. Fuente: https://ozonewatch.gsfc.nasa.gov/monthly/monthly 2015-09 SH.html

\footnotetext{
${ }^{1}$ Entre estas sustancias se incluyen principalmente los clorofluorocarbonos (CFCs)- entre otros compuestos- muy estables en la tropósfera y que sólo se degradan en la estratósfera bajo condiciones de elevada radiación ultravioleta. En estas condiciones, los CFCs liberan cloro, que destruye el ozono (Whitehead et al. 2000). El rol de los CFCs en la destrucción del ozono atmosférico fue propuesto por primera vez por Mario Molina \& F. Sherwood Rowland en 1974.
} 
La depleción de ozono estratosférico ha generado intensas investigaciones para establecer y predecir los efectos del incremento en la UV-B sobre los ecosistemas acuáticos (de Mora et al. 2000, Helbling \& Zagarese 2003, Häder et al. 2011, Llabrés et al. 2013). La UV-B puede penetrar en el agua hasta grandes profundidades, dependiendo no sólo de la concentración de ozono, sino también, entre otros factores, de la estación del año, la latitud y altitud, la nubosidad y particularmente, de las propiedades de la columna de agua (afectadas por la presencia de materia orgánica disuelta, fitoplancton y otras partículas disueltas) (Karentz \& Boch 2001, Hargreaves 2003, Whitehead et al. 2010). Las aguas antárticas oceánicas se caracterizan por una elevada penetración de la UV particularmente durante los eventos de depleción de ozono, aunque variable según las características del agua (Tedetti \& Sempéré, 2006) y se ha registrado la penetración de la UV-B a profundidades de hasta 60-70 m (Smith et al. 1992). En ambientes costeros antárticos, la penetración es menor, particularmente durante los meses de verano en sitios influidos por el ingreso de sedimento de origen terrestre proveniente de agua de deshielo (Richer et al. 2008, Huovinen et al. 2016). Sin embargo, puede alcanzar $20 \mathrm{~m}$ en primavera (Richter et al. 2008, $Z_{1 \%}$ ) y 13,3 m en verano (Huovinen et al. $2016, Z_{1 \% 313 \mathrm{~nm}}$ ).

En particular, la UV-B constituye un factor de estrés ambiental que puede limitar el desarrollo de productores primarios bentónicos al causar inhibición de la fotosíntesis y daños en el ADN, proteínas y lípidos, entre otros efectos (Villafañe et al. 2003, Bischof et al. 2006, Karsten et al. 2011, entre otros). Si bien la radiación ultravioleta A (UV-A, 315-400 nm) es menos dañina y no es afectada por la reducción de ozono, puede causar también efectos intensos sobre la inhibición de la fotosíntesis debido a los flujos elevados con los que naturalmente alcanza la superficie terrestre (Cullen \& Neale, 1994, Karentz \& Boch 2001).

Las algas bentónicas han desarrollado mecanismos de protección frente a la UV mediante la producción de sustancias que la absorben, así como de reparación de daños al ADN entre otros mecanismos (compilados en Villafañe et al. 2003, Bischof et al. 2006, Karsten et al. 2011, entre otros). Las micosporinas (MAASs) son las sustancias fotoprotectoras más comunes entre las algas rojas y diatomeas centrales en ambientes antárticos (Helbling et al. 1996, Ferreyra et al. 1998, Hoyer et al. 2001, Hernando et al. 2002). La producción de micosporinas en las algas rojas se relaciona con su patrón de distribución vertical, siendo las algas que habitan las aguas menos profundas, particularmente en el supra y eulitoral, las que sintetizan y acumulan las mayores cantidades (Hoyer et al, 2001, Bischof et al. 2006). Las macroalgas pardas y la mayoría de las algas verdes carecen de estas sustancias. Entre las macroalgas pardas, la existencia de florotaninos ha sido propuesta como un mecanismo de protección contra el exceso de irradiancia: se trata de compuestos polifenólicos que absorben parte de la UV-B y tienen, además, capacidad antioxidante (Bischof et al. 2006, Huovinen \& Gómez 2013). 
Los efectos negativos de la UV sobre los productores bentónicos a nivel molecular y fisiológico pueden afectar la estructura y funcionamiento de los ecosistemas (Bischof et al. 2006, Häder et al. 2011). En este sentido, se ha propuesto que el patrón general de zonación de las macroalgas antárticas refleja la sensibilidad de las especies a la UV, siendo las especies más sensibles las que habitan a mayores profundidades (Bischof et al. 1998, 2006). Por ejemplo, ciertas macroalgas verdes que se desarrollan en el intermareal poseen una rápida y elevada capacidad de aclimatación a la UV-B, mientras que especies de algas pardas que habitan en el submareal, como Desmarestia anceps o algas rojas que habitan debajo del canopeo provisto por otras especies son muy sensibles a la UV-B (Bischof et al. 2006). Trabajos recientes han demostrado que las macroalgas antárticas exhiben una notable tolerancia a la UV al menos en exposiciones de corto plazo (2 y 6 horas) (Huovinen \& Gómez 2013, Gómez \& Huovinen 2015). La producción de micosporinas en algas rojas del intermareal y submareal superior podría ser la causa de su elevada resistencia a la UV (Hoyer et al. 2001, Huovinen \& Gómez 2013). Entre las algas pardas endémicas dominantes, una elevada capacidad antioxidante y un elevado nivel de florotaninos determinarían su tolerancia a la UV (Gómez \& Huovinen 2015, Flores-Molina et al. 2016) aunque algunas especies submareales pueden exhibir daños al ADN (Huovinen \& Gómez 2013).

Los estadios iniciales de macroalgas en ambientes polares pueden ser más susceptibles a esta radiación que los talos adultos (Bischof et al. 2006, Wiencke et al. 2007, Roleda et al. 2009, Karsten et al. 2011). En particular, se ha demostrado que los efectos negativos de la UV-B sobre la fotosíntesis y el daño al ADN en propágulos de macroalgas se relacionan con la distribución vertical de los talos adultos, siendo más sensibles aquellos que provienen de especies colectadas a mayores profundidades (Wiencke et al. 2000). En ambientes antárticos, los estadios iniciales de macroalgas que habitan el intermareal presentan una elevada resistencia a la UV, con elevada capacidad de recuperación y escasos o nulos daños al ADN (Zacher et al. 2007c). En contraste, la germinación de esporas de especies que habitan el submareal es afectada negativamente por la UV ambiental, un efecto acentuado por la UV-B en condiciones de laboratorio (Zacher 2014). Asimismo, la UV puede causar una mayor inhibición de la fotosíntesis en esporas de especies submareales respecto a las intermareales (Navarro et al. 2016).

Los efectos de la UV sobre las diatomeas bentónicas antárticas provienen principalmente de estudios realizados en condiciones de laboratorio, enfocados sobre comunidades de fondos blandos (Wulff et al. 2008a,b,c), en los que la migración vertical puede ser un mecanismo efectivo para evitar la UV (Karsten et al. 2011). Estos ensambles presentaron una gran resistencia a la UV, mostrando bajos niveles de fotoinhibición y eficientes mecanismos de reparación de daños al ADN (Wulff et al. 2008a). Similarmente, el 
estudio de ensambles de diatomeas en el intermareal antártico reveló un efecto menor de la UV sobre la biomasa y composición taxonómica, aunque sólo se encontraron unas pocas especies, probablemente adaptadas a las condiciones extremas en este ambiente (Zacher et al. 2007b).

Por lo tanto, particularmente al inicio de la sucesión, una sensibilidad diferencial hacia la UV entre especies, o entre distintos estadios de una misma especie (esporas, juveniles o adultos, entre las macroalgas) podría modificar la estructura y funcionamiento de las comunidades (Lotze et al. 2002, Villafañe et al. 2003, Zacher et al. 2007a,b, Zacher 2014). Asimismo, los efectos de la UV sobre las comunidades de algas bentónicas pueden a su vez ser afectados por interacciones biológicas tales como el pastoreo (Sommaruga 2003).

\subsection{Efectos del pastoreo sobre las comunidades de algas marinas bentónicas antárticas}

El pastoreo se considera un factor estructurante de gran importancia para las comunidades de macroalgas marinas bentónicas (Iken 2012, Hurd et al. 2014). Similarmente, las comunidades dominadas por diatomeas pueden estar controladas por herbívoros, tanto por consumo o incluso indirectamente, al causar el desprendimiento de células (Nicotri 1977, Hillebrand et al. 2000, entre otros). Similarmente, se ha postulado que la estructura de las comunidades de las algas marinas bentónicas antárticas (microalgas y macroalgas) está afectada por el pastoreo (Peters 2003, Campana et al. 2011, Gómez et al. 2011, Wiencke \& Amsler 2012). En la Antártida, el consumo de diatomeas y macroalgas por gasterópodos, poliquetos, anfípodos y peces está documentado (Brêthes et al. 1994, Iken et al. 1997, 1998, Iken 1999, Amsler et al. 2005, Huang et al. 2006, Seefeldt et al. 2017). Sin embargo, el efecto del pastoreo sobre la estructura y funcionamiento de las comunidades bentónicas es aún bastante incierto. Los trabajos enfocados en evaluar el efecto de herbívoros a nivel de la comunidad se realizaron principalmente en ambientes intermareales y han demostrado que los gasterópodos pueden afectar la distribución de las algas, particularmente en el intermareal inferior al consumir diatomeas bentónicas y estadios juveniles de macroalgas (Kim 2001, Zacher et al. 2007a,b, Segovia-Rivera \& Valdivia 2016, Valdivia et al. 2018). El efecto del pastoreo por gasterópodos en ambientes submareales de sustrato rocoso ha sido menos explorado (Brêthes et al. 1994), sugiriendo que pueden limitar el desarrollo de comunidades dominadas por invertebrados sésiles (Bowden et al. 2006).

Asimismo, la presencia de defensas químicas contra herbívoros en las macroalgas afecta críticamente la estructura de las comunidades de algas bentónicas antárticas (Amsler et al. 2005, 2011, Aumack et al. 2010). En un extenso estudio en que se evaluó la 
palatabilidad de las macroalgas antárticas, Amsler et al. (2005) demostraron que las algas pardas dominantes y la mayoría de las algas rojas foliosas poseen defensas contra consumidores simpátricos tales como el anfípodo Gondogeneia antarctica, la estrella de mar Odontaster validus y el pez Nothotenia coriiceps. El consumo de algas por el erizo de mar Sterechinus neumayeri no fue testeada, pero estudios realizados en Mc Murdo revelaron que las dos macroalgas dominantes en esa área de estudio están protegidas químicamente contra este consumidor (Amsler et al. 1998). A su vez, este erizo suele estar cubierto por partes desprendidas de estas mismas algas, lo cual le confiere protección física contra sus predadores y a su vez mantiene talos fértiles en la zona eufótica (Amsler et al. 1999). Además, se ha postulado que el pastoreo por mesoconsumidores (anfípodos, principalmente) es central en la estructuración de las comunidades de macroalgas bentónicas al suprimir la presencia de epífitas filamentosas (Peters 2003). En el submareal antártico se han hallado escasas especies de algas filamentosas como epifitas de macroalgas (Wiencke \& Clayton 2002) y, en contraste, existe una elevada ocurrencia de endofitas filamentosas (Peters 2003), la mayoría de las cuales son muy palatables para los anfípodos (Amsler et al. 2009). En este sentido, se ha hipotetizado que existe una relación de mutualismo entre los anfípodos y las macroalgas, los que se alimentan de epifitas potencialmente perjudiciales, viviendo en un ambiente químicamente protegido contra sus depredadores provisto por las macroalgas (Amsler et al. 2014).

De acuerdo a la información disponible, es esperable que el efecto de los herbívoros sea particularmente más intenso sobre los estadios juveniles de macroalgas y las diatomeas bentónicas (Kim 2001, Brêthes et al. 1994, Zacher et al. 2007 a, b), tal como fue registrado en otros ambientes para etapas tempranas de la sucesión (Sousa 1979, Farrel 1991, Lubchenco 1983, y compilaciones en Sousa \& Connell 1992).

\subsection{Consideraciones para la formulación de los objetivos e hipótesis}

Tal como se ha descripto anteriormente, los estudios sobre los patrones sucesionales en el bentos antártico se enfocaron principalmente en ensambles de invertebrados sésiles (Barnes \& Conlan 2007, Dayton et al. 2016, Lagger et al. 2018). En esta Tesis se presenta el primer estudio sucesional a largo plazo realizado en un ambiente submareal antártico dominado por algas (Campana et al. 2017). Particularmente, pocas investigaciones han abordado el estudio simultáneo de las microalgas y macroalgas bentónicas en procesos sucesionales del bentos antártico, incluyendo análisis taxonómicos detallados. A vez, no existe información acerca de los efectos de factores ambientales y ecológicos que controlen estos procesos en el ambiente submareal, particularmente en estadios iniciales de la sucesión (Zacher et al. 2007a,b). 
Gran parte de la información sobre los efectos de la UV sobre las algas marinas bentónicas antárticas proviene de estudios en condiciones de laboratorio, que si bien aportan valiosa información acerca de los mecanismos subyacentes no suelen representar los radios PAR/UV que existen en condiciones naturales (Huovinen \& Gómez 2013, Zacher 2014). Además, los estudios realizados a nivel de especie pueden no reflejar las respuestas biológicas a nivel de comunidades debido a la posible existencia de efectos indirectos o sinérgicos (Bischof et al. 2006, Häder et al. 2011). Por lo tanto el estudio de los efectos de la UV se puede profundizar mediante i) un enfoque que incluya sus efectos en condiciones naturales y ii) el estudio simultáneo de los efectos de otro nivel trófico, como el de los herbívoros, particularmente en etapas tempranas de la sucesión, en las que los productores primarios bentónicos podrían ser vulnerables a estos factores (Sommaruga 2003, Villafañe et al. 2003, Bothwell et al. 1994, Zacher et al. 2007a,b).

\section{OBJETIVOS E HIPÓTESIS}

\section{Objetivo general}

El objetivo general de esta Tesis es describir en condiciones experimentales en terreno, los patrones de colonización y sucesión de productores primarios bentónicos (microalgas y macroalgas) en un ambiente costero rocoso antártico, con especial énfasis en los efectos de la radiación ultravioleta y el pastoreo sobre estos procesos en etapas tempranas de la sucesión.

\section{Objetivos específicos}

Los objetivos específicos son:

- Identificar y caracterizar taxonómicamente la flora de microalgas y macroalgas marinas bentónicas en procesos de colonización y sucesión.

- Describir atributos estructurales de la comunidad de algas marinas bentónicas en el curso de los procesos de colonización y sucesión a lo largo de cuatro años.

- Evaluar el efecto de la radiación ultravioleta (UV-A y UV-B) y el pastoreo sobre atributos estructurales de una comunidad de microalgas y macroalgas bentónicas en el curso de los procesos de colonización y sucesión en etapas tempranas.

Estos objetivos se enmarcan dentro de los Capítulos 3, 4 y 5 de esta Tesis, respectivamente. 


\section{Hipótesis}

Las hipótesis centrales que se plantean en esta investigación son las siguientes:

I) La sucesión de la comunidad de productores primarios bentónicos procede en el tiempo hacia una mayor complejidad en su estructura (mayor cobertura, riqueza y diversidad y mayor complejidad tridimensional).

II) Las comunidades en estadios iniciales de la sucesión son particularmente vulnerables a factores de estrés ambiental tales como la radiación ultravioleta. El pastoreo afecta la estructura de la comunidad de microalgas y macroalgas por reducción de biomasa y cambio en la composición de especies. A su vez, los efectos de ambos factores dependen del grado de desarrollo de la comunidad.

\section{Estructura general de la Tesis}

Esta Tesis consiste en seis capítulos, cuyo contenido se resume a continuación.

Capítulo 1. Introducción. Se presenta una introducción general a la temática abordada, incluyendo los objetivos e hipótesis.

Capítulo 2. Área de estudio y enfoque metodológico. Se incluye la descripción del área de estudio y se señalan aspectos metodológicos empleados para el desarrollo de los objetivos mediante el uso de sustratos artificiales.

Capítulo 3. Flora bentónica. Se describen los taxa hallados sobre los sustratos artificiales, acompañados de diagnosis, comentarios y discusiones sobre cada uno de ellos.

Capítulo 4. Patrones sucesionales de algas marinas bentónicas a largo plazo. Se describen los patrones sucesionales de la comunidad de algas marinas bentónicas mediante la realización de un experimento de cuatro años de duración. En este capítulo se ensaya la Hipótesis I.

Capítulo 5. Efectos de la radiación ultravioleta y el pastoreo sobre la colonización y sucesión de microalgas y macroalgas bentónicas. Se describen los efectos de ambos factores en etapas tempranas de la sucesión, obtenidos mediante la realización de un experimento de 73 días de duración. En este capítulo se ensaya la Hipótesis II.

Capítulo 6. Conclusiones.

Los capítulos 3, 4 y 5 presentan una introducción, los métodos específicos y una discusión acorde a los objetivos de ese capítulo. 
CAPÍTULO 2

Área de estudio y enfoque metodológico 


\section{1. ÁREA DE ESTUDIO}

El área de estudio en que la se llevó a cabo esta Tesis es caleta Potter (62 $14^{\prime} \mathrm{S}, 58^{\circ} 38^{\prime}$ O), un pequeño fiordo tributario de la bahía Guardia Nacional (Maxwell Bay), isla 25 de Mayo (King George Island), archipiélago de las islas Shetland del Sur (Fig. 2.1). Allí se encuentran la base argentina Carlini (anteriormente llamada Jubany) y el laboratorio argentino-alemán Dallmann, este último administrado conjuntamente por la Dirección Nacional del Antártico y el Alfred Wegener Institute Helmholtz Centre for Polar and Marine Research (AWI, Bremerhaven, Alemania) (Fig. 2.2). Esta base científica cuenta con facilidades logísticas para el desarrollo de tareas de investigación en ecología marina, tales como laboratorios equipados y personal para la realización de tareas de buceo y navegación. Los estudios realizados en esta área se enmarcan en programas de monitoreo de variables ambientales que se han llevado a cabo a lo largo de tres décadas, incluyendo estudios de la columna de agua y la dinámica del fitoplancton, y estudios ecológicos de las comunidades de macroalgas desde el año 1991 (Quartino et al. 2001, 2005, 2013, Quartino \& Boraso de Zaixso 2008, Schloss et al. 2012).

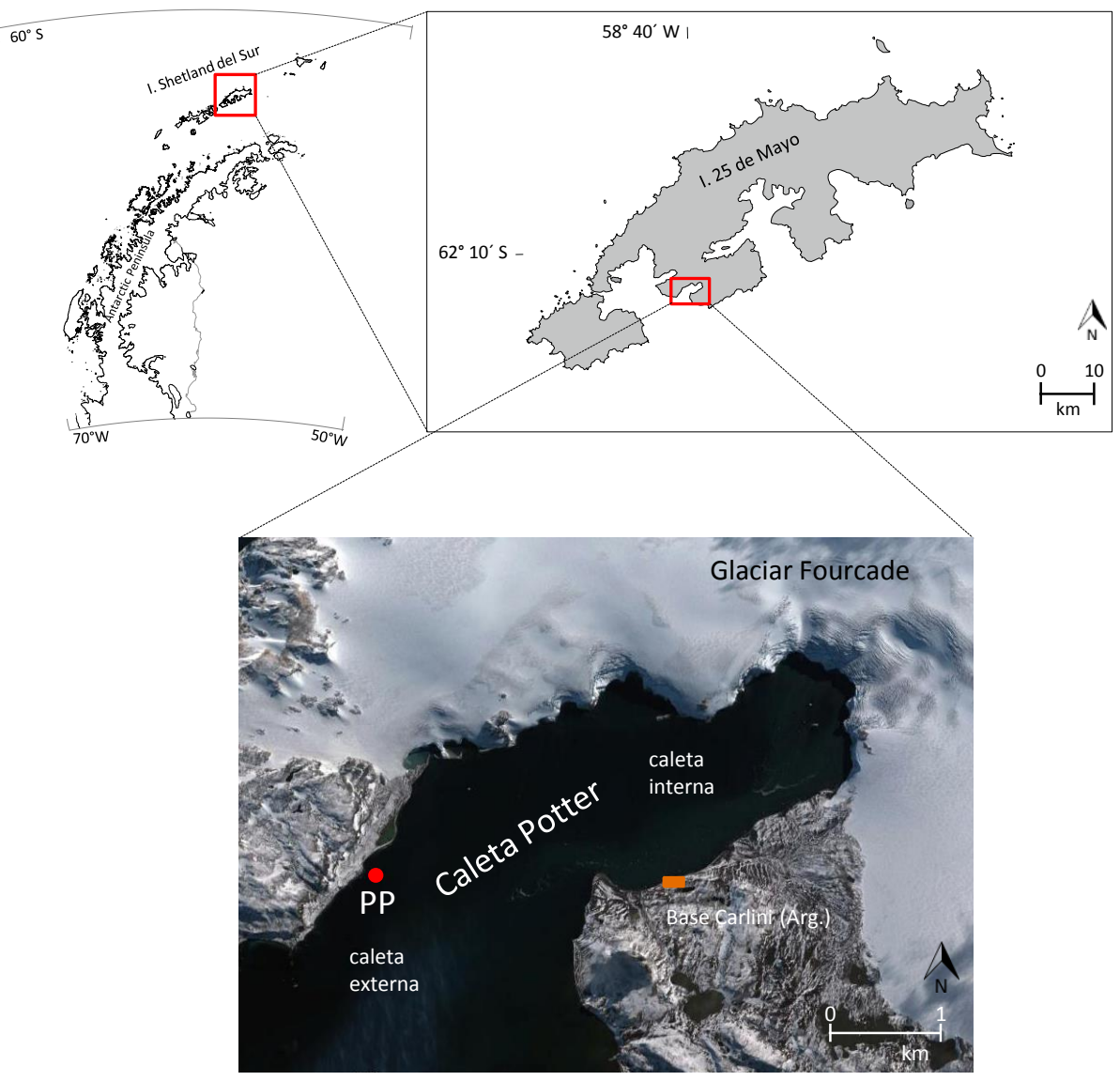

Fig. 2.1. Ubicación de caleta Potter, isla 25 de Mayo (King George Island), archipiélago Shetland del Sur en la península Antártica. Se señala el sitio de estudio, Peñón de Pesca (PP), ubicado en la caleta externa. 
Caleta Potter tiene una extensión de $4 \mathrm{~km}$ de longitud y 2,5 km de ancho, las costas norte y este de la caleta interna están rodeadas por el glaciar Fourcade mientras que la costa sur es una playa arenosa (Klöser et al. 1994a, Quartino et al. 2005) (Fig. 2.1). Se trata de un ambiente físico y biológicamente caracterizado por presentar dos áreas bien definidas: los sectores interno y externo, separados por una elevación transversal del fondo de aproximadamente $30 \mathrm{~m}$ de profundidad (Figs. 2.1, 2.3a). La zona interna presenta profundidades de hasta aproximadamente $50 \mathrm{~m}$, mientras que en la zona externa tiene profundidades mucho mayores, siendo en la entrada o boca de la caleta de entre 100 y 200 m (Klöser et al. 1994b, Schloss et al. 2012).

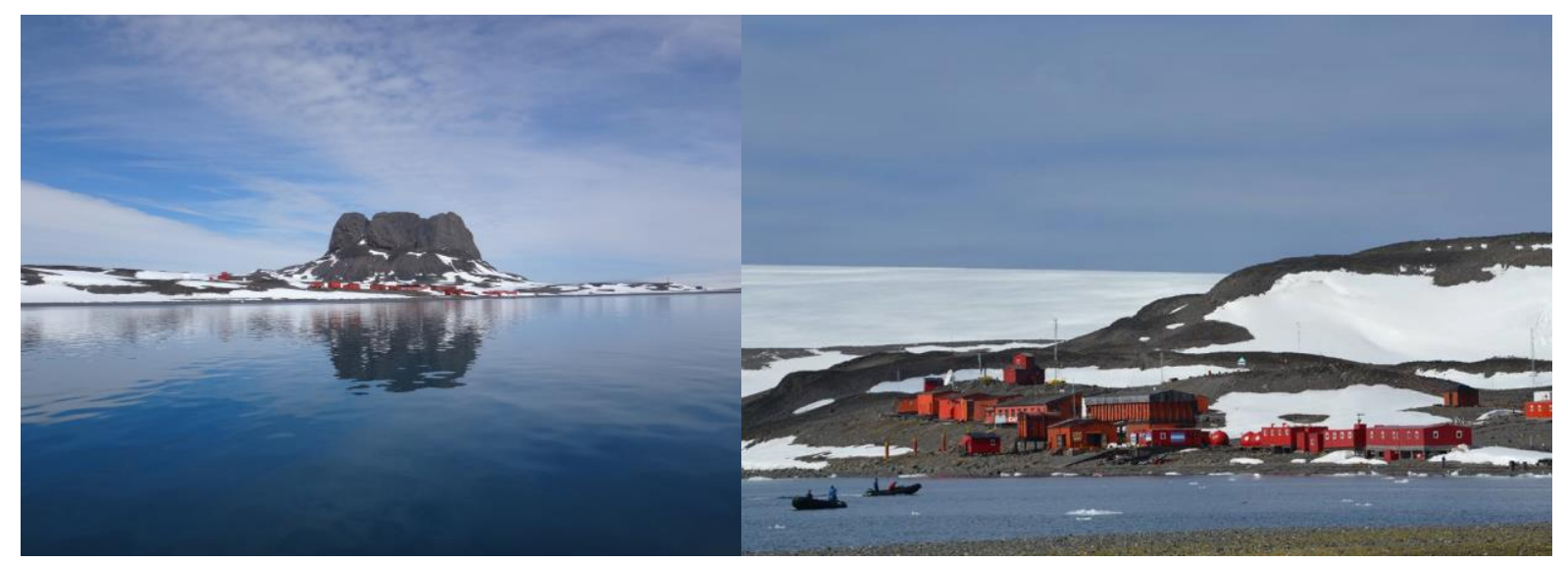

Fig. 2.2. Vistas de caleta Potter y base Carlini. Fotos: O. González.

Particularmente, la zona externa de la caleta posee sustrato rocoso en el que se desarrollan comunidades de macroalgas, con coberturas que puede alcanzar el $100 \%$ en algunos sitios, amplia distribución vertical (hasta 30 metros) y elevada biomasa (Klöser et al. 1996, Quartino et al. 2005, Quartino \& Boraso de Zaixso 2008). La caleta interna, de fondo predominantemente blando presenta una elevada densidad de filtradores bentónicos (Sahade et al. 1998, 2015). De hecho, la elevada producción primaria macroalgal del sector externo de la caleta (Quartino \& Boraso de Zaixso 2008) y los procesos de resuspensión del microfitobentos han sido postulados como el principal ingreso de carbono al sistema bentónico de la caleta interna (Tatián et al. 2002, 2004, 2008, Sahade et al. 2004, Quartino et al. 2008), dada la generalmente baja productividad primaria pelágica en este sitio (Schloss et al. 2002). Asimismo, en los últimos años se ha observado un marcado retroceso del glaciar Fourcade que rodea la caleta interna (Rückamp et al. 2011). Esto ha originado áreas libres de hielo en las zonas costeras próximas al glaciar, aptas para la colonización por organismos bentónicos y ha resultado en la expansión de las macroalgas hacia la caleta interna (Quartino et al. 2013, Deregibus et al. 2016, Lagger et al. 2017, 2018).

El trabajo se llevó a cabo en un sitio submareal ubicado en el área de Peñón de Pesca (62 $14.218^{\prime}$, S $\left.58^{\circ} 42.915^{\prime} \mathrm{W}\right)$, en el sector externo de la caleta (Figs. 2.1, 2.3). Este 
sitio se ubica en la costa noroeste y se considera moderadamente protegido del impacto de los témpanos que ingresan desde la bahía Guardia Nacional que son transportados hacia el interior de la caleta por un patrón de circulación de tipo ciclónico u horario causado por los vientos preponderantes del oeste (Klöser et al. 1994a,b, Roese \& Drabble 1998, Schloss et al. 2002). Este patrón de circulación determina además, una baja turbidez en la columna de agua en este sitio, permitiendo un alto grado de penetración de luz, tanto de PAR como de UV (Richter et al. 2008) respecto a los sitios ubicados en la caleta interna. Contrariamente, las propiedades ópticas y fisicoquímicas de la caleta interna se encuentran sumamente influenciadas no sólo por el patrón de circulación ciclónico superficial de agua sino por el ingreso de agua dulce durante los meses de deshielo, asociada al derretimiento glaciario, que aporta material particulado en suspensión a la columna de agua (Ferreyra et al. 2008, Schloss et al. 2012), resultando en una menor penetración de luz (Richter et al. 2008, Quartino et al. 2013, Deregibus et al. 2016).

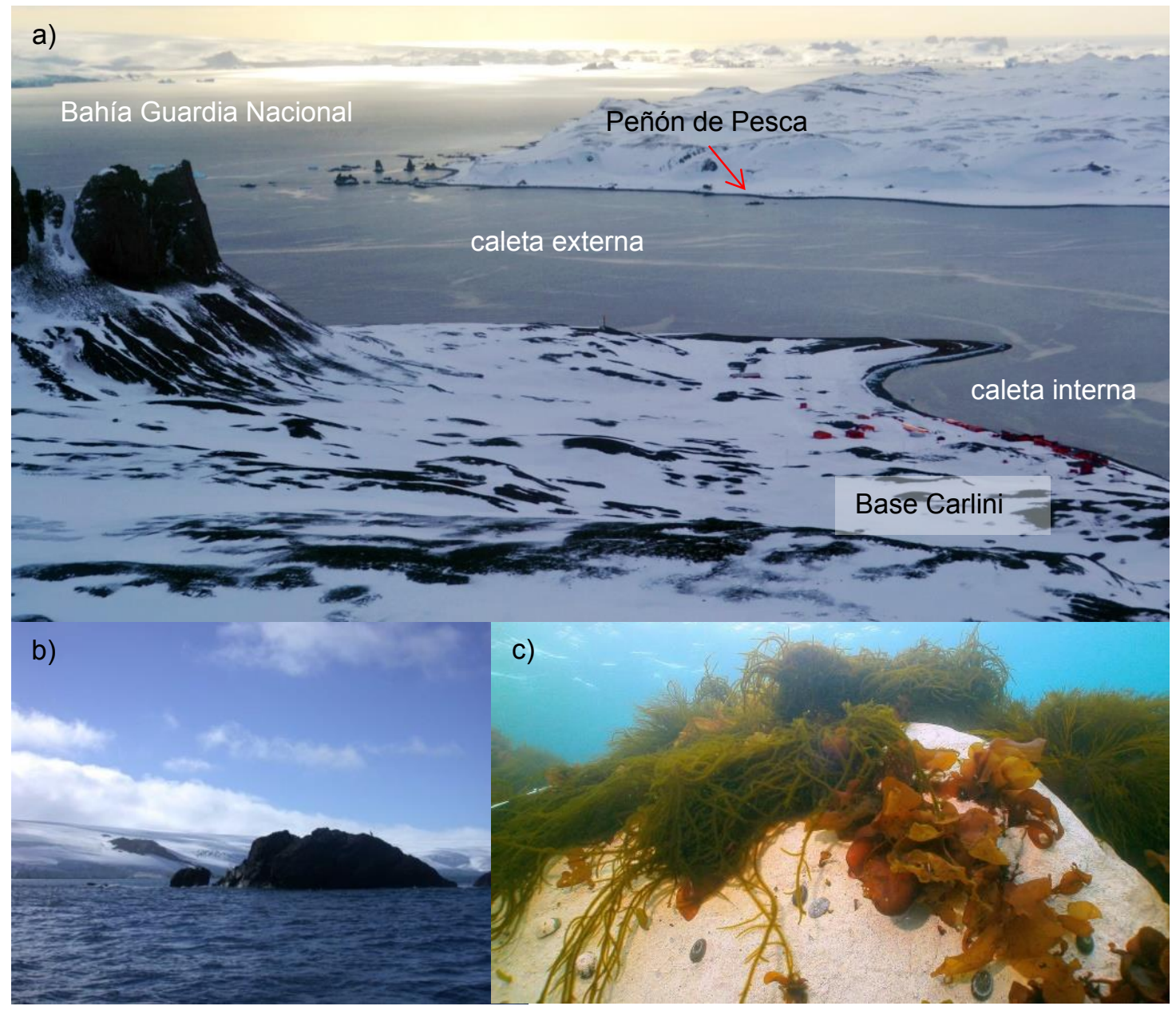

Fig. 2.3. a) Ubicación del sitio de estudio, Peñón de Pesca, en la caleta externa, b) Vista del Peñón de Pesca y c) vista del mismo sitio a bajas profundidades ( $<5 \mathrm{~m})$. Fotos: a) C. Matula, b) G. Campana, c) E. Mohr.

El Peñón de Pesca presenta un gran desarrollo de macroalgas, que se extienden 
hasta $30 \mathrm{~m}$ de profundidad (Quartino et al. 2005) (Fig. 2.3c). En este sitio, a bajas profundidades (0 a $10 \mathrm{~m}$ ) predomina la roca sólida y rocas mayores a $1 \mathrm{~m}$, y este tamaño disminuye a mayores profundidades, con rodados de 5 a $20 \mathrm{~cm}$ y grava a $30 \mathrm{~m}$ de profundidad (Quartino 2003). Los estudios realizados en caleta Potter revelaron patrones de zonación vertical de las macroalgas, diferenciando cuatro zonas: i) una franja mesolitoral de interfase con el sublitoral superior, afectada por el hielo en aguas poco profundas, con especies anuales y pseudoperennes, y caracterizado por Iridaea cordata, Monostroma hariotii y Adenocystis utricularis, con óptimos de densidad menores a $3 \mathrm{~m}$, ii) el sublitoral superior con Desmarestia menziesii y Ascoseira mirabilis con óptimos de densidad a $5 \mathrm{~m}$ y 3 $\mathrm{m}$ respectivamente, asociados a altos niveles de turbulencia, iii) un sublitoral medio con Desmarestia anceps, con óptimos a $18 \mathrm{~m}$ de profundidad y iv) una zona de aguas más profundas y baja turbulencia, con Himantothallus grandifolius (Klöser et al. 1996, Quartino 2003). Estos patrones de zonación están determinados por la profundidad, el tamaño y tipo de sustrato, la pendiente, la irradiancia, la turbulencia y la abrasión por hielo, entre otros factores (Klöser et al. 1996, Quartino et al. 2001, 2005).

El microfitobentos de sustrato duro de la caleta ha sido estudiado para ambientes intermareales de la península Barton (Kim 2001) y península Potter (Zacher et al. 2007b). Para ambientes submareales, se conocen muy pocos estudios sobre los patrones de distribución de las diatomeas bentónicas sobre diferentes hábitats que incluyan el análisis fondos rocosos (Klöser 1998), proviniendo la mayor parte de la información taxonómica y ecológica del estudio de ambientes de fondos blandos o de epifitas sobre macroalgas (Klöser 1998, Al-Handal \& Wulff 2008a, b). El estudio de Klöser (1998) identificó ensambles de diatomeas bentónicas en rocas y rodados submareales y sobre macroalgas arborescentes y briozoos, caracterizados por la presencia de Fragilaria striatula, Licmophora antarctica/belgicae y L. gracilis. Asimismo, sobre el sustrato rocoso se identificaron asociaciones de especies naviculoides, Pseudogomphonema kamstchaticum, especies del género Cocconeis y Amphora bongrainii, señalando que particularmente las especies Achnanthes sp. y Fragilaria striatula pueden forman floraciones en estos ambientes (Klöser 1998). En términos generales, este estudio reflejó que las características estructurales del hábitat y la exposición a las condiciones de stress y disturbio determinan la composición de los ensambles de diatomeas. 


\subsection{ENFOQUE METODOLÓGICO}

El enfoque empleado en esta Tesis para el desarrollo de los objetivos y la puesta a prueba de las hipótesis es experimental. En todos los casos, se utilizaron sustratos artificiales para permitir la colonización por las microalgas y macroalgas bentónicas (Fig. 2.4a-c). Los sustratos artificiales han demostrado ser una herramienta muy útil para el estudio de los procesos de sucesión, particularmente en regiones polares (compilado en Campana et al. 2011) y se han utilizado para la cuantificación e identificación detallada de microalgas y estadios iniciales de macroalgas (Zacher et al. 2007a,b, Fricke et al. 2008) e invertebrados sésiles (Bowden 2005, Bowden et al. 2006, entre otros). Una de las principales ventajas de su aplicación se basa en que permiten obtener condiciones uniformes para la colonización, por ejemplo, en las dimensiones y rugosidad del espacio provisto, y pueden ser utilizados para experimentos al proveer réplicas estandarizadas (Foster \& Sousa 1985, Stanwell Smith \& Barnes 1997). Cabe destacar que la aplicación de enfoques experimentales empleando sustratos artificiales permite una instalación y obtención de muestras relativamente rápidas mediante buceo autónomo, una característica importante en los ambientes polares, en los que las oportunidades de buceo están restringidas por las condiciones meteorológicas y el limitado tiempo de exposición a bajas temperaturas (Stanwell Smith \& Barnes 1997, Campana et al. 2011).

Los detalles del diseño de cada experimento, así como la metodología aplicada para los distintos aspectos contenidos en esta Tesis se detallan en el Capítulo correspondiente.

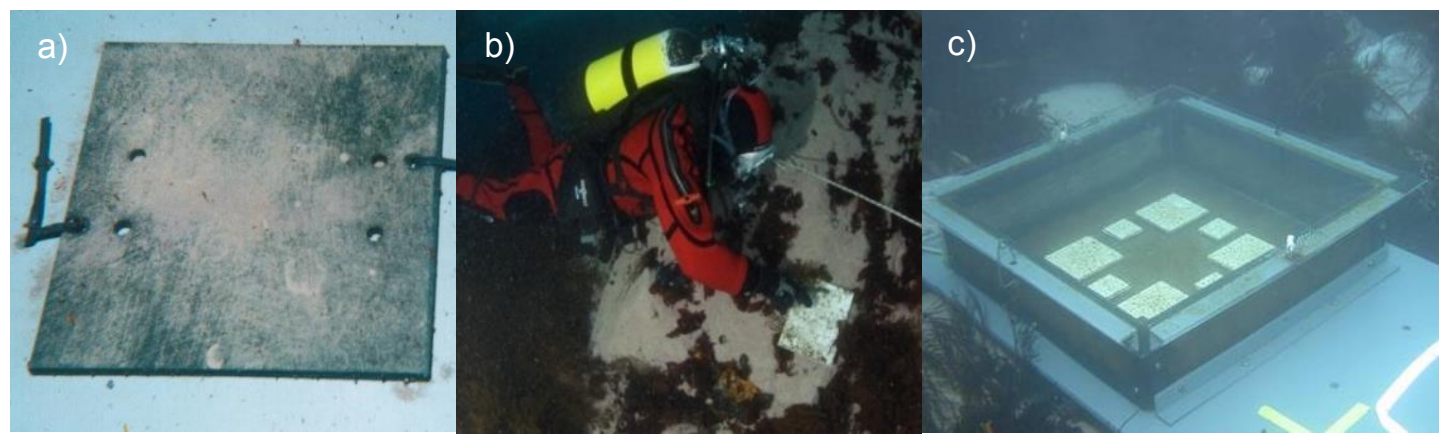

Fig. 2.4. Vistas subacuáticas de los sustratos artificiales empleados en esta Tesis. a) sustratos emplazados durante diez meses, destinados principalmente al análisis de flora diatomológica (Capítulo 3), b) sustratos emplazados durante cuatro años destinados al análisis de patrones sucesionales de algas bentónicas (Capítulo 4), c) sustratos emplazados para el estudio de la UV y el pastoreo sobre etapas tempranas de la sucesión (Capítulo 5). Fotos: a) G. Latorre, b) M. Mammana, c) K. Zacher. 
CAPÍTULO 3

Flora bentónica 


\subsection{INTRODUCCIÓN}

El conocimiento de la flora bentónica antártica se inicia con las primeras expediciones al continente, a principios del siglo XIX. El primer registro de diatomeas de Antártida fue el aportado por Ehrenberg (1843), a partir de muestras colectadas en la expedición británica Erebus y Terror (1839-1843). En el caso de las macroalgas, la primera colección fue realizada por C. Gaudichaud (1826) en la expedición francesa Uranie y Physiciennne (18171820). Luego siguieron una serie de expediciones que permitieron reunir colecciones ficológicas a partir de las cuales se realizaron estudios taxonómicos y biogeográficos, compilados principalmente en Wulff et al. (2011) para las microalgas bentónicas y Boraso \& Quartino (1993) y Wiencke et al. (2014) para las macroalgas.

A mediados del siglo $X X$ se incorpora el buceo autónomo como metodología de recolección de los organismos bentónicos incrementándose así el número de ejemplares coleccionados in situ en Antártida. Esto posibilitó ampliar el conocimiento sobre los patrones de zonación, ciclos de vida, fisiología y ecofisiología, particularmente de las macroalgas bentónicas (Wiencke et al. 2014).

Hasta el momento se han identificado 124 especies de macroalgas, pero es probable que este número sea mayor ya que aún hay regiones poco exploradas particularmente en la Antártida oriental (Wulff et al. 2011, Wiencke et al. 2014). Aproximadamente un 35\% de las especies de macroalgas en Antártida son endémicas, registrándose los mayores niveles de endemismo entre las Phaeophyceae (44\%) y las Rhodophyta (36\%) (Wiencke et al. 2014). Entre las algas pardas existe un orden endémico, el de las Ascoseirales (Wiencke \& Amsler 2012) y recientemente, se han descripto cuatro nuevos géneros de algas rojas endémicas (Hommersand et al. 2009). En caleta Potter, un total de 43 especies fueron registradas hasta el momento (Quartino et al. 2013).

El estudio de las microalgas bentónicas marinas en Antártida es menos extenso que el de las macroalgas (Wulff et al. 2011). El microfitobentos marino antártico está dominado por diatomeas, siendo estas últimas el grupo más estudiado entre las microalgas (Wulff et al. 2011). A pesar de esto, aún hay poco conocimiento de este grupo, en particular respecto a su identidad, ecología y biogeografía y es bastante incierto el conocimiento respecto al grado de endemismo (Wulff et al. 2011). Estudios recientes ampliaron el conocimiento de la taxonomía de diatomeas bentónicas con la identificación de nuevas entidades (Fernandes et al. 2007, Al-Handal et al. 2008, 2010). Otros estudios llevaron a cabo análisis detallados de la identidad de los taxa, enfocándose principalmente en el estudio de las diatomeas epifitas de macroalgas y en las halladas en fondos blandos en zonas costeras (Klöser 1998, AlHandal \& Wulff 2008a,b, Majewska et al. 2016). Asimismo, son muy escasos los trabajos que describan las características taxonómicas de las especies de diatomeas en ambientes 
bentónicos de sustrato rocoso (Klöser 1998, Al-Handal \& Wulff 2008b). Por otro lado, son pocos los registros de estadios iniciales de macroalgas antárticas en el ambiente natural (Zacher et al. 2007a) y su conocimiento proviene mayoritamente de cultivos realizados en condiciones controladas de laboratorio (Wiencke \& Clayton 2002, Wiencke et al. 2007).

El objetivo de este capítulo fue identificar y caracterizar taxonómicamente la flora bentónica (diatomeas y macroalgas) más representativa observada sobre los sustratos artificiales empleados en esta Tesis para el estudio de los procesos de colonización y sucesión. Se presentan los taxa hallados incluyendo su diagnosis, datos morfométricos, observaciones taxonómicas y comentarios sobre su distribución y hábitat en Antártida.

\subsection{MATERIALES y MÉTODOS}

\subsubsection{Flora diatomológica}

\section{Obtención de muestras}

Las diatomeas fueron obtenidas de sustratos artificiales emplazados en Peñón de Pesca a 5 metros de profundidad (Fig. 3.1), entre el 15 de marzo de 2004 y el 29 de enero de 2005. Los sustratos consistieron en placas de PVC rugoso de $20 \mathrm{~cm}$ de lado, que se retiraron mensualmente $(n=3)$ mediante buceo autónomo. Adicionalmente, se analizaron las muestras de las algas que colonizaron los sustratos empleados para la realización del experimento detallado en el Capítulo 5, desarrollado entre diciembre 2003 y marzo 2004.

El material fue removido por raspado y lavado empleando agua de mar filtrada a través de filtros de fibra de vidrio (Whatman GF/F, de 0,7 $\mu \mathrm{m}$ de tamaño de poro), y preservadas en formol (concentración final 4\%) o glutaraldehído (concentración final 2.5\%, para el caso de las muestras obtenidas en el marco del experimento que se detalla en el Capítulo 5).

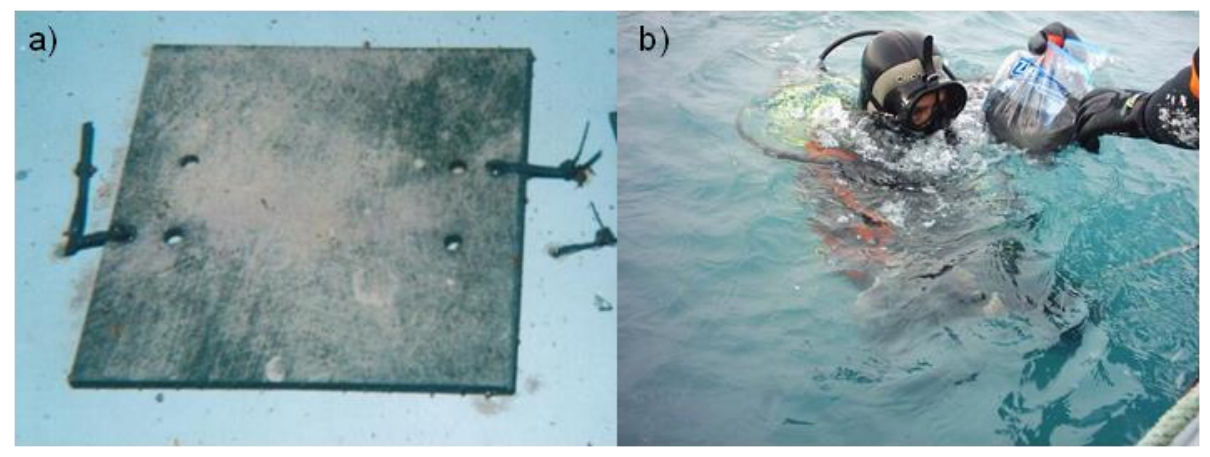

Fig. 3.1. a) Vista subacuática de un sustrato instalado en Peñón de Pesca a 5 metros de profundidad.

b) Muestreo del sustrato por buceo autónomo para su traslado al laboratorio. Fotos: a) G. Latorre, b) G. Campana 


\section{Análisis microscópico cualitativo}

El análisis taxonómico de diatomeas se realizó empleando técnicas de microscopia óptica (MO) y microscopía electrónica de barrido (MEB), a partir de alícuotas de cada muestra, aplicando técnicas recomendadas por Ferrario et al. (1995) y Prygiel \& Coste (2000). Las muestras fueron lavadas con agua destilada hasta remover sales y el preservante, aproximadamente cinco veces. Cada lavado incluyó la centrifugación del material durante 15 minutos a aproximadamente 2000 rpm, descartándose el sobrenadante. Este material así lavado se destinó a la realización de los preparados fijos "sin tratar".

Por otro lado, una fracción de este material fue expuesto a un tratamiento de oxidación de materia orgánica. Para ello, las muestras fueron tratadas con peróxido de hidrógeno $\left(\mathrm{H}_{2} \mathrm{O}_{2}, 100\right.$ volúmenes) manteniendo el material en estufa a $90^{\circ} \mathrm{C}$ durante tres horas. Seguidamente, fueron lavadas de acuerdo a lo indicado anteriormente y destinadas a la obtención de preparados fijos de material "tratado".

Para la realización de ambos tipos de preparados fijos ("sin tratar" y "tratados") se empleó Naphrax, un medio de montaje con alto índice de refracción. Adicionalmente, se realizaron preparados del material "sin tratar" y "tratado" para ser examinados mediante MEB. Para ello, se depositó material sobre pequeños trozos cuadrangulares de vidrio que, previo secado, fueron cubiertos con oro-paladio según la metodología recomendada por Ferrario et al. (1995).

Las observaciones de microscopía óptica de los preparados fijos fueron realizadas utilizando contraste de fase y contraste de interferencia diferencial mediante microscopios Leica DM 2500, equipados con una cámara fotográfica digital Leica DFC420 (División Ficología, Museo de La Plata). El material analizado mediante MEB se examinó con un microscopio electrónico de barrido Jeol JSM-6360 LV (Servicio de Microscopía Electrónica de Barrido, Museo de La Plata).

Los preparados permanentes fueron incorporados al Herbario (LPC) de la División Ficología "Dr. Sebastián A. Guarrera" del Museo de La Plata, Facultad de Ciencias Naturales y Museo, Universidad Nacional de La Plata, Argentina. Un duplicado de la colección líquida está depositado en el Instituto Antártico Argentino.

Los datos morfométricos de cada taxa se obtuvieron a partir de mediciones realizadas sobre microfotografías del material fijado (excepcionalmente sobre preparados transitorios), empleando el programa ImageJ (Ferreira \& Rasband, 2012). Cada taxón de diatomeas se clasificó de acuerdo a su presencia respecto a la totalidad de las muestras analizadas según: muy frecuente (presencia en más del $75 \%$ ), frecuente $(50-75 \%)$, poco frecuente $(25-50 \%)$, raro $(5-25 \%)$, muy raro $(1-5 \%)$ y excepcional $(<1 \%)$. 


\section{Análisis microscópico cuantitativo}

Para realizar los conteos, se agitó la muestra por inversión y rotación suave, de manera sistematizada y se realizaron conteos sobre alícuotas de $20 \mu \mathrm{l}$ obtenidas mediante una pipeta automática Transferpette ${ }^{\circledR}$ (Brand GMBH+CO KG, Alemania) (Villafañe \& Reid 1995). Se contaron 300 células usando un microscopio óptico Carl Zeiss Standard 25, a 400X de magnificación (Zacher et al. 2007b). De ser necesario, se utilizaron varias alícuotas de cada muestra original para asegurar un mínimo de 300 células, registrándose el número de campos contados en cada caso. Obtenido el número de campos necesarios para acumular 300 células y el volumen de la muestra se calculó la densidad de cada taxa (Nicotri 1977, Zacher et al. 2007b). Se contó el número de células vivas y células muertas. Se expresó la densidad celular por centímetro cuadrado de sustrato y la abundancia relativa porcentual de cada taxa.

\section{Consideraciones acerca de la identificación de especies de diatomeas}

La identificación de diatomeas se realizó según la bibliografía específica para cada taxa, siguiendo a Round et al. (1990) con actualizaciones, de ser necesario, según Cox (2015). En la diagnosis de las especies se empleó la terminología sugerida en Anonymous (1975), Barber \& Haworth (1981), Nagumo (2003), Riaux-Gobin \& Romero (2003) y De Stefano \& Romero (2005).

\section{Concepto de "Complejo"}

En este trabajo, bajo la denominación de "complejo" se agrupa a las especies de un género que son muy similares entre sí y que sólo son posibles de diferenciar fidedignamente realizando observaciones con alta magnificación sobre preparados realizados con un medio de alto índice de refracción. Asimismo, en montajes líquidos es común encontrar a las células en vista conectival cuando los caracteres diferenciales en la mayoría de los casos, lo requieren de su vista valvar. En base a esta premisa, los siguientes complejos han sido establecidos: "complejo Cocconeis fasciolata/costata", "complejo Cocconeis melchiori/ dallmannii/melchioroides" y "complejo Fragilaria islandica/striatula". Los taxa que integran cada complejo y la fundamentación para su agrupamiento se detallan junto a las diagnosis de los géneros implicados.

\subsubsection{Macroalgas}

Se analizaron los taxa desarrollados sobre la totalidad de los sustratos empleados en esta Tesis. Para la clasificación taxonómica, se siguió el criterio de Wiencke \& Clayton (2002), actualizando la posición taxonómica - cuando fuera necesario- según Guiry \& Guiry (2018). 
La bibliografía consultada para la identificación de cada taxa se detalla en cada diagnosis. Se consultó además la colección de macroalgas de caleta Potter, actualmente conservada en el Herbario (BAc) del Museo Argentino de Ciencias Naturales "Bernardino Rivadavia". La identificación de los estadios iniciales de macroalgas fue realizada bajo la supervisión del Dr. C. Wiencke, Seaweed Laboratory, Department of Functional Ecology, en el Alfred Wegener Institute for Polar and Marine Research (AWI, Bremerhaven, Alemania). Este laboratorio cuenta con una extensa colección de cultivos de macroalgas antárticas y material fotográfico que se utilizó como consulta adicional para el análisis taxonómico.

Los datos morfométricos correspondieron a los valores de las dimensiones máximas de los talos macroscópicos y los máximos y mínimos de los estadios iniciales de macroalgas fotografiados al MO y estereoscópico.

La distribución geográfica de las especies de macroalgas en la Antártida se basa en la compilación realizada por Wiencke \& Clayton (2002), incorporando las referencias bibliográficas de nuevos registros hasta la actualidad.

\subsection{RESULTADOS y DISCUSIÓN}

\subsubsection{Microalgas}

Las diatomeas fueron el único grupo representado dentro de las microalgas bentónicas incluídas en las Heterokontophyta, las cuales históricamente estuvieron caracterizadas por la presencia de clorofila a y c, y de flagelos heterodínamos. Aunque en las diatomeas sólo el espermatozoide de los géneros oógamos es flagelado, ellas aún se incluyen en las heterokontas por compartir la ultraestructura plastidial y la composición pigmentaria (Medlin \& Kaczmarska 2004, Cox 2015). El nombre de Heterokontophyta u Ochrophyta es generalmente utilizado para referirse a los niveles taxonómicos superiores entre las diatomeas (Cox 2015).

En el material analizado en esta Tesis, las diatomeas fueron el grupo de algas bentónicas mejor representado en los sustratos artificiales, con un total de 40 taxa, 37 de los cuales fueron descriptos y documentados mediante microfotografías. Las medidas morfométricas y su presencia respecto al total de las muestras analizadas se resumen en la Tabla 3.1. En la Fig. 3.2 se grafica la frecuencia de ocurrencia de los taxa hallados. Complementariamente, las variaciones mensuales entre marzo 2004 y enero 2005 de las densidades de cada taxón se muestran en la Fig. 3.2.

A continuación se resume la distribución sistemática de los géneros que se describen en esta Tesis según Cox (2015). 
I. Mediophyceae Medlin \& Kaczmarka

1. Biddulphiales

Biddulphiaceae: Trigonium

2. Eupodiscales

Eupodiscaceae: Odontella

3. Thalassiosirales

Thalassiosiraceae: Minidiscus, Thalassiosira

\section{Fragilariophyceae Round}

1. Fragilariales

Fragilariaceae: Fragilaria, Brandinia $\left({ }^{*}\right)$

2. Rhabdonematales

Grammatophoraceae: Grammatophora

3. Cyclophorales

Entopylaceae: Entopyla

4. Licmophorales

Licmophoraceae: Licmophora

Ulnariaceae: Pteroncola

III. Bacillariophyceae Haeckel

1. Lyrellales

Lyrellaceae: Petroneis

2. Mastogloiales

Achnanthaceae: Achnanthes

3. Cymbellales

Rhoicopheniaceae: Rhoicosphenia

4. Cocconeidales

Cocconeidaceae: Cocconeis

5. Naviculales

Berkeleyaceae: Parlibellus

Diploneidaceae: Diploneis

Naviculaceae: Navicula, Pseudogomphonema, Trachyneis

Pleurosigmataceae: Pleurosigma

6. Thalassiophysales

Catenulaceae: Amphora

7. Bacillariales

Bacillariaceae: Fragilariopsis, Nitzschia

8. Rhopalodiales

Entomoneidaceae: Entomoneis

(*) Brandinia es un género no incluido en Cox (2015). Fernandes et al. (2007) establecen este género y lo ubican en el orden Fragilariales.

Seguidamente se presentan los taxa hallados en orden alfabético, acompañados de una diagnosis e incluyendo observaciones y comentarios. 


\section{Achnanthes Bory}

Las células son solitarias o forman bandas cortas o largas que se fijan al sustrato por un pedúnculo mucilaginoso. Las células son heterovalvares, la valva con rafe es cóncava y la valva sin rafe es convexa. El frústulo presenta cerca de la parte media una curvatura según el eje transapical. En vista conectival muestra un cíngulo constituido por varias cópulas ornamentadas por hileras de grandes poroides.

Las especies de este género tienen un hábitat bentónico y epífítico y se distribuyen predominantemente en ambientes marinos, con unas pocas especies en agua dulce y salobre (Round et al. 1990, Cox 2015). Dos especies del género Achnanthes fueron halladas en las muestras de este estudio: Achnanthes brevipes y Achnanthes vicentii.

Achnanthes brevipes C. Agardh

Lám. I, Figs. 1-6, Lám. II, Figs. 1-6

Agardh 1824, p. 1; Scott \& Thomas 2005, p. 121-122, Fig. 2.65 a-d; Toyoda et al. 2005, p. 375-386, Figs. 1-31; Cox 2006, p. 67-81, Figs. 1, 3-4, 6-9, 16, 19, 24, 30, 34; Toyoda et al. 2006, p. 527-528.

Las células forman colonias filamentosas en forma de banda, las que se adhieren al sustrato por medio de un pedúnculo mucilaginoso. Cada una de ellas contiene a cada lado del plano transapical dos grandes plástidos con un pirenoide. Los frústulos son heterovalvares, monorafidales, curvos según el plano medio transapical. En vista valvar son elípticolanceolados y alargados-rectangulares en vista conectival, con polos redondeados.

La hipovalva es cóncava, con un rafe recto y una fascia que se expande hasta los bordes de la valva. En vista externa, los extremos distales del rafe son curvados hacia el mismo lado y ocupan parte del manto valvar. En vista interna el rafe muestra helictoglosas pequeñas. La epivalva es convexa, con un esternón poco evidente, que, en los ejemplares de mayor tamaño, es ligeramente excéntrico. La superficie valvar posee areolas poroides ordenadas en hileras uniseriadas, paralelas en el centro y radiales hacia los polos. Cada poro areolar está ocluido por prolongaciones silíceas que se proyectan desde los bordes tipo volae. E manto es bajo y está ornamentado por una hilera de areolas semejantes a las de la superficie valvar. La cintura está compuesta por unas pocas cópulas abiertas, la valvocópula al igual que el resto de las cópulas poseen dos hileras de grandes poros arreglados advalvar y abvalvarmente.

Datos morfométricos: El eje apical varió entre $20,8 \mu \mathrm{m}$ y $50,2 \mu \mathrm{m}$ y el eje transapical entre $6,6 \mu \mathrm{m}$ y $10,9 \mu \mathrm{m}$. La cantidad de estrías en $10 \mu \mathrm{m}$ varió entre 7 y 9 . La cantidad de areolas varió entre 10 y 15 en $10 \mu \mathrm{m}$.

\section{Observaciones y comentarios}

El género Achnanthes fue descripto por Bory (1822), incluyendo tres especies, una de las cuales fue Achnanthes adnata, la cual Boyer (1927), designó como la especie tipo del 

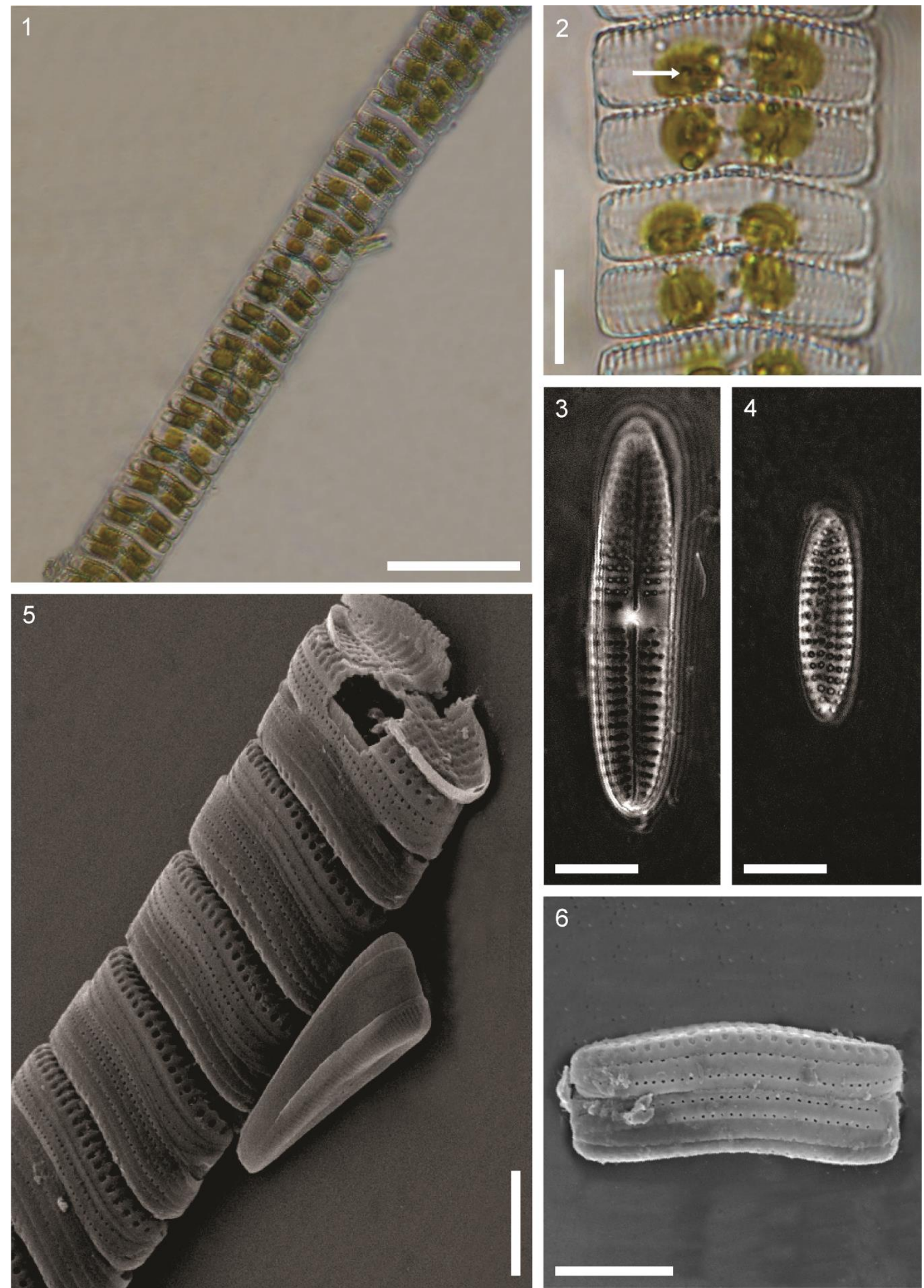

Lámina I. Achnanthes brevipes. Figs. 1-4 MO, Figs. 5-6 MEB. Fig. 1. Vista general de una colonia. Fig. 2. Células mostrando la ubicación de los cloroplastos y el pirenoide (flecha). Fig. 3. Vista de la valva con rafe. Fig. 4. Vista de la valva sin rafe. Fig. 5. Vista general de una colonia, revelando en detalle la cintura. Fig. 6. Vista general de dos frústulos, detalle del manto valvar y de las cópulas. Escalas: Fig. 1: $50 \mu \mathrm{m}$, Figs. 2-6: $10 \mu \mathrm{m}$. 

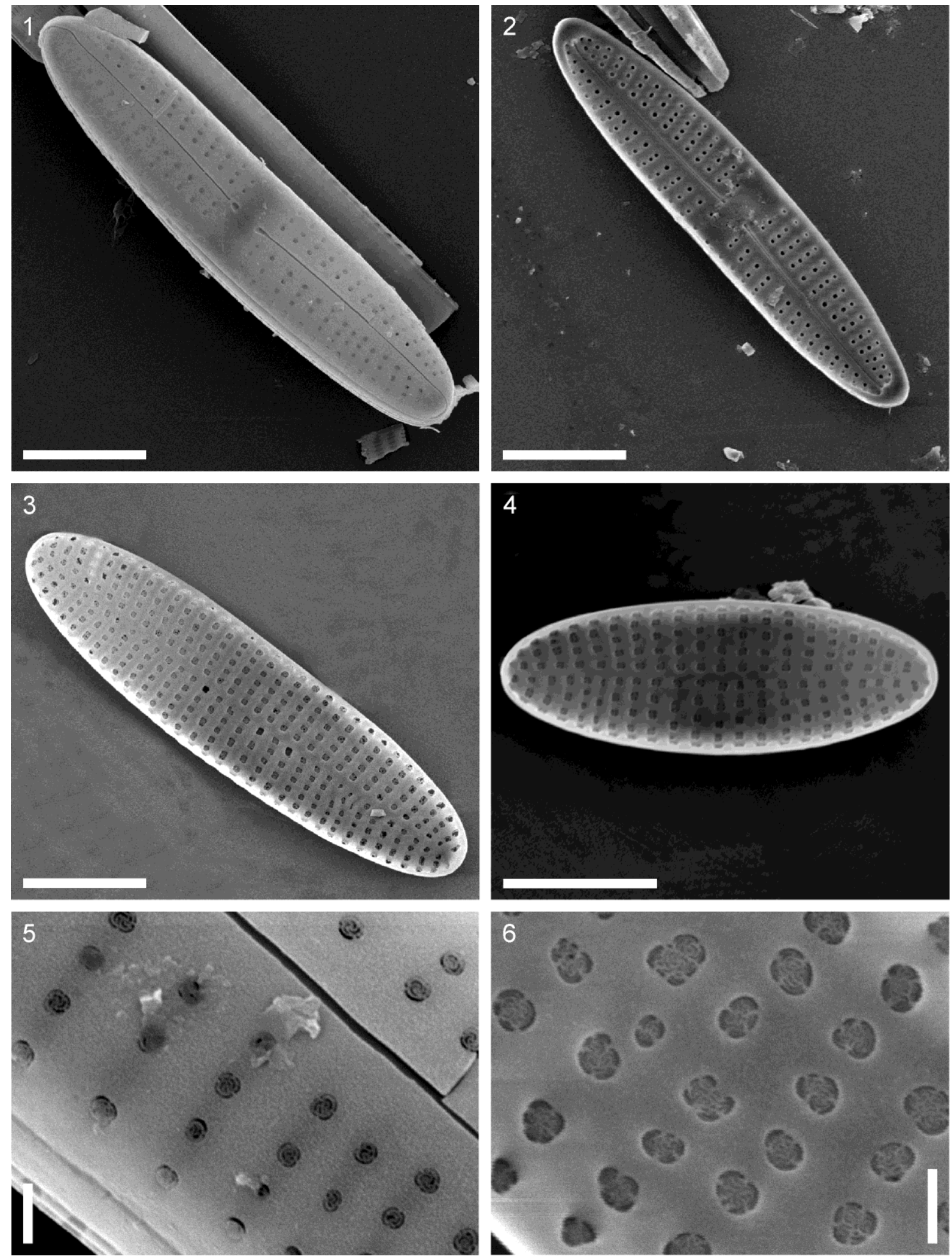

Lámina II. Achnanthes brevipes. Figs. 1-6, MEB. Fig. 1. Valva con rafe en vista externa, nótense las estrías uniseriadas, las fisuras del rafe curvadas en los polos hacia el mismo lado y una fascia que alcanza los bordes de la valva. Fig. 2. Valva con rafe en vista interna mostrando las fisuras terminales del rafe con pequeñas helictoglosas. Fig 3. Valva sin rafe en vista externa con estrías rectas en el centro y radiales hacia los polos. Fig. 4. Valva sin rafe en vista interna con un esternón poco evidente. Fig. 5. Detalle en vista externa de la valva con rafe, presentando los poros de las areolas cubiertos por una criba tipo volae. Fig. 6 . Detalle en vista interna de la valva sin rafe, nótense las cribas tipo volae. Escalas: Figs. 1-4: $10 \mu \mathrm{m}$, Figs. 5-6: $1 \mu \mathrm{m}$. 
género Achnanthes. Recientemente Toyoda et al. (2005), tipifican y priorizan el nombre $A$. brevipes en lugar del nombre $A$. adnata (Cox 2006), basados en que este nombre es el más conocido y ampliamente utilizado en la bibliografía.

En general los ejemplares analizados en esta Tesis coincidieron con la descripción presentada por la mayor parte de la bibliografía consultada (entre otros, Witkowski et al. 2000 , Scott \& Thomas 2005, Cox 2006), excepto en que nunca se observaron ejemplares con un esternón marcadamente desplazado hacia el margen. Se ha señalado para $A$. brevipes una elevada variabilidad en las dimensiones de la valva (Cleve 1894) así como disminuciones graduales en el tamaño de la célula con cambios marcados en la morfología de la valva, relacionadas con el ciclo de vida (Majewska et al. 2013a).

Se trata de una especie cosmopolita, marina y de ambientes salobres (Witkowski et al. 2000). En Antártida fue hallada en la flora de sedimento marino en las islas Windmill (Antártida oriental) (Cunningham \& Mc Minn 2004) y como epífita sobre rodofitas en Antártida occidental (Majewska et al. 2015, 2016) (Tabla 3.2). Si bien esta especie no fue descripta para la flora bentónica de caleta Potter, Klöser (1998) y Al-Handal \& Wulff (2008a) señalan la presencia de Achnanthes bongrainii (M. Peragallo) A. Mann, especie considerada como sinónimo de A. brevipes var. angustata (Greville) Cleve (Krebs 1983). Asimismo, se registró en esta misma área de estudio Achnanthes cf brevipes var. intermedia (Kützing) Cleve como epífita de algas rojas (Al Handal \& Wulff 2008b) (Tabla 3.2). Esta especie fue frecuente en el material analizado generalmente observada formando colonias acintadas (Tabla 3.1, Lám. I. Fig. 1).

Achnanthes vicentii Manguin

Lám. III, Fig. 1

Manguin 1957, p. 124, Lám. 5, Fig. 26; Manguin 1960, p. 308, Lám. 14, Figs. 162a-b, 163a-b; Scott \& Thomas 2005, p. 122, Fig. 2.66.

Los frústulos presentan valvas anchamente lanceoladas con polos redondeados. La valva con rafe presenta estrías triseriadas a cuadriseriadas, formadas por grandes poros y separadas por robustas virgas. Las estrías poseen un patrón de distribución alterno y están ordenadas radialmente hacia los polos. El rafe es filiforme, recto y está localizado centralmente. En vista externa presenta sus extremos distales curvados. El manto es liso y levemente inclinado.

Datos morfométricos: El eje apical fue de $7,4 \mu \mathrm{m}$ y el eje transapical de $4,2 \mu \mathrm{m}$. La cantidad de estrías en la valva con rafe fue de 12-14 en $10 \mu \mathrm{m}$ y la cantidad de areolas fue de 6-7 en $1 \mu \mathrm{m}$. 


\section{Observaciones y comentarios}

Esta especie fue hallada como epífita sobre macroalgas en Antártida occidental y oriental (Tabla 3.2). La presencia de esta especie fue excepcional en las muestras analizadas, tratándose del primer registro para ambientes bentónicos en caleta Potter.
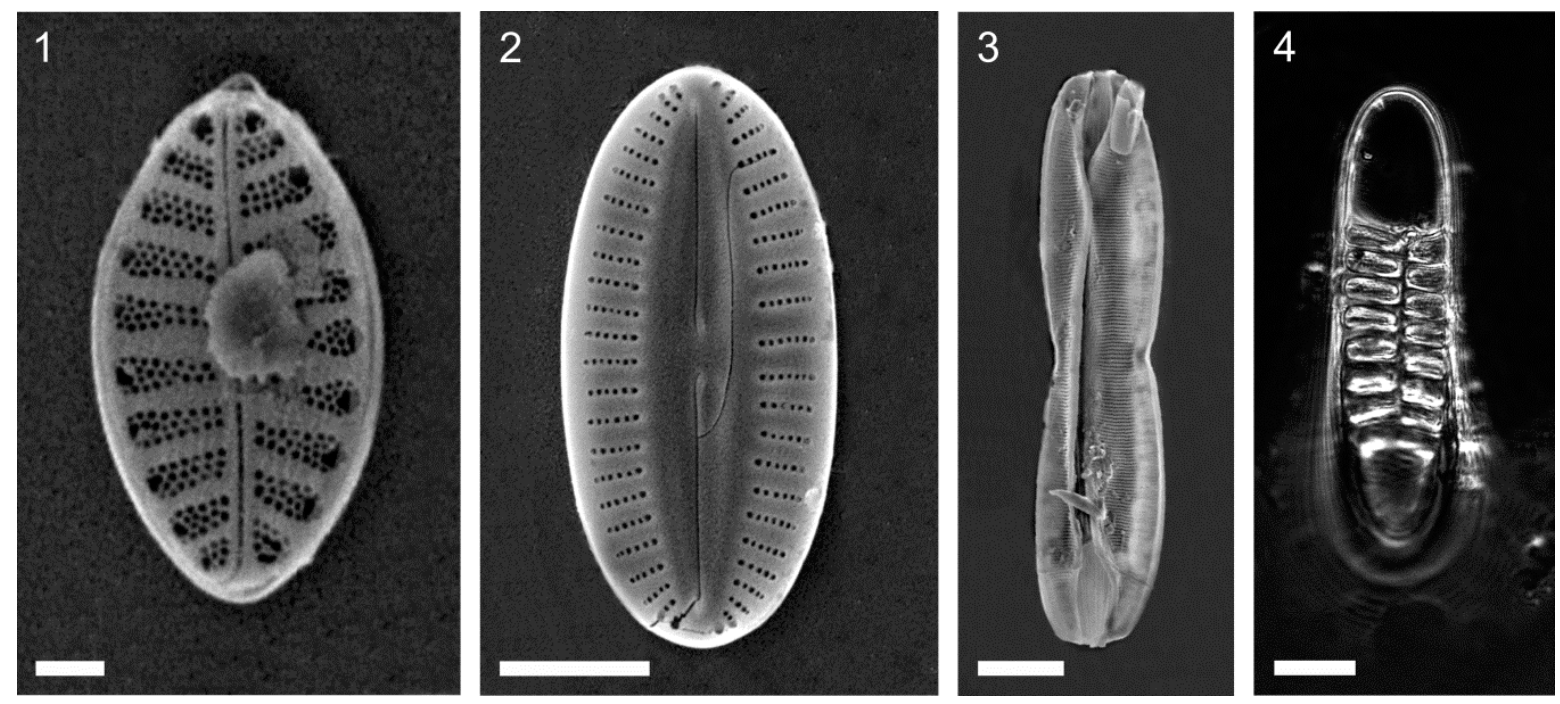

Lámina III. Figs. 1-3 MEB. Fig. 4. MO. Fig. 1. Achnanthes vicentii. Vista externa de la valva con rafe; nótense las estrías biseriadas a triseriadas. Fig. 2. Diploneis smithii. Vista general interna de una valva mostrando las características de las estrías y del rafe. Fig. 3. Entomoneis sp. Aspecto general del frústulo en vista conectival. Fig. 4. Entopyla ocellata. Vista valvar externa, nótense las estrías alternas y el angosto esternón. Escalas: Fig. 1: $1 \mu \mathrm{m}$, Fig. 2: $5 \mu \mathrm{m}$, Figs. 3-4: $10 \mu \mathrm{m}$.

\section{Amphora Ehrenberg ex Kützing}

El género Amphora forma parte de un grupo polifilético de diatomeas rafidales (Stepanek \& Kociolek 2014). Las células son solitarias, con un único plástido ubicado ventralmente, formado por cuatro lóbulos, con un pirenoide central (Levkov 2009). Los principales caracteres que lo diferencian de los géneros más afines son la marcada dorsiventralidad del frústulo y el rafe de ambas valvas localizado cerca del margen ventral (Nagumo 2003). La superficie valvar presenta estrías uniseriadas o biseriadas.

El género Amphora sensu lato incluye más de 800 especies (Stepanek \& Kociolek 2014) epífitas o epilíticas, la mayoría de ambientes marinos, con relativamente unas pocas especies representadas en agua dulce y salobre (Nagumo 2003). Una especie del género Amphora, Amphora marina, fue hallada en las muestras del presente estudio. Lám.73, Figs. 1-3, Lám. 74, Figs. 1-2, Lám. 75, Figs 1-3; Levkov 2009, p. 80-81, Lám. 76, Fig. 7.

Las valvas presentan una parte dorsal suavemente arqueada y una ventral moderadamente cóncava, con polos redondeados. El área axial es estrecha y la central sobre el lado dorsal 
alargada longitudinalmente y con una fascia hacia el lado ventral. En vista externa, las fisuras centrales del rafe están curvadas hacia el lado dorsal y las terminales están arqueadas de la misma forma. La superficie valvar presenta estrías uniseriadas formadas por areolas elípticas, paralelas en el centro y convergentes hacia los polos. El manto es profundo y el de la valva dorsal, con un borde hialino. El cíngulo está formado por la valvocópula y tres cópulas, la abvalvar más angosta y con una hilera de poros irregulares.

Datos morfométricos: En vista valvar, el eje apical varió entre 25,5 y $49,6 \mu \mathrm{m}$, el eje pervalvar varió entre 9,7 y 18,1 $\mu \mathrm{m}$. La cantidad de estrías dorsales en $10 \mu \mathrm{m}$ fue de 8,5-11 y la cantidad de estrías ventrales en $10 \mu \mathrm{m}$ fue de 10-12.

\section{Observaciones y comentarios}

Los ejemplares analizados de A. marina pueden ser fácilmente confundidos con Amphora proteus. Sin embargo, $A$. marina es más pequeña y presenta en la parte ventral sólo una areola por estría (Levcov 2009).

Al-Handal \& Wulff (2008a) registraron esta especie en la flora bentónica de sustrato blando en caleta Potter (Tabla 3.2). Sus ejemplares, al igual que los analizados para esta Tesis, presentaron un número ligeramente menor de estrías dorsales que los señalados en la descripción original de la especie (Levcov 2009). Esta especie fue registrada como rara en las muestras analizadas.
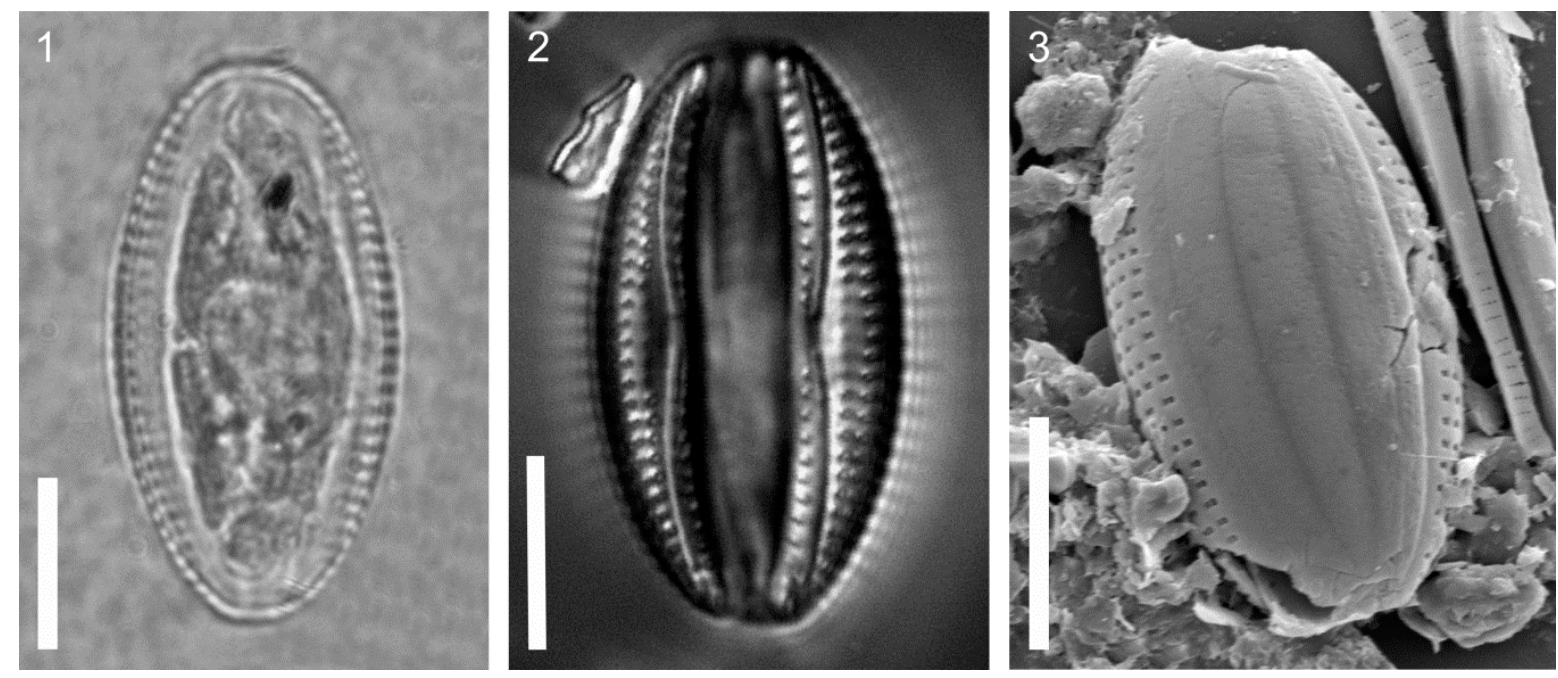

Lámina IV. Amphora marina. Figs. 1-2 MO, Fig. 3 MEB. Fig. 1. Vista general de una célula. Fig. 2. Frústulo en vista cingular mostrando detalles del rafe y de las estrías. Fig. 3. Frústulo en vista conectival; nótese el manto con un borde hialino y las cópulas. Todas las escalas corresponden a $10 \mu \mathrm{m}$. 


\section{Brandinia Fernandes}

Brandinia es un género arrafidal, monoespecífico, establecido en base a la especie Brandinia mosimanniae Fernandes \& Procopiak para ambientes epilíticos costeros de la Península Antártica.

Brandinia mosimanniae Fernandes \& Procopiak

Lám. V, Figs. 1-3

Fernandes \& Procopiak en Fernandes et al. 2007, p. 47, Figs. 1-6, 11-28; Ferrario et al. 2012, p. 228, Tabla 1; Majewska et al. 2016, p. 6, Tabla 2.

Las células son solitarias y poseen dos plástidos. Las valvas son lineares-lanceoladas, con ápices desde capitados a redondeados. La superficie de la valva es plana y las estrías son uniseriadas y paralelas, formadas por areolas poroides y separadas por virgas robustas. El esternón es angosto y se expande en la zona central. Cada valva presenta dos procesos labiados, uno en cada polo, generalmente uno sobre el esternón y el otro ligeramente desplazado. Los campos de poros (ocellulimbus) están ubicados sobre el manto valvar, cada uno formado por varias hileras longitudinales de pequeños poros. El cíngulo presenta bandas abiertas, cada una con una fila longitudinal de pequeños poros.

Datos morfométricos: El eje apical varió entre 102,0 y $124,8 \mu \mathrm{m}$ y el eje transapical entre 7,4 y $7,8 \mu \mathrm{m}$. La cantidad de estrías en $10 \mu \mathrm{m}$ varió entre 11 y 13 . El número de areolas varió entre 35 y 45 en $10 \mu \mathrm{m}$.

\section{Observaciones y comentarios}

Los ejemplares analizados coincidieron en general con los caracteres presentados en la descripción original de la especie aunque con un número ligeramente menor de estrías y areolas (12-20 en $10 \mu \mathrm{m}$ y 5-6 en $1 \mu \mathrm{m}$ según Fernández et al. 2007).

Brandinia comparte características morfológicas con el género Ulnaria (Fernandes et al. 2007, Ferrario et al. 2012) dado que ambos taxa presentan dos procesos labiados por valva. Sin embargo, a diferencia de Brandinia, la distribución del género Ulnaria está restringida a ambientes de agua dulce (Round et al. $1990=$ Synedra). Asimismo, $B$. mossimanniae presenta caracteres muy cercanos a Fragilaria striatula, particularmente cuando las valvas son observadas con baja magnificación. Brandinia presenta células solitarias, una superficie valvar con un área hialina central siempre presente, un menor número de estrías y dos procesos labiados por valva (Fernandes et al. 2007, Ferrario et al. 2012). Fragilaria a diferencia de Brandinia, sólo posee un proceso labiado por valva (Fernandes et al. 2007) y F. striatula se encuentra habitualmente formando colonias acintadas, a diferencia de la naturaleza solitaria de Brandinia (Fernandes et al. 2007, Ferrario et al. 2012). 
Brandinia mosimanniae es una especie marina, hallada en el sustrato duro de zonas intermareales y submareales de la Península Antártica (Fernandes et al. 2007) y reportada como epífita de algas rojas en bahía Lasserre (bahía del Almirantazgo) y la zona del Mar de Ross (Majewska et al. 2015, 2016) (Tabla 3.2). Esta especie fue registrada como rara en el material analizado y representa el primer registro para la flora bentónica de caleta Potter (Tabla 3.1).
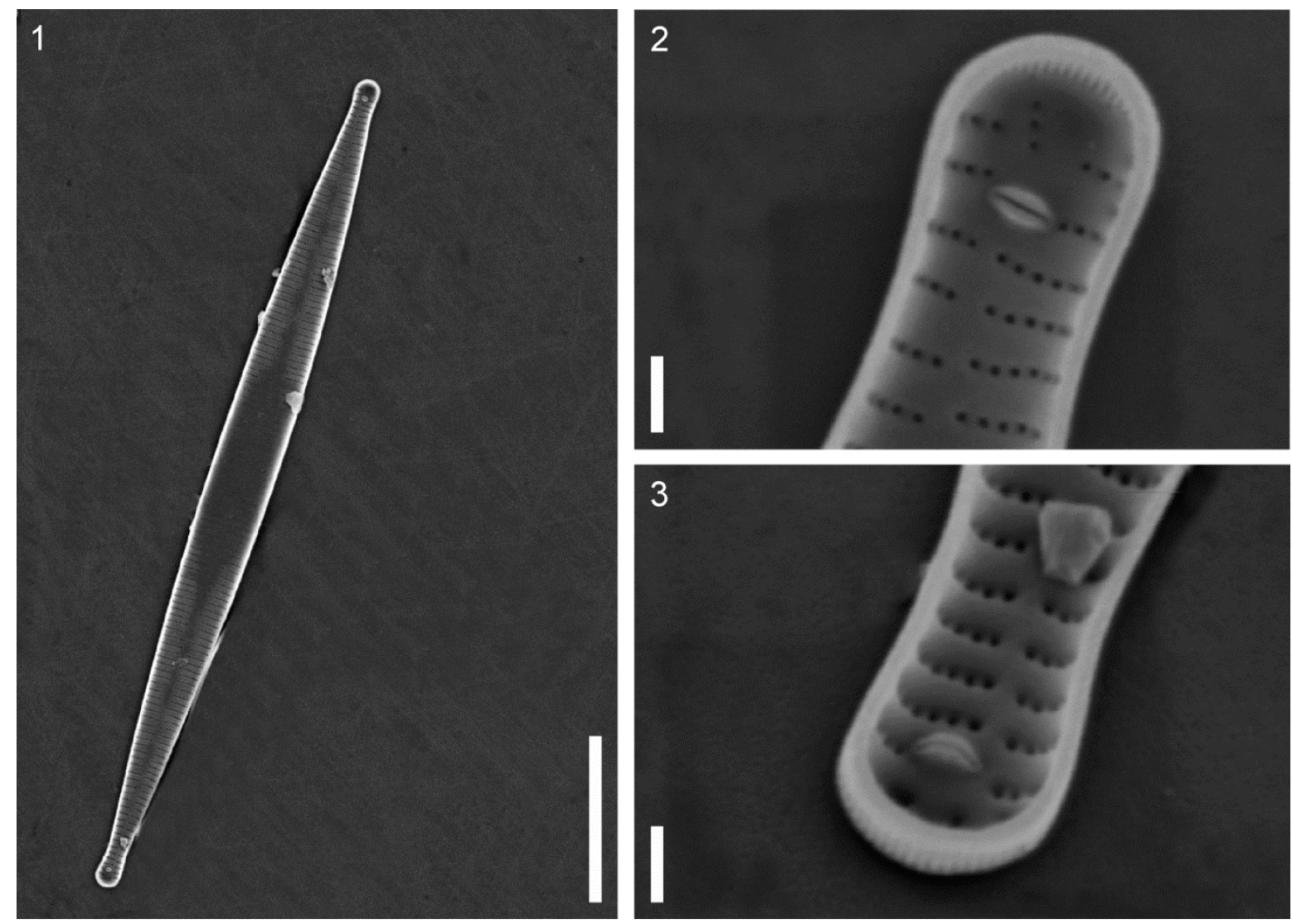

Lámina V. Brandinia mossimanniae. Figs. 1-3 MEB. Fig.1. Vista valvar interna; nótense las estrías uniseriadas paralelas, las dos rimopórtulas cerca de los ápices y el angosto esternón expandido en la región central. Figs. 2 3. Detalle de la ubicación de las rimopórtulas y el ocellolimbus en cada polo, en vista interna. Una rimopórtula se ubica sobre el esternón (Fig. 2) y la otra se encuentra ligeramente desplazada (Fig. 3). En Fig. 3, detalle del ápice levemente inclinado y el manto engrosado en la zona apical. Escalas: Fig. 1: 20 mm, Figs. 2-3: $1 \mu \mathrm{m}$.

\section{Cocconeis Ehrenberg}

El género Cocconeis agrupa organismos solitarios, monorafidales, con valvas elípticas, ovales hasta casi circulares y frústulos ligeramente curvos en vista conectival. La valva cóncava posee el rafe y es por la cual la célula se adhiere al sustrato, la valva convexa posee un esternón morfológicamente variable (Cox 2015). Los frústulos pueden estar formados por valvas ornamentadas por estrías poroides o por estrías con cámaras alveoladas en la valva sin rafe. Basados en la ultraestructura alveolar recientemente se 
estableció una nueva sección dentro del género Cocconeis denominada "Alveolate" (De Stefano \& Romero 2005).

Cocconeis es un género que se halla en ambientes dulceacuícolas y marinos, cosmopolita, con un habitat bentónico, hallándose adherido a diferentes sustratos mediante mucílago (Cox 2015). En este trabajo se hallaron siete especies de este género: Cocconeis antiqua, Coconeis aff. costata, Cocconeis dallmannii, Cocconeis fasciolata, Cocconeis melchiori?, Cocconeis melchioroides y Cocconeis orbicularis. Entre las especies del género Cocconeis es común encontrar similitudes morfológicas, o diferencias ultraestructurales que requieren para una correcta identificación no sólo del uso del MO sino también del ME. Por esta razón, para los conteos de las especies con estas caracteristicas, en este trabajo se establecieron los complejos: "complejo Cocconeis fasciolata/costata" y "complejo Cocconeis melchiori/dallmannii/melchioroides". Cada complejo precederá a una breve diagnosis las especies que lo integran.

Cocconeis antiqua Tempère \& Brun

Lám. VI, Figs.1-3, Lám VII, Figs. 1-4

Brun \& Tempère 1889, p. 32, Lám. 8, Fig. 5; De Stefano \& Romero 2005, p. 14-16, Lám. 1, Figs. 1-6, Lám. 5, Figs. 1-11, Lám. 6, Figs. 1-12; Scott \& Thomas 2005, p. 127-128, Fig. 2.69; Romero 2011, Figs. 2-4, 7-9, Figs. 13-18, Figs. 25-35.

Las células son elípticas. La valva con rafe externamente es convexa, con un manto cóncavo y presenta estrías transapicales uniseriadas, rectas en el centro y curvas hacia los extremos, cada una formada por poroides circulares. El rafe es recto, en vista externa muestra las fisuras terminales ubicadas a una corta distancia del margen valvar, cada una delimitada por una pequeña zona hialina en forma de flecha. El área central forma un estauro con un area hialina subcircular hacia uno de los lados. En vista interna las fisuras centrales están ubicadas cerca una de otra y las terminales muestran grandes y alargadas helictoglosas. La valva del esternón externamente es cóncava a lo largo del eje apical y abruptamente curva hacia el manto, que es convexo. La superficie valvar presenta estrías uniseriadas irregulares formadas por alveolos alargados trasapicalmente e interrumpidas según el eje apical por bandas hialinas de forma más o menos lenticulares. La valvocópula es abierta y lleva adosado un marcado fiambre.

Datos morfométricos: El eje apical varió entre 37,3 y $87,3 \mu \mathrm{m}$ y el eje transapical, entre 21,4 y $61,8 \mu \mathrm{m}$. En la valva con rafe, la cantidad de estrías en $10 \mu \mathrm{m}$ fue de 10-16 en el margen y 17-19 cerca del centro, con 18-20 areolas en $10 \mu \mathrm{m}$. En la valva sin rafe, la cantidad de estrías en $10 \mu \mathrm{m}$ fue de 25-26 en el margen y 20-21 cerca del centro. 


\section{Observaciones y comentarios}

Para la identificación de C. antiqua se adoptó el criterio de Romero (2011), quien considera como sinónimos de esta especie a Cocconeis gautierii var. gautierii y var. inornata, Cocconeis litigiosa y Cocconeis schuetii var. schuetii y minor.

Esta especie ha sido reconocida principalmente como una especie fósil, menos registrada en material reciente (De Stefano \& Romero 2005). Se trata de una especie cosmopolita y se encuentra distribuida en Antártida Oriental (Cremer et al. 2003) y occidental (Scott \& Thomas $2005=$ C. schuetii van Heurck), registrada en ambientes bentónicos de fondos blandos y rocosos y asociada a macroalgas (Tabla 3.2). En particular, para caleta Potter fue hallada en ambos tipos de sustratos y asociada a algas rojas y pardas (Tabla 3.2). Esta especie fue poco frecuente en el material analizado (Tabla 3.1).
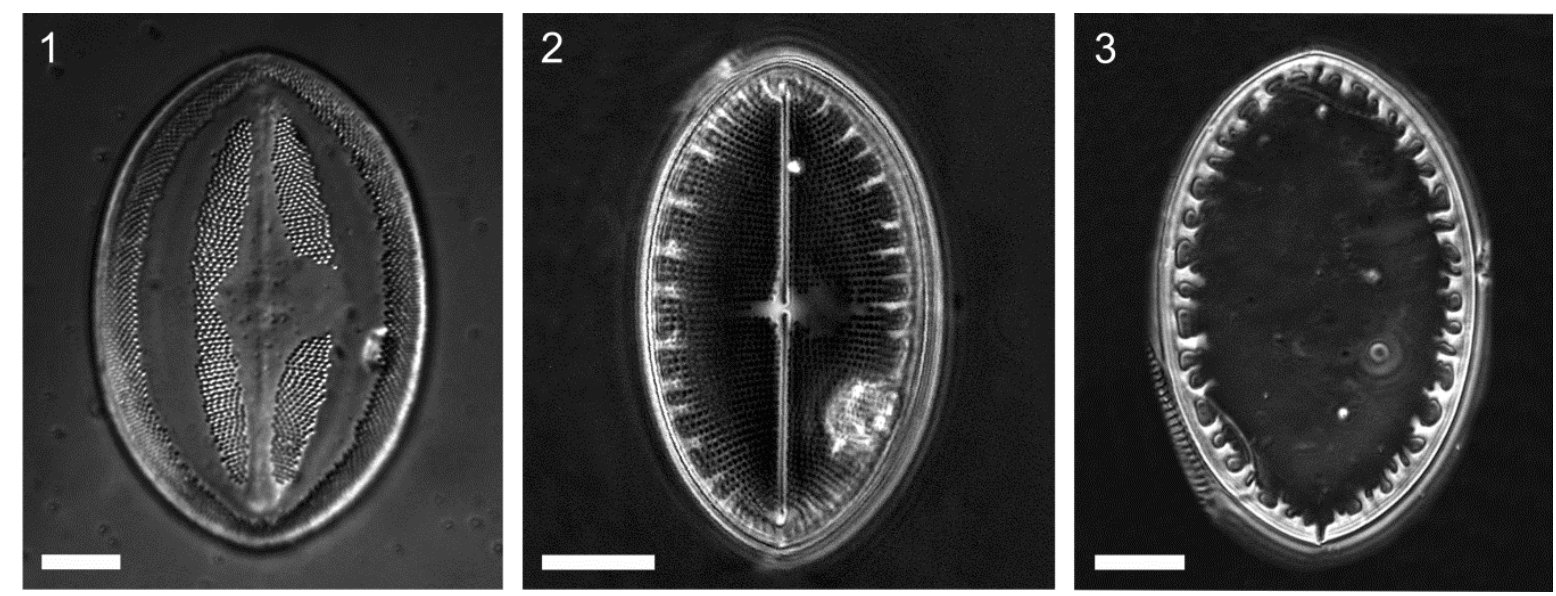

Lámina VI. Cocconeis antiqua. Figs. 1-3 MO. Fig. 1. Valva del esternón; obsérvense las estrías uniseriadas interrumpidas por bandas hialinas y el esternón delimitando una fascia extendida asimétricamente hacia uno de los márgenes valvares. Fig. 2. Valva con rafe en vista externa, nótense las prolongaciones ramificadas (fimbriae) de la valvocópula y una fascia asimétrica. Fig. 3. Valvocópula mostrando la típica estructura fimbriae. Todas las escalas corresponden a $10 \mu \mathrm{m}$.

\section{Complejo Cocconeis fasciolata/costata}

Las especies Cocconeis aff. costata y Cocconeis fasciolata fueron agrupadas para los conteos dentro del "complejo Cocconeis fasciolata/costata". Ambos taxa son similares principalmente en el número de estrías en la valva sin rafe, y marcadamente diferentes en el número de areolas en la valva con rafe. Estos caracteres, similares y diferenciales, son difíciles de visualizar al MO en montajes líquidos, por lo que una exacta determinación a nivel especifico no es posible. El nombre en el orden de las especies al definir este complejo se originó en que en la gran mayoría de los ejemplares analizados en los preparados fijos correspondieron a $C$. fasciolata. A continuación se describen ambos taxa analizados al $\mathrm{MO}$ y MEB. 

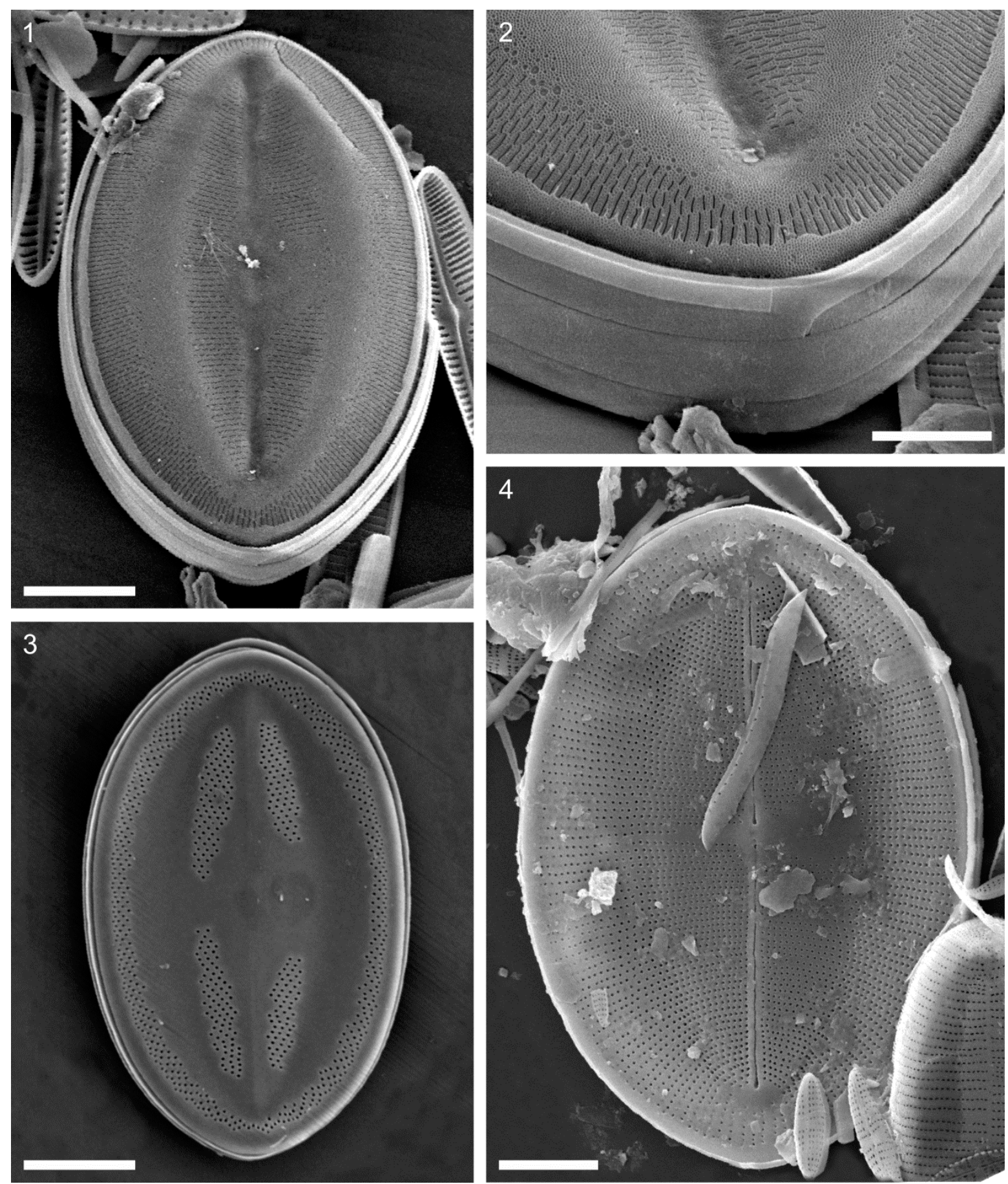

Lámina VII. Cocconeis antiqua. Figs. 1-4 MEB. Fig. 1. Vista valvar externa de la valva del esternón. Fig. 2. Detalle de uno de los polos valvares; nótese el borde no estriado del manto y el contorno irregular del himenio de los alveolos, y las cópulas lisas. Fig. 3. Vista valvar interna de la valva del esternón mostrando los forámenes de los alveolos. Fig. 4. Vista valvar interna mostrando un rafe filiforme con fisuras terminales lejos del borde valvar; nótese la distribución de las estrías uniseriadas, rectas hacia el centro, curvas hacia los extremos. Todas las escalas corresponden a $10 \mu \mathrm{m}$ excepto Fig. 2: $5 \mu \mathrm{m}$. 
Gregory 1855, p. 39, Lám. 4, Fig. 10; Frenguelli \& Orlando 1958, p. 82, Lám. 1, Figs. 12, 14-15; Romero \& Rivera 1996, p. 335-338, Figs. 54-64, Tabla 2; Riaux-Gobin \& Romero 2003, p. 30-31, Lám. 7, Figs. 12-14; Riaux-Gobin et al. 2014, p. 81-99, Figs. 2, 6-43.

Las células son solitarias, en vista valvar elípticas a ligeramente hexagonales, con extremos redondeados a subredondeados. La superficie de la valva con rafe presenta un marcado anillo marginal hialino algo elevado que delimita una hilera marginal de areolas. Las estrías son mayormente biseriadas, radiales a curvas hacia los polos. El rafe es recto, en vista externa con las fisuras terminales y centrales ligeramente dilatadas, estas últimas curvadas en direcciones opuestas. La superficie de la valva sin rafe es suavemente convexa y presenta estrías robustas triseriadas en la mayor parte de su longitud, formadas por areolas ordenadas en quincux. El esternón es estrecho, ligeramente lanceolado y se extiende hasta los extremos de la valva.

Datos morfométricos: El eje apical varió entre 11,3 y $26,0 \mu \mathrm{m}$ y el eje transapical entre 7,1 y $14,3 \mu \mathrm{m}$. La valva sin rafe, con 5-6 estrías en $10 \mu \mathrm{m}$ y $14-16$ areolas en $10 \mu \mathrm{m}$ y la valva con rafe con 11-12 estrías en $10 \mu \mathrm{m}$ y 33 areolas en $10 \mu \mathrm{m}$.

\section{Observaciones y comentarios}

Cocconeis costata es una especie caracterizada por presentar un amplio rango de variaciones morfológicas (Riaux-Gobin \& Romero 2003), y por haber sido erróneamente identificada en trabajos previos (Frenguelli \& Orlando 1958, Romero \& Rivera 1996, RiauxGobin et al. 2014). Se trata de una especie muy semejante a Cocconeis pinnata, de la cual se diferencia por la ausencia en vista interna de la valva con rafe en C. pinnata, de un anillo marginal elevado (Riaux- Gobin et al. 2014). Frenguelli \& Orlando (1958), ilustran tres valvas sin rafe (Lám. 1, Figs. 12,14-15), como C. pinnata en muestras de Antártida. Riaux- Gobin et al. (2014), consideran errónea esta identificación como así también la de Romero \& Rivera (1996), sugiriendo que ambas denominaciones corresponderían al grupo C. costata. Con la finalidad de corroborar la identidad de C. pinnata llevada a cabo por Frenguelli \& Orlando (1958), se consultó la Colección Frenguelli LPC, Museo de La Plata (Serie 46-1; Serie 28-2, véase Lám. 1, Figs. 12,14-15 en Frenguelli \& Orlando 1958), que contiene este material procedente de Bahía Esperanza e Isla Laurie (Antártida). Desafortunadamente sólo fue posible hacer un análisis al MO sobre los preparados fijos de la Colección, lo que no permitió analizar la ultraestructura valvar y así poder tener una acertada identificación de la especie.

Los ejemplares analizados en las muestras de esta Tesis al MO y MEB, morfológicamente son muy similares a $C$. costata, aunque la marcada variación observada en la estructura valvar principalmente en el número de areolas y estrías en la valva sin rafe 
así como en el número de hileras de areolas por estría, dificultan una identificación correcta y se los describe como $C$. aff. costata.

Cocconeis costata es una especie marina, posiblemente cosmopolita (Guiry \& Guiry 2018). En Antártida, esta especie ha sido registrada en fondos rocosos, blandos y como epífita de macroalgas (Frenguelli \& Orlando 1958, Klöser 1998, Al-Handal \& Wulff 2008a,b, entre otros).
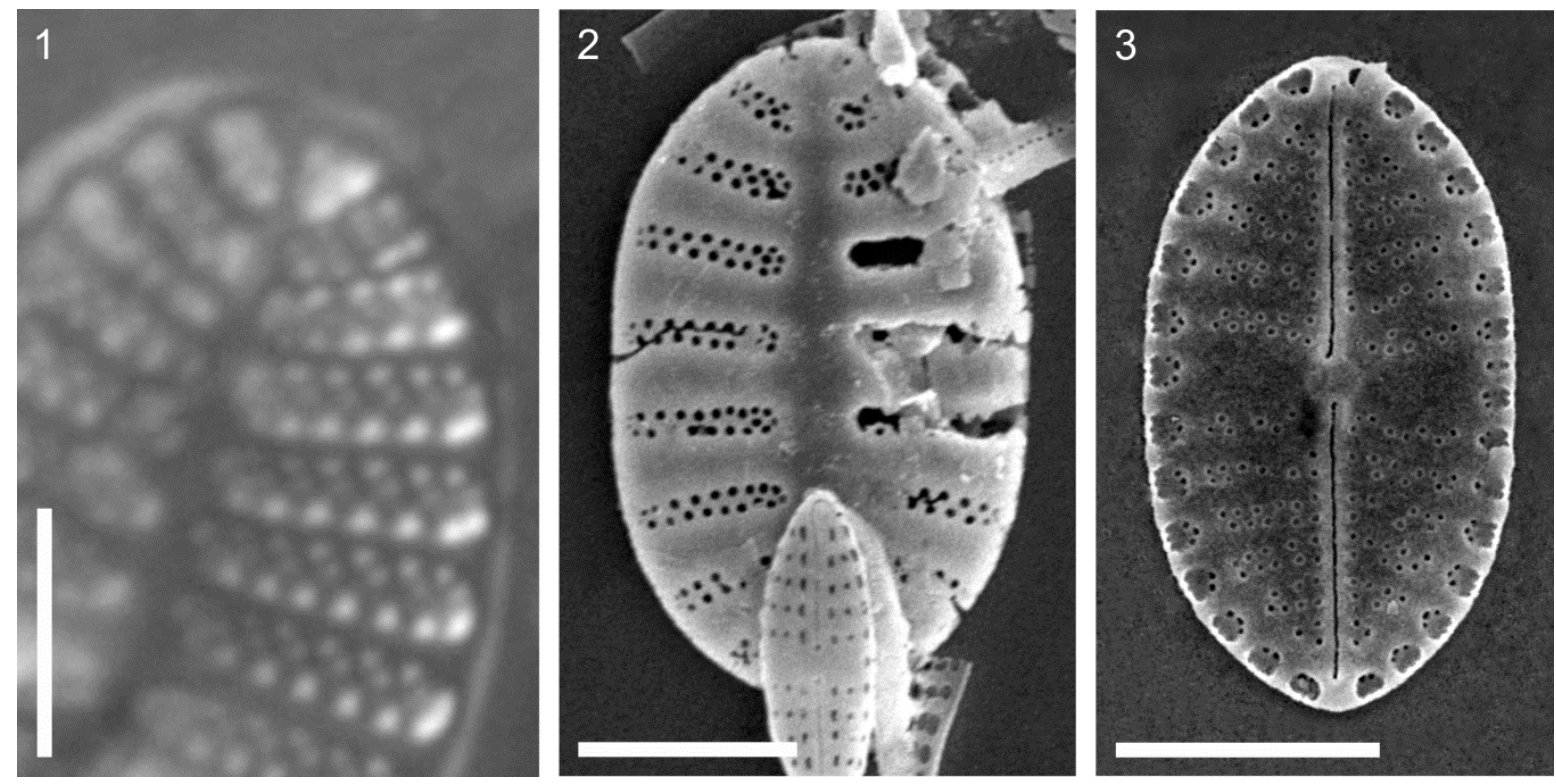

Lámina VIII. Cocconeis aff. costata. Fig. 1 MO, Figs. 2-3 MEB. Fig. 1. Detalle de una parte de la valva con esternón mostrando las estrías triseriadas. Fig. 2. Valva del esternón con estrias principalmente biseriadas, triseriadas en el límite con el esternón. Fig. 3. Valva con rafe en vista interna; nótense las estrías biseriadas y los extremos centrales del rafe orientados hacia distintas direcciones. Todas las escalas corresponden a $5 \mu \mathrm{m}$.

Cocconeis fasciolata (Ehrenberg) Brown

Lám. IX, Figs. 1-5

Brown 1920, p. 232; Riaux-Gobin \& Romero 2003, p. 26-27, Figs. 26-28, Lám. 19; Scott \& Thomas 2005, p. 127, Fig. 2.68; Al-Handal \& Wulff 2008a, Tabla 1-2, Fig. 37; Al-Handal \& Wulff 2008b, p. 426, Figs. 45, 51-52.

Las células son solitarias, elíptico-lanceoladas. La superficie de la valva con rafe posee estrías biseriadas rectas en el centro, radiales a curvadas hacia los polos, y formadas por areolas poroides, cada una cubierta externamente por un velo tipo rotae. Las areolas están ausentes en los polos, dejando una evidente área hialina. Un anillo marginal delimita hacia el margen a un grupo reducido de areolas. El rafe es recto, en vista externa con las fisuras terminales y centrales ligeramente dilatadas. La valva con esternón presenta estrías biseriadas, triseriadas cerca del margen el cual es estrecho a anchamente lanceolado y suavemente depreso en vista valvar externa. El número de estrías y areolas son similares 

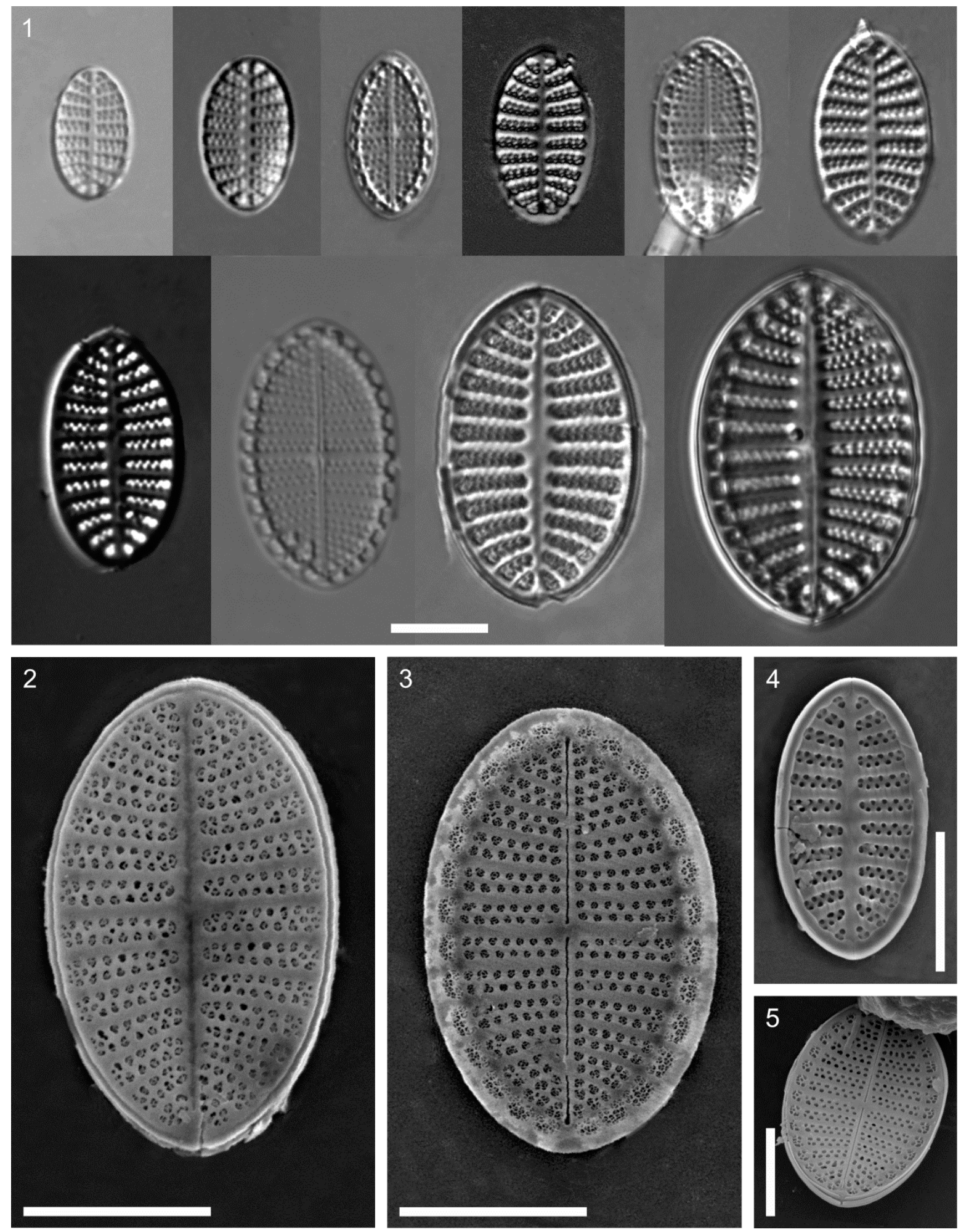

Lámina IX. Cocconeis fasciolata. Fig. 1 MO, Figs. 2-5 MEB. Fig. 1. Vista de valvas con y sin rafe mostrando un amplio espectro de tamaños. Nótese el mismo número de estrías en ambas valvas. Fig. 2. Vista externa de la valva sin rafe. Nótense las estrías biseriadas, triseriadas cerca del margen. Fig. 3. Valva con rafe en vista externa; nótese el anillo que separa las estrías biseriadas del grupo marginal de areolas complejas, y los extremos del rafe dilatados. Fig. 4. Vista interna de la valva sin rafe mostrando robustas virgas. Fig. 5. Vista interna de la valva con rafe, nótese la ausencia de areolas en el ápice, y las cópulas lisas y abiertas. Todas las escalas corresponden a $10 \mu \mathrm{m}$.

en ambas valvas; las areolas están arregladas en quincux. El cíngulo está formado por unas pocas cópulas lisas y abiertas. 
Datos morfométricos: El eje apical varió entre 13,5 y $50,4 \mu \mathrm{m}$ y el eje transapical entre 7,3 y 35,8 $\mu \mathrm{m}$. La cantidad de estrías y areolas es igual en ambas valvas. Presenta 4-7 estrías, con $10-18$ areolas en $10 \mu \mathrm{m}$.

\section{Observaciones y comentarios}

Cocconeis fasciolata es similar a C. costata, el mismo se diferencia principalmente por presentar un número igual de estrías y areolas en ambas valvas y por el significativamente mayor número de areolas en $C$. costata. Así también por la diferencia en la estructura del himen de sus areolas, el cual en $C$. costata está perforado radialmente y en $C$. fasciolata es tipo rotae (Riaux-Gobin \& Romero 2003).

Se trata de una especie ampliamente distribuida a nivel mundial como epifita y bentónica (Guiry \& Guiry 2018). En Antártida C. fasciolata ha sido registrada en sedimentos, y como epífita de algas rojas (Riaux Gobin \& Romero 2003, Tabla 3.2). Para caleta Potter ha sido registrada como epífita de macroalgas, y en sustratos duros y fondos blandos (Tabla $3.2)$.

\section{Complejo Cocconeis melchiori/dallmannii/melchioroides}

Dentro de este complejo se agruparon para los conteos a las especies Cocconeis dallmannii, Cocconeis melchiori? y Cocconeis melchioroides. El primer nombre en el orden de las especies fue elegido en reconocimiento a la especie $C$. melchiori creada por Frenguelli \& Orlando (1958). Estas especies están caracterizadas por presentar estrías marginales muy cortas en la valva sin rafe (Al-Handal et al. 2008, 2010), carácter poco común para el género Cocconeis. Asimismo, poseen una distribución aparentemente restringida a regiones australes y antárticas (Riaux Gobin \& Romero 2003, Al-Handal et al. 2008). Las diferencias principales entre estas tres especies radican fundamentalmente en la densidad de las estrías en la valva sin rafe, y en la estructura y número de estrías en ambas valvas, características que para una buena identificación no sólo requieren del uso de MO con preparados fijos sino también de microscopía electrónica.

A continuación se describen los tres taxa analizados mediante la obtención de preparados fijos observados al MO y la utilización de MEB. Tablas 1-2, Figs. 54-55, 134-135; Al-Handal \& Wulff 2008b, p. 425-426, Figs. 39-40, Tabla 2.

Las células son solitarias, con valvas anchamente elípticas a lanceoladas y polos subredondeados. La valva con rafe presenta estrías uniseriadas, rectilíneas a levemente curvadas y muy radiadas hacia los polos. El centro de la valva presenta una amplia área 
hialina, con tres a cinco estrías más cortas sobre el margen valvar. El rafe es recto y robusto en vista externa con los extremos de las fisuras centrales redondeadas y marcadamente apartadas, y en vista interna con las terminaciones centrales deflectas en dirección opuesta. Las fisuras terminales son de forma redondea, están alejados del margen, y en vista interna muestran pequeñas helictoglosas. La valva presenta una crista marginalis continua que separa el manto valvar, ornamentado por areolas agrupadas de a dos, de la superficie valvar. Hacia la periferia de la superficie pueden observarse pequeñas ornamentaciones fuertemente silicificadas, contiguas a las areolas. La superficie de la valva con esternón externamente es suavemente convexa, con cortas estrías marginales formadas por unas pocas areolas, que internamente abren en un foramen de perfil redondeado o piramidal.

Datos morfométricos: El eje apical varió entre 10,1 y $13,3 \mu \mathrm{m}$ y el eje transapical entre 7,1 y $12,1 \mu \mathrm{m}$. En la valva con rafe, la cantidad de estrías en $10 \mu \mathrm{m}$ fue de $17-20$, con 28 areolas en $10 \mu \mathrm{m}$. En la valva sin rafe, la cantidad de estrías en $10 \mu \mathrm{m}$ fue de 10-11.

\section{Observaciones y comentarios}

Cocconeis dallmannii se diferencia de C. melchiori? y de C. melchioroides básicamente por la mayor densidad de estrías en la valva sin rafe y por la estructura de las estrías reducidas a grupos de unas pocas areolas (dos-cinco), nunca areolas biseriadas paralelas como en $C$. melchiori o bi-triseriadas como en C. melchioroides. Por otro lado, considerando la valva con rafe, C. dallmannii presenta mayor número de estrías y menor cantidad de areolas que C. melchioroides. Asimismo, C. dallmanii posee estrías uniseriadas en la valva con rafe, a diferencia del arreglo uniseriado a biseriado en esta valva en C. melchioroides.

Cocconeis dallmannii es una especie marina, registrada en ambientes bentónicos de caleta Potter (Al-Handal \& Wulff 2008a, como Cocconeis sp 1, Al-Handal \& Wulff 2008b) (Tabla 3.2).

C. melchiori ? Frenguelli \& Orlando

Lám. X, Figs. 4-5

Frenguelli \& Orlando 1958, p. 81, Lám 1, Figs. 4-5; Al-Handal et al. 2008, Figs. 16-17.

Las células en vista valvar linear-elípticas a hexagonales, con extremos anchamente redondeados a suavemente cuneados. La valva con esternón presenta estrías cortas biseriadas, formadas por areolas ordenadas en quincux, paralelas en el centro y radiales hacia los polos.

Datos morfométricos: El eje apical varió entre 13,2 y $23,8 \mu \mathrm{m}$ y el eje transapical entre 8,0 y 11,6 $\mu \mathrm{m}$. En la valva con esternón, la cantidad de estrías en $10 \mu \mathrm{m}$ fue de 4,5-6, con 45 areolas en $10 \mu \mathrm{m}$. No se observó la valva con rafe. 


\section{Observaciones y comentarios}

Cocconeis melchiori fue establecida por Frenguelli \& Orlando (1958) en base únicamente a la descripción de la valva del esternón y acompañada por una breve diagnosis sin establecer la designación del material tipo. A pesar de que estos autores mencionan en su trabajo que no se encontró la valva con rafe, muestran una ilustración de una valva con rafe (Lám. I, Fig.11), que identifican como C. melchiori. Al no contar con una descripción sobre la valva con rafe que permita analizar esta figura y considerar que puede tratarse de un error, sólo se juzga la valva sin rafe.

Las características de los ejemplares analizados en esta Tesis coinciden con las dadas en la descripción original y presenta similitudes en las variables morfométricas respecto a otros datos reportados para Antártida por Romero (1995) (véase Tabla 1 en AlHandal et al. 2008). Se prefiere considerar como dudosa la validez de esta especie hasta que ambas valvas sean descriptas. Por ello, en este trabajo se opta por incluir las observaciones realizadas sobre la valva del esternón, a fin de compararlo con el resto de los taxa que integran este complejo.

Cocconeis melchioroides Al-Handal, Riaux-Gobin, Romero \& Wulff

Lám. X, Figs. 6-12

Al-Handal, Riaux-Gobin, Romero \& Wulff 2008, p. 272, Figs. 2-15, 18-32; Al-Handal \& Wulff 2008a, Figs. 56-57, 136-137; Al-Handal \& Wulff 2008b, p. 426, Figs. 30-31.

Las células en vista valvar son linear-elípticas, con polos subredondeados. La valva con rafe presenta estrías irregulares, uniseriadas a biseriadas en la misma valva, que internamente abren por un foramen de forma más o menos piramidal. En el margen de la valva las areolas se agrupan en número de dos a tres. El área central es cruciforme. El rafe es rectilíneo, con las fisuras centrales en vista externa en forma de ancla y separadas. Las fisuras terminales del rafe son redondeadas, poco marcadas y no llegan hasta los ápices. La superficie de la valva con esternón, externamente es suavemente convexa, con cortas estrías marginales, principalmente biseriadas (a triseriadas en las valvas de mayor tamaño), formadas por pequeñas areolas alternas u opuestas entre sí, las que delimitan un amplio esternón. Internamente la valva aparece como una sólida placa perforada hacia el margen por forámenes de forma más o menos piramidal que corresponden a la vista interna de las estrías.

Datos morfométricos: El eje apical varió entre 10,1 y $18,7 \mu \mathrm{m}$ y el eje transapical entre 6,4 y $11,3 \mu \mathrm{m}$. En la valva con rafe, la cantidad de estrías en $10 \mu \mathrm{m}$ fue de $12-14$, con 40 areolas en $10 \mu \mathrm{m}$. En la valva sin rafe, la cantidad de estrías en $10 \mu \mathrm{m}$ fue de (7) 8, con 40 45 areolas en $10 \mu \mathrm{m}$. 

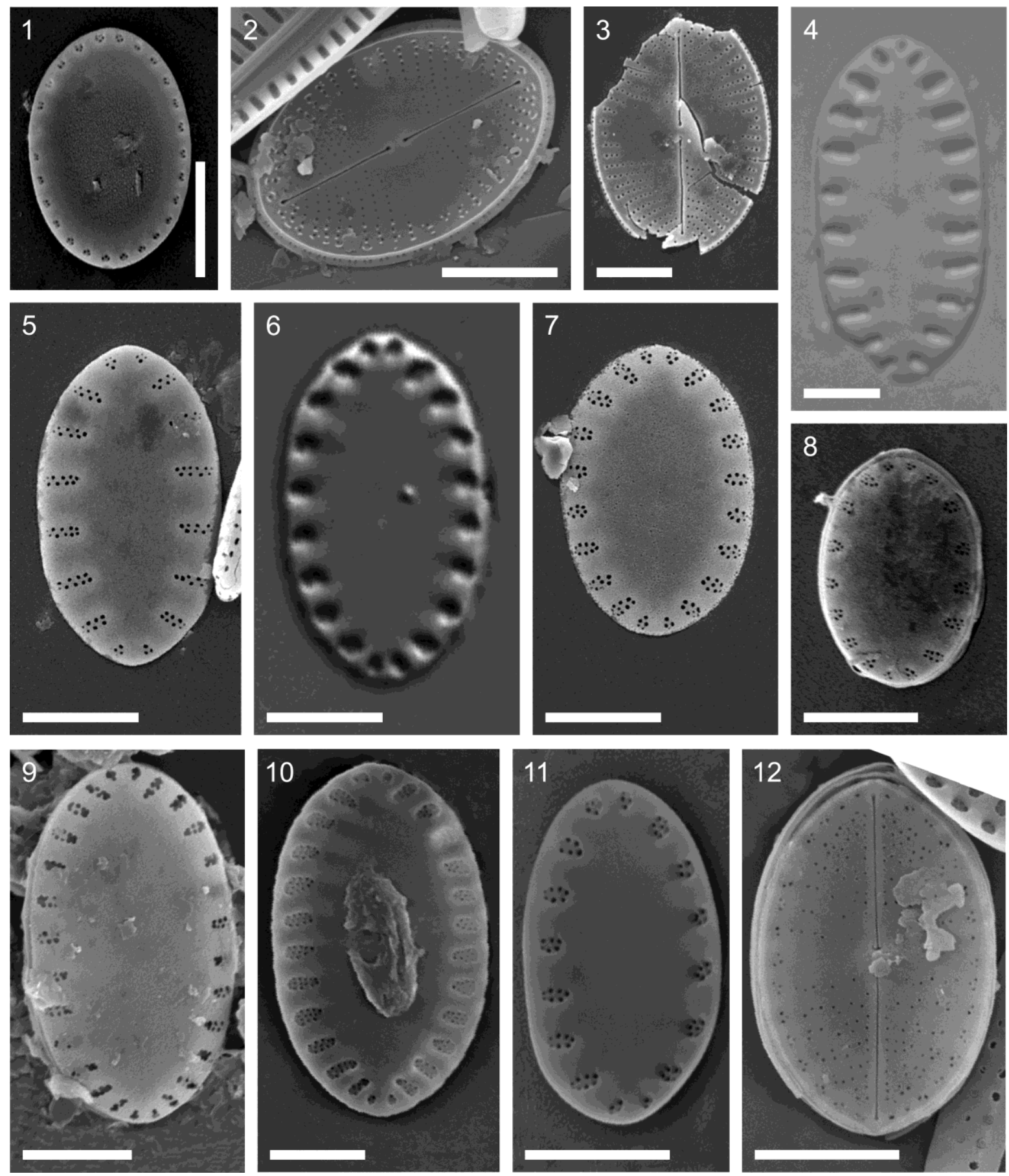

Lámina X. Complejo Cocconeis melchiori. Figs. 1-3, 5, 7-12 MEB, Figs. 4 \& 6 MO. Figs 1-3. Cocconeis dallmannii. Fig. 1. Vista externa de la valva con esternón. Nótense los grupos pequeños de areolas en arreglos piramidales o redondeados (flecha). Fig. 2. Valva con rafe en vista externa mostrando las estrías uniseriadas; nótense las fisuras terminales centrales y apicales redondeadas y las estrías más cortas en el área central, una crista marginalis continua y un manto con una fila de areolas dobles. Fig. 3. Vista externa de una valva con rafe que no presenta ornamentaciones silíceas. Figs. 4-5. Cocconeis melchiori?. Vistas de la valva con esternón con distintos niveles de magnificación. Figs. 6-12. Cocconeis melchioroides. Figs. 6-9. Vista externa de diferentes tamaños de valvas con esternón. Figs. 8-9. Frústulos mostrando parte de las cópulas (flecha). Figs. 10-11. Vista interna de valvas con esternón, con estrías triseriadas en especímenes más grandes y biseriadas en los de menor tamaño. Fig. 12. Valva con rafe en vista externa, con estrías irregulares uniseriadas y biseriadas; nótense los grupos de areolas marginales (flecha) y el rafe rectilíneo con fisuras centrales en forma de ancla. Todas las escalas corresponden a $5 \mu \mathrm{m}$. 


\section{Observaciones y comentarios}

El principal carácter utilizado en esta Tesis para diferenciar a $C$. melchioroides de $C$. melchiori fue el menor número de estrías y el arreglo de las areolas en hileras biseriadas paralelas de la valva del esternón en C. melchiori. En C. melchioroides, la distribución de las areolas es en líneas curvas tomando la estría forma piramidal.

Se trata de un taxón marino (Al Handal et al. 2008). Fue descripto para ambientes bentónicos en caleta Potter (Al-Handal \& Wulff 2008a, como Cocconeis sp 2, Tabla 3.2).

Cocconeis orbicularis Frenguelli \& Orlando

Lám. XI, Figs. 1-3

Frenguelli \& Orlando 1958, p. 83-84, Lám. I, Figs. 17-18; Riaux Gobin \& Romero 2003, p. 38, Lám. 57, Figs. 3-4.

Las células son solitarias, en vista valvar ampliamente elípticas con polos marcadamente redondeados. La valva con rafe presenta un esternón angosto que rodea a un rafe recto que no alcanza los polos. La superficie valvar está dividida a cada lado del rafe en dos zonas, una interna ornamentada por finas estrías uniseriadas y otra marginal caracterizada por áreas rectangulares con estrías difíciles de observar. La valva sin rafe presenta un esternón linear. Las estrías tetraseriadas están formadas por areolas fácilmente discernibles, separadas por costillas longitudinales (crista) que separan un área central, con areolas más pequeñas, de un área marginal.

Datos morfométricos: El eje apical varió entre 21,0 y $32,4 \mu \mathrm{m}$ y el eje transapical entre 12,7 y $17,4 \mu \mathrm{m}$. El número de estrías fue de $4-6$ en $10 \mu \mathrm{m}$ y $25-26$ areolas en $10 \mu \mathrm{m}$ (en la valva con rafe).

\section{Observaciones y comentarios}

Los escasos ejemplares hallados se asemejan a los descriptos por Frenguelli \& Orlando (1958, p. 159, Lám. I, Figs. 17 y 18), aunque estos presentaron dimensiones ligeramente mayores y un esternón lineal no anchamente lanceolado. Asimismo Riaux Gobin \& Romero (2003) hallaron valvas con un esternón que - a diferencia de la especie tipo - es ligeramente lanceolado, y que determinaron como Cocconeis cf orbicularis. El hallazgo de valvas con un esternón de forma variable (desde anchamente lanceolado a linear) establece un continuo que podría modificar la descripción original de la especie y que en este caso permite ubicar a los ejemplares analizados en esta Tesis como C. orbicularis.

En Antártida, ha sido registrada para ambientes bentónicos (Frenguelli \& Orlando $1958)$ y en los contenidos estomacales de Cumacea y Tanaidacea (Blazewicz-Paszkowycz \& Ligowski 2002) (Tabla 3.2). El hallazgo en este trabajo significa el primer registro para la flora bentónica de caleta Potter. Fue una especie muy rara en el material analizado (Tabla 3.1). 

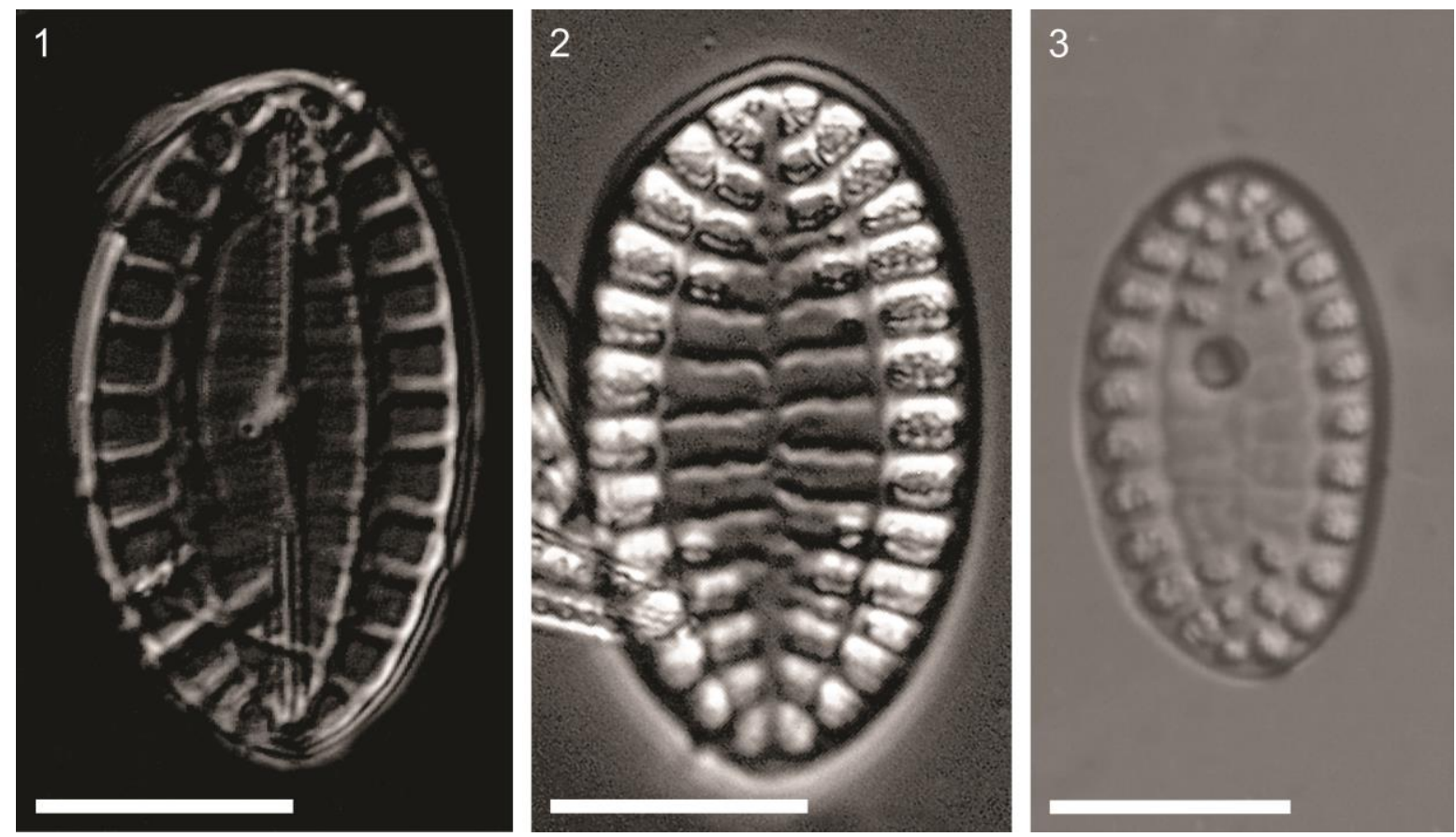

Lámina XI. Cocconeis orbicularis. Figs. 1-3 MO. Fig. 1. Vista de una valva con rafe; nótese el rafe rectilíneo y esternón angosto. Figs. 2-3. Vistas de valvas del esternón; nótense las dos series de estrías tetraseriadas y los engrosamientos longitudinales y transversales. Todas las escalas corresponden a $10 \mu \mathrm{m}$.

\section{Diploneis Ehrenberg ex Cleve}

Las células son solitarias, naviculoides, generalmente muy silicificadas y cada una con dos cloroplastos ubicados a cada lado del plano apical. Las valvas son linear-elípticas, con complejas estrías loculadas, interrumpidas por canales longitudinales que abren externamente por uno o unos pocos poros. Cada valva posee un rafe ubicado centralmente. La cintura está compuesta por unas pocas cópulas lisas (Cox 2015).

Son organismos con un hábitat principalmente marino y con unas pocas especies de agua dulce, epipélicos (Round et al. 1990). Una especie del género Diploneis, D. smithii fue registrada en las muestras analizadas en este trabajo.

Diploneis smithii (Brébisson) Cleve

Lám. III, Fig. 2

Cleve 1894, p. 96; Al-Handal \& Wulff 2008a, p. 54, Tabla 1, p. 55, Tabla 2, Fig. 96, Kellogg \& Kellogg 2002, p. 189.

Las valvas son elípticas, con ápices redondeados. La superficie valvar presenta estrías uniseriadas, paralelas en el centro y radiales hacia los extremos. En vista interna, el rafe presenta las fisuras centrales levemente curvadas hacia el mismo lado y las fisuras terminales provistas de pequeñas y alargadas helictoglosas.

Datos morfométricos: El eje apical fue de $19,6 \mu \mathrm{m}$ y el eje transapical de 9,2 $\mu \mathrm{m}$. Las estrías fueron de 11-12 en $10 \mu \mathrm{m}$, con 36 areolas en $10 \mu \mathrm{m}$. 


\section{Observaciones y comentarios}

Se trata de una especie cosmopolita regitrada en ambientes marinos, de agua dulce y salobre (Guiry \& Guiry 2018). En Antártida, fue registrada en la flora bentónica de fondos blandos en el área de caleta Potter (Tabla 3.2). La presencia de D. smithii en este trabajo fue excepcional (Tabla 3.1).

\section{Entomoneis Ehrenberg}

Es un género que agrupa organismos solitarios. Sus células son fuertemente comprimidas y giradas sobre su eje apical, apareciendo como bilobadas en vista cingular. Poseen uno o dos cloroplastos en forma de placa. El rafe es fibulado y está ubicado sobre una costilla estrecha y alta, más baja hacia el centro y los polos. La superficie valvar presenta estrías uniseriadas o biseriadas. El cíngulo contiene cópulas abiertas ornamentadas por poros (Patrick \& Reimer 1975). Es un género principalmente epipélico, distribuido en aguas salobres, en sedimentos marinos y en ambientes dulceacuícolas.

\section{Entomoneis sp.}

Lám. III, Fig. 3

Patrick \& Reimer 1975, p. 1-3; Al-Handal \& Wulff 2008a, p. 54-55, Figs. 116-119.

Los frústulos son rectangulares en vista conectival, con bordes bilobados y distintivas cópulas ornamentadas por hileras de poros. La superficie valvar presenta finas estrías uniseriadas, formadas por pequeñas areolas redondeadas.

Datos morfométricos: El eje apical fue de $67,7 \mu \mathrm{m}$ y el eje pervalvar varió entre 10,5 $\mu \mathrm{m}$ y $14 \mu \mathrm{m}$, con 23 estrías en $10 \mu \mathrm{m}$.

\section{Observaciones y comentarios}

Se ha enlistado una especie de este género como epífita de macroalgas en el Mar de Ross (Majewska et al. 2016). En caleta Potter, se han descripto tres especies de Entomoneis: Entomoneis gigantea Grunow, Entomoneis kjellmanii (Cleve) Poulin et Cardinal y Entomoneis paludosa (W. Smith) Reimer en sustratos blandos y esta última también sobre sustratos duros (Al-Handal \& Wulff, 2008a). El taxa analizado en esta Tesis se asemeja a $E$. paludosa principalmente por la densidad de estrías (19 a 23 en $10 \mu \mathrm{m}$, según Witkowski et al. 2000). Sin embargo, el aspecto del taxa hallado es más alargado y más angosto en vista conectival. Fue registrado como raro en el material analizado y en este caso, no fue posible determinar fehacientemente la identidad de esta especie. 


\section{Entopyla Ehrenberg}

Las células son arqueadas en vista conectival, con una valva cóncava y la otra convexa, ambas sin rafe. Las valvas presentan cámaras separadas lateralmente por gruesas paredes internas. Es un género representado en ambientes marinos y salobres, como bentónico o ticoplanctónico (Cox 2015, Guiry \& Guiry 2018). Sólo Entopyla ocellata fue hallada en el material analizado en este trabajo.

Entopyla ocellata (Arnott) Grunow Lám. III, Fig. 4 Grunow 1862, p. 428; Al-Handal \& Wulff 2008b, p. 414, Tabla 2, Figs. 57-72.

Los frústulos son arquedos en vista conectival y valvar. Sólo la valva cóncava posee campos de poros apicales. La superficie de la valva presenta estrías multiseriadas, arregladas en forma alterna, las que delimitan un estrecho esternón. En vista conectival se observa que la cintura está formada por varias cópulas.

Datos morfométricos: El eje apical varió entre 41,0 y $57,0 \mu \mathrm{m}$ y el eje transapical fue de $13,0 \mu \mathrm{m}$ con 3 estrías en $10 \mu \mathrm{m}$.

\section{Observaciones y comentarios}

Se trata de una especie marina, registrada como epífita sobre macroalgas en caleta Potter (Al-Handal \& Wulff 2008b, Guiry \& Guiry 2018). Asimismo, la variedad pulcella de E. ocellata fue hallada en la flora bentónica de caleta Potter (Al-Handal \& Wulff 2008a). Entopyla ocellata fue rara en el material analizado.

\section{Fragilaria Lyngbye}

Las células poseen dos cloroplastos alineados longitudinalmente y se unen por su cara valvar formando colonias en forma de bandas. Las valvas son lineares, linear-lanceoladas o elípticas con polos redondeados a capitados, ornamentadas por hileras de estrías uniseriadas. En cada polo se ubica en una suave depresión, un evidente ocellulimbus. EI esternón es linear, lanceolado, y en algunos casos llega a ocupar la mayor parte de la superficie valvar. El manto valvar es bajo y en algunas especies está separado del resto de la valva por la presencia de espinas. Un proceso labiado se observa próximo a uno de los polos. El cíngulo está compuesto por varias cópulas, generalmente cuatro por valva, ornamentadas por una hilera de poros (Round et al. 1990).

Fragilaria es un género bentónico (ocasionalmente planctónico), representado principalmente en agua dulce a excepción de unas pocas especies marinas (Round et al. 1990, Scott \& Thomas 2005, Hasle \& Syvertsen 1997, Cox 2015). Round et al. (1990) sugieren que el nombre de Fragilaria podría ser conservado sólo para las especies de agua 
dulce. Dos especies del género Fragilaria fueron hallados en el material analizado: Fragilaria islandica var. adeliae y Fragilaria striatula.

\section{Complejo Fragilaria islandica/striatula}

Las especies Fragilaria islandica var. adeliae y Fragilaria striatula fueron diferenciadas por la característica del esternón, el cual está ampliamente desarrollado en Fragilaria islandica. Los datos morfométricos de ambas especies fueron muy similares, por lo que su determinación en vista conectival, frecuentemente formando colonias, resultó imposible en los conteos, en los que por lo tanto, ambas se expresaron agrupadas en un complejo. A continuación se describen ambos taxa, cuya identificación se confirmó mediante la obtención de preparados fijos observados al MO y la utilización de MEB.

Fragilaria islandica Grunow var. adeliae Manguin Lám. XII, Figs. 1-4, Lám. XIII, Figs. 1-10 Manguin 1960, p. 298, Lám. 12, Fig. 128; Hasle et al. 1994, p. 255, Fig. 56, 76-78; Scott \& Thomas 2005, p. 137, Figs. 2.76; Cefarelli et al. 2016 (Como Fragilaria cf. islandica var. adeliae), Figs. 8a-c.

Las células están reunidas por su cara valvar formando largas bandas rectangulares aparentemente unidas por un mucílago y retorcidas en forma más o menos helicoidal. En vista valvar las células son linear-lanceoladas con extremos rostrados. La superficie valvar posee areolas ordenadas en hileras uniseriadas mayormente restringidas al margen valvar delimitando un esternón que prácticamente ocupa toda la superficie valvar. El manto es bajo y muestra estrías con una hilera de areolas. Un proceso labiado está ubicado cerca de uno de los polos, el cual abre externamente por una fisura perpendicular al eje apical. Un ocellulimbus está localizado en el manto valvar en cada uno de los polos. La cintura está compuesta por varias cópulas que muestran una hilera de areolas a lo largo del margen.

Datos morfométricos: El eje apical varió entre 17,0 y $56,4 \mu \mathrm{m}$, el eje transapical varió entre 3,9 y $7,8 \mu \mathrm{m}$. La cantidad de estrías en $10 \mu \mathrm{m}$ fue de $11,5-16,5$, con $45-65$ areolas en 10 $\mu \mathrm{m}$.

\section{Observaciones y comentarios}

Esta especie puede ser confundida con Synedropsis recta Hasle, Medlin \& Syvertsen principalmente en observaciones al microscopio óptico. Sin embargo, la presencia de un ocellulimbus en el género Fragilaria las separa fácilmente, puesto que Synedropsis se caracteriza por la presencia de un campo apical compuesto por alargadas fisuras longitudinales así como por la formación de colonias principalmente estrelladas (Hasle et al. 1994). Los ejemplares analizados en este estudio comparados con los datos de los autores 
consultados presentaron un mayor rango de tamaño (Scott \& Thomas 2005, eje apical: 21 a $36 \mu \mathrm{m})$.

Se trata de una especie marina, costera, con registros para Antártida occidental y oriental (Manguin 1960, Scott \& Thomas 2005). Se halló como epífita de rodofitas en la zona de bahía Lasserre (bahía del Almirantazgo) y el Mar de Ross (Tabla 3.2). Este es el primer registro de la especie en ambientes bentónicos de caleta Potter. Fragilaria islandica var. adeliae se halló formando colonias visibles macroscópicamente (Lám XII, Fig. 1).
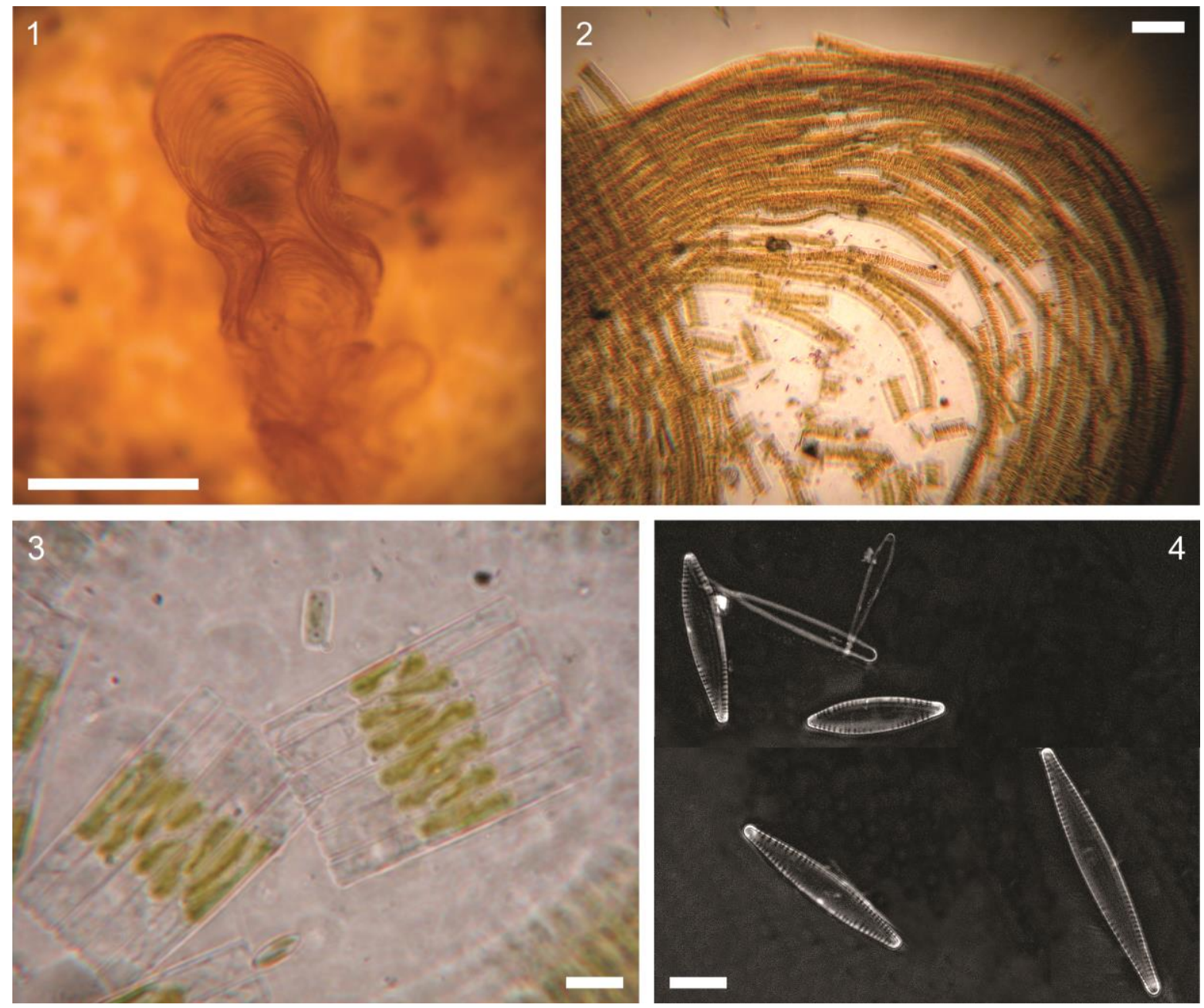

Lámina XII. Fragilaria islandica var. adeliae. Figs. 1-4 MO. Fig. 1 Vista general de una colonia macroscópica. Fig. 2. Detalle de una parte de la colonia. Fig. 3. Células mostrando los dos evidentes cloroplastos. Fig. 4. Valvas con marcada variabilidad morfológica. Escalas: Fig. 1: $1 \mathrm{~mm}$, Fig. 2: $100 \mu \mathrm{m}$, Figs. 3-4: $10 \mu \mathrm{m}$. 

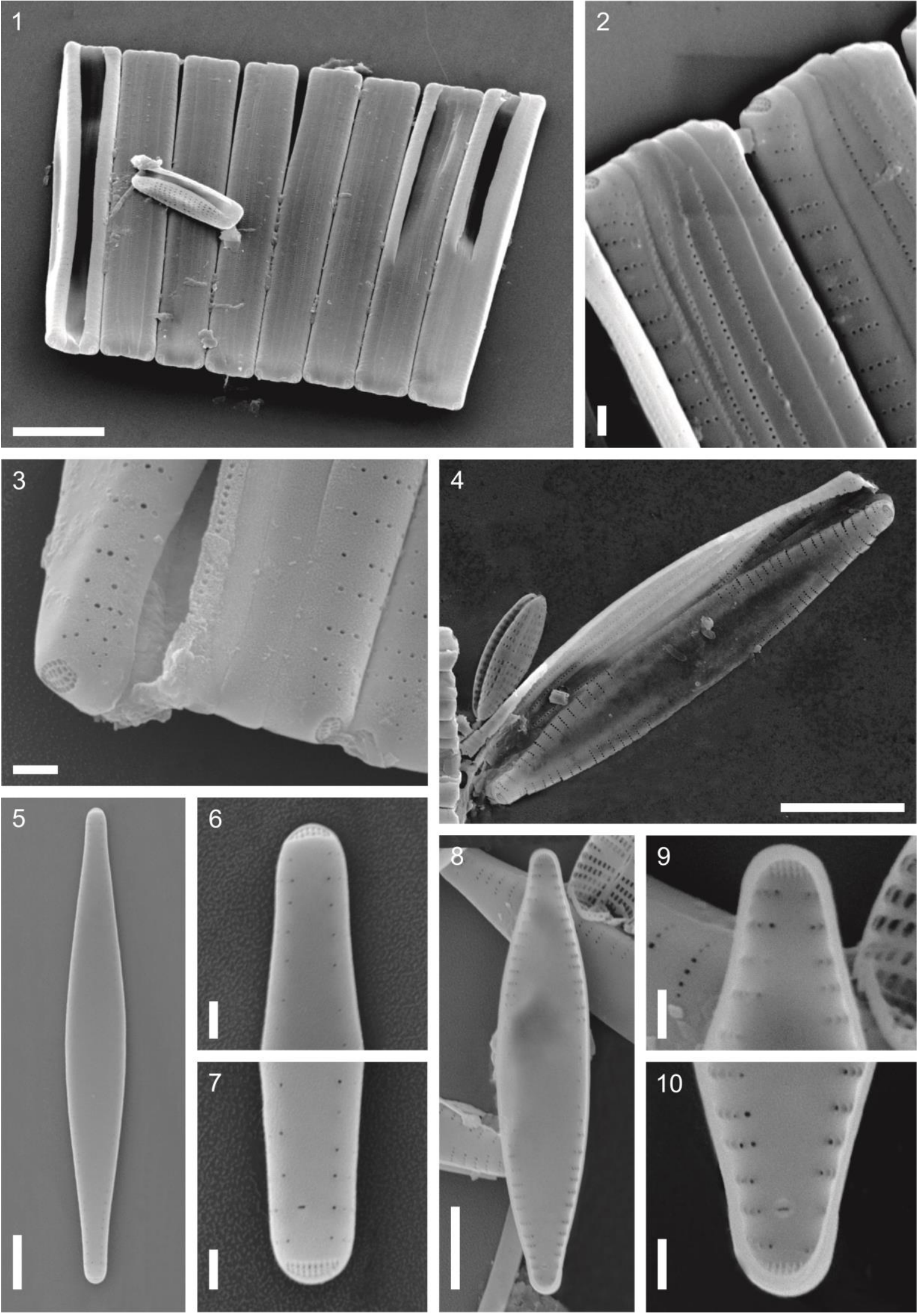

Lámina XIII. Fragilaria islandica var. adeliae. Figs. 1-10 MEB. Fig. 1. Vista general de una colonia. Fig. 2. Células en vista conectival, note la almohadilla que las une y las numerosas cópulas con hileras de poros. Fig. 3. Parte del frústulo mostrando el ocellulimbus. Fig. 4. Superficie valvar con estrías radiales hacia los extremos y un ancho esternón. Fig. 5. Vista externa de la valva. Figs. 6-7. Detalle de ambos polos mostrando el ocellulimbus y la salida del proceso labiado (Fig. 7). Fig. 8. Vista interna de la valva. Fig. 9. Extremo sin proceso labiado. Fig. 10. Extremo con proceso labiado. Escalas: Figs. 1, 4: $10 \mu \mathrm{m}$, Figs. 2-3, 6-7, 9-10: $1 \mu \mathrm{m}$, Figs. 5, 8: $5 \mu \mathrm{m}$. 
Lyngbye 1819, p. 183, Lám. 63, Fig. a; Hasle \& Syvertsen 1981, p. 111-115, Figs. 1-23; Poulin et al. 1984a, p. 358, Figs. 61-67; Hasle \& Syvertsen 1997, p. 246, Lám. 51, Figs. a-b; Rivera \& Cruces 2002, p. 365-341, Figs. 1-26; Witkowski et al. 2000, p. 55, Lám. 28, Figs. 1-6; Fernandes et al. 2007, Figs. 7-10; Al-Handal \& Wulff 2008b, p. 428, Fig. 94.

Las células forman colonias acintadas, cada una de ellas con dos grandes plástidos. En vista cingular son rectangulares, y linear lanceoladas en vista valvar, con polos redondeados a subcapitados. La superficie valvar posee areolas ordenadas en hileras uniseriadas las que delimitan un angosto esternón. El manto es bajo y está ornamentado por hileras de areolas semejantes a las de la superficie valvar. Un proceso labiado está ubicado cerca de uno de los polos el cual abre externamente por una fisura perpendicular al eje apical. Un ocellulimbus está localizado en el manto valvar de cada polo. La cintura está compuesta por cuatro cópulas abiertas, la valvocópula al igual que el resto de las cópulas posee una hilera de areolas de posición advalvar.

Datos morfométricos: El eje apical varió entre 43,7 y $60,6 \mu \mathrm{m}$, el eje transapical varió entre 5,9 y $7,8 \mu \mathrm{m}$. La cantidad de estrías en $10 \mu \mathrm{m}$ fue de $14-16$ y la cantidad de areolas en 10 $\mu \mathrm{m}$ fue de $45-50$.

\section{Observaciones y comentarios}

Fragilaria striatula es fácilmente confundible con $F$. islandica var. adeliae con baja magnificación y en vista conectival. Los ejemplares analizados presentaron un número ligeramente menor de estrías comparado con los datos reportados por muchos autores, aunque coincidieron con los registros de esta especie reportados por Poulin et al. (1984a).

Se trata de una especie cosmopolita, marina, principalmente bentónica y epífita de macroalgas (Hasle \& Syvertsen 1997, Witkowski et al. 2000, Rivera \& Cruces 2002), con registros en ambientes bentónicos para Antártida occidental y oriental (Cremer et al. 2003, Al-Handal \& Wulff 2008b, Majewska et al. 2016). En caleta Potter fue hallada sobre sustratos artificiales (Campana et al. 2008), fondos rocosos y como epífita de macroalgas (Tabla 3.2). Esta especie se halló formando colonias visibles macroscópicamente. 

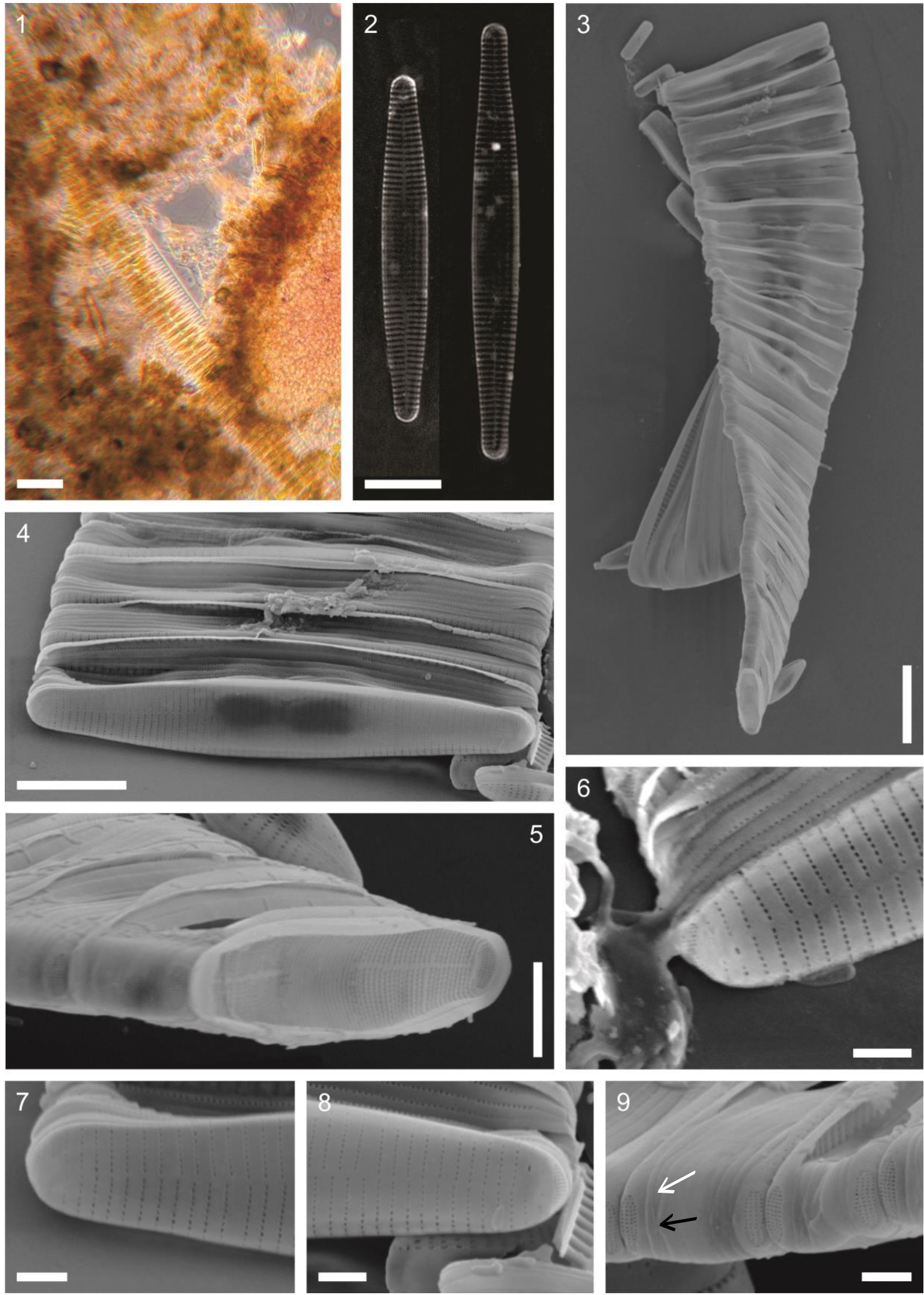

Lámina XIV. Fragilaria striatula. Figs. 1-2 MO, Figs. 3-9 MEB. Fig. 1. Aspecto general de una colonia. Fig. 2. Valvas de diferentes tamaños mostrando la distribución de las estrías. Fig. 3. Aspecto general de una colonia. Fig. 4. Parte de una colonia, nótense las numerosas cópulas que componen la cintura. Fig. 5. Superficie valvar interna con estrías uniseriadas que delimitan un angosto esternón. Fig. 6. Detalle del área de fijación al sustrato. Figs. 7-8. Diferentes extremos de una misma valva. Fig. 7. Polo sin proceso labiado. Fig. 8. Polo con el proceso labiado ubicado hacia uno de los lados de la superficie valvar. Fig. 9. Detalle del ocellulimbus, de las cópulas abiertas (flecha blanca), y de las lígulas (flecha negra). Escalas: Fig. 1: $50 \mu \mathrm{m}$, Figs. 2-5: $10 \mu \mathrm{m}$, Figs. 6-9: $2 \mu \mathrm{m}$. 
Fragilariopsis Hustedt

Las células generalmente forman colonias acintadas, raramente se observan como solitarias. Poseen dos plástidos en forma de placa ubicados uno a cada lado del plano transapical. Las celulas son linear-lanceoladas, isopolares o heteropolares con extremos generalmente redondados. La supeficie valvar tiene estrías generalmente biseriadas o multiseriadas formadas por pequeños poros redondeados. El sistema del rafe es marcadamente excéntrico y fibulado, ubicado entre la unión de la superficie valvar y el manto, nunca sobre una elevación de la superficie valvar. El cíngulo está compuesto por varias cópulas abiertas, algunas de las cuales están ornamentadas por una o más hilera de poros (Round et al. 1990, Hasle \& Syvertsen 1997).

Fragilariopsis es un género representado en ambientes marinos bentónicos, abundante principalmente en aguas polares (Round et al. 1990, Hasle \& Syvertsen 1997). Dos especies del género Fragilariopsis, Fragilariopsis kerguelensis y Fragilariopsis rhombica/separanda fueron halladas en el material analizado.

Fragilariopsis kerguelensis (O'Meara) Hustedt Lám. XV, Fig. 1

Hustedt 1952, p. 294; Hasle \& Syvertsen 1997, p. 296-297, Lám. 66, Tabla. 73; Scott \& Thomas 2005, p. 179, Fig. 2.101 a-f; Cefarelli et al. 2010, p. 1470, 1472, Figs. 3 a-h, 7 f-g.

Los frústulos son fuertemente silicificados, en vista valvar elípticos, suavemente curvados hacia los extremos y rectangulares en vista conectival. La superficie de la valva presenta estrías biseriadas, rectas a suavemente curvadas hacia los extremos.

Datos morfométricos: El eje apical fue de 39,0 $\mu \mathrm{m}$, el eje transapical de 8,4 con 6-7 estrías en $10 \mu \mathrm{m}$.

\section{Observaciones y comentarios}

Frenguelli (1943) mantiene el nombre de Fragilariopsis antarctica en lugar de $F$. kerguelensis en el material analizado de islas Orcadas. Más tarde, este mismo autor (1960) crea la variedad elliptica sobre material de Terra Adelia, taxón que más tarde Hasle (1965), desconoce como tal.

Se trata de una especie marina, muy abundante en aguas antárticas (Scott \& Thomas 2005, Cefarelli et al. 2010). Para ambientes bentónicos, fue hallada como epífita de Phyllophora antarctica en la zona del Mar de Ross y en el microfitobentos de fondos blandos (Tabla 3.2). Esta especie fue muy rara en el material analizado y consituye el primer registro para ambientes bentónicos de caleta Potter. 
Hustedt 1952, p. 296, Figs. 6-7; Hustedt 1958, p. 165, Lám. 10, Figs. 108-112; Hasle \& Medlin 1990, p. 181, Làm 24.1, Fig. 6, Lám. 24.4, Figs. 1-10; Hasle \& Syvertsen 1997, p. 300-302, Lám. 68, Tabla. 73; Cefarelli et al. 2010, p. 1475-1478, Figs. 5a-e, 6a-d; Scott \& Thomas 2005, p.183-184.

Las células son anchamente lanceoladas con márgenes paralelos, puntiformes hacia los extremos.

\section{Observaciones y comentarios}

Fragilariopsis rhombica (O'Meara) Hustedt se diferencia de Fragilariopsis separanda Hustedt principalmente por presentar esta última estrías con sólo una hilera de poroides en lugar de dos, como presenta F. rhombica. Estos caracteres diferenciales no pudieron observarse en los preparados transitorios donde esta especie estuvo presente por lo que se las coloca bajo el nombre de cualquiera de estos dos taxa. Ambos taxa se hallan en aguas antárticas (Scott \& Thomas 2005, Cefarelli et al. 2010). Para ambientes bentónicos, F. rhombica fue hallada en fondos blandos (Al-Handal \& Wulff 2008a) y como epífita de macroalgas (Al-Handal \& Wulff 2008b, Majewska et al. 2016). La presencia de este taxa fue excepcional en el material analizado.

\section{Grammatophora Ehrenberg}

Las células se unen entre sí por sus polos y forman colonias rectas o en zig-zag y se fijan al sustrato a través de una almohadilla mucilaginosa. Cada una de ellas posee cuatro cloroplastos. Los frústulos son cuadrangulares a rectangulares en vista conectival. Las valvas carecen de rafe, cada una posee dos procesos labiados y en cada polo muestran un campo de poros. Presentan estrías uniseriadas que delimitan un angosto y recto esternón. Las estrías de la superficie valvar se continúan sobre el manto y alrededor de los ápices por debajo del campo de poros. La cintura está compuesta por numerosas cópulas donde cada valvocópula, generalmente lisa, muestra septos desde rectos a fuertemente ondulados (Lobban 2015).

Son organismos con un hábitat marino costero, asociados a macroalgas $u$ otras superficies (Cox 2015). Una especie del genero Grammatophora, Grammatophora artica, fue registrada en este estudio.

Grammatophora arctica Cleve

Lám. XV, Fig. 3

Cleve 1867, p. 664, Lám. 23, Fig. 1; Al-Handal \& Wulff 2008b, p. 428, Figs. 70-74, p. 414, Tabla 2; Poulin et al. 1984b, p. 278, Figs. 15-18. 
Los frústulos en vista conectival son rectangulares. El manto valvar es profundo, con finas estrías distribuidas uniformemente. La cintura posee varias cópulas; en cada valvocópula se observa un septo marcadamente alargado y casi recto.

Datos morfométricos: El eje apical fue de 42,0 $\mu \mathrm{m}$. Las estrías fueron de 12-13 en $10 \mu \mathrm{m}$.

\section{Observaciones y comentarios}

Se trata de una especie marina (Al-Handal \& Wulff 2008b). En Antártida, fue registrada como epífita de macroalgas (Al-Handal \& Wulff 2008b, Majewska et al. 2016) (Tabla 3.2).

La presencia de $G$. arctica en este trabajo fue muy rara en el material analizado.
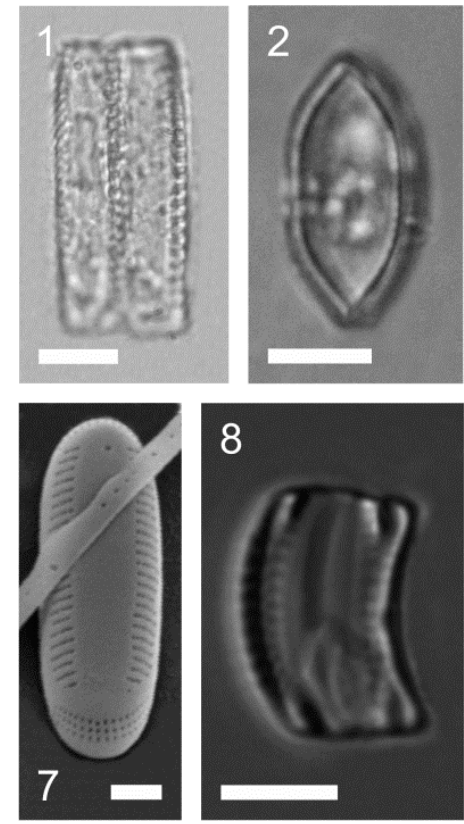
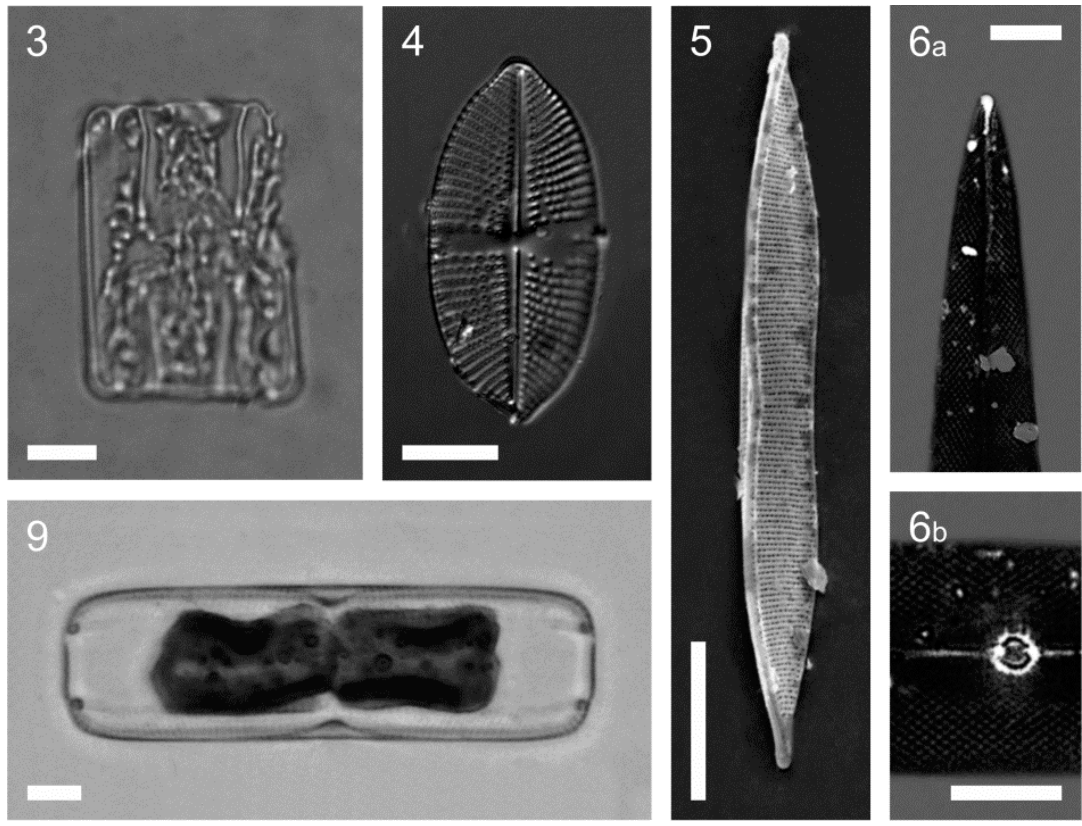

Lámina XV. Figs. 1-4, 6, 8-9 MO. Figs. 5,7 MEB. Fig.1. Fragilariopsis kerguelensis. Frústulos en vista conectival. Fig. 2 Fragilariopsis rhombica/separanda. Vista valvar de una célula; nótense los bordes paralelos en su parte media. Fig. 3. Grammatophora arctica. Vista general de una célula mostrando los característicos septos. Fig. 4. Petroneis sp. Vista valvar. Fig. 5 Nitszchia pellucida. Frústulo en vista valvar mostrando las estrias uniseriadas finamente punteadas y un rafe con un evidente nódulo central. Fig. 6. Pleurosigma sp. Vista valvar mostrando el patrón de estriación en un polo (a) y el área central (b). Fig. 7. Pteroncola carlinii. Vista valvar mostrando el ancho esternón, las estrias alveoladas, el proceso labiado y el campo apical de poros. Fig. 8. Rhoicosphenia genuflexa. Vista conectival de un frústulo; nótese la presencia de pseudoseptos en ambas valvas. Fig. 9. Trachyneis aspera. Frústulo en vista conectival, mostrando dos evidentes cloroplastos. Todas las escalas corresponden a $10 \mu \mathrm{m}$ excepto Fig. 7: $1 \mu \mathrm{m}$ y Fig. 8: $5 \mu \mathrm{m}$.

\section{Licmophora Agardh}

El género Licmophora agrupa organismos solitarios o reunidos en colonias en forma de abanico o circulares formadas células ubicadas sobre un pedúnculo mucilaginoso que se fija a diferentes tipos de sustratos (Round et al. 1990, Honeywill 1998). Numerosos y pequeños cloroplastos discoides se observan por célula. Los frústulos son cuneiformes en vista cingular y con valvas heteropolares, sin rafe, ornamentadas por estrías uniseriadas y por un angosto esternón central. En el polo basal, sobre el manto se sitúa la "multiscissura" (campo 
de fisuras apicales), la que en algunas especies posee por encima una hilera de pequeños poros. Se observan dos o tres procesos labiados por frústulo, raramente una hilera a lo largo del esternón (Sar \& Ferrario 1990). El cíngulo está formado por copulas abiertas, cada una de ellas con una o más hileras de poros.

Licmophora es un género ampliamente representado en ambientes marinos, como epifitico o epilítico (Cox 2015). Tres especies de este género han sido identificadas en este estudio: Licmophora antarctica, Licmophora belgicae y Licmophora gracilis.

Licmophora antarctica M. Peragallo

Lám. XVI, Figs. 1-12, Lám. XVII, Figs. 1-7

Peragallo 1921, p. 70, Lám. 4, Fig. 10; Carlson 1913, p. 30, Lám. 3, Figs. 23-24; Frenguelli \& Orlando 1958, p. 111-112, Lám. 5, Figs. 1-2; Al-Handal \& Wulff 2008a, p. 54, 56, Tablas 1-2, Fig. 8; Al-Handal \& Wulff 2008b, p. 428-429, Figs. 2-5; Fernandes et al. 2014, p. 469-470, Figs. 1-9.

Las células se unen por su cara valvar e integran colonias fijas, en forma de abanico o forma circulares acomodadas alrededor de un eje, dejando un espacio central. Cada una contiene numerosos cloroplastos esféricos con pirenodes. Los frústulos son heterovalvares, en vista valvar claviformes con ambos ápices redondeados. La superficie valvar es plana con un esternón muy estrecho, a ambos lados del cual se distribuyen las estrías uniseriadas, opuestas a ligeramente alternas y formadas por areolas redondeadas a levemente elípticas. En el polo apical se observa un pequeño proceso labiado, difícil de observar, orientado apicalmente y ubicado entre la unión de la superficie valvar y el manto. En polo inferior el proceso labiado esta presente sólo en una de las valvas, y es de gran tamaño e internamente está orientado transapicalmente. Externamente ambos tipos de procesos se abren a través de una angosta fisura. El manto es bajo, gradualmente estriado hacia la parte superior. En la parte basal se observa la multiscissura, formada por alrededor de 20 evidentes rajaduras. Entre esta estructura y las estrías hay una serie de poros pequeños distribuidos en semicírculo. El cíngulo está compuesto por dos a tres cópulas abiertas. La valvocópula, al igual que el resto de las cópulas, está ornamentada por hileras de poros o cortas estrías, ubicadas advalvar y abvalvarmente.

Datos morfométricos: En vista valvar, el eje apical varió entre 71,6 y $156,7 \mu \mathrm{m}$, el eje transapical mayor entre 9,2 y 11,9 $\mu \mathrm{m}$. La cantidad de estrías en $10 \mu \mathrm{m}$ fue de 7,5-8,5, con $19-20$ areolas en $10 \mu \mathrm{m}$.

\section{Observaciones y comentarios}

Licmophora antarctica es una especie descripta con el mismo nombre para dos taxa posiblemente diferentes. Carlson (1913) fue quien utilizó el nombre por primera vez y luego lo hizo Peragallo en 1921. En base a esto, VanLandingham (1971), consideró como válido el nombre de Licmophora antarctica Carlson 1913. 

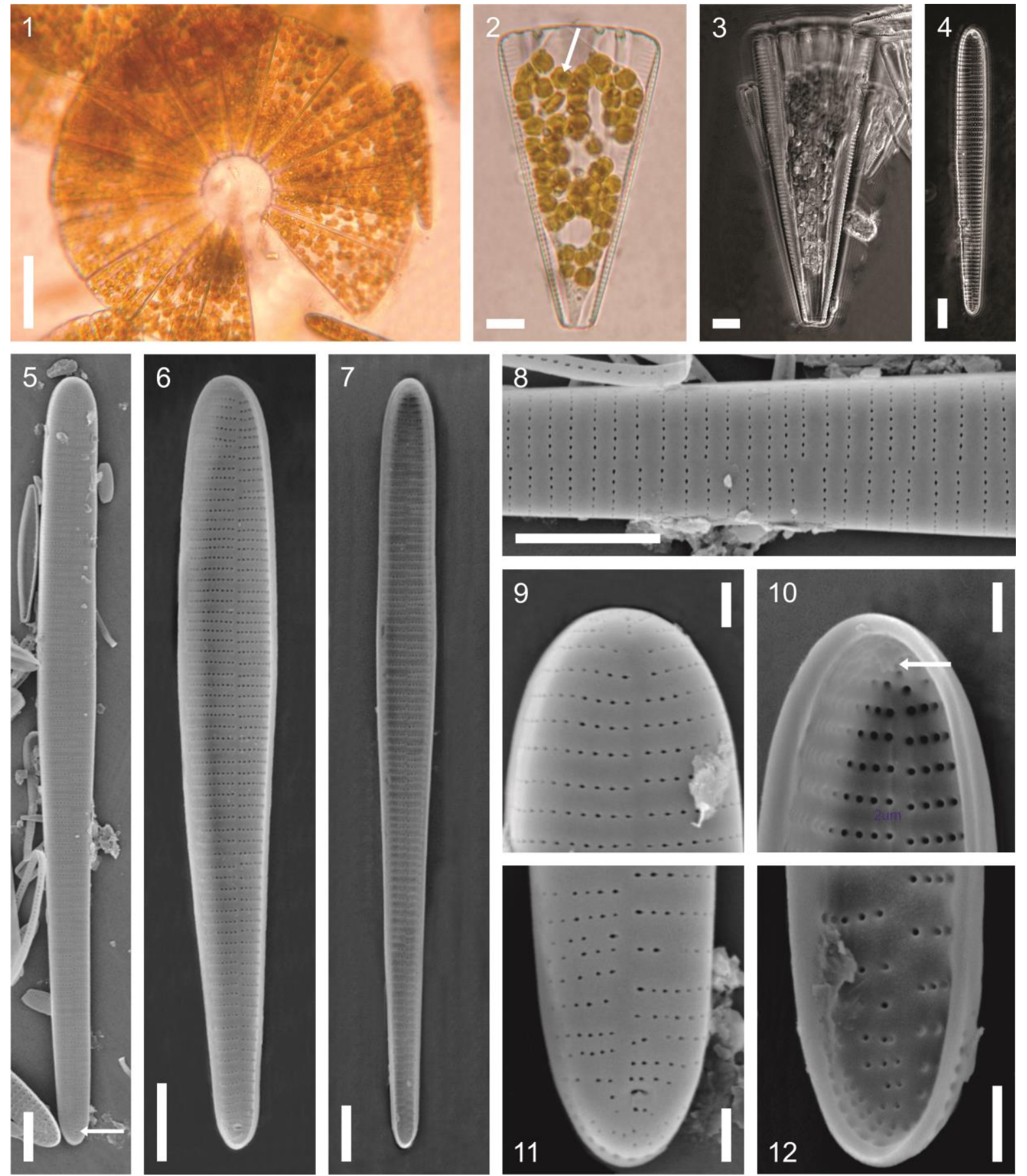

Lámina XVI. Licmophora antarctica. Figs. 1-4 MO, Figs. 5-12 MEB. Fig. 1. Vista general de una colonia. Fig. 2. Célula en vista conectival con numerosos cloroplastos discoides y pirenoides (flecha). Fig. 3. Célula en vista conectival; nótese el manto y la valvocópula finamente estriados. Fig. 4. Vista general de una valva con estrías uniseriadas. Fig. 5. Valva en vista externa, note en el polo basal la salida del proceso labiado (flecha). Fig. 6. Valva en vista interna; nótese la salida del proceso labiado en el polo basal. Fig.7. Valva en vista interna, sin proceso labiado en la base y con un proceso labiado muy pequeño en el polo superior. Fig. 8. Parte central de la valva mostrando la disposición de las estrías a cada lado del esternón. Fig. 9. Detalle en vista externa del polo apical y el manto. Fig. 10. Detalle en vista interna del pequeño proceso labiado (flecha) ubicado en el polo apical. Fig. 11. Detalle del polo basal mostrando la salida del proceso labiado, parte de la multiscissura y poros en semicírculo. Fig.12. Detalle del polo basal en vista interna, sin proceso labiado. Escalas: Fig. 1: 50 um, Figs. 2-8: $10 \mu \mathrm{m}$, Figs. 9-12: $2 \mu \mathrm{m}$.

Frenguelli \& Orlando (1958), priorizan a L. antarctica Peragallo (1921), cuestionando que su material "nada tiene que ver con L. antarctica de Carlson (1913)". Posteriormente Fernandes et al. 2014 adopta el mismo criterio que estos autores, reconociéndolas como 
especies diferentes. Por otro lado Al-Handal \& Wulff (2008a,b), consideran a ambas entidades dentro de un mismo taxón.

Comparando los datos morfométricos brindados por los autores señalados anteriormente con los ejemplares de caleta Potter analizados en esta Tesis, se encuentra que los valores de estos últimos se ajustan más con los datos de Peragallo (1921), y con el material consultado (preparado 50, Bahía Margarita, Antártida), de Frenguelli \& Orlando, depositado en la "Colección de Diatomeas Antárticas", División Ficología, Museo de La Plata. Por su historial se considera que esta especie requiere de una investigación nomenclatural profunda a fin de clarificar su real identidad.

Dentro del material analizado algunos especímenes se corresponden con Licmophora antarctica var. minor creada por Frenguelli \& Orlando (1958, Lám. 5, Figs. 5-7), quienes la ilustran sin describirla. Las figuras de esta variedad indican un eje apical de 61,7 $\mu \mathrm{m}$ a $78,3 \mu \mathrm{m}$ y un eje transapical de $8,3 \mu \mathrm{m}$ a $10 \mu \mathrm{m}$, y 6-7 estrías en $10 \mu \mathrm{m}$. Estos valores están contenidos en el rango de los registrados en los especímenes analizados en esta Tesis. De acuerdo con estos registros que documentan un continuo en el rango de las medidas, se considera que esto invalida la creación de esta variedad.

Esta especie ha sido ampliamente registrada particularmente en Antártida occidental como epifita y habitando sustratos duros y en sedimentos (Frenguelli \& Orlando 1958, Fernandes et al. 2014). Esta especie fue frecuente en el material analizado en este trabajo (Tabla 3.1).

\section{Licmophora belgicae M. Peragallo}

Peragallo 1921, p. 70, Lám. 4, Figs. 5-6; Frenguelli \& Orlando 1958, p. 112, Lám. 5, Figs. 8-10; AlHandal \& Wulff 2008a, p. 54, 57, Tablas 1-2, Figs. 7, 9 (como L. decora); Simonsen 1992, p. 28, Lám. 24, Figs. 1-5 (como L. decora); Fernandes et al. 2014, p. 470-471, Figs. 10-20.

Las células son solitarias, algunas veces unidas por su cara valvar en grupos de dos a tres. Cada célula posee numerosos cloroplastos esféricos, ligeramente elípticos y con pirenoides. Los frústulos son heterovalvares con ambos polos redondeados y en vista valvar son claviformes, algunos especímenes con márgenes levemente ondulados. La superficie valvar es plana con un esternón evidente, a ambos lados del cual se distribuyen las estrías uniseriadas, opuestas a ligeramente alternas y formadas por areolas redondeadas. En el polo apical y parte del manto las estrías son más numerosas. Las virgas son irregulares, presentando diferente grosor a lo largo del eje apical. En ambos polos se observa un proceso labiado, el ubicado en el polo inferior, es de mayor tamaño e internamente está orientado transapicalmente. El proceso del polo apical es pequeño, levemente desplazado del eje apical, y está ubicado entre la unión de la superficie valvar y el manto. Interiormente abre por una abertura elongada en dirección apical semejante a la hendidura externa. Uno de los dos procesos labiados puede estar ausente en alguna de las valvas. El manto es 
bajo, y gradualmente estriado hacia la parte superior. En el polo basal se observa la multiscissura rodeada por una serie de poros pequeños distribuidos irregularmente.

El cíngulo está formado por dos a tres cópulas abiertas, la valvocópula al igual que el resto de las cópulas está ornamentada por hileras de poros o cortas estrías.

Datos morfométricos: El eje apical varió entre 62,5 y $149,2 \mu \mathrm{m}$, el eje transapical mayor entre 14,9 y $19,3 \mu \mathrm{m}$. La cantidad de estrías en $10 \mu \mathrm{m}$ fue de $11-13$, con 17-22 areolas en $10 \mu \mathrm{m}$.
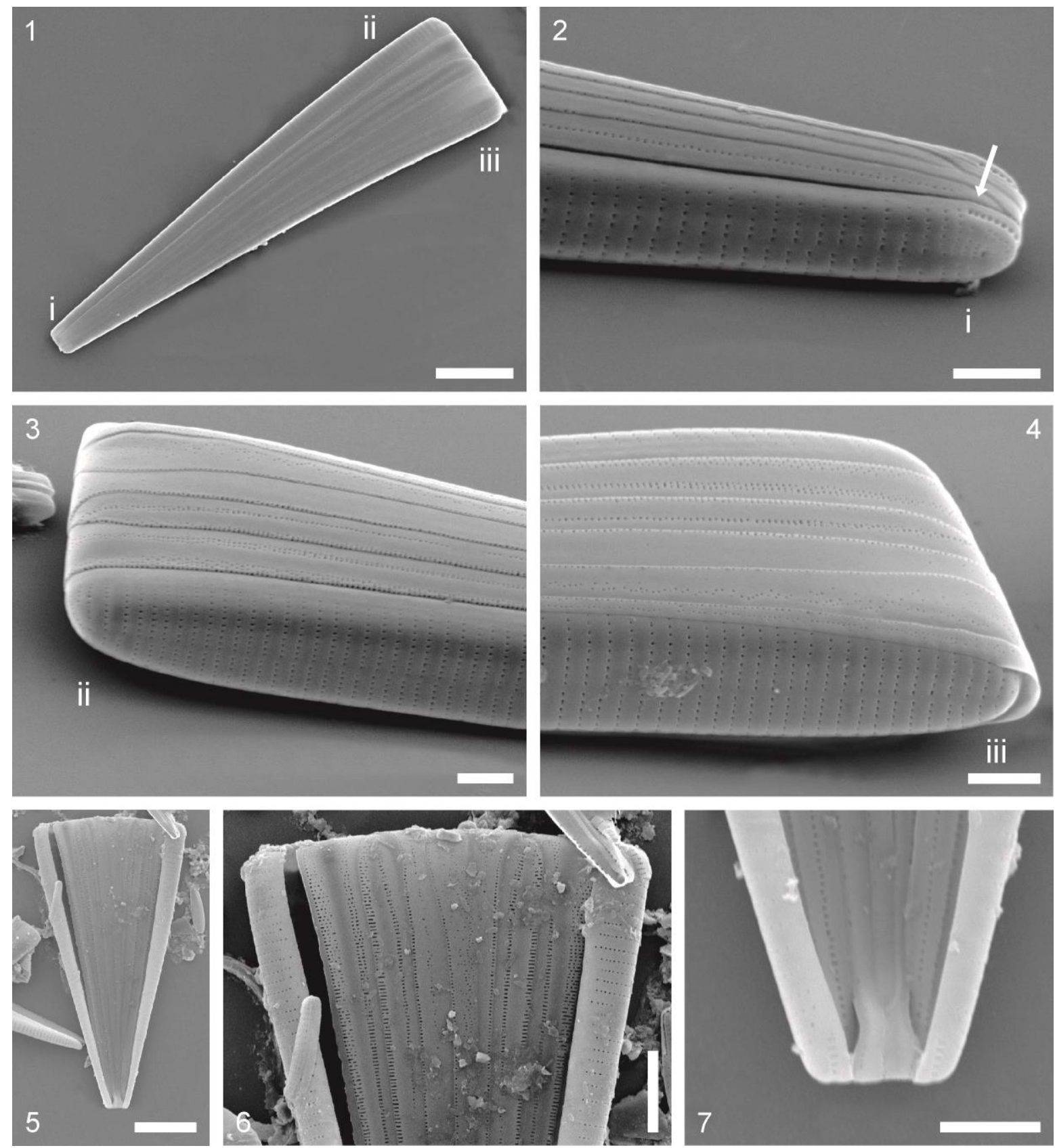

Lámina XVII. Licmophora antarctica. Figs. 1-7 MEB. Fig. 1. Frústulo en vista cingular. Fig. 2. Parte externa del polo basal mostrando la salida del proceso labiado y de la multiscissura y de la cintura mostrando una valvocópula abierta (flecha). Figs. 3 y 4 . Detalle de las cópulas ornamentadas por hileras de pequeños poros y/o estrías, en vista externa. Fig. 5. Frústulo en vista cingular. Figs. 6- 7. Detalle de la ornamentación del manto valvar y de las copulas. Escalas: Figs. 1,5: $20 \mu \mathrm{m}$, Fig. 6: $10 \mu \mathrm{m}$, Figs. 2-4, 7: $5 \mu \mathrm{m}$. 


\section{Observaciones y comentarios}

Licmophora belgicae es una especie establecida por Peragallo (1921: 70), en base a una ilustración de Van Heurck (1909, Lám 3, Fig. 1). Más tarde, Heiden (en Heiden \& Kolbe 1928) crea la especie Licmophora decora en base a la misma ilustración. Hustedt (1958) consideró entonces a $L$. decora como un sinónimo de $L$. belgicae. Recientemente Fernandes et al. (2014), examinan el material de Heiden y concluyen que se trata del mismo taxón, por lo que corroboran que $L$. belgicae tiene prioridad sobre $L$. decora.

Las medidas morfométricos de los ejemplares analizados en esta Tesis coincidieron con los datos compilados en Fernandes et al. (2014) y en particular con los hallados en la flora bentónica de caleta Potter por Al-Handal \& Wulff (2008a, como L. decora). En particular se consultó el material de Frenguelli \& Orlando (serie 12), hallándose alta similitud en los patrones de la estriación con L. belgicae var.minor Peragallo (1921, p. 70, pl. 4, figs 5-6; eje apical 90-130).

Se trata de una especie marina (Al-Handal \& Wulff 2008a). Fue registrada en Antártida como epífita y en sustratos blandos y rocosos (Frenguelli \& Orlando 1958, Fernandes et al. 2014). En caleta Potter L. belgicae/antarctica fue registrada como epífita de macroalgas y sobre sustratos duros (Klöser 1998) y en la flora bentónica por Al-Handal \& Wulff (= L. decora, 2008a). Fue registrada como poco frecuente en este estudio.

Licmophora gracilis (Ehrenberg) Grunow

Lám. IXX, Figs. 1-3

Grunow 1867, p. 34, Lám. 17, Fig. 6; Frenguelli \& Orlando 1958, p. 112-113, Lám. 4, Figs. 38-42; Honeywill 1998, p. 239-240, Fig. 9; Witkowski et al. 2000, p. 65, Lám. 18, Figs. 12-15, Lám. 19, Figs. 7-15; Al- Handal \& Wulff 2008a, p. 56, Figs. 29-30; Al-Handal \& Wulff 2008b, p. 429, Tabla 1, Figs. 68; Fernandes et al. 2014, p. 471-472, Figs. 21-34.

Las células son solitarias, con numerosos cloroplastos esféricos. Las valvas son heteropolares, espatuladas o clavadas, con ambos polos redondeados. La superficie valvar es plana con un esternón recto y muy angosto, a ambos lados del cual se distribuyen las estrías uniseriadas, principalmente distribuidas en forma alterna. Las areolas son levemente alargadas según el eje transapical. Las virgas se observan irregulares, presentando diferente grosor a lo largo del eje apical. Cada frústulo presenta dos procesos labiados, uno en el polo inferior de una de las valvas y el otro en el polo apical de la otra valva. El manto es recto y pronunciado, estriado y con mayor densidad de estrías hacia la parte apical. En la base se observa una multiscissura formada por alrededor de siete a nueve marcadas fisuras. El cíngulo está formado por dos a tres cópulas abiertas, la valvocópula presenta hileras de poros o cortas estrías ubicadas advalvarmente y abvalvarmente.

Datos morfométricos: En vista valvar, el eje apical varió entre 28,5 y $59,7 \mu \mathrm{m}$, el eje transapical mayor entre 4,9 y 6,9 $\mu \mathrm{m}$. La cantidad de estrías en $10 \mu \mathrm{m}$ fue de 17-20. 

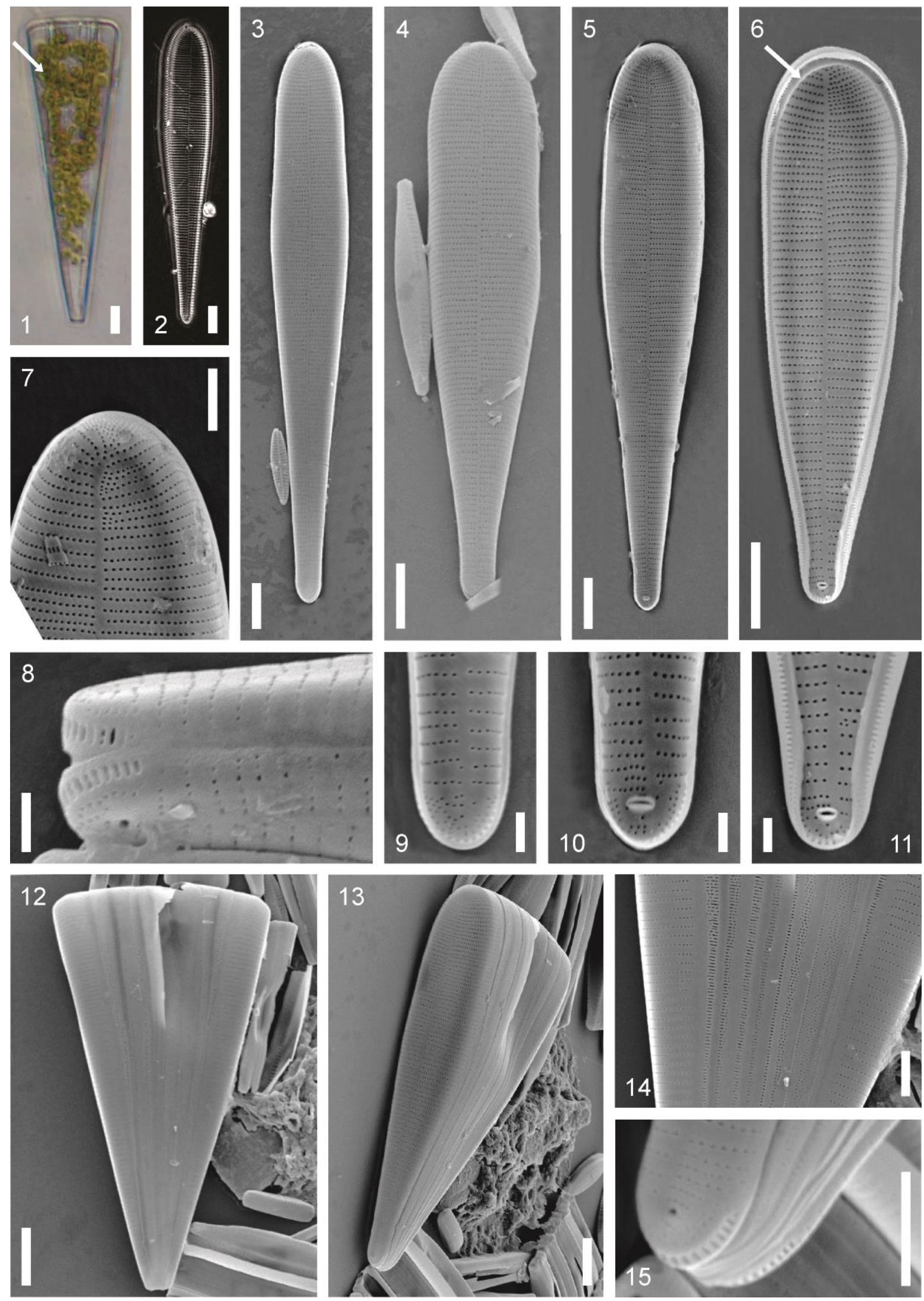

Lámina XVIII. Licmophora belgicae. Figs. 1-2 MO, Figs. 3-15 MEB. Fig. 1. Célula con cloroplastos discoides con pirenoides (flecha). Fig. 2. Vista valvar interna. Figs. 3 y 4 . Vista externa de valvas con distintas formas. Fig. 5. Vista interna, nótese la salida de los procesos labiados en ambos polos. Fig. 6. Vista interna, nótese el diferente grosor de las virgas y el septo apical reducido (flecha). Fig. 7. Detalle del polo apical en vista interna con un pequeño proceso labiado. Fig. 8. Multiscissura ubicada en el manto. Fig. 9. Vista externa del polo basal; nóte la distribución irregular de los poros y la ausencia de proceso labiado. Figs. 10-11. Detalles del polo basal. Figs. 12-13. Frústulo en diferentes posiciones. Fig. 14. Detalle de la valvocópula y cópulas. Fig. 15. Detalle de las cópulas abiertas, del proceso labiado y de la multiscissura. Escalas: Figs. 1- 6, 12-13: 10 m, Figs. 7, 1415: $5 \mu \mathrm{m}$, Figs. 8-11: $2 \mu \mathrm{m}$. 


\section{Observaciones y comentarios}

Los ejemplares analizados fueron morfológicamente similares a los estudiados por Fernandes et al. (2014) para Antártida. El escaso material registrado no permitió confirmar ubicación de los procesos labiados indicados para esta especie.

Se trata de una especie marina, cosmopolita (Witkowski et al. 2000, Guiry \& Guiry 2018), con varios registros en Antártida como epífita y en sustratos duros y blandos (Tabla 3.2). En caleta Potter fue anteriormente hallada en sustrato duro y blando, y frecuentemente como epífita de rodofitas y feofitas (Tabla 3.2). En este estudio fue frecuente en el material analizado.
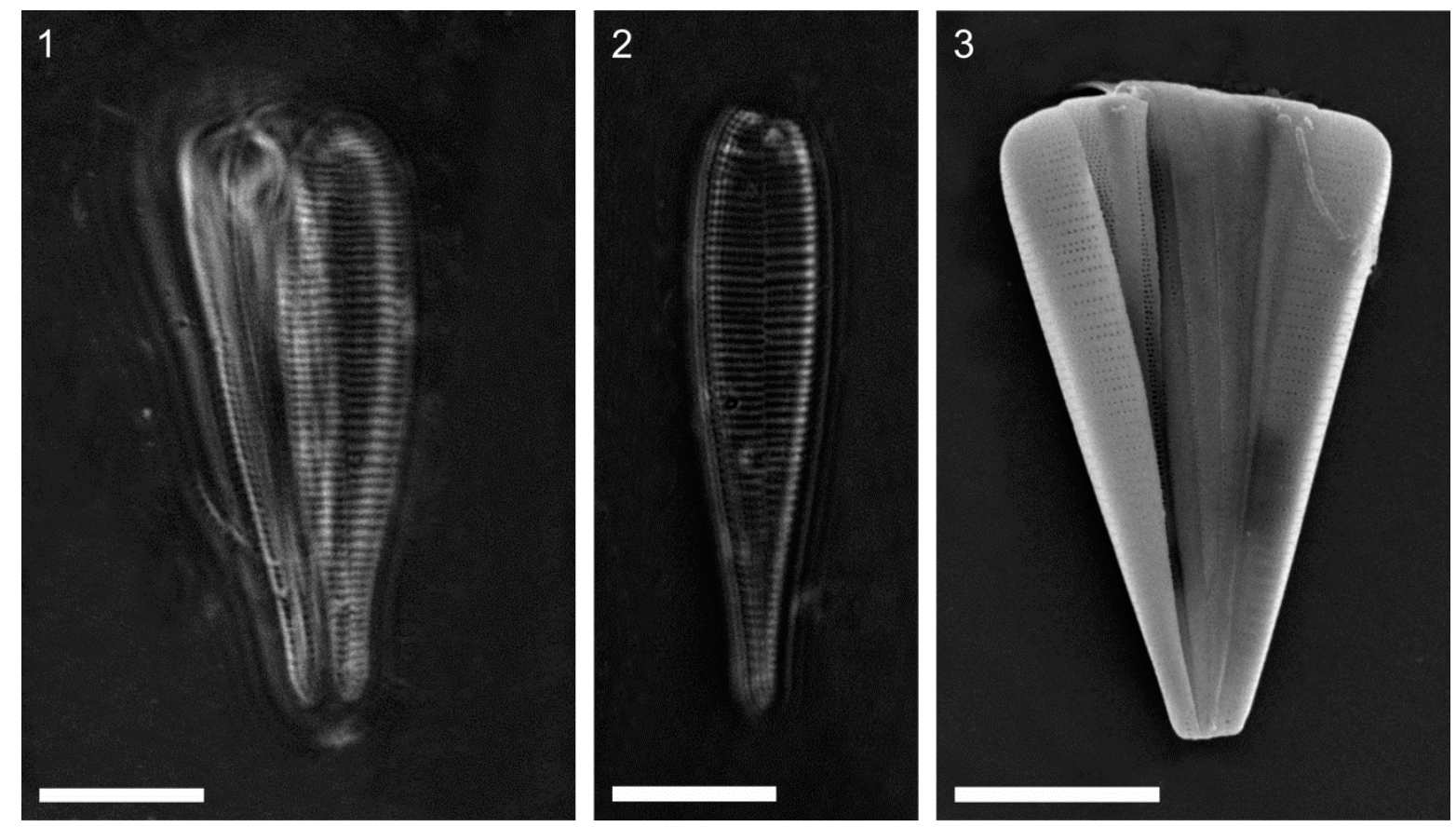

Lámina IXX. Licmophora gracilis. Figs. 1-2 MO, Fig. 3 MEB. Figs. 1-2. Células en vista valvar externa, nótese la distribución de las estrías y el estrecho esternón. Fig. 3. Frústulo en vista conectival, con numerosas cópulas y manto profundo. Todas las escalas corresponden a $10 \mu \mathrm{m}$.

\section{Minidiscus Hasle}

Minidiscus es uno de los géneros de diatomeas marinas planctónicas más pequeños, generalmente con un diámetro menor a $10 \mu \mathrm{m}$. Fue descripto originalmente como Coscinodiscus trioculatus (Taylor 1967) y posteriormente transferido por Hasle (1973) al género Minidiscus. Se caracteriza por tener los procesos reforzados ubicados lejos del margen valvar - generalmente en número de tres- y un proceso labiado localizado cerca del área central. Es un género cosmopolita, que puede ocurrir con elevada abundancia en aguas antárticas (Kang et al. 2003).

Minidiscus chilensis fue la única especie de este género hallada en este trabajo. 
Rivera en Rivera \& Koch 1984, p. 281-282, Figs. 5-14; Ferrario 1988, p. 311-318, Lám. 1 Fig. 3, Lám. 2 Figs. 1-2; Kang et al. 2003, Figs. 2-3; Quiroga \& Chrétiennot-Dinet 2004, p. 341-348, Figs. 7-8, 16; Al-Handal \& Wulff 2008a, p. 60, Figs. 52-53.

Las células son solitarias, discoidales. La superficie valvar externamente presenta una elevación en la zona central, adyacente a la cual se haya una depresión. El manto valvar es cóncavo y está rodeado por un evidente margen hialino. La mayor parte de las areolas se distribuyen regularmente en cortas estrías marginales orientadas radialmente, y prácticamente faltan hacia el centro de la valva. Sobre la parte elevada de la valva se observan, a modo de un triángulo isósceles, tres procesos reforzados: dos en la parte superior de la elevación y el otro localizado cerca o en la depresión. Entre los dos procesos reforzados ubicados en la parte superior se observa un proceso labiado orientado radialmente. Entre uno de los procesos reforzados y el proceso labiado se observa un poro ocluido internamente por una capa silícea (Rivera \& Koch, 1984, Figs. 7-8).

Datos morfométricos: El diámetro varió entre 3,2 y $5,8 \mu \mathrm{m}$, la cantidad de estrías en $1 \mu \mathrm{m}$ fue de 8-12 y el número de areolas en $1 \mu \mathrm{m}$ fue de 12-14.

\section{Observaciones y comentarios}

De acuerdo a Kang et al. (2003), M. chilensis es un organismo numéricamente muy importante en el nanoplancton marino antártico, pero fácilmente subestimado debido a su pequeño tamaño. Estos autores señalan la importancia de incluir este taxon en el análisis cuantitativo a fin de entender la estructura ecológica de las aguas abiertas antárticas. En particular, esta especie puede alcanzar una elevada dominancia estacional habiendo representado alrededor del $87 \%$ de las valvas halladas en trampas de sedimento ubicadas en el Estrecho de Brandfield (Kang et al. 2003).

A juzgar por las ilustraciones de Minidiscus trioculatus que presentan Al-Handal \& Wulff (2008a, p. 60, Figs. 52-53) de material proveniente de caleta Potter queda poca duda de que esta entidad es M. chilensis (ver Quiroga \& Chrétiennot-Dinet 2004). Por lo tanto el registro de $M$. chilensis en esta Tesis no se considera como primera cita para este sitio.

Minidiscus chilensis es una especie marina y cosmopolita (Rivera \& Koch, 1984, Ferrario 1988, Hasle \& Syvertsen 1997, Quiroga \& Chrétiennot-Dinet 2004). Su presencia en las muestras de este trabajo fue excepcional. 

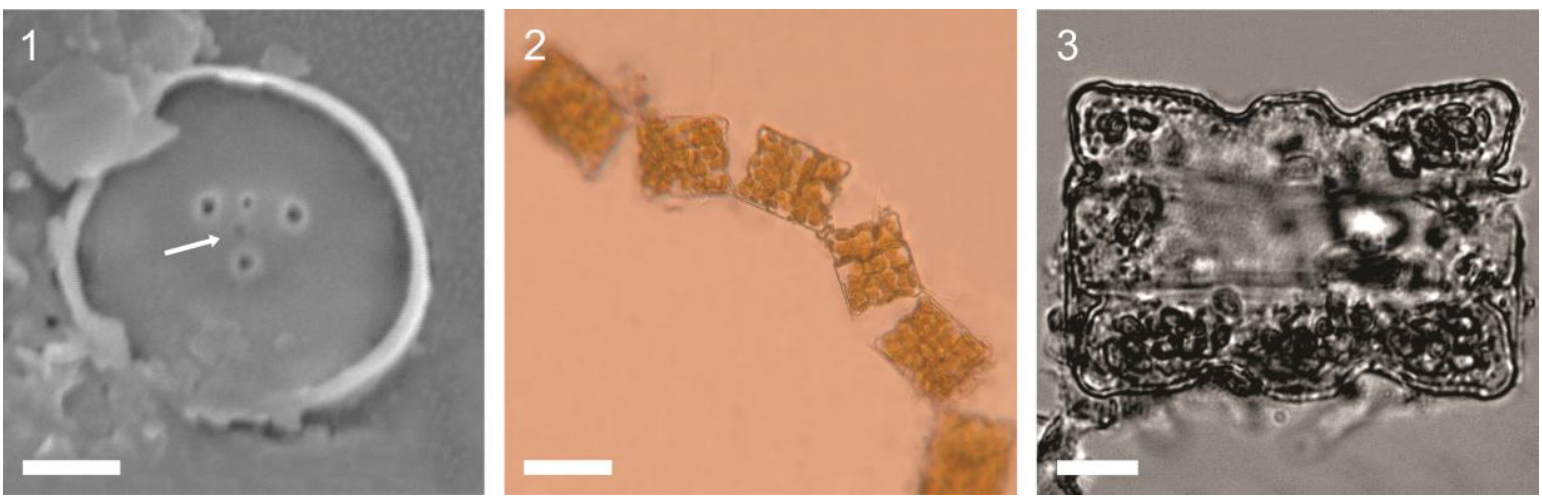

Lámina XX. Fig. 1 MEB, Figs. 2-3 MO. Fig. 1. Minidiscus chilensis. Valva en vista externa mostrando los tres procesos reforzados (de mayor tamaño), el proceso labiado y el poro (flecha). Figs. 2-3. Odontella aurita. Fig. 2. Células unidas formando cadenas en zig-zag. Fig. 3. Frústulo en vista conectival; nótese la ancha valvocópula. Escalas: Fig. 1: $1 \mu \mathrm{m}$, Fig. 2: $50 \mu \mathrm{m}$, Fig. 3: $10 \mu \mathrm{m}$.

\section{Navicula Bory}

Navicula es un género que incluye organismos principalmente solitarios, en el que cada célula posee dos grandes cloroplastos en forma de placa, ubicados uno a cada lado del plano apical y con un pirenoide de forma redondeada. El frústulo en vista valvar tiene un contorno linear-lanceolado y en vista conectival es rectangular. Ambas valvas poseen un rafe y presentan estrías uniseriadas formadas por lineolas. La cintura está formada por unas pocas cópulas, generalmente lisas y anchas (Round et al. 1990, Cox 2015).

Se trata de un género ampliamente representado en ambientes dulceacuícolas, salobres y marinos, que incluye taxa principalmente bentónicos y más raramente planctónicos (Cox 2015).

Tres especies del género Navicula fueron identificadas en este trabajo: Navicula directa, Navicula glaciei y Navicula perminuta.

Navicula directa (W. Smith) Ralfs

Lám. XXI, Figs. 1-6

Ralfs en Pritchard 1861, p. 906; Poulin 1990, p. 138-139, 144-145, Lám. 18.1, Fig. 24; Hasle \& Syvertsen 1997, p. 278-281, Lám. 73, Figs. a-b, Tabla 70; Witkowski et al. 2000, p. 275, Lám. 129, Fig. 1, Lám. 133, Figs. 10-12; Fernandes \& Procopiak 2003, p. 3-4, Figs. 2-12; Scott \& Thomas 2005, p. 157 , Fig. 2.87 a-d.

Las células son naviculiformes, comprimidas en vista conectival. En vista valvar son linear lanceoladas, con ápices agudos a levemente rostrados. La superficie valvar presenta estrías paralelas en la parte central y ligeramente oblicuas hacia los ápices. En vista externa, las fisuras centrales del rafe muestran sus extremos levemente expandidos y las fisuras terminales orientadas hacia la misma dirección y en forma de gancho. Las helictoglosas se observan sobre un puente silíceo establecido entre ambos márgenes valvares. El esternón del rafe está engrosado principalmente hacia uno de los lados.

Datos morfométricos: El eje apical varió entre 72,5 y $101,5 \mu \mathrm{m}$ y el eje transapical entre 9,7 y $12,4 \mu \mathrm{m}$, las estrías fueron de 8-9 en $10 \mu \mathrm{m}$, con 30-33 areolas en $10 \mu \mathrm{m}$. 


\section{Observaciones y comentarios}

Las características morfológicas y dimensiones encontradas en los especímenes analizados coincidieron con los reportados en la bibliografía consultada (Poulin 1990, Witkowski et al. 2000, Fernandes \& Prokopiak 2003, Scott \& Thomas 2005, Al-Handal \& Wulff, 2008a).

Se trata de una especie cosmopolita, marina, principalmente bentónica, que puede ser hallada en el plancton (Hasle \& Syvertsen 1997, Witkowski et al. 2000, Scott \& Thomas 2005). En Antártida, fue hallada en sedimento y sustrato duro y como epífita de macroalgas al igual que en caleta Potter (Tabla 3.2). En este estudio, $N$. directa fue frecuente.
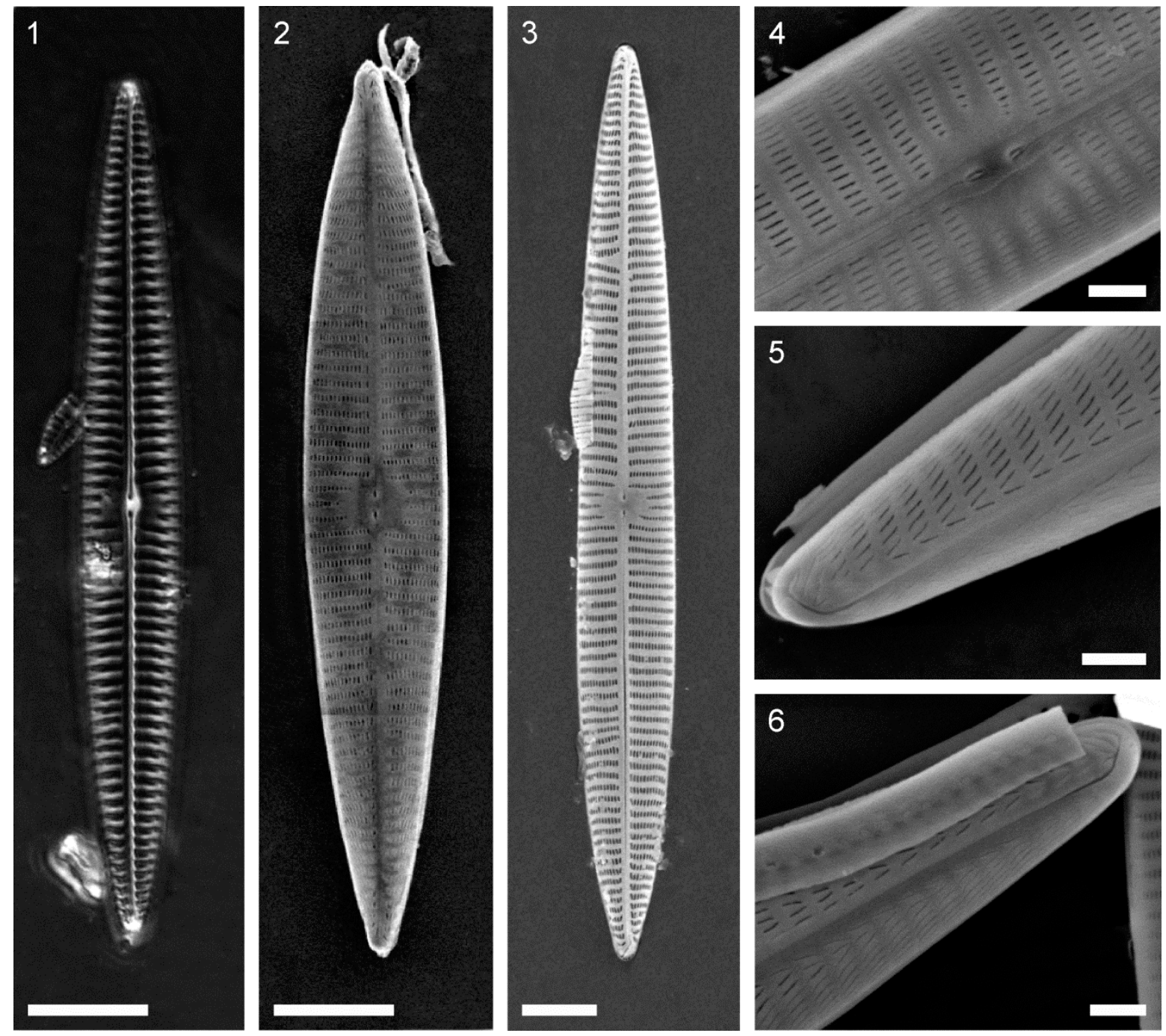

Lámina XXI. Navicula directa. Fig. 1 MO, Figs 2-6 MEB. Fig. 1. Vista valvar externa. Figs. 2-3. Diferentes formas y tamaños de células en vista valvar. Fig. 4. Detalle de la parte central en vista valvar externa mostrando las fisuras centrales del rafe y las estrías. Figs. 5-6. Vista de ambos extremos exponiendo las fisuras terminales del rafe en forma de gancho. Nótese la diferente orientación de las lineolas en la parte central y apical de la valva. Escalas: Figs. 1-3: $10 \mu \mathrm{m}$, Figs. 4-6: $2 \mu \mathrm{m}$.

Van Heurck 1909, p. 11, Lám. 1, Fig. 13; Whitaker \& Richardson 1980, p. 252-253, Fig. 4; Poulin \& Cardinal 1982, p. 2837, Fig. 28; Kang et al. 1999, p. 171, Fig. 2; Fernandes \& Prokopiak 2003, p. 4, Figs. 13-14; Scott \& Thomas 2005, p. 158, Fig. 2.89. 
Las células en vista valvar son elíptico-lanceoladas, con ápices subrostrados. La superficie valvar presenta estrías uniseriadas formadas por lineolas, levemente radiadas en el área central y más paralelas cerca de los ápices. A cada lado de la fascia se observan una o dos cortas estrías. El rafe es recto, en vista externa las fisuras centrales presentan sus extremos ligeramente dilatados y desviados hacia el mismo lado. Las fisuras terminales tienen forma de gancho orientados en la misma dirección. En vista interna, estas fisuras muestran pequeñas helictoglosas. El manto valvar es bajo y con estrías semejantes a las de la superficie valvar.

Datos morfométricos: El eje apical varió entre 13,8 y $24,0 \mu \mathrm{m}$ y el eje transapical entre 5,3 y $7,5 \mu \mathrm{m}$, las estrías fueron de $14-18,5$ en $10 \mu \mathrm{m}$, presentando (33) 37,5-40 areolas en 10 $\mu \mathrm{m}$.

\section{Observaciones y comentarios}

Navicula glaciei es considerada como una especie de distribución bipolar, asociada al hielo marino (von Quillfeldt et al. 2003, Janech et al. 2006, Ryan et al. 2012). En Antártida, fue señalada como epífita sobre algas rojas en la zona del Mar de Ross y bahía Lasserre (bahía del Almirantazgo), como epipélica y presentando elevada abundancia en costas rocosas (Tabla 3.2). Se ha sugerido que esta especie podría ser una importante contribuyente para las comunidades fitoplanctónicas de la región (Fernandes \& Prokopiak 2003). Fue hallada como poco frecuente en este estudio y su hallazgo representa el primer registro para la flora bentónica de caleta Potter.
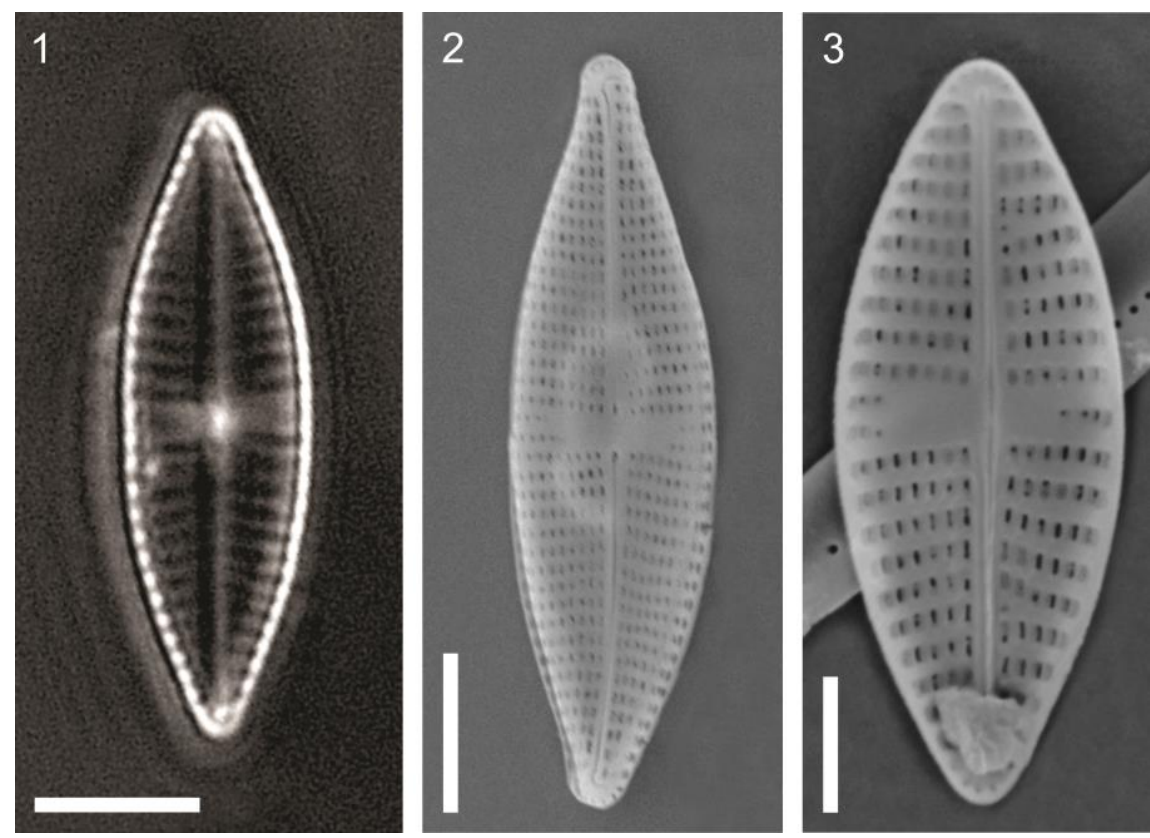

Lámina XXII. Navicula glaciei. Fig. 1 MO, Figs. 2-3 MEB. Fig. 1. Vista general de una valva, nótense los extremos subrostrados. Fig. 2. Vista valvar externa mostrando las fisuras centrales y terminales del rafe con extremos orientados en la misma dirección. Fig. 3. Vista interna de una valva mostrando las marcadas virgas, las pequeñas helictoglosas y la disposición de las estrías uniseriadas. Escalas: Figs. 1-2: $5 \mu \mathrm{m}$, Fig. 3: 2,5 $\mu \mathrm{m}$. 
Grunow en Van Heurck 1880, Lám. 14, Fig. 7; Lange Bertalot 2001, p. 54-55, Lám. 33, Figs. 20-27; Busse \& Snoeijs 2002, p. 277, Figs. 11-15, 34-40; Cefarelli et al. 2016, p. 453-454, Fig. 10a.

Las células poseen valvas linear-lanceoladas con ápices obtusamente redondeados. La superficie valvar presenta estrías formadas por lineolas que no llegan hasta los ápices. Las estrías son levemente radiales en el centro y convergentes hacia los polos. La fascia generalmente con una o dos cortas estrías a cada lado del margen valvar, raramente lisa. EI rafe es rectilíneo, con los extremos de las fisuras terminales centrales relativamente distantes en vista externa, y muy cercanos en vista interna. En los polos, las fisuras terminales en vista externa son en forma de gancho y orientadas hacia el mismo lado y en vista interna, terminadas en pequeñas helictoglosas, cada una rodeada por una evidente área hialina. El cíngulo contiene unas pocas cópulas lisas y anchas.

Datos morfométricos: El eje apical varió entre 5,3 y 18,9 $\mu \mathrm{m}$ y el eje transapical entre 1,9 y $5,2 \mu \mathrm{m}$. La cantidad de estrías en $10 \mu \mathrm{m}$ varió entre 14 y 20 (25 en el ejemplar de menor tamaño). El número de lineolas en $10 \mu \mathrm{m}$ varió entre 27 y 40 (50 únicamente en un ejemplar de menor tamaño).

\section{Observaciones y comentarios}

Existe cierta controversia en la bibliografía respecto a la identificación de $N$. perminuta (Witkowski et al. 2000, Al-Handal \& Wulff 2008a, Cefarelli et al. 2016). Esto posiblemente se deba a que se trata de organismos de pequeñas dimensiones y en su mayoría los datos provienen de observaciones al microscopio óptico. Sumado a esto, esta especie puede presentar una amplia variación en la forma de la valva (Al-Handal \& Wulff 2008a), en algunos casos, atribuidos a condiciones de stress ambiental (Majewska et al. 2013a).

El trabajo de Busse \& Snoeijs (2002) describe detalladamente a N. perminuta empleando MEB. Comparando los resultados de estos autores con los obtenidos a partir de los numerosos ejemplares analizados en esta Tesis se puede concluir que la especie presente en este estudio corresponde a $N$. perminuta.

Cabe destacar que $N$. perminuta presenta caracteres morfológicos y morfométricos similares a Navicula australoshetlandica Van de Vijver, descripta para ambientes salobres y de agua dulce en Antártida (Van de Vijver et al. 2011). El carácter principal que las diferencia es el mayor desarrollo del esternón del rafe hacia uno de sus lados en $N$. australoshetlandica (Van de Vijver et al. 2011, Fig.15), carácter que no fue observado en los ejemplares de $N$. perminuta analizados en esta Tesis ni en el trabajo de Busse \& Snoeijs (2002, Fig. 38). Dada la semejanza entre ambos taxa y la marcada variabilidad morfológica que caracteriza a $N$. perminuta, se considera que son necesarios estudios ulteriores a fin de dilucidar si estas corresponden o no a la misma especie. 

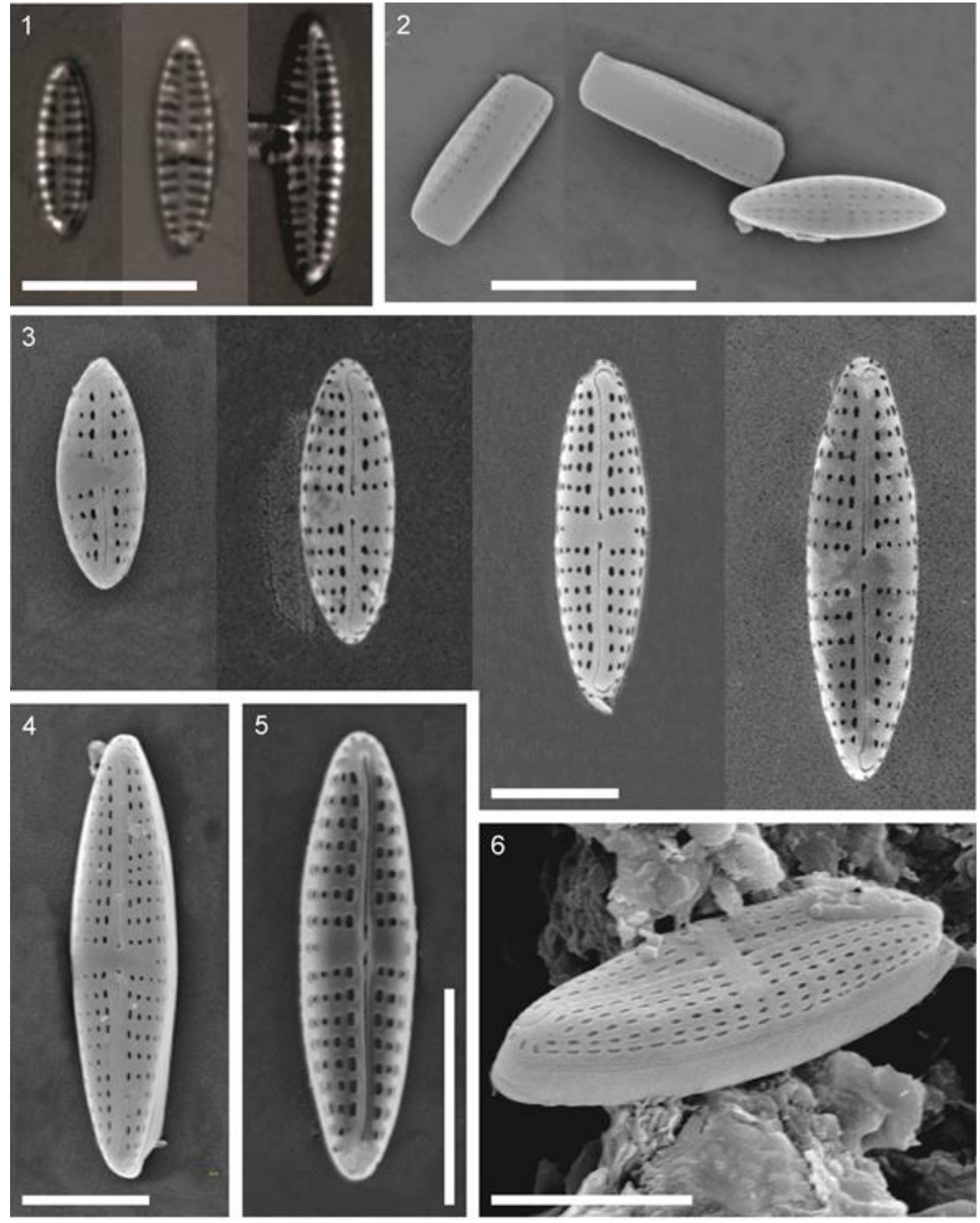

Lámina XXIII. Navicula perminuta. Fig. 1 MO, Figs. 2-6, MEB. Fig. 1. Diferentes tamaños de un frústulo en vista valvar. Fig. 2. Frústulos en vista valvar y conectival. Fig. 3. Frústulos con diferentes rangos de tamaño; nótense las estrías cortas ubicadas sobre la fascia y las terminaciones centrales y apicales de las fisuras del rafe en vista externa. Figs. 4-5. Valvas en vista externa e interna, respectivamente; nótense los extremos terminales centrales del rafe relativamente distantes en vista externa y muy cercanos en vista interna, como así también las pequeñas helictoglosas rodeadas de un área hialina. Fig. 6. Frústulo mostrando la disposición de las lineolas en el borde marginal de la valva, el manto y las cópulas lisas. Escalas: Figs. 1-2: $10 \mu \mathrm{m}$, Figs. 3-6: $5 \mu \mathrm{m}$. 
Es una especie cosmopolita, hallada en ambientes marinos costeros y de aguas salobres (Kuylenstierna 1989-1990, Lange Bertalot 2001, Witkowski et al. 2000). En ambientes antárticos, fue dominante sobre sustratos artificiales instalados en la zona intermareal de Península Potter (Zacher et al. 2007b) y estuvo ampliamente distribuida como epífita de algas rojas en la zona del Mar de Ross (Majewska et al. 2016). Es probable que el taxón descripto en esta Tesis sea el mismo que Al Handal \& Wulff $(2008 a, b)$ determinaron como Navicula cf perminuta para ambientes bentónicos antárticos (Tabla 3.2). Esta especie estuvo presente en la totalidad de las muestras analizadas (Tabla 3.1).

\section{Nitzschia Hassall}

Nitzschia es un género caracterizado por reunir organismos generalmente solitarios o formando colonias de diferentes tipos que pueden estar incluidas en un tubo mucilaginoso. Las células son lineares, generalmente sigmoides con dos o raramente cuatro cloroplastos. Cada valva posee un rafe fibulado, habitualmente excéntrico, ubicado sobre una quilla. En el frústulo, los rafes se encuentran ubicados en márgenes opuestos. La superficie valvar presenta estrías generalmente uniseriadas. La cintura posee cópulas muy variables en número, generalmente ornamentadas por hileras de poros (Round et al. 1990).

Este género ha sido señalado para ambientes marinos y de agua dulce, generalmente como epipélico o planctónico (Cox 2015).

Nitzschia pellucida fue la única especie de este género identificada en este estudio.

\section{Nitzschia pellucida Grunow}

Lám. XV, Fig. 5

Grunow en Cleve \& Grunow 1880, p. 80, Lám. 5, Fig. 96; Bérard-Therriault et al. 1999, p. 66, Lám. 58f-h. Al-Handal \& Wulff 2008a, p. 54 Tabla 1, p. 56 Tabla 2, Fig. 123.

Los frústulos en vista conectival son rectangulares, en vista valvar rectos o linear-elípticos con un sistema del rafe fibulado, excéntrico, ligeramente contraído en el centro, donde se observa un evidente nódulo. La superficie valvar posee estrías uniseriadas equidistantes y paralelas entre sí, cada una formada por pequeños poros circulares.

Datos morfométricos: El eje apical fue de $47,0 \mu \mathrm{m}$ y el eje transapical de 4,6 $\mu \mathrm{m}$. Las estrías fueron $27-28$ en $10 \mu \mathrm{m}$ y las fíbulas, $10-11$ en $10 \mu \mathrm{m}$, con 40 areolas en $10 \mu \mathrm{m}$.

\section{Observaciones y comentarios}

Se trata de una especie cosmopolita, marina y de aguas salobres (Al-Handal \& Wulff 2008a). En caleta Potter fue hallada en fondos de sustrato blando (Tabla 3.2). Su presencia fue excepcional en este estudio (Tabla 3.1). 


\section{Odontella Agardh}

Las valvas son de contornos bipolares a multipolares y es uno de los géneros ubicados en la familia Eupodiscaceae, un grupo monofilético dentro de las diatomeas (Ashworth et al. 2013), caracterizado por la presencia de estructuras ocelares y areolas poroides. El género Odontella es un componente habitual en el litoral marino, epífito sobre macroalgas o arraigado a otros sustratos.

Odontella aurita (Lyngbye) Agardh

Lám. XX, Figs. 2-3

Agardh 1832, p. 56; Ferrario \& Sastre 1990, Figs. 1-10; Hasle \& Syvertsen 1997, p. 236, Lám. 49, Figs. 2a-b, Tabla 62; Scott \& Thomas 2005, p. 48; Lavigne et al. 2015, p. 314.

Las células están unidas entre sí formando cadenas en zig-zag y tienen numerosos y pequeños cloroplastos discoides. Los frústulos están fuertemente silicificados y son variables morfométricamente respecto a los ejes apical y pervalvar. En vista cingular, son rectangulares y muestran el margen del manto valvar replegado alrededor de la valva, así como una ancha valvocópula finamente estriada. En vista valvar son elípticos, con una superficie provista al centro de una protuberancia más o menos marcada y otras en los extremos sobre las cuales se ubica un ocelo.

Datos morfométricos: El eje apical varió entre 41,5 y 55,0 $\mu \mathrm{m}$, el eje pervalvar entre 38,2 y $54,7 \mu \mathrm{m}$, considerando las elevaciones. El número de areolas en la superficie valvar fue de 8-14 en $10 \mu \mathrm{m}$ y el número de areolas en las cópulas fue de 9-14 en $10 \mu \mathrm{m}$.

\section{Observaciones y comentarios}

Debido al insuficiente material sólo fue posible analizar parte de los caracteres diagnósticos. No obstante, los especímenes examinados mostraron caracteres afines a $O$. aurita, una especie citada para aguas antárticas (Frenguelli \& Orlando 1958, Hasle \& Syvertsen 1997, Scott \& Thomas 2005) y muy similar a Odontella obtusa, la cual anteriormente fue propuesta como sinónimo (Smith 1856, p. 49, Fig. 319) o como una variedad de O. aurita (Hustedt 1930, p. 848, Fig. 502). En base a estos antecedentes y la alta variabilidad que esta especie presentó en el estuario del Río Chubut, Argentina (Ferrario \& Sastre 1990), se considera a los ejemplares hallados en caleta Potter en este trabajo como O. aurita.

Se trata de una especie marina, cosmopolita, planctónica, bentónica o epífita (Frenguelli \& Orlando 1958, Round et al. 1990, Hasle \& Syvertsen 1997). Fue muy rara en el material analizado en este trabajo, habiéndosela observado formando filamentos en zigzag (Tabla 3.1). 


\section{Parlibellus Cox}

Los taxa comprendidos en el género Parlibellus anteriormente fueron parte del género Navicula (Cox 1978, 1988, Round et al. 1990). Las células son más o menos romboidales a naviculiformes y pueden ser solitarias o estar reunidas en tubos mucilaginosos. El rafe es recto y no alcanza a los polos valvares; internamente está bordeado por una costilla silícea y posee conspicuas helictoglosas. La cintura está compuesta por cópulas abiertas, con pequeños poros. Son organismos con un hábitat marino costero, epífitos o epilíticos (Cox 2015).

Una especie de este género, Parlibellus delognei, fue registrada en el material analizado.

Parlibellus delognei (Van Heurck) Cox

Lám. XXIV, Figs. 1-6, Lám. XXV, Figs. 1-6

Cox 1978, Figs. 1a-c, 2-3, 12, 15-23 (=Navicula grevillii); Cox 1988, p. 19, Figs. 1-2, 11, 15; Witkowski et al. 2000, p. 321, Lám. 104, Figs. 1-5; Al-Handal \& Wulff 2008a, Tablas 1-2, Figs. 79-80.

Las células generalmente están reunidas dentro de un tubo mucilaginoso, cada una de ellas tiene dos cloroplastos lobados, los que observados en vista conectival toman la forma de una mariposa. La superficie valvar posee estrías uniseriadas ligeramente más espaciadas hacia el centro de la valva. Las fisuras terminales del rafe en vista externa están curvadas hacia el mismo lado, e internamente muestran imperceptibles helictoglosas. En vista externa, las fisuras centrales del rafe están suavemente expandidas e internamente terminadas en angostos canalículos. En el centro de la valva, se observan unos pocos poros aislados los cuales no tienen salida interna. La cintura está compuesta por numerosas cópulas abiertas, cada una ornamentada por dos hileras de poros.

Datos morfométricos: El eje apical varió entre 60,1 y $71,1 \mu \mathrm{m}$ y el eje transapical entre 20,9 y $24,6 \mu \mathrm{m}$. La cantidad de estrías en $10 \mu \mathrm{m}$ fue de 16-17. La cantidad de areolas en 10 $\mu \mathrm{m}$ fue de 29.

\section{Observaciones y comentarios}

Parlibellus delognei es una especie marina y cosmopolita (Witkowski et al. 2000). Fue hallada en la flora bentónica de caleta Potter (Al-Handal \& Wulff 2008a) y como epífita de rodofitas en el Mar de Ross (Majewska et al. 2016) (Tabla 3.2). La presencia de esta especie fue muy rara (Tabla 3.1) y se registró formando colonias mucilaginosas visibles macroscópicamente (Lám. XXIV, Fig. 1). 

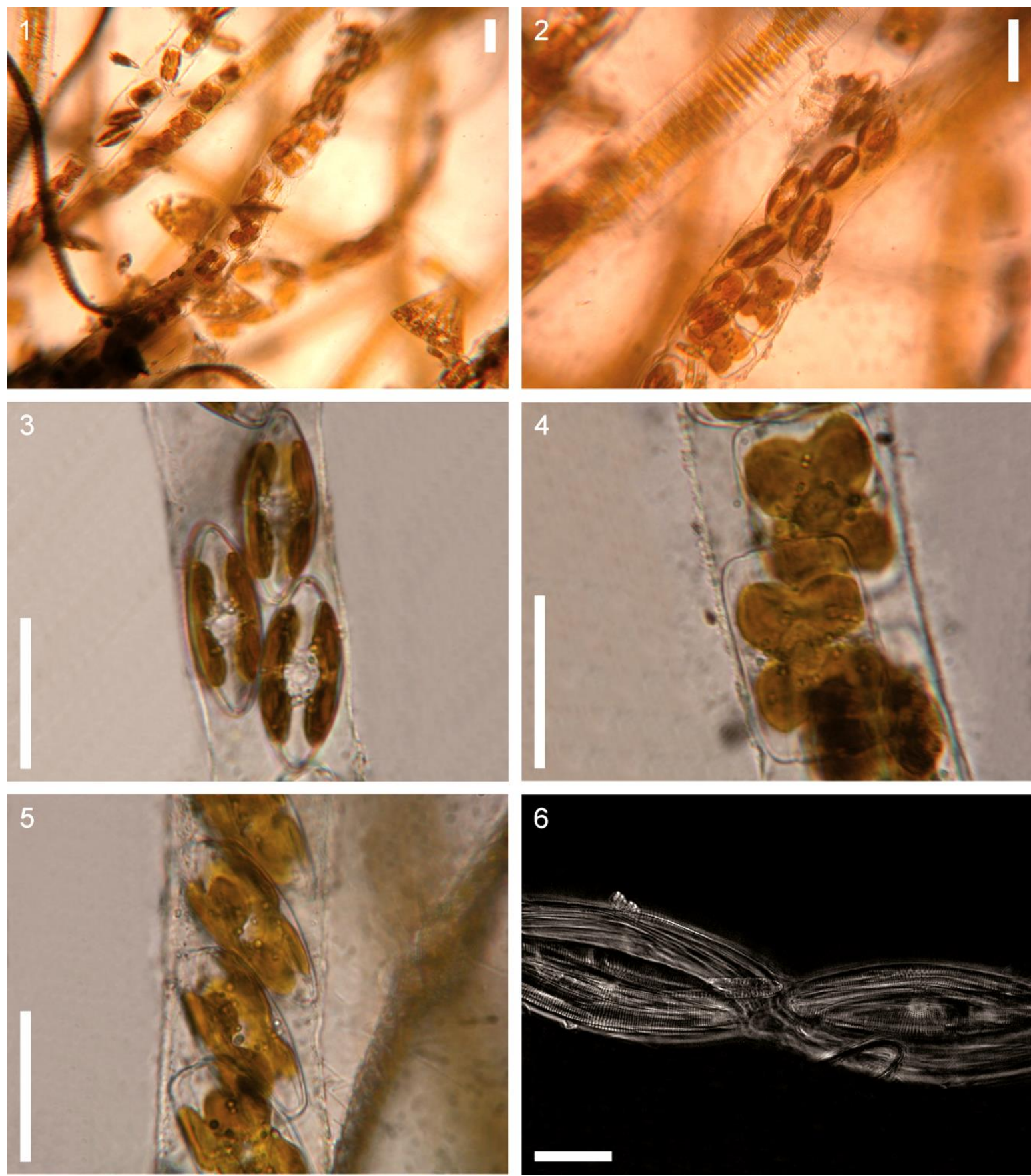

Lámina XXIV. Parlibellus delognei. Figs. 1-6 MO. Fig. 1. Vista general de varias colonias filiformes mucilaginosas. Fig. 2. Parte de una colonia con células en diferentes vistas dentro del cordón mucilaginoso. Fig. 3. Células en vista valvar mostrando los cloroplastos ubicados a cada lado de la célula. Fig. 4. Cloroplastos observados en vista cingular, con la característica forma de mariposa. Fig. 5. Detalle de los cloroplastos desde otra vista. Fig. 6. Detalle de dos células en contacto por sus extremos valvares. Escalas: Figs. 1-5: 50 um, Fig. 6 : $20 \mu \mathrm{m}$. 

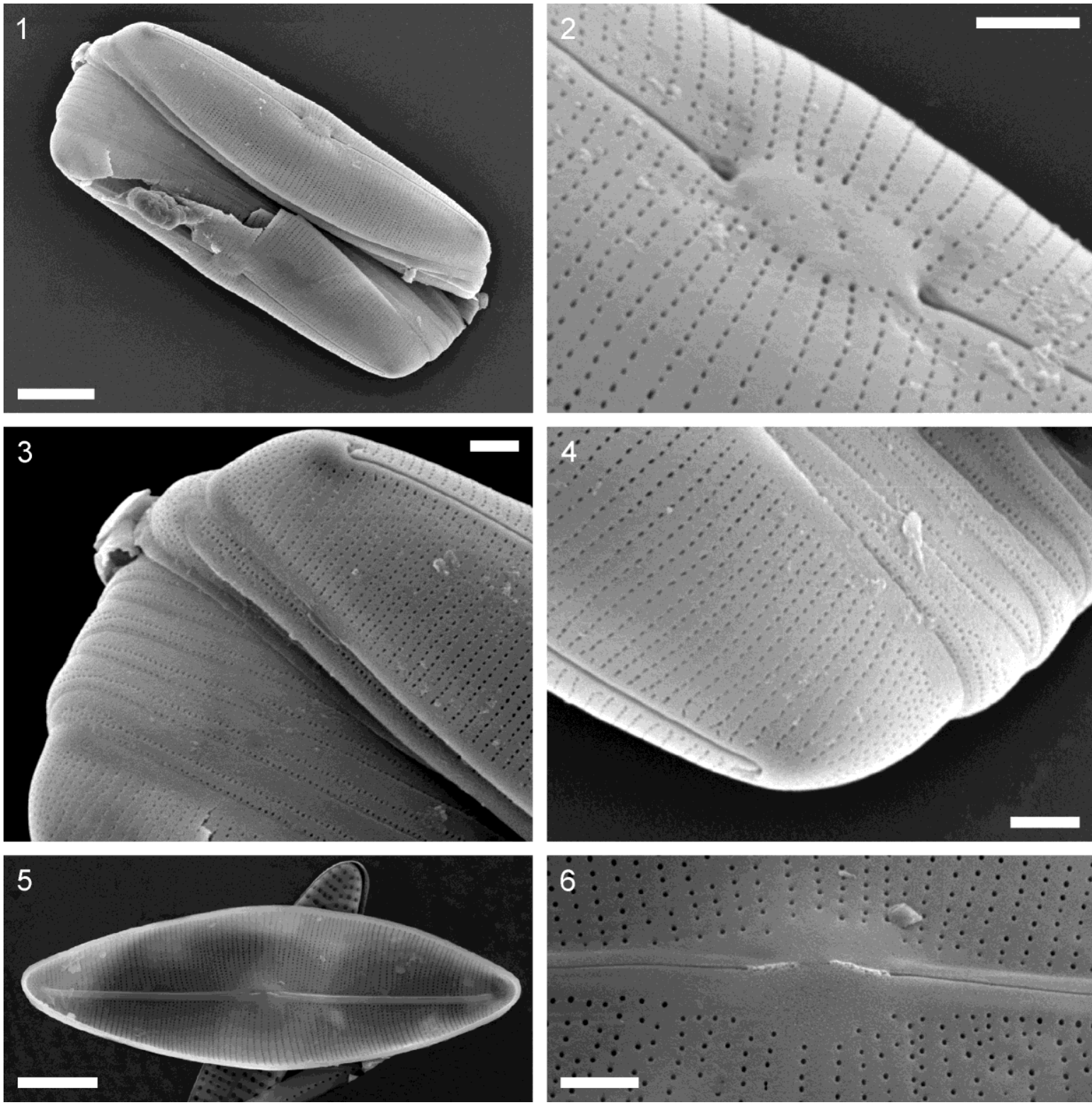

Lámina XXV. Parlibellus delognei. Figs. 1-6 MEB. Fig. 1. Frústulo en vista cingular. Fig. 2. Centro de la valva en vista externa; nótese la distribución de las estrías uniseriadas y las fisuras proximales del rafe suavemente expandidas, así como algunos poros irregularmente distribuidos en el área central. Fig. 3. Frústulo mostrando una de las fisuras terminales del rafe, el profundo manto valvar con un borde hialino y la cintura compuesta de varias cópulas abiertas ornamentadas de hileras de pequeños poros. Fig. 4. Parte externa de uno de los ápices de la valva, detalle de las cópulas. Fig. 5. Valva en vista interna. Fig. 6. Detalle del centro valvar en vista interna; nótese la presencia de angostos canalículos en las fisuras proximales del rafe. Escalas: Figs. 1, 5: $10 \mu \mathrm{m}$, Figs. 2-4, 6: $2 \mu \mathrm{m}$. 


\section{Petroneis Stickle \& Mann}

El género Petroneis fue establecido por Stickle \& Mann (en Round et al. 1990). Las células son solitarias, naviculiformes, cada una con dos plástidos generalmente con márgenes lobados. Las valvas son lineares a anchamente elípticas, generalmente con polos rostrados y una superficie plana con estrías uniseriadas. El rafe es recto y está ubicado centralmente. La cintura posee unas pocas cópulas ornamentadas por estrías formadas por grandes poroides. Petroneis es un género de diatomeas birafidales, representado en ambientes marinos, como epipélico, principalmente sobre fondos arenosos.

Una especie del género Petroneis fue hallada en el material analizado.

Petroneis sp.

Lám. XV, Fig. 4

Al-Handal \& Wulff 2008a, Figs. 87-89, 125, Tablas 1-2; Al-Handal \& Wulff 2008b, Fig. 114, Tabla 2.

Lo escaso del material analizado sólo permitió observar las características generales de las valvas, las que fueron anchamente elípticas y con polos rostrados.

Datos morfométricos: El eje apical fue de $38,7 \mu \mathrm{m}$ y el eje transapical de $17,4 \mu \mathrm{m}$, con 11 estrías y 18 areolas en $10 \mu \mathrm{m}$.

\section{Observaciones y comentarios}

La presencia de esta especie fue excepcional en las muestras analizadas (Tabla 3.1). Para caleta Potter se han registrado varios taxa de este género asociados a hábitats bentónicos aunque la mayoría de ellos no han sido identificados a nivel de especie (Al-Handal \& Wulff 2008a, b).

\section{Pleurosigma Hassall}

Las células son solitarias, sigmoides, lanceoladas o rómbicas con dos o cuatro cloroplastos con pirenoides, extendidos de polo a polo. Los frústulos son birafidales con valvas ornamentadas por estrías con areolas loculares ordenadas en hileras en diagonal. En vista conectival, estrechas mostrando cópulas abiertas y lisas.

Son organismos que habitan en ambientes marinos y salobres, como epilíticos sobre arena, ocasionalmente planctónicos (Round et al. 1990, Cox 2015).

Una especie, Pleurosigma sp. fue registrada en el material analizado. 
Pleurosigma sp.

Lám. XV, Fig. 6

Al-Handal \& Wulff 2008a, Figs. 99-100, Tablas 1-2; Al-Handal \& Wulff 2008b, Fig. 103-104, Tabla 2.

Las valvas son lanceoladas, sigmoides hacia los extremos con lados más o menos paralelos en la mayor parte de su longitud, ornamentadas por estrías oblicuas y transversas. Los polos son redondeados. El rafe central es recto, curvo hacia los polos. Area central hialina redondeada y terminal alargada según el eje apical.

Datos morfométricos: El eje apical varió entre 171,3 y $218,0 \mu \mathrm{m}$ y el eje transapical entre 19,8 y $20,3 \mu \mathrm{m}$. La cantidad de estrías oblicuas fue de 16 y la de estrías transversales de 14 en $10 \mu \mathrm{m}$.

\section{Observaciones y comentarios}

La presencia de esta especie fue rara en las muestras analizadas (Tabla 3.1). Para caleta Potter se han registrado dos taxa de este género asociados a hábitats bentónicos (Al-Handal \& Wulff 2008a, b).

\section{Pseudogomphonema Medlin}

El género Pseudogomphonema fue establecido por Medlin (en Medlin \& Round 1986) en base a la separación de las especies de Gomphonema con un hábitat dulceacuícola. Las diferencias más contrastantes entre ambos géneros residen en la estructura de las cópulas, las cuales en Pseudogomphonema son lisas y en Gomphonema tienen una o dos hileras de poros. Además, en Pseudogomphonema las bandas están modificadas por la presencia de un único y muy desarrollado pseudosepto que está ubicado en el polo basal, como un puente a través de la valva y que está fusionado con la helictoglosa. Asimismo lleva una cámara que hacia el lado externo se abre a través de una hilera de poros alargados no ocluidos. El esternón del rafe es asimétrico y está más desarrollado hacia uno de los márgenes del rafe. El cíngulo contiene cuatro cópulas lisas, dos de las cuales aparecen reducidas en el polo basal.

Pseudogomphonema es un género marino, representado por organismos con un habitat bentónico, epifítitico o endofítico en macroalgas y de distribución cosmopolita (Witkowski et al. 2000, Al-Handal \& Wulff 2008a, Cox 2015).

\section{Pseudogomphonema kamtschaticum (Grunow) Medlin}

Lám. XXVI, Figs.1-6, Lám. XXVII, Figs. 1- 10

Medlin en Medlin \& Round 1986, p. 216, Figs. 23-26, 64-70; Witkowski et al. 2000, p. 343, pl. 60, Figs. 13-16; Scott \& Thomas 2005, p. 163-164, Figs. 2.93 \& 2.94a-b.

Las células son solitarias y se fijan al sustrato por medio de un pedúnculo mucilaginoso corto. Poseen dos cloroplastos en forma de placa, cada uno de ellos con un pirenoide 
redondeado. Los frústulos son heteropolares, cuneados en vista conectival y linearlanceolados, con ambos ápices redondeados en vista valvar. La superficie valvar es plana en el centro y curvada uniformemente hacia el manto, que es profundo. Las estrías uniseriadas son radiales hacia los extremos y están formadas por una hilera de lineolas. Las virgae están fuertemente desarrolladas. Se observa un pseudosepto en el polo basal. El sistema del rafe en vista externa muestra ambas fisuras terminales en forma de gancho y las centrales ligeramente ensanchadas y próximas entre sí. En vista interna las fisuras terminales poseen pequeñas helictoglosas y las centrales son marcadamente alargadas. El cíngulo está formado por cópulas lisas y abiertas, con la valvocópula de mayor ancho.

Datos morfométricos: El eje apical varió entre 23,3 y $56,5 \mu \mathrm{m}$ y el eje transapical entre 5,5 y 7,2 $\mu \mathrm{m}$. La cantidad de estrías en $10 \mu \mathrm{m}$ fue de 12-15, en número menor en la valva primaria y de mayor densidad en los ápices (16-21 en $10 \mu \mathrm{m})$. El número de poroides en 10 um fue de 60-70.

\section{Observaciones y comentarios}

Los ejemplares analizados presentaron una morfología similar a los registrados anteriormente en caleta Potter (Al-Handal \& Wulff 2008a,b) aunque con un menor número de estrías (12-15 en $10 \mu \mathrm{m})$ que las reportadas en la descripción original de la especie (1623 en $10 \mu \mathrm{m}$, Medlin \& Round 1986). Esta especie presenta un amplio rango de variación en las dimensiones de la valva y en la densidad de las estrías (Witkowski et al. 2000, Scott \& Thomas 2005).

En caleta Potter, $P$. kamtschaticum fue registrada en sustrato blando y como epífita en varios taxa de algas rojas y pardas, en algunos casos con elevada abundancia (Tabla 3.2). Asímismo, fue hallada sobre como epifita de rodofitas en otros ambientes antárticos (Majewska et al. 2016). Esta especie fue muy frecuente en el material analizado. Se observaron células solitarias- frecuentemente en estado de división o formando manchones irregulares sobre los sustratos.

\section{Pteroncola Holmes \& Croll}

Los frústulos son solitarios o forman colonias en zig-zag, en vista valvar linear-elípticos y rectangulares en vista conectival. Las valvas son ligeramente domadas, con una superficie ornamentada por estrias alveoladas que abren externamente por una hilera de pequeños poros e internamente por un foramen. Presenta un esternón estrecho o muy desarrollado, y un campo de poros ubicado en cada extremo valvar.

Pteroncola es un género de diatomeas arafidales, representado en ambientes marinos, como bentónico, epifitico, epilítico y epizoico así como planctónico y de distribución cosmopolita. Una especie del género Pteroncola, Pteroncola carlinii, fue hallada en el material analizado. 

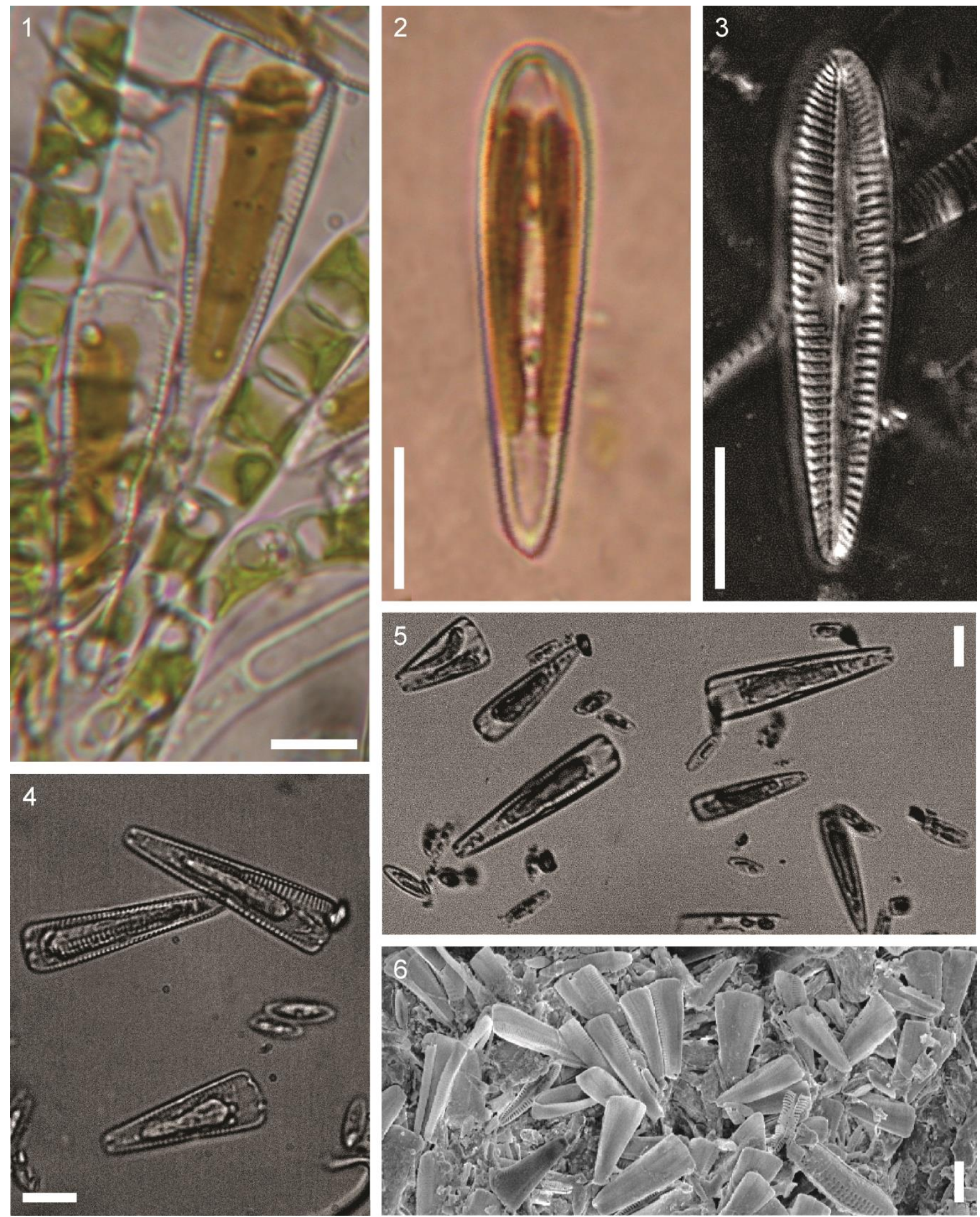

Lámina XXVI. Pseudogomphonema kamtschaticum. Figs. 1-5 MO, Fig. 6 MEB. Fig. 1. Vista de material vivo, nótese el corto pedúnculo por las que se fijan al sustrato. Fig. 2. Célula en vista valvar mostrando cloroplastos parietales. Fig. 3. Frústulos en vista valvar. Fig. 4-6. Vista de células principalmente en vista conectival, nótese el rango de tamaños y su abundancia dentro de un mismo preparado. Todas las escalas corresponden a $10 \mu \mathrm{m}$. 

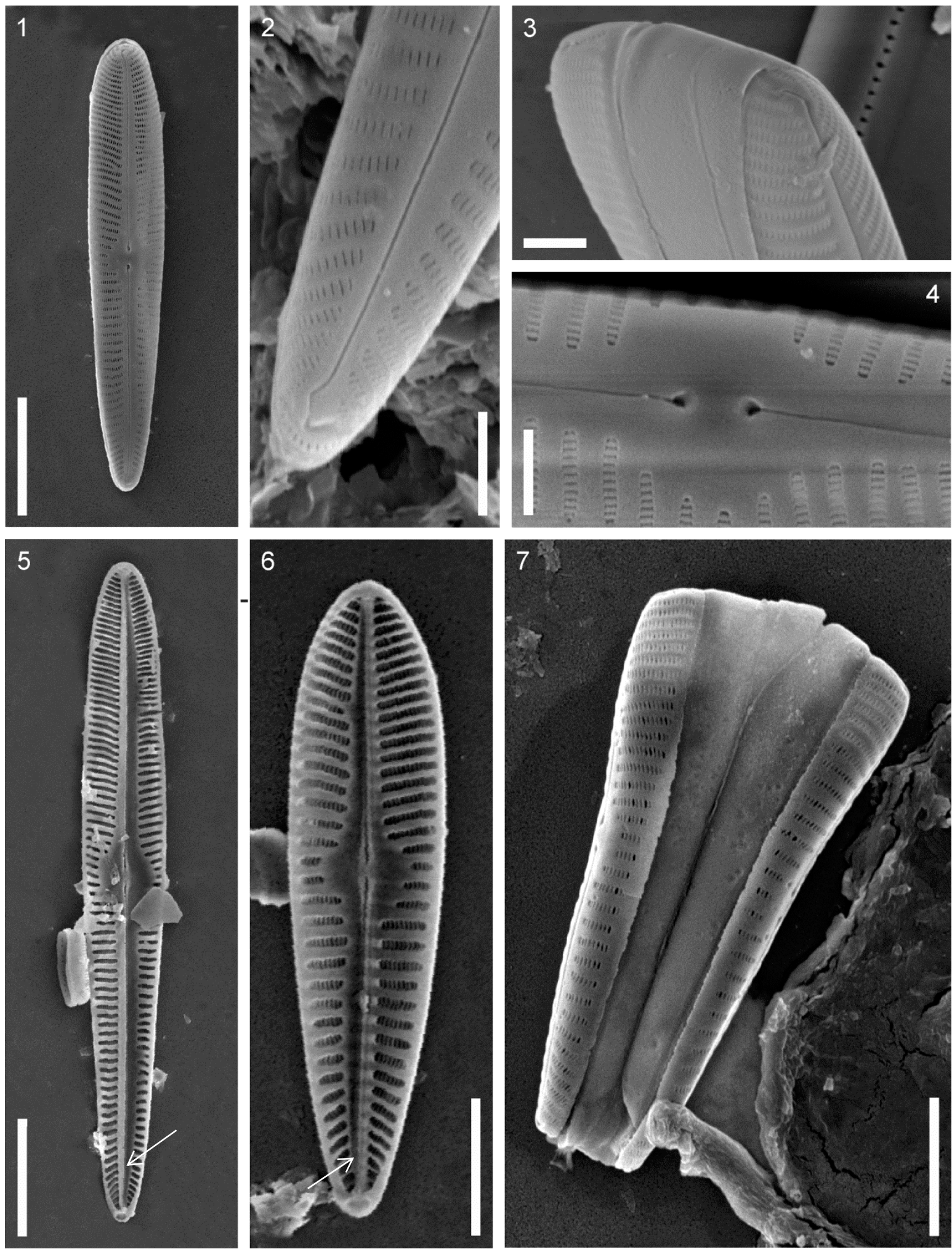

Lámina XXVII. Pseudogomphonema kamtschaticum. Figs. 1-7 MEB. Fig. 1. Vista valvar externa, nótense las estrías orientadas radialmente y la asimetría del esternón del rafe. Fig. 2. Detalle del polo basal en vista externa mostrando la fisura terminal del rafe en forma de gancho. Fig. 3. Detalle del polo apical en vista externa y parte de la cintura. Fig. 4. Vista externa de la parte central de la valva, nótense las fisuras terminales del rafe. Figs. 5-6. Valvas de diferentes tamaños en vista interna, revelando en el polo basal una pequeña cámara (flecha, Fig. 5) y la helictoglosa ubicada sobre el pseudosepto (flecha, Fig. 6). Fig. 7. Frústulo en vista conectival con la valvocópula y las cópulas lisas. Escalas: Figs. 1, 5: $10 \mu \mathrm{m}$, Figs. 2-4, $2 \mu \mathrm{m}$, Figs. 6-7: $5 \mu \mathrm{m}$. 
Almandoz \& Ferrario en Almandoz et al. 2014, p. 188-194, Figs. 1-15.

Las células son solitarias, rectangulares en vista conectival, y linear-elípticas suavemente arqueadas en vista valvar, con ápices redondeados. La superficie valvar presenta estrías alveoladas, las que delimitan un ancho esternón. Un campo apical compuesto por tres hileras horizontales de poros está ubicado sobre el manto valvar, el cual es liso y profundo. Un proceso labiado se observa próximo a uno de los extremos de la valva.

Datos morfométricos: El eje apical fue de 5,6 $\mu \mathrm{m}$ y el eje transapical entre 2,1 $\mu \mathrm{m}$, con 11 estrías en $10 \mu \mathrm{m}$.

\section{Observaciones y comentarios}

Se trata de una especie marina, recientemente descripta para el fitoplancton de aguas costeras de caleta Potter (Almandoz \& Ferrario 2014). El análisis realizado en este trabajo sobre $P$. carlinii representa el primer registro para ambientes bentónicos en caleta Potter. Se trató de una especie con presencia excepcional en este estudio, probablemente procedente de la fracción fitoplanctónica.

\section{Rhoicosphenia Grunow}

Las células son alargadas en vista valvar y algo curvas, más o menos cuneadas en vista conectival. Cada célula posee un cloroplasto. Las valvas tienen diferentes formas y estructuras, con estrías uniseriadas o biseriadas formadas por poros alargados apicalmente. El sistema del rafe es diferente en las dos valvas. En la valva ventral, cóncava, es completo y en la dorsal, convexa, reducido. En los polos se observa la presencia de pseudoseptos formados por proyecciones internas de los márgenes valvares. Un campo de poros está ubicado en el ápice inferior de cada frústulo (Round et al. 1990, Cox 2015).

Son organismos que habitan en ambientes dulceacuícolas, salobres o marinos, como epilíticos o epifíticos (Cox 2015). Una especie del genero Rhoicosphenia, Rhoicosphenia genuflexa, fue registrada en este estudio.

Rhoicosphenia genuflexa (Kützing) Medlin Lám. XV, Fig. 8

Medlin en Medlin \& Fryxel 1984, p. 257, Figs. 1-28, Witkowski et al. 2000, p. 345, Lám. 58, Figs. 1922, Lám. 59, Figs. 4-9, Al-Handal \& Wulff 2008a, p. 55, Tabla 1, p. 56, Tabla 2, Fig. 28; Al-Handal \& Wulff 2008b, p. 431, Figs. 120-122.

Los frústulos en vista conectival y valvar son isopolares. La valva cóncava tiene un sistema de rafe completo mientras que la valva convexa tiene un sistema incompleto, con sólo dos cortas ramas. Internamente el borde valvar en los ápices se expande formando cortos 
pseudoseptos de igual tamaño en ambas valvas. La cintura está formada por varias cópulas.

Datos morfométricos: El eje apical fue de $24,2 \mu \mathrm{m}$ y el eje pervalvar fue de $7,2 \mu \mathrm{m}$, con 13 estrías en $10 \mu \mathrm{m}$.

\section{Observaciones y comentarios}

Se trata de una especie cosmopolita, marina, común como epífita de macroalgas (Witkowski et al. 2000). En caleta Potter fue registrada anteriormente sobre sustratos artificiales instalados en el intermareal, y como epífita de macroalgas (Tabla 3.2). La presencia de $R$. genuflexa en este trabajo fue muy rara (Tabla 3.1).

\section{Thalassiosira Cleve emend. Hasle}

Las células son discoides a cilíndricas y están unidas entre sí formando largas cadenas, raramente solitarias o dentro de una masa mucilaginosa. Las valvas están formadas por areolas loculares, con un foramen circular externo y una criba interna. Los procesos reforzados están ordenados en un anillo marginal y otros normalmente ubicados en el centro de la valva. Un proceso labiado, raramente más, se encuentra localizado cerca o en el anillo de los procesos reforzados, ocasionalmente central.

Thalassiosira comprende numerosas especies planctónicas distribuidas principalmente en ambientes marinos y unas pocas en agua dulce y salobre (Hasle 1978, Round et al. 1990, Hasle \& Syversten 1997). Es un género cosmopolita con un elevado número de especies en aguas antárticas (Johansen \& Fryxell 1985). Sólo Thalassiosira antarctica fue registrada en este estudio.

\section{Thalassiosira antarctica Comber}

Lám. XXVIII, Figs. 1-3

Comber 1896, p. 491, pl. 11; Hasle \& Heimdal 1968, p. 357-369, Figs. 1-21; Johansen \& Fryxell 1985, p. 158, Figs. 15-16, 37-39; Scott \& Thomas 2005, p. 89-90, Fig. 244.

Células unidas en cadenas por medio de cordones mucilaginosos que se generan desde los procesos estructurados centrales. Las valvas son circulares, con una superficie convexa ornamentada por areolas arregladas en hileras radiales a fasciculadas. Los procesos estructurados están ubicados en dos anillos marginales, los del anillo externo en mayor número que los del anillo interno. Otros procesos reforzados se observan aproximadamente en número de siete ubicados en el centro de la valva. Un evidente proceso labiado se observa entre dos procesos reforzados del anillo interno. El manto valvar es bajo y muestra un anillo hialino marginal. El cíngulo tiene una valvocópula con un borde advalvar liso y con areolas arregladas en finas estrías. 
Datos morfométricos: El diámetro fue de $26,8 \mu \mathrm{m}$. La cantidad de estrías en $10 \mu \mathrm{m}$ fue de $19-20$ y las areolas de 18-20 en $10 \mu \mathrm{m}$.

\section{Observaciones y comentarios}

En general, la presencia en la flora bentónica de formas planctónicas tales como los miembros del género Thalassiosira, ha sido relacionada con los sustratos blandos que promueven su retención (Al-Handal \& Wulff 2008a). Probablemente los escasos ejemplares de $T$. antarctica hallados en los sustratos artificiales provengan de la sedimentación desde el fitoplancton, del cual constituye un importante componente (Johansen \& Fryxell 1985, Ahn et al. 1997, Ferrario, comunicación personal). Asimismo, esta especie fue hallada rara y esporádicamente asociada con macroalgas (Majewska et al. 2016). En este trabajo, resultó muy rara (Tabla 3.1) y es el primer registro para ambientes bentónicos en caleta Potter.
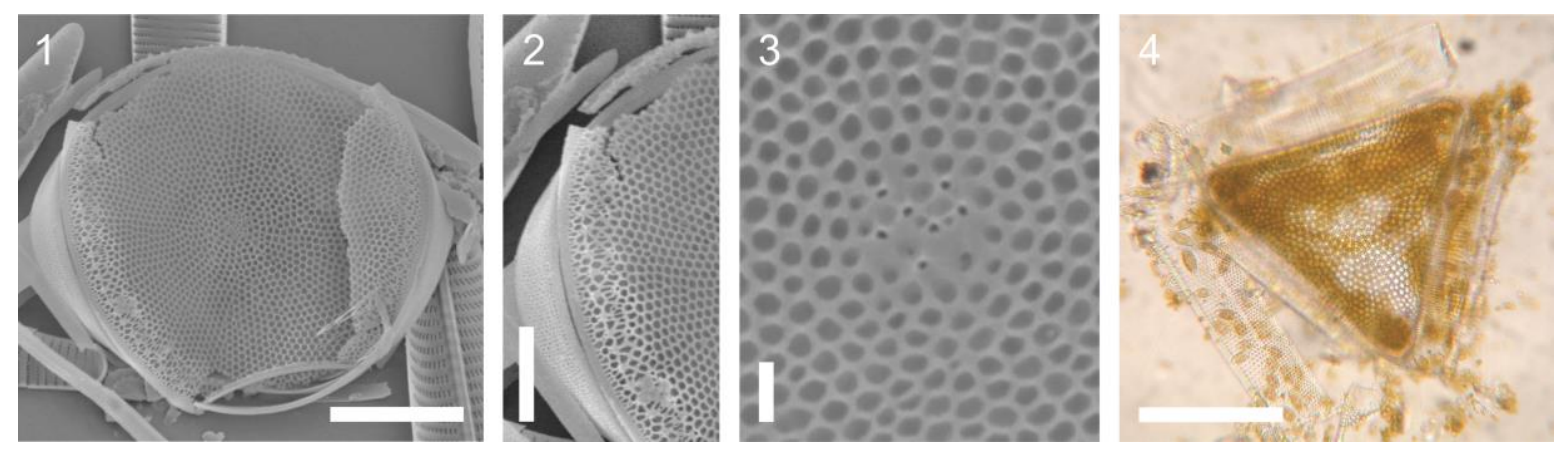

Lámina XXVIII. Figs. 1-3 MEB, Fig. 4 MO. Figs. 1-3. Thalassiosira antarctica. Fig. 1. Vista general del frústulo. Fig. 2. Detalle de los procesos reforzados ubicados en forma de dos anillos marginales. Fig. 3. Detalle de los procesos reforzados (siete), ubicados en el centro valvar. Fig. 4. Trigonium arcticum. Vista general de una valva mostrando lados ligeramente convexos y detalle de una valvocópula finamente estriada. Escalas: Fig. 1: $10 \mu \mathrm{m}$, Fig. 2: $5 \mu \mathrm{m}$, Fig. 3: $1 \mu \mathrm{m}$, Fig. 4: $100 \mu \mathrm{m}$.

\section{Trachyneis Cleve}

Es un género caracterizado por presentar células solitarias con dos grandes cloroplastos generalmente de bordes lobados y un pirenoide difícil de observar. Los frústulos son naviculiformes con ambas valvas con un sistema de rafe central rodeado a ambos lados por un esternón de diferente ancho. Las fisuras centrales del rafe internamente son redondeadas y externamente sinuosas; las terminales externamente están expandidas en forma de gancho. La superficie valvar presenta por areolas tipo lineolas las que en el centro delimitan un marcado estauro. El cíngulo contiene cópulas lisas y abiertas (Round et al. 1990).

Es un género con especies epipélicas, distribuidas en el litoral marino. Sólo Trachyneis aspera fue registrada en este estudio. 
Trachyneis aspera (Ehrenberg) Cleve

Lám. XV, Fig. 9

Cleve 1894: 191; Simonsen, 1974, p. 43; Witkowski et al. 2000, p. 355, Lám. 159, Figs. 1-6, 9; Scott \& Thomas 2005, p. 164, Fig. 2.95; Al-Handal \& Wulff 2008a, p. 55-56, Fig. 126; Al-Handal \& Wulff 2008b, p. 432, Figs. 89-90, 101.

Las células se presentan solitarias. Los frústulos en vista valvar son linear lanceolados con ápices redondeados. La superficie valvar es curva, con estrías uniseriadas formadas por lineolas. Cada valva presenta las fisuras centrales del rafe suavemente dilatadas en vista interna, y sinuosas en vista externa. Las fisuras terminales en vista externa están expandidas en forma de gancho y en vista interna presenta pequeñas helictoglosas. En el centro de la valva, se observa un conspicuo estauro que se extiende hasta el borde del manto valvar.

Datos morfométricos: El eje apical varió entre $64,4 \mu \mathrm{m}$ y $103,7 \mu \mathrm{m}$ y el eje pervalvar entre $22,5 \mu \mathrm{m}$ y $27,9 \mu \mathrm{m}$, con $7,5-8,5$ estrías en $10 \mu \mathrm{m}$.

\section{Observaciones y comentarios}

Se trata de una especie marina bentónica, cosmopolita y registrada ampliamente en ambientes antárticos (Witkowski et al. 2000, Scott \& Thomas 2005, Majewska et al. 2016). Para caleta Potter, fue hallada como epífita de macroalgas y sobre sustratos duros y blandos (Tabla 3.2). Se ha señalado que esta especie puede presentar variaciones de tamaño de acuerdo a su hábitat, con menores dimensiones cuando se encuentra como epífita de macroalgas (Al-Handal \& Wulff 2008b). Los ejemplares analizados en esta Tesis fueron similares en dimensiones a los reportados para las formas bentónicas, registrándose como muy rara en el material analizado en este trabajo (Tabla 3.1).

\section{Trigonium Cleve}

Es un género marino, epifito sobre macroalgas, caracterizado por poseer frústulos de contornos triangulares a multiangulares en vista valvar. Es uno de los géneros ubicados en la familia Eupodiscaceae, un grupo multifilético dentro de las diatomeas (Ashworth et al. 2013), caracterizado por la presencia de estructuras pseudo-ocelares y por areolas loculares.

Trigonium es un género cosmopolita pero principalmente distribuido en aguas templadas (Round et al. 1990). De las tres especies reportadas para ambientes antárticos, Trigonium arcticum, Trigonium curvatus (Nair et al. 2015) y Trigonium formosum (Ferrario \& Ferreyra 1984), sólo la primera ha sido registrada en los muestreos llevados a cabo en esta Tesis. 
Cleve 1867, p. 663; Hoban 1983, p. 277, Figs. 37-42; Ferrario \& Ferreyra 1984, p. 144-145, Figs 1-16; Al-Handal \& Wulff 2008b, p. 432, Figs. 16-21, Tabla 2.

Células triangulares con numerosos cloroplastos discoides. En vista valvar muestra lados ligeramente cóncavos y una superficie cubierta de areolas poligonales arregladas en hileras radiales de menor tamaño hacia los ángulos donde en cada uno de ellos forman evidentes pseudo-ocelos. El manto valvar es bajo con areolas ordenadas en hileras que se continúan de la superficie valvar. La valvocópula es alta y está cubierta de finos poros arreglados e hileras verticales rectas.

Datos morfométricos: En vista valvar, el alto desde la base al proceso fue de $170 \mu \mathrm{m}$, la cantidad de estrías en $10 \mu \mathrm{m}$ fue de 3 y el de las areolas 2,5 en $10 \mu \mathrm{m}$.

\section{Observaciones y comentarios}

En Antártida fue registrada como rara en el plancton y en el bentos (Frenguelli \& Orlando, 1958 como Triceratium arcticum) y como epifita de macroalgas (Ferrario \& Ferreyra 1984, Scott \& Thomas 2005, Majewska et al. 2016) (Tabla 3.2). En algunos estudios fue identificada como la única diatomea central que alcanza cierta dominancia como epifita de macroalgas (Thomas \& Jiang 1986). En caleta Potter, fue registrada como epifita de macroalgas (Al-Handal \& Wulff 2008b). Fue excepcional en las muestras analizadas en este trabajo (Tabla 3.1).

Recientemente Nair et al. (2015) crearon la especie Trigonium curvatus para Antártida, especie muy semejante a $T$. arcticum. Estos autores distinguen a este nuevo taxón de $T$. arcticum en base a caracteres que no son reales, tales como la ausencia de procesos labiados centrales en $T$. arcticum cuando se ha documentado que estos están presentes en esta especie en elevados números (25 a más de 40) (Ferrario \& Ferreyra 1984, Hoban 1983). 
Tabla 3.1. Taxa de diatomeas hallados en el material analizado. Se indican sus características morfométricas y su presencia respecto al total de las muestras analizadas (\% de muestras en el que el taxa estuvo presente). Las mediciones corresponden a la vista valvar con excepción de A. marina (entre paréntesis, datos del eje pervalvar y el número de estrías dorsales en $10 \mu \mathrm{m}$ ) y Entomoneis sp. (en vista conectival, con dimensiones menores y mayores del eje pervalvar). vr: valva con rafe; ve: valva del esternón; c: área central.

\begin{tabular}{|c|c|c|c|c|c|}
\hline Taxa & $\begin{array}{l}\text { Eje apical } \\
(\mu \mathrm{m})\end{array}$ & $\begin{array}{l}\text { Eje transapical } \\
(\mu \mathrm{m})\end{array}$ & $\begin{array}{l}\text { Estrías } \\
\text { en } 10 \mu \mathrm{m}\end{array}$ & $\begin{array}{l}\text { Areolas } \\
\text { en } 10 \mu \mathrm{m}\end{array}$ & $\%$ \\
\hline Achnanthes brevipes C. Agardh & $20,8-50,2$ & $6,6-10,9$ & $7-9$ & $10-15$ & 57,0 \\
\hline Achnanthes vicentii Manguin & 7,4 & 4,2 & $12-14$ & $60-70$ & 0,7 \\
\hline Amphora marina W. Smith & $25,5-49,6$ & $(9,7-18,1)$ & $(8,5-11)$ & & 18,3 \\
\hline Brandinia mosimanniae Fernandes \& Procopiak & $102,0-124,8$ & $7,4-7,8$ & $11-13$ & $35-45$ & 6,3 \\
\hline Cocconeis antiqua Tempère \& Brun & $37,3-87,3$ & $21,4-61,8$ & $\begin{array}{l}\text { vr: } 10-16 m, 17-19 c \\
\text { ve: } 25-26 m, 20-21 c\end{array}$ & vr: $18-20$ & 38,0 \\
\hline Complejo Cocconeis fasciolata/costata & & & & & 66,9 \\
\hline Cocconeis aff. costata Gregory & $11,3-26,0$ & $7,1-14,3$ & vr: $11-12$, ve: 5 - 6 & vr: 33, ve: 14 - 16 & \\
\hline Cocconeis fasciolata (Ehrenberg) Brown & $13,5-50,4$ & $7,3-35,8$ & $4-7$ & $10-18$ & \\
\hline Complejo Cocconeis melchiori/dallmannii/melchioroides & & & & & 26,1 \\
\hline Cocconeis dallmannii Al-Handal, Riaux-Gobin, Romero \& Wulff & $10,1-13,3$ & $7,1-12,1$ & vr: 17 - 20, ve: 10 - 11 & vr: 28 & \\
\hline Cocconeis melchiori? Frenguelli \& Orlando & $13,2-23,8$ & $8,0-11,6$ & ve: $4,5-6$ & ve: 45 & \\
\hline Cocconeis melchioroides Al-Handal, Riaux-Gobin, Romero \& Wulff & $10,1-18,7$ & $6,4-11,3$ & vr: 12 - 14, ve: $7-8$ & vr: 40 , ve: $40-45$ & \\
\hline Cocconeis orbicularis Frenguelli \& Orlando & $21,0-32,4$ & $12,7-17,4$ & $4-6$ & vr: $25-26$ & 2,1 \\
\hline Diploneis smithii (Brébisson) Cleve & 19,6 & 9,2 & vr: $11-12$ & vr: 36 & 0,7 \\
\hline Entomoneis sp. & 67,7 & $10,5-14,0$ & 23 & & 17,6 \\
\hline Entopyla ocellata (Arnott) Grunow & $41,0-57,0$ & & & & 8,5 \\
\hline Complejo Fragilaria islandica/striatula & & & & & 96,5 \\
\hline Fragilaria islandica Grunow var. adeliae Manguin & $17,0-56,4$ & $3,9-7,8$ & $11,5-16,5$ & $45-65$ & \\
\hline Fragilaria striatula Lyngbye & $43,7-60,6$ & $5,9-7,8$ & $14-16$ & $45-50$ & \\
\hline Fragilariopsis kerguelensis (O'Meara) Hustedt & $35,0-39,0$ & 8,4 & $5-7$ & & 1,4 \\
\hline Fragilariopsis rhombica/separanda & 25,3 & 11,0 & 10 & & 0,7 \\
\hline
\end{tabular}


Tabla 3.1. Continuación. Taxa de diatomeas hallados en el material analizado. Se indican sus características morfométricas y su presencia respecto al total de las muestras analizadas (\% de muestras en el que el taxa estuvo presente). Las mediciones corresponden a la vista valvar con excepción de $G$. arctica y R. genuflexa (en vista conectival), O. aurita (longitud del eje apical), $T$. arcticum (longitud entre la base y el proceso, en vista valvar). Para $N$. perminuta se detallan entre paréntesis valores únicos hallados en el individuo de menor tamaño. c: área central; a: área apical; o: estrías oblicuas, t: estrías transapicales.

\begin{tabular}{|c|c|c|c|c|c|}
\hline Taxa & $\begin{array}{l}\text { Eje apical } \\
(\mu \mathrm{m})\end{array}$ & $\begin{array}{l}\text { Eje transapical } \\
(\mu \mathrm{m})\end{array}$ & $\begin{array}{l}\text { Estrías } \\
\text { en } 10 \mu \mathrm{m}\end{array}$ & $\begin{array}{l}\text { Areolas } \\
\text { en } 10 \mu \mathrm{m}\end{array}$ & $\%$ \\
\hline Grammatophora arctica Cleve & 42,0 & & $12-13$ & & 1,4 \\
\hline Licmophora antarctica M. Peragallo & $71,6-156,7$ & $9,2-11,9$ & $7,5-8,5$ & $19-20$ & 62,0 \\
\hline Licmophora belgicae M. Peragallo & $62,5-149,2$ & $14,9-19,3$ & $11-13$ & $17-22$ & 39,4 \\
\hline Licmophora gracilis (Ehrenberg) Grunow & $28,5-59,7$ & $4,9-6,9$ & $17-20$ & & 69,7 \\
\hline Minidiscus chilensis Rivera & $3,2-5,8$ & & $80-120$ & $120-140$ & 0,7 \\
\hline Navicula directa (W. Smith) Ralfs & $72,5-101,5$ & $9,7-12,4$ & $8-9$ & $30-33$ & 59,9 \\
\hline Navicula glaciei Van Heurck & $13,8-24,0$ & $5,3-7,5$ & $14-18,5$ & $33-40$ & 29,6 \\
\hline Navicula perminuta Grunow & $5,3-18,9$ & $1,9-5,2$ & $14-20(25)$ & $27-40(50)$ & 100,0 \\
\hline Nitzschia pellucida Grunow & 47,0 & 4,6 & 27 & 40 & 0,7 \\
\hline Odontella aurita (Lynbye) Agardh & $41,5-55,0$ & $38,2-54,7$ & & $8-14$ & 2,1 \\
\hline Parlibellus delognei (Van Heurck) Cox & $60,1-71,1$ & $20,9-24,6$ & $16-17$ & 29 & 1,4 \\
\hline Petroneis sp. & 38,7 & 17,4 & 11 & & 0,7 \\
\hline Pleurosigma sp. & $171,3-218,0$ & $19,8-20,3$ & $\mathrm{o:} 16, \mathrm{t}: 14$ & & 5,6 \\
\hline Pseudogomphonema kamtschaticum (Grunow) Medlin & $23,3-56,5$ & $5,5-7,2$ & $12-15 c, 16-21 a$ & $60-70$ & 98,6 \\
\hline Pteroncola carlinii Almandoz \& Ferrario & 5,6 & 2,1 & 11 & & 0,7 \\
\hline Rhoicosphenia genuflexa (Kützing) Medlin & 24,2 & 7,2 & 13 & & 4,9 \\
\hline Thalassiosira antarctica Comber & 26,8 & & $19-20$ & $18-20$ & 3,5 \\
\hline Trachyneis aspera (Ehrenberg) Cleve & $64,4-103,7$ & $22,5-27,9$ & $7,5-8,5$ & & 2,1 \\
\hline Trigonium arcticum (Brightwell) Cleve & 170 & & 3 & 2,5 & 0,7 \\
\hline
\end{tabular}


Tabla 3.2. Taxa hallados en esta Tesis y registrados en otros ambientes bentónicos antárticos (señalados con un símbolo o letra). Las referencias se detallan al pie de la tabla.

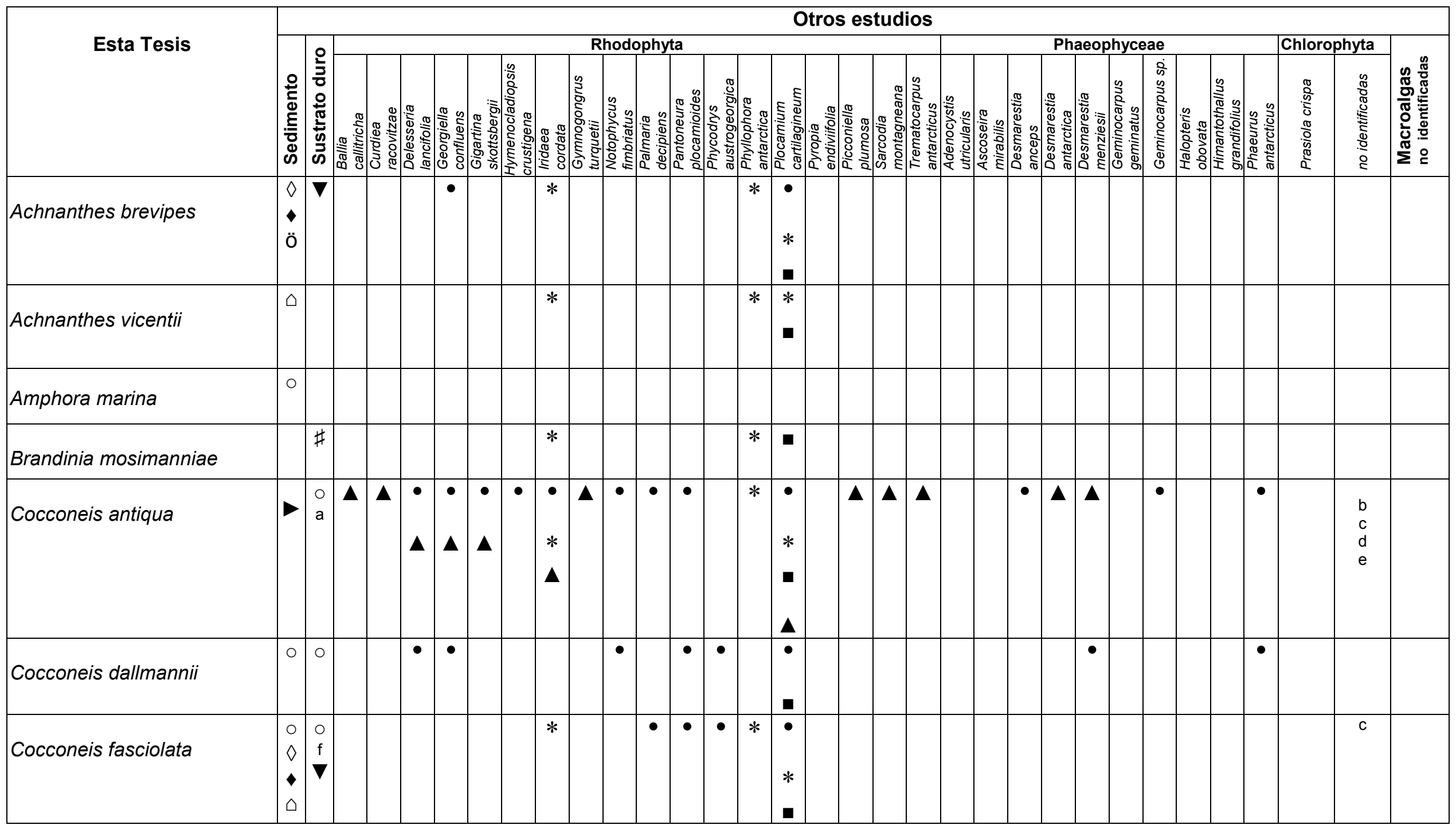


Tabla 3.2. Continuación. Taxa hallados en esta Tesis y registrados en otros ambientes bentónicos antárticos (señalados con un símbolo o letra). Las referencias se detallan al pie de la tabla.

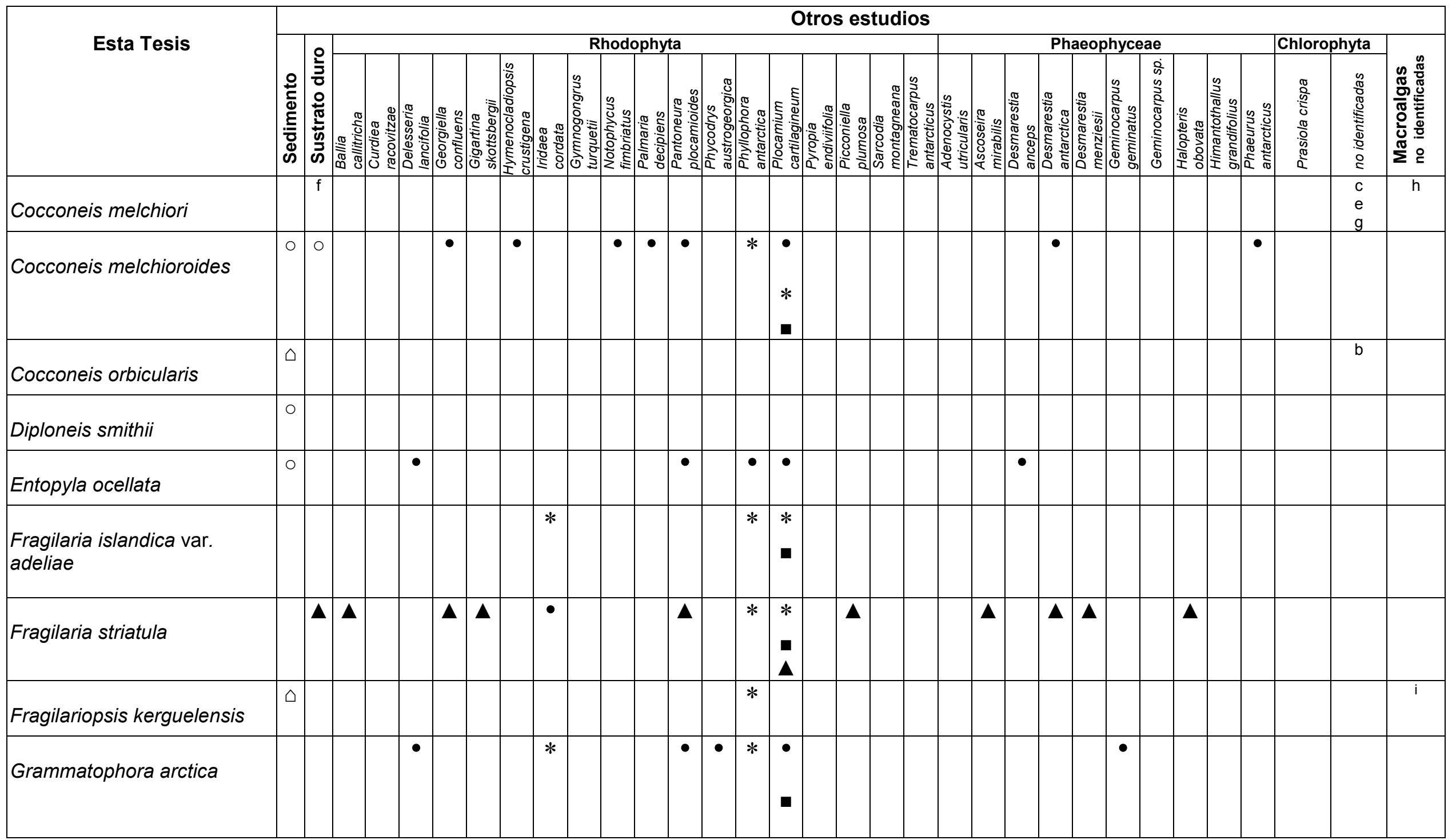


Tabla 3.2. Continuación. Taxa hallados en esta Tesis y registrados en otros ambientes bentónicos antárticos (señalados con un símbolo o letra). Las referencias se detallan al pie de la tabla.

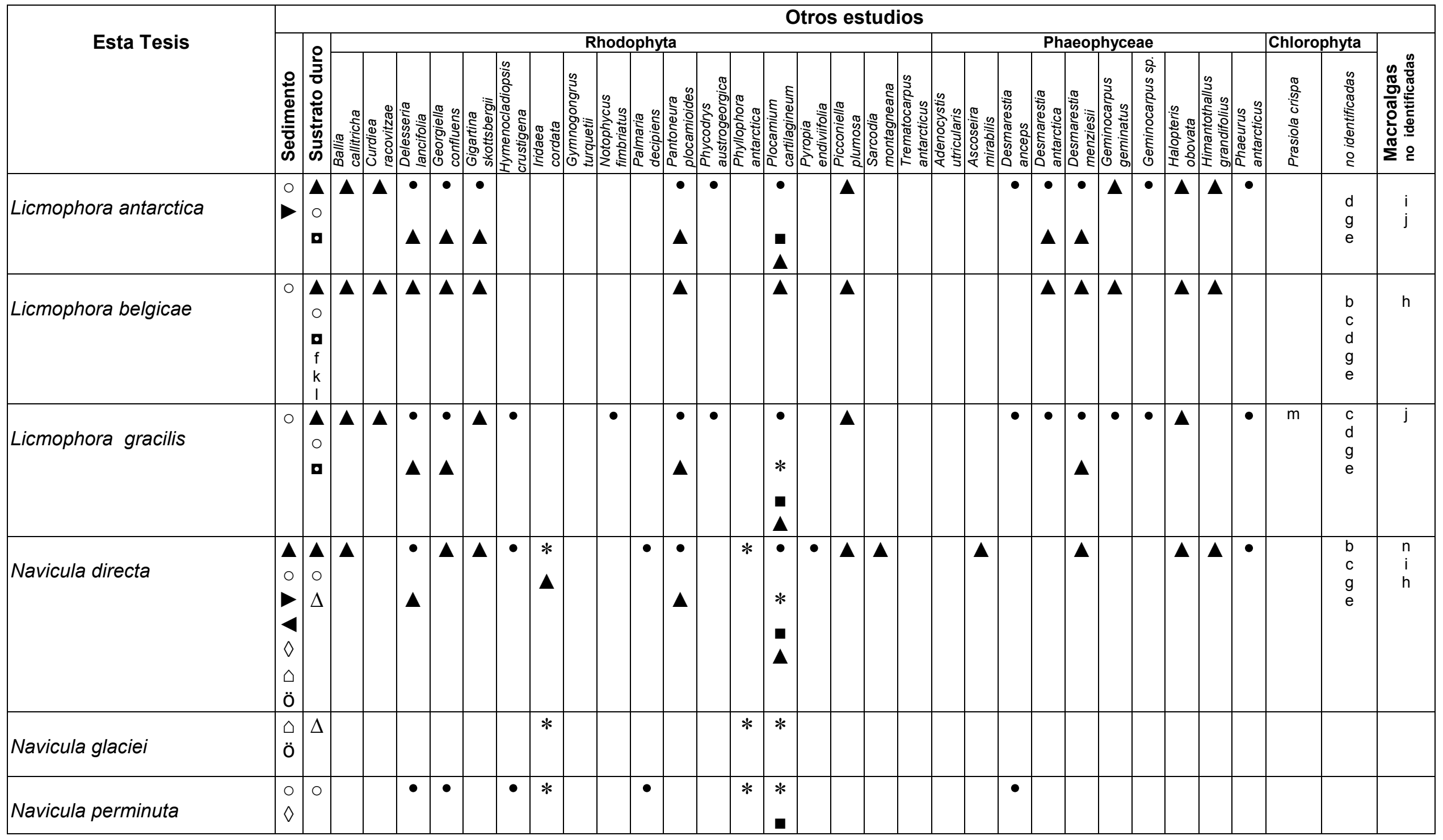


Tabla 3.2. Continuación. Taxa hallados en esta Tesis y registrados en otros ambientes bentónicos antárticos (señalados con un símbolo o letra). Las referencias se detallan al pie de la tabla.

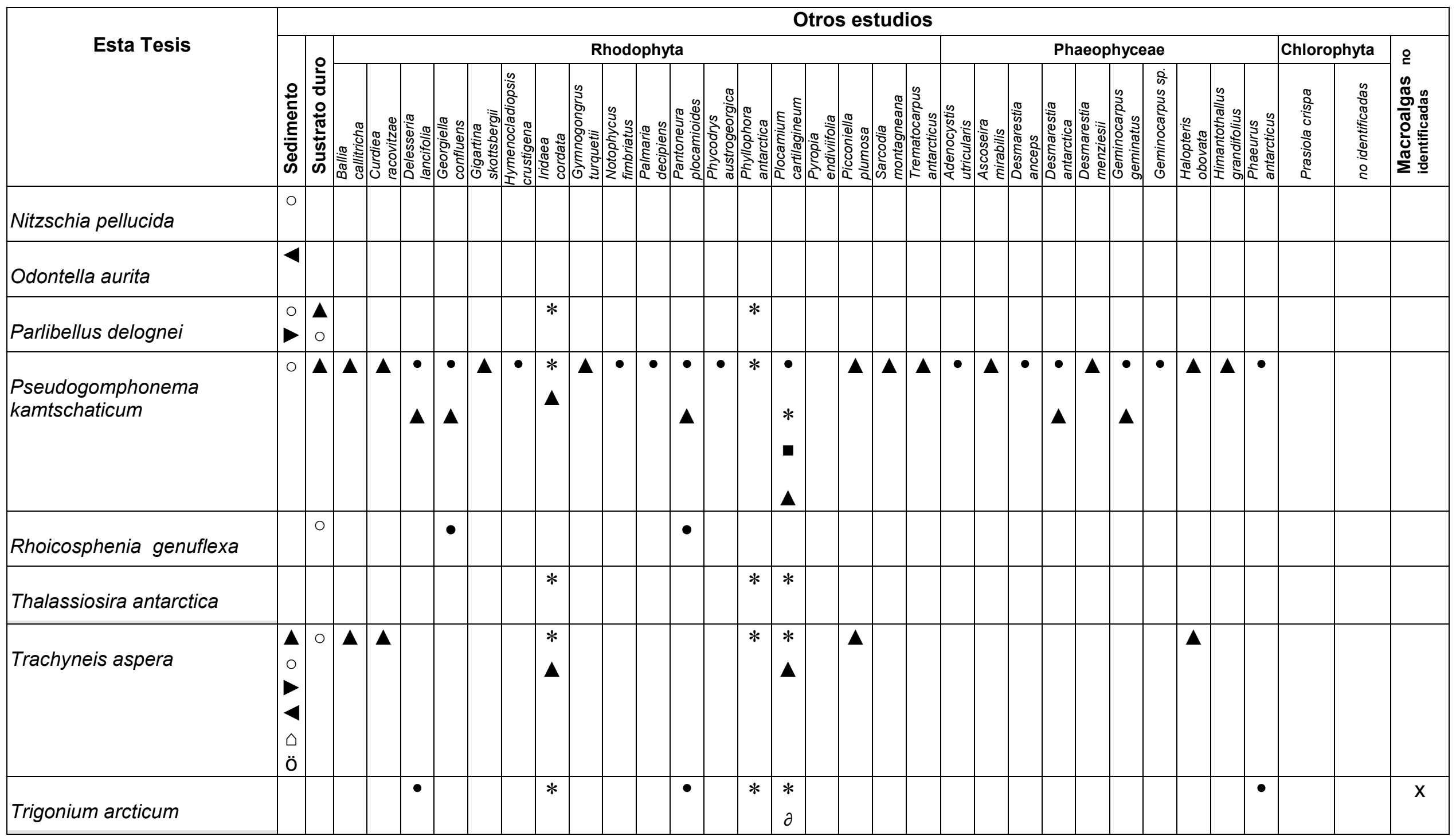


Tabla 3.2. Referencias. Cada símbolo corresponde a una referencia bibliográfica, para la que se detallan los autores, observaciones y área de colección. Las letras corresponden a las series de diatomeas y silicoflagelados del sector antártico sudamericano analizadas en Freguelli \& Orlando (1958). Los principales sinónimos que siguen los autores citados para algunos taxa enlistados en esta Tabla son: C. antiqua: C. schuetii, C. schuetii var. minor, C. litigiosa; C. fasciolata: C. costata var. pacifica; F. kerguelensis: F. antarctica, Nitzschia kerguelensis; L. belgicae: L. decora.

\begin{tabular}{|c|c|c|c|}
\hline & Estudio & Observaciones & Área de colección \\
\hline$\nabla$ & Krebs (1983) & $\begin{array}{l}\text { Intermareal rocoso. Se registraron } 30 \text { taxa, pero sólo se nombran los tres más } \\
\text { abundantes. }\end{array}$ & Archipiélago de Palmer \\
\hline$\partial$ & $\begin{array}{l}\text { Ferrario \& Ferreyra } \\
(1984)\end{array}$ & Epifitas de Plocamium cartilagineum. & Bahia Paraiso \\
\hline $\mathrm{X}$ & $\begin{array}{l}\text { Thomas \& Jiang } \\
(1986)\end{array}$ & $\begin{array}{l}16 \text { taxa de macroalgas (no especificada la presencia de cada taxa de } \\
\text { diatomeas sobre las especies de macroalgas) intermareales y submareales. }\end{array}$ & Colinas Vestfold \\
\hline$\Delta$ & Gilbert et al. (1991b) & Microfitobentos de fondos blandos (12 m). & Islas Orcadas del Sur \\
\hline$\Delta$ & Klöser (1998) & $\begin{array}{l}\text { Sedimento, sustrato rocoso y macroalgas, desde el intermareal hasta } 30 \mathrm{~m} \text { de } \\
\text { profundidad. Este trabajo incluye bajo la misma categoría a } L \text {. antarctica y } L \text {. } \\
\text { belgicae. }\end{array}$ & $\begin{array}{l}\text { Caleta Potter, } \\
\text { Islas Shetland del Sur }\end{array}$ \\
\hline$\Delta$ & $\begin{array}{l}\text { Fernandes \& } \\
\text { Prokopiak (2003) }\end{array}$ & Sustrato rocoso en el eulitoral y sublittoral. & Islas Shetland del Sur. \\
\hline$\diamond$ & $\begin{array}{l}\text { Cunningham \& Mc } \\
\text { Minn (2004) }\end{array}$ & $\begin{array}{l}\text { Sedimento de aguas poco profundas. Identificación de taxa de mayor } \\
\text { abundancia. }\end{array}$ & Islas Windmill \\
\hline Ö & Mc Minn et al. (2004) & $\begin{array}{l}\text { Sedimento superficial, entre } 4,5 \text { y } 12,6 \mathrm{~m} \text {. Identificación de taxa de mayor } \\
\text { abundancia. }\end{array}$ & Islas Windmill \\
\hline$\diamond$ & $\begin{array}{l}\text { Cunningham et al. } \\
(2005)\end{array}$ & Sedimento superficial $(5 \mathrm{~cm})$, Identificación de taxa de mayor abundancia. & Islas Windmill \\
\hline$\#$ & $\begin{array}{l}\text { Fernandes et al. } \\
(2007)\end{array}$ & Sustrato rocoso de zonas intermareales y submareales. & Península Antártica \\
\hline O & $\begin{array}{l}\text { Al-Handal \& Wulff } \\
\text { (2008a) }\end{array}$ & $\begin{array}{l}\text { Sedimento marino superficial }(1 \mathrm{~cm}) \text { en varios sitios submareales }(3,5-11 \mathrm{~m}) \text { y } \\
\text { sobre sustratos artificiales emplazados en el intermareal. }\end{array}$ & $\begin{array}{l}\text { Caleta Potter, } \\
\text { Islas Shetland del Sur }\end{array}$ \\
\hline O & $\begin{array}{l}\text { Al-Handal \& Wulff } \\
(2008 b)\end{array}$ & Macroalgas colectadas de pozas de marea y ambientes submareales (5-7 m). & $\begin{array}{l}\text { Caleta Potter, } \\
\text { Islas Shetland del Sur }\end{array}$ \\
\hline & Wulff et al. (2008a) & Sedimento marino superficial $(1 \mathrm{~cm})$ en varios sitios submareales $(5-7 \mathrm{~m})$. & $\begin{array}{l}\text { Caleta Potter, } \\
\text { Islas Shetland del Sur. }\end{array}$ \\
\hline & Wulff et al. (2008c) & Sedimento marino superficial $(5-7 \mathrm{~m})$. & $\begin{array}{l}\text { Caleta Potter, } \\
\text { Islas Shetland del Sur }\end{array}$ \\
\hline • & $\begin{array}{l}\text { Fernandes et al. } \\
(2014)\end{array}$ & $\begin{array}{l}\text { Sustrato rocoso en la zona intermareal. Licmophora antarctica no fue hallada } \\
\text { en el primer sitio. }\end{array}$ & Islas Shetland del Sur \\
\hline $\mathbf{\square}$ & Majewska et al. (2015) & Epifitas sobre Plocamium cartilagineum. & $\begin{array}{l}\text { Bahía Lasserre (Admiralty } \\
\text { Bay), Islas Shetland del Sur }\end{array}$ \\
\hline$*$ & Majewska et al. (2016) & Tres especies de algas rojas $(5-25 \mathrm{~m})$. & $\begin{array}{l}\text { Estrecho de Mc Murdo, Mar } \\
\text { de Ross }\end{array}$ \\
\hline $\mathrm{a}$ & Serie 45 & Rocas descubiertas en bajamar. & Bahia Esperanza \\
\hline b & Serie 8 & $\begin{array}{l}\text { Algas filamentosas verdes en charcos de agua salada dejadas por el mar en } \\
\text { marea baja. }\end{array}$ & Archipiélago Melchior \\
\hline $\begin{array}{l}\text { C } \\
\text { d } \\
\text { g }\end{array}$ & Series 9,10 y 11 & Algas verdes en charcos de agua marina que se cubren en pleamar. & Archipiélago Melchior \\
\hline $\mathrm{e}$ & Serie 12 & Algas verdes que proliferan sobre cascotes rocosos. & Archipiélago Melchior \\
\hline $\mathrm{f}$ & Serie 14 & Rocas. & Archipiélago Melchior \\
\hline $\mathrm{h}$ & Serie 18 & Macroalgas en baja mar. & Puerto Paraíso \\
\hline $\mathrm{i}$ & Serie 5 & Algas de la costa próximas a surgente termal y emanaciones sulfurosas. & Isla Decepción \\
\hline j & Serie 25 & $\begin{array}{l}\text { Fieltro verde en anfractuosidades de las rocas de la costa cubiertas en } \\
\text { pleamar. }\end{array}$ & Islas Orcadas del Sur \\
\hline $\mathrm{k}$ & Serie 19 & $\begin{array}{l}\text { Fieltro de color castaño sobre rocas, en charcos de aguas marinas dejadas } \\
\text { en bajamar, cubiertos en pleamar. }\end{array}$ & Puerto Paraíso \\
\hline $\mathrm{I}$ & Serie 39 & Fieltro de algas de color castaño en charcos de aguas marinas. & Bahia Esperanza \\
\hline $\mathrm{m}$ & Serie 7 & Epifitas sobre Prasiola crispa. & Isla Decepción \\
\hline $\mathrm{n}$ & Serie 2 & Algas pardo-verduzcas en el intermareal. & Isla Decepción \\
\hline
\end{tabular}




\subsubsection{Macroalgas}

Entre las macroalgas, se registraron 13 taxa que se agruparon en tres categorías taxonómicas superiores: Heterokontophyta, Rhodophyta y Chlorophyta. Dentro de las Heterokontophyta, se registraron cuatro taxa de la clase Phaeophyceae, comúnmente llamadas algas pardas. Respecto a las Rhodophyta (algas rojas o rodofitas) se registraron seis taxa pertenecientes a la clase Florideophyceae. En el caso de las Chlorophyta (algas verdes o clorofitas) se encontraron tres taxa correspondientes a la clase Ulvophyceae. Se enlistan los taxa hallados y su clasificación taxonómica según Wiencke \& Clayton (2002) y actualizados según Guiry \& Guiry (2018).

\section{Heterokontophyta}

\section{Phaeophyceae Kjellman}

1. Ectocarpales

Adenocystaceae: Adenocystis utricularis (Bory) Skottsberg

2. Desmarestiales

Desmarestiaceae: Desmarestia sp. (cf $D$. anceps Montagne/D. menziesii J. Agardh) Phaeurus antarcticus Skottsberg

3. Ascoseirales

Ascoseiraceae: Ascoseira mirabilis Skottsberg

\section{Rhodophyta}

I. Florideophyceae Cronquist

1. Acrochaetiales

Acrochaetiaceae: Rhodochorton cf purpureum (Lightfoot) Rosenvinge

2. Palmariales

Palmariaceae: Palmaria decipiens (Reinsch) Ricker

3. Gigartinales

Gigartinaceae: Gigartina skottsbergii Setchell \& Gardner Iridaea cordata (Turner) Bory de Saint-Vincent

4. Corallinales

Corallinaceae

5. Ceramiales

Delesseriaceae

\section{Chlorophyta}

I. Ulvophyceae K.R. Mattox \& K.D. Stewart

1. Ulotrichales

Monostromataceae: Monostroma hariotii Gain

Ulotrichaceae: Ulothrix flacca (Dillwyn) Thuret Urospora penicilliformis (Roth) Areschoug 
A continuación, se incluyen breves diagnosis de los taxa hallados, acompañadas de observaciones y comentarios respecto a su historia de vida, endemismo, hábitat y distribución en Antártida.

\section{Clase Phaeophyceae \\ Orden Ectocarpales \\ Familia Adenocystaceae}

\section{Adenocystis J. D. Hooker \& Harvey}

El talo está compuesto por vesículas simples en forma de clava, rellenas de líquido, con un háptero discoidal pequeño. En la madurez, la superficie de los talos presenta pequeñas depresiones (criptostomas) y un penacho terminal de pelos caducos e incoloros. Las células poseen varios cloroplastos discoides con pirenoides laterales. La corteza posee células isodiamétricas y la médula está formada por filamentos reticulados o ramificados embebidos en depósitos de mucílago. Este género se caracteriza por poseer esporocistos uniloculares en soros del talo macroscópico.

Adenocystis utricularis (Bory) Skottsberg

Lám. XXIX, Figs. 1-6

Skottsberg 1907, p. 39; Skottsberg 1921, p. 39-41, Figs. 16 a-f; Lamb \& Zimmermann 1977, p. 160162, Figs. 31-32; Ricker 1987, p. 112-114, Fig. 46; Wiencke \& Clayton 2002, p. 96, Lám. 30, Figs. 13; Quartino 2003, p. 70, Fig. 4.12; Boraso de Zaixso 2013, p. 66, Lám. 4.3, Fig. 10.

Los talos tienen forma de saco de color marrón oliváceo, sin ramificaciones y con una médula central con mucilago. Presentan un estípite corto y un disco basal pequeño. La superficie del talo presenta pequeñas criptas (criptostomas), con largos pelos uniseriados. La corteza está formada externamente por células pigmentadas e internamente por células incoloras isodiamétricas a periclinalmente oblongas. La médula posee una cavidad central con filamentos incoloros embebidos en mucilago. Los cloroplastos son discoidales.

Presenta esporangios uniloculares que se desarrollan sobre la superficie, entre células estériles y no en soros discretos. Los talos juveniles son cilíndricos y sólidos y se vuelven vesiculados con el tiempo a partir del desarrollo de una protuberancia distal hueca y bulbosa. Las plantas macroscópicas se originan de un microtalo crustoso o filamentoso.

Datos morfométricos: La longitud máxima de los talos fue de $6,3 \mathrm{~cm}$. 

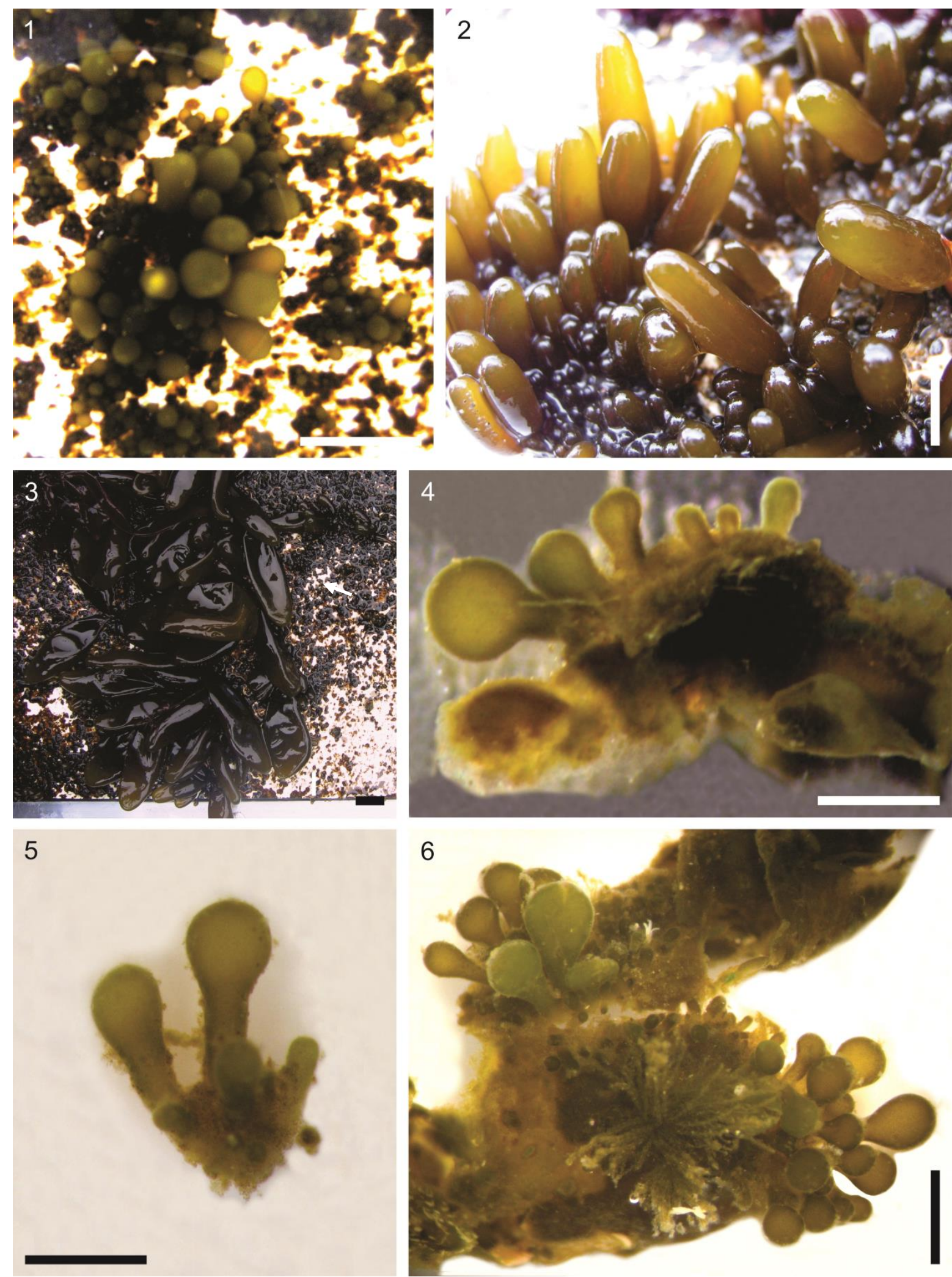

Lámina XXIX. Adenocystis utricularis. Fig. 1. Talos jóvenes. Fig. 2. Talos desarrollados en forma de sacos o vesículas turgentes. Fig. 3. Talos de mayor edad con vesículas perforadas y fláccidas; la flecha señala microtalos crustosos sobre el sustrato. Figs. 4-5. Talos cilíndricos y sólidos de individuos juveniles. Fig. 6. Talos macroscópicos juveniles desarrollándose de microtalos crustosos y filamentosos. Escalas: Figs. 1-3: $1 \mathrm{~cm}$, Figs. 4-6: $1 \mathrm{~mm}$. 


\section{Observaciones y comentarios}

En las muestras analizadas se observaron plantas adultas, jóvenes y juveniles de muy pequeño tamaño con talos sólidos y cilíndricos, así como la fase crustosa de esta especie (Müller 1984, Ricker 1987). Crece epilítica, epífita o epizoica, en el intermareal inferior frecuentemente junto a Palmaria decipiens y el submareal superior pudiendo distribuirse hasta $20 \mathrm{~m}$ de profundidad (Wiencke \& Clayton 2002). Los estadios iniciales pueden formar parches densos en las costas rocosas a principios del verano y crecen formando clusters extensos de la fase macroscópica de sacos turgentes llenos de agua y mucilago, que con el tiempo se perforan quedando fláccidos (Ricker 1987).

Esta especie se distribuye en Antártida y Subantártida (Wiencke \& Clayton 2002). Se encuentra ampliamente documentada para la Antártida occidental (Mystikou et al. 2014, Wiencke et al. 2014, Pellizari et al. 2017). En caleta Potter ha sido registrada para el intermareal (Marcías et al. 2017) y submareal hasta $5 \mathrm{~m}$ de profundidad, en nuevas áreas libres de hielo y en sitios con alto impacto glaciario (Quartino et al. 2005, 2013, Campana et al. 2017).

\section{Orden Desmarestiales Familia Desmarestiaceae}

\section{Desmarestia Lamouroux}

El talo es erecto, cilíndrico, comprimido o ligulado, simple o ramificado; puede ser muy robusto. El háptero es ramificado o discoide. Las ramas son opuestas o alternas. Los ejes y ramas terminados en una porción filamentosa delicada que puede perderse en el talo adulto, sin pelos feofíceos. La corteza consiste en una densa capa de pequeñas células isodiamétricas con varios plástidos lenticulados con pirenoides. La médula formada por largas células elongadas longitudinalmente embebidas en un tejido de células hifales angostas. En algunas especies, se produce ácido sulfúrico en vacuolas.

Los esporocistos son uniloculares y se encuentran esparcidos en la superficie del talo. El ciclo de vida es heteromórfico con esporofitos macroscópicos y gametofitos microscópicos filamentosos ramificados, monoicos o dioicos.

Desmarestia spp. (cf. D. anceps Montagne/D. menziesii J. Agardh) Lám. XXX, Figs. 1-3 Lamb \& Zimmermann 1977, p. 150-156, Figs. 17-24; Moe \& Silva 1977, Fig. 1a; Wiencke \& Clayton 2002, p. 99 \& 101, L. 31 - 32 (Lám. 32, Figs. 1-3, 5-6).

Talo tupido con frondes comprimidas de color marrón. Presenta un pequeño disco basal. Eje principal con ramificaciones principalmente opuestas. Esporofitos jóvenes con ramas opuestas. 
Datos morfométricos: La longitud máxima de los talos fue de $7,15 \mathrm{~cm}$.

\section{Observaciones y comentarios}

Se hallaron únicamente individuos juveniles. De acuerdo a las características observadas probablemente se trate de alguna de las especies perennes $D$. menziesii J. Agardh o $D$. anceps Montagne. Se excluye a $D$. antarctica R.L. Moe \& P.C. Silva, que posee varios ejes principales con láminas liguladas y aplanadas, de mayores dimensiones (Wiencke \& Clayton 2002, Campana et al. 2017).
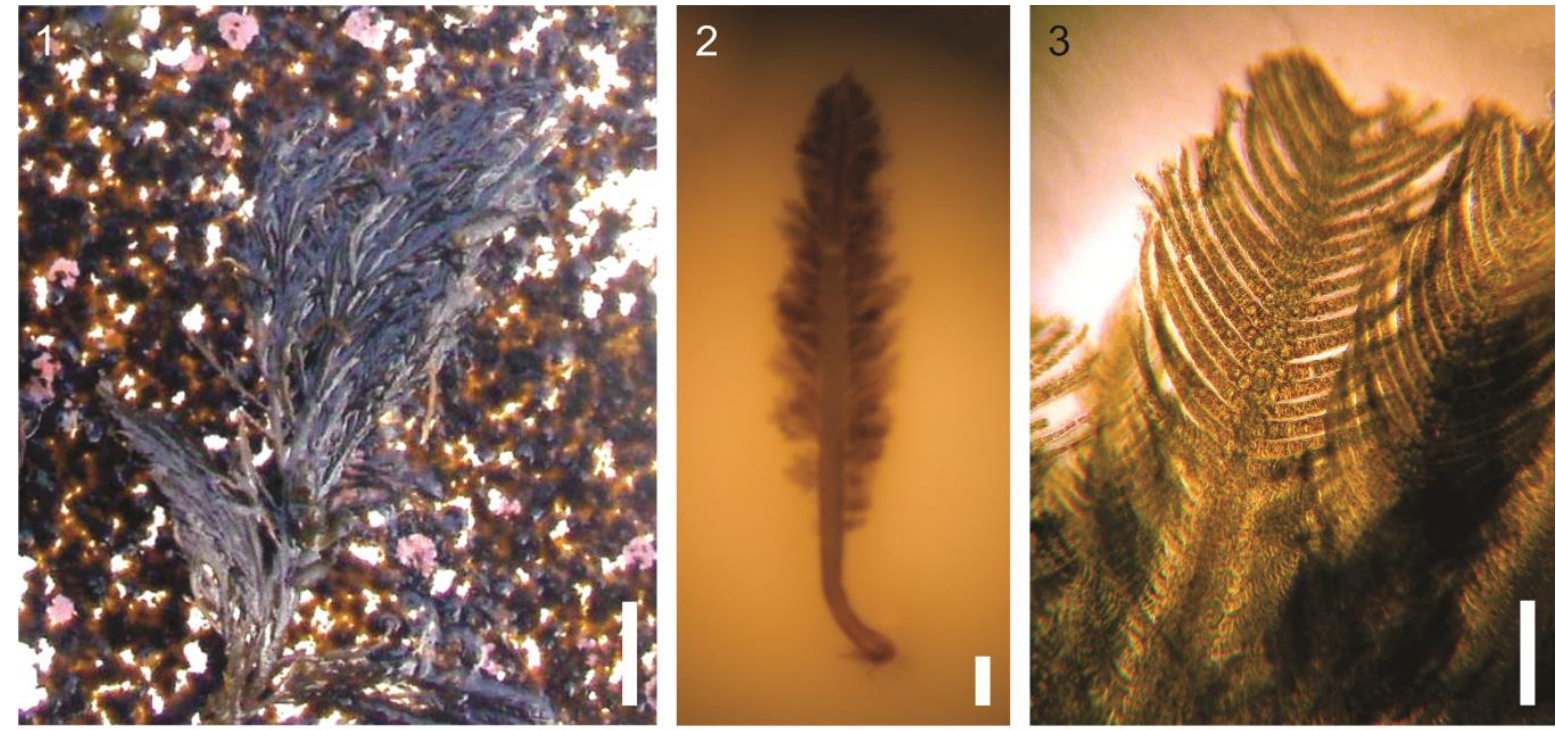

Lámina XXX. Desmarestia spp. Fig. 1. Vista general de un talo desarrollándose sobre una placa sucesional. Fig. 2. Esporofito joven con estípite y varios pares de ramas opuestas. Fig. 3. Detalle de corticación y ramificación en un esporofito joven. Escalas: Fig. 1: $1 \mathrm{~cm}$, Fig. 2: $1 \mathrm{~mm}$, Fig. 3: $200 \mu \mathrm{m}$.

\section{Phaeurus Skottsberg \\ Género monoespecífico}

Phaeurus antarcticus Skottsberg

Lám. XXXI, Figs. 1-6

Skottsberg 1907, p. 24-28, Figs. 18-22, Lám. 4; Lamb \& Zimmermann 1977, p. 159, Figs. 27-30; Clayton \& Wiencke 1990, Figs. 1-35; Wiencke \& Clayton 2002, p. 102-103, Lám. 35, Figs. 1-5; Quartino 2003, p. 68, Fig. 4.11.

Los talos (esporofito) son de color pardo, cilíndricos, erectos, ramificados frecuentemente en forma opuesta y bilateral, densamente cubiertos por filamentos uniseriados asimiladores que se originan de la capa más externa de la corteza. Se adhieren al sustrato mediante un disco basal pequeño. El talo tiene un filamento principal, axial, longitudinal, rodeado por una vaina de delgadas hifas pigmentadas entrelazadas. Estas están rodeadas por una médula gruesa de células elongadas, incoloras y finalmente por una corteza de células pigmentadas, pequeñas, isodiamétricas que poseen numerosos plástidos lenticulares sin pirenoides. Pelos feofíceos ausentes. 
Los esporocistos son uniloculares, encadenados, se forman en las partes más antiguas del talo y se encuentran en soros. El ciclo de vida es heteromórfico con esporofitos macroscópicos y gametofitos microscópicos filamentosos ramificados, dioicos. Es una especie anual.

Datos morfométricos: La máxima longitud de talos fue de 1,2 m.

\section{Observaciones y comentarios}

Se hallaron estadios jóvenes y adultos que revelaron rápido crecimiento (ver Capítulo 4). Esta especie crece epilítica o epífita, en el intermareal y frecuentemente en el submareal hasta $10 \mathrm{~m}$ bajo el canopeo de Desmarestia menziesii (Wiencke \& Clayton 2002).

Es una especie endémica. Ha sido registrada en Antártida occidental (Wiencke \& Clayton 2002, Pellizari et al. 2017). En caleta Potter fue hallada en el intermareal y submareal hasta $10 \mathrm{~m}$ de profundidad (Quartino et al. 2005, Marcias et al. 2017) y en nuevas áreas libres de hielo (Quartino et al. 2013).

\section{Orden Ascoseirales}

Familia Ascoseiraceae

\section{Ascoseira Skottsberg \\ Género monoespecífico}

Ascoseira mirabilis Skottsberg

Lám. XXXI, Fig. 7

Skottsberg 1907, p. 149, Figs. 178-187; Lamb \& Zimmermann 1977, p. 168-171, Figs. 35-36; Wiencke \& Clayton 2002, p. 104, Lám. 36, Figs. 1-7; Quartino 2003, p. 74, Fig. 4.14.

Los talos son multiaxiales, consisten en una a varias frondes en forma de cinta, de textura coriácea de color pardo oliváceo, con diminutas estriaciones longitudinales. El estípite es sólido, corto, aplanado, a menudo retorcido, y bifurcado repetidamente. El grampón es discoide. Inicialmente, las ramas consisten en una sola lámina que se escinde repetidamente en forma aproximadamente simétrica, desde el borde hacia adentro. El talo es parenquimatoso y diferenciado en una capa externa de pequeñas células pigmentadas hasta una corteza de grandes células isodiamétricas grandes. La médula con filamentos que se extienden longitudinalmente y canales conductores rodeados por filamentos hifales. Los canales conductores se extienden desde la base hasta el extremo de las frondes, y contienen compuestos fenólicos que podrían tener una función de conducción durante el período de crecimiento activo. Los individuos son monoicos, con conceptáculos dispersos en ambas caras de las frondes y que contienen cadenas de gametangios que liberan gametas biflageladas isógamas. La generación diploide es de vida libre. Es una especie perenne. 
Datos morfométricos: La dimensión máxima del talo fue de $13,1 \mathrm{~cm}$ de largo por 2,2 cm de ancho de lámina.

\section{Observaciones y comentarios}

Se hallaron sólo individuos juveniles. Esta especie crece desde el intermareal inferior hasta $12 \mathrm{~m}$ de profundidad (Wiencke \& Clayton 2002). Es una especie endémica, que ha sido registrada en Antártida occidental (Wiencke \& Clayton 2002, Silberfeld et al. 2011, Wiencke et al. 2014, Pellizari et al. 2017). En caleta Potter fue hallada en el intermareal y en el submareal hasta $10 \mathrm{~m}$ de profundidad (Quartino et al. 2005, Marcías et al. 2017) y en nuevas áreas libres de hielo (Quartino et al. 2013).
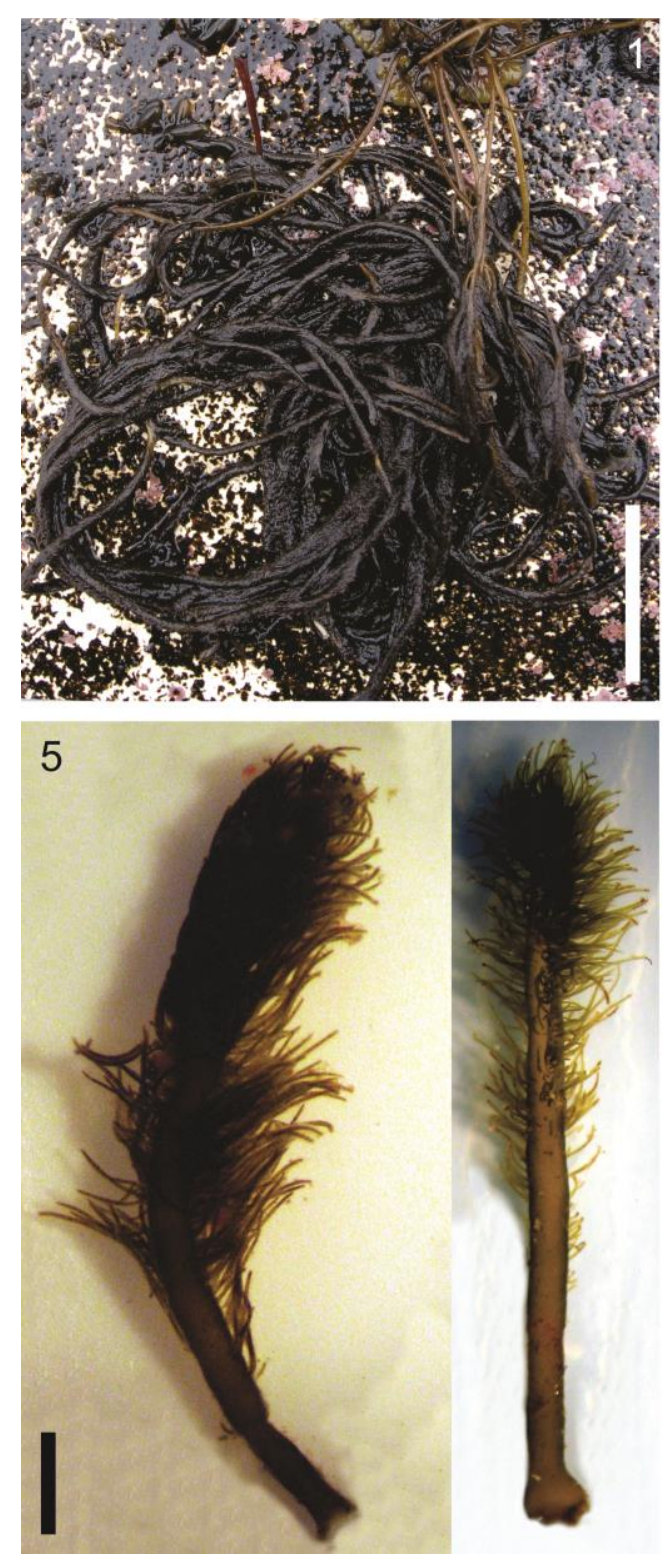
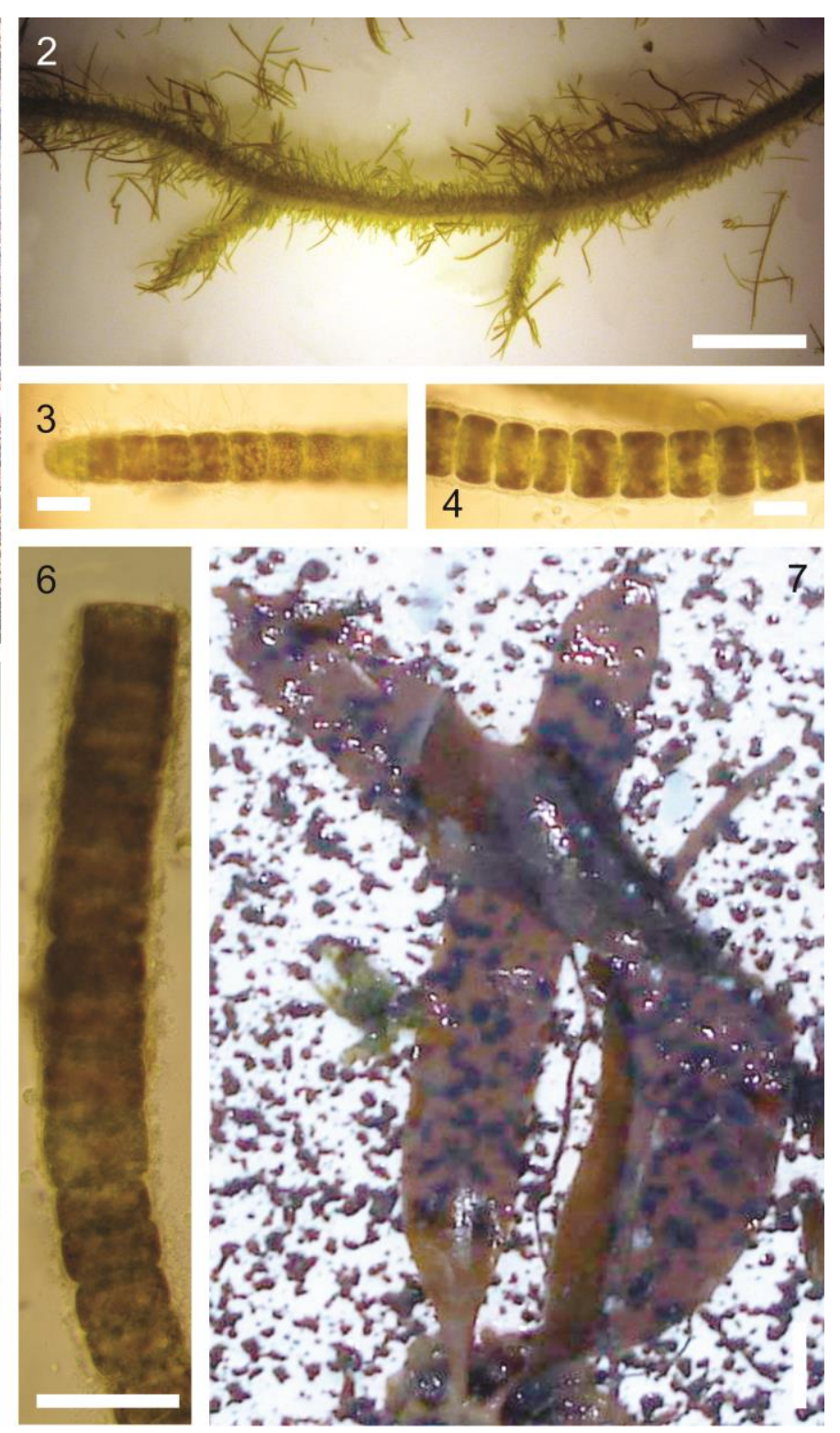

Lámina XXXI. Figs. 1-6. Phaeurus antarcticus. Fig. 1. Esporofito fijado al sustrato. Fig. 2. Esporofito joven con ramificaciones. Figs. 3-4. Detalle de pelos uniseriados que recubren el talo. Fig. 5. Dos esporofitos jóvenes, nótense el eje central cubierto por filamentos asimiladores y el pequeño disco basal. Fig. 6. Detalle de los filamentos asimiladores uniseriados de esporofitos jóvenes. Fig. 7. Ascoseira mirabilis. Talo fijado al sustrato; nótese el estípite bifurcado y el grampón discoide. Escalas: Fig. 1: $5 \mathrm{~cm}$, Fig. 2: 2 mm, Figs. 3-4, 6: 50 $\mu \mathrm{m}$, Fig. 5: $1 \mathrm{~mm}$, Fig. 7: $1 \mathrm{~cm}$. 


\section{Rhodophyta \\ Clase Florideophyceae \\ Orden Acrochaetiales \\ Familia Acrochaetiaceae}

\section{Rhodochorton Nägeli}

El talo es heterotrico y consiste en filamentos uniseriados, ramificados. Las células poseen uno a varios cloroplastos parietales sin pirenoides, desde discoides hasta irregularmente alargados. Este género se caracteriza por el desarrollo de una fase tetraspórica directamente a partir del carpogonio fertilizado o de una estructura tipo carposporofito intercalada. Ausencia de carposporas libres. Tetrasporas cruciadas.

Rhodochorton cf. purpureum (Lightfoot) Rosenvinge

Lám. XXXII, Figs. 1-3

Rosenvinge 1900, p. 75; Ricker 1987, p. 156, Figs. 66-67; Wiencke \& Clayton 2002 (como Audouinella pupurea), p. 47-48, Lám. 2 Figs. 6-7; Hommersand et al. 2009, p. 510-511.

Los talos forman matas de filamentos erectos enmarañados o en forma de césped delgado, espaciadamente ramificados, de color rojo purpúreo. Presentan un sistema de rizoides compactos. Las células de los filamentos son más largas que anchas, y poseen con un solo plástido reticulado sin pirenoides, que luego puede ser fragmentado. Tetrasporangia cruciadas.

Datos morfométricos: Los filamentos se observaron formando una mata de forma irregular, de 120-250 $\mu \mathrm{m}$ de extensión.

\section{Observaciones y comentarios}

Los ejemplares analizados fueron de pequeñas dimensiones, firmemente adheridos al sustrato de color rojo intenso. Esta especie usualmente crece epilítica o epífita, en el intermareal, a menudo en grietas, o en el submareal (Wiencke \& Clayton 2002).

Es una especie cosmopolita. Ha sido registrada en la Antártida occidental y oriental (Wiencke \& Clayton 2002, Hommersand et al. 2009). Este consiste en el primer registro de esta especie para caleta Potter. 

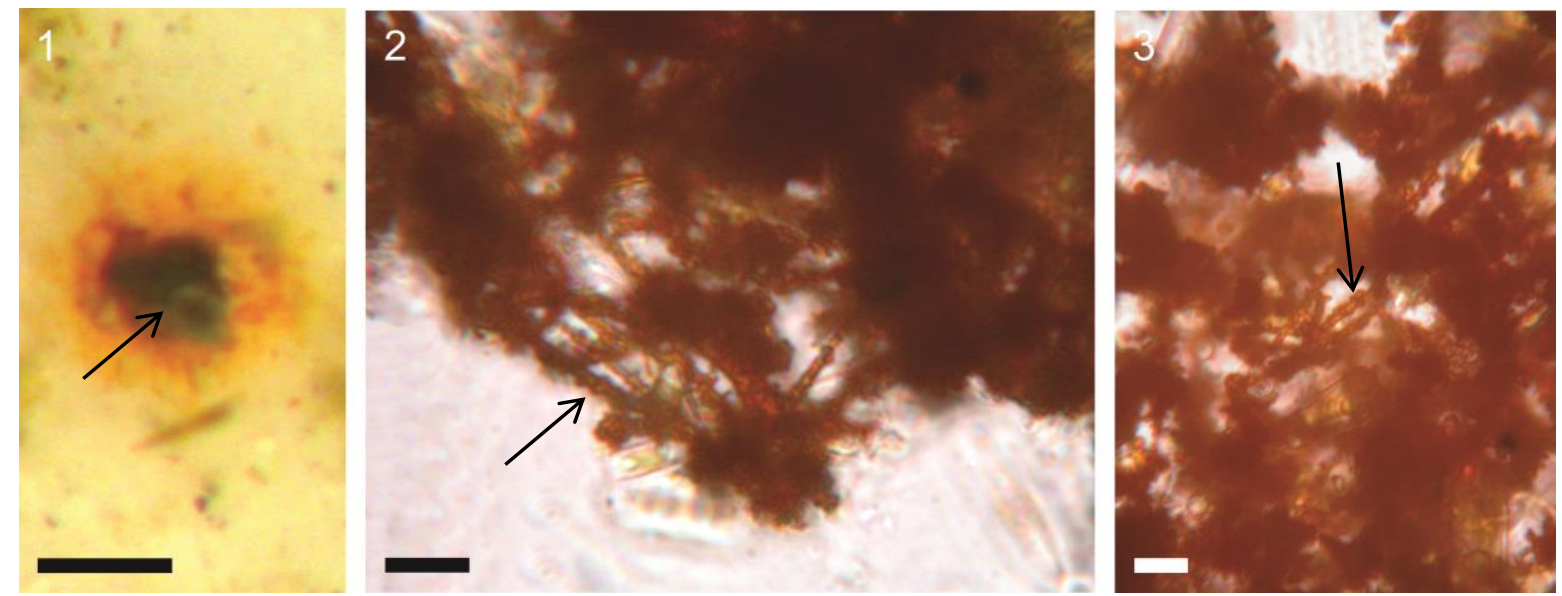

Lámina XXXII. Rhodochorton cf. purpureum. Fig. 1. Aspecto general de R. cf. purpureum adherido a una placa sucesional. Figs. 2-3. Detalle de los filamentos uniseriados. Escalas: Fig. 1: $100 \mu \mathrm{m}$, Figs. 2-3: $10 \mu \mathrm{m}$.

\section{Orden Palmariales \\ Familia Palmariaceae}

\section{Palmaria Stackhouse}

El talo es laminar, las frondes no ramificadas o partidas dicotómicamente, o dilaceradas, volviéndose cartilaginosas con la edad. Los estípites son aplanadas y surgen de un disco basal. La médula es incolora y la corteza es fotosintética. Presenta cromatóforos parietales sin pirenoides. Generalmente los talos que se encuentran son tetrasporofitos.

Palmaria decipiens (Reinsch) Ricker

Lám. XXXIII, Figs. 1-7

Ricker 1987, p. 218, Figs. 91-92; Wiencke \& Clayton 2002 p. 54-55, Lám. 5, Figs 1-6; Quartino 2003, p. 82, Fig. 4.18; Zacher et al. 2007a, Fig. 6.

Los talos son alargados rosados o púrpura, adheridos al sustrato mediante un disco basal, sin ramificaciones, cilíndricos en la base y planos arriba. Las frondes son oblongas, lanceoladas, fláccidas, delicadas, membranosas, algo onduladas en los márgenes. Las frondes del primer año son simples y en las plantas de más edad, las frondes proliferan de las porciones basales de la lámina del año anterior, algunas veces muy divididas. La médula está formada por células grandes isodiamétricas e incoloras, de paredes delgadas. La corteza posee una a tres capas de células pequeñas pigmentadas, a menudo elongadas anticlinalmente. Tetrasporocistos cruciados, inmersos en la corteza engrosada externa, ubicados en las regiones prolíferas. Es una especie pseudoperenne.

Datos morfométricos: La máxima longitud de las láminas fue de $15,1 \mathrm{~cm}$ y el ancho máximo fue de $3,5 \mathrm{~cm}$. Los estadios iniciales tuvieron un diámetro de 87,6 a 162,5 $\mu \mathrm{m}$.

\section{Observaciones y comentarios}

Se hallaron individuos juveniles y adultos de más de un año, evidenciados por la presencia de frondes proliferando desde una lámina anterior. Asimismo, se registraron estadios iniciales firmemente adheridos al sustrato. Esta especie usualmente crece epilítica y algunas 
veces epifitica, puede ser muy abundante en el intermareal y submareal superior (Wiencke \& Clayton 2002, Hommersand et al. 2009) pudiendo estar presente hasta $30 \mathrm{~m}$ (Wiencke \& Clayton 2002).

Se encuentra ampliamente distribuida en Antártida (Wiencke \& Clayton 2002, Runcie \& Riddle 2006, Hommersand et al. 2009, Becker et al. 2011, Mystikou et al. 2014, Wiencke et al. 2014, Pellizzari et al. 2017). En caleta Potter se encuentra en la zona intermareal y en el submareal superior, cerca de $5 \mathrm{~m}$ de profundidad (Klöser et al. 1996, Quartino et al. 2005, Marcías et al. 2017). Fue hallada en sitios con alto impacto glaciario y nuevas áreas libres de hielo (Quartino et al. 2013, Deregibus et al. 2016, Campana et al. 2017).

\section{Orden Gigartinales \\ Familia Gigartinaceae}

\section{Gigartina Stackhouse}

Talos con estructura multiaxial, desde cilíndricos hasta foliáceos, adheridos con discos o procesos basales. La médula está formada por filamentos incoloros anastomosados o por células de varias formas y tamaños. La corteza formada por células sucesivamente más pequeñas de las cuales las más externas están pigmentadas. Los cistocarpios son prominentes y se ubican sobre las papilas

Los tetrasporocistos se dividen en forma cruciada y se agrupan en soros globosos o achatados que se desarrollan en la corteza interna.

Ciclo trigenético con tetrasporofito y gametofitos isomórficos.

Gigartina skottsbergii Setchell \& Gardner

Lám. XXXIV, Fig. 1

Setchell \& Gardner 1936, p. 472-473; Wiencke \& Clayton 2002, p. 60-61, Lám. 8, Figs. 1-4; Quartino 2003, p. 96, Fig. 4.25; Boraso de Zaixso 2013, p. 146.

Los talos son umbilicados irregularmente lobados, grueso y cartilaginosos de color rojo oscuro. Su posición es paralela al sustrato, y se fijan por medio de un corto estipe ubicado en la cara abaxial y por medio de hápteros secundarios.

Presentan papilas pediceladas sobre la cara superior y a veces en la inferior. Son numerosas en las plantas cistocárpicas, en las plantas tetrasporofíticas se encuentran esparcidas y concentradas en las partes basales y las plantas masculinas presentan pocas o ninguna. La lámina puede presentar perforaciones de tamaño variable. La médula está formada por filamentos incoloros entremezclados. La corteza formada por células de menor tamaño, gradualmente más pequeñas y pigmentadas hacia la superficie. Los tetrasporofitos forman tetrasporas cruciadas en los estratos corticales internos. Los cistocarpos se ubican dentro de las papilas. Es una especie pseudoperenne. 

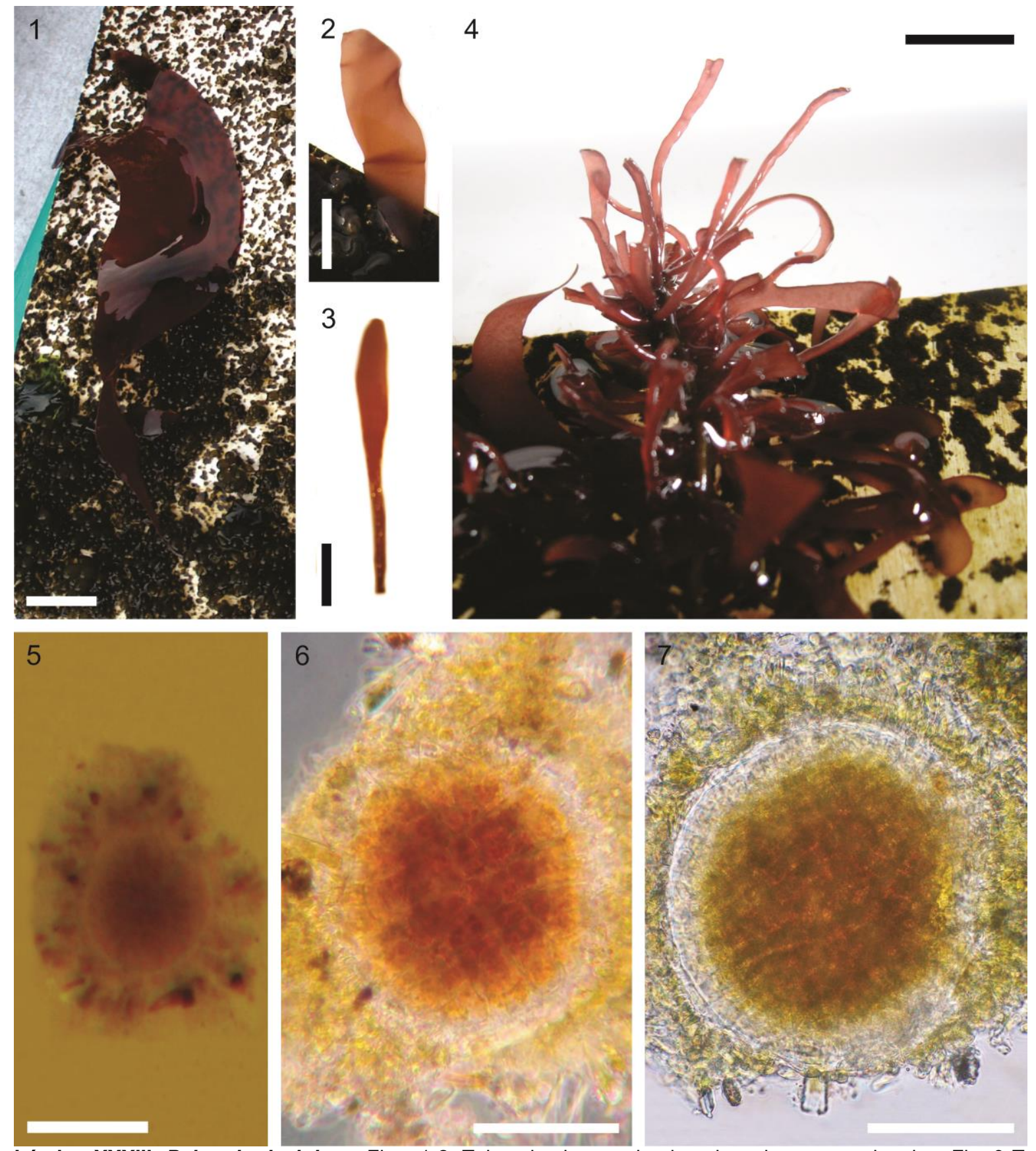

Lámina XXXIII. Palmaria decipiens. Figs. 1-2. Talos simples creciendo sobre placas sucesionales. Fig. 3 Talo juvenil. Fig. 4. Frondes juveniles creciendo a partir de porciones basales de una lámina del año anterior. Fig. 5 . Aspecto general de un estadio inicial adherido a una placa sucesional. Figs 6-7. Estadios iniciales observados a distintos niveles de magnificación. Escalas: Figs. 1-2: 2 cm, Figs. 3-4: 1 cm, Fig. 5: $100 \mu \mathrm{m}$, Figs. 6-7: $50 \mu \mathrm{m}$.

Datos morfométricos: Los estadios iniciales tuvieron un diámetro de 497,3 a 552,7 $\mu \mathrm{m}$.

\section{Observaciones y comentarios}

Sólo fueron hallados pequeños estadios iniciales firmemente adheridos al sustrato, no habiéndose registrado organismos adultos. Los ejemplares de colecciones antárticas son morfológicamente similares a las de Sudamérica e islas Malvinas pero probablemente correspondan a un taxa diferente (Hommersand et al. 2009). Esta especie crece epilítica, 
puede estar presente en el intermareal inferior y frecuentemente en el submareal superior, aunque puede ser hallada hasta $30 \mathrm{~m}$ de profundidad (Wiencke \& Clayton 2002).

Se ha registrado para Antártida occidental (Wiencke et al. 2014, Pellizzari et al. 2017). En caleta Potter presenta el mismo patrón general de distribución vertical (Klöser et al. 1996, Quartino et al. 2005, Marcías et al. 2017), habiendo sido hallada en nuevas áreas libres de hielo (Quartino et al. 2013).

\section{Iridaea Bory de Saint-Vincent}

El talo es folioso, entero o lobado irregularmente, raramente más o menos ramificado en forma dicotómica sin venas, con estípite corto cilíndrico o aplanado que sale de un pequeño disco basal. Algunas especies son iridiscentes bajo el agua. La médula es incolora, de filamentos entremezclados, con mucho espacio intercelular, la corteza es de filamentos anticlinales cortos. Las tetrasporas son cruciadas. Los esperamatangia forman soros sobre la superficie de la fronde. Los cistocarpios están total o parcialmente inmersos en el talo y generalmente sin ostiolo bien definido. El ciclo de vida presenta alternacia de fases somaticas isomorficas

Iridaea cordata (Turner) Bory de Saint-Vincent

Lám. XXXIV, Figs. 2-5

Bory de Saint-Vincent 1826, p. 16; Lamb \& Zimmerman 1977, p. 193, 195, 199 (como Iridaea obovata), Figs. 69-71; Ricker 1987, p. 195- 197, Fig. 82; Kim et al. 2001, p. 354, Figs. 33-34; Wiencke \& Clayton 2002, p. 61-62, Lám. 9, Figs. 1-4; Quartino 2003, p. 98, Fig. 4.26; Zacher et al. 2007a, Fig. 6; Boraso de Zaixso 2013, p. 152.

Los talos son erectos, lanceolados u ovales de color marrón rojizo a púrpura. La base es con forma de cuña, con estipe aplanado. El disco basal es pequeño. Las plantas adultas usualmente perforadas en la senectud. La médula está compuesta por filamentos reticulares incoloros. La corteza consiste en cadena anticlinales de células pigmentadas casi isodiamétricas. Los tetrasporocistos se originan en la corteza interna y forman esporas cruciadas en soros subcorticales. Los cistocarpios embebidos en la medula y espermatangia superficial. Es una especie pseudoperenne.

Datos morfométricos: La máxima longitud de las láminas fue de $25 \mathrm{~cm}$ y el ancho máximo de las láminas fue de 9,4 cm. Los estadios iniciales tuvieron un diámetro de 499,1 a 656,1 $\mu \mathrm{m}$.

\section{Observaciones y comentarios}

Se registraron organismos adultos y estadios iniciales firmemente adheridos al sustrato. Aunque morfológicamente similares, probablemente se trate de un taxa diferente al de las plantas de Sudamérica e islas Malvinas (Hommersand et al. 2009). Esta especie usualmente crece epilítica y en pozas de marea del intermareal junto a $P$. decipiens y $A$. utricularis, pero 
más comúnmente en el submareal poco profundo pudiéndose encontrar ejemplares hasta $30 \mathrm{~m}$ de profundidad.

Se encuentra ampliamente distribuida en Antártida occidental y oriental (Wiencke \& Clayton 2002, Hommersand et al. 2009, Mystikou et al. 2014, Pellizzari et al. 2017). En caleta Potter se encuentra en la zona intermareal y en el submareal sobre sustratos rocosos (Klöser et al. 1996, Quartino et al. 2005, Marcías et al. 2017). Fue hallada en nuevas áreas libres de hielo (Quartino et al. 2013).

1

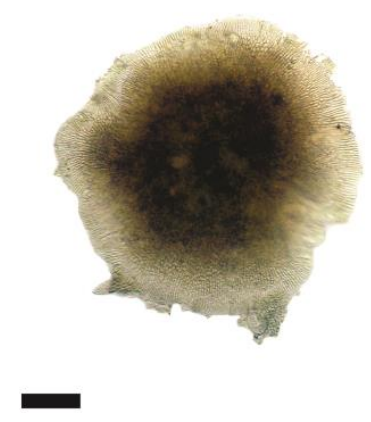

4

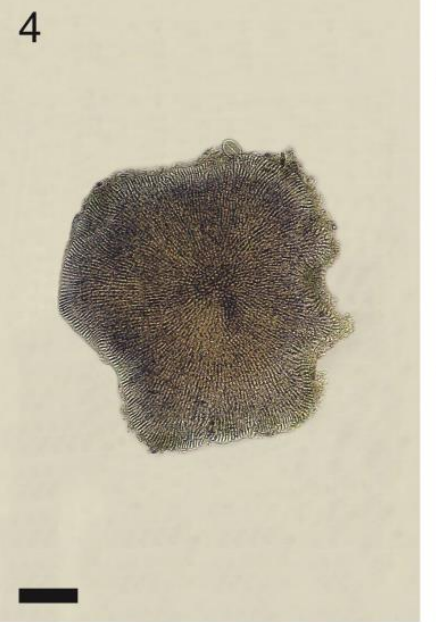

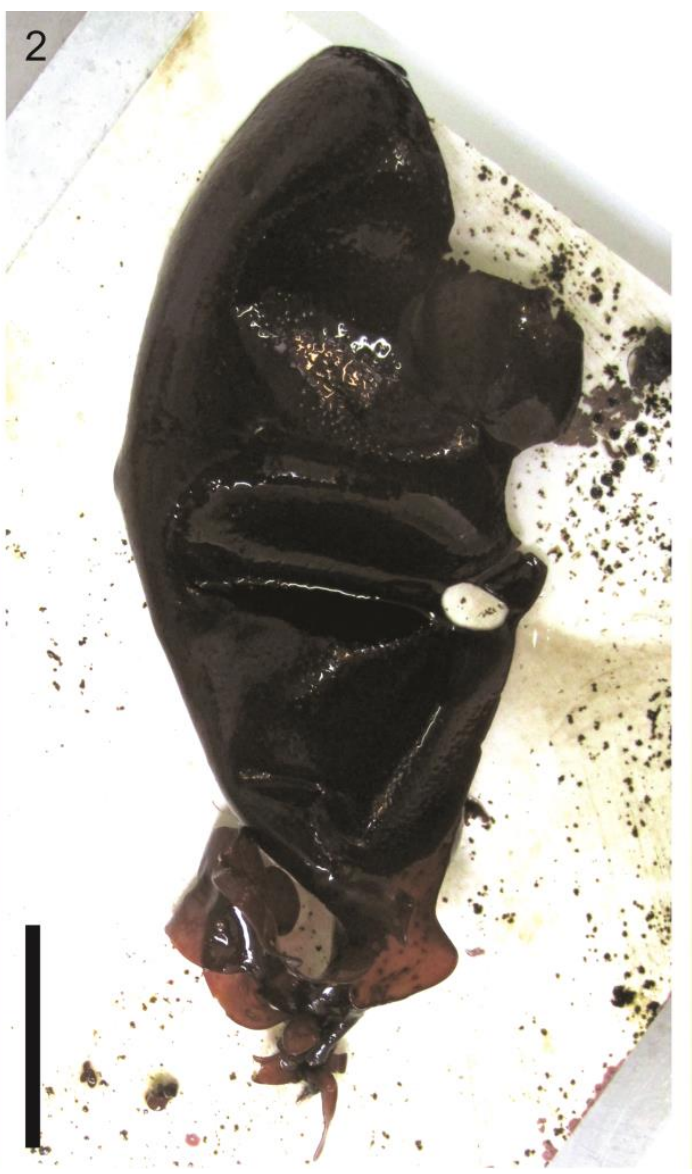

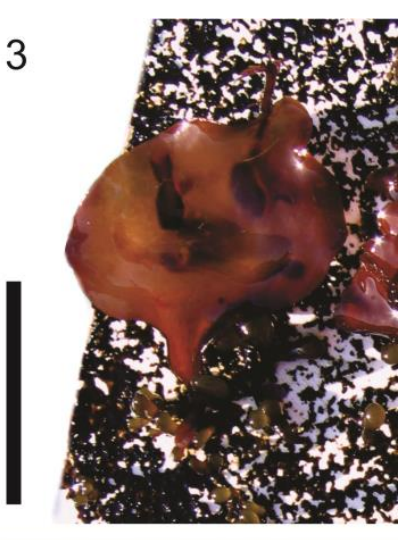

5

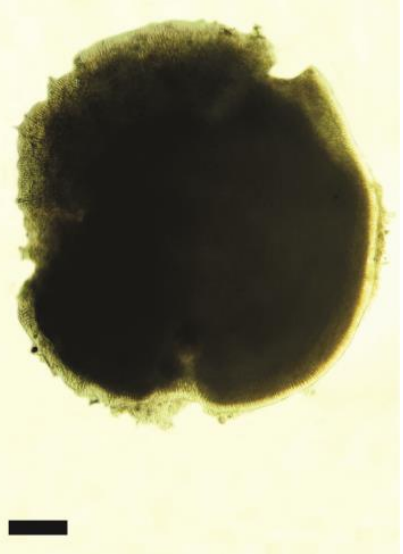

Lámina XXXIV. Fig. 1. Gigartina skottsbergii. Vista general de un estadio inicial. Figs. 2-5. Iridaea cordata. Fig. 2 Talo adulto sobre un sustrato; nótese la lámina perforada. Fig. 3. Talo juvenil sobre un sustrato; nótese la base de la lámina en forma de cuña. Figs. 4-5. Estadios iniciales con distinto desarrollo. Escalas: Figs. 1, 4-5: $100 \mu \mathrm{m}$, Figs. 2-3: $5 \mathrm{~cm}$. 
Algunos taxa no pudieron ser identificados a nivel de género y/o especie, por lo cual fueron agrupados a nivel de Familia. Este es el caso de las algas rojas crustosas, las que fueron identificadas como pertenecientes a la familia Corallinaceae (Orden Corallinales), (Lám. XXXV, Figs. 1-2). Para la mayoría de las especies antárticas el status taxonómico de este orden es incierto y requiere de profundas investigaciones (Wiencke \& Clayton 2002). Asimismo, fueron registrados morfotipos de pequeñas dimensiones que fueron identificados como estadios iniciales y organismos juveniles de la familia Delesseriaceae (Orden Ceramiales) (Lám. XXXV, Figs. 3-6).

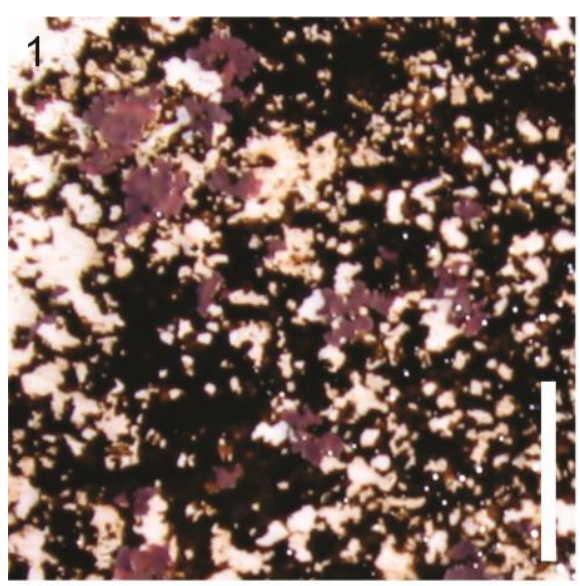

4

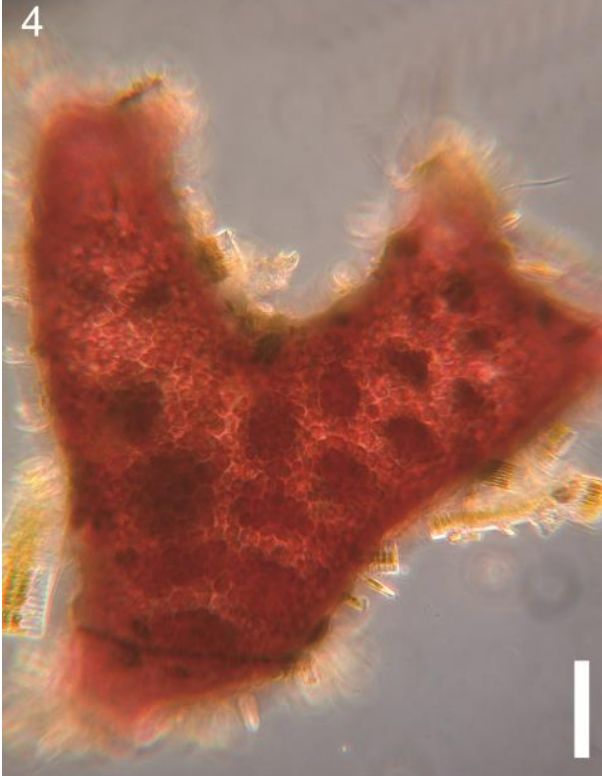

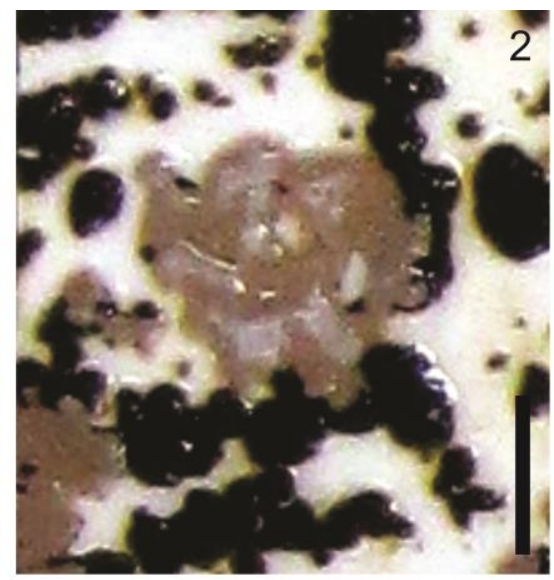
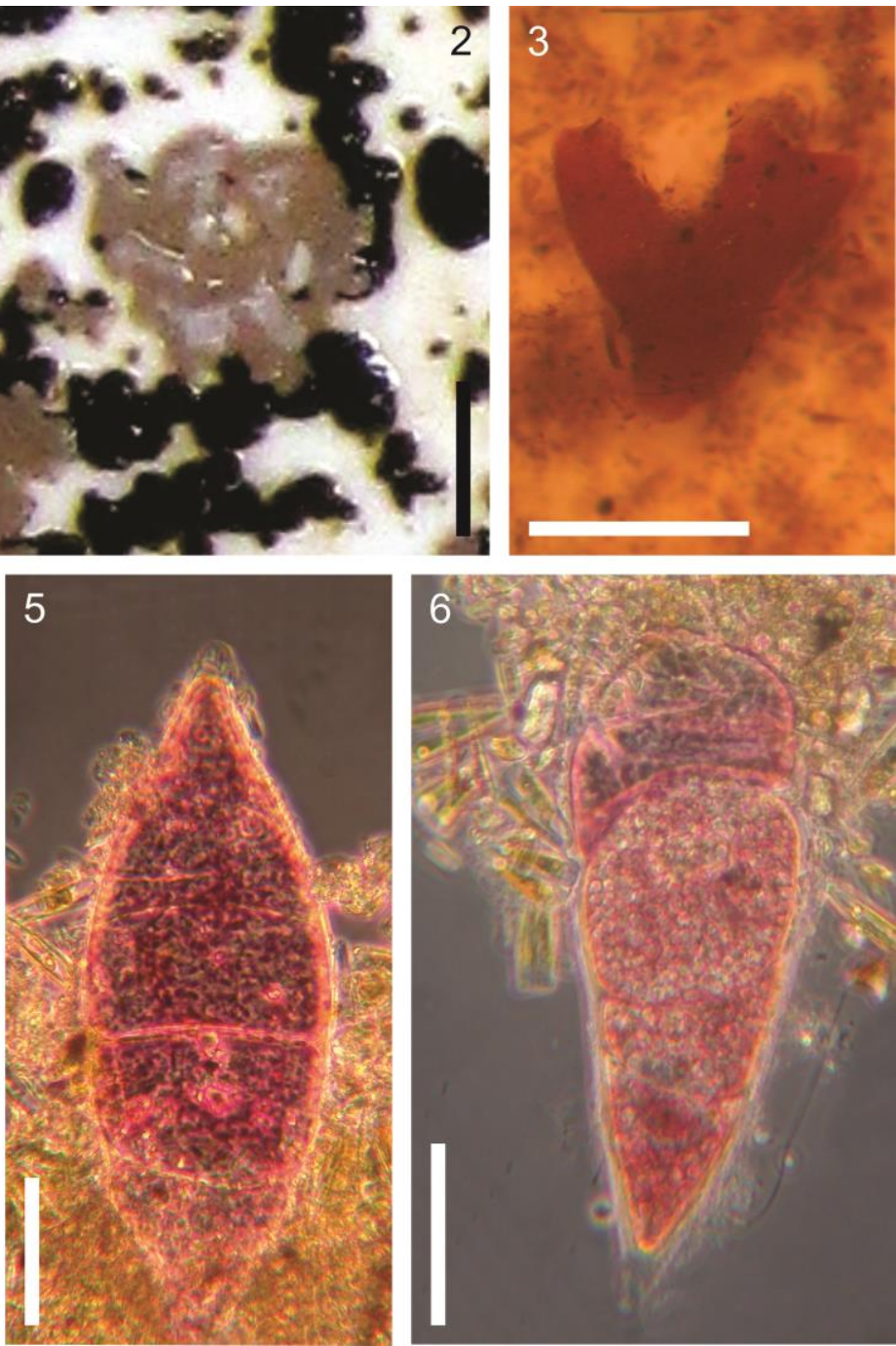

Lámina XXXV. Figs. 1-2 Familia Corallinaceae. Fig. 1. Vista general de una placa sucesional con individuos de algas rojas crustosas de la familia Corallinaceae. Fig. 2. Detalle de algas rojas crustosas creciendo sobre estadios iniciales de A. utricularis. Figs. 3-6 Familia Delesseriaceae. Fig. 3. Vista general de un individuo sobre una placa sucesional. Fig. 4. Detalle del mismo ejemplar. Figs. 5-6. Estadios iniciales sobre los que se observan diatomeas epífitas. Escalas: Fig. 1: 1 cm, Fig. 2: 5 mm, Fig. 3: $500 \mu \mathrm{m}$, Fig. 4: $100 \mu \mathrm{m}$, Figs. 5-6: $50 \mu \mathrm{m}$. 


\section{Chlorophyta}

Clase Ulvophyceae

Orden Ulotrichales

Familia Monostromataceae

\section{Monostroma Thuret}

El talo consiste en una lámina monostromática, a veces en forma de saco. Las células presentan paredes más o menos gelatinosas con un cromatóforo parietal, generalmente con un solo pirenoide en la lámina. Su ciclo de vida es con alternancia heteromórfica de generaciones sexuales y asexuales.

\section{Monostroma hariotii Gain}

Lám. XXXVI, Figs. 1-2

Gain 1911, p. 726, Lám. 38; Lamb \& Zimmerman 1977, p. 138, Fig. 4; Wiencke \& Clayton 2002, p. 107, Lám. 38, Figs. 1-4; Quartino 2003, p. 50, Fig. 4.2; Boraso de Zaixso 2013, p. 28.

Las frondes son de color verde brillante, uniestratificadas, delicadas, en forma de saco. En algunos casos, los sacos pueden lacerarse y abrirse. Se adhieren al sustrato con un pequeño pedúnculo basal. Es una especie anual.

Datos morfométricos: La máxima longitud de los talos fue de $2,8 \mathrm{~cm}$.

\section{Observaciones y comentarios}

Los ejemplares analizados fueron de pequeñas dimensiones, encontrándose en la naturaleza individuos de hasta $35 \mathrm{~cm}$ de largo (Wiencke \& Clayton 2002). Esta especie crece epilítica tanto en el intermareal como en el submareal hasta $20 \mathrm{~m}$ de profundidad, así como epífita sobre otras macroalgas (Wiencke \& Clayton 2002).

Se trata de una especie ampliamente distribuida en Antártida occidental y oriental (Wiencke \& Clayton 2002, Runcie \& Riddle 2006, Pellizzari et al. 2017). En caleta Potter se encuentra en la zona intermareal y con mayor abundancia en el submareal superior, cerca de $5 \mathrm{~m}$ de profundidad, particularmente sobre sustratos rocosos con arena en los intersticios (Klöser et al. 1996, Quartino et al. 2005); asimismo fue hallada en sitios con alto impacto glaciario y nuevas áreas libres de hielo (Quartino et al. 2013, Campana et al. 2017).

\section{Familia Ulotrichaceae}

\section{Ulothrix Kützing}

El talo está compuesto por filamentos uniseriados y no ramificados, de color verde claro. Las células poseen un cloroplasto parietal en forma de anillo abierto, con uno a varios pirenoides. El ciclo de vida es heteromórfico, con un esporofito unicelular. 
Ulothrix flacca (Dillwyn) Thuret

Lám. XXXVI, Figs. 3-7

Le Jolis 1863, p. 56; Skottsberg 1953, p. 532, Fig. 1; Lockhorst 1978, p. 207-220, Figs. 6-10, Lám. 57; Sar 1985, Lám. 1, Figs. 1-11; Wiencke \& Clayton 2002, p. 108, Lám. 38, Fig. 5; Boraso de Zaixso 2013, p. 31. Lám 3.1, Figs. 2-4.

El talo está compuesto por filamentos rectos o retorcidos, entrelazados, solitarios o formando tapices de color verde. Los filamentos pueden presentar grupos de células necrosadas. La célula basal es levemente alargada y la célula apical redondeada. Las células son cilíndricas, más cortas que anchas, mostrando un diámetro menor y un alto mayor hacia la base del filamento. El cloroplasto es parietal, en forma de anillo abierto; en los filamentos jóvenes, cubriendo entre la mitad y las tres cuartas partes del diámetro de la célula, en la maduras puede estar parcialmente cerrado. La pared celular se cubierta por una vaina de mucilago de espesor variable. Es una especie anual.

Datos morfométricos: La máxima longitud de los filamentos fue de 6,3 $\mathrm{mm}$. Las células presentaron un diámetro de entre $12,5 \mu \mathrm{m}$ y $27,7 \mu \mathrm{m}$ (excepcionalmente: $47,5 \mu \mathrm{m}$ ) y un alto de entre 4,3 y 19,7 $\mu \mathrm{m}$. Generalmente, las células con diámetro mayor y alto menor hacia el ápice del filamento; las células basales fueron más elongadas, con un ancho de 10,0-13,0 $\mu \mathrm{m}$ y un alto de $41,0-48,7 \mu \mathrm{m}$.

\section{Observaciones y comentarios}

Los organismos de $U$. flacca fueron hallados frecuentemente adheridos al sustrato en grupos conformados por varios filamentos. Las dimensiones de los filamentos, células y relación largo/ancho celular fueron similares a los registrados para la costa de Buenos Aires, Argentina (Sar 1985). Crece epilítica formando matas densas en el intermareal superior, y en áreas de aguas salobres (Lokhorst 1978).

Se trata de una especie cosmopolita, que se ha registrado en la Península Antártica y en las Islas Shetland del Sur (Skottsberg 1953, Pellizzari et al. 2017). Para caleta Potter, este trabajo incluye el primer registro de esta especie. Cabe señalar que se requieren estudios ulteriores para determinar la presencia de las especies del género Ulothrix en Antártida, habiéndose registrado hasta el momento cinco especies: $U$. australis Gain, $U$. flacca (Dillwyn) Thuret, U. implexa (Kützing) Kützing, U. subflaccida Wille, U. zonata (Weber \& Mohr) Kützing (Wiencke \& Clayton 2002, Pellizzari et al. 2017). Frecuentemente se hace referencia a su presencia en las zonas intermareales a nivel genérico, en matas mixtas junto a Urospora penicilliformis (Kim 2001). 


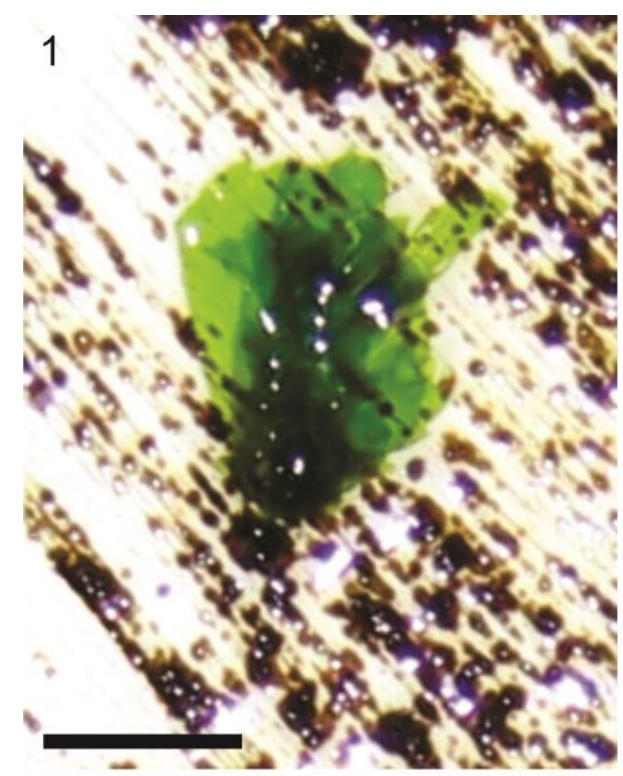

2

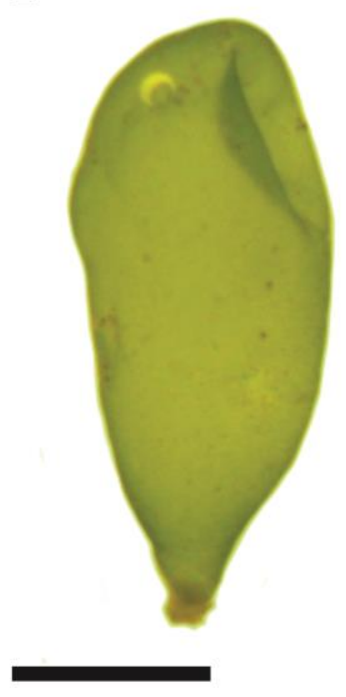

5

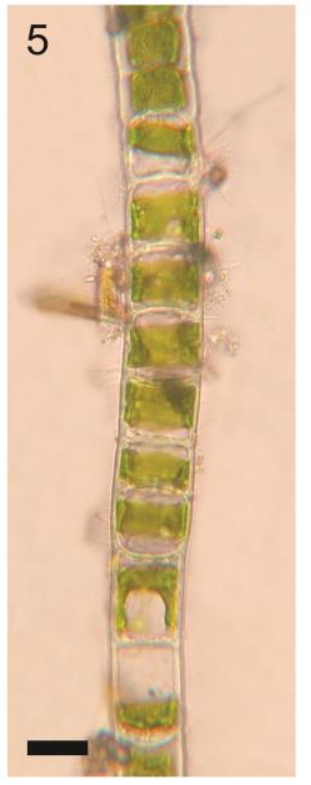

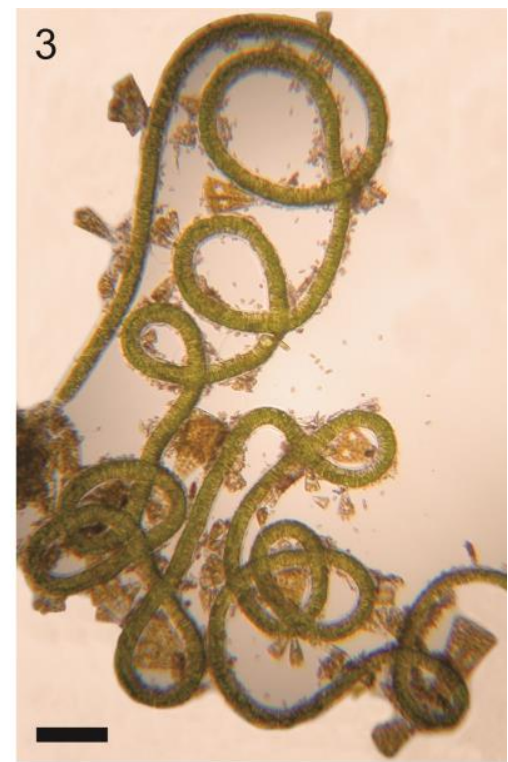
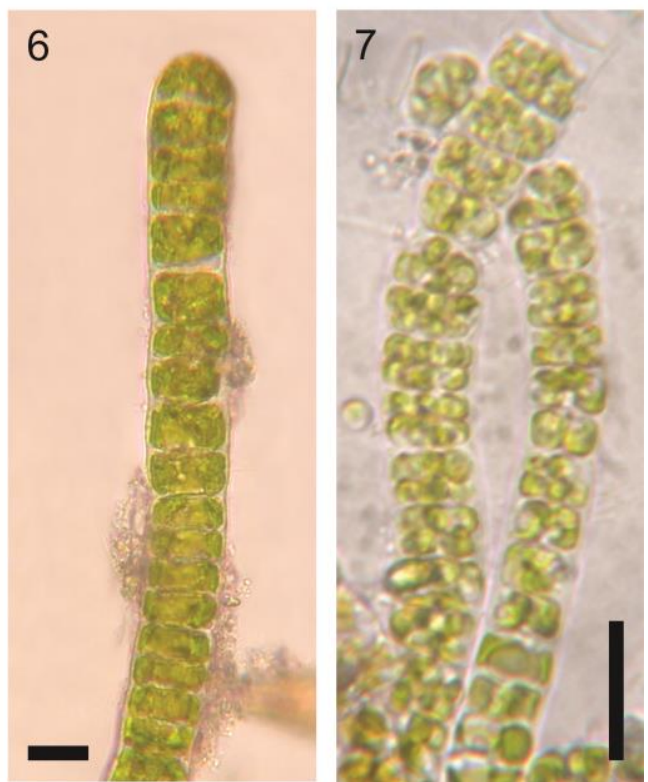

Lámina XXXVI. Figs. 1-2. Monostroma hariotii. Fig. 1. Vista general sobre un sustrato. Fig. 2. Detalle de un individuo; nótese el talo en forma de saco y el pequeño pedúnculo basal. Figs. 3-7. Ulothrix flacca. Fig. 3. Vista general de un filamento completo. Fig. 4. Porción basal de filamentos, nótense las células basales alargadas. Fig. 5. Porción de un filamento mostrando células vegetativas con un cloroplasto parietal en forma de anillo abierto. Fig. 6. Extremo apical de un filamento, nótese la célula apical redondeada y las células de diámetro mayor que su altura. Fig. 7. Filamentos conteniendo células vegetativas y reproductivas. Escalas: Figs. 1-2: $1 \mathrm{~cm}$, Figs. 3-4, Figs. 5-7: $20 \mu \mathrm{m}$.

\section{Urospora Areschoug}

El talo consiste en un filamento uniseriado y no ramificado. La región basal presenta generalmente varias células modificadas como rizoides. Las células son uninucleadas o multinucleadas, con un cloroplasto parietal inicialmente, y reticulado en los adultos, y varios pirenoides. El ciclo de vida es heteromórfico. 
Urospora penicilliformis (Roth) Areschoug

Lám. XXXVII, Figs. 1-3

Areschoug 1874, p. 4-7, L. 1, Figs. 1-6; Lokhorst \& Trask 1981, p. 375-385, Figs. 6-7, Lám- 5; Ricker 1987, p. 52-54, Fig. 23; Cormaci et al. 1992, p. 550-551, Figs. 27-33; Wiencke \& Clayton 2002, p. 106, Lám. 37, Figs. 3-5; Boraso de Zaixso 2013, p. 32. Lám 3.1, Fig. 8.

El talo consiste en un filamento no ramificado de color verde a verde oscuro, individuales o formado matas. Las células son cilíndricas o con forma de barril, las de la región basal con rizoides. Las células basales son generalmente más cortas que anchas. Las células maduras poseen un cloroplasto reticulado, que ocupa la célula completa, con numerosos pirenoides. Las zoosporas son cuadriflageladas y presentan una prolongación posterior aguzada. Es una especie anual.

Datos morfométricos: La máxima longitud de los filamentos fue de $2.8 \mathrm{~cm}$. Las células presentaron un diámetro de entre $50,5 \mu \mathrm{m}$ y $111,7 \mu \mathrm{m}$ (excepcionalmente: $450-925 \mu \mathrm{m}$ ) y un alto de entre 27,5 y $100 \mu \mathrm{m}$.

\section{Observaciones y comentarios}

Este taxa se observó principalmente como filamentos individuales o aislados, no gregarios. Escasos ejemplares presentaron dimensiones celulares que excedieron las descriptas por Wiencke \& Clayton (2002) para Antártida (hasta $250 \mu \mathrm{m}$ ). Ricker (1987) señala que $U$. penicilliformis puede presentar alta variabilidad en las dimensiones de los filamentos y formas celulares, y establece que los filamentos de mayor tamaño de $U$. penicilliformis pueden ser morfológicamente similares a Chaetomorpha mawsonii Lucas, sugiriendo que podría tratarse incluso del mismo taxa. A partir de que recientemente $C$. mawsonii -un taxón que sólo había sido citado para Antártida oriental (Wiencke et al. 2014)- ha sido registrada en las islas Shetland del Sur (Pellizari et al. 2017), se sugiere que en próximas investigaciones se focalicen estudios taxonómicos y/o moleculares a partir de monocultivos para elucidar la identidad de ambos taxa. Crece epilítica o epifítica, formando matas densas en el intermareal, tanto en pozas de marea como en sitios expuestos al oleaje (Lamb \& Zimmerman 1977, Wiencke \& Clayton 2002).

Urospora penicilliformis es una especie cosmopolita. Está ampliamente distribuida en Antártida occidental y oriental (Wiencke \& Clayton 2002, Wiencke et al. 2014), aparece en diciembre y alcanza su desarrollo máximo alrededor de mediados de febrero (Lamb \& Zimmerman 1977, Kim 2001). En caleta Potter se ha observado formando matas mixtas con Ulothrix spp. sobre la línea de marea alta (Roleda et al. 2009). 

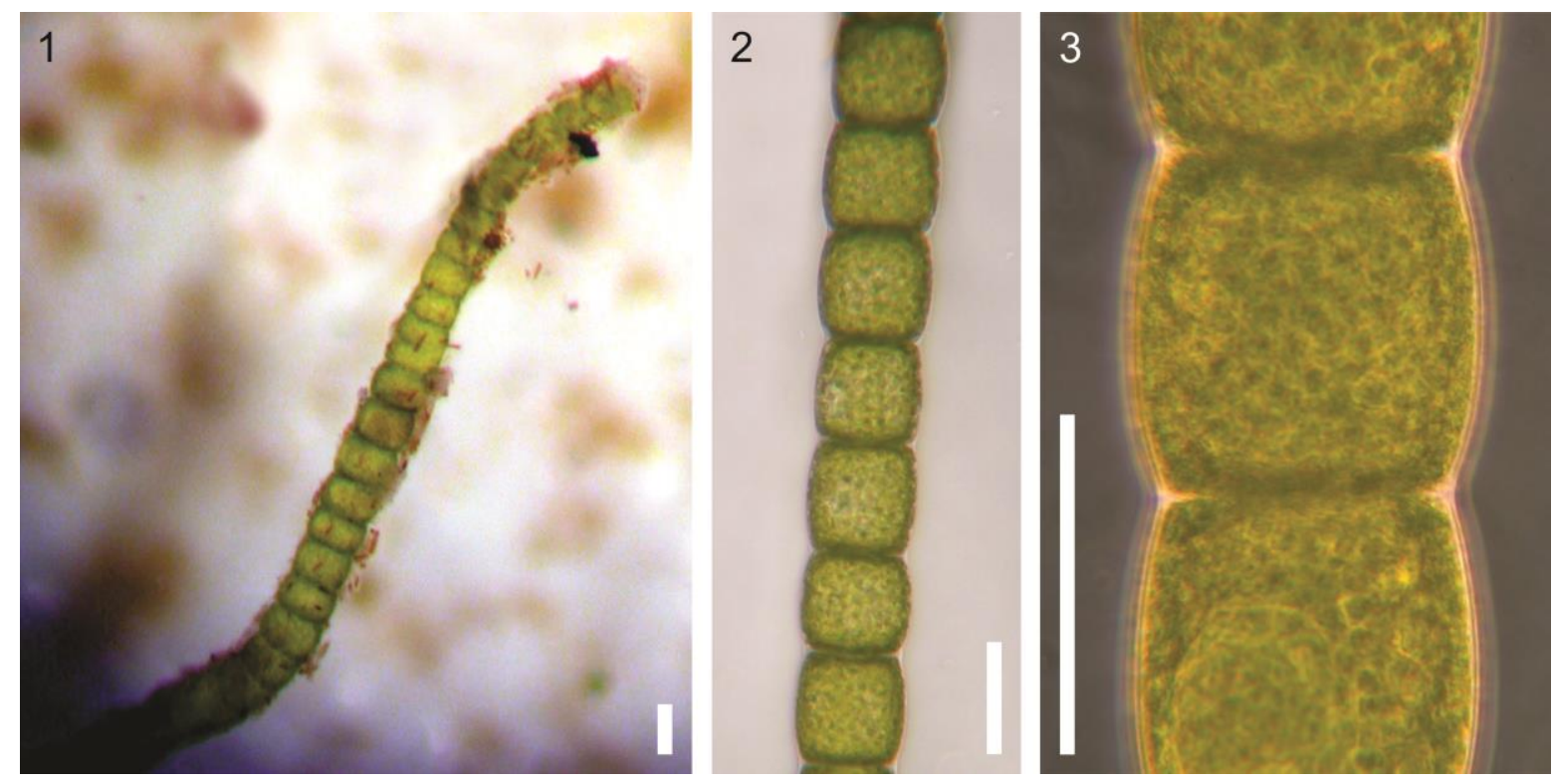

Lámina XXXVII. Urospora penicilliformis. Fig. 1. Filamento fijo al sustrato. Fig. 2. Porción de un filamento mostrando células cilíndricas o con forma de barril. Fig. 3. Detalle del filamento anterior; nótese el cloroplasto reticulado y numerosos pirenoides. Todas las escalas corresponden a $100 \mu \mathrm{m}$.

\subsubsection{Consideraciones finales}

En este capítulo se abordó el estudio de las microalgas y macroalgas desarrolladas en procesos de colonización y sucesión en un ambiente submareal antártico de caleta Potter. Se registraron un total de 40 taxa de diatomeas y 13 taxa de macroalgas. De cada taxón se realizó una caracterización taxonómica acompañada de breves comentarios y discusiones.

\subsubsection{Diatomeas}

Del análisis sistemático y taxonómico de las diatomeas, la clase Bacillariophyceae presentó el mayor número de géneros (14) con un total de 26 taxa. El género Cocconeis estuvo representado por el mayor número de especies (ocho).

Entre los grupos de mayor representación en las muestras se observaron formas típicamente bentónicas, que se adherien al sustrato, incluyendo formas coloniales que alcanzaron dimensiones macroscópicas (como el caso de A. brevipes, $F$. islandica var. adeliae, $F$. striatula y $P$. delognei), grupos pedunculados (como $P$. kamtsachaticum y las especies del género Licmophora) y grupos adnatos, de firme adhesión al sustrato a través de la mayor parte de la superficie valvar, como las especies del género Cocconeis (Tabla 3.1, Fig. 3.2).

Navicula perminuta es la única especie que estuvo presente en la totalidad de las muestras analizadas (Fig. 3.2). En algunos casos, resultando la especie dominante (> 50\% de la abundancia relativa, Figs. 3.2 y 3.3, Apéndice 3.1). Esta especie es común en la 
formación de biofilms (Bowden et al. 2007), y habitualmente se halla adherida a sustratos intermareales y como epifita de macroalgas en la Antártida (Zacher et al. 2007b, Majewska et al. 2016).

Del total de los taxa, algunos fueron registrados con una muy baja presencia (raros a excepcionales) por lo que no fue posible determinar fehacientemente su posición taxonómica. Tal fue el caso de Entomoneis sp., Pleurosigma sp., Petroneis sp. y tres taxa sólo observados en preparados transitorios: Navicula sp., Cocconeis $s p$. y Corethron sp., no incluyéndose una diagnosis de estos tres últimos taxa.

Se crearon tres complejos para agrupar aquellas especies difíciles de reconocer en los conteos con microscopía óptica en preparados transitorios. Ellos fueron: "complejo $C$. fasciolata/costata", "complejo C. melchiori/dallmannii/melchioroides" y "complejo $F$. islandica/striatula".

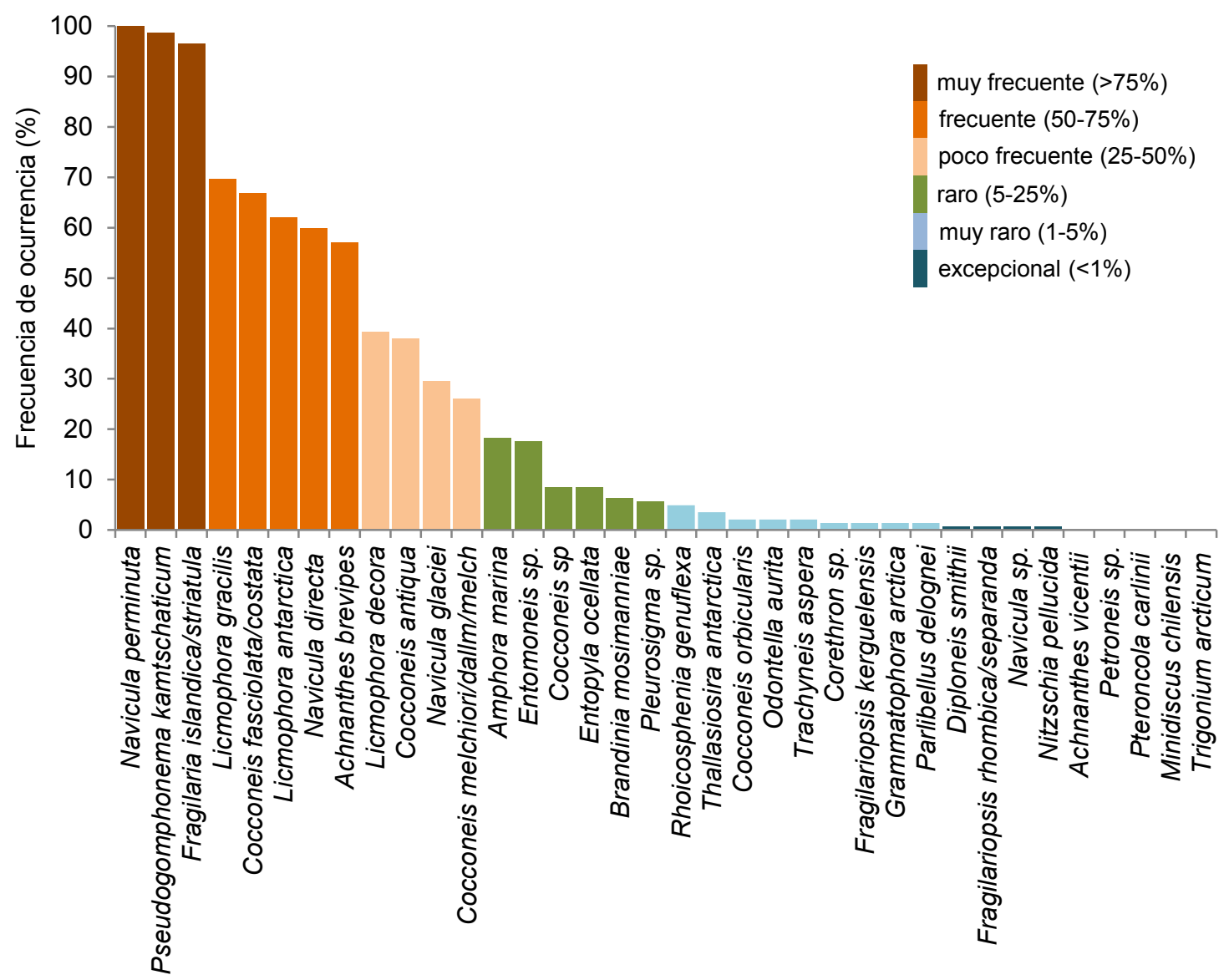

Fig. 3.2. Frecuencia los taxa de diatomeas hallados respecto a la totalidad de las muestras analizadas. 


\section{Primeros registros en caleta Potter}

Se registraron por primera vez para ambientes bentónicos de caleta Potter las especies $A$. vicentii, B. mosimanniae, C. orbicularis, F. islandica var. adeliae, F. kerguelensis, N. glaciei, $P$. carlinii y $T$. antarctica. No se incluye a $M$. chilensis como primera cita porque a juzgar por las ilustraciones de M. trioculatus que presentan Al-Handal \& Wulff (2008a, p 60, Figs. 52-53) esta entidad es M. chilensis (Quiroga \& Chrétiennot-Dinet 2004).

\section{Consideraciones taxonómicas}

Dada la alta variabilidad morfológica que presenta $N$. perminuta y la limitada diferencia que existe con la especie Navicula australoshetlandica recientemente creada para ambientes salobres y de agua dulce en Antártida (Van de Vijver et al. 2011) se sugiere que son necesarios futuros estudios moleculares-filogenéticos a fin de corroborar su real identidad.

A pesar de que $T$. arcticum es una especie muy similar a $T$. curvatus recientemente creada para Antártida (Nair et al. 2018). Según Nair et al (2015), T. arcticum no posee procesos labiados centrales y utilizan este criterio básico para diferenciarlo de la especie creada por ellos. Sin embargo, tal como han demostrado otros autores (Hoban 1983, Ferrario \& Ferreyra 1984), T. arcticum posee procesos labiados centrales en gran número (más de 25).

\section{Variación temporal de la composición del microfitobentos}

Si bien no fue el objetivo de este capítulo realizar un análisis profundo de los ensambles de diatomeas (abordado en detalle en el Capítulo 5), cabe destacar algunos patrones generales observados. En la Fig. 3.3 se muestran las variaciones mensuales en las abundancias relativas y la densidad de los taxa entre abril 2004 y enero 2005.

Las diatomeas estuvieron presentes en todas las muestras colectadas a lo largo del año, lo cual también se observó en estudios anuales realizados en ambientes de fondos rocosos antárticos (Brêthes et al. 1994). Los ensambles estuvieron dominados por $N$. perminuta, el único taxón que presentó abundancias relativas porcentuales superiores al 50 $\%$ durante todo el período del estudio (Fig, 3.3a). Como hemos mencionado, esta especie de pequeñas dimensiones es muy abundante en ambientes bentónicos rocosos antárticos (Zacher et al. 2007b, Majewska et al. 2016). Además, P. kamtschaticum y los complejos $C$. fasciolata/costata y $F$. islandica/striatula presentaron contribuciones importantes a la abundancia relativa, aunque variables entre meses. En particular, los taxa mencionados y $C$. antiqua estuvieron presentes en todas las ocasiones de muestreo. La contribución de los taxa típicamente planctónicos tales como $T$. antarctica (presente en abril y agosto), y las especies del género Fragilariopsis (presentes en septiembre y noviembre) fue esporádica y con muy bajas abundancias relativas (y densidad de células, Apéndice 3.1) por lo que se 
evidenció una relativamente baja contribución del plancton a los ensambles desarrollados sobre los sustratos artificiales en el fondo rocoso. Esto podría asociarse a que caleta Potter suele tener una biomasa fitoplanctónica baja respecto a otros ambientes costeros antárticos $\left(<2\right.$ mg cl-a m³ ${ }^{3}$ (Schloss \& Ferreyra 2002, Schloss et al. 2008, 2012) durante los meses de primavera y verano, habiéndose detectado sólo recientemente la ocurrencia de blooms fitoplanctónicos de mayor intensidad en esta área (Schloss et al. 2014).

a)

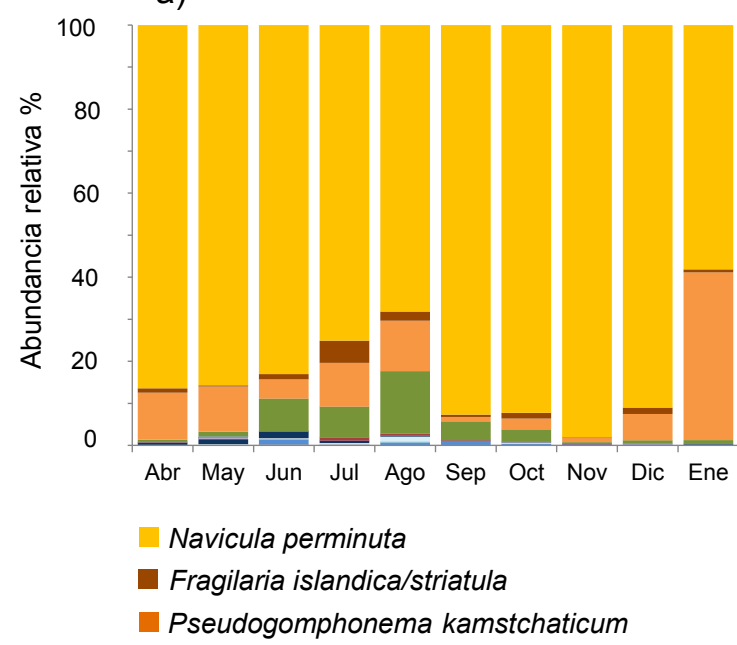

b)

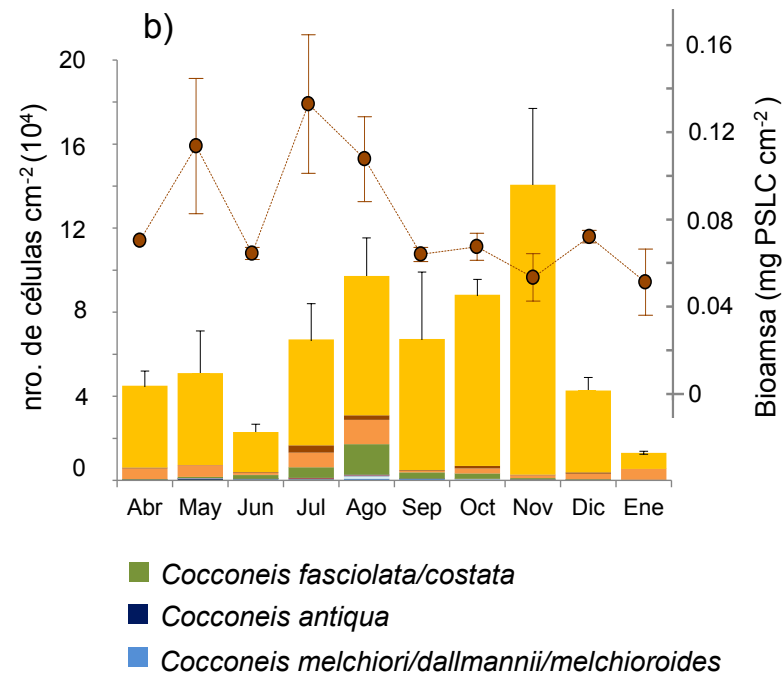

Fig. 3.3. Abundancia relativa porcentual (a) y densidad de taxa de diatomeas (b) expresada como nro. de celulas por centímetro cuadrado (+/- error estándar), entre abril de 2004 y enero de 2005. La leyenda incluye sólo los taxa mas abundantes. Los datos completos se encuentran en el Apéndice 3.1. En (b) se grafican las medias +/- los valores máximos y mínimos de biomasa expresados como peso seco libre de cenizas (PSLC) por $\mathrm{cm}^{2}$, determinados sobre dos placas adicionales. Se determinó el peso seco empleando filtros Whatman GF/F precombustionados y prepesados, según la metodología descripta en el Capítulo 5. EI PSLC se determinó por diferencia entre el peso seco y el peso luego de su combustión a $500^{\circ} \mathrm{C}$ durante cinco horas (Ferreyra et al. 2008).

Asimismo, se observó una tendencia de aumento en la densidad de células, particularmente a partir de junio, reflejado asimismo en los valores de referencia de biomasa (Fig. 3.3b). A partir del mes de junio se produce un aumento en la disponibilidad de luz para las algas bentónicas submareales debido al incremento en la duración del día así como a mayores valores de irradiancia (Wiencke 1990, Quartino 2003, Zacher et al. 2011) lo cual podría asociarse a un aumento en la densidad de células, coincidentemente con el mayor aporte de grupos de diatomeas de mayores dimensiones (tales como el complejo $F$. islandica/striatula, P. kamtschaticum y el complejo C. fasciolata/costata) y los máximos valores de biomasa observados (Fig. 3.3b). En este sentido, si bien las diatomeas bentónicas antárticas están adaptadas a condiciones de muy baja irradiancia (Longhi et al. 2003, Gómez et al. 2011), responden rápidamente a las condiciones de luz favorables con aumentos en la biomasa (Gilbert 1991b, Dayton et al. 1986). Por otro lado, entre los meses 
de agosto y septiembre, los grupos de mayores dimensiones presentaron menores abundancias. Se plantea como hipótesis que el pastoreo por Nacella concinna, el gasterópodo de mayor tamaño en el área de estudio, podría haber causado estos cambios mediados por un consumo no selectivo de todos los grupos algales, durante su migración desde el submareal más profundo hacia el intermareal a fin del invierno y principios de la primavera (Brêthes et al. 1994, Kim 2001, Zacher et al. 2007b). Un estudio más profundo, que incluya el monitoreo mensual de las condiciones ambientales, particularmente la irradiancia subacuática y la determinación de la presencia de consumidores es necesario para profundizar el entendimiento de las variaciones observadas. Los resultados obtenidos sugirieren que para este ambiente, la disponibilidad de luz (que es modificada por la estacionalidad, la presencia de una cobertura de hielo marino, la ocurrencia de blooms fitoplanctónicos y el ingreso de sedimento de origen terrestre) así como una creciente presión de pastoreo a partir de fines del invierno serían factores de importancia en el control de la dinámica de estas comunidades en los fondos rocosos.

\subsubsection{Macroalgas}

Entre los trece taxa de macroalgas hallados en los sustratos artificiales se encontraron tres endémicos dentro de las Phaeophyceae (Heterokontophyta): $P$. antarcticus, A. mirabilis y Desmarestia spp. En el caso de las especies de distribución Subantártica, dos de ellas (G. skottsbergii e I. cordata) correspondientes al orden Gigartinales están actualmente siendo estudiadas a nivel molecular a fin de elucidar si corresponden a taxa diferentes, endémicos para la Región Antártica (Hommersand et al. 2009). Particularmente, cabe destacar la importancia del registro de macroalgas en estadios iniciales y juveniles.

Asimismo, se registraron por primera vez para caleta Potter $U$. flacca y $R$. cf purpureum.

El análisis de la presencia y abundancia de las especies de macroalgas halladas se realiza en detalle en los Capítulos 4 y 5 de esta Tesis. 
CAPÍTULO 4

\section{Patrones sucesionales de algas marinas bentónicas a largo plazo}




\subsection{INTRODUCCIÓN}

\section{Conceptos generales}

La sucesión puede ser definida como el reemplazo de especies durante la recolonización luego de un disturbio o de la creación de nuevo espacio (Connell 1987, Sousa \& Connell 1992, Mc Cook 1994, Platt \& Connell 2003, Noël et al. 2009). Este término fue utilizado en sentido ecológico por primera vez por Dureau de la Malle en 1825 pero su desarrollo conceptual a través de la teoría clásica de sucesión fue realizado por Clements (1916), quien postula a la sucesión como un proceso determinista, que culmina en una etapa estable, denominada "climax" (Vargas Abarzúa \& Zúñiga Molinier 2010, Terradas 2001). Las líneas de investigación posteriores contribuyeron a visualizar a la sucesión como un proceso ordenado, direccional y previsible, con modificaciones en atributos estructurales y funcionales de las comunidades, de modo general, con tendencias hacia aumentos en la biomasa y la diversidad, cambios en la abundancia relativa (o reemplazo) de especies de selección de tipo $r$ por especies de selección de tipo $K$, y como un proceso tendiente a la maximización de la complejidad, de la autoorganización y de la eficiencia energética (Odum 1969, Margalef 1991). El único mecanismo implicado para el devenir de la sucesión (o para el reemplazo de especies) en este modelo clásico era el de la facilitación; más tarde Connell \& Slatyer (1977) incluyen los mecanismos de inhibición y tolerancia describiendo cómo el resultado neto de los efectos de las especies pioneras sobre las tardías (o la falta de interacciones) conducen las trayectorias sucesionales. Sin embargo, estos mecanismos representarían extremos de un continuo, y las fuerzas y direcciones de estas interacciones pueden ser variables dentro de una secuencia sucesional (Connell et al. 1987).

En la década del ochenta, la teoría ecológica incorporó al disturbio como parte insoslayable de la sucesión y a la dinámica de parches como resultante del tiempo transcurrido desde el disturbio (Sousa 1979, 2001, Pickett \& White 1985). Recientemente, Meiners et al. (2015) señalaron la importancia de estudiar los múltiples factores que actúan como conductores o fuentes de variación de este proceso, tales como las características del sitio y su historia o régimen de disturbios, la disponibilidad de especies y la performance de las mismas a escalas mayores, en un contexto evolutivo y geográfico.

\section{Procesos sucesionales en ambientes marinos bentónicos}

El trabajo experimental realizado en ambientes marinos de sustrato rocoso ha contribuido a entender a la sucesión como un proceso continuo, cuyas trayectorias son susceptibles de ser modificadas por factores físicos y procesos o interacciones biológicas (Dayton 1971, Lubchenco 1983, Farrel 1991, Benedetti Cecchi 2000, Nöel et al. 2009, Hurd et al. 2014). Incluso se han aplicado conceptos más amplios de sucesión, definida como un cambio en 
los patrones de composición y estructura de los ensambles luego de que se genera nuevo sustrato, apoyando la idea de que cada sucesión es un evento particular que incluso incluye cambios no direccionales (Platt \& Connell 2003, Maggi et al. 2011).

En los fondos marinos rocosos la colonización biológica del sustrato comienza con la aparición de bacterias, algas unicelulares, propágulos de macroalgas y larvas de invertebrados (Connell 1987, Wahl 1989). Luego alcanzan desarrollo las diatomeas, y las algas filamentosas y foliosas pueden monopolizar el espacio, en el que a continuación se establecen algas cespitosas o invertebrados sésiles; finalmente, aparecen algas perennes, de formas complejas que forman canopeo o macroinvertebrados sésiles de mayor tamaño (Nöel et al. 2009). Sin embargo, a una escala espacial algo mayor, coexisten parches en distintas etapas de recolonización mediadas por la intensidad y frecuencia de los disturbios (Sousa 2001). El patrón de recolonización luego de un disturbio dependerá de la disponibilidad e identidad de los propágulos y su distancia de dispersión (Jenkins et al. 2009), del tamaño del parche creado, del momento en que se produce el disturbio y del pastoreo, entre otros factores (Sousa 1984, Farrel 1991, Benedetti Cecchi 2000, Hurd et al. 2014).

Estos procesos han sido principalmente estudiados en intermareales de ambientes templados y tropicales, mientras que las trayectorias sucesionales en ambientes submareales ha recibido menos atención (ver compilaciones en Connell 1987, Sousa 2001, Noël et al. 2009, Hurd et al. 2014). En estos últimos, la heterogeneidad del hábitat (Pacheco et al. 2010), la productividad del ambiente (Pacheco et al. 2011) y la composición de la comunidad bentónica circundante (Uribe et al. 2015) pueden determinar la composición de los ensambles de las etapas sucesionales.

Los ciclos de vida de las macroalgas incluyen propágulos unicelulares (cigotas, esporas o gametas), que se dispersan, establecen y fijan al sustrato, desarrollándose en un nuevo individuo (Clayton 1992), luego de sobrevivir a grandes mortandades antes y después de establecerse (Schiel \& Foster 2006, Hurd et al. 2014). Los estadios iniciales y juveniles son muy sensibles a factores de estrés ambiental y pueden ser afectados negativamente por el pastoreo y la competencia (Santelices 1990, Amsler et al. 1992, Jenkins et al. 2009) por lo que resulta complejo predecir las trayectorias sucesionales una vez que se genera sustrato nuevo (Hurd et al. 2014). Sin embargo, se observa con cierta regularidad que la sucesión de las macroalgas puede implicar una transición desde ensambles formados por especies efímeras hacia comunidades compuestas por algas que forman canopeo (Noël et al. 2009). Las formas oportunistas, representativas de las comunidades jóvenes ocupan rápidamente el espacio nuevo, son efímeras, anuales o pseudoperennes, poseen baja biomasa y rápido crecimiento, mientras que las formas características de etapas maduras son perennes, tienen crecimiento más lento, poseen sustancias de reserva y defensas químicas, entre 
otras características (Littler \& Littler 1980, Nöel et al. 2009, Hurd et al. 2014). Asimismo, las especies pioneras y las tardías pueden asociarse a las diferentes estrategias de vida propuestas por Kain (1989). Las especies pioneras, generalmente unicelulares o filamentosas, presentan características coincidentes con las de las algas de respuesta estacional (season responders), dado que su crecimiento responde a condiciones ambientales favorables - tales como un aumento en la disponibilidad de luz - con una estrategia de vida oportunista (Wiencke et al. 2007). Las especies tardías corresponderían al grupo de las anticipadoras estacionales (season anticipators), en las que el crecimiento y la reproducción se sincronizan con el fotoperíodo (Lüning \& tom Dieck 1989), su crecimiento es relativamente más lento, y producen sustancias de reserva que pueden ser utilizadas durante el invierno, cuando las condiciones de luz son menos favorables (Kain 1989).

\section{Procesos sucesionales en el bentos antártico}

El bentos antártico está sometido a disturbios mediados por la abrasión por hielo, originando procesos de recolonización que causan la coexistencia de parches de distinto grado de desarrollo (Gutt 2001, Barnes \& Conlan 2007, Teixidó et al. 2007). La escasa información existente sobre los patrones sucesionales proviene de estudios enfocados en comunidades de fauna sésil (Barnes et al. 1996, Stanwell-Smith \& Barnes 1997, Bowden et al. 2006, Teixidó et al. 2007, Lagger et al. 2018) y, particularmente en ambientes de fondos blandos (Dayton et al. 2016). Estos estudios observaron i) una cobertura muy baja del sustrato aun luego de tres años $(<10 \%)$, postulando procesos sucesionales relativamente predecibles, como resultado de un lento crecimiento de los organismos y de una elevada estacionalidad ambiental (Bowden 2005, Bowden et al. 2006), ii) la ocurrencia de grandes cambios interanuales asociados a eventos episódicos de colonización masiva (Dayton 1989, Dayton et al. 2016), iii) una rápida colonización por algunas especies luego del colapso de barreras de hielo (Raes et al. 2010, Gutt et al. 2011, Fillinger et al. 2013) y iv) el hallazgo de comunidades complejas en nuevas áreas libres de hielo, en las que se discute su tiempo de colonización no habiéndose establecido si se desarrollaron durante años bajo el hielo o fueron de reciente colonización (Lagger et al. 2017, 2018). Sin embargo, prevalece como paradigma para los ensambles de invertebrados bentónicos en la Antártida la lentitud de los procesos ecológicos de colonización y sucesión (Lagger et al. 2018).

Estudios recientes realizados en nuevas áreas libres de hielo generadas luego del retroceso glaciar en áreas costeras demostraron la capacidad de las macroalgas para colonizar estos sitios, revelando que la complejidad de las comunidades se relaciona positivamente con el tiempo transcurrido desde la generación de espacio, y con el nivel de estrés y disturbio impuesto por la proximidad al glaciar en retroceso (Quartino et al. 2013, Deregibus 2017). Sin embargo, no existen estudios sobre los patrones de sucesión primaria 
de algas bentónicas en ambientes submareales antárticos, principalmente desarrollados a largo plazo y con observaciones continuas durante los meses de otoño e invierno (Campana et al. 2017).

El objetivo de este capítulo fue describir atributos estructurales de la comunidad de algas marinas bentónicas en el curso del proceso de sucesión primaria, a lo largo de cuatro años. Los objetivos específicos fueron:

- Analizar la composición taxonómica de algas marinas bentónicas presentes en el curso de este proceso.

- Determinar los cambios en la cobertura, riqueza, equitatividad y diversidad en el tiempo.

- Analizar los cambios en la composición de las comunidades en el tiempo.

Para ello, se estudiaron los patrones sucesionales en un ambiente submareal antártico mediante la instalación de sustratos artificiales, que fueron observados en detalle durante los meses de primavera y verano, y mensualmente a través de imágenes fotográficas. La sucesión primaria se evaluó en términos de la ocurrencia de cambios significativos en la identidad y abundancia de los taxa en el tiempo (Foster et al. 2003, Maggi et al. 2011).

\subsection{MATERIALES Y MÉTODOS}

\section{Monitoreo de variables ambientales}

En Peñón de Pesca (Cap. 2, Figs. 2.1 y 2.3) se realizaron mediciones de temperatura, salinidad, PAR, UV-A y UV-B en la columna de agua con una frecuencia aproximadamente mensual, entre enero de 2009 y febrero de 2012.

Las mediciones de PAR se realizaron mediante un radiómetro LI-COR (LI 1400, Lincoln, Estados Unidos) provisto de un sensor subacuático para PAR LI-192 (Lincoln, Estados Unidos). Las mediciones de UV-A y UV-B se realizaron con un radiómetro Solar Light (PMA 2100, Solar Light Co. Inc., Philadelphia, Estados Unidos), provisto de sensores de banda ancha para UV-A (PMA2110-UW) y UV-B (PMA2106-UW). A partir de estos datos, se determinó el coeficiente de atenuación de la luz $\left(\mathrm{K}_{\mathrm{d}}\right)$ asumiendo una reducción exponencial de la irradiación, según Kirk (2011), como:

$$
\operatorname{Ln} I_{z}=-K_{d} x z+L n I_{0} \quad \text { (ecuación 4.1) }
$$


donde $I_{z}$ es la irradiancia a la profundidad $z$ (en metros) e $I_{0}$ es la irradiancia incidente inmediatamente debajo de la superficie del agua. Los valores bajos de $\mathrm{K}_{\mathrm{d}}$ se asocian a una menor atenuación de la irradiancia, mientras que los valores elevados se asocian a aguas con mayor turbidez y mayor extinción de la luz (Kirk 2011).

El coeficiente de atenuación de PAR se calculó a partir de mediciones realizadas a 0 $\mathrm{m}$ (inmediatamente debajo de la superficie del agua) y a $10 \mathrm{~m}$. Los coeficientes de extinción para UV-A y UV-B se calcularon a partir de la regresión lineal del logaritmo natural de $I_{z}$ respecto a la profundidad (ecuación 4.1), midiendo la irradiancia a intervalos de $1 \mathrm{~m}$. Asimismo, se determinó la profundidad a la cual la irradiancia incidente es atenuada un $10 \%$ $\left(Z_{10 \%}\right)$ (Hargreaves 2003).

La temperatura y la salinidad fueron registradas mediante un CTD Seabird SEB19 Plus v2 (Sea-Bird Electronics, Washington, Estados Unidos). Las condiciones superficiales de la columna de agua se expresaron como el promedio de mediciones continuas realizadas entre $0,5 \mathrm{~m}$ y $10 \mathrm{~m}$ de profundidad según Schloss et al. (2012).

Todas las variables ambientales se registraron, de ser factible, el mismo día en horas del mediodía. El monitoreo de PAR se realizó con mayor frecuencia, particularmente durante primavera y verano. La totalidad de fechas de toma de variables ambientales en Peñón de Pesca se detalla en el Apéndice 4.1. Para el año 2008 se emplearon los datos de temperatura y salinidad correspondientes a un sitio ubicado en la caleta externa, en proximidad al sitio de estudio (Schloss et al. 2012).

Los datos de temperatura del aire corresponden a las mediciones realizadas en la estación meteorológica del Servicio Meteorológico Nacional (SMN) de la Fuerza Aérea Argentina ubicada en la Base Carlini, a $10 \mathrm{~m}$ sobre el nivel del mar. Las temperaturas medias mensuales fueron calculadas como el promedio de las mediciones de temperatura media diaria durante el período experimental (Schloss et al. 2012, 2014, Bers et al. 2013). La presencia de hielo marino fue registrada a través de observaciones directas en terreno, desde la Base Carlini, por los científicos invernantes.

\section{Diseño y muestreo de las comunidades}

En el submareal de Peñón de Pesca se instalaron, mediante buceo autónomo, 53 sustratos de polietileno blanco levemente rugoso de $20 \mathrm{~cm} \times 25 \mathrm{~cm}$. Los sustratos artificiales fueron fijados al sustrato rocoso mediante brocas instaladas previamente con un rotopercutor subacuático Atlas DKR 36R (Atlas Copco AB, Suecia). Cada sustrato contenía una perforación en la parte superior central, que se ubicó en la broca, y se ajustó a ella mediante una tuerca y arandela ambas de acero inoxidable (Fig. 4.1). Los sustratos fueron numerados para permitir su identificación. La instalación se realizó entre el 17 y el 26 de febrero de 2008, a aproximadamente $3 \mathrm{~m}$ de profundidad. Esta última varió levemente debido a la 
necesidad de encontrar sustrato rocoso adecuado para la fijación de los sustratos artificiales, de modo de que estuvieran potencialmente protegidos de la abrasión por grandes témpanos durante el periodo experimental de cuatro años.

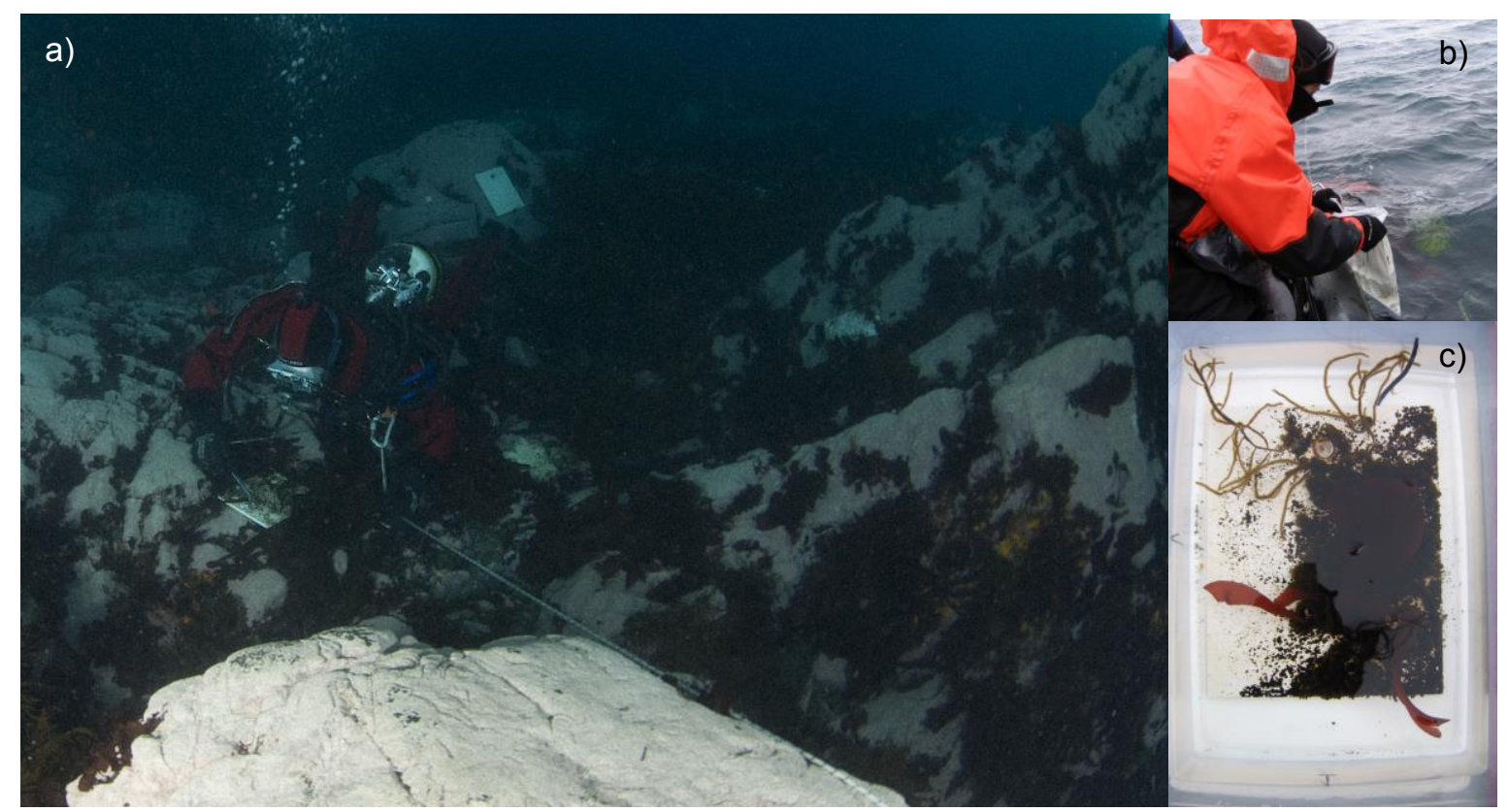

Fig. 4.1. a) Vista subacuática de un muestreo mediante buceo autónomo, b) toma del sustrato en la superficie para su traslado al laboratorio, c) vista de un sustrato artificial colonizado, nótese la perforación en el área superior central. Foto a) M. Mammana.

Se aplicaron dos enfoques para el estudio de la colonización y sucesión de macroalgas:

1. Análisis fotográficos, realizados durante todo el período experimental y de frecuencia aproximadamente mensual.

2. Análisis en condiciones de laboratorio de los sustratos colonizados, realizados en primavera y verano, que permitieron la identificación de individuos de menor tamaño y el registro de la presencia de algas cuando existieron varias capas superpuestas debido al canopeo.

Para ambos métodos de análisis, en cada oportunidad de muestreo, se retiraron mediante buceo autónomo cinco sustratos al azar que fueron colocados en bolsas Ziploc. Luego del análisis, los sustratos se reubicaron en su posición original de emplazamiento. En el Apéndice 4.1 se enumeran los muestreos realizados por ambos métodos. En el análisis de los resultados, se referirá como "año 1" al periodo comprendido entre la instalación y 12 meses de colonización (febrero de 2008 a febrero de 2009), "año 2" al período entre 13 y 24 
meses de colonización (marzo de 2009 a febrero de 2010), "año 3" al período entre 25 y 36 meses de colonización (marzo 2010 a febrero 2011) y "año 4" entre 37 y 48 meses de colonización (marzo 2011 a febrero 2012).

\section{Análisis fotográficos mensuales}

Los muestreos fotográficos se iniciaron luego de 12 meses de colonización, en febrero de 2009 y se continuaron mensualmente hasta febrero de 2012, luego de cuatro años de iniciada la colonización. Debido a restricciones climáticas o logísticas no se realizaron algunos muestreos, particularmente durante el invierno.

Cada sustrato fue fotografiado de manera estandarizada en el bote, en condiciones de baja iluminación. De ser necesario, las fotografías digitales fueron corregidas mediante pequeñas rotaciones empleando el programa Corel DRAW X5. El análisis del porcentaje de cobertura de cada sustrato se realizó mediante el programa de uso libre Coral Point Count with Excel extensions (CPCe) (Kohler \& Gill 2006). El porcentaje de cobertura total y de cada taxa se realizó mediante la superposición de una grilla de 100 puntos, de $16 \mathrm{~cm} \times 16 \mathrm{~cm}$, dejando un margen en el borde de aproximadamente $2 \mathrm{~cm}$. Se asignó un $1 \%$ de cobertura a cada taxón $>2 \mathrm{~mm}$ (o film visible, para el caso de las diatomeas) que coincidió con un punto de la grilla. Los taxa fuera de la grilla no fueron considerados.

\section{Análisis en condiciones de laboratorio en primavera y verano}

Los muestreos en condiciones de laboratorio se realizaron durante primavera y verano. Se iniciaron luego de 22 meses de colonización, en diciembre de 2009 y se condujeron hasta febrero de 2012, luego de cuatro años de iniciada la colonización. Mediante este análisis se determinó el porcentaje de cobertura (cobertura total, de macroalgas, de diatomeas, y de cada taxa), se calcularon los índices ecológicos de riqueza, equitatividad y diversidad, y se estudiaron los cambios sucesionales mediante técnicas multivariadas.

Los sustratos muestreados fueron transportados al laboratorio en contenedores frigorizados, en condiciones de oscuridad hasta el Laboratorio Dallmann. Allí se colocaron individualmente en acuarios con agua de mar filtrada (filtro de 0,7 $\mu \mathrm{m}$ de tamaño de poro), aireadores, fotoperiodo natural y condiciones controladas de temperatura durante un período máximo de una semana. El agua de los acuarios fue renovada parcialmente diariamente o cada dos días.

El porcentaje de cobertura se determinó mediante el método de point quadrat (Foster et al. 1991, Kim 2001). Los sustratos se colocaron en un recipiente refrigerado, cubiertos por $5 \mathrm{~cm}$ de agua de mar filtrada $\left(\sim 0^{\circ} \mathrm{C}\right)$. Para la determinación del porcentaje de cobertura se diseñó un "muestreador" que consistía en dos placas de acrílico transparente, colocadas en forma paralela, que contenían una grilla de $16 \mathrm{~cm} \times 16 \mathrm{~cm}$, con 100 perforaciones $(10 \times 10)$ 
de $3 \mathrm{~mm}$ cada una (Fig. 4.2 b). Para evitar efectos de borde (Foster \& Sousa 1985), se muestreó solo la parte central del sustrato $\left(256 \mathrm{~cm}^{2}, 51.2 \%\right.$ de la superficie total), dejando un margen de aproximadamente $2 \mathrm{~cm}$ de distancia al orificio superior y al resto de los lados. Se registraron las macroalgas visibles macroscópicamente y las matas de diatomeas, considerando todos los estratos, es decir, la capa que formó el canopeo y los organismos debajo del mismo. El porcentaje de cobertura se determinó pasando una varilla a través de cada perforación, asignándose un $1 \%$ de cobertura a cada macroalga (o mata de diatomeas) interceptadas por la punta de la varilla. Cuando ocurrieron capas de macroalgas superpuestas, el organismo superior fue cuidadosamente movido a un costado y la varilla se bajó para registrar al organismo que se encontraba debajo. De esta manera, en algunos casos, la superposición resultó en porcentajes de cobertura total que excedieron el 100\%. Las diatomeas fueron incluidas en el análisis cuando existieron matas gruesas o largos filamentos coloniales (mayores a $2 \mathrm{~mm}$ ). Se detectaron films amarronados similares a los analizados para los muestreos fotográficos, pero no fueron analizados en detalle y, por lo tanto, fueron excluidos del análisis, así como las macroalgas cuyo grampón estuvo fuera del área de muestreo.

Los muestreos se realizaron en primavera y verano, durante el "año 2" (luego de 22 y 24 meses de colonización), durante el "año 3" (36 meses de colonización) y el "año 4" (45 y 48 meses de colonización). Debido a restricciones climáticas y logísticas no se pudo realizar este muestreo durante el primer año (primavera y verano) ni en la primavera del segundo año.

Se determinó la riqueza (S) como el número total de especies (o taxa, de acuerdo al nivel taxonómico de la identificación). Las diatomeas se consideraron como un solo taxa. La equitatividad (Índice de Pielou, J') y la diversidad (Índice de Shannon, H') se calcularon empleando el porcentaje de cobertura de cada taxón (Magurran 2004) mediante el programa PRIMER 5 (Plymouth, Estados Unidos).

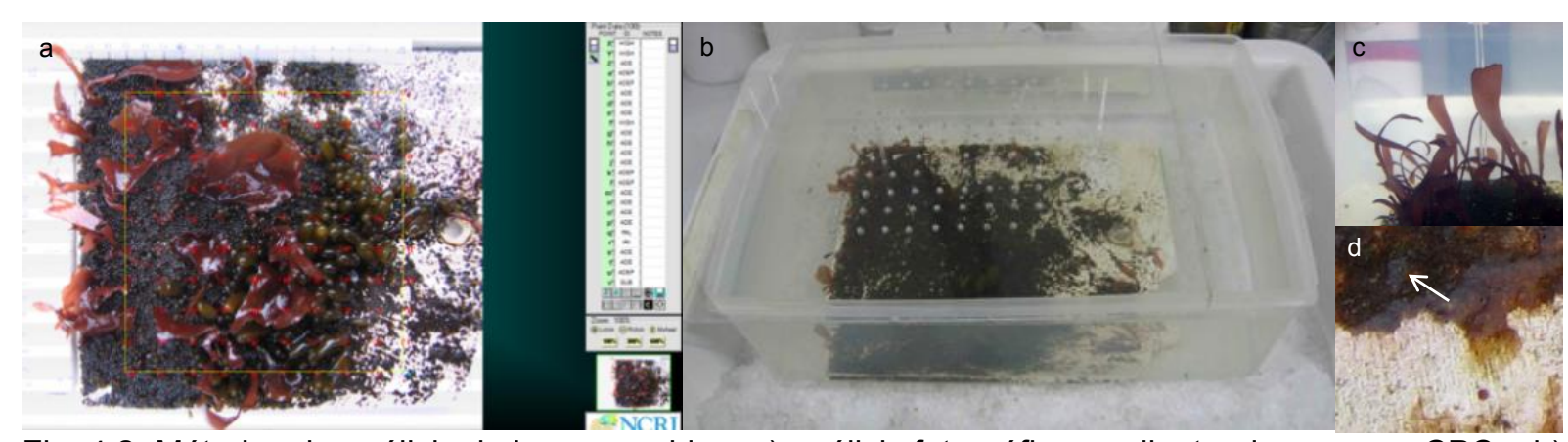

Fig. 4.2. Métodos de análisis de los ensambles. a) análisis fotográfico mediante el programa CPCe, b) muestreo en condiciones de laboratorio, c) detalle del procedimiento de registro de algas de canopeo y taxa subyacentes, d) matas de diatomeas registradas para el muestreo en condiciones de laboratorio. 
El análisis detallado en el laboratorio permite detectar organismos pequeños y registrar el canopeo y los organismos debajo de las capas. Es por ello que todos los análisis estadísticos se realizaron con los datos obtenidos mediante este análisis (Foster et al.1991). Los muestreos fotográficos fueron complementarios en el sentido de que estuvieron enfocados en visualizar los cambios en la composición de las especies mensualmente, a lo largo de todo el año, incluyendo los meses de otoño e invierno.

\section{Análisis estadísticos}

Para evaluar diferencias estacionales (entre primaveras y veranos) e interanuales en las condiciones del ambiente luminoso subacuático, se evaluaron los cambios en el coeficiente de atenuación de PAR ( $\mathrm{K}_{\mathrm{d}}$ PAR) mediante ANOVA de una vía a un nivel de significación de $\alpha=0,05$. Asimismo, el análisis de la cobertura total (todos los taxa presentes), la cobertura de macroalgas, la cobertura de diatomeas, y de los índices ecológicos (riqueza, equitatividad y diversidad) en el tiempo (luego de 22, 24, 36, 45 y 48 meses de colonización) se realizó mediante ANOVA de una vía, a un nivel de significación de $\alpha=0,05$.

La homogeneidad de varianzas fue testeada usando el Test de Cochran (Zar 1996). Los tests Post-Hoc para comparaciones de medias múltiples se realizaron utilizando el Test de Duncan a un nivel de significación $\alpha=0,05$. Se utilizó el programa Statistica 7.0 para los análisis mencionados.

Para detectar cambios en la composición y abundancia de taxa en los diferentes tiempos de colonización, se realizaron análisis multivariados, usando el índice de similitud de Bray Curtis. Este índice se calculó a partir de los datos de porcentaje de cobertura de los taxa, previamente transformados como raíz cuadrada, para disminuir el peso de taxa de elevada abundancia (Clarke \& Warick 2001). Para detectar diferencias entre los ensambles de diferente tiempo de colonización, se realizó un análisis de similitud (ANOSIM), a un nivel de significación de $\alpha=0,05$. Se trata de un procedimiento de permutación no paramétrico que genera un estadístico $\mathrm{R}$, que es una medida de la distancia entre los grupos. Los valores de $\mathrm{R}$ cercanos a 1 indican mayor separación entre grupos y los valores de $\mathrm{R}$ más cercanos a 0 indican mayor similitud entre los grupos analizados (Clarke \& Warick 2001). Los datos de cada año fueron analizados en un mismo grupo, por año (i.e. para el "año 1" se incluyen los muestreos de 22 y 24 meses de colonización y para el "año 3", los muestreos de 45 y 48 meses de colonización). Esto se debió a que, para ambos años, no se registraron diferencias significativas en los ensambles entre estaciones (ANOSIM 22 meses vs 24 meses: $R=-$

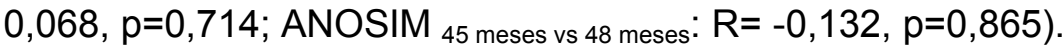

Además, se realizó un análisis de escalamiento no métrico multidimensional (nonmetric multidimensional scaling o nMDS, por sus siglas en inglés) para visualizar el ordenamiento de las muestras. Este análisis permitió ordenarlas en una configuración de 
dos dimensiones, que intenta preservar los rankings de similitud entre muestras (Clarke \& Warick 2001).

Finalmente, se realizó un procedimiento de SIMPER (Porcentaje de Similitud) para cuantificar la contribución relativa de cada taxa a las disimilitudes observadas entre los tiempos de colonización. Es decir, se identificaron los taxa que más contribuyeron a las disimilitudes observadas. Todos los análisis multivariados se realizaron usando el programa PRIMER 5 (Plymouth Marine Laboratory).

\subsection{RESULTADOS}

\section{Monitoreo de variables ambientales}

Durante los meses más cálidos (diciembre, enero y febrero), la temperatura media en la Base Carlini varió entre $0,3^{\circ} \mathrm{C}$ y $2,9^{\circ} \mathrm{C}$. El valor medio de los meses más fríos (julio y agosto) varió entre $-10{ }^{\circ} \mathrm{C}$ y $-3,1{ }^{\circ} \mathrm{C}$ (Fig. 4.3). El congelamiento de la caleta alcanzó al Peñón de Pesca en 2008, 2009 y 2011.

Los valores medios estacionales de la irradiancia subacuática de PAR, UV-A y UV-B se detallan en la Tabla 4.1. Las irradiancias máximas registradas a $3 \mathrm{~m}$ de profundidad en el sitio de estudio fueron de 1033,2 $\mu \mathrm{mol} \mathrm{m}^{-2} \mathrm{~s}^{-1}, 15,54 \mathrm{~W} \mathrm{~m}^{-2}$ y 0,43 $\mathrm{W} \mathrm{m}^{-2}$ para PAR, UV-A y UV-B, respectivamente.

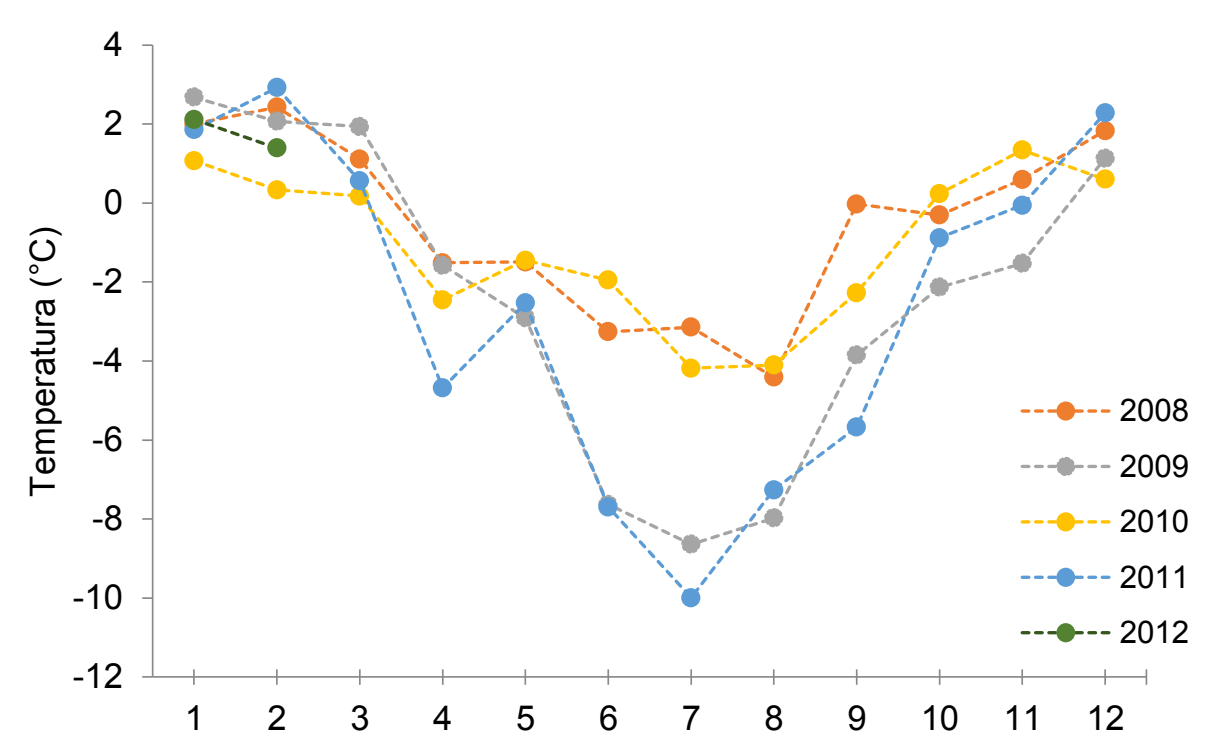

Fig. 4.3. Temperatura media mensual en la Base Carlini durante el periodo experimental (entre enero de 2008 y febrero de 2012), calculadas a partir del promedio de temperaturas diarias para cada mes (datos provistos por la Dra. I. Schloss, según Schloss et al. 2012, 2014 y Bers et al. 2013). 
Tabla 4.1. Irradiancia de PAR, UV-A y UV-B en primavera, verano y otoño en el sitio experimental a 3 $\mathrm{m}$ de profundidad. Se indican las medias +/- el desvío estándar, entre paréntesis el número de mediciones realizadas, y los valores máximos y mínimos registrados entre enero de 2009 hasta el fin del experimento en febrero de 2012.

\begin{tabular}{|c|c|c|c|c|c|}
\hline & Primavera & Verano & & Otoño & \\
\hline PAR $\left(\mu \mathrm{mol} \mathrm{m} \mathrm{m}^{-2} \mathrm{~s}^{-1}\right)$ & $491,92 \pm 181.50$ & $324,87 \pm 96,57$ & (8) & $50,55 \pm 8,54$ & (6) \\
\hline Máximo & 1033,2 & 927,1 & & 118,2 & \\
\hline Mínimo & 258,0 & 22,4 & & 19,9 & \\
\hline UV-A $\left(W m^{-2}\right)$ & $6,62 \pm 1,68$ & $5,58 \pm 1,37$ & $(10)$ & $0,91 \pm 0,15$ & (6) \\
\hline Máximo & 12,6 & 15,54 & & 1,29 & \\
\hline Mínimo & 1,26 & 2,45 & & 0,95 & \\
\hline UV-B $\left(W m^{-2}\right)$ & $0,19 \pm 0.08$ & $0,12 \pm 0,02$ & (9) & $0,02 \pm 0,01$ & (6) \\
\hline Máximo & 0,43 & 0,22 & & 0,04 & \\
\hline Mínimo & 0,05 & $<0,01$ & & 0,01 & \\
\hline
\end{tabular}

En las estaciones cálidas (primaveras y veranos), la profundidad de penetración del $10 \%$ de la radiación incidente fue mayor a 5 metros para PAR y UV-A, y mayor a $3 \mathrm{~m}$ para UV-B (Fig. 4.4). Los valores de $K_{d}$ variaron entre 0,083 y 0,39 para PAR, 0,28 y 0,11 para UV-A y entre 0,75 y 0,26 para UV-B (Fig. 4.5). 

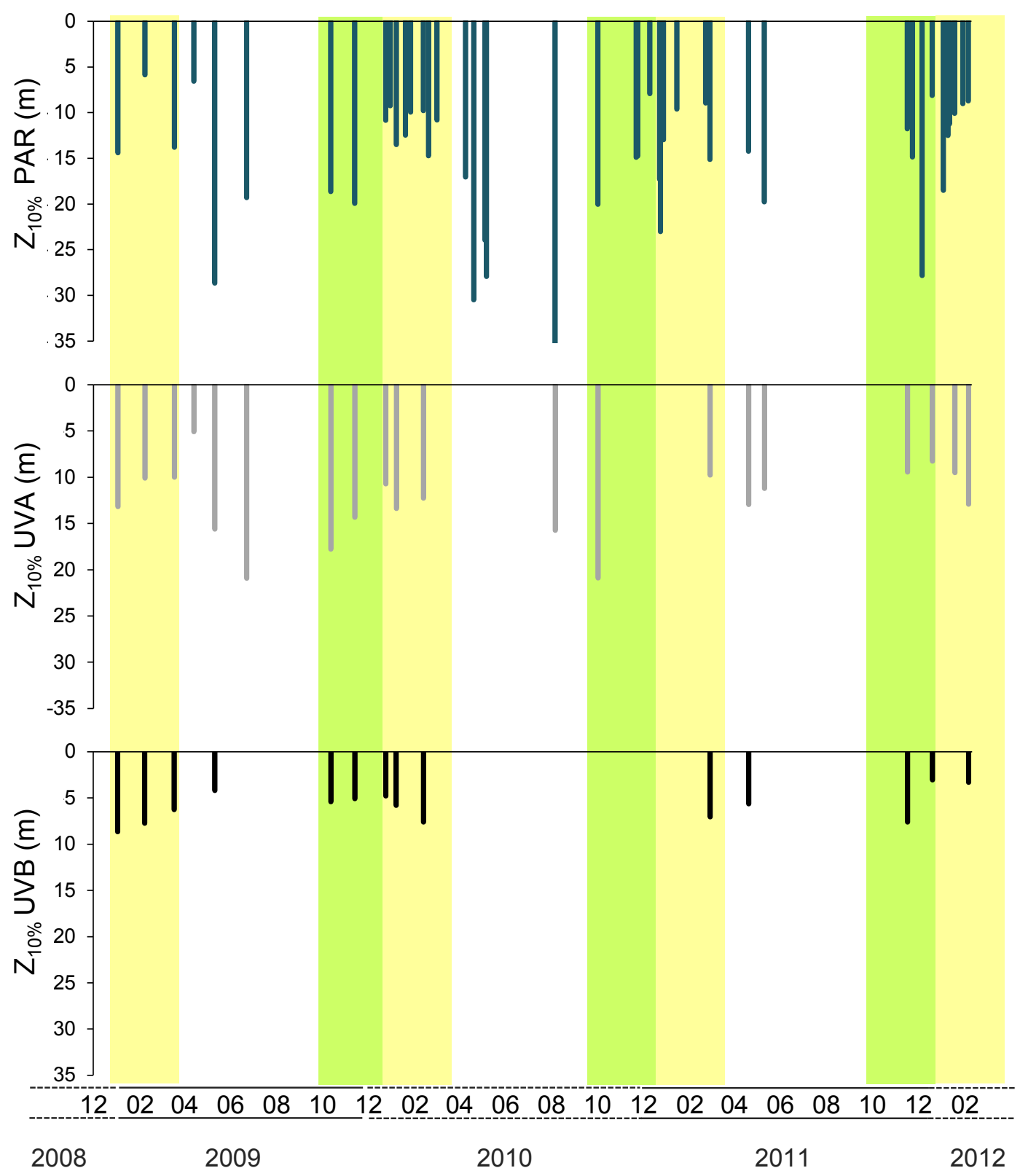

Fig. 4.4. Profundidad de penetración del $10 \%$ de la luz incidente $\left(Z_{10 \%}\right)$ para PAR, UV-A y UV-B en el sitio de estudio, a partir de las mediciones realizadas entre enero de 2009 y febrero de 2012 . Se señalan las estaciones cálidas (los veranos sombreados en amarillo y las primaveras, en verde). 


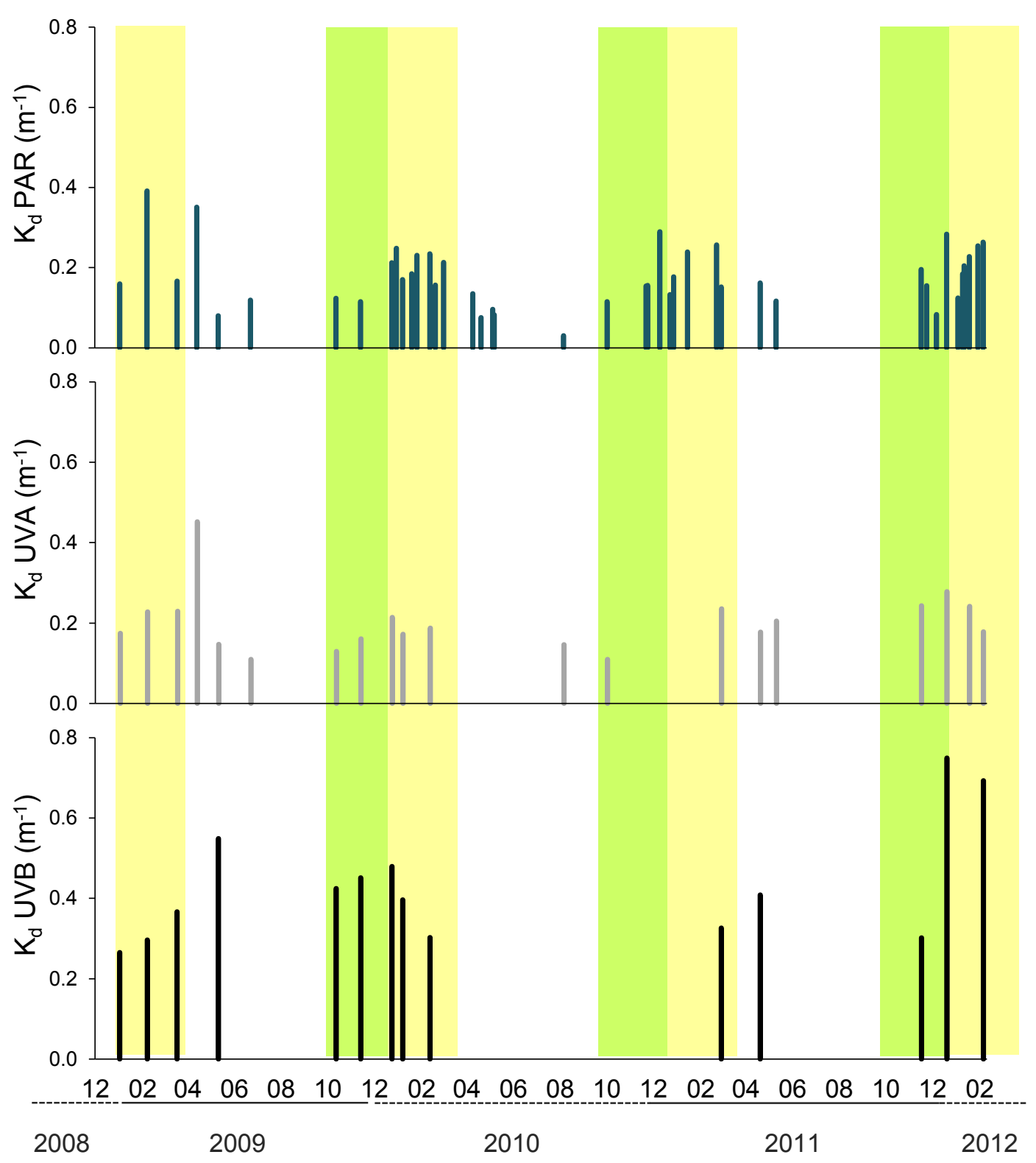

Fig. 4.5. Coeficientes de atenuación de la luz $\left(K_{d}\right)$ de PAR, UV-A y UV-B en el sitio de estudio, calculado a partir de mediciones realizadas entre enero de 2009 y febrero de 2012. Se señalan las estaciones cálidas (los veranos sombreados en amarillo y las primaveras, en verde).

No hubo diferencias en la penetración de la luz entre las mediciones de primavera y verano (ANOVA: $F_{1,31}=3,420, p=0,0739$ ), ni cambios en las estaciones cálidas (primaveras y veranos) entre años (ANOVA: $F_{3,29}=0,469, p=0,706$ ). El análisis separado de las primaveras y los veranos entre años tampoco arrojó diferencias significativas (ANOVA verano: $F_{3,19}=$ 0,754, $p=0,533$, ANOVA primavera: $F_{2,7}=0,485, p=0,635$ ) (Fig. 4.6).

El máximo de temperatura del agua en Peñón de Pesca fue de $2,9^{\circ} \mathrm{C}$ en diciembre 2011 y el mínimo se registró en agosto de 2010 , con $-1.6{ }^{\circ} \mathrm{C}$ (Fig. 4.7). La salinidad varió entre 32,1 psu en agosto 2010 y 34,2 psu, en mayo 2009 (Fig. 4.7). Durante 2008, la 
temperatura y la salinidad medidas en un sitio próximo en la caleta externa variaron entre 1,67 en febrero y $-1,75$ en agosto y entre 33,47 en diciembre y 34,23 en agosto, respectivamente (Schloss et al. 2012).

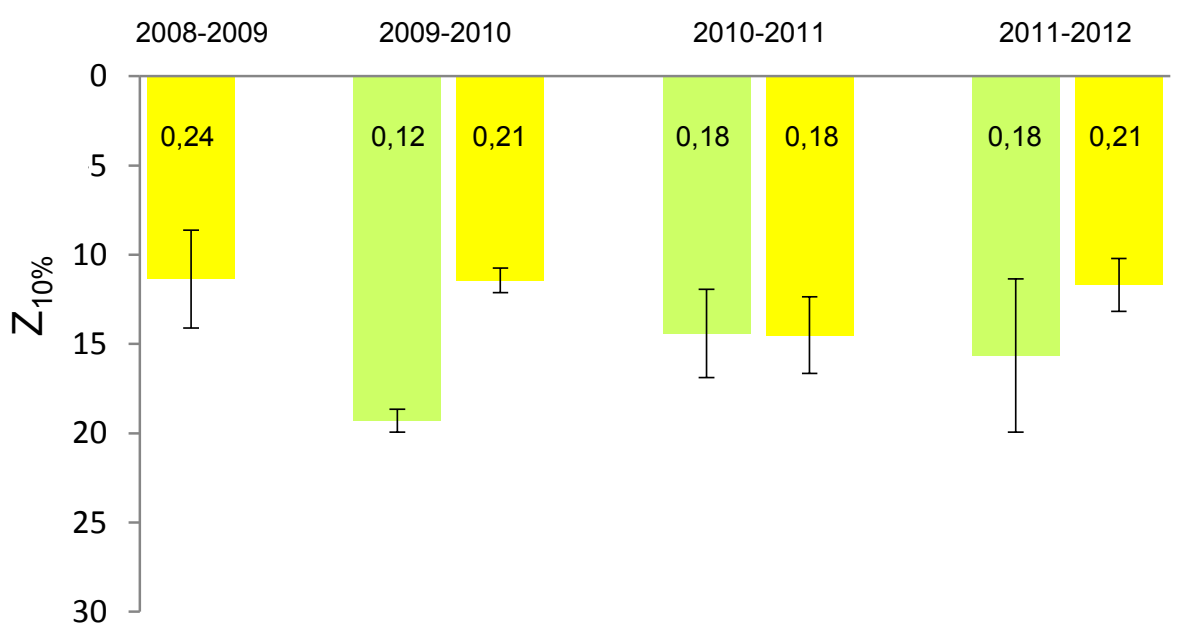

Fig. 4.6. Profundidad de penetración del $10 \%$ de la PAR incidente (Z10\%) para las estaciones cálidas (veranos, en amarillo y primaveras, en verde) Se grafican las medias +/- error estándar de las mediciones realizadas entre enero de 2009 y febrero de 2012. Se indican los coeficientes de atenuación medios $\left(K_{d}\right.$ PAR) dentro de las barras.

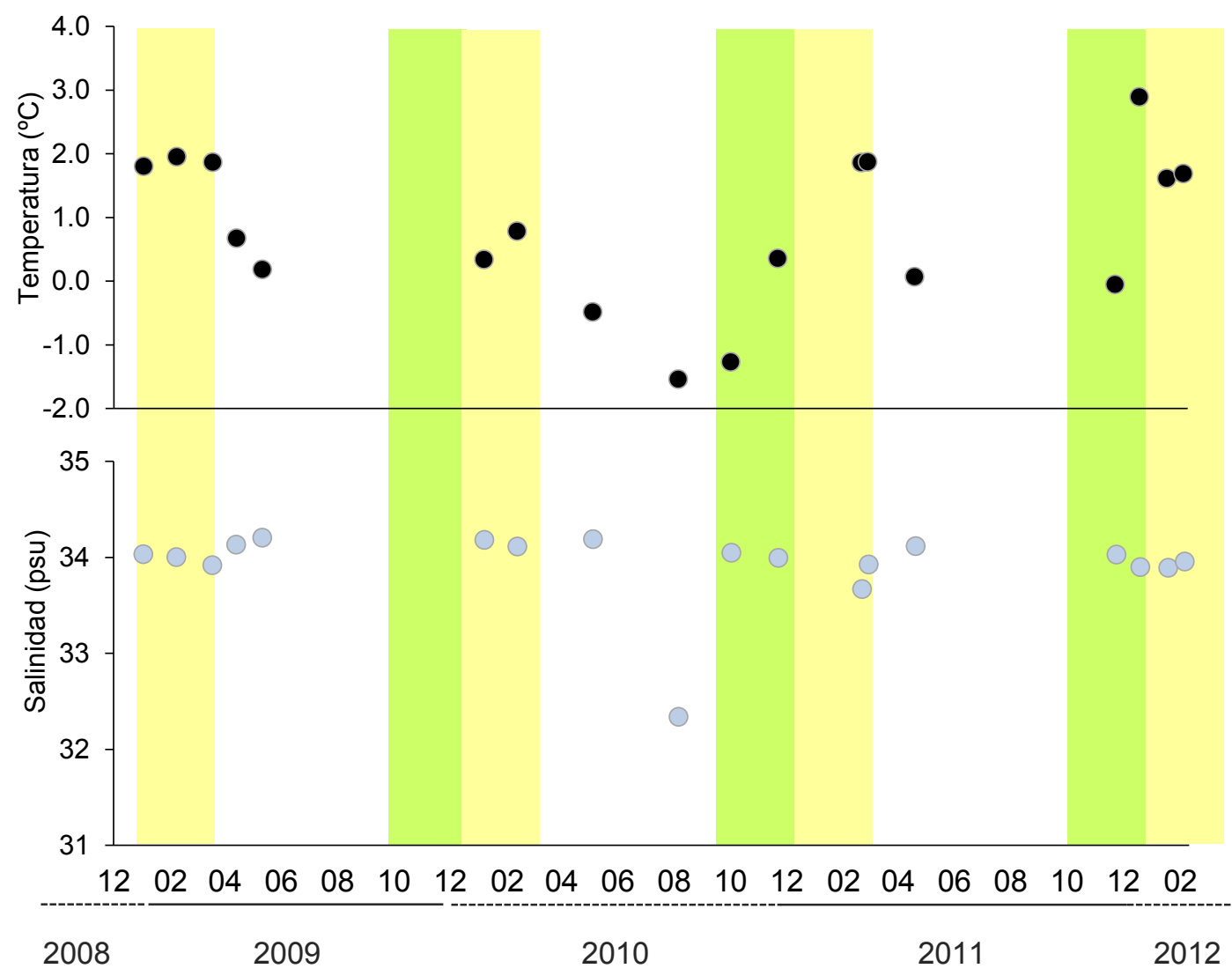

Fig. 4.7. Temperatura y salinidad en Peñón de Pesca para la capa superficial $(0,5$ a $10 \mathrm{~m})$ entre enero de 2009 y febrero de 2012. Se señalan las estaciones cálidas (los veranos sombreados en amarillo y las primaveras, en verde). 


\section{Patrones generales de la composición de especies}

Los ensambles estuvieron dominados por algas, y en particular por macroalgas. Las matas de diatomeas estuvieron compuestas por diatomeas coloniales, principalmente Fragilaria islandica/striatula y Achnanthes brevipes. No se registraron invertebrados sésiles, aunque el macrozoobentos fue muy abundante en la cara del sustrato artificial que se encontraba en contacto con el fondo marino.

Se registraron ocho taxa de macroalgas: una especie de Chlorophyta: Monostroma hariotii, cuatro especies de Phaeophyceae: Adenocystis utricularis, Ascoseira mirabilis, Desmarestia sp. (cf D. anceps/menziesii) y Phaeurus antarcticus, dos especies de Rhodophyta: Iridaea cordata, Palmaria decipiens, y ejemplares de algas rojas crustosas (Corallinaceae, Rhodophyta). Asimismo, se identificaron pequeños estadios juveniles de $P$. decipiens y de $A$. utricularis, además de la fase crustosa de esta última especie, en particular en los análisis de laboratorio de primavera y verano (Cap. 3, Láminas XXIX y XXXIII).

La presencia de cada especie de macroalga en los muestreos y su clasificación de acuerdo al tiempo de vida (en anuales, pseudoperennes o perennes sensu Knight y Parke 1931), estrategia de vida (de respuesta estacional o anticipadoras estacionales sensu Wiencke \& Clayton 2002) y endemismo, se detallan en la Tabla 4.2.

Las especies de macroalgas anuales dominaron los ensambles, con $A$. utricularis presente en cada muestreo y aportando la mayor ocupación del espacio prácticamente durante todo el período experimental (Tabla 4.2, Fig. 4.8c). Monostroma hariotii presentó mayores coberturas en los veranos del año 1 y año 2 y estuvo ausente luego de 27 meses de colonización. Phaeurus antarcticus fue registrada por primera vez en los muestreos fotográficos, con muy baja cobertura luego de dos años de colonización (longitud aproximada de $6 \mathrm{~cm}$ ) y alcanzó una cobertura máxima en los ensambles de 36 meses de colonización, en el verano del año 3 (Fig.4.8c). En este tiempo de colonización formó un canopeo denso y alcanzó una longitud máxima de $120 \mathrm{~cm}$ (longitud media: $61,3 \mathrm{~cm}$ +/- 13,8 d.e.).

Entre las macroalgas pseudoperennes, $P$. decipiens estuvo presente principalmente hasta el tercer año, con muy baja cobertura en los ensambles del último año (Fig. 4.8d). Iridaea cordata fue registrada por primera vez en los muestreos de laboratorio de la primavera del año 2, con muy baja cobertura, y presentó mayores coberturas (y la presencia de organismos de mayor tamaño) en la primavera y el verano del año 4 (Fig. 4.8d). 


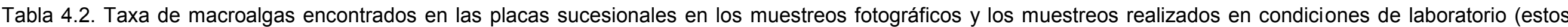

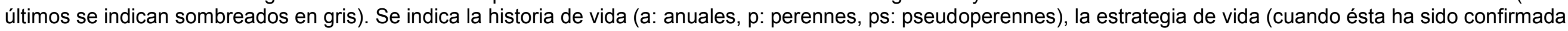

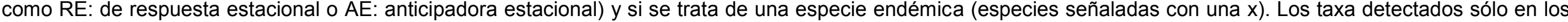

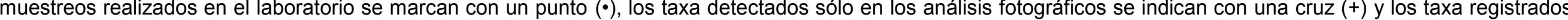

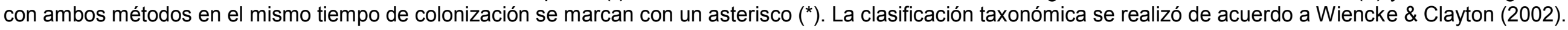

\begin{tabular}{|c|c|c|c|c|c|c|c|c|c|c|c|c|c|c|c|c|c|c|c|c|c|c|c|c|c|c|c|}
\hline \multirow[t]{2}{*}{ Taxa } & \multirow[t]{2}{*}{ 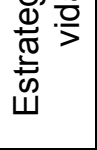 } & \multirow[t]{2}{*}{ 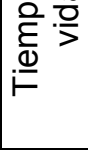 } & \multirow[t]{2}{*}{$\begin{array}{l}\frac{E}{d} \\
\frac{d}{C} \\
\text { W }\end{array}$} & $\stackrel{0}{\stackrel{0}{\Perp}}$ & $\stackrel{\sqrt[\pi]{2}}{2}$ & 量 & $\ddot{\circ}$ & \multirow{2}{*}{\multicolumn{2}{|c|}{$\frac{0}{2}$}} & \multirow[t]{2}{*}{$\stackrel{\oplus}{\Psi}$} & \multirow[t]{2}{*}{ 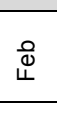 } & \multirow[t]{2}{*}{$\stackrel{\frac{L}{\pi}}{\Sigma}$} & \multirow[t]{2}{*}{ 亳 } & \multirow[t]{2}{*}{$\sum^{\widehat{\pi}}$} & \multirow{2}{*}{$\frac{\subsetneq}{亏}$} & \multirow[t]{2}{*}{$\bar{\jmath}$} & \multirow[t]{2}{*}{ 这 } & \multirow[t]{2}{*}{$\stackrel{\circ}{\infty}$} & \multirow[t]{2}{*}{$\overrightarrow{\mathrm{O}}$} & \multirow[t]{2}{*}{ zo } & $\stackrel{\oplus}{\tilde{\Psi}}$ & \multirow[t]{2}{*}{$\stackrel{0}{\stackrel{0}{\perp}}$} & \multirow[t]{2}{*}{ 产 } & \multirow[t]{2}{*}{$\sum^{\frac{\pi}{2}}$} & \multirow[t]{2}{*}{ ò } & \multirow{2}{*}{$\begin{array}{l}\stackrel{Ð}{\Psi} \\
2012 \\
\end{array}$} & \multirow[t]{2}{*}{$\stackrel{0}{\stackrel{0}{0}}$} \\
\hline & & & & & & 20 & & & & & & & & & & & & & & & 2011 & & & & & & \\
\hline \multicolumn{28}{|l|}{ Phaeophyceae } \\
\hline Adenocystis utricularis & $\mathrm{RE}$ & a & & + & + & + & + & + & * & + & * & + & + & + & + & + & + & + & + & + & + & * & + & + & * & + & * \\
\hline Ascoseira mirabilis & $\mathrm{AE}$ & $\mathrm{p}$ & $x$ & & + & & & & & & & & & & & & & & & & & & & & & & \\
\hline Desmarestia sp. & $\mathrm{AE}$ & $\mathrm{p}$ & $x$ & & & + & & & & & & & & & & & & & & & & & & & & & \\
\hline Phaeurus antarcticus & $\mathrm{AE}$ & a & $x$ & & & & & & & & + & + & + & + & + & + & + & & + & + & + & * & + & + & & & \\
\hline \multicolumn{28}{|l|}{ Rhodophyta } \\
\hline Iridaea cordata & $\mathrm{RE}$ & $\mathrm{sp}$ & & & & & & & $\bullet$ & & * & + & & + & & + & & + & + & + & & & & + & * & & * \\
\hline Palmaria decipiens & $\mathrm{AE}$ & $s p$ & & + & + & + & & + & * & + & * & + & + & + & & + & + & + & + & + & & & & & & & * \\
\hline Corallinaceae & & $p$ & & + & + & + & + & + & * & & * & + & + & + & + & + & + & + & + & + & + & * & + & + & * & + & * \\
\hline \multicolumn{28}{|l|}{ Chlorophyta } \\
\hline Monostroma hariotii & & a & & + & & & & & $\bullet$ & + & * & + & + & + & & & & & & & & & & & & & \\
\hline
\end{tabular}



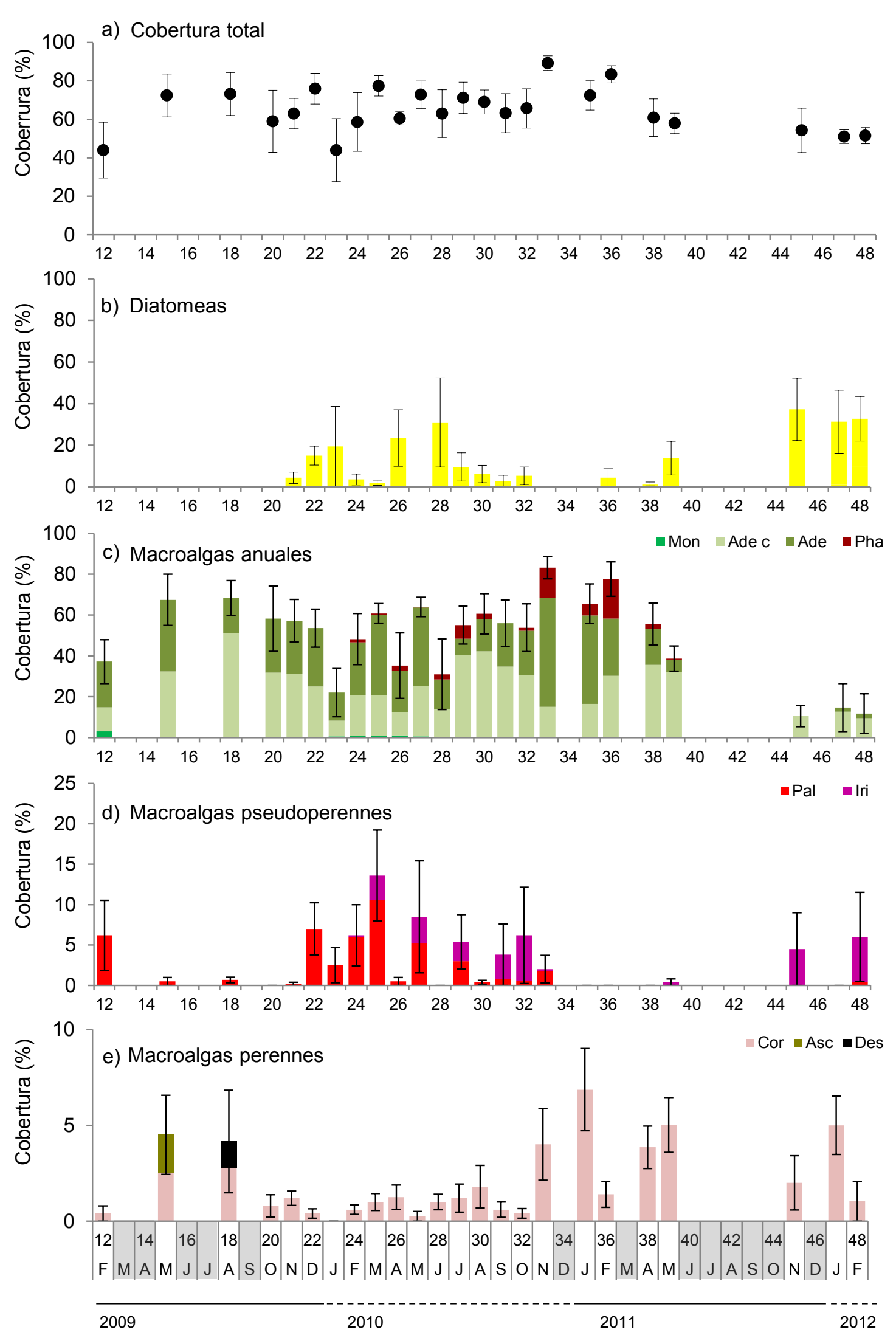

Fig. 4.8. Cobertura de algas obtenida mediante análisis de imágenes de los sustratos colonizados. Se indica la cobertura total (a), de diatomeas (b), y de macroalgas anuales (c), pseudoperennes (d) y perennes (e). En el eje $x$, se indican los meses de colonización, el mes y año de cada muestreo. Nótense las diferentes escalas para el gráfico de macroalgas pseudoperennes y perennes. Mon: Monostroma hariotii, Ade: Adenocystis utricularis Ade c: fase crustosa de A. utricularis, Pha: Phaeurus antarcticus, Pal: Palmaria decipiens, Iri: Iridaea cordata, Cor: Corallinaceae, Asc: Ascoseira mirabilis, Des: Desmarestia sp. 
Las algas rojas crustosas (Corallinaceae) fueron detectadas desde el año 1 y mostraron una tendencia hacia una mayor ocupación del espacio en el tiempo en los muestreos de laboratorio, que permitieron registrar a este grupo debajo del canopeo (Tabla 4.2, Fig. 4.8 y y 4.9 ).

En particular, en los muestreos fotográficos se identificaron pequeños talos de dos especies perennes, endémicas y anticipadoras estacionales: las algas pardas $A$. mirabilis y Desmarestia sp. (cf $D$. menziesii o anceps), ambas detectadas en otoño e invierno, respectivamente, durante el año 2 (Tabla 4.2, Fig. 4.8e).

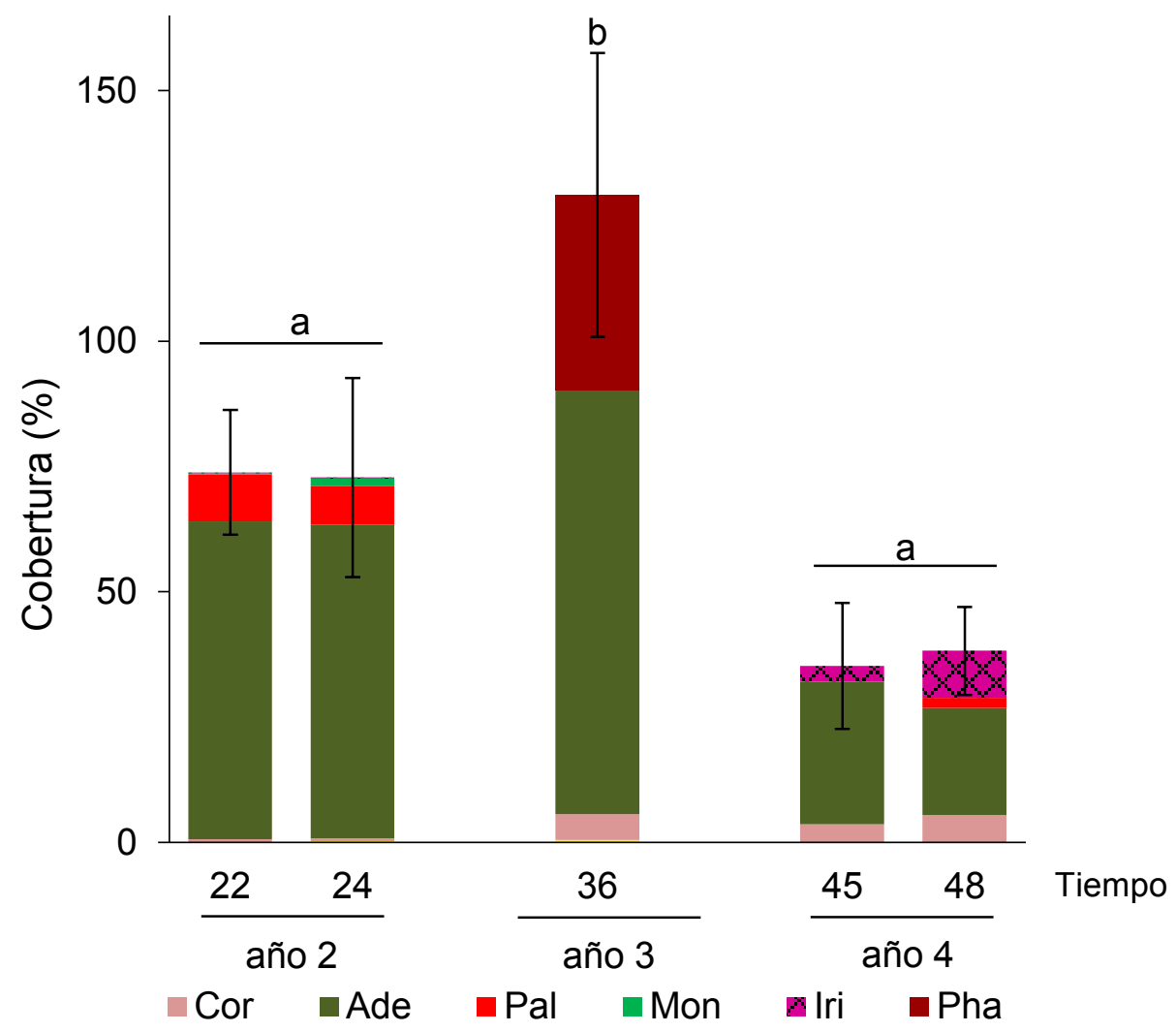

Fig. 4.9. Cobertura de algas en primavera y verano, analizada en condiciones de laboratorio. Se grafica el porcentaje de cobertura total ( \pm error estándar) y el porcentaje de cobertura de cada taxa, para cada tiempo de colonización, expresado en meses (eje $x$, superior) y años (eje $x$, inferior). Las letras indican diferencias significativas entre los porcentajes de cobertura total (macroalgas y diatomeas; las matas de diatomeas estuvieron presentes únicamente luego de 24 y 36 meses y presentaron una cobertura < 1\%) (ANOVA, $p<0,05$; Test Post Hoc de Duncan, $p<0,05$ ). Las medias que comparten la misma letra no difieren significativamente. Cor: Corallinaceae, Ade: Adenocystis utricularis, Pal: Palmaria decipiens, Mon: Monostroma hariotii, Iri: Iridaea cordata, Pha: Phaeurus antarcticus. 


\section{Cobertura de algas e índices ecológicos}

La cobertura total cambió en el tiempo (ANOVA: $F_{4,20}=4,52, p=0,0092$ ), con mayores valores en los ensambles del año 3 (> 100\%) (Test de Duncan, p<0,05) (Fig. 4.9).

Las macroalgas dominaron los ensambles, aumentando su cobertura entre el segundo y el tercer año y mostrando, al igual que en el caso de la cobertura total, una reducción significativa en el cuarto año ( $<50 \%$ ) (ANOVA: $F_{4,20}=4,50, p=0,0094$, Test de Duncan, $p<0,05$ ) (Fig. 4.9). Los resultados obtenidos fueron comparables a los valores hallados en los muestreos fotográficos (Fig. 4.8a).

Las matas de diatomeas estuvieron presentes en muy pequeñas cantidades $(<1 \%)$ en el segundo y tercer año en los muestreos de verano (24 y 36 meses de colonización) sin cambios significativos (ANOVA de una vía, $F_{4,20}=0,80, p=0,539$ ). En los muestreos fotográficos se observaron las variaciones en la cobertura de diatomeas en niveles de mayor resolución que en el caso de los muestreos de laboratorio, dado que se registraron los films de menor abundancia (< $2 \mathrm{~mm}$ de espesor), observándose mayor cobertura en los ensambles del cuarto año (Fig. 4.8b).

No se registraron cambios significativos entre los ensambles de distinto tiempo de colonización en la riqueza (ANOVA de una vía, $F_{4,20}=1,143, p=0,365$ ) ni en la diversidad (ANOVA de una vía, $F_{4,18}=1,35, p=0,286$ ). Sin embargo, se observó un cambio significativo en la equitatividad (ANOVA de una vía, $F_{4,18}=4,33, p=0,0126$ ), con mayores valores en los ensambles del cuarto año (Test de Duncan, $p<0,05$ ) (Fig. 4.10).

Riqueza (S)

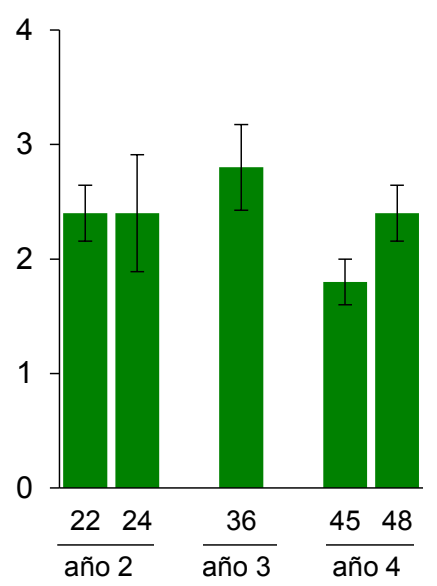

Equitatividad (J')

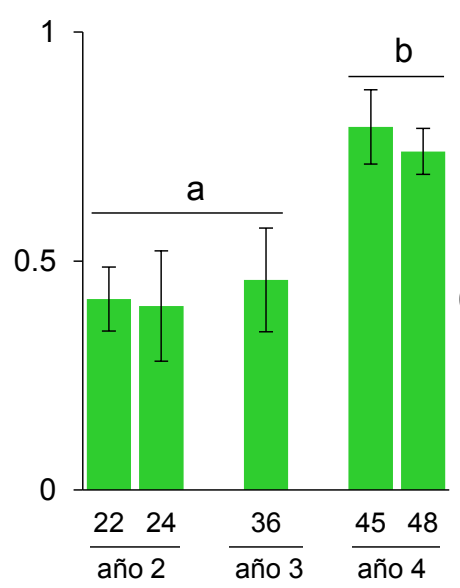

Diversidad $\left(\mathrm{H}^{\prime}\right)$

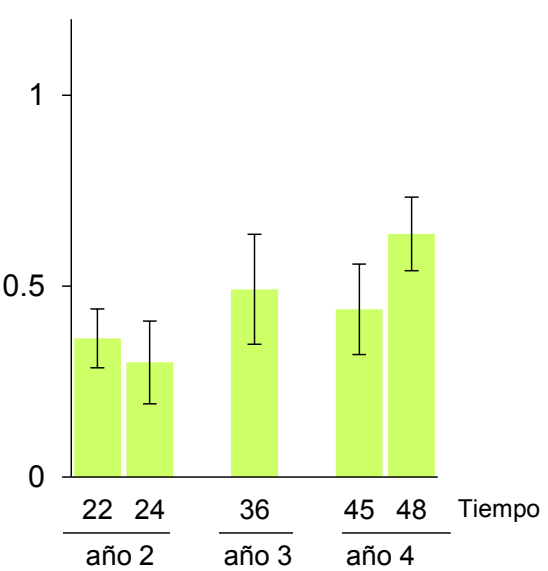

Fig. 4.10. Riqueza (número de taxa), equitatividad (índice de Pielou) y diversidad (índice de Shannon) en primavera y verano, obtenidos a partir del análisis de las placas sucesionales en condiciones de laboratorio. En los tres casos, se grafica la media ( \pm error estándar). Las letras indican diferencias significativas (ANOVA, $p<0,05$; Test Post Hoc de Duncan, $p<0.05$ ). 


\section{Cambios en la composición de taxa en el tiempo}

El análisis de los ensambles mediante ANOSIM reveló diferencias entre los años sucesivos, globalmente y considerando los distintos pares de años (Tabla 4.3). El ordenamiento mediante escalamiento no métrico multidimensional (nMDS) permitió obtener una representación en dos dimensiones potencialmente adecuada, dado el valor de stress de 0,11 (Clarke \& Warick, 2001) (Fig. 4.11). En este ordenamiento, se observan relativamente agrupados a los ensambles de cada año.

Los taxa que más contribuyeron a las diferencias entre los ensambles de cada año (los que contribuyeron al $90 \%$ de las disimilitudes) fueron $P$. antarcticus, $A$. utricularis, $P$. decipiens y las algas rojas crustosas (Corallinaceae) (análisis SIMPER, Tabla 4.3).

Los ensambles del año 2 estuvieron compuestos por $A$. utricularis, $P$. decipiens, $M$. hariotii, y una muy baja cobertura de algas coralinas, diatomeas e $I$. cordata (esta última, sólo presentó un $1 \%$ de cobertura en el mismo sustrato en diciembre y en febrero) (Fig. 4.9). Entre el año 2 y el año 3, las diferencias entre los ensambles se asociaron principalmente a la gran cobertura de $P$. antarcticus, una mayor ocupación del espacio por $A$. utricularis y algas rojas crustosas (Corallinaceae), y la desaparición de $P$. decipiens (Tabla 4.3, análisis SIMPER, Fig. 4.9).

Entre el año 3 y el año 4, la menor cobertura de $A$. utricularis, la desaparición de $P$. antarcticus, la disminución de la cobertura de algas rojas crustosas y la presencia de $I$. cordata fueron los principales responsables de los cambios entre los ensambles (Tabla 4.3, análisis SIMPER, Fig. 4.9).

Asimismo, los ensambles de los años 2 y 4 también difirieron entre sí, principalmente debido a la menor cobertura de $A$. utricularis y $P$. decipiens, el aumento de la cobertura de las algas rojas crustosas e $I$. cordata y la desaparición de $M$. hariotii en el año 4. 
Tabla 4.3. Resultados de los análisis ANOSIM y SIMPER. a) Resultados del ANOSIM (R global y nivel de significación) y pruebas de pares entre los ensambles de algas de cada año (valor $R$ y nivel de significación para las comparaciones entre pares de años). Se indican en negrita los valores de $p$ $<0,05$. b) Resultados de SIMPER, indicándose el porcentaje de disimilitud total promedio entre los ensambles de los diferentes años y la contribución de cada taxa a la disimilitud total, expresada en porcentaje). Pha: Phaeurus antarcticus, Ade: Adenocystis utricularis, Pal: Palmaria decipiens, Cor: Corallinaceae, Mon: Monostroma hariotii, Diat: matas de diatomeas, Iri: Iridaea cordata.

\begin{tabular}{|c|c|c|c|c|c|c|}
\hline \multirow[t]{2}{*}{ a) ANOSIM } & \multicolumn{6}{|c|}{ R global: $0,359 p=\mathbf{0 , 0 0 1}$} \\
\hline & \multicolumn{2}{|c|}{ año 2- año 3} & \multicolumn{2}{|c|}{ año 3- año 4} & \multicolumn{2}{|c|}{ año 2- año 4} \\
\hline $\mathrm{R}$ & \multicolumn{2}{|c|}{0,297} & \multicolumn{2}{|c|}{0,437} & \multicolumn{2}{|c|}{0,375} \\
\hline $\mathrm{p}$ & \multicolumn{2}{|c|}{0,032} & \multicolumn{2}{|c|}{0,005} & \multicolumn{2}{|c|}{0,002} \\
\hline b) SIMPER & \multicolumn{2}{|c|}{$44,58 \%$} & \multicolumn{2}{|c|}{$49,09 \%$} & \multicolumn{2}{|c|}{$51,17 \%$} \\
\hline \multirow[t]{7}{*}{ Taxa } & Pha & 33,11 & Ade & 39,95 & Ade & 43,27 \\
\hline & Ade & 26,37 & Pha & 32,67 & Pal & 20,33 \\
\hline & & 17,36 & Cor & 12,81 & Cor & 18,18 \\
\hline & Cor & 13,90 & Iri & 8,12 & Iri & 10,59 \\
\hline & Mon & 5,09 & Pal & 4,22 & Mon & 6,82 \\
\hline & Diat & 2,70 & Diat & 2,22 & Diat & 0,82 \\
\hline & & 1,47 & Mon & 0,00 & Pha & 0,00 \\
\hline
\end{tabular}




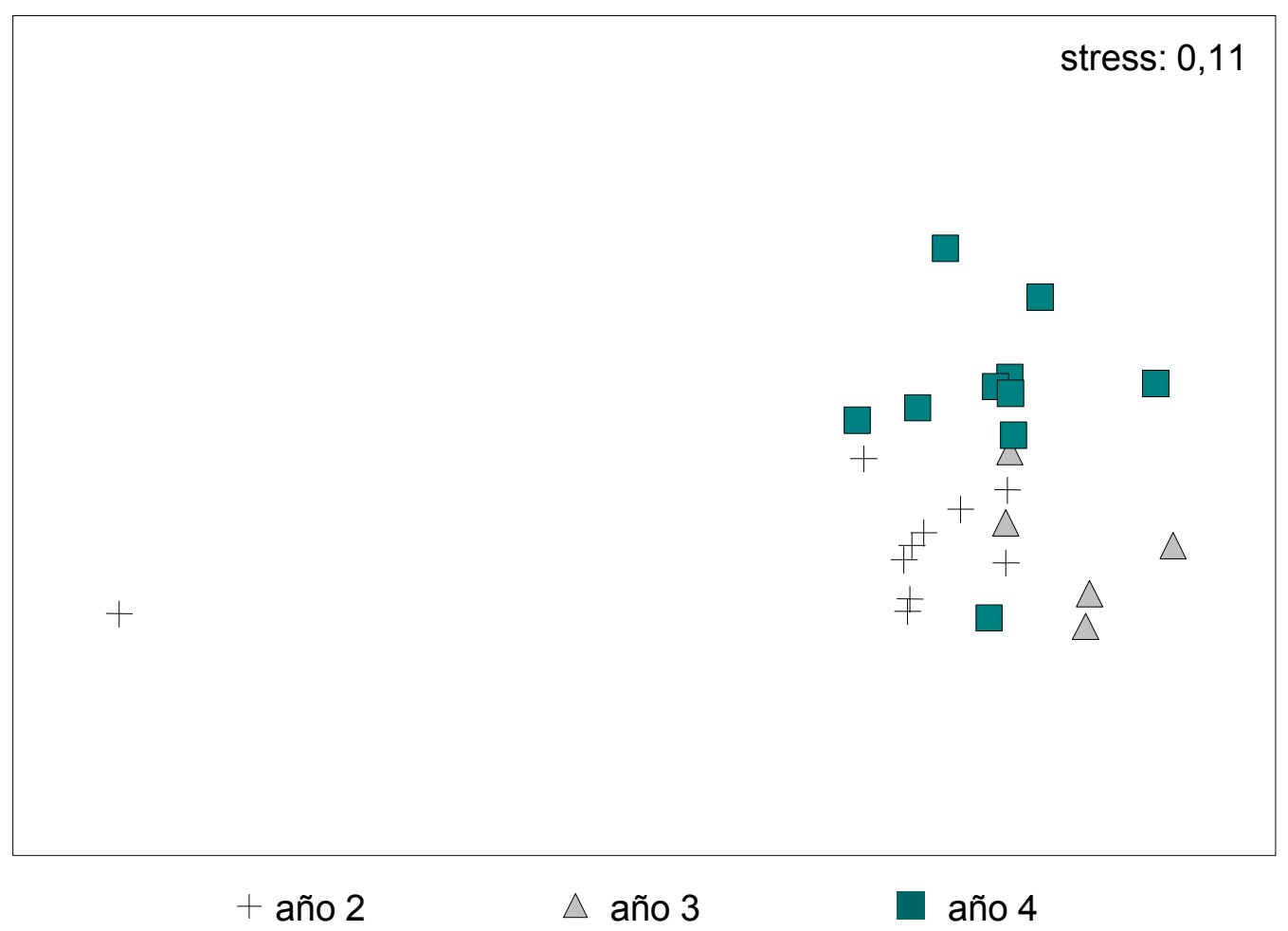

Fig. 4.11. Ordenamiento de ensambles de algas obtenido mediante escalamiento no métrico multidimensional (nMDS). El ordenamiento en dos dimensiones se obtuvo a partir de la construcción de una matriz de similitud empleando el índice de Bray Curtis; la matriz fue obtenida a partir de los datos de porcentaje de cobertura de cada taxa previamente transformadas como raíz cuadrada. Para los años 2 y 4 , se incluyeron los muestreos realizados en primavera y verano (i.e. el año 2 incluye los ensambles de 22 y 24 meses de colonización, el año 3 incluye los ensambles de 36 meses de colonización y para el año 4 , los ensambles de 45 y 48 meses de colonización).

\section{4. DISCUSIÓN}

En este capítulo se describen parámetros estructurales de la comunidad de macroalgas en el curso de los procesos de colonización y sucesión en un ambiente submareal antártico, a lo largo de cuatro años. Entre los resultados más relevantes, se señalan los siguientes: i) los ensambles estuvieron dominados por algas, y en particular por macroalgas, habiéndose registrado ocho taxa, ii) el espacio estuvo ocupado principalmente por pocas especies de macroalgas anuales -particularmente por Adenocystis utricularis- que pueden alcanzar una elevada cobertura, de aproximadamente un $70 \%$ en sólo dos años, iii) un incremento en la cobertura de algas en el tiempo, y una disminución, entre el tercer y el cuarto año de colonización, coincidentemente con un incremento en la equitatividad y una tendencia al incremento de la diversidad, y iv) un cambio significativo en la composición de especies entre años, en los ensambles analizados en las primaveras y veranos. 


\section{Patrones estructurales en la sucesión de algas submareales}

\section{Composición de especies y patrones sucesionales}

En términos generales, las especies $M$. hariotii y $P$. decipiens se identificaron en etapas iniciales, luego de uno y dos años de colonización; $P$. antarcticus e $I$. cordata fueron más abundantes en etapas posteriores, luego de tres y cuatro años respectivamente; mientras que la dominancia de $A$. utricularis fue evidente prácticamente durante todo el período experimental. Asimismo, ocurrió un crecimiento gradual de las algas rojas crustosas (Corallinaceae), desde el primer año, con mayor ocupación del espacio en el tiempo (Fig. 4.9).

En etapas tempranas de la sucesión (menos de tres meses de colonización), pequeños estadios iniciales de $P$. decipiens y $M$. hariotii fueron registrados en ambientes intermareales (Zacher et al. 2007a, Campana et al. 2011). Ambas especies fueron las únicas macroalgas registradas en una nueva área libre de hielo señalada como la más impactada por la proximidad del glaciar, evidenciando su capacidad para colonizar nuevo espacio (Quartino et al. 2013). Monostroma hariotii es una especie anual que puede presentar elevada abundancia en ambientes intermareales sometidos a condiciones de elevado estrés y disturbio (Wiencke \& Clayton 2002, Kim 2001, Marcías et al. 2017) y se ha postulado su rol de especie pionera en ambientes submareales sometidos a abrasión por hielo (Klöser et al. 1996). De modo similar, $P$. decipiens resiste cambios marcados en la salinidad y en la disponibilidad de luz, y puede crecer rápidamente en ambientes intermareales previamente sometidos a abrasión por hielo (Becker et al. 2011, Deregibus et al. 2016, Marcías et al. 2017), habiéndose señalado que posee una elevada capacidad competitiva, por lo que podría ser considerada como oportunista en los procesos de colonización (Becker et al. 2011). En este sentido, los ensambles hallados en este estudio luego de un año de colonización son consistentes con este patrón.

Por otro lado, fue evidente el reclutamiento y dominancia de $A$. utricularis durante prácticamente todo el período experimental. Aparentemente, cuando esta especie se establece, tiende a monopolizar el sustrato y podría inhibir la colonización por otras especies. Se trata de una especie anual, oportunista estacional, con una fase crustosa que sobrevive durante el invierno y que se señaló como bianual cuando se encuentra en el submareal (Wiencke 1990). Por lo tanto, podría haber impedido el establecimiento de otras especies o resistir la invasión por otras especies (Sousa 1979), que solo pueden crecer y colonizar el sustrato cuando se produce el colapso de $A$. utricularis, entre el tercer y el cuarto año.

Sólo se registraron dos taxa perennes foliosos durante el otoño e invierno del año 2 , luego de 15 y 18 meses de colonización: las algas pardas A. mirabilis y Desmarestia sp. (cf 
anceps/menziesii). Resulta poco claro por qué estas especies no persistieron en el tiempo. Algunas de las razones que podrían explicar esto son: i) la remoción de estos pequeños talos debido a la abrasión por hielo, ii) la ocurrencia de competencia interespecífica por espacio con $A$. utricularis, una especie de gran capacidad de colonización y rápido crecimiento, y/o, iii) condiciones abióticas desfavorables para estas especies después del invierno; en particular, una elevada irradiancia pudo haber causado la supervivencia de los taxa más tolerantes a estas condiciones. Las algas pardas Ascoseira mirabilis, Desmarestia anceps y $D$. menziesii son especies adaptadas a condiciones de baja luminosidad, susceptibles a la UV (Wiencke \& Clayton 2002, Rautenberger \& Bischof 2008) y principalmente de distribución en el submareal a mayores profundidades (Quartino et al. 2005). Los sustratos artificiales donde se encontraron estas algas en otoño e invierno estuvieron expuestos a elevados PAR y UV durante la primavera siguiente, y posiblemente sometidas a un elevado estrés lumínico debido a la ausencia de canopeo sobre las placas. Se ha demostrado que en condiciones de laboratorio, la aplicación de $100 \mu \mathrm{mol} \mathrm{m} \mathrm{m}^{-2} \mathrm{~s}^{-1} \mathrm{de}$ PAR durante 10 a 15 días causa una respuesta de estrés en la fotosíntesis de $D$. menziesii e induce un estrés aún mayor en $D$. anceps, una especie que se encuentra a mayores profundidades que D. menziesii (Savaglia comunicación personal, Wiencke \& Clayton 2002). Por lo tanto, es posible que la especie del género Desmarestia no sobreviviera debido a la elevada irradiancia recibida durante la primavera. Una explicación similar se puede aplicar para el caso de $A$. mirabilis, ya que especialmente las gametas de esta especie son muy sensibles a la PAR y a un aumento en la UV (Roleda et al. 2007). De hecho, durante la siguiente primavera y verano, se encontraron las mayores coberturas de $P$. decipiens y las especies $I$. cordata y $A$. utricularis, todas ellas muy tolerantes a condiciones de elevada luminosidad, de rápido crecimiento y que se encuentran frecuentemente en el intermareal (Kim 2001).

Los dos enfoques empleados para el seguimiento de la colonización y sucesión en el tiempo (muestreos detallados en el laboratorio en primavera/verano y muestreos fotográficos mensuales) mostraron patrones sucesionales similares, e información complementaria. Por un lado, los muestreos en el laboratorio, mediante el método de point quadrat, permitieron obtener información más adecuada para la determinación de la cobertura e índices ecológicos (Foster et al. 1991). Esto se vio favorecido por la observación más detallada que posibilitó detectar los taxa debajo del canopeo y que dieron, indirectamente, una medida de la estructura tridimensional de los ensambles. Por otro lado, los análisis fotográficos en terreno dieron cuenta de procesos sucesionales más rápidos, tales como la aparición y desaparición de especies en otoño e invierno. Esto último es de gran relevancia puesto que prácticamente no existe información acerca de la estructura de las comunidades de macroalgas antárticas durante los meses de invierno (Quartino et al. 2013). Por lo tanto, los 
muestreos fotográficos podrían constituir una herramienta complementaria a los análisis detallados de laboratorio -que implican mucho tiempo de operación- permitiendo contar con una mayor resolución temporal y que las fotografías puedan ser tomadas por técnicos no especializados en ficología para ser analizadas en detalle a posteriori.

\section{Cobertura e índices ecológicos}

Luego de 12 meses de colonización, los ensambles presentaron una cobertura relativamente baja ( $44 \% \pm 14,51$, estimada por el método fotográfico), la cobertura fue relativamente más elevada en el año 2 (72,8 \pm 19,8 \%), y alcanzó valores máximos en el verano del año 3, luego de 36 meses de colonización (129,2 $\pm 28,3 \%)$. En este último caso, esto ocurrió debido a una gran ocupación del espacio por $A$. utricularis y a la existencia de varias capas superpuestas causadas principalmente por el canopeo de $P$. antarcticus. Esta última especie posee talos ramificados que, para este tiempo de colonización tuvieron una longitud máxima de 1,2 m (Cap. 3., p. 97-98) causando canopeo y aumento en la complejidad tridimensional de los ensambles. A continuación, se produjo una disminución significativa de la cobertura en el verano del año 4 (38,2 \pm 8,8 \%), luego de 48 meses de colonización. En otros estudios se ha postulado que en comunidades dominadas por especies oportunistas (sensu Littler \& Littler 1980, con altas tasas de crecimiento y rapidez en la ocupación del espacio) puede ocurrir un colapso de las poblaciones ("crash"), debido a que estas sobrepasan su capacidad de carga (Hurd et al. 2014). Este hecho podría explicar la disminución significativa de la cobertura entre el año 3 y el año 4, particularmente para el caso de A. utricularis (Campana et al. 2017). Podría entonces postularse una mayor competencia intra e interespecífica por sustrato (y/o luz) que lleva finalmente a una disminución de la cobertura. En el caso de $P$. antarcticus, Wiencke (1990) observó en condiciones de laboratorio la desintegración de los talos luego de la liberación de esporas, por lo que la desaparición de esta especie luego del año 3 podría, además, relacionarse con su historia de vida. Al liberarse espacio, I. cordata puede ser capaz de colonizar el sustrato y alcanzar su cobertura máxima, en el verano del año 4. Los ensambles del cuarto año, además contuvieron la fase crustosa de $A$. utricularis y algas rojas crustosas.

En este estudio se observó que las algas rojas crustosas tienen el potencial de establecerse y crecer sobre la fase crustosa de $A$. utricularis, por lo que podrían reemplazarla en la ocupación del sustrato (Cap. 3, Lámina XXXIV: Figs. 1-3). Sin embargo, se deberían llevar a cabo experimentos de competencia entre ambas especies, y estudios de campo para develar si existe esta interacción (Connell 1987). Una gran ocupación del espacio por algas rojas crustosas puede ser un rasgo característico de comunidades maduras del mismo sitio de estudio, a bajas profundidades (Klöser et al 1994a). Asimismo, se las ha señalado como indicadoras de sitios con menor grado de disturbio en submareales 
antárticos (Barnes et al. 1996), donde se las encuentra frecuentemente bajo el canopeo formado por grandes Desmarestiales (Irving et al. 2005, Clark et al. 2011). Estudios a largo plazo podrían revelar el rol de estas algas en los procesos sucesionales (Barner et al. 2016), habiéndose postulado -para otros ambientes- que favorecen el reclutamiento de propágulos de colonizadores tardíos, al proveer hábitats estructuralmente simples y con mayor rugosidad que el sustrato natural (Maggi et al. 2010).

\section{Consideraciones acerca del clímax en comunidades de algas marinas bentónicas en Antártida}

En contraste con el concepto clásico de sucesión que propone una secuencia lineal hacia una comunidad climácica (sensu Clements 1916), los estudios experimentales contribuyeron a entenderla como un proceso continuo, con trayectorias que pueden ser desviadas por factores físicos y biológicos (Noël et al. 2009) y, en sentido más amplio, incluye cualquier patrón de cambio temporal en la estructura (composición y abundancia) de los ensambles luego de que se genera espacio (Maggi et al. 2011). En este estudio, las trayectorias sucesionales se evaluaron de acuerdo a los cambios significativos, interanuales, observados en la composición y abundancia relativa de los taxa (Foster et al. 2003, Maggi et al. 2011).

Luego de cuatro años de colonización, la composición de especies de los ensambles se asemeja a las comunidades de macroalgas halladas en la misma zona a bajas profundidades. En el estudio de Quartino et al. (2005) se identificó a $5 \mathrm{~m}$ de profundidad un ensamble de algas caracterizado por I. cordata, $A$. utricularis y $M$. hariotii, con baja riqueza de especies de macroalgas. A profundidades mayores, estos autores identificaron un ensamble caracterizado por D. menziesii, A. mirabilis, Curdiea racovitzae, Gigartina skottsbergii y Trematocarpus antarcticus (previamente identificada como Kallymenia antarctica). Los ensambles de algas hallados en el presente estudio estuvieron compuestos por algas de rápido crecimiento y ausencia de grandes talos de algas perennes. Esto apoya la idea de que los ambientes submareales de baja profundidad en Antártida se sostienen en etapas tempranas de la sucesión, con baja diversidad (Witman \& Dayton 2001).

Para los submareales antárticos dominados por macroalgas, se han definido a las comunidades climácicas como aquellas dominadas por las grandes Desmarestiales, que forman parches extensos, estables en el tiempo (Campana et al. 2011). Estas especies representativas de etapas avanzadas o maduras de la sucesión son algas perennes, foliosas, de elevada biomasa, estructura tridimensional más compleja, proveedoras de hábitat y defendidas químicamente, tales como $A$. mirabilis, D. menziesii, D. anceps, e Himantothallus grandifolius, anticipadoras estacionales que reúnen muchos de los atributos de las especies que se encuentran en comunidades maduras (sensu Littler \& Littler 1980, 
Nöel et al. 2009, Wiencke \& Amsler 2012). La aparición de Desmarestia sp. y A. mirabilis luego de 15 meses de colonización indicaría que potencialmente en el sistema bentónico antártico se podría alcanzar una comunidad madura o climácica en unos pocos años, a mayores profundidades. Sin embargo, la repetida abrasión por hielo, la competencia interespecífica y/o una elevada irradiancia, podrían desviar esta trayectoria y sostener a estas comunidades en etapas tempranas de la sucesión. La persistencia de grandes parches de $D$. menziesii y $D$. anceps en el submareal antártico a mayores profundidades podría relacionarse con las características generales de los bosques submareales de macroalgas, debido a la mayor longevidad de sus principales componentes, la mayor estabilidad de las condiciones ambientales a mayores profundidades y a su relativamente bajo consumo, sugerido por el alto contenido de defensas anti herbívoros (Cognetti et al. 2001, Witman \& Dayton 2001, Amsler et al. 2005, 2011).

En los procesos sucesionales se espera que ocurra un incremento de la biomasa (o cobertura), la riqueza, la equitatividad y la diversidad en el tiempo (Odum 1969). Sin embargo, en estudios realizados en ambientes marinos rocosos, las tendencias de cambio de la diversidad en el tiempo pueden ser más variables y dependientes del estado de avance o desarrollo de los ensambles (Niell 1979, Noël et al. 2009). Inicialmente, en etapas tempranas, la diversidad tiende a aumentar en el tiempo, alcanza valores máximos en estadios intermedios, y, finalmente, puede disminuir en el clímax o en etapas maduras, si una o unas pocas especies dominan el sustrato e impiden el reclutamiento de otras especies (Sousa 1979, 2001). Sin embargo, estos sistemas presentan una mayor complejidad de hábitat provisto por macroalgas más complejas estructuralmente que favorecen la presencia de pequeños organismos que viven asociados a estas especies fundacionales (sensu Dayton 1972) (Bruno \& Bertness 2001, Nöel et al. 2009). En el presente estudio, se produjo un aumento en la cobertura hasta el tercer año, seguido de una disminución significativa en el cuarto año del experimento, que se atribuye a fenómenos de competencia intra y/o interespecífica por espacio y luz. La liberación de espacio permitió la colonización por otras especies (sobre todo $I$. cordata) con una tendencia hacia el aumento de la diversidad debido a un aumento significativo en la equitatividad (Fig. 4.12).

Cabe destacar que en este estudio las diatomeas estuvieron entre los taxa que menos contribuyeron a las diferencias entre los ensambles de diferente tiempo de colonización. Este grupo es característico de etapas tempranas de la colonización del sustrato y la sucesión (Wahl 1989, Zacher et al. 2007b, Fricke et al. 2008) y, dado que los muestreos se iniciaron a partir del primer año, es probable que esta sea la razón por la que no se hayan registrado en elevada abundancia. Los films de diatomeas observados mediante el muestreo fotográfico mostraron una abundancia variable y relativamente mayor hacia fines de primavera y verano (Kim 2001, Campana et al. 2017). 


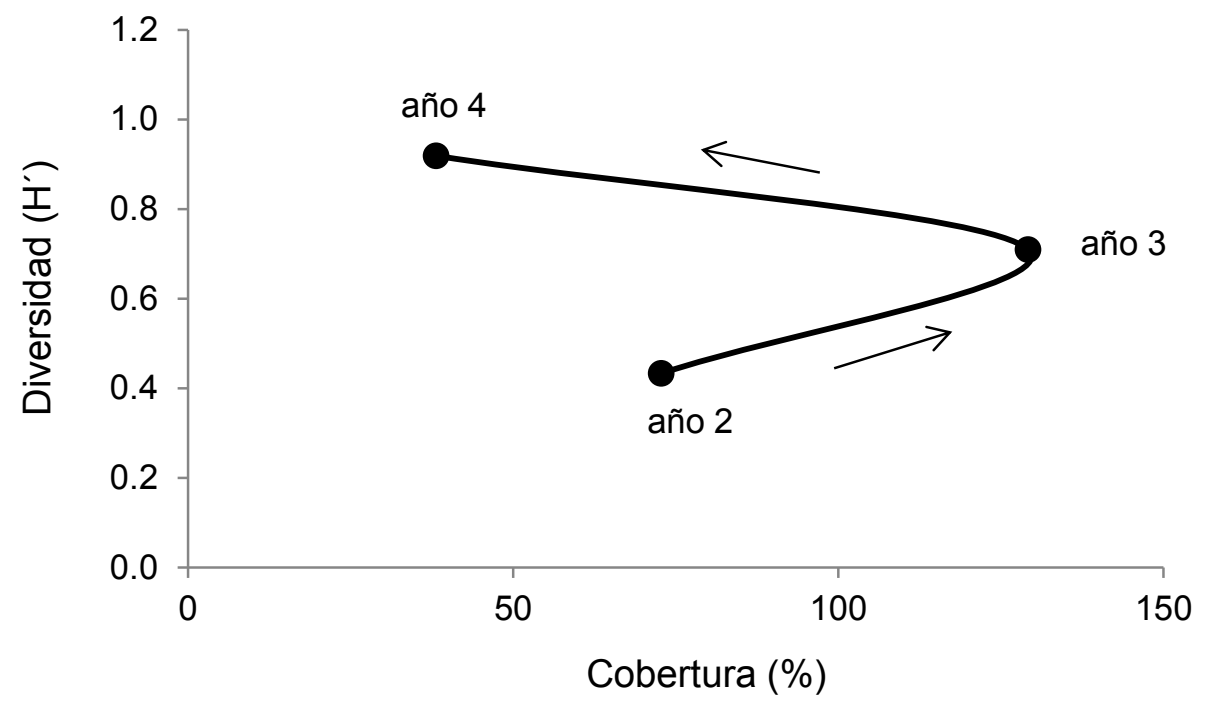

Fig. 4.12. Diagrama de fases que ilustra la variación de la cobertura y la diversidad de los ensambles luego de dos, tres y cuatro años de colonización, a partir de la información obtenida para los muestreos detallados realizados en el laboratorio. Se observa un incremento en la diversidad en el tiempo, mientras que la cobertura incrementa entre el año 2 y 3 y disminuye entre el año 3 y el año 4.

El grado de penetración de la luz en Peñón de Pesca fue estable entre las estaciones cálidas (primaveras y veranos) de los años analizados, probablemente debido a la ubicación de este sitio en la caleta externa (Cap. 2), con valores de penetración de la radiación similares a los hallados en otros estudios en el mismo sitio y en la caleta externa (Richter et al. 2008, Hernández 2016) y mayores a los medios registrados para la zona interna de la caleta (Quartino et al. 2013, Deregibus et al. 2016, Campana et al. 2017). En los sitios ubicados en la caleta interna, la penetración de la luz puede ser disminuida, particularmente en los meses de verano, como resultado del ingreso de sedimento de origen terrestre proveniente del derretimiento glaciar (Quartino et al. 2013, Deregibus et al. 2016, Hernández 2016). Sin embargo, en un experimento similar al presentado en esta Tesis, y realizado en un sitio expuesto al derretimiento glaciario, con un año de diferencia (iniciado en diciembre de 2008), se observaron patrones sucesionales convergentes: i) los ensambles estuvieron dominados por algas, ii) el sustrato fue colonizado por unas pocas especies oportunistas, particularmente $A$. utricularis que alcanzó coberturas similares ( $70 \%)$ en dos años, iii) se produjo un cambio significativo en la composición de las comunidades entre años y iv) se observó un incremento de la cobertura de macroalgas hasta el tercer año seguida de una disminución entre el tercer y cuarto año. El sitio ubicado en la caleta interna, presentó menor riqueza de macroalgas y una tendencia hacia la disminución de la diversidad en el tiempo, lo cual fue atribuido a la menor disponibilidad de esporas en nuevas áreas libres de hielo, a la mayor sedimentación y a la consiguiente menor irradiación en el sitio expuesto al derretimiento glaciario, así como a mayor disturbio mediado por hielo desprendido desde el 
glaciar (Campana et al. 2017), características biológicas y ambientales de las comunidades de macroalgas desarrolladas en nuevas áreas libres de hielo (Quartino et al. 2013, Deregibus et al. 2016). De modo que, teniendo en cuenta los diferentes tiempos de inicio de ambos experimentos se puede postular que los patrones sucesionales de algas marinas bentónicas en el submareal antártico pueden ser predecibles (Campana et al. 2017).

\section{Corolario}

En este Capítulo se determinaron los patrones de colonización y sucesión primaria de algas marinas bentónicas luego de cuatro años en un ambiente submareal antártico.

- Las comunidades estuvieron dominadas por algas bentónicas.

- Se determinó un cambio interanual en los ensambles. En términos generales y teniendo en cuenta las variaciones en las abundancias de los taxa presentes, se identificaron a $P$. decipiens y $M$. hariotii en etapas tempranas y a $P$. antarcticus, $I$. cordata y las algas rojas crustosas (Corallinaceae) en las etapas más avanzadas.

- Adenocystis utricularis presentó una elevada abundancia y probablemente tenga una elevada capacidad competitiva siendo capaz de inhibir el reclutamiento de otras especies.

- Las comunidades se encuentran en etapas tempranas de la sucesión respecto a las comunidades climácicas predichas para Antártida, pero reflejaron a la comunidad circundante.

En base a los resultados obtenidos, la primera hipótesis planteada: "la sucesión de la comunidad de productores primarios bentónicos procede en el tiempo hacia una mayor complejidad en su estructura (mayor cobertura, riqueza y diversidad y mayor complejidad tridimensional)" fue confirmada parcialmente. Las comunidades procedieron hacia mayores valores de cobertura y diversidad aunque, una vez alcanzada la máxima cobertura y complejidad tridimensional, interacciones competitivas pudieron haber mediado la liberación de espacio, y la colonización por otras especies. Sin embargo, los ensambles fueron similares a las comunidades circundantes, probablemente sostenidas en etapas tempranas de la sucesión.

Si bien los enfoques experimentales presentan dificultades logísticas en la Antártida, y en particular en los ambientes submareales, son fundamentales para elucidar mecanismos y evaluar la influencia de factores específicos sobre estos procesos (Meiners et al. 2015, Barner et al. 2016). En el siguiente capítulo se profundiza el estudio de las comunidades de algas bentónicas antárticas evaluando los efectos de factores abióticos e interacciones biológicas (la UV y el pastoreo, respectivamente) en etapas tempranas de la colonización y sucesión. 
CAPÍTULO 5

Efectos de la radiación ultravioleta y el pastoreo sobre la colonización y sucesión de microalgas y macroalgas bentónicas 


\subsection{INTRODUCCIÓN}

Las comunidades bentónicas antárticas están expuestas a factores de estrés y disturbio marcados y son afectadas por interacciones biológicas tales como el pastoreo y la competencia, que determinan su estructura y la colonización del sustrato, e influirán en el reemplazo de las especies en el tiempo (Introducción de esta Tesis, Campana et al. 2011). Como hemos mencionado, la UV-B es un factor de estrés ambiental que causa inhibición de la fotosíntesis y daños a biomoléculas, y si bien la UV-A es menos dañina, puede causar inhibición de la fotosíntesis asociada a los flujos elevados con los que alcanza la superficie (Cullen \& Neale, 1994, Karentz \& Boch 2001, Villafañe et al. 2003, Bischof et al. 2006, Karsten et al. 2011, entre otros). La UV es considerada un factor que puede determinar la composición y zonación vertical de las macroalgas antárticas (Bischof et al. 2006). Para el caso del diatomeas bentónicas en Antártida se ha postulado que poseen eficientes mecanismos de reparación de daños al ADN aunque la mayoría de los estudios se centraron en ambientes de fondos blandos (Wulff et al. 2008a,b,c).

Particularmente al inicio de la sucesión, se espera que una sensibilidad diferencial hacia la UV entre distintos grupos de algas bentónicas (por ejemplo, entre macroalgas y diatomeas), entre distintas especies, o entre distintos estadios de una misma especie, produzca modificaciones en la estructura y funcionamiento de estas comunidades (Wulff et al. 2000, Lotze et al. 2002). Un hecho de particular importancia para los procesos sucesionales es que los propágulos de macroalgas puedan ser más afectados que los talos adultos debido a su mayor metabolismo, menor pigmentación, estructuras más delgadas o su proveniencia desde aguas más profundas, no afectadas por la UV (Coehlo et al. 2000, Wiencke et al. 2000, Molis \& Wahl 2004). Asimismo, una sensibilidad diferencial a la UV entre los propágulos de macroalgas de diferentes especies puede favorecer la colonización del sustrato nuevo por especies más resistentes a esta radiación (Bischof et al. 2006). Los estudios experimentales sobre propágulos de macroalgas antárticas demostraron que estas etapas iniciales están adaptadas a la sombra y son afectadas por la UV, siendo las esporas de macroalgas que habitan el submareal más sensibles a esta radiación respecto a especies que habitan el intermareal antártico (Zacher et al. 2007c, Zacher 2014, Navarro et al. 2016).

Además de los factores abióticos, el pastoreo es un factor estructurante de la sucesión (Introducción de esta Tesis, Sousa 1979, Lubchenco 1983, Farrel 1991 y compilaciones en Sousa \& Connel 1992). Los herbívoros abren un nuevo espacio, disponible para la colonización, aumentando la heterogeneidad y permitiendo la coexistencia de parches de diferentes etapas serales o de recolonización (Sommer 1999a). Por otro lado, pueden ejercer un control de tipo top-down sobre la comunidad en estudio (Lotze et al. 2001, Worm et al. 2000). 
Los estudios sobre los efectos de la UV sobre las comunidades de productores primarios bentónicos marinos en procesos sucesionales son relativamente escasos (Santas et al. 1998, Reizopoulou et al. 2000, Molis \& Wahl 2004, Wahl et al. 2004, Dobretsov et al. 2005). Los resultados de dichos estudios en general fueron inconsistentes, mediados por la UV-A o la UV-B, y dependientes de la composición de las comunidades y el grado de desarrollo o tiempo de exposición experimental. Con excepción de un estudio (Dobretsov et al. 2005), los efectos de la UV (o la UV-B) fueron más intensos en etapas tempranas de la sucesión (aproximadamente entre dos y tres meses). Los estudios sobre ensambles dominados por diatomeas estuvieron enfocados principalmente en ambientes de fondos blandos, habiéndose detectado efectos negativos de la UV ambiental sobre la producción primaria (Wulff et al. 1999) o la fotosíntesis y la biomasa (Roux et al. 2002). Sin embargo, la biomasa y la composición de especies pueden no ser afectadas en otros estudios frente a incrementos de la UV-B (Sundbäck et al. 1997) y se ha revelado cierta resistencia de las diatomeas pennadas a la UV-B (Peletier et al. 1996), que puede estar mediada por la migración vertical en el sedimento (Sundbäck et al. 1997, Waring et al. 2007). Asimismo, las etapas tempranas de la colonización del microfitobentos pueden ser más vulnerables a la UV-B respecto a las comunidades ya establecidas y esta radiación puede ser un factor de control, particularmente en ambientes en los que la abrasión por hielo genera eventos de colonización (Villafañe et al. 2003).

Por otro lado, la UV puede afectar interacciones entre especies, tales como la competencia, la herbivoría, la predación, el mutualismo y el parasitismo (Sommaruga 2003, Wahl 2008), con consecuencias en la estructura y funcionamiento de las comunidades. Por ejemplo, la herbivoría puede ser afectada si la UV modifica la palatabilidad algal (Pavia et al. 1997) o si causa efectos negativos directos sobre estos consumidores (Bothwell et al. 1994, pero ver Hill et al. 1997, Zacher et al. 2007a,b).

Existe poco conocimiento sobre los efectos simultáneos de la UV y el pastoreo sobre la estructura de las comunidades de productores primarios bentónicos marinos y los trabajos se enfocaron principalmente en estudios realizados sobre plataformas flotantes ubicadas a baja profundidad (<50 cm) (Lotze et al. 2002, Molis \& Wahl 2009). En general, los resultados dependieron del ambiente en estudio y muchos de los efectos observados fueron transitorios. Para Antártida, sólo se conoce un trabajo que evalúa simultáneamente los efectos de ambos factores, realizado en el intermareal de Península Potter (Zacher et al. 2007a,b), por lo que los efectos en comunidades bentónicas del submareal son desconocidos. 
El objetivo de este capítulo fue evaluar experimentalmente el efecto de la radiación ultravioleta (UV-A y UV-B) ambiental y el pastoreo sobre atributos estructurales de una comunidad de microalgas y macroalgas bentónicas en el curso de los procesos de colonización y sucesión en etapas tempranas. Los objetivos específicos fueron:

- Evaluar el efecto de la UV y el pastoreo sobre la biomasa, cobertura, composición taxonómica e índices de diversidad de las comunidades de algas bentónicas a dos niveles de resolución (macroscópico y microscópico).

- Evaluar el efecto de ambos factores sobre los ensambles de diatomeas (densidad de células, composición taxonómica e índices de diversidad).

Para ello se realizó un experimento in situ variando la intensidad del pastoreo y la composición espectral de la radiación ambiental.

\subsection{MATERIALES Y MÉTODOS}

\section{Diseño experimental}

Se emplazaron mediante buceo autónomo 32 unidades experimentales en el submareal de Peñón de Pesca a una profundidad de 2 m (Fig. 5.1). Cada unidad experimental consistió en una estructura de PVC de base cuadrada, de $50 \mathrm{~cm}$ de lado y $10 \mathrm{~cm}$ de alto. En cada una de ellas se ubicaron placas de cerámico no vidriado levemente rugoso, que actuaron como sustratos para la colonización algal. Las placas se fijaron con velcro al fondo de la unidad experimental para permitir su remoción en cada muestreo. Se colocaron ocho placas por unidad experimental:

- cuatro de $10 \mathrm{~cm}$ x $10 \mathrm{~cm}$, empleadas para el análisis de la comunidad a dos niveles de magnificación.

- cuatro de $5 \mathrm{~cm} \times 5 \mathrm{~cm}$, empleadas para realizar un análisis detallado de los ensambles de diatomeas.

\section{Tratamientos}

El experimento comprendió un diseño factorial para evaluar los efectos combinados de la irradiancia y el pastoreo en el curso de la colonización y sucesión.

Para analizar el efecto de la irradiancia, las unidades experimentales fueron cubiertas por diferentes tipos de filtros ópticos de corte (Zacher et al. 2007a,b) a fin de incluir los siguientes tratamientos:

a) PAR + UV-A + UV-B (PAB, $\lambda>280$ nm): se utilizó una lámina de Plexiglass GS 2458 (Röhm, Darmstadt, Alemania) de $3 \mathrm{~mm}$, para permitir el paso de PAR, UV-A y UV-B.

b) PAR + UV-A (PA, $\boldsymbol{\lambda}>320 \mathrm{~nm}$ ): se utilizó una lámina de Plexiglass GS 2458 (Röhm, Darmstadt, Alemania) de $3 \mathrm{~mm}$, cubierto por un film transparente de poliester Folanorm 
SF/AS (folex imaging $\mathrm{GmbH}$, Alemania) de $13 \mathrm{~mm}$, que restringe el corte a $320 \mathrm{~nm}$ para permitir el paso de PAR y UV-A.

c) PAR (P, $\lambda>400 \mathrm{~nm}$ ): se utilizó una lámina de 3mm de Plexiglas GS 231(Röhm, Darmstadt, Alemania), que permite únicamente el paso de PAR.

El porcentaje de transmitancia de los filtros empleados se muestra en la Fig. 5.2.

Para analizar el efecto del pastoreo se efectuaron los siguientes tratamientos:

a) Sin clausura: permitió el libre acceso de los herbívoros a través de los laterales de las unidades experimentales

b) Con clausura: la entrada de los herbívoros se limitó mediante la clausura lateral de las unidades experimentales, utilizando una red plástica de malla de $1 \mathrm{~mm}$.

Además, para evaluar posibles efectos de artefacto, se incluyeron dos tratamientos control:

a) Media clausura (mc): las unidades experimentales contuvieron orificios rectangulares (dos orificios de $15 \mathrm{~cm} \times 5 \mathrm{~cm}$ por cada lado) en la clausura lateral. Este tratamiento se empleó para detectar posibles respuestas diferenciales asociadas a la limitación del flujo de agua debidas a la clausura lateral. Estas unidades experimentales constaban de filtros PAB.

b) Radiación Solar Directa (rd): en estas unidades experimentales no se colocó ningún filtro ni clausura lateral. Este tratamiento se empleó para detectar posibles respuestas diferenciales asociadas sólo a la presencia de filtros.

En la Tabla 5.1 se presenta un resumen de todos los tratamientos del diseño experimental. Se incluyeron cuatro unidades experimentales (que actuaron como réplicas) por tratamiento.

Tabla 5.1. Combinación de los todos los tratamientos incluyendo ambos factores: Pastoreo e Irradiancia. Se indica el número de unidades experimentales para cada tratamiento. Cada unidad experimental contuvo ocho placas de cerámico (cuatro de $10 \mathrm{~cm} \times 10 \mathrm{~cm}$ y cuatro de $5 \mathrm{~cm} \times 5 \mathrm{~cm}$ ).

Tratamientos

PAB

PA

$\mathbf{P}$

directa

$\begin{array}{llll}\text { Sin clausura } & 4 & 4 & 4 \\ \text { Con clausura } & 4 & 4 & 4 \\ \text { Media clausura } & 4 & & \end{array}$




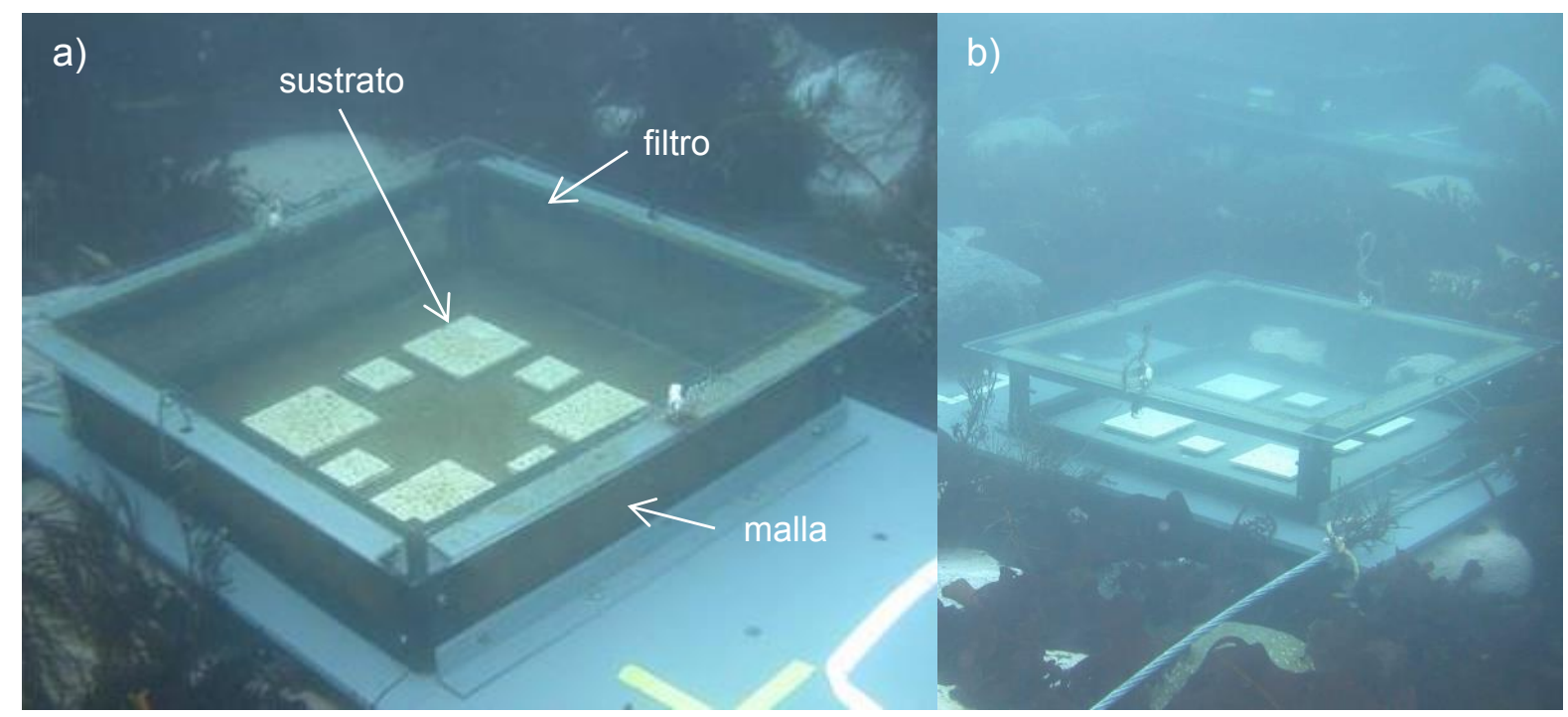

Fig. 5.1. Vistas subacuáticas de unidades experimentales. Se señala la disposición de los sustratos sobre el fondo, la posición superior del filtro óptico de corte y la presencia de una malla lateral en una unidad experimental con clausura (a). En b) se muestra una unidad experimental sin clausura lateral. Fotos: K. Zacher.

Los filtros fueron limpiados in situ mediante buceo autónomo 1 a 2 veces por semana. Además, los films de poliéster fueron renovados aproximadamente cada dos semanas para minimizar efectos de envejecimiento o fouling sobre la transparencia. Asimismo, se realizaron censos por buceo autónomo, cada tres a cuatro semanas, a fin de identificar los herbívoros presentes en las unidades experimentales.

El experimento se realizó entre el 20 de diciembre de 2003 y el 2 de marzo de 2004. Los muestreos se realizaron en cuatro oportunidades: el 12/1, 29/1, 17/2 y 2/3, luego de 23 , 40, 59 y 73 días de colonización respectivamente. En cada fecha se tomaron al azar, mediante buceo autónomo, una placa de $10 \times 10 \mathrm{~cm}$ y una de $5 \times 5 \mathrm{~cm}$ de cada unidad experimental.

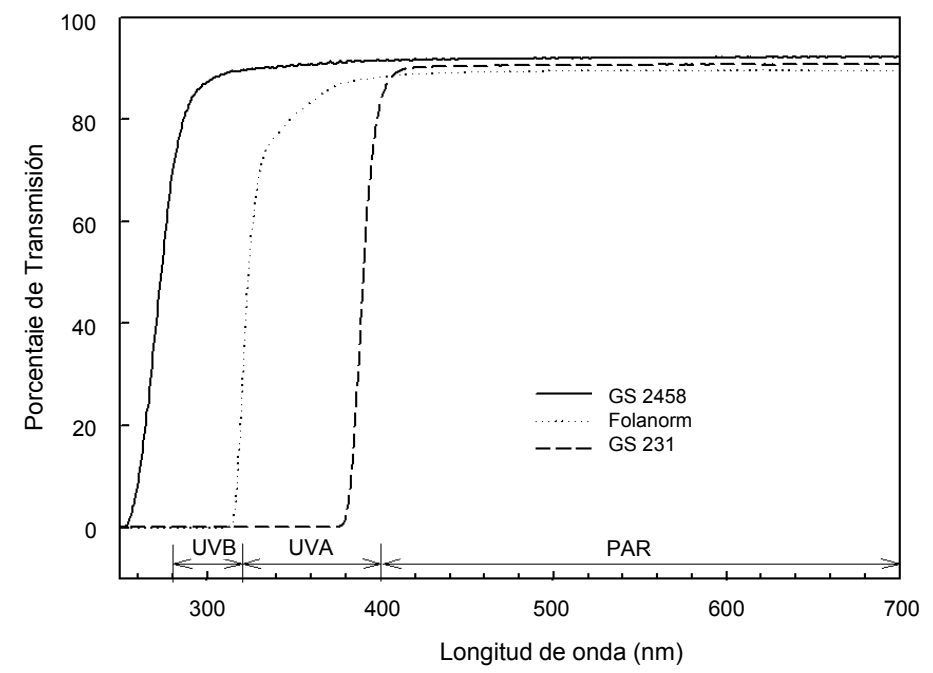

Fig. 5.2. Porcentaje de transmitancia de los filtros de corte empleados para los tratamientos de irradiancia: Plexiglas GS 2458 (Tratamiento PAB), Plexiglas GS 2458 + Folanorm (Tratamiento PA) y Plexiglas GS (231) (Tratamiento P), modificado de Zacher et al. 2007b. La transparencia del filtro GS 231 y GS 2458 disminuye en promedio $1.11 \%$ (desvío estándar: +/-0,01) y 1,31\% (desvío estándar: +/-0,01) por mes, respectivamente (Zacher et al. 2007b). 


\section{Mediciones de radiación solar}

Se registraron continuamente la UV-A y UV-B atmosféricas mediante un espectrorradiómetro de 32 canales (intervalo $1 \mathrm{~nm}$ ) ( $(\mathrm{sitec}$, Alemania) ubicado sobre el techo del Laboratorio Dallmann. Los datos de irradiancia máxima y dosis diarias fueron provistos por el AWI (Richter et al. 2008). Complementariamente se realizaron mediciones de PAR, diariamente, entre las 12.30 y las $13.30 \mathrm{hs}$ en la proximidad del laboratorio Dallmann, empleando un data logger Li-Cor (LI-1000, Li-Cor, Lincoln, Estados Unidos), equipado con un sensor plano LI-190 (Lincoln, Estados Unidos).

Las mediciones de luz en la columna de agua se realizaron mediante un radiómetro PUV-500 (Biospherical Instruments Inc.) a 305, 320, 360, $380 \mathrm{~nm}$ y PAR, en intervalos de 5 segundos, a una velocidad de $3 \mathrm{~m} \mathrm{~min}^{-1}$, desde la superficie hasta 25 metros de profundidad en sentido ascendente (Hernández 2016). A partir de estos datos, se determinó el coeficiente de atenuación de la luz $\left(\mathrm{K}_{\mathrm{d}}\right)$ asumiendo una reducción exponencial de la irradiación, según Kirk (2011):

$$
\operatorname{Ln} I_{z}=-K_{d} X z+L n I_{0} \quad \text { (ecuación 4.1) }
$$

donde $I_{z}$ es la irradiación a la profundidad $z$ (en metros) e $I_{0}$ es la irradiación incidente inmediatamente debajo de la superficie del agua. Los coeficientes de extinción para cada longitud de onda se calcularon a partir de la regresión lineal del logaritmo natural de lz respecto a la profundidad. Asimismo, se determinó la profundidad de penetración del 10\% $\left(Z_{10 \%}\right)$, y del $1 \%\left(Z_{1 \%}\right)$, de la radiación incidente, para cada longitud de onda (Hargreaves 2003). En particular, la $Z_{10 \%}$ de la UV-B ha sido definida como "zona fotoactiva" (Neale et al. 2003).

\section{Análisis de laboratorio}

En cada oportunidad de muestreo se determinó la biomasa y la composición taxonómica de las comunidades desarrolladas sobre los sustratos artificiales, luego de 23, 40, 59 y 73 días de colonización.

\section{Biomasa}

Los organismos de cada placa fueron removidos mediante raspado, empleando agua de mar filtrada $(0,7 \mu \mathrm{m}$ de tamaño de poro). La biomasa se determinó como peso seco, por secado en estufa durante 48 hs a $80^{\circ} \mathrm{C}$ (Lotze et al. 2002) a partir de volúmenes de muestras filtradas empleando filtros de fibra de vidrio Whatman GF/F $(0,7 \mu \mathrm{m}$ de tamaño de poro), y se expresó como $\mathrm{mg}$ de peso seco por $\mathrm{cm}^{2}$. 


\section{Composición taxonómica}

A fin de analizar la composición taxonómica de las comunidades desarrolladas en los sustratos artificiales, se registró la cobertura de los grupos algales presentes en las placas de $10 \times 10 \mathrm{~cm}$ (Fig. 5.3) a dos niveles:

- A nivel macroscópico, se determinó el porcentaje de cobertura de los organismos (o colonias de diatomeas) mayores a $2 \mathrm{~mm}$ de longitud (Lotze et al. 2002). Para ello se empleó una lámina de Plexiglass transparente, marcada con 50 puntos al azar, cada punto representando un $2 \%$ de cobertura).

- A nivel microscópico, se determinó el porcentaje de cobertura de los taxa considerando los organismos, estadios iniciales o colonias de diatomeas mayores a $0,2 \mathrm{~mm}$ de longitud. En cada placa se observaron cuatro submuestras de $\sim 50 \mathrm{~mm}^{2}$ empleando un microscopio estereoscópico Carl Zeiss provisto de una grilla de $10 \mathrm{x}$ 10. A fin de evitar efectos de borde, se consideró el área total exceptuando un margen de $1 \mathrm{~cm}$ (Foster \& Sousa 1985).

Con el objeto de obtener un análisis detallado de los ensambles de diatomeas, se realizaron conteos celulares a partir de las muestras obtenidas de los sustratos de $5 \times 5 \mathrm{~cm}$ (Fig. 5.3). Estos sustratos fueron congelados inmediatamente después de cada muestreo y la densidad de células totales y de cada grupo se expresó por centímetro cuadrado de sustrato, según el procedimiento detallado en el Capítulo 3. No se observó ningún efecto adverso o alteración de la muestra asociada al congelamiento.

\section{Diversidad, riqueza y equitatividad}

La diversidad se estimó mediante el índice de Shannon-Weaver, según:

$$
H^{\prime}=\sum_{i=1}^{k} p_{i} \operatorname{Ln} p_{i}
$$

donde $\mathrm{p}_{\mathrm{i}}$ (o abundancia relativa) es el porcentaje de cobertura (o número de individuos, para el caso de las diatomeas) del taxón i, dividido por el porcentaje de cobertura (o número de individuos) de la totalidad de los taxa. La riqueza (S) se expresó como el número total de taxa y la equitatividad se calculó empleando el índice de Pielou (J) (Margalef 1981, Magurran 2004). Los cálculos de diversidad y equitatividad se realizaron mediante el programa PRIMER 6 (Clarke \& Warick 2001). 


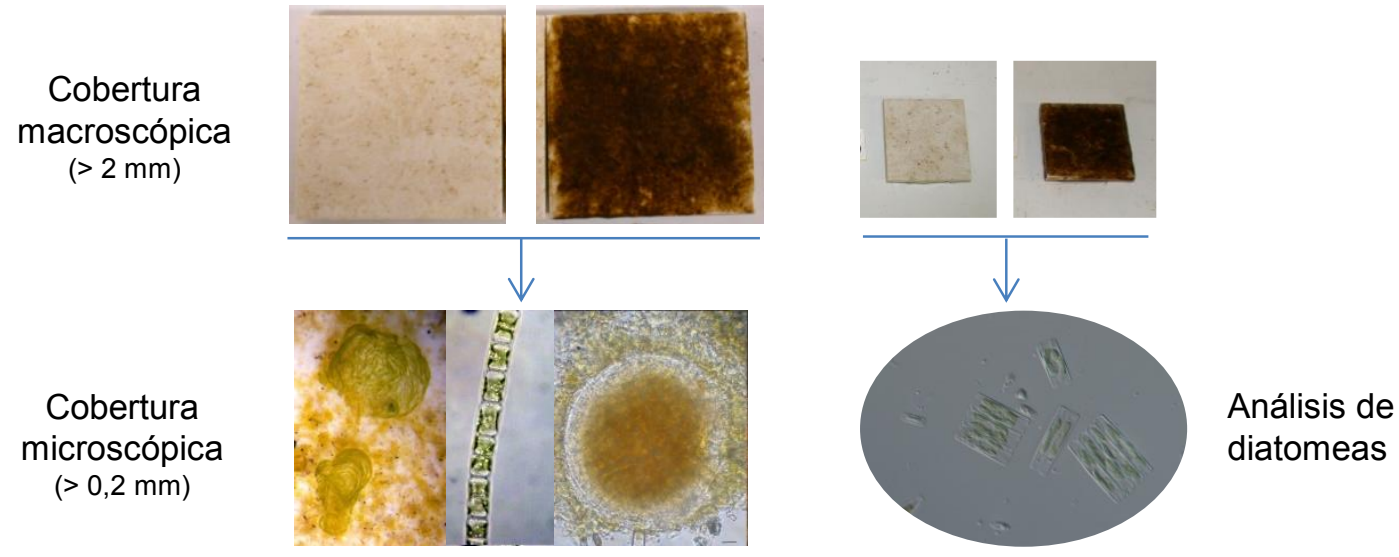

Fig. 5.3. Esquema del análisis de las placas colonizadas. Las placas de $10 \times 10 \mathrm{~cm}$ se emplearon para los análisis de porcentaje de cobertura a dos niveles: macroscópico (porcentaje de cobertura de los organismos o colonias de diatomeas mayores a $2 \mathrm{~mm}$ de longitud) y microscópico (porcentaje de cobertura de los taxa considerando los organismos, estadios iniciales o colonias de diatomeas mayores a $0,2 \mathrm{~mm}$ de longitud). Las placas de $5 \times 5 \mathrm{~cm}$ se dedicaron exclusivamente a los conteos de diatomeas. En cada caso, se muestran placas pastoreadas y no pastoreadas (izquierda y derecha, respectivamente).

\section{Análisis estadísticos}

Para el análisis de biomasa, cobertura macroscópica total y por grupos, cobertura microscópica (de diatomeas, clorofitas y rodofitas), densidad de diatomeas e índices de diversidad, los efectos de cada tratamiento se testearon empleando ANCOVA, a un nivel de significación $\alpha=0,05$, tomando la irradiancia y el pastoreo como variables independientes y el tiempo como covariable (Zar 1996). Las tablas que contienen los resultados de estos análisis se pueden consultar en el Apéndice 5.1 (Tablas A5.1.1 - A5.1.16). Las pruebas post hoc para comparaciones de medias se realizaron utilizando el Test de Duncan a un nivel de significación $\alpha=0.05$. La homogeneidad de varianzas se verificó mediante el Test de Cochran (Zar 1996).

Dado que las muestras se tomaron en forma sucesiva, es de interés analizar los cambios en las variables mencionadas para cada tiempo de colonización. En este caso, las comparaciones por muestreo se realizaron mediante el Test de Kruskal-Wallis utilizando un nivel de significación de $\alpha=0.05$; esta prueba no paramétrica no asume distribución normal de los datos y es más robusta que el ANOVA paramétrico en casos de muestras pequeñas (Zar 2010). En los casos en que no se verificó homogeneidad de varianzas, el nivel de significación requerido para rechazar la hipótesis nula se cambió mediante la corrección de Bonferroni $\left(\alpha^{`}=0,125\right)$ para disminuir la probabilidad de cometer un error de tipo I (Quinn \& Keough 2002). En los casos en que existieron diferencias significativas, se realizaron comparaciones múltiples de rankings medios (Statistica 7, Electronic Manual).

Cada uno de los tratamientos control fueron comparados con el tratamiento sin clausura PAB mediante una prueba de Mann-Whitney a un nivel de significación $p<0.05$, previa verificación de homogeneidad de varianzas. Excepto en tres de 80 comparaciones 
realizadas se observaron efectos de artefacto asociados únicamente a la presencia de filtros. Por este motivo se puede descartar la ocurrencia de efectos de artefacto asociados a la presencia de la clausura lateral y asumir que no existió un efecto relevante asociado a la presencia del filtro óptico en las unidades experimentales.

Para todos los análisis mencionados se utilizó el programa Statistica 7.

Para detectar cambios en la composición de taxa entre tratamientos y para cada tiempo de colonización, se realizaron análisis de similitud de dos vías (ANOSIM), a un nivel de significación de $\alpha=0,05$. Se trata de un procedimiento de permutación no paramétrico que genera un estadístico $R$, que es una medida de la distancia entre los grupos. Este estadístico puede variar entre -1 y 1 (Clarke et al. 1999). Los valores de $R$ cercanos a 1 indican mayor separación entre grupos y los valores de $\mathrm{R}$ más cercanos a 0 indican mayor similitud entre los grupos analizados (Clarke \& Warick 2001). Estos análisis se realizaron empleando el índice de similitud de Bray Curtis, calculado a partir del porcentaje de cobertura de los taxa de macroalgas y diatomeas coloniales, previamente transformados como raíz cuarta y la densidad, previamente transformada como raíz cuadrada, para el caso del análisis de diatomeas (Clarke \& Warick 2001).

Para visualizar el ordenamiento de las muestras se realizó un análisis de escalamiento no métrico multidimensional (non-metric multidimensional scaling o nMDS por sus siglas en inglés). Este análisis permitió ordenarlas en una configuración de dos dimensiones, que intenta preservar los rankings de similitud entre muestras (Clarke \& Warick 2001).

Finalmente, se realizó un procedimiento de SIMPER (Porcentaje de Similitud) para cuantificar la contribución relativa de cada taxa a las disimilitudes observadas entre tratamientos, para aquellos casos en los que el test ANOSIM resultó significativo. Este procedimiento permite identificar a los taxa que más contribuyeron a las disimilitudes observadas. Todos los análisis multivariados se realizaron usando el programa PRIMER 6 (Plymouth Marine Laboratory).

\section{3. RESULTADOS}

\section{Radiación atmosférica y subacuática}

Las mediciones de radiación solar atmosférica durante el período experimental presentaron valores máximos de irradiancia de PAR, UV-A y UV-B a fines de diciembre de 2003, con valores mínimos a fines de febrero y principios de marzo de 2004 (Tabla 5.2, Fig. 5.4). 
Las unidades experimentales, instaladas a una profundidad promedio de $2 \mathrm{~m}$, recibieron, respecto a la irradiancia incidente, $30 \%( \pm 14), 41 \%( \pm 17), 49 \%( \pm 19), 60 \%( \pm$ 21) y $65 \%$ ( \pm 20$)$ para las longitudes de onda de $305 \mathrm{~nm}, 320 \mathrm{~nm}, 340 \mathrm{~nm}, 380 \mathrm{~nm}$ y PAR, respectivamente. La profundidad máxima de atenuación del $10 \%$ de la irradiancia incidente $\left(Z_{10 \%}\right)$ a $305 \mathrm{~nm}$ fue de $5 \mathrm{~m}$ y de $7,3 \mathrm{~m}, 9,7 \mathrm{~m}, 15,5 \mathrm{~m}$ y $18 \mathrm{~m}$ para las longitudes de onda de $320 \mathrm{~nm}, 340 \mathrm{~nm}, 380 \mathrm{~nm}$ y PAR, respectivamente. La radiación UV-B de $305 \mathrm{~nm}$ fue atenuada al $1 \%\left(Z_{1 \%}\right)$ a profundidades máximas de $10 \mathrm{~m}$, la UV-A a $14,4 \mathrm{~m}, 19,4 \mathrm{~m}$ y $31,1 \mathrm{~m}$ (a 320 nm, 340 nm y 380 nm respectivamente), mientras que la PAR mostró un $Z_{1 \%}$ a 36,2 m. Los valores medios de $Z_{10 \%}$ y $Z_{1 \%}$ se detallan en la Fig. 5.5.

Tabla 5.2. Radiación solar atmosférica. Se presentan los valores de irradiancia, dosis diarias (de UVA y UV-B) y valores máximos y mínimos durante el periodo experimental, entre el 20 de diciembre de 2003 y el 2 de marzo de 2004. Se indican las medias +/- el desvío estándar (de). Los datos correspondientes a las dosis diarias de UV-A y UV-B fueron suministrados por el AWI.

\begin{tabular}{lccccc}
\hline & PAR & \multicolumn{2}{c}{ UV-A } & \multicolumn{2}{c}{ UV-B } \\
\cline { 2 - 6 } & $\begin{array}{c}\text { Irradiancia } \\
\left(\mu \mathrm{mol} \mathrm{m}^{-2} \mathrm{~s}^{-1}\right)\end{array}$ & $\begin{array}{c}\text { Irradiancia } \\
\left(\mathrm{W} \mathrm{m}^{-2}\right)\end{array}$ & $\begin{array}{c}\text { Dosis diaria } \\
\left(\mathrm{kJ} \mathrm{m}^{-2}\right)\end{array}$ & $\begin{array}{c}\text { Irradiancia } \\
\left(\mathrm{W} \mathrm{m}^{-2}\right)\end{array}$ & $\begin{array}{c}\text { Dosis diaria } \\
(\mathrm{kJ} \mathrm{m}-2)\end{array}$ \\
\hline Media (de) & $973(471)$ & $36,8(9,00)$ & $420,4(132,5)$ & $1,5(0,4)$ & $15,4(4,9)$ \\
\hline Máximo & 2126 & 54,0 & 680,6 & 2,2 & 24,5 \\
\hline Mínimo & 283 & 15,6 & 166,5 & 0,6 & 5,9 \\
\hline
\end{tabular}

\section{Presencia de consumidores}

Los consumidores hallados en las unidades experimentales fueron los gasterópodos de dieta principalmente herbívora Nacella concinna (Strebel 1908) y Laevilacunaria antarctica (Martens 1885) (Peck \& Veal 2001, Iken 1999). Asimismo, se observaron anfípodos, entre los que se identificó al herbívoro Gondogeneia antarctica (Chevreux 1906) como el más abundante (Momo et al. 1998). 


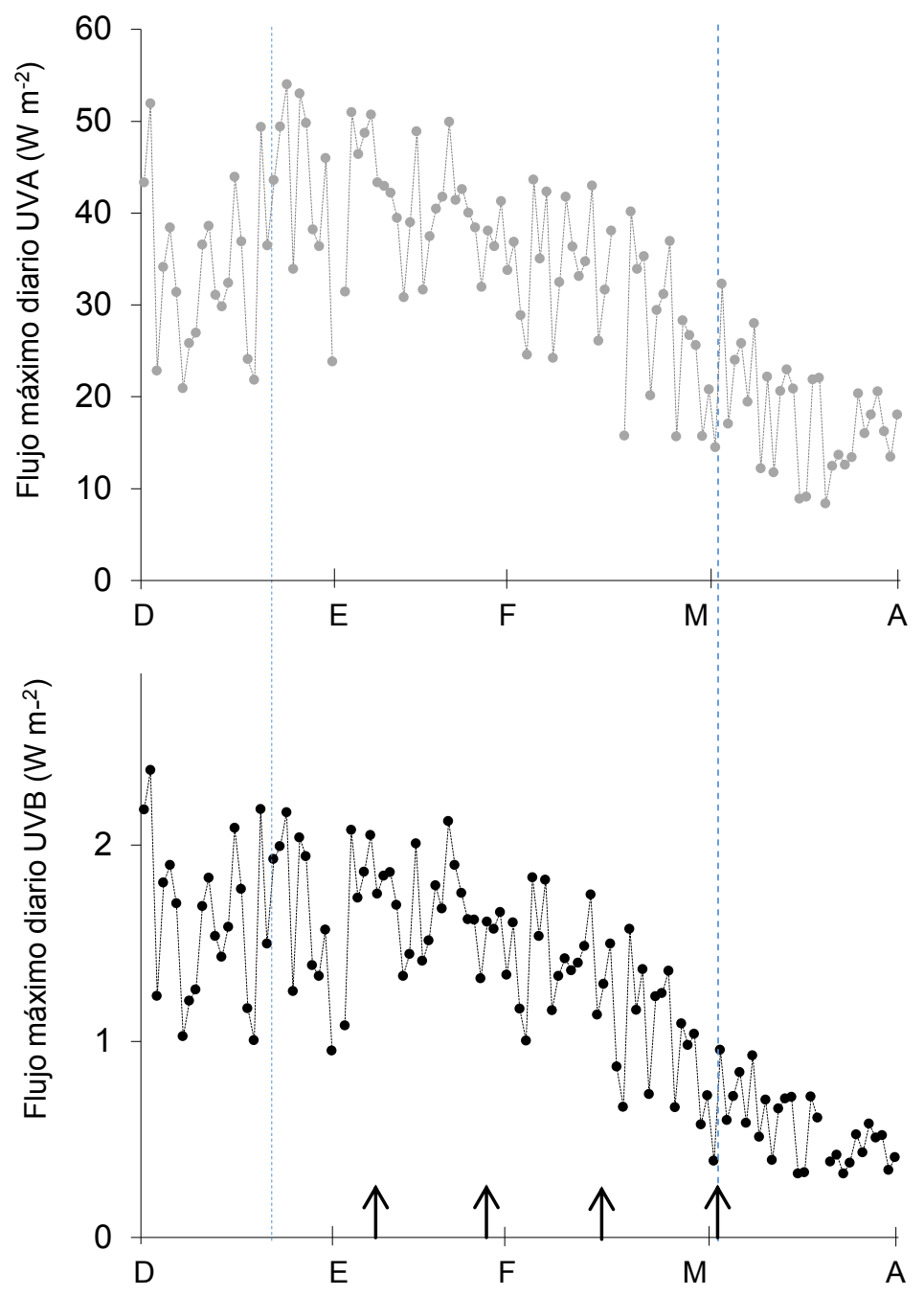

Fig. 5.4. Flujo máximo diario de UV-A y UV-B entre diciembre de 2003 y marzo de 2004 para la Base Carlini, Laboratorio Dallmann. Las líneas punteadas señalan el tiempo experimental y las flechas, la fecha de realización de los cuatro muestreos.

a)

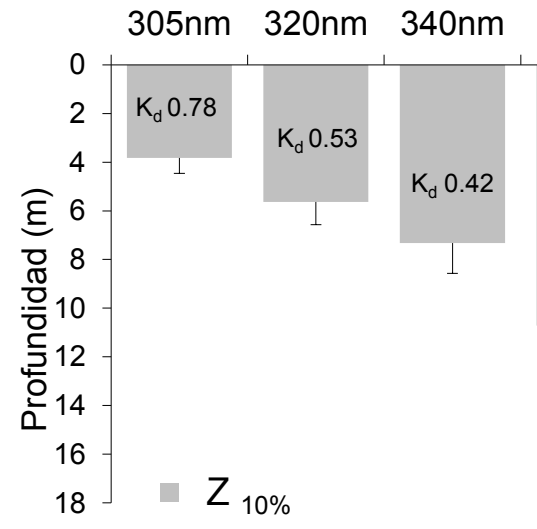

b)

PAR $\quad 305 \mathrm{~nm} \quad 320 \mathrm{~nm} \quad 340 \mathrm{~nm} \quad 380 \mathrm{~nm} \quad$ PAR
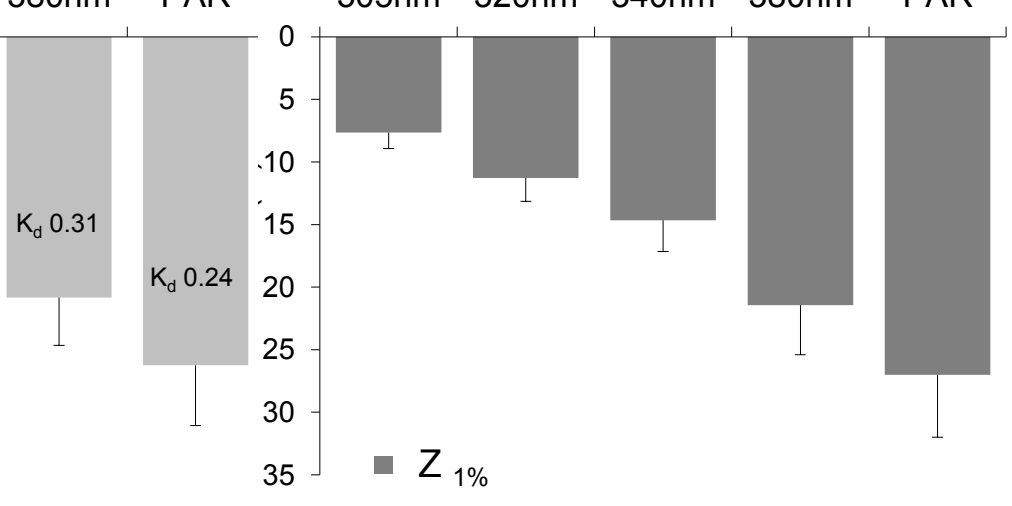

Fig. 5.5. Ambiente luminoso subacuático. Se grafica la profundidad de penetración del $10 \%\left(Z_{10 \%}\right)$ (a) y del $1 \%\left(Z_{1 \%}\right)(b)$ de la radiación incidente. En (a) se indican los coeficientes de atenuación $\left(K_{d}\right)$ para 
cada longitud de onda, dentro de las barras. Se grafican las medias +/- error estándar de las mediciones realizadas durante enero y febrero 2004, en la zona externa de Caleta Potter $(n=5)$.

\section{Biomasa y cobertura macroscópica}

El pastoreo disminuyó significativamente la biomasa de las comunidades en las unidades experimentales que no tuvieron clausura ( $p<0,05$, Fig. 5.6a). Del mismo modo, la cobertura total a nivel macroscópico fue reducida por el pastoreo ( $p<0,05$, Fig. 5.6b). En ambos casos, este efecto resultó más intenso en las comunidades pastoreadas que sólo recibieron PAR (Fig. 5.6a y b).

a)

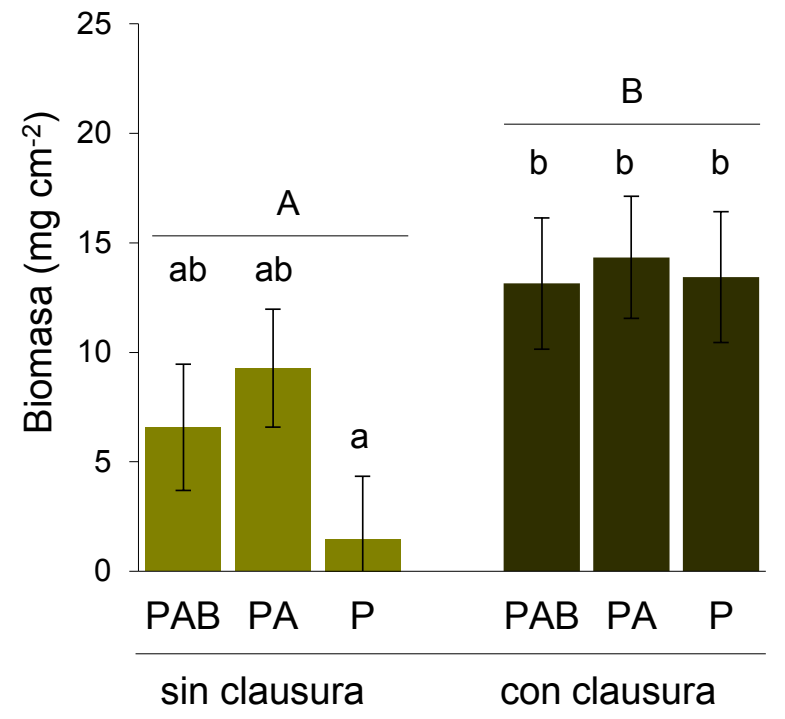

b)

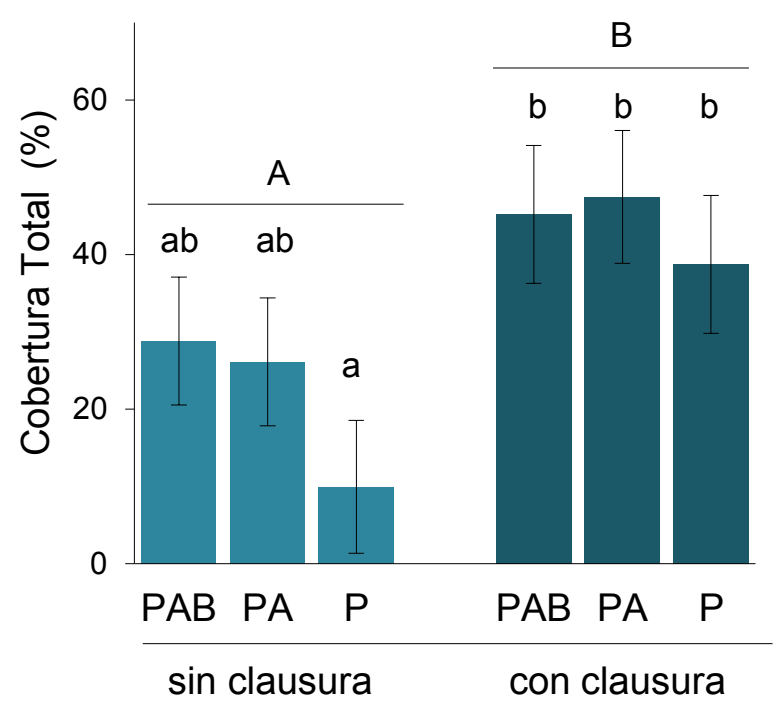

Fig. 5.6. Biomasa y cobertura macroscópica total. Efectos de la UV y el pastoreo sobre la biomasa (a) y la cobertura macroscópica (b) de las comunidades pastoreadas y no pastoreadas (sin clausura y con clausura respectivamente) sometidas a los diferentes tratamientos de irradiancia. Se indican las medias +/- error estándar. Las letras mayúsculas indican los resultados del test ANCOVA significativos $(p<0,05)$. Las letras minúsculas indican las diferencias significativas del test de Duncan $(p<0,05)$. PAB: PAR + UV-A + UV-B, PA: PAR + UV-A, P: sólo PAR.

El análisis para cada tiempo de colonización reveló una reducción significativa de la biomasa luego de 23, 40 y 59 días (Fig. 5.7). Los mayores valores de biomasa se observaron a partir de los 40 días de colonización, en las comunidades no pastoreadas (Fig. $5.7 b)$. 

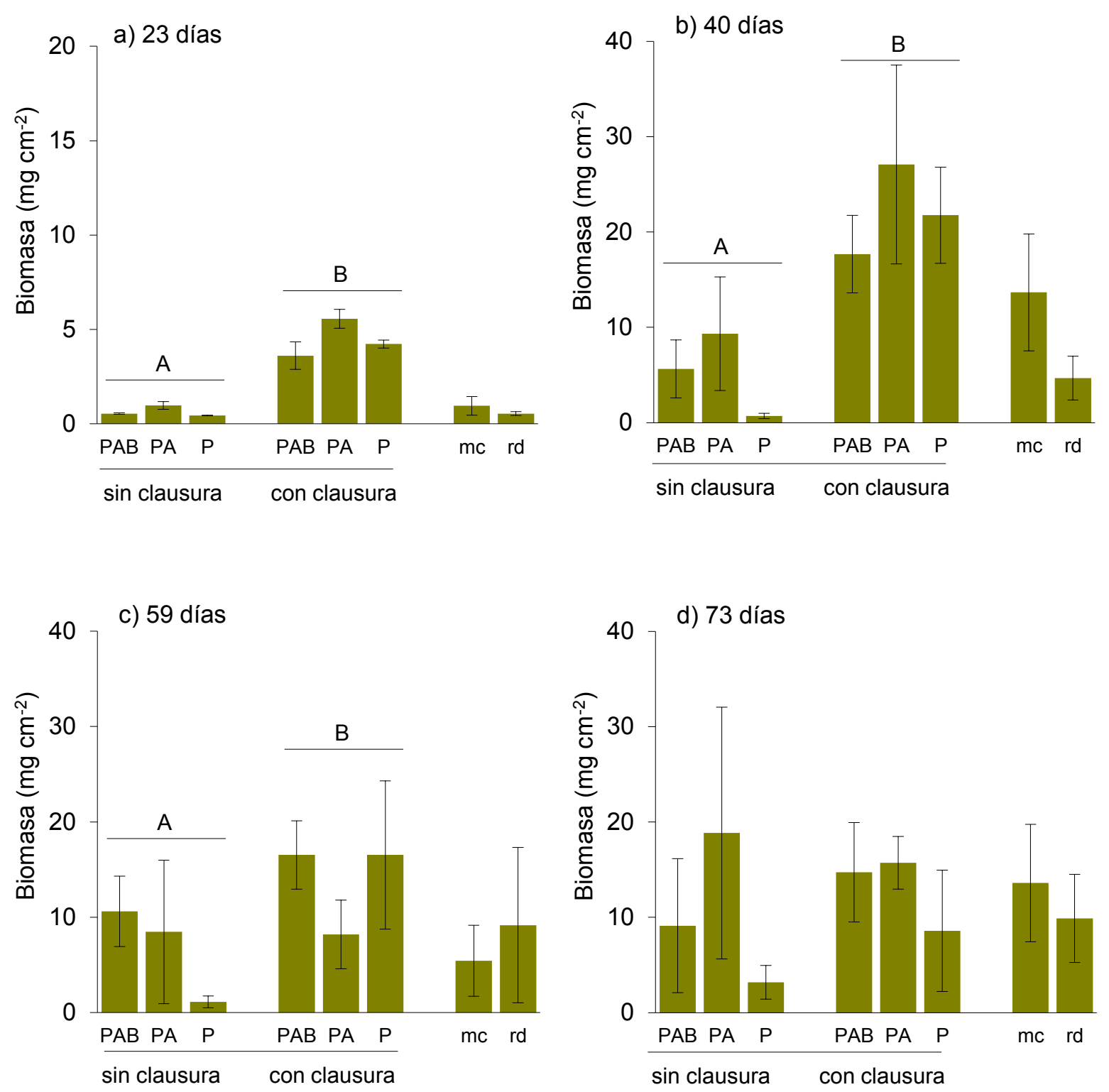

Fig. 5.7. Biomasa luego de 23, 40, 59 y 73 días de colonización (a-d respectivamente). Se indican las medias +/- el error estándar. Las letras mayúsculas indican los resultados significativos del Test de Kruskal Wallis $(p<0,05)$. PAB: PAR + UV-A + UV-B, PA: PAR + UV-A, P: sólo PAR, mc: media clausura, rd: radiación solar directa.

A nivel macroscópico, las comunidades estuvieron conformadas por matas visibles de diatomeas y clorofitas filamentosas, particularmente Urospora penicilliformis. Existieron diferencias en los porcentajes de cobertura macroscópica de diatomeas y clorofitas de acuerdo al grado de desarrollo de la comunidad: a partir de 23 días de colonización, se observó una transición desde comunidades compuestas prácticamente sólo por diatomeas hacia comunidades con un mayor porcentaje de cobertura de clorofitas (Fig. 5.8). En las comunidades de 23 días de colonización se redujo significativamente la cobertura macroscópica total en las placas pastoreadas ( $p<0,05$, Fig. $5.8 a$ ). 
a) 23 días

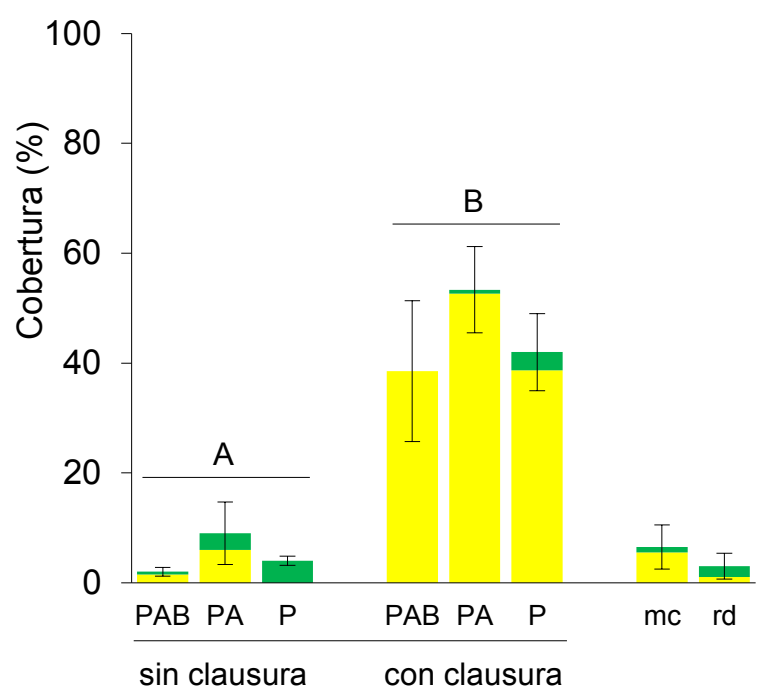

c) 59 días
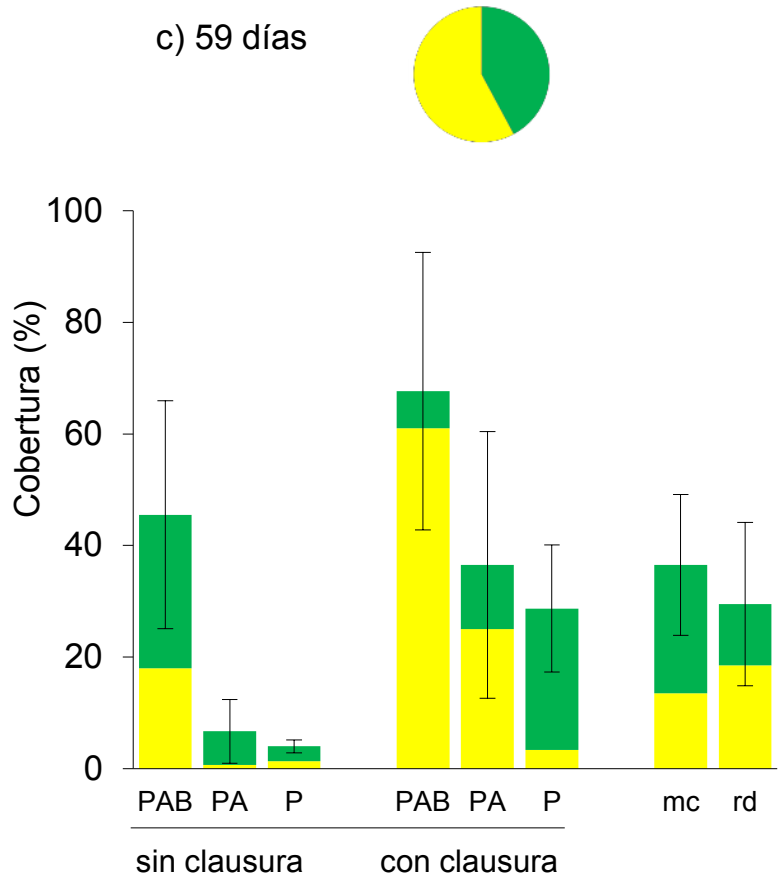

a) 40 días
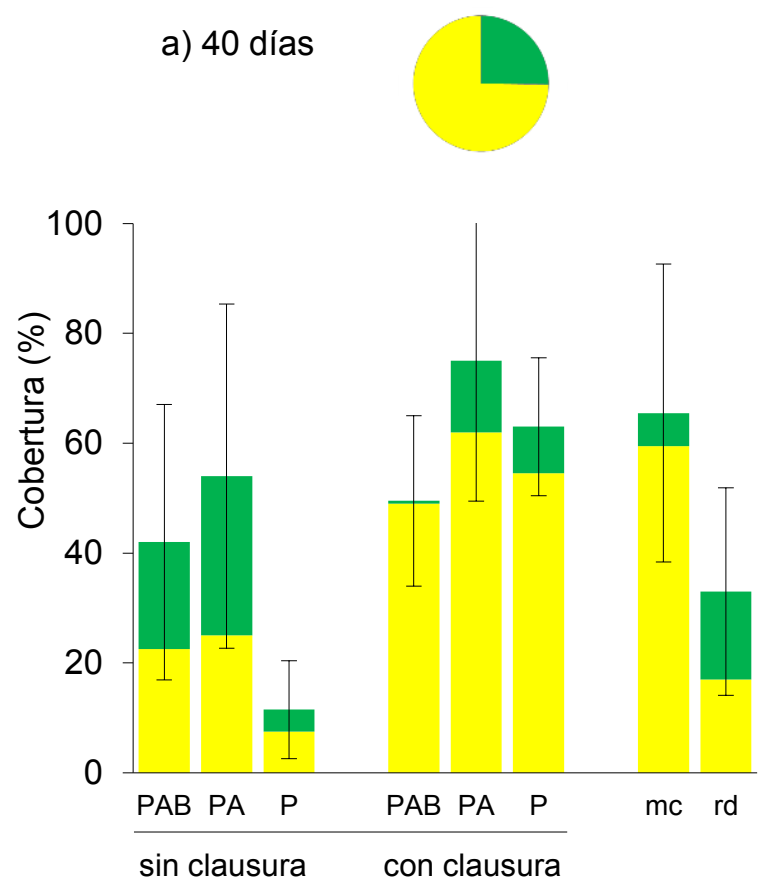

d) 73 días

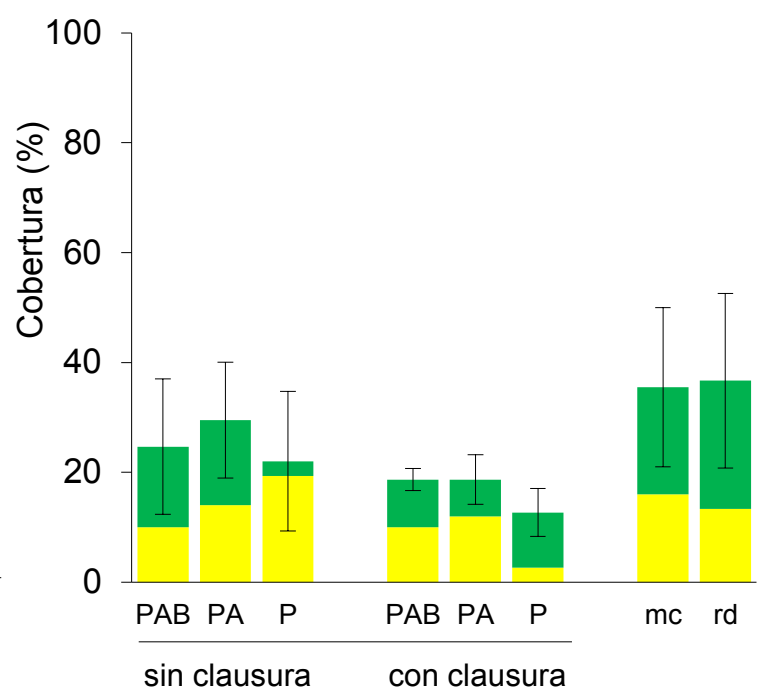

Fig. 5.8. Composición taxonómica y cobertura macroscópica luego de 23, 40, 59 y 73 días de colonización (a-d, respectivamente). Se muestran los promedios de las abundancias relativas de la cobertura macroscópica de diatomeas (en amarillo) y clorofitas (en verde) para cada muestreo (gráfico circular) y el porcentaje de cobertura de diatomeas y clorofitas para cada tratamiento. Se indican las medias +/- el error estándar para la cobertura total. Las letras mayúsculas indican los resultados significativos del Test de Kruskal Wallis $(p<0,05)$, PAB: PAR+ UV-A + UV-B, PA: PAR + UV-A, P: sólo PAR, mc: media clausura, rd: radiación solar directa. 
El análisis individual de la cobertura macroscópica de diatomeas y de clorofitas reflejó diferencias de los factores analizados (pastoreo e irradiancia) sobre cada grupo algal. Para las diatomeas, la cobertura fue afectada significativamente por el pastoreo, provocando su disminución (Fig. 5.9a). Las diferencias entre placas pastoreadas y no pastoreadas estuvieron ausentes en las comunidades que recibieron sólo PAR (Fig. 5.9a). Para las clorofitas se observó un patrón diferente, ya que el porcentaje de cobertura no fue afectado por el pastoreo ni el tipo de radiación recibida (Fig. 5.9b).

a)

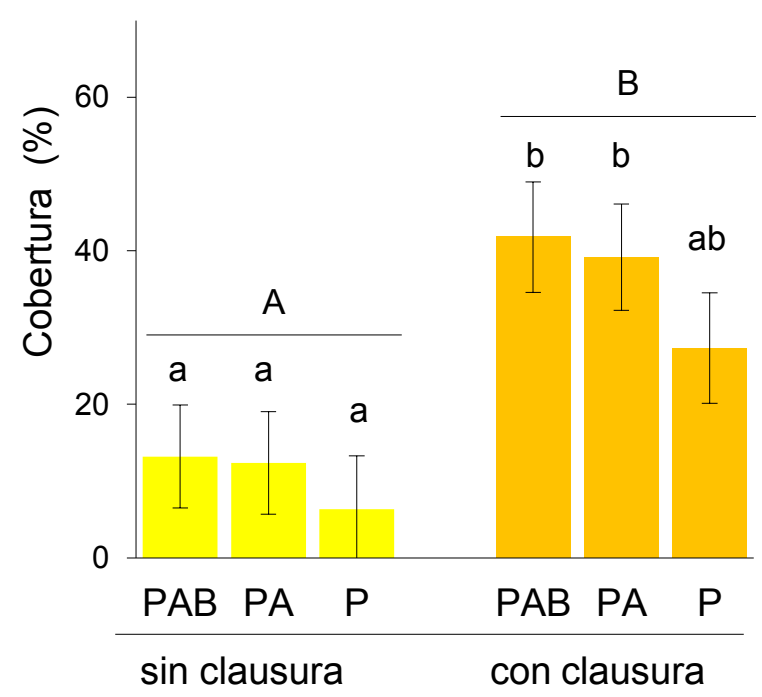

b)

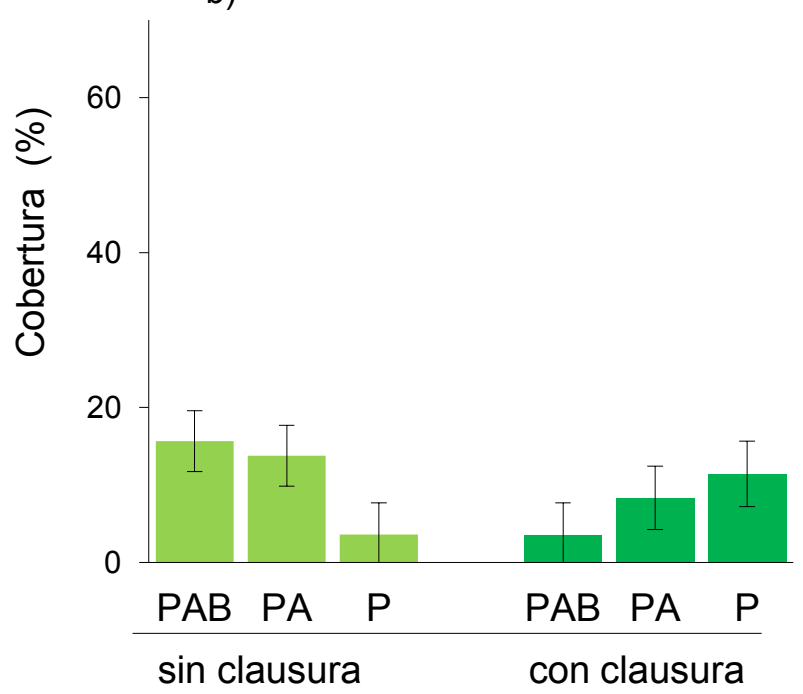

Fig. 5.9. Cobertura macroscópica de diatomeas y clorofitas. Efectos de la UV y el pastoreo sobre la cobertura macroscópica de diatomeas (a, en amarillo) y clorofitas (b, en verde) en las comunidades pastoreadas y no pastoreadas (sin clausura y con clausura respectivamente) sometidas a los diferentes tratamientos de irradiancia. Se indican las medias +/- error estándar. Las letras mayúsculas indican los resultados del test ANCOVA significativos $(p<0,05)$; las letras minúsculas indican las diferencias significativas del test de Duncan $(p<0,05)$. PAB: PAR + UV-A+ UV-B, PA: PAR + UV-A, P: sólo PAR. 
El análisis para cada tiempo de colonización mostró reducciones significativas de la cobertura macroscópica de diatomeas en las comunidades pastoreadas, a los 23 y 40 días de colonización (Fig. 5.10a, b).
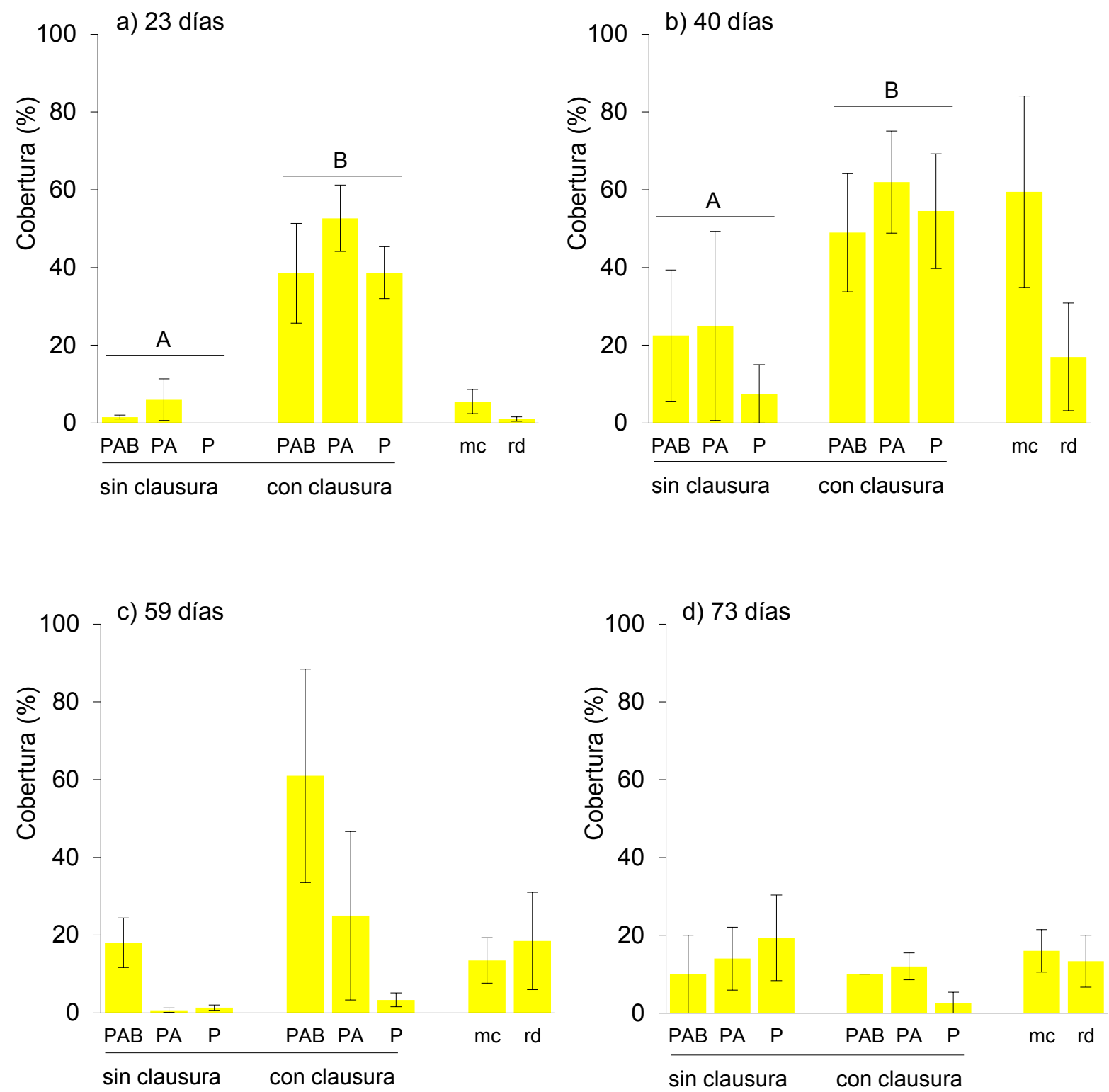

Fig. 5.10. Cobertura macroscópica de diatomeas luego de 23, 40, 59 y 73 días de colonización (a-d respectivamente). Se indican las medias +/- error estándar. PAB: PAR+ UV-A + UV-B, PA: PAR + UVA, P: sólo PAR, mc: media clausura, rd: radiación solar directa. 
En el caso de las clorofitas, en las comunidades de 23 días de colonización, la cobertura macroscópica fue afectada por el tipo de radiación recibida, con menores valores en el tratamiento que recibió PAR + UV-A + UV-B (Fig. 5.11a). Para este tiempo de colonización, no se registraron clorofitas a nivel macroscópico en las placas no pastoreadas (Fig. 5.11a).
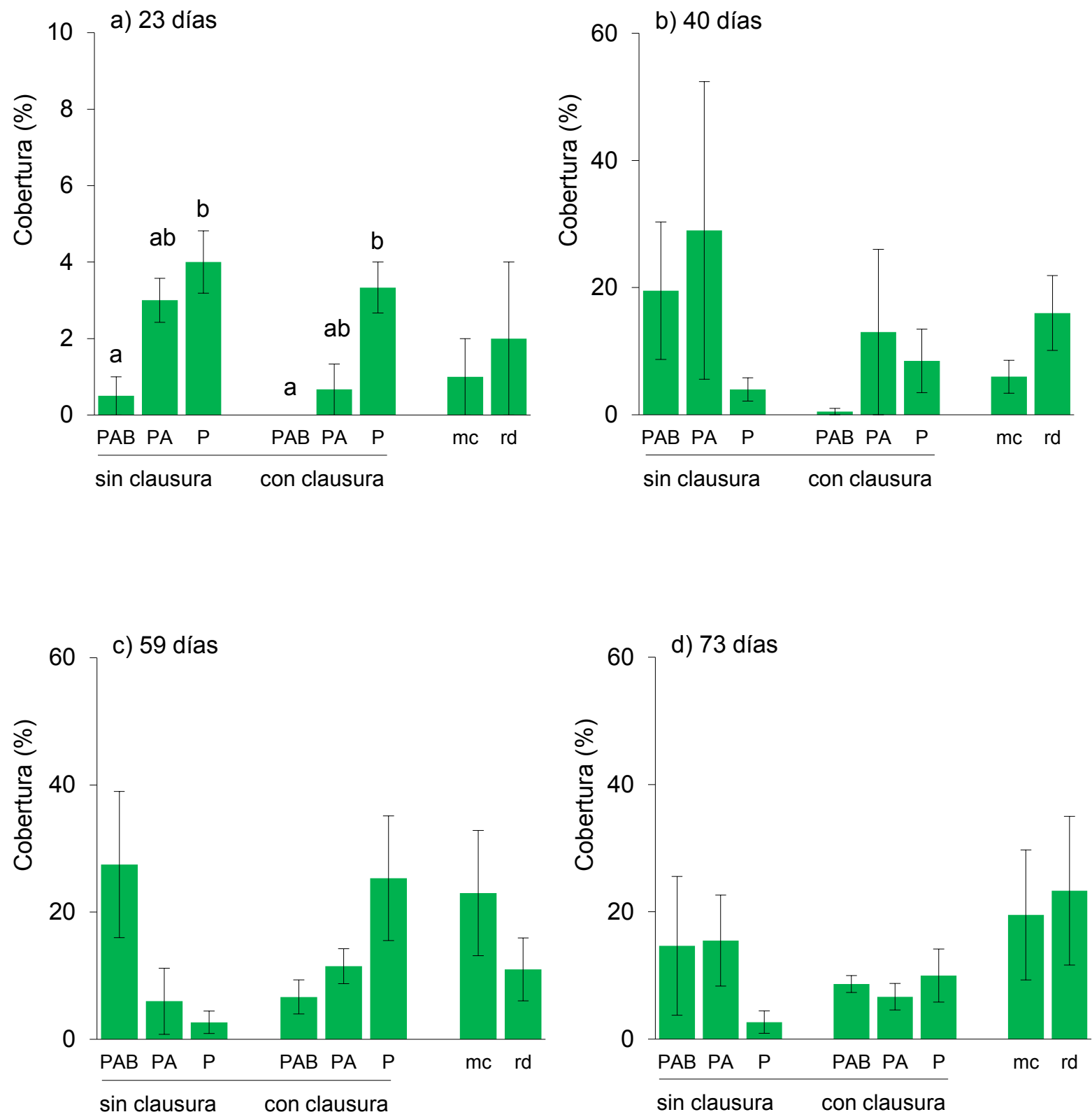

Fig. 5.11. Cobertura macroscópica de clorofitas luego de 23, 40, 59 y 73 días de colonización (a-d respectivamente). Se indican las medias +/- error estándar. Las letras indican diferencias significativas del test de comparaciones múltiples de rankings medios, a los 23 días de colonización. En este caso, se obtuvieron diferencias significativas para el factor irradiancia (Test de Kruskal-Wallis, $p<0,05)$. Nótese la escala diferente para el muestreo de 23 días. PAB: PAR + UV-A + UV-B, PA: PAR + UV-A, P: sólo PAR, mc: media clausura, rd: radiación solar directa. 


\section{Cobertura microscópica}

A nivel microscópico, las comunidades estuvieron dominadas por diatomeas bentónicas. En particular, se observaron formas coloniales de Fragilaria islandica var. adeliae, F. striatula y Achnanthes brevipes (Lám. XX, Cap. 3). Entre las macroalgas, se identificaron dos especies de clorofitas filamentosas: U. penicilliformis y Ulothrix flacca. Además, se observaron pequeños estadios iniciales de rodofitas, entre ellas, Palmaria decipiens, Rhodocorthon cf. purpureum y morfotipos de la familia Delesseriaceae que se agruparon en una misma categoría (Fig. 5.12).

23 días

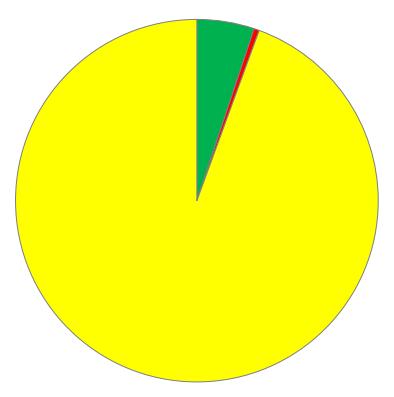

59 días

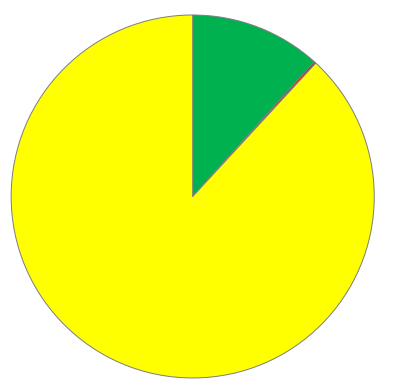

40 días

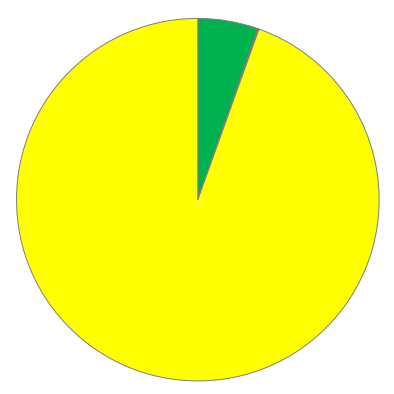

73 días

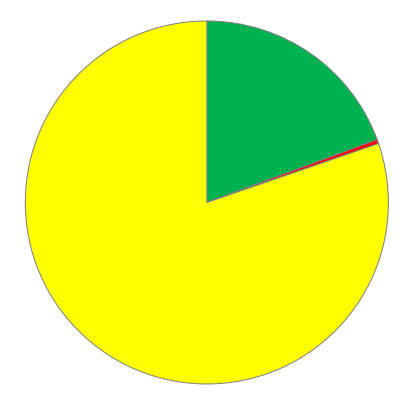

Fig. 5.12. Composición taxonómica luego de 23, 40, 59 y 73 días de colonización, a nivel microscópico. Se muestran los promedios de las abundancias relativas de la cobertura microscópica de diatomeas (en amarillo), clorofitas (en verde) y rodofitas (en rojo).

El análisis a este nivel de resolución indicó diferencias en las respuestas de los tres grupos algales a los distintos tratamientos. Entre las diatomeas, el porcentaje de cobertura fue reducido por el pastoreo ( $p<0,05$, Fig. 5.13a). Entre las comunidades pastoreadas, la cobertura fue significativamente menor en las que la UV-B estuvo ausente (en los tratamientos que recibieron PAR y PAR + UV-A) comparadas con todas las comunidades 
que no tuvieron clausura (Test de Duncan, $p<0,05$ ). El porcentaje de cobertura microscópico de clorofitas no fue afectado por el pastoreo ni el tipo de radiación recibida ( $p>0,05$, Fig. $5.13 b)$. Las rodofitas presentaron una respuesta diferente, ya que su porcentaje de cobertura fue afectado por el tipo de radiación recibida y el pastoreo, con mayores valores para los tratamientos pastoreados en los que la UV estuvo ausente (aquellos que recibieron sólo PAR) (ANCOVA, $p<0,05$; Test de Duncan, $p<0,05$, Fig. 5.13c).

a)

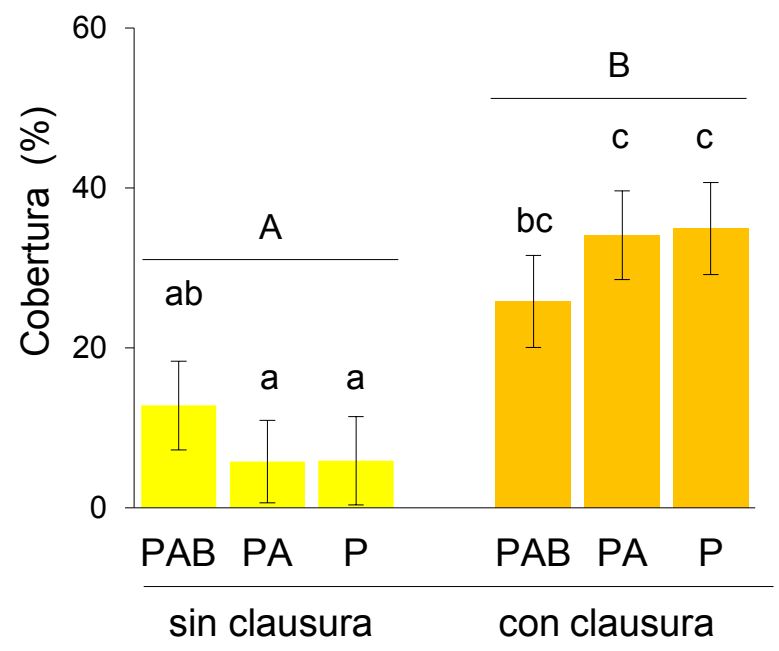

c)

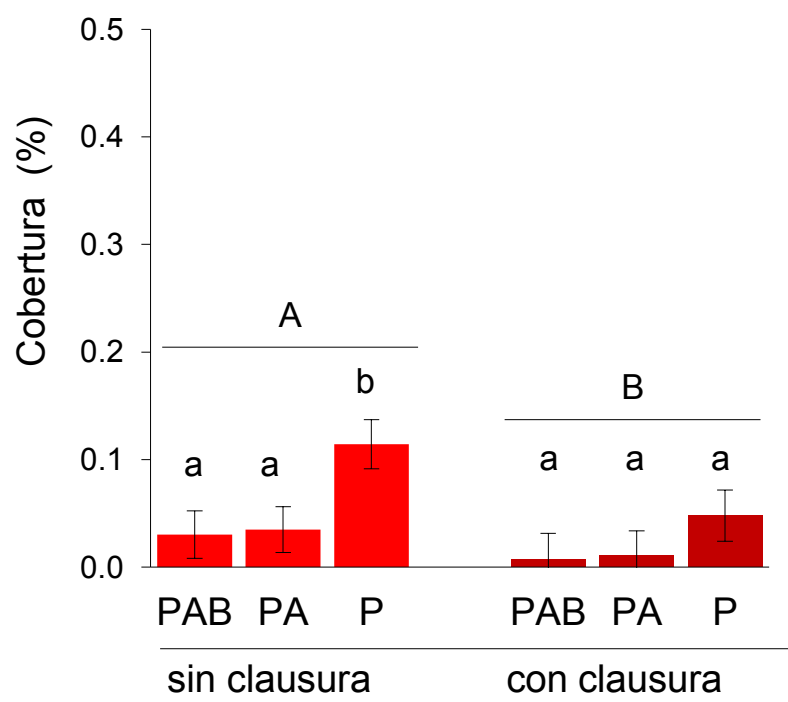

b)

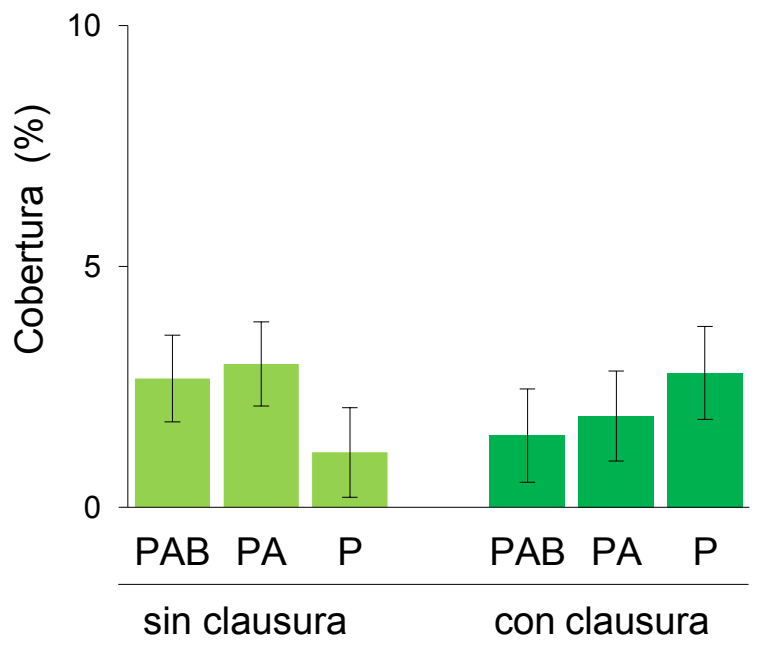

Fig. 5.13. Cobertura microscópica de diatomeas, clorofitas y rodofitas. Efectos de la UV y el pastoreo sobre la cobertura microscópica de diatomeas (a), clorofitas (b) y rodofitas (c). Se indican las medias $+/$ - error estándar. Las letras mayúsculas indican los resultados del test ANCOVA significativos para el factor pastoreo, para la cobertura microscópica de diatomeas y rodofitas $(p<0,05)$. Las letras minúsculas indican las diferencias significativas del Test de Duncan. PAB: PAR + UV-A + UV-B, PA: PAR + UV-A, P: sólo PAR. 
Para el caso de las diatomeas, el análisis para cada tiempo de colonización reveló menores valores de cobertura luego de 23 y 40 días, sin registrarse efectos de la irradiancia (Test de Kruskal Wallis, $p<0,05$, Fig. 5.14). No hubo efectos del pastoreo o de la irradiancia luego de 59 y 73 días de colonización.
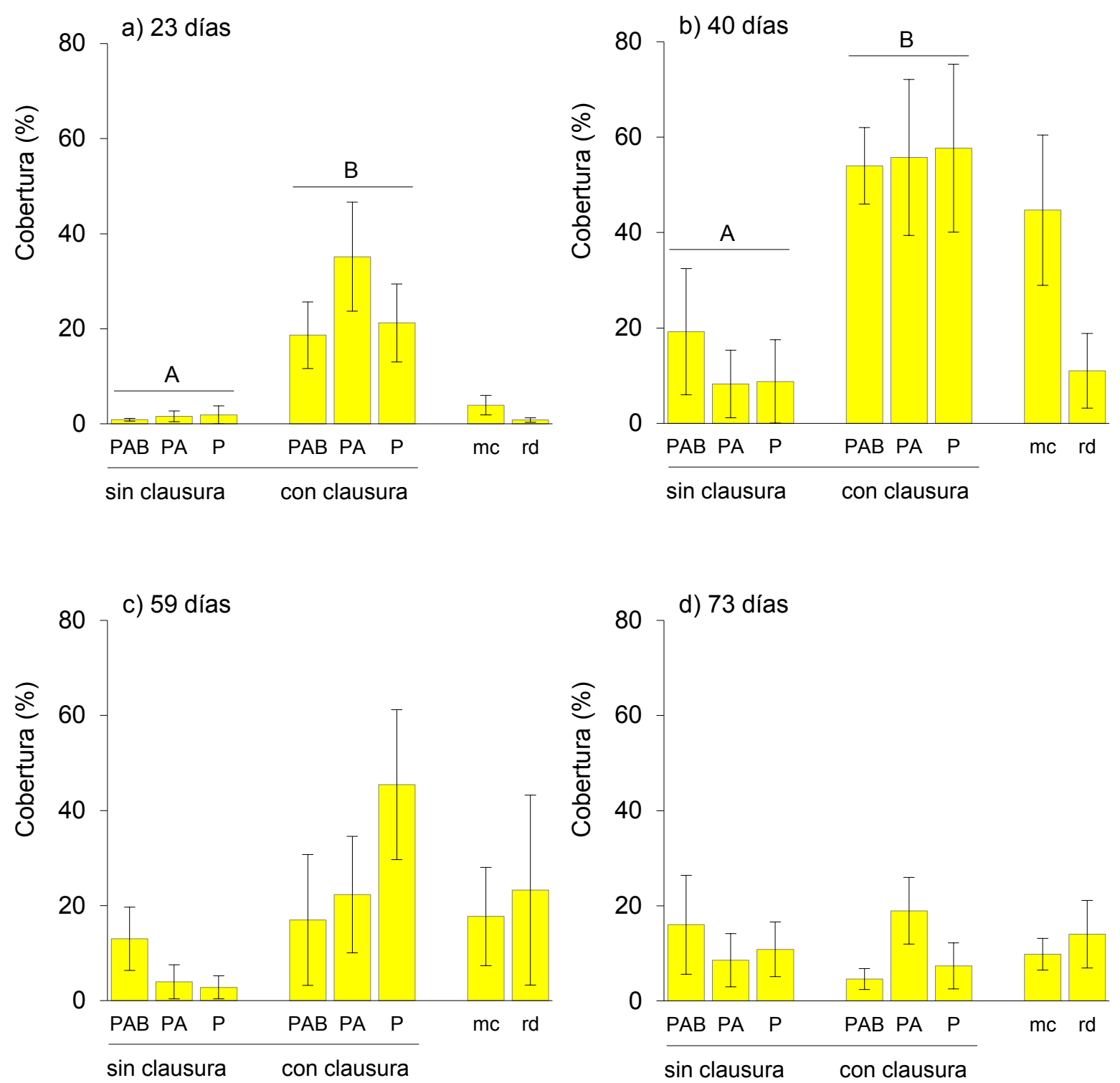

Fig. 5.14. Cobertura microscópica de diatomeas luego de 23, 40, 59 y 73 días de colonización (a-d respectivamente). Se indican las medias $+/$ - error estándar. Las letras indican diferencias significativas del Test de Kruskal Wallis, para el factor pastoreo $(p<0,05)$, a los 23 días de colonización. PAB: PAR + UV-A + UV-B, PA: PAR + UV-A, P: sólo PAR, mc: media clausura, rd: radiación solar directa. 
Para el caso de las clorofitas, el porcentaje de cobertura microscópico fue reducido significativamente por el pastoreo únicamente en el muestreo de 23 días (Test de Kruskal Wallis, $p<0,05)$. En los demás muestreos se observaron tendencias similares a las del resultado global (Fig. 5.15).
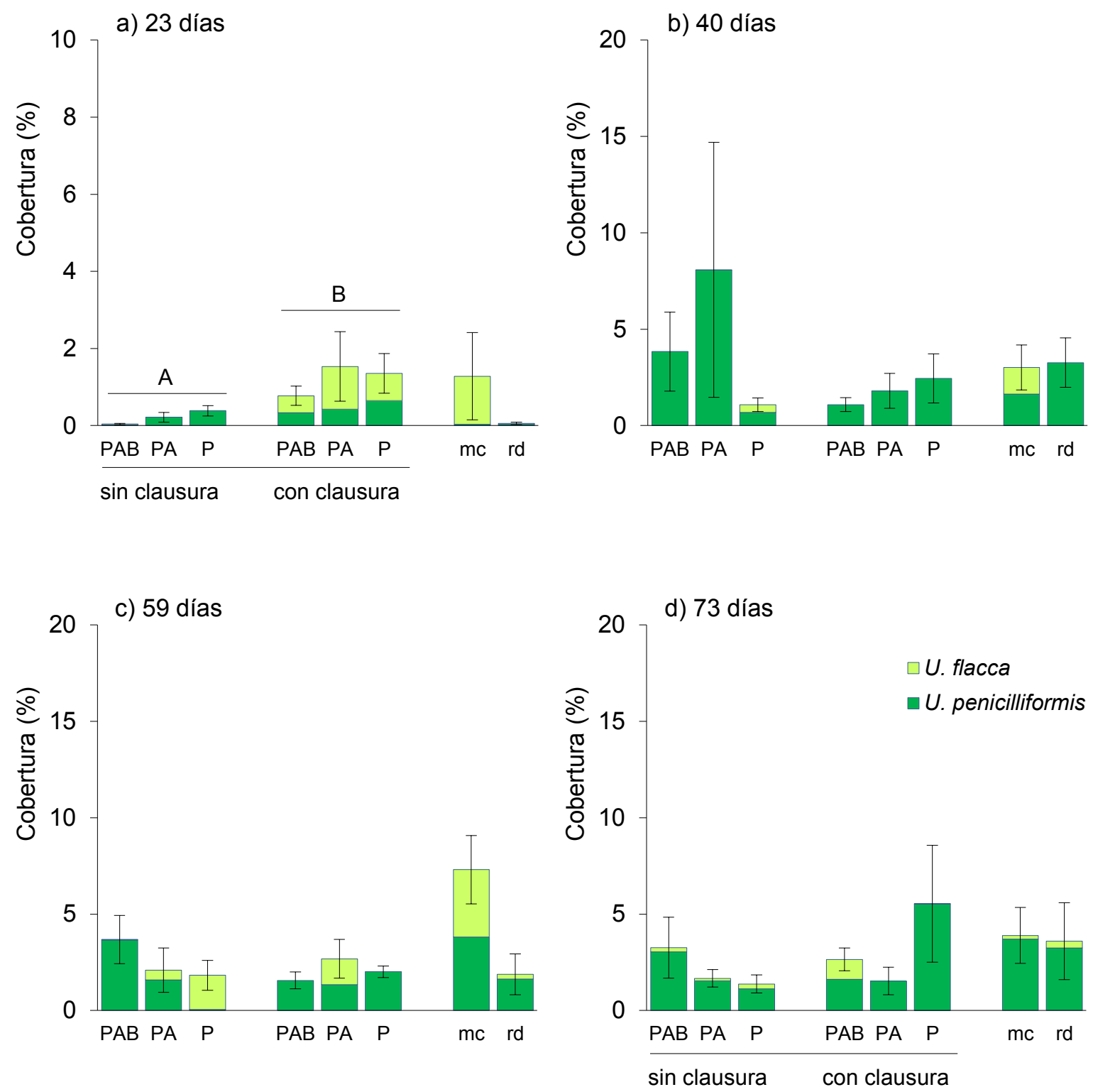

Fig. 5.15. Cobertura microscópica de clorofitas luego de 23, 40, 59 y 73 días de colonización (a-d respectivamente). Se indican las medias +/- error estándar. Las letras indican diferencias significativas del Test de Kruskal Wallis, para el factor pastoreo $(p<0,05)$, a los 23 días de colonización. Nótese la escala diferente para el muestreo de 23 días. PAB: PAR + UV-A + UV-B, PA: PAR + UV-A, P: sólo PAR, mc: media clausura, rd: radiación solar directa. 
Luego de 23 días de colonización, el porcentaje de cobertura de rodofitas fue mayor en las comunidades pastoreadas (Fig. 5.16a). Luego de 40 días, hubo un efecto significativo de la irradiancia recibida, aunque los resultados del test post hoc no fueron significativos. No hubo efectos significativos del pastoreo o el tipo de radiación recibida en los demás tiempos de colonización. Se observó una elevada dispersión de los datos en el último muestreo, debido a la aparición de unos pocos estadios juveniles de $P$. decipiens de mayor tamaño.
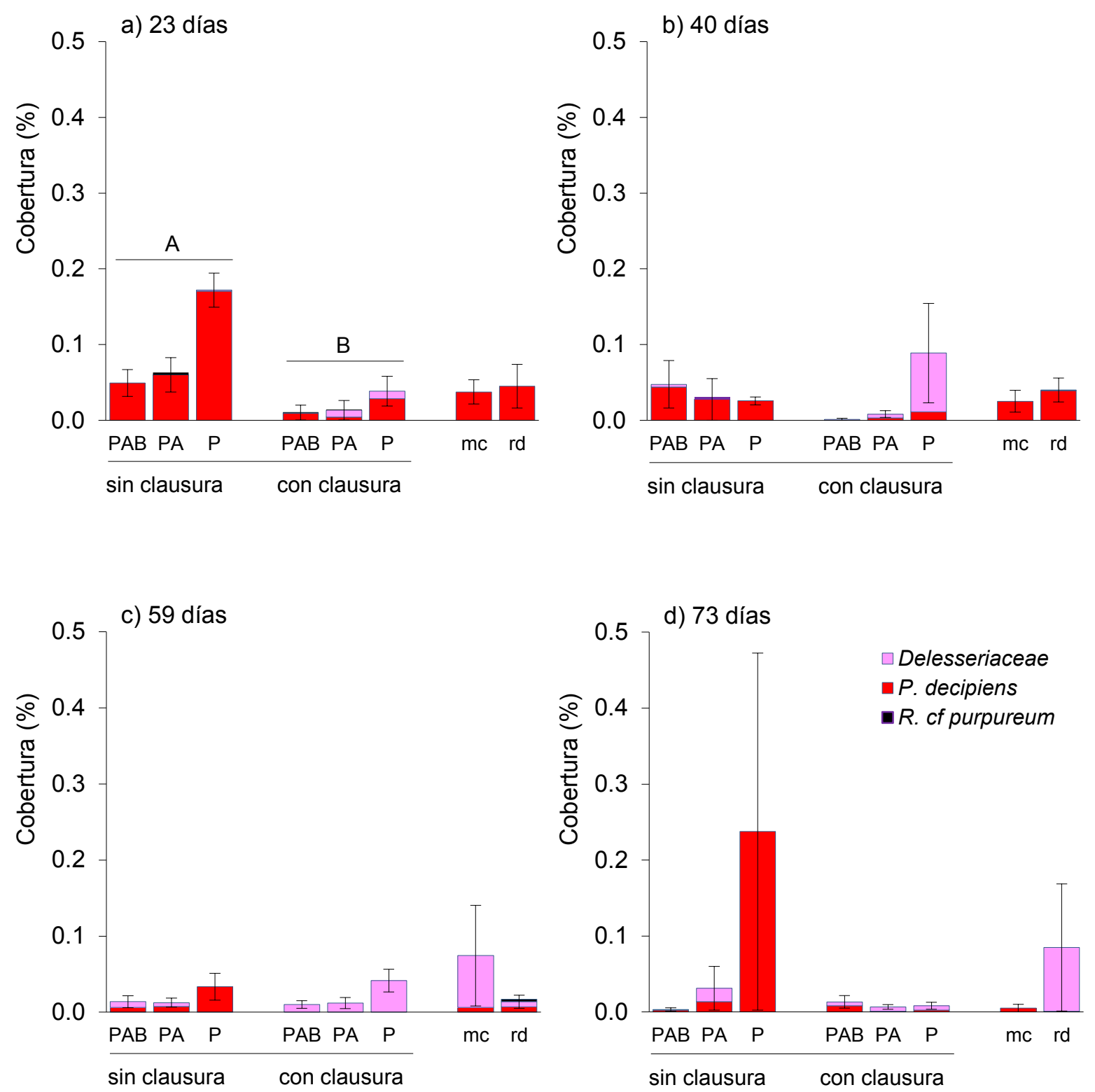

Fig. 5.16. Cobertura microscópica de rodofitas luego de 23, 40, 59 y 73 días de colonización (a-d respectivamente). Se indican las medias +/- error estandar. Las letras indican diferencias significativas del Test de Kruskal Wallis, para el factor pastoreo $(p<0,05)$, a los 23 días de colonización. PAB: PAR + UV-A + UV-B, PA: PAR + UV-A, P: sólo PAR, mc: media clausura, rd: radiación solar directa. 


\section{Índices ecológicos y composición}

La riqueza de taxa de la comunidad no fue afectada por los factores analizados $(p<0,05$, Fig. 5.17). La equitatividad fue mayor en las comunidades pastoreadas ( $p<0,05$, Fig. 5.17) para todos los tratamientos de irradiancia. Del mismo modo, la diversidad fue mayor en las comunidades pastoreadas ( $p<0,05$, Fig. 5.17). Se detectó mayor diversidad en las comunidades pastoreadas en las que la UV-B estuvo ausente (En los tratamientos que recibieron UV-A y PAR, y los que recibieron sólo PAR) respecto a las comunidades no pastoreadas que recibieron UV-A.
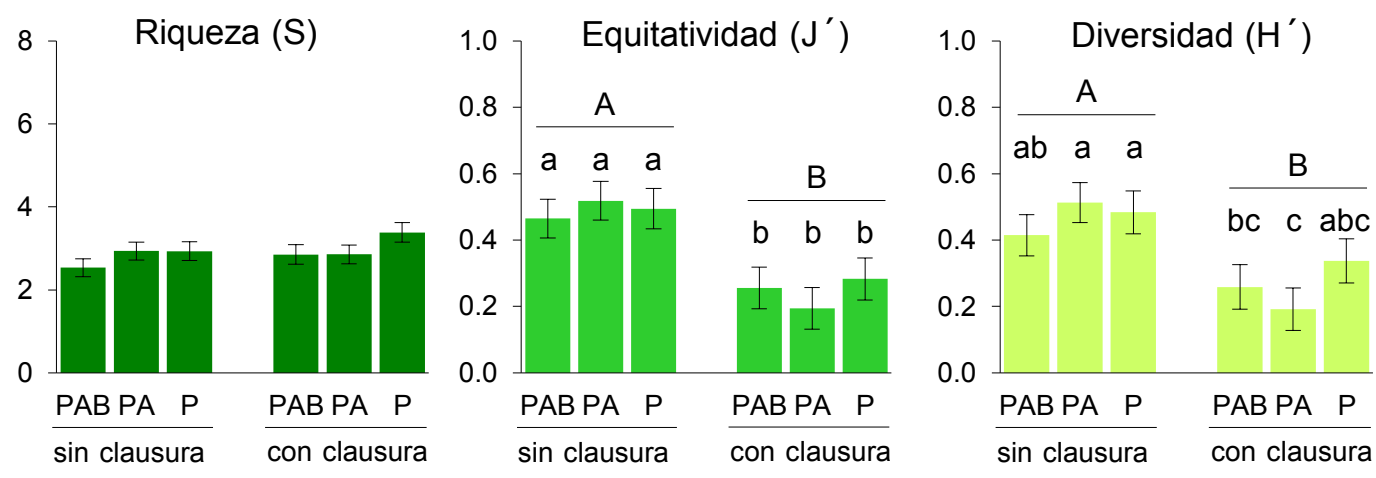

Fig. 5.17. Riqueza, equitatividad y diversidad de las comunidades. Se indican las medias $+/-$ error estándar. Las letras mayúsculas indican los resultados significativos del test ANCOVA/MANOVA $(p<0.05)$, las letras minúsculas indican las diferencias significativas del Test de Duncan $(p<0.05)$. PAB: PAR + UV-A + UV-B, PA: PAR + UV-A, P: sólo PAR. PAB: PAR + UV-A + UV-B, PA: PAR + UVA, P: sólo PAR.

En el análisis por tiempo de colonización, no se observaron efectos de la radiación recibida o el pastoreo sobre la riqueza de las comunidades (Fig. 5.18). Sin embargo, se observaron mayores valores de equitatividad en las placas pastoreadas luego de 23, 40 y 59 días de colonización, y un aumento de la diversidad luego de 23 y 59 días. No se registraron efectos de la radiación recibida o del pastoreo en las comunidades de 73 días de colonización. 
a) 23 días

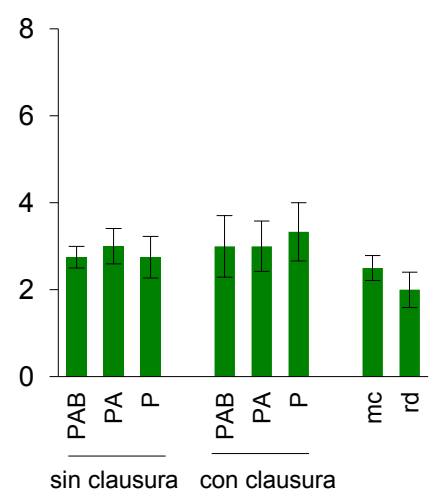

b) 40 días

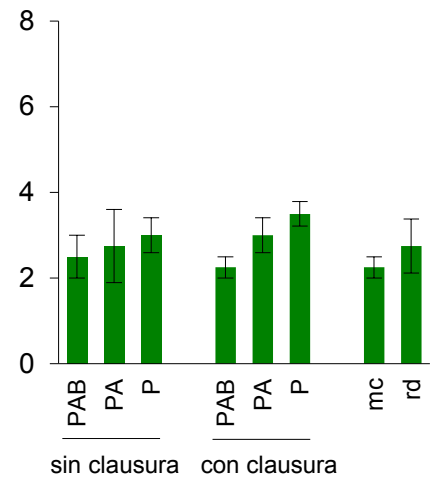

c) 59 días

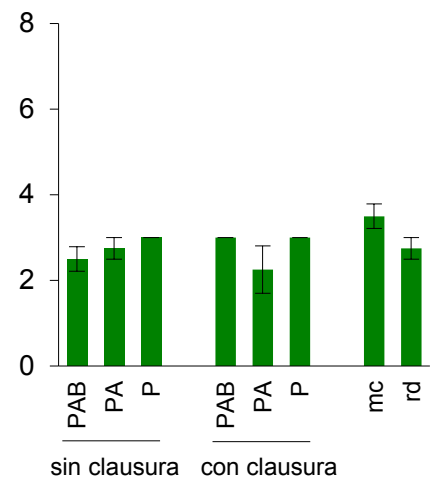

d) 73 días

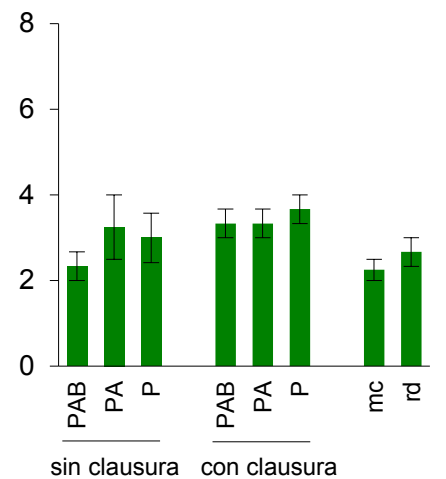

Equitatividad

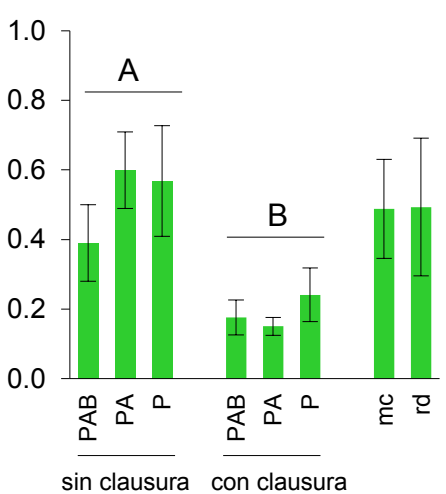

Diversidad

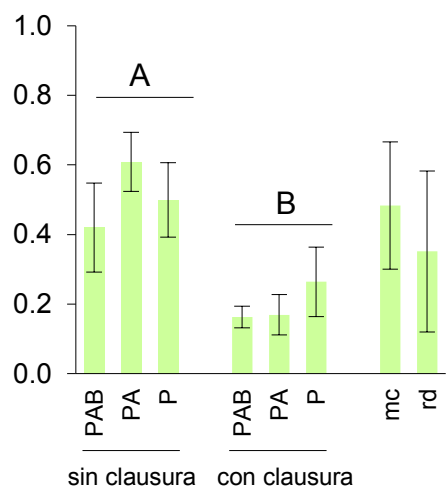

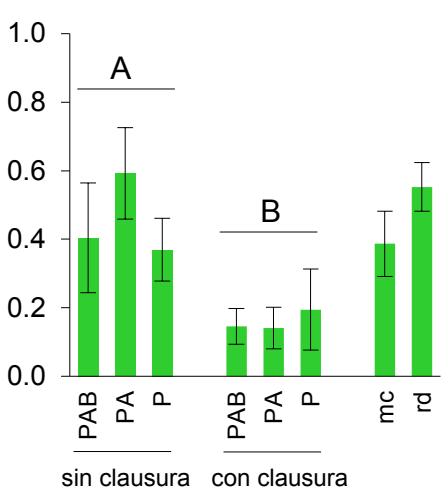

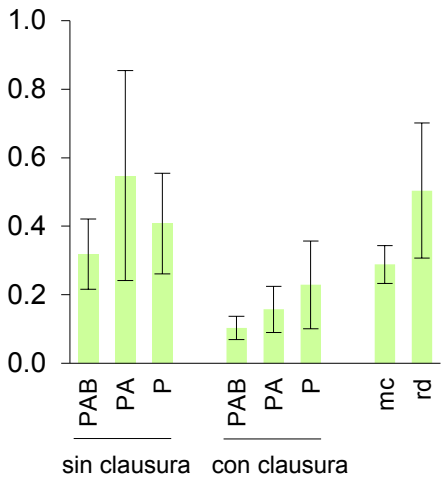

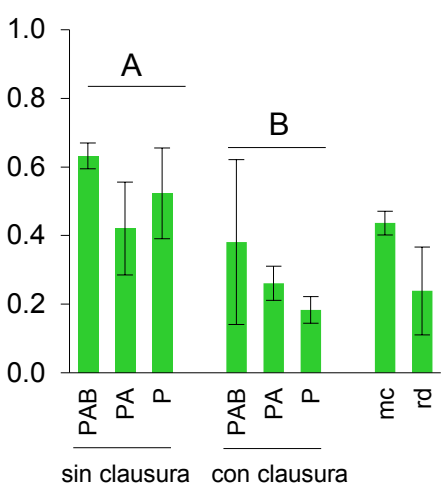

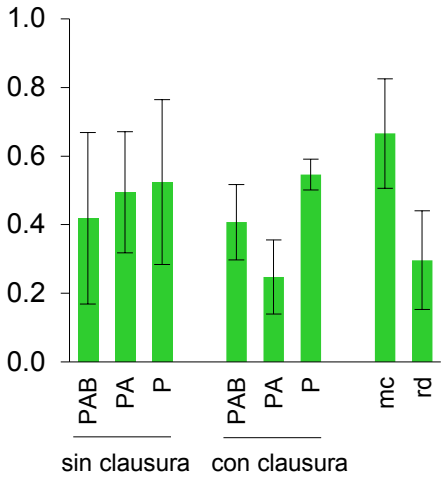

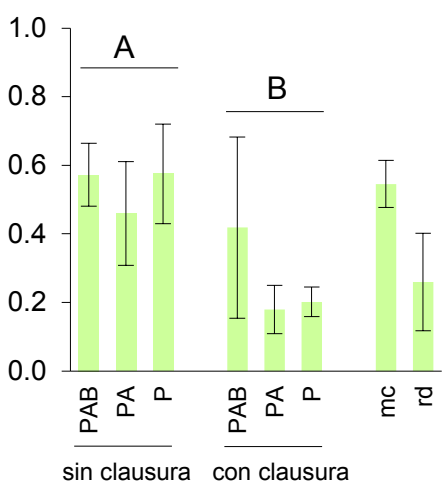

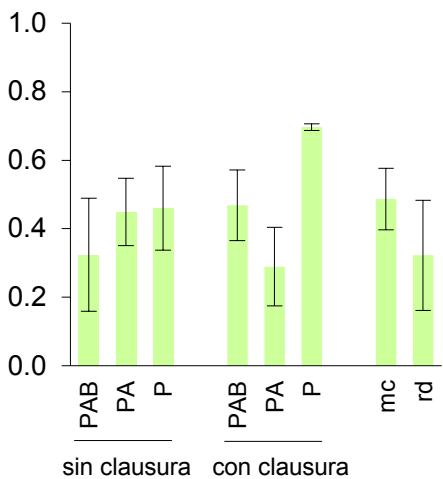

Fig. 5.18. Riqueza, equitatividad y diversidad de las comunidades a nivel microscópico, luego de 23, 40, 59 y 73 días de colonización (a-d respectivamente). Se indican las medias +/- error estandar. Las letras indican diferencias significativas entre tratamientos pastoreados y no pastoreados (Test de Kruskal Wallis, $p<0,05 ; p<0,0125$ para J luego de 23 días de colonización). PAB: PAR + UV-A + UVB, PA: PAR + UV-A, P: sólo PAR, mc: media clausura, rd: radiación solar directa. 
La composición de la comunidad fue afectada por el pastoreo luego de 23 y 40 días de colonización (ANOSIM, Tabla 5.3). Los tratamientos de irradiancia no afectaron la composición de las comunidades en ningún caso (ANOSIM, Tabla 5.3).

El ordenamiento mediante escalamiento no métrico multidimensional (nMDS) se observa en la Fig. 5.19. Se obtuvieron representaciones en dos dimensiones, caracterizadas como buenas (para los muestreos de 23 y 40 días, stress $<0,1$ ) y excelentes (para el caso de 59 y 73 días de colonización, stress <0,05) según Clarke \& Warick (2001) (Fig. 5.19).

Tabla 5.3. Análisis de Similitud (ANOSIM) para las comunidades de 23, 40, 59 y 73 días de colonización, para los factores pastoreo (sin clausura y con clausura) e irradiancia (PAB, PA y P). Se indica el $R$ global y el nivel de significación. En negrita se indican los resultados significativos $(p<$ $0,05)$.

\begin{tabular}{|c|c|c|}
\hline \multirow{2}{*}{$\begin{array}{c}\text { Tiempo de } \\
\text { colonización }\end{array}$} & \multicolumn{2}{|c|}{ ANOSIM de dos vías } \\
\hline & Pastoreo & Irradiancia \\
\hline 23 días & R: $0,676 p=0,001$ & $R: 0,131 p=0,122$ \\
\hline 40 días & R: $0,385 p=0,002$ & $R: 0,027 p=0,349$ \\
\hline 59 días & $\mathrm{R}: 0,124 p=0,194$ & $R:-0,023 p=0,505$ \\
\hline 73 días & R: $0,099 p=0,202$ & R: $-0,016 p=0.526$ \\
\hline
\end{tabular}

Luego de 23 días de colonización, la composición de las comunidades pastoreadas y no pastoreadas fue significativamente diferente. Los taxa que más contribuyeron a las diferencias entre los ensambles pastoreados y no pastoreados fueron las diatomeas coloniales, U. flacca, U. penicilliformis y Palmaria decipiens, que juntas, contribuyeron al 93,39\% de la disimilitud entre tratamientos (SIMPER, Tabla 5.4a). Los estadios juveniles de la familia Delesseriaceae y $R$. cf purpureum contribuyeron en menor medida $(<10 \%)$ a las diferencias entre tratamientos (SIMPER, Tabla 5.4a). El pastoreo, por lo tanto, afectó negativamente a la cobertura de diatomeas y clorofitas, a los estadios juveniles de la familia Delesseriaceae y de $R$. cf purpureum y favorecieron la cobertura de $P$. decipiens (Tabla 5.4). Las diferencias significativas entre los ensambles de las comunidades pastoreadas y no pastoreadas se evidenciaron en el ordenamiento en dos dimensiones, observándose una separación entre las muestras sin clausura y con clausura (Fig. 5.19a). 
Tabla 5.4. Resultados del Análisis SIMPER. Se indica el porcentaje de disimilitud total promedio para los ensambles de 23 y 40 días de colonización, entre las comunidades sin clausura (pastoreadas) y con clausura (no pastoreadas), y la contribución de cada taxa a la disimilitud total, expresada en porcentaje). Se indican en negrita los taxa que contribuyeron al $90 \%$ de la disimilitud entre tratamientos. El análisis se realizó a partir de los datos de porcentaje de cobertura de cada taxa previamente transformadas como raíz cuarta.

\section{SIMPER}

\begin{tabular}{|c|c|c|c|c|}
\hline \multirow[t]{3}{*}{ a ) 23 días } & \multicolumn{4}{|c|}{ \% Disimilitud: 53,81} \\
\hline & \multicolumn{2}{|c|}{ Abundancia promedio } & \multirow{2}{*}{$\begin{array}{c}\% \\
\text { Contribución } \\
\text { relativa }\end{array}$} & \multirow{2}{*}{$\begin{array}{c}\% \\
\text { Contribución } \\
\text { acumulada }\end{array}$} \\
\hline & $\begin{array}{l}\text { Sin } \\
\text { clausura }\end{array}$ & $\begin{array}{l}\text { Con } \\
\text { clausura }\end{array}$ & & \\
\hline Diatomeas & 0,80 & 2,12 & 46,71 & 46,71 \\
\hline Ulothrix flacca & 0,05 & 0,49 & 16,56 & 63,26 \\
\hline Urospora penicilliformis & 0,50 & 0,54 & 16,43 & 79,70 \\
\hline Palmaria decipiens & 0,52 & 0,17 & 13,70 & 93,39 \\
\hline Delesseriaceae & 0,02 & 0,13 & 4,28 & 97,67 \\
\hline Rhodochorton cf purpureum & 0,03 & 0,04 & 2,33 & 100 \\
\hline
\end{tabular}

\begin{tabular}{|c|c|c|c|c|}
\hline \multirow[t]{3}{*}{ b) $\mathbf{4 0}$ días } & \multicolumn{4}{|c|}{$\%$ Disimilitud: 51,50} \\
\hline & \multicolumn{2}{|c|}{ Abundancia promedio } & \multirow{2}{*}{$\begin{array}{c}\% \\
\begin{array}{c}\text { Contribución } \\
\text { relativa }\end{array} \\
\end{array}$} & \multirow{2}{*}{$\begin{array}{c}\% \\
\text { Contribución } \\
\text { acumulada }\end{array}$} \\
\hline & $\begin{array}{l}\text { Sin } \\
\text { clausura }\end{array}$ & $\begin{array}{l}\text { Con } \\
\text { clausura }\end{array}$ & & \\
\hline Diatomeas & 1,08 & 2,66 & 55,86 & 55,86 \\
\hline Urospora penicilliformis & 0,94 & 1,05 & 20,17 & 76,03 \\
\hline Palmaria decipiens & 0,32 & 0,09 & 8,59 & 84,62 \\
\hline Ulothrix flacca & 0,23 & 0 & 7,76 & 92,38 \\
\hline Delesseriaceae & 0,03 & 0,23 & 6,76 & 99,14 \\
\hline Rhodochorton cf purpureum & 0,03 & 0 & 0,86 & 100 \\
\hline
\end{tabular}

Tal como ocurrió para el caso del muestreo de 23 días de colonización, sólo el pastoreo afectó la composición de las comunidades luego de 40 días. Los taxa que más contribuyeron a las diferencias entre los ensambles pastoreados y no pastoreados $(92,38 \%$ de la disimilitud) fueron las diatomeas coloniales, $U$. penicilliformis, $P$. decipiens y $U$. flacca (SIMPER, Tabla 5.4b). La presencia de estadios iniciales de la familia Delesseriaceae y de $R$. cf purpureum contribuyeron en menor medida $(<10 \%)$ a las diferencias entre tratamientos (SIMPER, Tabla 5.4b). El pastoreo, por lo tanto, afectó negativamente a la cobertura de diatomeas, de U. penicilliformis y de la familia Delesseriaceae y positivamente a la cobertura de $P$. decipiens, $U$. flacca y $R$. cf purpureum. Estos dos últimos taxa estuvieron ausentes en las comunidades no pastoreadas. En el ordenamiento en dos dimensiones, se observó una mayor dispersión entre los grupos pastoreados, mientras que los no pastoreados se observaron agrupados. Este patrón fue similar en los demás tiempos de colonización (Fig. $5.19 b-d)$. 


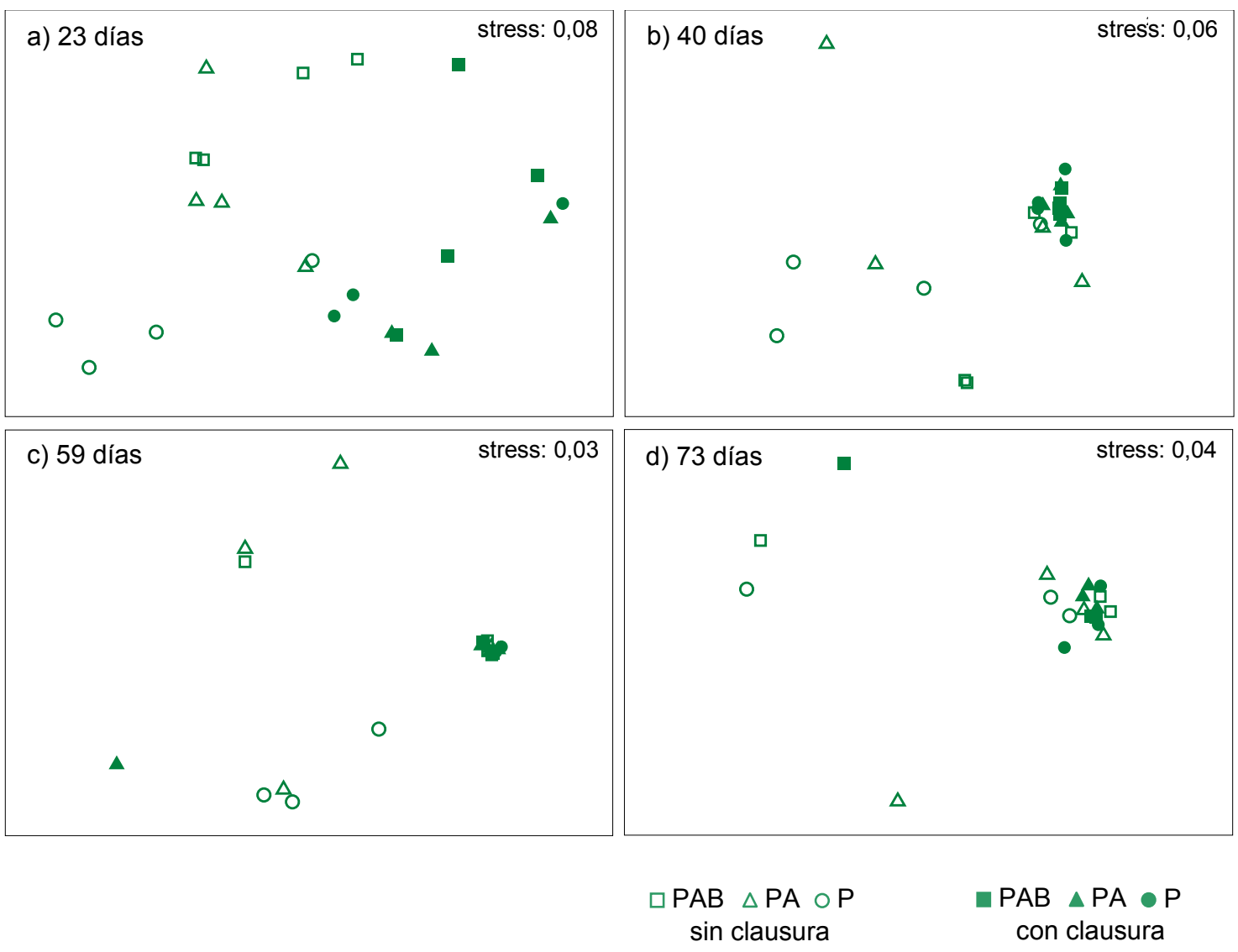

Fig. 5.19. Ordenamiento de ensambles de las comunidades a nivel microscópico, obtenido mediante escalamiento no métrico multidimensional (nMDS) luego de 23, 40, 59 y 73 días de colonización. El ordenamiento en dos dimensiones se obtuvo a partir de la construcción de una matriz de similitud empleando el índice de Bray Curtis, a partir de los datos de porcentaje de cobertura de cada taxa previamente transformadas como raíz cuarta.

\section{Ensambles de diatomeas}

\section{Densidad de diatomeas}

El pastoreo disminuyó significativamente la densidad de diatomeas, estimada como el número total de células por $\mathrm{cm}^{2}(p<0,05$, Fig. 5.20). Entre las comunidades pastoreadas, las que recibieron sólo PAR presentaron una densidad significativamente menor que las que recibieron el espectro completo (en el tratamiento PAB). Además, difirieron significativamente de las comunidades pastoreadas que recibieron sólo PAR y PAR + UV-A, El número de células vivas no fue afectado por el pastoreo ni el tipo de radiación recibida, mientras que el número de células muertas sólo fue afectado por el pastoreo, con menores valores en las comunidades pastoreadas respecto a las no pastoreadas $(p<0,05)$. 


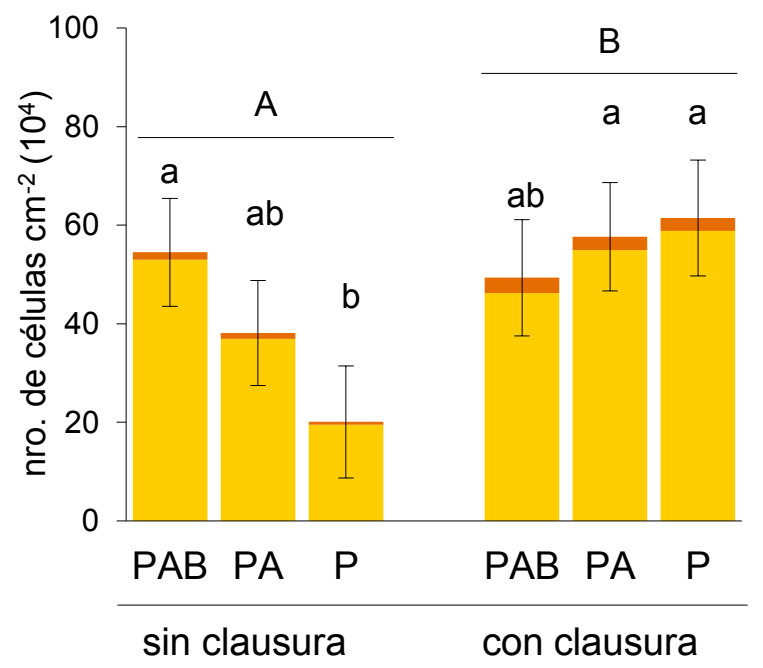

Fig. 5.20. Densidad de células de diatomeas. Efectos de la UV y el pastoreo sobre el número total de células. Se muestran las medias $+/$ - el error estándar (ANCOVA, $p<0,05$ ), Las letras mayúsculas indican los resultados significativos del test ANCOVA/MANOVA $(p<0,05)$, Las letras minúsculas indican las diferencias significativas del Test de Duncan $(p<0,05)$, Se indican además, las células vivas (en naranja) y los frústulos vacíos o células muertas (en marrón). PAB: PAR + UV-A + UV-B, PA: PAR + UV-A, P: sólo PAR.

En el análisis para cada muestreo, se observó una disminución significativa de la densidad de diatomeas totales y vivas en los tratamientos pastoreados luego de 23 días de colonización ( $p<0,0125$, Fig. 5.21a). Se detectó un efecto de artefacto asociado a la presencia de filtros únicamente en el muestreo de 23 días de colonización, con mayores valores en este control (rd) respecto al tratamiento pastoreado que recibió PAR + UV-A + UV-B (Fig. 5.21a). Para el caso del muestreo de 40 días de colonización, se registró una densidad mayor de células muertas en los tratamientos con clausura (Test de Kruskal Wallis, $p<0,05$, Fig. 5.21b).

\section{Composición taxonómica}

Se identificaron 25 taxa de diatomeas, con clara dominancia de formas pennadas que representaron el $92 \%$ del total de taxa hallados. Los ensambles de los tratamientos con clausura presentaron gran abundancia de formas coloniales formando matas densas, particularmente durante la primera mitad del experimento. En términos generales, los taxa Fragilaria islandica/striatula, Navicula perminuta y Pseudogomphonema kamtschaticum presentaron las mayores abundancias relativas y densidades (Apéndice 5.2, Figs. 5.22-23). 

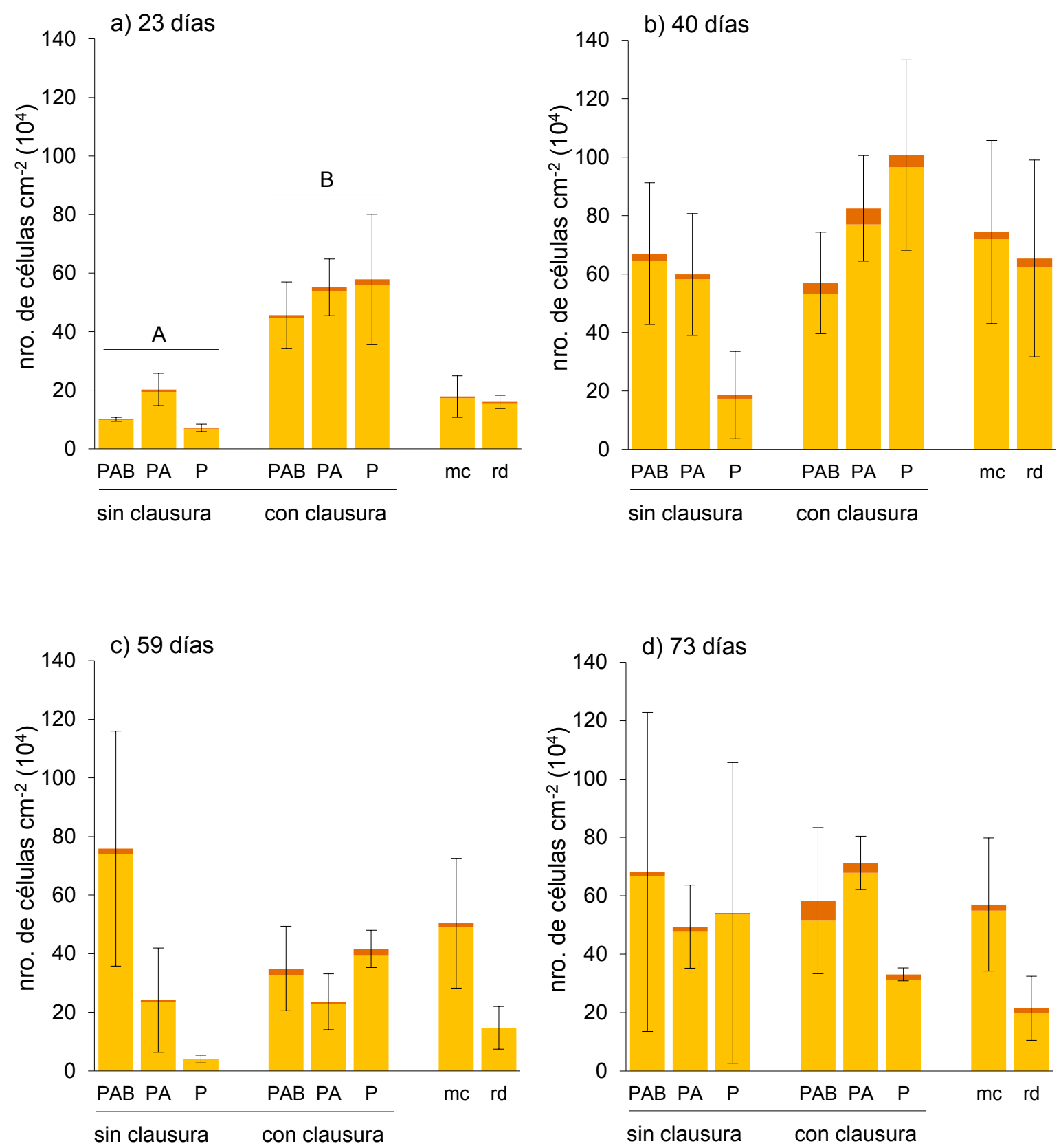

Fig. 5.21. Densidad total de células de diatomeas luego de 23, 40, 59 y 73 días de colonización (a-d, respectivamente). Se indican las medias $+/-$ el error estándar. Las letras indican diferencias significativas entre tratamientos pastoreados y no pastoreados para la densidad total y la densidad de células vivas (Test de Kruskal Wallis, $p<0,0125$ ). Se indican además, las células vivas (en naranja) y los frústulos vacíos o células muertas (en marrón). PAB: PAR + UV-A + UV-B, PA: PAR + UV-A, P: sólo PAR, mc: media clausura, rd (radiación solar directa). Solo se detectaron efectos de artefacto para la densidad de células totales y vivas en el muestreo de 23 días, y de células muertas en el muestreo de 59 días (Test de Mann Whitney, $p<0,05$ ). 

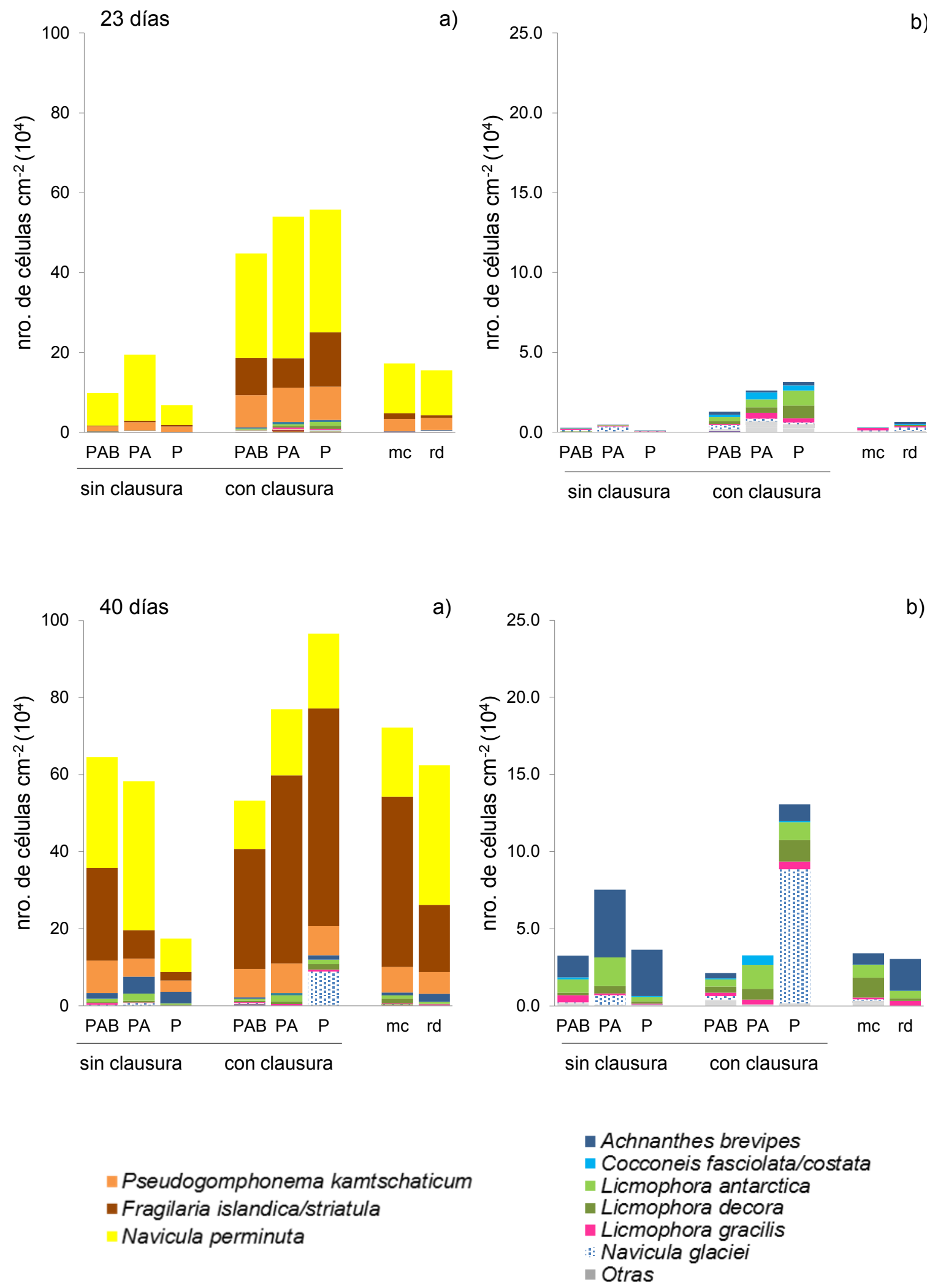

Fig. 5.22. Composición de taxa de diatomeas luego de 23 y 40 días de colonización, Se indica con diferentes colores la densidad de células vivas de a) el total de las especies y b) los taxa excluyendo a los tres dominantes (Navicula perminuta, Pseudogomphonema kamtschaticum y el complejo Fragilaria islandica/striatula). 

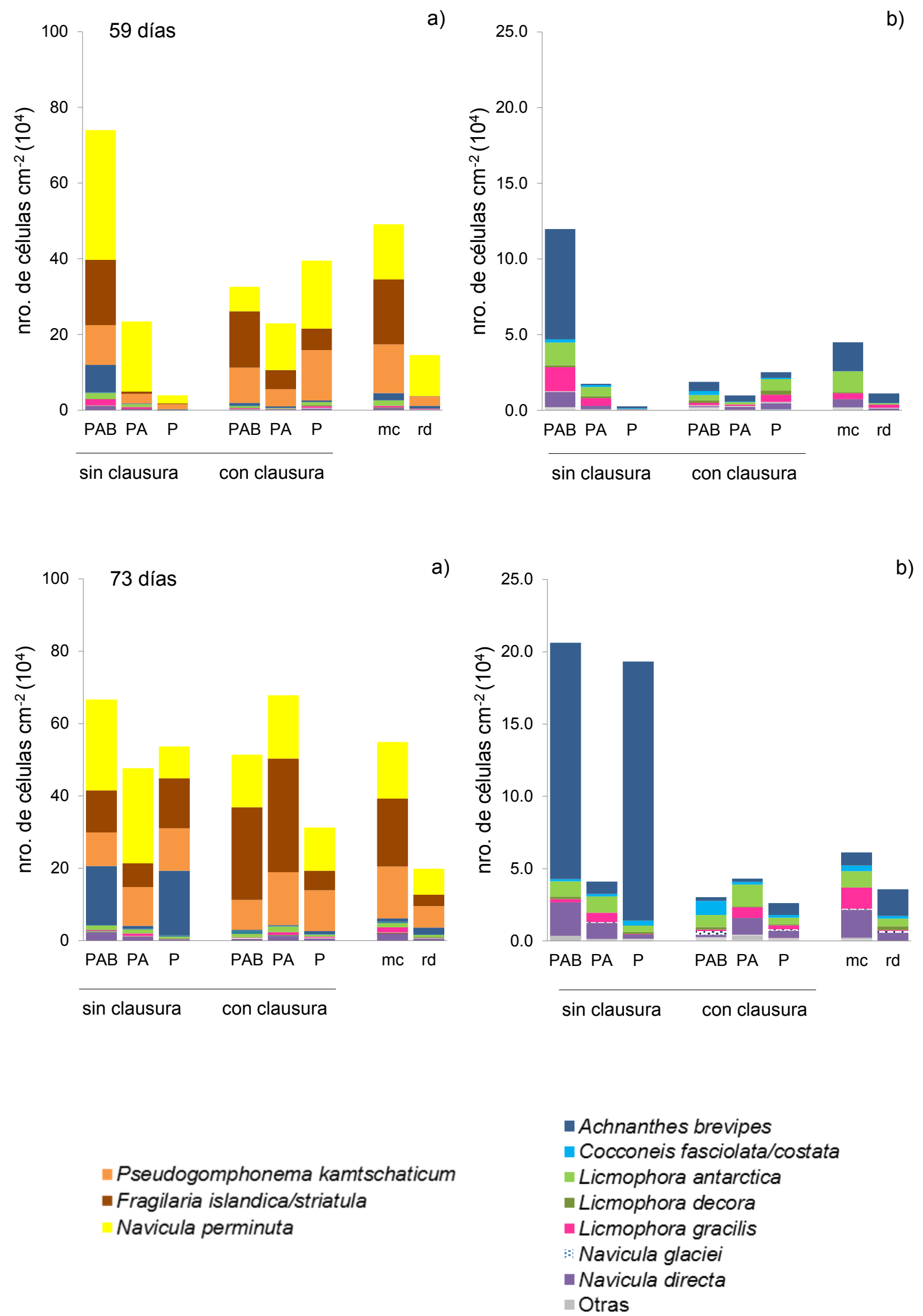

Fig. 5.23. Composición de taxa de diatomeas luego de 59 y 73 días de colonización. Se indica con diferentes colores la densidad de células vivas de a) el total de las especies y b) los taxa excluyendo a los tres dominantes (Navicula perminuta, Pseudogomphonema kamtschaticum y el complejo Fragilaria islandica/striatula). 


\section{Índices ecológicos y composición}

Entre los índices ecológicos analizados, sólo la riqueza fue reducida por el pastoreo ( $p<$ 0,05, Fig. 5.24). La irradiancia no afectó los valores de ninguno de los índices ecológicos analizados.
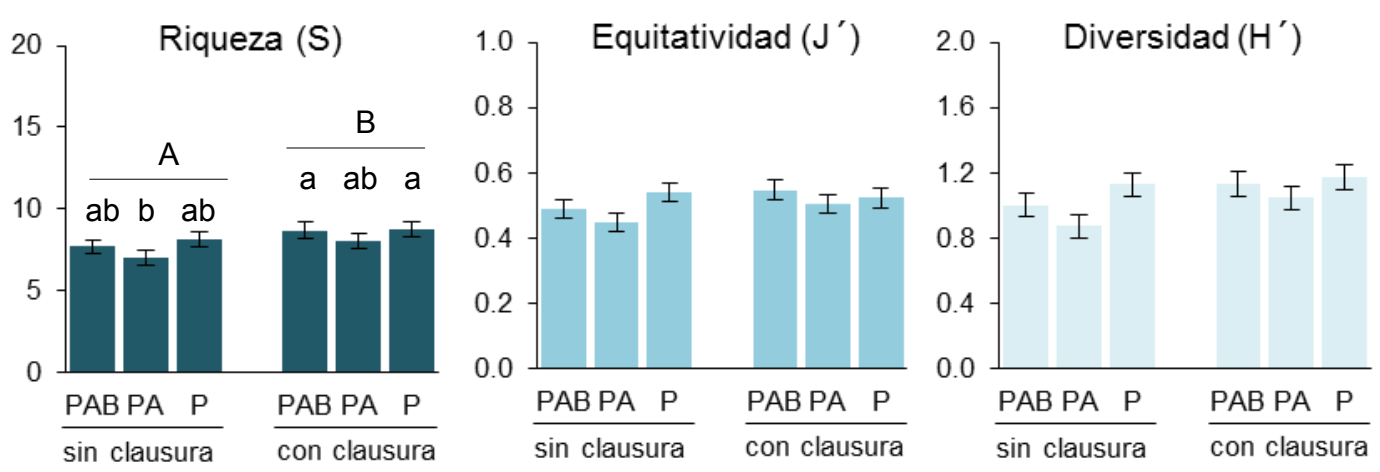

Fig. 5.24. Riqueza, equitatividad y Diversidad de taxa de diatomeas. Se indican las medias +/- error estándar. Las letras mayúsculas indican los resultados significativos del test ANCOVA/MANOVA $(p<0,05)$, las letras minúsculas indican las diferencias significativas del Test de Duncan $(p<0,05)$. PAB: PAR + UV-A + UV-B, PA: PAR + UV-A, P: sólo PAR, PAB: PAR + UV-A + UV-B, PA: PAR + UVA, P: sólo PAR.

En el análisis para cada tiempo de colonización, en las comunidades de 23 días, la riqueza, la equitatividad y la diversidad fueron reducidas significativamente por el pastoreo (Fig. 5.25a) y no existieron efectos de la irradiancia en ningún tiempo de colonización. 
a) 23 días

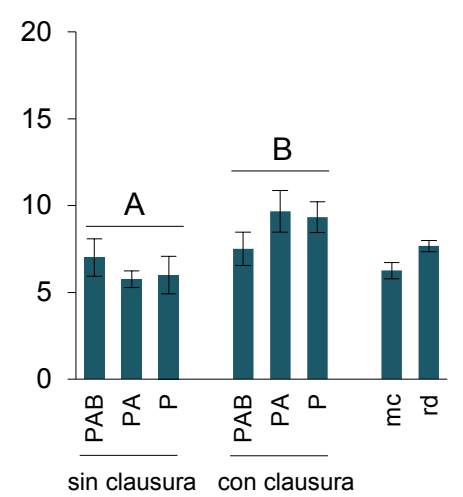

b) 40 días

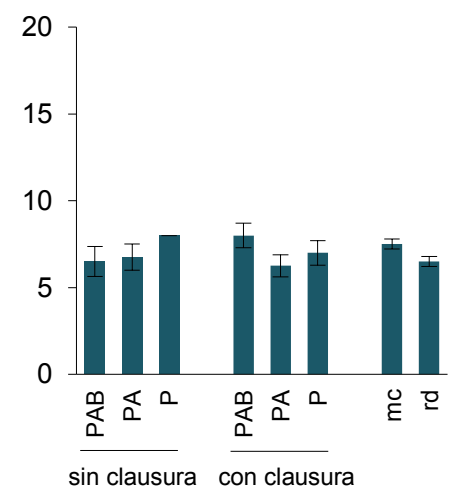

c) 59 días

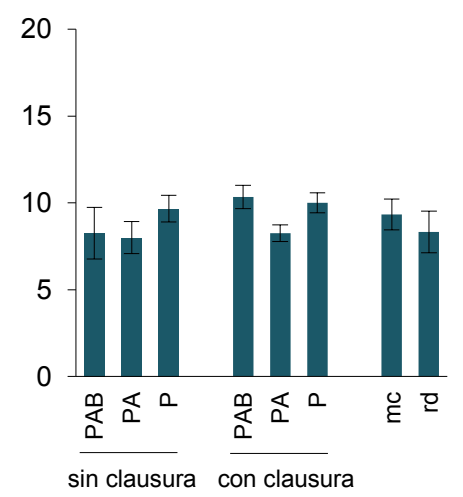

d) 73 días

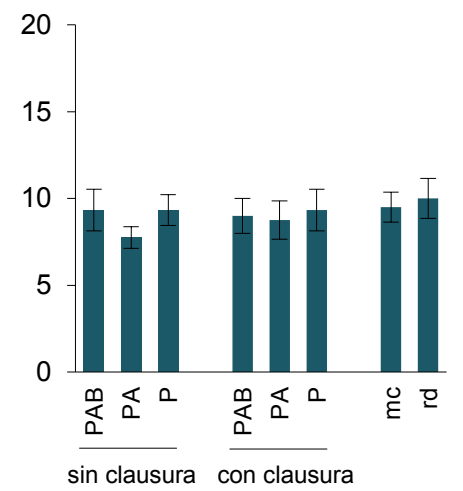

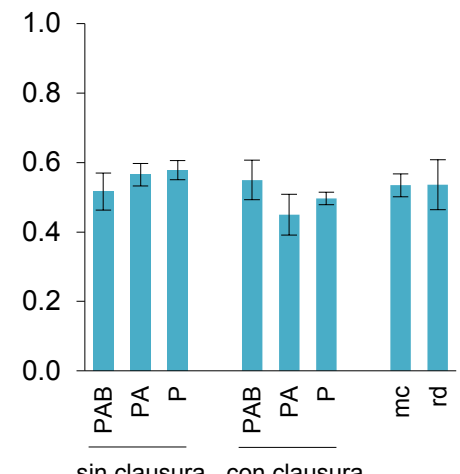

sin clausura con clausura
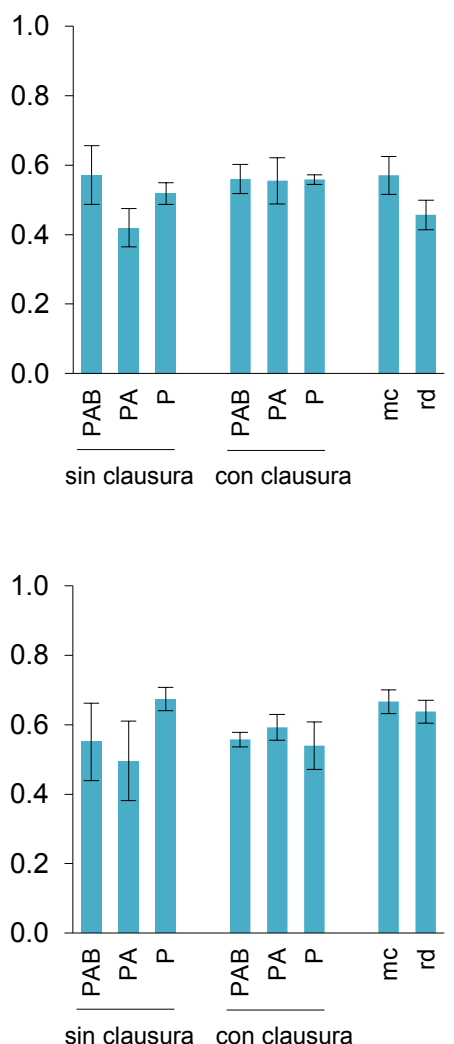

Diversidad

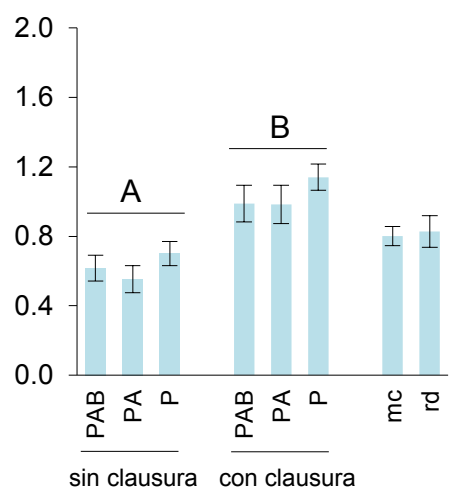

sin clausura con clausura
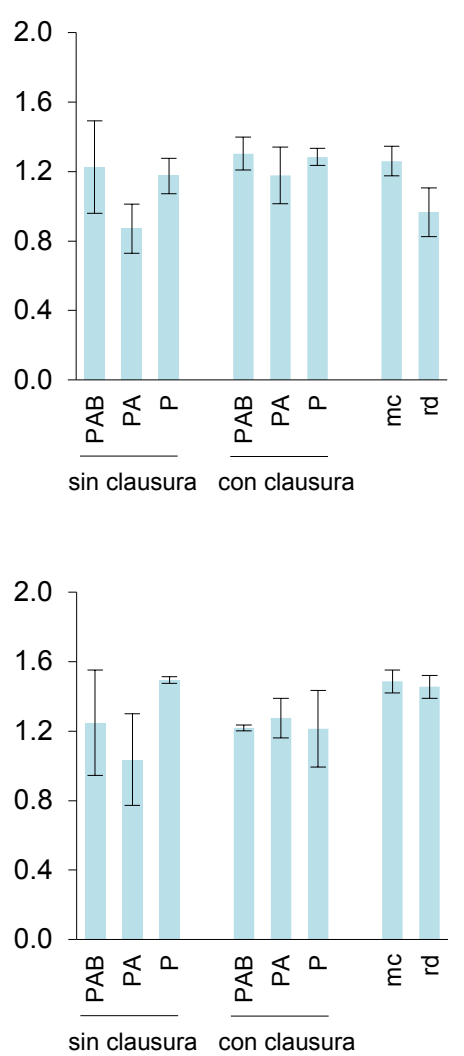

Fig. 5.25. Riqueza, equitatividad y diversidad luego de 23, 40, 59 y 73 días de colonización (a-d, respectivamente). Se indican las medias +/- error estándar. Las letras indican diferencias significativas entre tratamientos pastoreados y no pastoreados (Test de Kruskal Wallis, $p<0,0125$ ). 
La composición de los ensambles de diatomeas fue afectada por el pastoreo luego de 23 y 40 días de colonización (ANOSIM, Tabla 5.5). Los tratamientos de irradiancia no afectaron la composición de las comunidades en ningún caso (ANOSIM, Tabla 5.5).

Tabla 5.5. Análisis de Similitud (ANOSIM) para los ensambles de diatomeas luego de 23, 40, 59 y 73 días de colonización, para el factor "pastoreo" (sin clausura y con clausura) y la irradiancia recibida (PAB, PA y P). Se indica el R global y el nivel de significación. En negrita se indican los resultados significativos $(p<0,05)$.

\begin{tabular}{ccc}
\hline \multirow{2}{*}{$\begin{array}{c}\text { Tiempo de } \\
\text { colonización }\end{array}$} & \multicolumn{2}{c}{ ANOSIM } \\
\cline { 2 - 3 } & Pastoreo & Irradiancia \\
\hline 23 días & R: $\mathbf{0 , 7 3 3} \mathbf{p = 0 , 0 0 1}$ & R: $-0,012 p=0,501$ \\
\hline 40 días & R: $\mathbf{0 , 2 4 0} \mathbf{p = 0 , 0 3 7}$ & R: $-0,005 p=0,443$ \\
\hline 59 días & R: $0,220 p=0,059$ & R: $0,138 p=0,126$ \\
\hline 73 días & R: $0,158 p=0,121$ & R: $0,164 p=0,103$ \\
\hline
\end{tabular}

El análisis mediante escalamiento no métrico multidimensional (nMDS) permitió obtener buenas representaciones en dos dimensiones del ordenamiento de las muestras (stress < 0,1) (Clarke \& Warick 2001) (Fig. 5.26). Las diferencias significativas entre los ensambles de las comunidades pastoreadas y no pastoreadas se evidenciaron parcialmente en el ordenamiento en dos dimensiones. En términos generales, hubo mayor agrupamiento de las muestras no pastoreadas en los ensambles de 23 y 40 días (Fig. 5.26).

Como se ha mencionado, el pastoreo afectó la composición de las comunidades luego de 23 días de colonización. Los taxa que más contribuyeron a las diferencias entre los ensambles pastoreados y no pastoreados fueron $N$. perminuta, $F$. islandica/striatula, $P$. kamtschaticum, Licmophora antarctica, Licmophora decora, Cocconeis fasciolata/costata, Navicula glaciei, A. brevipes y Licmophora gracilis que en conjunto contribuyeron al 90,99\% de la disimilitud. Los demás taxa contribuyeron en menor medida $(<10 \%)$ a las diferencias entre tratamientos (SIMPER, Tabla 5.6). En particular, N. perminuta, F. islandica/striatula y P. kamtschaticum, contribuyeron al $66,8 \%$ de la disimilitud. La abundancia de los taxa fue afectada negativamente por el pastoreo, con excepción de los dos taxa que menos contribuyeron a las diferencias entre ensambles (Entomoneis sp. y Pleurosigma sp.) (Fig. 5.22, y Tabla 5.6). Particularmente, Brandinia mosimanniae, Nitzschia pellucida, Diploneis smithii, Grammatophora arctica, Entopyla ocellata, Cocconeis antiqua y Trachyneis aspera estuvieron ausentes en las comunidades pastoreadas. 
Tabla 5.6. Resultados de SIMPER, indicándose el porcentaje de disimilitud total promedio para los ensambles de diatomeas de 23 días de colonización, entre las comunidades sin clausura (pastoreadas) y con clausura (no pastoreadas), y la contribución de cada taxa a la disimilitud total, expresada en porcentaje. Se señalan en negrita los taxa que contribuyeron a un $90 \%$ de la disimilitud.

\begin{tabular}{|c|c|c|c|c|}
\hline & & \multicolumn{3}{|c|}{ SIMPER } \\
\hline & & \multicolumn{3}{|c|}{ sin clausura vs con clausura } \\
\hline \multirow[t]{3}{*}{23 días } & & \multicolumn{3}{|c|}{ \% Disimilitud: 47,05} \\
\hline & \multicolumn{2}{|c|}{ Abundancia promedio } & \multirow{2}{*}{$\begin{array}{c}\% \\
\text { Contribución } \\
\text { relativa }\end{array}$} & \multirow{2}{*}{$\begin{array}{c}\% \\
\text { Contribución } \\
\text { acumulada }\end{array}$} \\
\hline & $\begin{array}{l}\text { Sin } \\
\text { clausura }\end{array}$ & $\begin{array}{l}\text { Con } \\
\text { clausura }\end{array}$ & & \\
\hline Navicula perminuta & 298,50 & 539,86 & 26,56 & 26,56 \\
\hline Fragilaria islandica/striatula & 47,65 & 284,51 & 23,65 & 50,20 \\
\hline Pseudogomphonema kamtschaticum & 115,76 & 276,42 & 16,59 & 66,80 \\
\hline Licmophora antarctica & 4,37 & 58,09 & 5,53 & 72,32 \\
\hline Licmophora decora & 4,17 & 51,49 & 4,81 & 77,13 \\
\hline Cocconeis fasciolata/costata & 5,34 & 39,51 & 3,68 & 80,82 \\
\hline Navicula glaciei & 28,27 & 29,45 & 3,53 & 84,35 \\
\hline Achnanthes brevipes & 8,38 & 33,76 & 3,40 & 87,74 \\
\hline Licmophora gracilis & 16,45 & 38,99 & 3,24 & 90,99 \\
\hline Cocconeis melchiori/dallmanni/melchioroides & 2,90 & 22,40 & 2,30 & 93,29 \\
\hline Amphora marina & 9,78 & 11,12 & 1,67 & 94,96 \\
\hline Brandinia mosimanniae & 0 & 9,68 & 1,26 & 96,22 \\
\hline Navicula directa & 2,03 & 4,69 & 0,63 & 96,85 \\
\hline Nitzschia pellucida & 0 & 6,23 & 0,62 & 97,47 \\
\hline Diploneis smithii & 0 & 6,61 & 0,58 & 98,05 \\
\hline Grammatophora arctica & 0 & 4,45 & 0,45 & 98,50 \\
\hline Entopyla ocellata & 0 & 5,70 & 0,44 & 98,94 \\
\hline Cocconeis antiqua & 0 & 4,67 & 0,41 & 99,35 \\
\hline Trachyneis aspera & 0 & 2,47 & 0,37 & 99,71 \\
\hline Entomoneis sp. & 1,6 & 0 & 0,18 & 99,89 \\
\hline Pleurosigma sp. & 0,87 & 0 & 0,11 & 100 \\
\hline
\end{tabular}

Del mismo modo, el pastoreo afectó la composición de los ensambles de diatomeas luego de 40 días de colonización. Los taxa que más contribuyeron a las diferencias entre los ensambles pastoreados y no pastoreados fueron $F$. islandica/striatula, N. perminuta, $P$. kamtschaticum, A. brevipes, N. glaciei, L. antarctica y L. decora que en conjunto contribuyeron al 90,18 \% de la disimilitud, (SIMPER, Tabla 5.7). Los demás taxa contribuyeron en menor medida $(<10 \%)$ a las diferencias entre tratamientos (SIMPER, Tabla 5.7). Similarmente a lo ocurrido en el muestreo de 23 días de colonización, $F$. islandica/striatula $N$. perminuta, y $P$. kamtschaticum contribuyeron a más del $65 \%$ de las diferencias entre ensambles. En este caso, $F$. islandica/striatula y $P$. kamtschaticum fueron afectados negativamente por el pastoreo (Tabla 5.7). Sin embargo, $N$. perminuta fue afectada positivamente (Tabla 5.7), aunque con menores valores medios en los tratamientos 
que recibieron sólo PAR (Fig. 5.22b). Este también fue el caso de $A$. brevipes, que fue favorecido por el pastoreo. Navicula glaciei, L. antarctica y $L$. decora fueron afectadas negativamente por el pastoreo. Entre los taxa que menos contribuyeron a la disimilitud (< $10 \%$ ) se observaron menores abundancias en los tratamientos pastoreados para cinco taxa (L. gracilis, C. fasciolata/costata, Navicula directa, C. antiqua y Cocconeis melchiori/dallmanni/melchioroides), mientras que Rhoicosphenia genuflexa y Amphora marina sólo estuvieron presentes en las comunidades pastoreadas (Tabla 5.7, Apéndice $5.2)$.

Tabla 5.7. Resultados de SIMPER, indicándose el porcentaje de disimilitud total promedio para los ensambles de diatomeas de 40 días de colonización, entre las comunidades sin clausura (pastoreadas) y con clausura (no pastoreadas), y la contribución de cada taxa a la disimilitud total, expresada en porcentaje. Se señalan en negrita los taxa que contribuyeron a un $90 \%$ de la disimilitud,

\section{SIMPER}

sin clausura vs con clausura

\begin{tabular}{|c|c|c|c|c|}
\hline \multirow[t]{3}{*}{40 días } & & \multicolumn{3}{|c|}{ \% Disimilitud: 50,56} \\
\hline & \multicolumn{2}{|c|}{ Abundancia promedio } & \multirow{2}{*}{$\begin{array}{c}\% \\
\text { Contribución } \\
\text { relativa }\end{array}$} & \multirow{2}{*}{$\begin{array}{c}\% \\
\text { Contribución } \\
\text { acumulada }\end{array}$} \\
\hline & $\begin{array}{l}\text { Sin } \\
\text { clausura }\end{array}$ & $\begin{array}{l}\text { Con } \\
\text { clausura }\end{array}$ & & \\
\hline Fragilaria islandica/striatula & 239,58 & 589,83 & 35,23 & 35,23 \\
\hline Navicula perminuta & 430,66 & 371,09 & 20,58 & 55,81 \\
\hline Pseudogomphonema kamtschaticum & 204,93 & 269,27 & 9,86 & 65,67 \\
\hline Achnanthes brevipes & 105,84 & 40,16 & 7,62 & 73,29 \\
\hline Navicula glaciei & 16,83 & 69,11 & 6,17 & 79,47 \\
\hline Licmophora antarctica & 74,38 & 86,5 & 5,77 & 85,24 \\
\hline Licmophora decora & 29,56 & 72,76 & 4,94 & 90,18 \\
\hline Licmophora gracilis & 31,27 & 43,00 & 3,22 & 93,40 \\
\hline Cocconeis fasciolata/costata & 19,17 & 30,94 & 2,85 & 96,25 \\
\hline Navicula directa & 11,47 & 16,16 & 1,69 & 97,94 \\
\hline Cocconeis antiqua & 4,39 & 10,76 & 1,04 & 98,98 \\
\hline Cocconeis melchiori/dallmanni/melchioroides & 3,79 & 10,86 & 0,85 & 99,83 \\
\hline Rhoicosphenia genuflexa & 0,81 & 0 & 0,09 & 99,93 \\
\hline Amphora marina & 0,66 & 0 & 0,07 & 100 \\
\hline
\end{tabular}




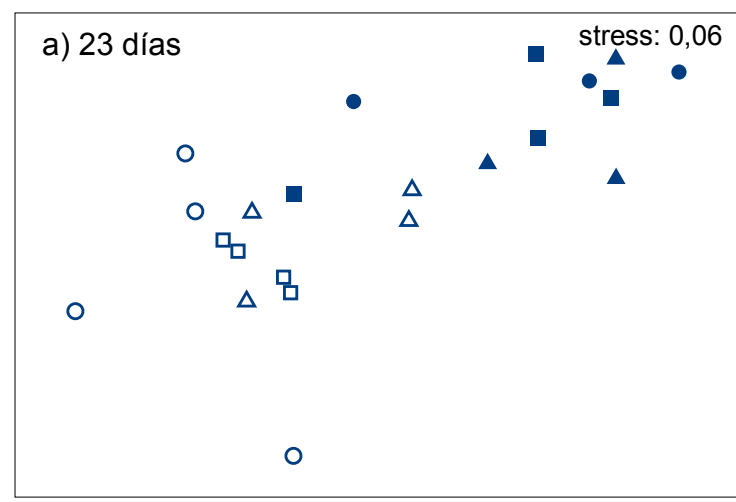

c) 59 días

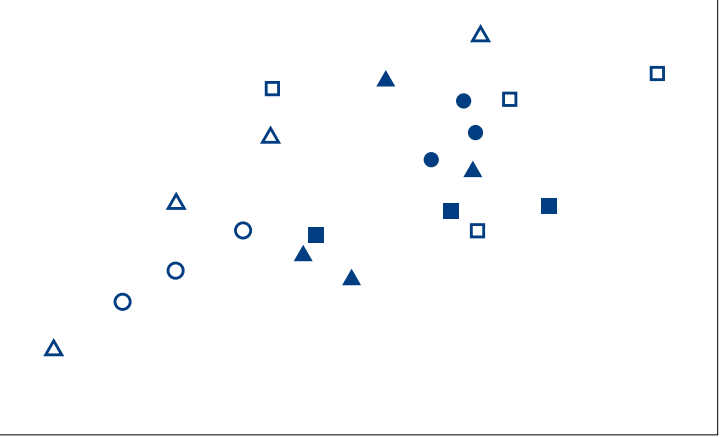

b) 40 días

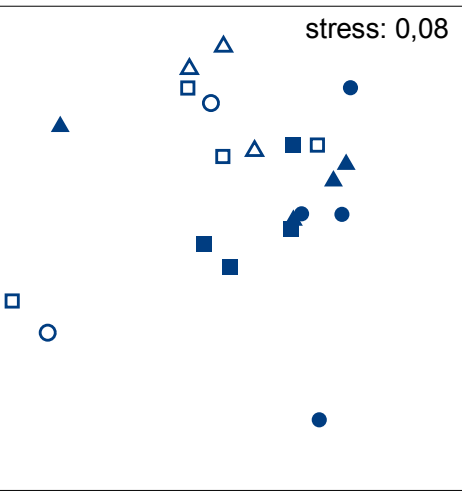

d) 73 días

$8^{\circ}$

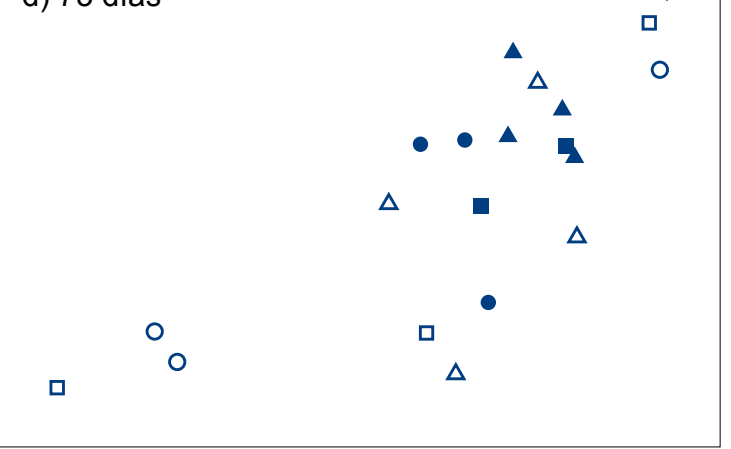

$\square \mathrm{PAB} \triangle \mathrm{PA} \circ \mathrm{P}$

sin clausura
$\mathrm{PAB} \triangle \mathrm{PA} \odot \mathrm{P}$

con clausura

Fig. 5.26. Ordenamiento de ensambles de diatomeas, obtenido mediante escalamiento no métrico multidimensional (nMDS) luego de 23, 40, 59 y 73 días de colonización. El ordenamiento en dos dimensiones se obtuvo a partir de la construcción de una matriz de similitud empleando el índice de Bray Curtis a partir de la densidad de taxa, previamente transformada como raíz cuadrada.

\subsection{DISCUSIÓN}

En este estudio, la radiación ultravioleta y el pastoreo resultaron factores estructurantes de la comunidad de productores primarios bentónicos en el curso de los procesos de colonización y sucesión en el ambiente submareal antártico. El pastoreo se evidencia como el principal factor que afecta la estructura de esta comunidad: i) causando disminución de la biomasa y la cobertura macroscópica, y de la cobertura, densidad y riqueza de taxa de diatomeas y ii) favoreciendo el desarrollo de rodofitas y la diversidad de la comunidad. La radiación ultravioleta (UV-A y UV-B) afectó negativamente a las rodofitas y al establecimiento inicial de clorofitas filamentosas. Generalmente, los efectos de ambos factores fueron evidentes en las etapas más tempranas del desarrollo de las comunidades, especialmente luego de 23 y 40 días de colonización. En varios casos, los efectos observados fueron particularmente más intensos (más positivos o más negativos) en las comunidades pastoreadas que no recibieron radiación ultravioleta. 


\section{Patrones generales de la colonización y sucesión}

Las comunidades estuvieron compuestas por diatomeas- con mayor densidad y abundancia relativa de grupos con firme adhesión al sustrato, pedunculados y coloniales filamentosos, pequeños propágulos de rodofitas (particularmente $P$. decipiens) y por clorofitas filamentosas, cuya cobertura fue aumentando en el tiempo. Esta composición taxonómica se asemeja a la hallada experimentalmente en sitios de altas latitudes para etapas tempranas de la sucesión, en períodos relativamente cortos (menores a cuatro meses) (Wahl et al. 2004, Zacher et al. 2007 a,b, Fricke et al. 2008). Contrariamente, en ambientes templados y tropicales, las macroalgas desarrolladas sobre sustratos artificiales pueden dominarlo en sólo dos a tres meses, habiéndose postulado que la sucesión procede más rápidamente que en ambientes polares (Wahl et al. 2004).

La biomasa de las comunidades fue mucho mayor a la registrada en un experimento similar realizado en un intermareal cercano al de este estudio (Zacher et al. 2007a), incluso para períodos de tiempo similares en los que ambos experimentos fueron simultáneos (Zacher \& Campana 2008). La mayor biomasa registrada en el submareal no se relacionó con el efecto de la UV -que se espera sea más intenso en el intermareal- sino a una menor influencia de otros factores de estrés o a una menor intensidad de disturbio y pastoreo en el submareal, comparado con el intermareal antártico (Richter et al. 2008, Zacher \& Campana 2008, Zacher et al. 2011).

\section{Efectos de la UV y el pastoreo sobre la biomasa y composición taxonómica a nivel macroscópico}

El pastoreo redujo la biomasa y la cobertura total de la comunidad a nivel macroscópico y no se observaron efectos directos de la UV sobre estos atributos. Las diatomeas constituyeron el grupo algal que probablemente más contribuyó a la biomasa y cobertura de la comunidad, particularmente durante la primera mitad del experimento y se observó un mayor aporte a la cobertura por parte de las clorofitas en el tiempo.

La reducción de biomasa fue causada principalmente por el pastoreo de los gasterópodos $N$. concinna y $L$. antarctica que fueron excluidos de las unidades experimentales con clausura, observándose en los tratamientos sin clausura los caminos o rastros característicos que estos organismos dejan a su paso. El pastoreo por anfípodos podría considerarse, en este caso, de un impacto menor comparado con la acción de estos gasterópodos (Zacher et al. 2007a,b). Ocasionalmente se hallaron anfípodos también en los tratamientos con clausura, lo que apoyaría la idea de que este grupo tuvo un impacto menor sobre las comunidades. 
Nacella concinna es un gasterópodo que puede alcanzar grandes dimensiones $(<5,8$ $\mathrm{cm}$ ), notable en las costas intermareales y submareales de la Península Antártica e islas adyacentes hasta $54^{\circ}$ de latitud sur (Suda et al. 2015). Su fuente de alimento principal es el microfitobentos (Peck \& Veal 2001, Corbisier et al. 2004) habiéndose registrado un incremento de su masa corporal en los períodos en los que esta comunidad es más abundante (Brêthes et al. 1994). Además, se ha descripto su pastoreo sobre biofilms, macroalgas rojas crustosas, foliosas y filamentosas, briozoos y poliquetos sésiles (Shabica 1976, Iken et al. 1998, Kim 2001). La densidad de este molusco en el submareal en verano puede ser de más de 100 individuos por metro cuadrado pudiendo duplicarse este valor durante el invierno (Brêthes et al. 1994). Varios estudios sostienen que esto se debe a la migración estacional de este molusco en los meses de verano, desde el submareal hacia el intermareal, coincidentemente con un mayor desarrollo algal en esta zona (Walker 1971, Brêthes et al. 1994, Kim 2001). Particularmente para el intermareal antártico, N. concinna es considerado un factor estructurante de las comunidades de productores primarios bentónicos (Kim 2001, Segovia-Rivera \& Valdivia 2016, Valdivia et al. 2018). Es esperable entonces que el pastoreo por $N$. concinna cause un efecto más intenso en las comunidades en etapas tempranas de la sucesión, cuando el microfitobentos alcanza su mayor abundancia y los propágulos y estadios juveniles de algunas macroalgas son más susceptibles respecto a los organismos adultos (Kim 2001). En el intermareal superior, se ha demostrado que reduce la biomasa y la abundancia relativa de todos los grupos algales que conformaron el biofilm con excepción de las algas verdes (Valdivia et al. 2018).

El otro gasterópodo identificado en las unidades experimentales fue $L$. antarctica. Este molusco de menores dimensiones que $N$. concinna $(<1 \mathrm{~cm})$ es conspicuo en el intermareal y submareal superior antártico, hasta $12 \mathrm{~m}$ de profundidad, donde se lo encuentra asociado a los frondes de macroalgas y sobre el fondo rocoso (Picken 1979, Valdivia et al. 2014, Amsler et al. 2015). Se trata de un herbívoro que se alimenta de macroalgas y diatomeas epífitas, siendo estas últimas el grupo que contribuye mayoritariamente a su dieta (Iken 1999).

Ambos gasterópodos redujeron la biomasa de la comunidad tal como se observó en estudios realizados en el intermareal antártico (Iken 1999, Zacher et al. 2007a). En particular, el efecto sobre la biomasa y la cobertura macroscópica fue causado principalmente por el consumo de diatomeas coloniales (Nicotri 1977, Sommer 1999b, Hillebrand et al. 2000) dado que no existió un efecto significativo sobre la cobertura macroscópica de clorofitas (Figs. 5.9a-b). En este caso, las comunidades pastoreadas difirieron de las no pastoreadas excepto en el tratamiento que recibió sólo PAR (Fig. 5.9a), lo que podría relacionarse con la presencia de colonias de diatomeas de menores dimensiones en los tratamientos con clausura. 
En el caso de la cobertura macroscópica de clorofitas, la única diferencia significativa se observó en la primera fecha de muestreo, con menores valores en las comunidades que recibieron UV-B. Sin embargo, los resultados de los muestreos posteriores fueron los que contribuyeron al resultado global, observándose distintas direcciones (no significativas) de los efectos de la UV en comunidades pastoreadas y no pastoreadas (Fig. 5.9b).

La especie que alcanzó las mayores dimensiones entre las macroalgas, y responsable de la cobertura macroscópica de clorofitas fue $U$. penicilliformis. Esta especie presenta una sensibilidad diferencial a la UV en distintas etapas de su ciclo de vida: los propágulos son levemente más sensibles a daños al ADN inducidos por la UV-B respecto a los individuos adultos (Roleda et al. 2009), tal como ocurre en otras especies de macroalgas (Coelho et al. 2000, Karsten et al. 2011). En el presente estudio, sólo el establecimiento de $U$. penicilliformis fue afectado negativamente por la UV, tanto en las comunidades pastoreadas como en las no pastoreadas. Una vez establecidos, los efectos de la UV no son significativos probablemente debido a la elevada resistencia de los adultos de esta especie a este factor de stress (Roleda et al. 2011). Los organismos de U. penicilliformis poseen una vaina de mucilago y paredes celulares muy gruesas, cubiertas por una capa de deposiciones minerales que le conferirían protección frente a las condiciones ambientales extremas del intermareal, y particularmente a la UV (Roleda et al. 2011). Si bien la interacción entre la UV y el pastoreo no fue significativa, podría sugerirse que, en las unidades experimentales con clausura, la presencia de matas de diatomeas podría limitar la llegada de luz a los filamentos de $U$. penicilliformis, afectándola negativamente. En cambio, en las comunidades pastoreadas, sólo se observó una menor cobertura de $U$. penicilliformis, en aquellas en las que la UV estuvo ausente, coincidentemente con una posible mayor actividad de pastoreo que podría causar la ruptura de los filamentos de estos organismos.

\section{Efectos de la UV y el pastoreo sobre la cobertura, la diversidad y la composición de las comunidades a nivel microscópico}

El análisis de la comunidad a nivel microscópico permitió evaluar los efectos de la UV y el pastoreo a un mayor nivel de resolución, evaluando estos efectos sobre las diatomeas coloniales, ambas especies de clorofitas filamentosas y sobre los estadios iniciales de algas rojas. Los herbívoros redujeron significativamente la cobertura microscópica de diatomeas, no hubo efecto sobre la cobertura de clorofitas y favorecieron el establecimiento de rodofitas. La reducción de abundancia del grupo dominante (las diatomeas) y el aumento en la cobertura de rodofitas causados por el pastoreo fueron posiblemente las causas del incremento en la equitatividad, que resultó en un aumento de la diversidad. Un efecto similar se observó en ambientes intermareales antárticos, en los que el pastoreo por gasterópodos 
produjo aumentos en la diversidad de ensambles de macroalgas (Zacher et al. 2007a) Sin embargo, en ese estudio, no se consideraron a las diatomeas, y el aumento de la diversidad fue atribuido a una mayor heterogeneidad espacial, causada por la existencia de biofilms no afectados por el pastoreo y áreas visiblemente consumidas (Sommer 2000).

La UV afectó negativamente a los propágulos de rodofitas (Zacher et al. 2007a). Sin embargo no hubo otros efectos directos de la UV sobre la composición de los ensambles ni los índices de diversidad, a diferencia de los resultados obtenidos para comunidades del intermareal antártico, en los que la UV-A causó una reducción de la riqueza de macroalgas, y la UV-B disminución de la diversidad y cambios en la composición taxonómica (Zacher et al. 2007a). Sólo el pastoreo afectó la composición de las comunidades, luego de 23 y 40 días de colonización.

Igual que a nivel macroscópico, la cobertura microscópica de clorofitas no fue afectada significativamente por el pastoreo ni por la UV (Figs. 5.9b \& 5.13b). Nuevamente, la única diferencia significativa se observó en la primera fecha de muestreo, con menor cobertura de clorofitas en las comunidades pastoreadas. Este efecto se asocia principalmente a la escasa o incluso nula presencia de $U$. flacca en las comunidades pastoreadas luego de 23 días de colonización (Fig. 5.15a y Tabla 5.4a). La estructura más delicada y el menor tamaño de los estadios iniciales encontrados en este estudio para $U$. flacca respecto a $U$. penicilliformis, podría haberla hecho vulnerable al pastoreo. En los tratamientos con clausura, la mayor cobertura de esta especie (U. flacca) podría relacionarse con la existencia de canopeo de diatomeas que conferiría cierta protección contra la excesiva iluminación en estadios iniciales. Para esta especie (U. flacca), luego de 40 días se observaron patrones de abundancia opuestos entre los tratamientos pastoreados y no pastoreados (SIMPER, Tabla 5.4b): estuvo ausente en las comunidades no pastoreadas y presente en las pastoreadas. Este patrón podría ser explicado por una sensibilidad diferencial a la luz de los organismos de esta especie con distinto grado de desarrollo. Se espera que los filamentos adultos de $U$. flacca tengan elevados requerimientos lumínicos dado que es una especie principalmente intermareal (Wiencke \& Clayton 2002). Sin embargo, sus esporas o estadios juveniles podrían ser vulnerables tanto frente al pastoreo como a condiciones de irradiación elevada (tal como en el caso de $U$. penicilliformis).

La abundancia de U. penicilliformis fue mayor en las comunidades no pastoreadas en ambos tiempos de colonización. Una mayor sensibilidad de los propágulos a las condiciones de UV podría explicar estas tendencias (Roleda et al. 2011). Para el muestreo de 40 días no debería descartarse la idea de que el menor valor promedio en las comunidades pastoreadas estuviera sesgado por una mayor actividad de pastoreo que causara ruptura o fragmentación de los talos en los tratamientos que recibieron sólo PAR (ver Fig. 5.15b). 
Las rodofitas se vieron favorecidas por el pastoreo pero fueron afectadas negativamente por la UV. Como hemos mencionado, los herbívoros consumieron principalmente diatomeas y estadios juveniles de algas verdes, por lo que su acción podría haber reducido el canopeo, disminuido el fouling sobre los propágulos establecidos y/o generado sitios libres para la colonización por rodofitas. En consecuencia, pudo haber disminuido la competencia por luz (o espacio) resultando en un efecto positivo global para las rodofitas (Huang \& Boney 1985). Simultáneamente, la cobertura de rodofitas fue afectada negativamente por la UV (Zacher et al. 2007a). La mayor cobertura de rodofitas en los tratamientos sin clausura que recibieron solo PAR podría además asociarse a una mayor intensidad de pastoreo en estas comunidades.

Los resultados globales se relacionan principalmente con los efectos de ambos factores sobre la rodofita dominante, $P$. decipiens. Los propágulos de esta especie se hallaron muy firmemente adheridos al sustrato sin ser consumidas por los herbívoros (observación personal, Zacher et al. 2007a). En contraste, la cobertura de la familia Delesseriaceae fue afectada negativamente por el pastoreo. Los morfotipos hallados se encontraron frecuentemente entre los filamentos de diatomeas, presentaron una estructura más delicada, y se despegaban del sustrato con facilidad, por lo que es esperable que fueran consumidos por los herbívoros en las comunidades sin clausura (Amsler et al. 1992, Zacher et al. 2007a), particularmente cuando los efectos del pastoreo causaron cambios en las comunidades, luego de 23 y 40 días de colonización. Por otro lado, en los tratamientos con clausura, su mayor abundancia podría relacionarse también con una mayor sensibilidad a la radiación solar ( $y$ a la UV) característica de las especies que crecen a mayores profundidades o debajo del canopeo provisto por otras macroalgas (Häder et al. 2003, Bischof et al. 2006, Karsten et al. 2011, entre otros). La presencia de matas de diatomeas poco sensibles a la UV podría generar una cubierta protectora para este grupo, que se vio entonces favorecido en las comunidades con clausura (Karsten et al. 1998, Molis \& Wahl 2004, Wahl et al. 2004). Algunas especies de la familia Delesseriaceae tales como Phycodrys austrogeorgica y Delesseria lancifolia presentan una sensibilidad extrema a la UV y podrían incluso carecer de mecanismos protectores contra una radiación elevada (Bischof et al. 2006), tales como la producción de MAAs (Hoyer et al. 2001, 2002). Otra especie de la familia Delesseriaceae, habitual en el submareal antártico es Neuroglossum delesseriae, la cual puede sufrir fotodaño y decoloración en sus tejidos luego de la exposición a la UV (Hoyer et al. 2002). Estas especies habitan el submareal medio en Antártida, pero se encuentran generalmente bajo el canopeo de grandes Desmarestiales (Wiencke \& Clayton 2002).

La ocurrencia de Rhodocorthon cf purpureum fue ocasional y fue la especie que menos contribuyó a las diferencias entre los ensambles. Luego de 23 días se encontró una 
cobertura ligeramente mayor en los tratamientos no pastoreados, y luego de 40 días se vio beneficiada por el pastoreo. Estos resultados podrían atribuirse a una sensibilidad diferencial al pastoreo en esta etapa del ciclo de vida, con mayor sensibilidad inmediatamente después de su establecimiento. Sin embargo, una vez establecidos, podría beneficiarse de la ausencia de canopeo, debido a sus mayores requerimientos lumínicos. Esta especie habita el intermareal y submareal superior, por lo que debe haber desarrollado eficientes mecanismos de reparación o protección frente a la UV (Hoyer et al. 2002).

\section{Efectos de la UV y el pastoreo sobre los ensambles de diatomeas}

El pastoreo resultó el principal factor de control de la estructura de los ensambles de diatomeas bentónicas, la cual no fue afectada por la UV ambiental. Los herbívoros causaron un impacto negativo sobre la densidad de células totales y sobre la abundancia de la mayoría de los taxa y causaron una disminución de la riqueza que no impactó sobre la diversidad de los ensambles. Entre los tratamientos pastoreados se registró un menor número de células totales en las placas en las que la UV estuvo ausente.

La densidad de diatomeas estuvo dentro del mismo orden de magnitud respecto a un experimento similar realizado en el intermareal de península Potter (valor máximo: $\sim 60 \times 10^{4}$ células $\mathrm{cm}^{-2}$, Zacher et al. 2007b), aunque en los tratamientos sin clausura, la densidad obtenida en esta Tesis fue considerablemente mayor. Se ha postulado que una mayor actividad de pastoreo y/o mayor abrasión por hielo en el intermareal comparado con el ambiente submareal (Zacher et al. 2007b) serían los responsables de tales diferencias entre estos ambientes. En términos generales la densidad hallada en esta Tesis es mayor a la registrada para comunidades de epifitas desarrolladas sobre macroalgas en el mar de Ross

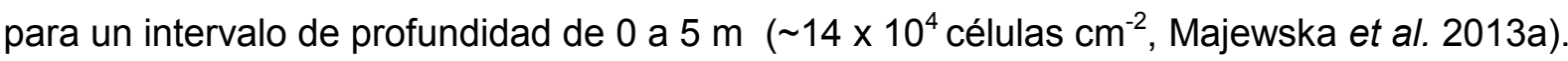
Por otro lado, el número de taxa hallados es menor comparado con otros estudios realizados sobre epifitas de macroalgas antárticas (Al-Handal et al. 2008b, Majewska et al. 2016) y sobre el microfitobentos desarrollado en ambientes de sustrato blando (Al-Handal et al. 2008a). Una mayor acción del pastoreo por $N$. concinna en los ambientes de sustrato duro respecto a los sustratos blandos podría ser una explicación para las tendencias observadas en este estudio (Daglio et al. 2018).

Algunos atributos funcionales de la comunidad del microfitobentos pueden ser afectados negativamente por la UV ambiental, tales como la eficiencia fotosintética y la producción de carbohidratos (carbohidratos coloidales, glucano y exopolímeros) (Wulff et al. 1999). Sin embargo, en este estudio la UV no fue identificada como un factor de mortalidad, dado que el número de células vivas no resultó afectado en las comunidades que recibieron UV. Estos resultados son comparables con otros realizados con diatomeas bentónicas, en 
los que se detectó una gran resistencia a la UV-B (Peletier et al. 1996, Sündback et al. 1996) y particularmente en ensambles de microfitobentos antártico en los que los efectos negativos sobre la eficiencia fotosintética y los daños al ADN fueron transitorios (Wulff et al. 2008a). La migración vertical es un mecanismo posible para evitar, al menos en el corto plazo, los daños que causa la UV-B en los ambientes de sustrato blando (Sündback et al. 1996, 1997, Underwood et al. 1999, Waring et al. 2007). Sin embargo, este mecanismo podría ser descartado en los ensambles analizados en esta Tesis, por lo que estas diatomeas bentónicas deben poseer otros mecanismos de defensa. En diatomeas del género Thalassiosira se ha detectado la producción de sustancias fotoprotectoras tales como MAAs (Hernando \& Ferreyra 2005). Sin embargo, debemos considerar que los ensambles de diatomeas en este estudio estuvieron conformados principalmente por diatomeas pennadas, las cuales han demostrado producir muy bajas (o incluso nulas) concentraciones de sustancias que absorben UV (Helbling et al. 1996, Sündback et al. 1996, Wulff et al. 1999). En base a esto, se ha postulado que las diatomeas bentónicas poseen eficientes mecanismos de defensa y reparación (Peletier et al. 1996). En particular, la especie dominante, $N$. perminuta tiene una elevada resistencia a la UV-B, con gran capacidad de recuperación de la eficiencia fotosintética, por lo que se ha sugerido que posee eficientes mecanismos de reparación (Waring et al. 2006). Asimismo, la estructura de su pared celular podría conferir protección al ADN (Aguirre et al. 2018).

Los ensambles de microfitobentos de sustrato blando en Antártida muestran una elevada resistencia a la UV, sin afectar (o afectando sólo transitoriamente) la eficiencia fotosintética, el crecimiento y la densidad de células (Wulff et al. 2008a,b). En estos ensambles, se observó una recuperación completa de la eficiencia fotosintética y mínimos daños al ADN al ser irradiados experimentalmente con UV-B, en un diseño experimental en el que recibieron una dosis siete veces mayor a la estimada para condiciones naturales (Wulff et al. 2008a). Estos autores propusieron que la presencia de una pared celular gruesa y otros pigmentos accesorios contribuyen a la menor susceptibilidad a la UV-B en estos ensambles antárticos aunque los mecanismos para la eficiente y elevada capacidad de reparación deben ser elucidados (Wulff et al. 2008a, Ellegaar et al. 2016, Aguirre et al. 2018).

El pastoreo se evidenció como el factor principal que afectó la riqueza y composición de los ensambles. La riqueza fue reducida y, similarmente al análisis de la comunidad a nivel microscópico, la composición taxonómica de los ensambles de diatomeas fue afectada por el pastoreo luego de 23 y 40 días de colonización. Los tres taxa que más contribuyeron a las diferencias entre tratamientos pastoreados y no pastoreados fueron $F$. islandica/striatula, Psedogomphonema kamtschaticum y $N$. perminuta, taxa hallados con 
elevada frecuencia entre las diatomeas bentónicas en el bentos antártico (Zacher et al. 2007b, Al-Handal \& Wulff 2008a,b, Majewska et al. 2016).

En términos generales, la mayoría de los taxa fueron afectados negativamente por el pastoreo. Los cambios en los ensambles se produjeron principalmente por una mayor susceptibilidad de taxa coloniales y pedunculados al pastoreo (Hillebrand et al. 2000, entre otros).

F. islandica/striatula forman largos filamentos acintados (Capítulo 3, Láminas. XII y XIV). Estas colonias filamentosas pueden superponerse formando una mata conspicua y causando canopeo. La morfología de las colonias y la ubicación de los filamentos en las partes más externas de la mata de diatomeas puede haber facilitado su ingestión, haciéndola fácilmente accesible para los herbívoros (Nicotri 1977, Hillebrand et al. 2000).

Las especies pedunculadas o epifitas pueden hallarse tanto fijas al sustrato rocoso, sobre los filamentos de diatomeas coloniales o sobre las clorofitas filamentosas. Tal es el caso de $P$. kamtschaticum y los taxa pertenecientes al género Licmophora, diatomeas pedunculadas sobre los que se ha demostrado su susceptibilidad al pastoreo por gasterópodos (Sommer 1999b, Zacher et al. 2007b).

Navicula perminuta fue una especie dominante, particularmente en los ensambles pastoreados (>72 \% y $>40 \%$ en los muestreos de 23 y 40 días de colonización) respectivamente. Esta especie fue afectada negativamente por el pastoreo en el muestreo de 23 días y, contrariamente, presentó una mayor abundancia en las comunidades pastoreadas de 40 días de colonización. Su consumo diferencial estaría explicado por la disponibilidad de otras fuentes de alimento (por ejemplo, menor disponibilidad de formas coloniales de $F$. islandica/striatula luego de 23 días). Sus pequeñas dimensiones y fuerte adhesión al sustrato (Holland et al. 2004) pueden haber causado un menor consumo en el segundo muestreo (a los 40 días), particularmente cuando había disponibles grupos de más fácil remoción. En el segundo muestreo, la menor abundancia de esta especie en los tratamientos con clausura también puede atribuirse a una limitación de la llegada de luz causada por el canopeo producido por otros grupos. De hecho, el incremento en la abundancia relativa de especies que crecen firmemente adheridas al sustrato o debajo de canopeo en tratamientos pastoreados es consistente con estudios realizados en ambientes de agua dulce (compilados en Steinman 1996).

El patrón hallado para $A$. brevipes fue diferente entre el primer muestreo y el segundo. Su abundancia fue afectada negativamente por los herbívoros en el primer muestreo y positivamente en el segundo muestreo. Su menor abundancia relativa en términos generales y su distribución en parches probablemente sea la causa de las diferencias observadas (Nicotri 1977). 
El hecho de que los herbívoros afecten negativamente a los taxa de diatomeas que forman colonias filamentosas y de gran tamaño ha demostrado ser un factor que causa drásticos efectos sobre la fisonomía de las comunidades de microfitobentos en ambientes de agua dulce (Steinman 1996) y marinos (Nicotri 1977, Sommer 1999a,b, Hillebrand et al. 2000). Los herbívoros reducen significativamente la cobertura de las especies que forman el canopeo y por lo tanto se produce un aumento en la abundancia relativa de especies de menores dimensiones y formas de crecimiento postrado (Nicotri 1977, Hillebrand et al. 2000).

Los cambios en la estructura taxonómica de los taxa dominantes observados en este estudio se atribuyen, entonces, principalmente a una susceptibilidad diferencial de las diatomeas hacia el pastoreo. Esta susceptibilidad se explicaría por la morfología, su distribución y la fuerza de adhesión al sustrato (Nicotri 1977, Hillebrand et al. 2000). Por otro lado, la relación asimétrica entre los herbívoros dominantes y las algas bentónicas en este estudio, determinada por el pequeño radio alga: herbívoro (Steinman 1996) sugiere que no existe una verdadera selección de alimento (Nicotri 1977, Steinman 1996). Tal como se reporta en otros estudios, una selección pasiva del alimento, determinada por las diferencias en las formas de crecimiento de las algas y la facilidad de acceso explican las tendencias observadas (Zacher et al. 2007b).

\section{Efectos combinados de la UV y el pastoreo}

Hasta el momento existe escasa información acerca de los efectos de la UV sobre las interacciones entre las algas y los herbívoros, particularmente en los sistemas marinos (Lotze \& Worm 2002, Lotze et al. 2002, Zacher et al. 2007a,b). En este estudio, los efectos directos de la UV sobre las comunidades estudiadas fue menor comparado con el efecto causado por el pastoreo. Sin embargo, se observaron efectos más intensos (más positivos o más negativos) sobre algunos parámetros analizados, cuando la UV o la UV-B estuvieron ausentes (por ejemplo, sobre la biomasa, la cobertura macroscópica, la cobertura microscópica de diatomeas, el porcentaje de cobertura de rodofitas y la equitatividad de la comunidad). En este sentido, se puede sugerir que existieron efectos directos de la UV sobre las algas que disminuyeron su palatabilidad, o efectos indirectos, mediados a través de un efecto negativo de la UV sobre los herbívoros, que disminuyeron su actividad y/o densidad cuando la UV (o la UV-B) estuvo presente (Bothwell et al. 1994, Lotzte et al. 2002, Roux et al. 2002).

Por un lado, la producción de metabolitos inducida por la UV podría modificar la susceptibilidad de las algas frente a la herbivoría, ya sea por un incremento (Pavia et al. 1997) o una disminución de la palatabilidad (Bischof et al. 2006). Sin embargo, otros estudios no demostraron ningún efecto de la UV sobre la producción de estas sustancias 
(Macaya et al. 2005). Las macroalgas antárticas poseen defensas químicas contra herbívoros (Amsler et al. 2011) pero al menos su producción no está relacionada con la exposición a la UV-B (Fairhead et al. 2006). En contraste, no existen estudios sobre la presencia de defensas químicas contra herbívoros en las diatomeas polares bentónicas, grupo dominante en este estudio. Además de las defensas estructurales (como la de poseer una pared celular silícea), bioensayos experimentales mostraron que algunas diatomeas pueden producir metabolitos que disminuyen el éxito reproductivo de invertebrados (Caldwell et al. 2002, Ruocco et al. 2018 pero ver Taylor et al. 2007). En general, la ecología química de las microalgas es escasamente conocida para aguas antárticas (Avila et al. 2007). Sin embargo, el estudio de la presencia de defensas químicas en las diatomeas bentónicas requiere atención y particularmente, sería importante dilucidar si pueden ser inducidas en respuesta a restricciones ecológicas (Mc Clintock \& Baker 1997) o factores de estrés ambiental tales como la UV. Por otro lado, la UV-B podría disminuir el contenido nutricional de las algas (a través de una menor producción de glucanos) así como la producción de exopolímeros o EPS (extrapolimeric substances, por sus siglas en inglés) (Waring et al. 2007, Daglio et al. 2018). Sin embargo, no existe esta información para ambientes antárticos.

Por otro lado, la mayoría de los estudios realizados hasta el momento indicarían que el pastoreo no es afectado por la exposición a la UV en ambientes de agua dulce (DeNicola \& Hoagland 1996, Hill et al. 1997, Vinebrooke \& Leavitt 1999) y marinos (Lotze et al. 2002, Sommaruga 2003, Zacher et al. 2007a,b, Molis \& Wahl 2009). Sin embargo, Bothwell et al. (1994) observaron efectos negativos directos de la UV (principalmente de la UV-A) sobre los herbívoros (larvas de quironómidos), con un consiguiente incremento en la biomasa algal. Asimismo, en ambientes intermareales se ha observado una menor biomasa algal (en comunidades dominadas por diatomeas bentónicas) en tratamientos en los que se excluyó la UV, asumiendo una mayor presión de pastoreo por microconsumidores en estos tratamientos (Roux et al. 2002).

En base a los resultados obtenidos, se sugiere la necesidad de realizar estudios que exploren los efectos de la UV sobre las interacciones entre las algas bentónicas y sus consumidores. En particular, evaluando i) los efectos de la UV sobre la palatabilidad algal y ii) la existencia de efectos negativos directos sobre la densidad o tasa de consumo de los herbívoros.

\section{Efectos de la UV y el pastoreo en el tiempo}

Los efectos de los factores analizados fueron observados particularmente durante la primera mitad del experimento (Lotze et al. 2002, Wahl et al. 2004, Molis \& Wahl 2009). Se han propuesto tres modelos para explicar las disminuciones de los efectos de la UV en procesos 
sucesionales i) disminución de la intensidad de la UV en el tiempo, ii) aclimatación de los organismos a la UV (desarrollo de mecanismos de protección morfológicos y químicos) y iii) cambios en la estructura de las comunidades como resultado de la sucesión (o inducidos por la UV) hacia un estado menos sensible a este factor de estrés (Wahl et al. 2004).

Por un lado, ocurre una menor irradiancia en el área de estudio (modelo i) coincidentemente con la segunda mitad del experimento. Peñón de Pesca presenta condiciones ópticas relativamente estables y con mayor transparencia que los sitios de la caleta interna, más afectados por la influencia de agua de deshielo (Richter et al. 2008, Quartino et al. 2013, Deregibus et al. 2016, Hernández 2016, Campana et al. 2017). Por lo tanto, es esperable que la menor radiación atmosférica en el tiempo se reflejara en una menor irradiancia en la columna de agua en el sitio de estudio. En este sentido, sería conveniente sostener mediciones continuas de PAR y UV subacuáticas que permitieran establecer las dosis recibidas a lo largo del año.

Además, ocurrieron cambios en la estructura de las comunidades como resultado de la sucesión y, mediados por la UV y el pastoreo, hacia un estado menos sensible a ambos factores (modelos ii y iii). Por un lado, los efectos del pastoreo fueron más intensos particularmente sobre las diatomeas, grupo que tendió a bajar su cobertura en el tiempo. Por otro lado, el efecto negativo de la UV sobre las clorofitas filamentosas desaparece cuando los filamentos crecen y a su vez, parecen no ser afectados por el pastoreo. Finalmente, el alga roja dominante, $P$. decipiens, no es afectada negativamente por el pastoreo, ni por la UV a lo largo del tiempo, lo cual coincide con su capacidad para soportar condiciones de estrés ambiental (Becker et al. 2011). 


\section{Corolario}

En base a los resultados obtenidos, podemos postular que los efectos de la UV y el pastoreo en etapas tempranas de la sucesión podrían reflejarse mediante el siguiente diagrama conceptual (Fig. 5.27):

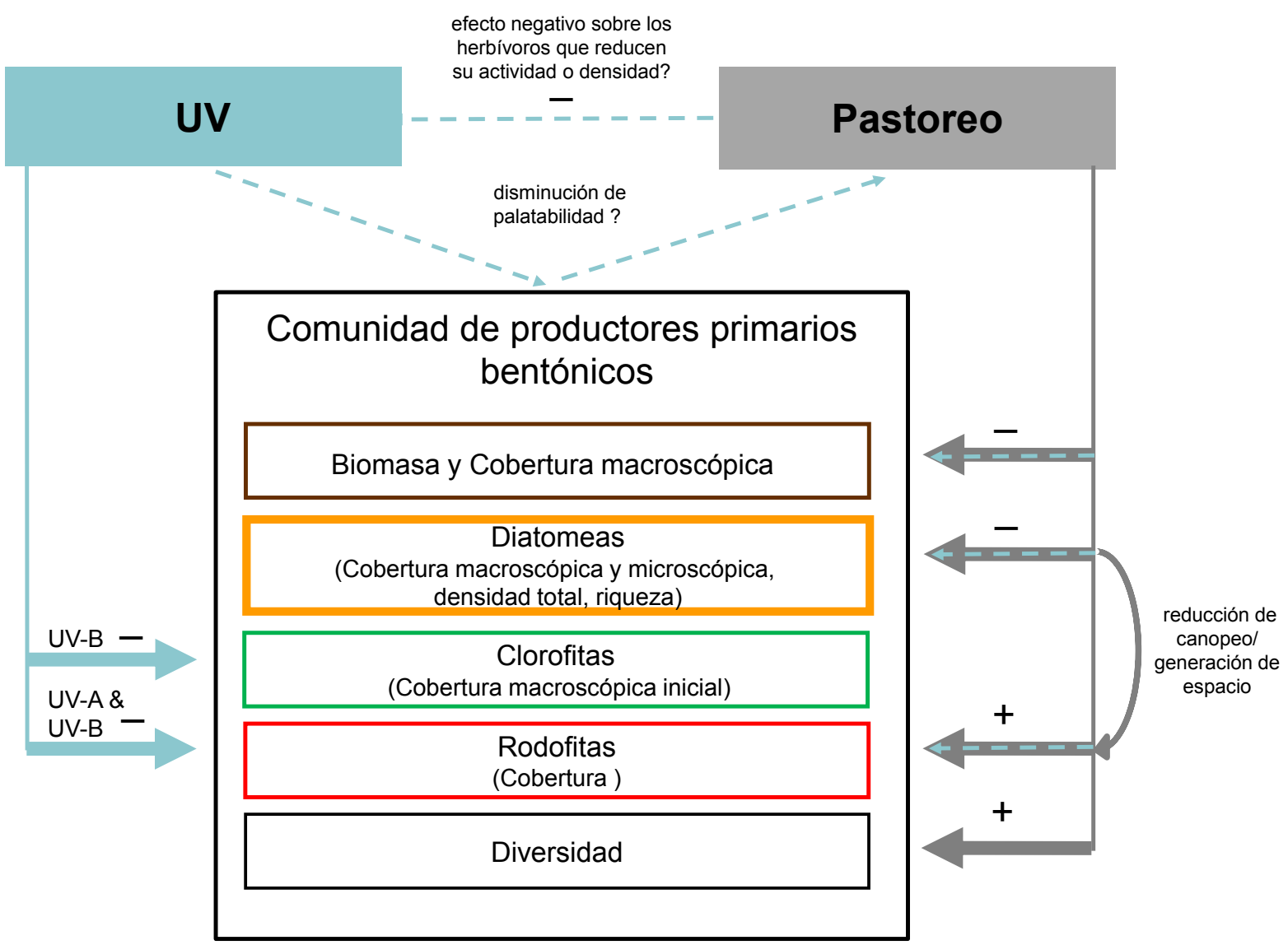

Fig. 5. 27. Principales efectos globales de la UV (en celeste) y el pastoreo (en gris) sobre la comunidad de productores primarios bentónicos. Se indican posibles efectos hipotéticos de interacción entre los herbívoros y la UV (flechas discontinuas, en celeste).

La UV afecta de manera diferente a los grupos algales: limita el establecimiento y/o crecimiento de algas verdes filamentosas (efecto causado por la UV-B) y la cobertura de rodofitas, sin afectar a las diatomeas. Este último, que es el grupo claramente dominante del espacio, es muy resistente a esta radiación (flechas continuas en celeste, Fig. 5.27).

El pastoreo reduce la biomasa y cobertura macroscópica de la comunidad, afecta negativamente a las diatomeas y tiene un efecto positivo sobre la cobertura de rodofitas y la diversidad de la comunidad (Fig. 5.27, flechas en gris). Los herbívoros consumen principalmente a las diatomeas. El consumo de diatomeas sería beneficioso para el establecimiento de ciertas especies de rodofitas de firme adhesión al sustrato, particularmente para $P$. decipiens, debido posiblemente a una disminución del sombreado 
causado por el canopeo de diatomeas (y/o a la generación de nuevo espacio). Asimismo, los herbívoros alteran la estructura tridimensional de la comunidad, consumiendo preferencialmente diatomeas coloniales y a las formas pedunculadas dominantes. Por otro lado, el pastoreo podría causar un incremento en la diversidad algal, relacionada con un aumento en la equitatividad.

Dado que algunos efectos del pastoreo fueron más intensos en los casos en los que la UV o la UV-B estuvieron ausentes, se podría postular que un efecto directo de la UV que causara una disminución de palatabilidad algal o un efecto directo negativo sobre los herbívoros (que disminuyen su densidad o actividad cuando esta radiación está presente) podrían ser explicaciones para estas tendencias (Fig. 5.27, flechas celestes con líneas discontinuas).

En resumen,

- La colonización comenzó con la aparición de diatomeas, algas verdes filamentosas y propágulos de algas rojas.

- El pastoreo se evidencia como el principal factor estructurante de las comunidades en etapas tempranas de la sucesión. Su efecto es particularmente evidente sobre los ensambles de diatomeas, introduciendo cambios en su fisonomía.

- Las matas de diatomeas bentónicas, resistentes a la UV, pueden proveer un ambiente de sombreado que protege a los propágulos de macroalgas que presentan mayor sensibilidad en esta etapa de su ciclo de vida. Por otro lado, el pastoreo sobre las diatomeas puede disminuir la competencia por la luz (y/o espacio) y por lo tanto, favorecer el establecimiento y crecimiento de especies de macroalgas menos sensibles a la UV.

- Se observaron efectos más intensos del pastoreo en las comunidades en las que la UV o la UV-B estuvieron ausentes. Una disminución en la palatabilidad algal o un efecto negativo directo sobre los herbívoros, que disminuyen su densidad o su actividad en estas condiciones podrían ser explicaciones para estas tendencias.

- Los efectos de la UV y el pastoreo dependieron del grado de desarrollo de las comunidades, siendo más intensos durante la primera mitad del experimento.

En base a los resultados obtenidos, se acepta la segunda hipótesis planteada: "Las comunidades en estadios iniciales de la sucesión son particularmente vulnerables a factores de estrés ambiental tales como la radiación ultravioleta. El pastoreo afecta la estructura de la comunidad de microalgas y macroalgas por reducción en la biomasa y cambio en la composición de especies. A su vez, los efectos de ambos factores dependen del grado de desarrollo de la comunidad". 
CAPÍTULO 6

Conclusiones 
En esta Tesis se identificaron experimentalmente los patrones de colonización y etapas siguientes de la sucesión de algas marinas bentónicas en un ambiente submareal antártico. Se realizó una caracterización taxonómica detallada de las microalgas y macroalgas bentónicas que integran las comunidades en estos procesos, se estudiaron los patrones sucesionales a largo plazo (cuatro años) y se analizaron los efectos de la UV y el pastoreo sobre etapas tempranas de la sucesión.

\section{Aspectos florísticos}

Se identificaron 40 taxa de diatomeas y 13 de macroalgas. Las diatomeas Achnanthes vicentii, Brandinia mosimanniae, Cocconeis orbicularis, Fragilaria islandica var. adeliae, Fragilariopsis kerguelensis, Navicula glaciei, Pteroncola carlinii y Thalassiosira antarctica y, entre las macroalgas, Rhodochorton cf. purpureum y Ulothrix flacca son nuevas citas para ambientes bentónicos de Caleta Potter.

En términos generales se observó que los ensambles de diatomeas están dominados por unos pocos taxa, entre ellos Navicula perminuta, Pseudogomphonema kamtschaticum y diatomeas coloniales del género Fragilaria. El aporte de las formas típicamente planctónicas de los géneros Fragilariopsis, Minidiscus y Thalassiosira fue muy escaso.

\section{Patrones generales de la colonización y etapas siguientes de la sucesión}

El estudio de los procesos de colonización y sucesión de algas marinas bentónicas (Capítulos 4 y 5) permitió describir algunas características principales de estos procesos para un ambiente rocoso del submareal antártico.

El sustrato nuevo es colonizado inicialmente por grupos pioneros que ocupan el espacio rápidamente: la colonización se inicia con dominancia de diatomeas, ocurriendo una ocupación gradual del espacio por algas verdes filamentosas. Desde el inicio de la colonización se establecen propágulos de algas rojas, particularmente Palmaria decipiens. Los estadios iniciales de esta especie probablemente desarrollan el esporofito en la siguiente primavera, lo cual es coincidente con su aparición en comunidades de un año de colonización.

A escalas temporales mayores, las macroalgas anuales y pseudoperennes dominan el sustrato, alcanzando aproximadamente un $70 \%$ de cobertura en sólo dos años. Se observaron cambios interanuales en la composición de taxa y tendencias hacia aumentos en la diversidad luego de cuatro años. La cobertura aumenta en el tiempo y adquiere la máxima 
complejidad tridimensional en tres años, luego de lo cual se produce una disminución, posiblemente mediada por interacciones de competencia intra- e interespecífica.

Luego de cuatro años se observan similitudes respecto a la comunidad de algas circundante, la elevada irradiancia y posiblemente el disturbio por hielo en estas relativamente bajas profundidades (menores a $5 \mathrm{~m}$ ) mantienen a las comunidades en etapas tempranas de la sucesión, con ausencia de individuos adultos de grandes algas pardas del orden Desmarestiales, característicos de los submareales antárticos a mayores profundidades.

\section{Efectos de la UV y el pastoreo: factores que controlan la colonización y sucesión en etapas tempranas}

El pastoreo se evidenció como el principal factor que afecta la estructura de las comunidades en desarrollo, mientras que los efectos directos de la UV sobre las algas fueron relativamente menores.

La UV afecta el establecimiento de algas verdes filamentosas (un efecto causado principalmente por la UV-B) y estadios iniciales de rodofitas. Las diatomeas bentónicas, grupo dominante en la ocupación del sustrato, están probablemente adaptadas al estrés que impone la UV ambiental en ambientes antárticos y posiblemente han desarrollado mecanismos de protección y reparación que deben ser explorados. El rol de este grupo en la colonización del sustrato rocoso es de gran importancia para el proceso de sucesión en este ambiente submareal.

El canopeo provisto por diatomeas puede afectar positiva o negativamente el establecimiento y/o crecimiento de macroalgas, dependiendo de la sensibilidad diferencial a la elevada radiación (incluyendo la UV), entre especies o entre estadios de su ciclo de vida. Las especies de macroalgas que habitan aguas más profundas pueden ser beneficiadas por este canopeo (e.g. Delesseriaceae), así como los propágulos de ciertas especies que poseen elevados requerimientos lumínicos (e.g. las algas verdes filamentosas). Sin embargo estas últimas podrían verse perjudicadas en estadios de mayor desarrollo.

Por otro lado, los herbívoros consumen principalmente a las diatomeas (y posiblemente a ciertas macroalgas cuando sus estructuras son más delicadas, en estadios iniciales). El consumo de diatomeas causa un cambio drástico en la fisonomía de los ensambles por reducción de grupos filamentosos y pedunculados, y provoca disminución de la riqueza de los ensambles. Esto resultaría en un efecto positivo para el establecimiento de rodofitas de elevados requerimientos lumínicos y firme adhesión al sustrato, tales como la especie Palmaria decipiens, particularmente cuando la UV está ausente. 
Algunos efectos del pastoreo fueron más intensos en las comunidades que no recibieron UV (o UV-B). Este resultado reflejaría varios efectos posibles, entre ellos: i) la existencia de un efecto negativo directo de la UV sobre el pastoreo, disminuyendo la actividad de los herbívoros, o ii) un aumento de la palatabilidad de las algas cuando esta radiación está ausente.

Los resultados de este estudio revelan que los efectos de la UV ambiental y el pastoreo afectan la estructura y probablemente el funcionamiento de las comunidades de productores primarios bentónicos en etapas tempranas de la sucesión, lo cual podría introducir modificaciones en los flujos de materia y energía en la red trófica costera.

\section{Consideraciones metodológicas}

El enfoque experimental empleando sustratos artificiales en terreno permitió caracterizar taxonómicamente comunidades de algas marinas bentónicas con diferente grado de desarrollo mediante su traslado al laboratorio. Cabe destacar la ventaja del uso de sustratos artificiales para el estudio de procesos sucesionales en el bentos antártico, dado que proveen condiciones uniformes, réplicas estandarizadas y permiten una relativamente fácil manipulación por buzos, particularmente en aguas polares (Foster \& Sousa 1985, StanwellSmith \& Barnes 1997, Campana et al. 2011). Asimismo, sería conveniente realizar también estudios empleando sustratos naturales, los que pueden proveer una heterogeneidad espacial (en rugosidad, tamaño, posición) que puede afectar el establecimiento y la supervivencia de los organismos colonizadores (e.g. Bertness et al. 2002).

En etapas tempranas de la sucesión, resultaron adecuados los sustratos de menores dimensiones, dado que permitieron una relativamente fácil manipulación, la replicación en el diseño experimental, el estudio de la estructura de la comunidad a distintos niveles y el análisis de los ensambles de diatomeas. Asimismo, esta metodología hizo posible identificar estadios iniciales de algas rojas y clorofitas filamentosas difíciles de identificar en condiciones de campo en el submareal.y realizar un registro fotográfico de diatomeas coloniales.

En el caso de los análisis de la sucesión a largo plazo- a partir de un año de colonización, en este estudio- se emplearon sustratos de mayor tamaño, que fueron analizados en detalle en el laboratorio y mediante muestreos fotográficos. Los análisis de laboratorio emplearon el método de point cuadrat, el cual es el más adecuado para la determinación de índices ecológicos y de la cobertura de la comunidad particularmente en etapas avanzadas de la sucesión, cuando existen varias capas superpuestas (Foster et al. 1991). Por otro lado, el muestreo fotográfico es una buena metodología para detectar cambios estacionales en las comunidades de algas bentónicas antárticas, complementa a 
los análisis detallados de laboratorio y permite aumentar la resolución temporal en la toma de muestras. Las fotografías pueden ser tomadas durante todo el año, incluyendo los meses de otoño e invierno, por técnicos no especializados en ficología y ser analizadas a posteriori.

Finalmente, se destaca la necesidad de realizar mediciones de PAR y UV continuas en el ambiente submareal para establecer las variaciones en las dosis recibidas a lo largo del año.

\section{Consideraciones finales y perspectivas futuras}

Esta Tesis proporciona una línea de base para lograr un conocimiento más profundo de los patrones de colonización y sucesión de algas marinas bentónicas antárticas. Sin embargo, se requiere más información acerca de los procesos sucesionales de las algas marinas bentónicas antárticas para lograr un mayor conocimiento de la magnitud de los factores abióticos y bióticos sobre la estructura y funcionamiento de estos ecosistemas. El enfoque experimental empleado en este estudio ha sido aplicado para el conocimiento de estos procesos en sitios con influencia glaciaria y nuevas áreas libres de hielo generadas recientemente en caleta Potter como resultado del retroceso glaciar (Campana et al. 2017, Deregibus 2017).

El detallado análisis taxonómico llevado a cabo mediante el uso de microscopía óptica y electrónica permitió ampliar el conocimiento acerca de la identidad de los taxa que forman las comunidades de microalgas marinas bentónicas antárticas. A pesar de los recientes trabajos taxonómicos realizados (Al-Handal \& Wulff 2008a,b, Al Handal et al. 2008, 2010 Fernandes et al. 2007, 2014, incluyendo esta Tesis) es necesario, tal como fue enfatizado por otros autores (Wulff et al. 2011, Fernandes et al. 2012), intensificar los estudios taxonómicos a fin de elucidar las incertezas que aún existen respecto a la identificación y posición nomenclatural de varios taxa (por ejemplo, $N$. perminuta, Cocconeis melchiori, Trigonium curvatus).

Las etapas tempranas de la sucesión demostraron ser particularmente vulnerables a la UV y el pastoreo y están probablemente controladas por complejas interacciones entre factores abióticos e interacciones biológicas. En particular, considerando que el efecto de la UV sobre los sistemas antárticos continúa siendo un factor de estrés ambiental, surge la necesidad de realizar estudios que exploren los efectos de esta radiación sobre las interacciones entre las algas bentónicas y sus consumidores, tales como los efectos de la UV sobre la palatabilidad algal (e. g. Pavia et al. 1997, Macaya et al. 2005, Fairhead et al. 2006) así como sobre la fisiología y el comportamiento de los herbívoros (Sommaruga 2003, Obermüller et al. 2007). 
La Antártida, y particularmente la península Antártica es una de las regiones más afectadas por los fenómenos asociados al calentamiento climático (Turner et al. 2009), los cuales ya han demostrado ejercer una fuerte influencia sobre la estructura de las comunidades marinas bentónicas (Quartino et al. 2013, Moon et al. 2015, Sahade et al. 2015). Por un lado el notable retroceso de los sistemas glaciarios del oeste de la península Antártica ha originado nuevas áreas libres de hielo que han sido colonizadas por macroalgas (Quartino et al. 2013, Deregibus et al. 2016, Deregibus 2017) e invertebrados bentónicos (Sahade et al. 2015, Lagger et al. 2017, 2018). Asimismo, se han registrado recientemente blooms de diatomeas bentónicas en fondos blandos en sitios afectados por el derretimiento glaciar (Ahn et al. 2016). Por otro lado, se ha postulado que ocurrirá un aumento en el disturbio causado por la abrasión por hielo, como resultado de i) la disminución en la formación de hielo marino que permite un mayor movimiento de los témpanos existentes y ii) por el aporte de nuevos témpanos provenientes de los glaciares en retroceso (Barnes 2017). En este contexto, se espera que ocurran más eventos de colonización y recolonización en el bentos costero antártico (Smale \& Barnes 2008, Quartino et al. 2013, Barnes 2017, Deregibus et al. 2017).

En estos sistemas, una disminución en la formación de hielo marino (temporal y espacial) podría causar un aumento en la disponibilidad de PAR en la columna de agua, incrementando la producción primaria en estas áreas (Johnston et al. 2007, Mc Clintock et al. 2008, Clark et al. 2013) y pudiendo favorecer la colonización por macroalgas en aguas más profundas (Miller \& Pearse 1991). Sin embargo, esto también representaría un aumento en la incidencia de la UV. Por otro lado, particularmente durante los meses de verano, un incremento en el ingreso de sedimento de origen terrestre como resultado del derretimiento glaciar podría disminuir la penetración de la UV, pero simultáneamente disminuir la PAR afectando la estructura de las comunidades y el balance de carbono de las macroalgas (Quartino et al. 2013, Deregibus et al. 2016, Hernández 2016, Campana et al. 2017). A su vez, una mayor sedimentación puede afectar la supervivencia o establecimiento de los propágulos de macroalgas (Zacher et al. 2016a).

En este ambiente severamente afectado por los fenómenos asociados al cambio global, los patrones sucesionales de las algas bentónicas pueden entonces modificarse debido a la susceptibilidad de las especies a los cambios abióticos (una mayor provisión de espacio pero simultáneamente, aumentos en la temperatura, modificaciones del ambiente luminoso subacuático, aumento del disturbio causado por icebergs, aumentos en la sedimentación, acidificación, entre otros) y a posibles cambios en las interacciones entre ellas (tales como en la competencia y el pastoreo, o por la invasión por especies de climas templado-fríos) (Campana et al. 2011, Schoenrock et al. 2015, Navarro et al. 2016, Zacher et al. 2016a,b). Esto tendría consecuencias no sólo para las comunidades de algas 
bentónicas sino también para su fauna asociada, como se ha demostrado para comunidades del bentos en el Ártico (Bartsch et al. 2016, Paar et al. 2016). Además, la red trófica detrítica en aguas costeras polares puede ser afectada causando cambios estructurales o funcionales en el zoobentos de sustrato blando que depende de las microalgas y macroalgas bentónicas para su mantenimiento, y que a su vez, ya ha demostrado ser susceptible al cambio climático y el retroceso glaciar (Torre et al. 2014, 2017; Pasotti et al. 2015; Sahade et al. 2015, Lagger et al. 2017, 2018).

Por todo lo antes mencionado se considera necesario profundizar el estudio de la taxonomía, ecofisiología y ecología de las algas marinas bentónicas en la Antártida. Estas investigaciones permitirán evaluar y ayudar a predecir la respuesta de estas comunidades, que cumplen un rol fundamental en un sistema seriamente afectado por los fenómenos asociados al cambio global tales como el calentamiento climático y el incremento de la radiación ultravioleta $B$. 
Bibliografía citada 
Agardh, C. A. 1824. Systema Algarum. Lundae Berlingianis. [i]-xxxvii, [1]-312.

Agardh, C. A. 1832. Conspectus criticus diatomacearum 4: 49-66. Berlingianiis, Lund.

Aguirre, G. E. 2015. Ecología del mesozooplancton marino en ambientes costeros de altas latitudes: Canal de Beagle (extremo sur de Sudamérica) y Caleta Potter (Isla 25 de Mayo, Antártida). Facultad de Ciencias Exactas y Naturales. Universidad de Buenos Aires. $194 \mathrm{pp}$.

Aguirre, L. E., Ouyang, L., Elfwing, A., Hedblom, M. Wulff, A. \& Inganäs, O. 2018. Diatom frustules protect DNA from ultraviolet light. Sci. Rep. 8: 5138.

Ahn, I.-Y., Chung, H., Kang, J.-S. \& Kang, S.-H. 1997. Diatom composition and biomass variability in nearshore waters of Maxwell Bay, Antarctica, during the 1992/1993 austral summer. Polar Biol. 17:123-130.

Ahn, I.-Y., Moon, H.-W., Jeon, M., Kang, S.-H. 2016. First record of massive blooming of benthic diatoms and their association with megabenthic filter feeders on the shallow seafloor of an Antarctic fjord: does glacier melting fuel the bloom? Ocean Sci. J. 51: 273-279.

Al-Handal, A. Y. \& Wulff, A. 2008a. Marine benthic diatoms from Potter Cove, King George Island, Antarctica. Bot. Mar. 51: 51-68.

Al-Handal, A. Y. \& Wulff, A. 2008b. Marine epiphytic diatoms from the shallow sublittoral zone in Potter Cove, King George Island, Antarctica. Bot. Mar. 51:411-435.

Al-Handal, A. Y., Riaux-Gobin, C., Romero, O. E. \& Wulff, A. 2008. Two new marine species of the diatom genus Cocconeis Ehrenberg: C. melchioroides sp. nov. and C. dallmannii sp. nov., from King George Island, Antarctica. Diatom Res. 23: 269-281.

Al-Handal, A. Y., Riaux-Gobin, C. \& Wulff, A. 2010. Cocconeis pottercovei sp. nov. and Cocconeis pinnata var. matsii var. nov., two new marine diatom taxa from King George Island, Antarctica. Diatom Res. 25: 1-11.

Almandoz, G. O., Ferrario, M. E., Sullivan, M. J. Ector, L. \& Schloss, I. R. 2014. A new Pteroncola species (Bacillariophyceae) from the South Shetland Islands, Antarctica. Phycologia 53: 188-194.

Amsler, C. D., Reed, D. C. \& Neushul, M. 1992. The microclimate inhabited by macroalgal propagules. Eur. J. Phycol. 27: 253-270.

Amsler, C. D., Rowley, R. J., Laur, D. R., Quetin, L. B. \& Ross, R. M. 1995. Vertical distribution of Antarctic peninsular macroalgae: cover, biomass and species composition. Phycologia 34: 424-430.

Amsler, C. D., McClintock, J. B. \& Baker, B. J. 1998. Chemical defense against herbivory in the Antarctic marine macroalgae Iridaea cordata and Phyllophora antarctica (Rhodophyceaea). J. Phycol. 34: 53-59.

Amsler, C.D., McClintock, J. B. \& Baker, B. J. 1999. An antarctic feeding triangle: defensive interactions between macroalgae, sea urchins, and sea anemones. Mar. Ecol. Prog. Ser. 183: 105-114.

Amsler, C. D., Iken, K., McClintock, J. B., Amsler, M. O., Peters, K. J., Hubbard, J. M., Furrow, F. B. \& Baker, B. J. 2005. Comprehensive evaluation of the palatability and chemical defenses of subtidal macroalgae from the Antarctic Peninsula. Mar. Ecol. Prog. Ser. 294: 141-159.

Amsler, C. D., Amsler, M. O., McClintock, J. B. \& Baker, B. J. 2009. Filamentous algal endophytes in macrophytic Antarctic algae: prevalence in hosts and palatability to mesoherbivores. Phycologia 48: 324-334.

Amsler, C. D., Iken, K., McClintock, J. B. \& Baker, B. J. 2011. Defenses of polar macroalgae against herbivores and biofoulers. En: C. Wiencke (ed.) Biology of polar benthic algae (Cap. 5, pp. 101-120). Walter de Gruyter GmbH \& Co. K.G., Berlin/New York. 337 pp.

Amsler, C. D., McClintock, J. B. \& Baker, B. J. 2014. Chemical mediation of mutualistic interactions between macroalgae and mesograzers structure unique coastal communities along the Western Antarctic Peninsula. J. Phycol. 50: 1-10.

Amsler, M. O., Huang, Y. M., Engl, W., McClintock, M. J. \& Amsler, C. D. 2015. Abundance and diversity of gastropods associated with dominant subtidal macroalgae from the western Antarctic Peninsula. Polar Biol. 38: 1171-1181. 
Anonymous. 1975. Proposals for a standardization of diatom terminology and diagnoses. Beihefte zur Nova Hedwigia 53: 323-354.

Areschoug, J. E. 1874. Observationes phycologicae II. De Urospora mirabili Aresch et. de chlorozoosporarum copulatione. Nova Acta Regiae Societatis Scientiarum Upsaliensis, Ser. 3 (9): 1-13, Lám. I-II.

Ashworth, M. P., Nalov T. \& Theriot, E. C. 2013. Revisiting Ross and Sims (1971): Toward a molecular phylogeny of the Biddulphiaceae and Eupodiscaceae (Bacillariophyceae). J. Phycol. 49: 1207-1222.

Atencio, A. G., Bertolín, L., Longhi, M. L, Ferreyra, G. A., Ferrario, M. E. \& Schloss, I. R. 2008. Spatial and temporal variability of chlorophyll-a and particulate organic matter in the sediments and the water column of Potter Cove, Antarctica. En: C. Wiencke, G. A. Ferreyra, D. Abele \& S. Marenssi (eds.) The Antarctic ecosystem of Potter Cove, King George Island (Isla 25 de Mayo). Reports on Polar and Marine Research (Ber. Polarforsch. Meeresforsch.) 571: 154-161.

Aumack, C. F., Amsler, C. D., McClintock, J. B. \& Baker, B. J. 2010. Chemically mediated resistance to mesoherbivory in finely branched macroalgae along the western Antarctic Peninsula. Eur. J. Phycol. 45: 19-26.

Aumack, C. F., Amsler, C. D., McClintock, J. B. \& Baker, B. J. 2011. Changes in amphipod densities among macroalgal habitats in day versus night collections along the Western Antarctic Peninsula. Mar. Biol. 158: 1879-1885.

Avila, C., Taboada, S. \& Núñez-Pons, L. 2007. Antarctic marine chemical ecology: what is next? Mar. Ecol. 29: 1-71.

Barber, H. G. \& Haworth, E. Y. 1981. A guide to the morphology of the diatom frustule. Feshwater Biological Association Scientific Publication 44. $112 \mathrm{pp}$.

Barner, A. K., Hacker, S. D., Menge, B. A. \& Nielse, K. J. 2016. The complex net effect of reciprocal interactions and recruitment facilitation mantains an intertidal kelp community. J. Ecol. 104: 33-43.

Barnes, D. K. A. 2017. Iceberg killing fields limit huge potential for benthic blue carbon in Antarctic shallows. Global Change Biol. 23: 2649-2659.

Barnes, D. K. A., Rothery, P. \& Clarke, A. 1996. Colonisation and development in encrusting communities from the Antarctic intertidal and sublittoral. J. Exp. Mar. Biol. Ecol. 196: 251-265.

Barnes, D. K. A. \& Conlan, K. E. 2007. Disturbance, colonization and development of Antarctic benthic communities. Phil. Trans. R. Soc. B 362: 11-38.

Bartsch, I., Paar, M., Fredriksen, S., Schwanitz, M., Daniel, C., Hop, H. \& Wiencke, C. 2016. Changes in kelp forest biomass and depth distribution in Kongsfjorden, Svalbard, between 1996-1998 and 2012-2014 reflect Arctic warming. Polar Biol. 39: 2021-2036.

Becker, S. B., Quartino, M. L., Campana, G. L., Bucolo, P., Wiencke, C. \& Bischof, K. 2011. The biology of an Antarctic rhodophyte, Palmaria decipiens: recent advances. Antarct. Sci. 23: 419-430.

Benedetti Cecchi, L. 2000. Predicting direct and indirect interactions during succession in a mid-littoral rocky shore assemblage. Ecol. Monogr. 70: 45-72.

Bérard-Therriault, L., Poulin, M. \& Bossé, L. 1999. Guide d'identification du phytoplancton marin de l'estuaire et du Golfe du Saint-Laurent incluant également certains protozoaires. Publication Spéciale Canadienne des Sciences Halieutiques et Aquatiques 128: 1-387.

Bers, A. V., Momo, F. R., Schloss, I. R. \& Abele, D. 2013. Analysis of trends and sudden changes in long-term environmental data from King George Island (Antarctica): relationships between global climatic oscillations and local system response. Clim. Change 116: 789-803.

Bertness, M. D., Trussell, G. C., Ewanchuk, P. J. \& Silliman, B. R. 2002. Do alternate stable community states exist in the Gulf of Maine rocky intertidal zone? Ecology 83: 34343448.

Bischof, K., Hanelt, D. \& Wiencke, C. 1998. UV-Radiation can affect depth zonation of Antarctic macroalgae. Mar. Biol. 131:597-605. 
Bischof, K., Gómez, I., Molis, M., Hanelt, D., Karsten, U., Lüder, U.H., Roleda, M., Zacher, K. \& Wiencke, C. 2006. Ultraviolet radiation shapes seaweeds communities. Rev. Environ. Sci. Biotechnol. 5: 141-166.

Blazewicz-Paszkowycz, M. \& Ligowski, J. 2002. Diatoms as food source indicator for some Antarctic Cumacea and Tanaidacea (Crustacea). Antarct. Sci. 14: 11-15.

Boraso de Zaixso, A. L. 2013. Elementos para el estudio de las macroalgas de Argentina. Con colaboración de J.M. Zaixso. Comodoro Rivadavia: Universitaria de la Patagonia, Argentina. 207 pp.

Boraso de Zaixso, A. L. \& Quartino, M.L. 1993. Estudios sobre algas marinas bentónicas en Argentina. Naturalia Patagónica, Cs. Biol. 1: 35-57.

Bory de Saint-Vincent, J. B. 1822. Collaborator in dictionnaire classique d'historie naturelle, Paris.

Bory de Saint-Vincent, J. B. 1826. Iridée. Iridea. En: Audouin, I. et al. (eds), Dictionnaire Classique d'Histoire Naturelle. Vol. 9. Paris.

Bothwell, M. L., Sherbot, D. M. J. \& Pollock, C. M. 1994. Ecosystem response to solar ultraviolet-B radiation: Influence of trophic-level interactions. Science 265: 97-100.

Bowden, D. A. 2005. Seasonality of recruitment in Antarctic sessile marine benthos. Mar. Ecol. Prog. Ser. 297: 101-118.

Bowden, D. A., Clarke, A., Peck, L. S. \& Barnes, D. K. A. 2006. Antarctic sessile marine benthos: colonisation and growth on artificial substrata over three years. Mar. Ecol. Prog. Ser. 316:1-16.

Boyer, C. S. 1926-1927. Synopsis of North American diatomaceae. Proceedings of the Biological and Microscopical Section of the Academy of Natural Sciences of Philadelphia 1:1-17.

Brêthes, J. C., Ferreyra, G. \& de la Vega, S. 1994. Distribution, growth and reproduction of the limpet Nacella (Patinigera) concinna (Strebel 1908) in relation to potential food availability, in Esperanza Bay (Antarctic Peninsula). Polar Biol. 14: 161-170.

Brouwer, P. E. M., Geilen, E. F. M., Gremmen, N. J. M. \& Vanlent, F. 1995. Biomass, cover and zonation pattern of sublittoral macroalgae at Signy Island, South Orkney Islands, Antarctica. Bot. Mar. 38: 259-270.

Brown, N. E. 1920. Some new and old Antarctic diatoms. Part III. English Mechanic and World of Science, 111(2881): 232-233.

Brun, J. \& Tempère, J. 1889. Diatomées fossiles du Japon. Memoires de la Société de Physique et d'Histoire Naturelle de Genève 30:1-75.

Bruno, J. F. \& Bertness, M. D. Habitat modification and facilitation in benthic marine communities. En: M. D. Bertness, S. D. Gaines, \& M. E. Hay (eds.). Marine community ecology. (Cap. 8, pp. 85-130). Sinauer Associates, Inc., Sunderland, Massachusetts. $550 \mathrm{pp}$.

Busse, S. \& Snoeijs, P. 2002. Navicula sjoersii sp. nov., N. bossvikensis sp. nov. and $N$. perminuta Grunow from the Baltic Sea. Diatom Res. 17: 271-282.

Caldwell, G. S., Olive, P. J. W. \& Bentley, M.G. 2002. Inhibition of embryonic development and fertilization in broadcast spawning marine invertebrates by water soluble diatom extracts and the diatom toxin 2-trans,4-trans decadienal. Aquat. Toxicol. 60: 123-137.

Campana, G. L., Quartino, M. L., Yousif, A. \& Wulff, A. 2008. Effects of UV radiation and grazing on the structure of a subtidal benthic diatom assemblage in Antarctica. En: C. Wiencke, G. A. Ferreyra, D. Abele \& S. Marenssi (eds.) The Antarctic ecosystem of Potter Cove, King George Island (Isla 25 de Mayo). Reports on Polar and Marine Research (Ber. Polarforsch. Meeresforsch.) 571: 302-310.

Campana, G. L., Zacher, K., Fricke, A., Molis, M., Wulff, A., Quartino, M.L. \& Wiencke. C. 2011. Drivers of colonization and succession in Polar benthic macro- and microalgal communities. En: C. Wiencke (ed.) Biology of Polar Benthic Algae. (Cap. 14, pp. 299320). Walter de Gruyter GmbH \& Co. K.G., Berlin/New York. 337 pp.

Campana, G. L., Zacher, K., Deregibus, D., Momo, F. M., Wiencke, C. \& Quartino, M.L. 2017. Succession of Antarctic benthic algae (Potter Cove, South Shetland Islands): structural patterns and glacial impact over a four-year period. Polar Biol. doi:10.1007/s00300017-2197-x. 
Carlson, G. W. F. 1913. Süsswasseralgen aus der Antarktis, Südgeorgien und den Falkland Inseln // Schwedischen Sudpolar-Expedition 1901-1903. Stockholm: Litographisches Institut des Generalstabs. 547-640.

Cefarelli, A. O., Ferrario, M. E., Almandoz, G. O., Atencio, A. G., Akselman, R. \& Vernet, M. 2010. Diversity of the diatom genus Fragilariopsis in the Argentine Sea and Antarctic waters: morphology, distribution and abundance. Polar Biol. 33:1463-1484.

Cefarelli, A. O., Vernet, M. \& Ferrario, M. E. 2011. Phytoplankton composition and abundance in relation to free-floating Antarctic icebergs. Deep-Sea Res. II 58:1436-1450.

Cefarelli, A.O., Ferrario, M.E. \& Vernet, M. 2016. Diatoms (Bacillariophyceae) associated with free-drifting Antarctic icebergs: taxonomy and distribution. Polar Biol. 39: 443-459.

Clark, G., Stark, J., Perrett, L., Hill, N. \& Johnston, E. 2011. Algal canopy as a proxy for the disturbance history of understorey communities in East Antarctica. Polar Biol. 34: 781790.

Clark, G. F., Stark, J. S., Johnston, E. L., Runcie, J. W., Goldsworthy, P. M., Raymond, B. \& Riddle, M. J. 2013. Light-driven tipping points in polar ecosystems. Global Change Biol. 19: 3749-3761.

Clarke, K. R. \& Warick, R. M. 2001. Change in marine communities: An approach to statistical analysis and interpretation. PRIMER-E, Plymouth.

Clayton, M. N. \& Wiencke, C. 1990. The anatomy, life-history and development of the Antarctic brown alga Phaeurus antarcticus (Desmarestiales, Phaeophyceae). Phycologia 29: 303-315.

Clayton, M. N. 1992. Propagules of marine macroalgae: Structure and development. Br. Phycol. J. 27: 219-232.

Clayton, M. N. 1994. Evolution of the Antarctic marine benthic algal flora. J. Phycol. 30: 897904.

Clements, F. E. 1916. Plant succession. An analysis of the development of vegetation. Carnegie Institution of Washington, Washington. $512 \mathrm{pp}$.

Cleve, P. T. 1867. Diatomaceer från Spetsbergen. Öfversigt af Kongl. VetenskapsAkademiens Förhandlingar, Stockholm 24(10): 661-670.

Cleve, P. T. 1894. Synopsis of the naviculoid diatoms. Part I. Kongliga Svenska Vetenskapsakademiens Handlingar, Serie 426 (2): 1-194.

Cleve, P. T. \& Grunow, A. 1880. Beiträge zur Kenntniss der arctischen Diatomeen. Kongliga Svenska Vetenskaps-Akademiens Handlingar 17(2): 1-121.

Coelho, S. M., Rijstenbil, J. W. \& Brown, M. T. 2000. Impacts of anthropogenic stresses on the early development stages of seaweeds. J. Aquat. Ecosyst. Stress Recovery 7: 317333.

Cognetti, G., Sarà, M. \& Magazzù, G. 2001. Biología Marina. Ariel S.A., Barcelona. 619 pp.

Comber, T. 1896. On the occurrence of endocysts in the genus Thalassiosira. Journal of the Royal Microscopical Society 9: 489-491.

Connell, J. H. 1987. Change and persistence in some marine communities. En: A.J. Gray, M.J. Crawley \& P.J. Edwards (eds.) Colonization, succession and stability. (Cap. 16, pp. 339-352), British Ecological Society, Blackwell Scientific Publications.

Connell, J. H. \& Slatyer, R. O. 1977. Mechanisms of succession in natural communities and their role in community stability and organization. Am. Nat. 111: 1119-1144.

Connell, J. H., Noble, I. R. \& Slatyer, R. O. 1987. On the mechanisms producing successional change. Oikos 50: 136-137.

Corbisier, T. N., Petti, M. A. V., Skowronski, R. S. P. \& Brito, T. A. S. 2004. Trophic relationships in the nearshore zone of Martel Inlet (King George Island, Antarctica): delta C-13 stable-isotope analysis. Polar Biol. 27: 75-82.

Cormaci, M., Furnari, G. \& Scammacca, B. 1992. The benthic algal flora of Terra Nova Bay (Ross Sea, Antarctica). Bot. Mar. 35: 541-552.

Cox, E. J. 1978. Taxonomic studies on the diatom genus Navicula Bory. Navicula grevillii (C.A.Ag.) Heiberg and N. comoides (Dillwyn) H. \& M. Peragallo. Bot. J. Linn. Soc. 76: 127-143. 
Cox, E. J. 1988. Taxonomic studies on the diatom genus Navicula V. The establishment of Parlibellus gen. nov. for some members of Navicula sect. Microstigmaticae. Diatom Res. 3: 9-38.

Cox, E. J. 2006. Achnanthes sensu stricto belongs with genera of the Mastogloiales rather than with other monoraphid diatoms (Bacillariophyta). Eur. J. Phycol. 41: 67-81.

Cox, E. J. 2015. Diatoms, Diatomeae (Bacillariophyceae s.I., Bacillariophyta). En: W. Frey (ed.), Syllabus of Plant Families. Adolf Engler's Syllabus der Pflanzenfamilien, Part 2/1: Photoautotrophic eukaryotic algae (pp. 64-103). Borntraeger Science Publishers, Stuttgart. $324 \mathrm{pp}$.

Cremer, H., Roberts, D., McMinn, A., Gore, D. \& Melles, M. 2003. The holocene diatom flora of marine bays in the Windmill Islands, East Antarctica. Bot. Mar. 46: 82-106.

Cullen, J. \& Neale, P. 1994. Ultraviolet radiation, ozone depletion and marine photosyntesis. Photosynth. Res. 39: 303-320.

Cunningham, L. \& Mc Minn, A. 2004. The influence of natural environmental factors on benthic diatom communities from the Windmill Islands, Antarctica. Phycologia 43: 744-755.

Cunningham, L., Snape, I., Stark, J. S. \& Riddle, M. J. 2005. Benthic diatom community response to environmental variables and metal concentrations in a contaminated bay adjacent to Casey Station, Antarctica. Mar. Pollut. Bull. 50: 264-275.

Daglio, Y., Sacristán, H., Ansaldo, M. \& Rodríguez, M. C. 2018. Benthic diatoms from Potter Cove, 25 de Mayo (King George) Island, Antarctica: Mucilage and glucan storage as a C-source for limpets. Polar Sci. 15: 39-48.

Dayton, P. K. 1971. Competition, disturbance and community organization: The provision and subsequent utilization of space in a rocky intertidal community. Ecol. Monogr. 41: 351389.

Dayton, P. K. 1972. Toward an understanding of community resilience and the potential effects of enrichments to the benthos at McMurdo Sound, Antarctica. Proceedings of the Colloquium on Conservation Problems (pp. 81-96). Allen Press, Lawrence, Kansas.

Dayton, P. K. 1989. Interdecadal variation in an Antarctic sponge and its predators from oceanographic climate shifts. Science 245: 1484-1486.

Dayton, P. K., Watson, D., Palmisano, A., Barry, J. P., Oliver, J. S. \& Rivera, D. 1986. Distribution patterns of benthic microalgal standing stock at McMurdo Sound, Antarctica. Polar Biol. 6: 207-213.

Dayton, P. K., Jarrell, S., Kim, S., Thrush, S., Hammerstrom, K. Slattery, M. \& Parnell, E. 2016. Surprising episodic recruitment and growth of Antarctic sponges: Implications for ecological resilience. J. Exp. Mar. Biol. Ecol. 482: 38-55.

de Mora, S., Demers, S. \& Vernet, M. 2000. The effects of UV radiation in the marine environment. Cambridge University Press, Cambridge. 324 pp.

De Nicola, D. M. \& Hoagland, K. D. 1996. Effects of solar spectral irradiance (visible to UV) on a prairie stream epilithic community. J. North Am. Benthol. Soc. 15: 155-169.

Deregibus, D., Quartino, M. L., Campana, G. L., Momo, F. R., Wiencke, C. \& Zacher, K. 2016. Photosynthetic light requirements and vertical distribution of macroalgae in newly icefree areas in Potter Cove, South Shetland Islands, Antarctica. Polar Biol. 39 153-166.

Deregibus, D. 2017. Efecto del retroceso glaciario inducido por el cambio climático sobre la comunidad de algas marinas bentónicas en nuevas áreas libres de hielo en un ecosistema costero antártico (Caleta Potter, I. 25 de Mayo, I. Shetland del Sur). Facultad de Ciencias Exactas y Naturales. Universidad de Buenos Aires. 194 pp.

Deregibus, D., Quartino, M. L., Zacher, K., Campana, G. L. \& Barnes, D. K. A. 2017. Understanding the link between sea ice, ice scour and Antarctic benthic biodiversity; the need for cross station and nation collaboration. Polar Rec. 53: 143-152.

De Stefano, M. \& Romero, O. E. 2005. A survey of alveolate species of the diatom genus Cocconeis (Ehr.) with remarks on the new section Alveolate. Bibliotheca Diatomologica, Band 52. J. Cramer, Berlin-Stuttgart. $133 \mathrm{pp}$.

Dobretsov, S. V., Qian, P.-Y. \& Wahl, M. 2005. Effect of solar ultraviolet radiation on the formation of shallow, early successional biofouling communities in Hong Kong. Mar. Ecol. Prog. Ser. 290: 55-65. 
Donahue, W. F. \& Clare, J. J. 1999. Effects of ultraviolet radiation on trophic interactions not detected? Limnol. Oceanogr 44: 470-473.

Dureau de la Malle, A. 1825. Mémoire sur l'alternance ou sur ce problème: la succession alternative dans la reproduction des espèces végétales vivant en société, est-elle une loi générale de la nature. (Memoir on alternation or on alternative succession in the reproduction of plant species living in a community - is it a general law of nature?). Annales des sciences naturelles, 15: 353-381.

Ellegaard, M., Lenau, T., Lundholm, N., Maibohm, C., Mørk Friis, S. M., Rottwitt, K. \& Su, Y. 2016. The fascinating diatom frustule-can it play a role for attenuation of UV radiation? J. Appl. Phycol. 28: 3295-3306.

El-Sayed, S. Z. 1968. On the productivity of the South-west Atlantic Ocean and the waters west of the Antarctic Peninsula. En: W. Schmidt \& G. Llano (eds.) Biology of the Antarctic Seas III, (pp 15-47). Washington DC, American Geophysical Union.

Ehrenberg, C. G. 1843. Verbreitung und Einfluss des mikroskopischen Lebens in Süd- und Nord-Amerika. Abh. Königl. Akad. Wiss. Berlin. 1: 291-445.

Everitt, D. A. \& Thomas, D. P. 1986. Observations of seasonal changes in diatoms at inshore localities near Davis Station, East Antarctica. Hydrobiologia 139: 3-12.

Fairhead, V., Amsler, C. D. \& Mc Clintock, J. B. 2006. Lack of defense or phlorotannin induction by UV radiation or mesograzers in Desmarestia anceps and D. menziesii (Phaeophyceae). J. Phycol. 42: 1174-1183.

Farrell, T. M. 1991. Models and mechanisms of succession: An example from a rocky intertidal community. Ecol. Monogr. 61: 95-113.

Fernandes, L. F. \& Procopiak, L. K. 2003. Observations on valve structures of Navicula directa (Wm. Smith) Ralfs in Pritchard and Navicula glaciei V. Heurck from rocky substrates in Antarctic Peninsula. Hoehnea 30: 1-10.

Fernandes, L. F., Prokopiak, L. K. \& Portinho, D. 2007. Brandinia mosimanniae gen. nov. et sp. nov., a new marine epilithic diatom from the Antarctic coasts. Diatom Res. 22: 4556.

Fernandes, L. F., Calixto, M., Lange, P. \& Rivera Tenenbaum, D. 2012. Benthic diatoms in the plankton of Admiralty Bay (Western Antarctic Peninsula): Taxonomy and potential implications to the pelagic community. Annual Activity Report 2012 INCT. doi: 10.4322/apa.2014.104.

Fernandes, L. F., Calixto-Feres, M., Rivera Tenenbaum, D., Procopiak, L. K., Portinho, D. \& Hinz, F. 2014. Fine morphology of four Licmophora (Bacillariophyta, Licmophorales) species from Admiralty Bay and Elephant Island, Antarctic Peninsula. Iheringia, Sér. Bot., Porto Alegre 69: 465-477.

Ferrario, M. E. 1988. Ultrastructure de deux taxa de la famille Thalassiosiraceae: Thalassiosira subtilis var. maxima var. nov. et Minidiscus chilensis présents sur les cotes de L'Atlantique Sud (Argentine). Cryptogamie, Algologie 9: 311-318.

Ferrario, M. E. \& Ferreyra, G. A. 1984. A reappraisal of Trigonium arcticum (Brightwell) Cleve and $T$. formosum (Brightwell) Cleve, from Bahía Paraíso (Antarctica). Eighth International Diatom Symposium, Paris, 141-154.

Ferrario, M. E. \& Sastre, V. 1990. Ultraestructura, polimorfismo y ecología de Odontella aurita (Lyngbye) Agardh (Bacillariophyceae) en el estuario del Río Chubut, Argentina. Revista de la Facultad de Oceanografía Pesquera y Ciencias Alimentarias de la Universidad Nacional Federico Villareal 2: 98-106.

Ferrario, M. E., Sar, E. \& Sala, S. 1995. Metodología básica para el estudio de fitoplancton con especial referencia a las Diatomeas. En: K. Alveal, M. E. Ferrario, E. C. Oliveira \& E. Sar (eds.) Manual de Métodos Ficológicos (pp. 1-23). Universidad de Concepción, Concepción. 863 pp.

Ferrario, M. E., Cefarelli, A. O., Robison, B. \& Vernet, M. 2012. Thalassioneis signyensis (Bacillariophyceae) from Northwest Weddell Sea icebergs, an emendation of the generic description. J. Phycol. 48: 222-230.

Ferreira, T. \& Rasband, W. 2012. Image J User Guide IJ 1.46r. Image J: Image processing and analysis in Java. https://imagej.nih.gov/ij/index.html; http://imagej.nih.gov/ij/docs/guide. 
Ferreyra, G. A., Schloss, I. R. \& Abele, D. 1998. UV-absorbing compounds in surface waters of Potter Cove: preliminary results. En: C. Wiencke, G. A. Ferreyra, W. Arntz \& C. Rinaldi (eds.) The Potter Cove coastal ecosystem, Antarctica. Reports on Polar Research (Ber. Polarforsch.) 299: 316-321.

Ferreyra, G. A., Schloss, I. R., Mercuri, G., Ferreyra, L. \& Richter, K.-U. 2008. The potential ecological significance of dissolved and particulate matter in the water column of Potter Cove, King George Island (Isla 25 de Mayo), South Shetland Islands. En: C. Wiencke, G. A. Ferreyra, D. Abele \& S. Marenssi (eds.) The Antarctic ecosystem of Potter Cove, King George Island (Isla 25 de Mayo). Reports on Polar and Marine Research (Ber. Polarforsch. Meeresforsch.) 571: 47-55.

Fillinger, L., Janussen, D., Lundälv, T. \& Richter, C. 2013. Rapid glass sponge expansion after climate-induced Antarctic ice shelf collapse. Curr. Biol. 23: 1330-1334.

Fischer, G. \& Wiencke, C. 1992. Stable carbon isotope composition, depth distribution and fate of macroalgae from the Antarctic peninsula region. Polar Biol. 12: 341-348.

Fogt, R. L. \& Stammerjohn, S. 2015. Antarctica. En: Blunden, J. \& Arndt, D.S. (eds.). State of the Climate in 2014. Bull. Amer. Meteor. Soc. 96: S149-S167.

Foster, M. S. \& Sousa, W. P. 1985. Succession. En: M. M. Littler \& D. S. Littler (eds.) Handbook of Phycological Methods - Ecological field methods: macroalgae. (Cap. 13, pp 269-290). Cambridge University Press. 617 pp.

Foster, M. S., Harrold, C. \& Hardin, D. D. 1991. Point vs. photo quadrat estimates of the cover of sessile marine organisms. J. Exp. Mar. Biol. Ecol. 146: 193-203.

Foster, M. S., Nigg, E. W., Kiguchi, L. M., Hardinb, D. D. \& Pearse, J. S. 2003. Temporal variation and succession in an algal-dominated high intertidal assemblage. J. Exp. Mar. Biol. Ecol. 289: 15-39.

Frenguelli, J. 1943. XVIII Contribución al conocimiento de las diatomeas argentinas. Diatomeas de las Orcadas del Sur. Rev. Mus. La Plata 5: 221-265.

Frenguelli, J. \& Orlando, H. A. 1958. Diatomeas y silicoflagelados del sector antártico sudamericano. Instituto Antártico Argentino, Buenos Aires. 191 pp.

Frenguelli, J. 1960. Diatomeas y silicoflagelados recogidos en Tierra Adelie durante las Expediciones Polares Francesas de Paul-Emile Victor (1950-1952). Rev. Algol. 1: 348.

Fricke, A., Molis, M., Wiencke, C., Valdivia, N. \& Chapman, A. S. 2008. Natural succession of macroalgal-dominated epibenthic assemblages at different water depths and after transplantation from deep to shallow water on Spitsbergen. Polar Biol. 31:1191-1203.

Gain, L. 1911. Une nouvelle espèce de Monostroma prouvenant de la région antarctique sudaméricaine. Compte Rendu Hebdomadaire des Séances de l'Académie des Sciences. Paris. 152: 724-726.

Garibotti, I. A., Vernet, M., Ferrario, M. E., Smith, R.C., Ross, R.M. \& Quetin, L. B. 2003. Phytoplankton spatial distribution patterns along the western Antarctic Peninsula (Southern Ocean). Mar. Ecol. Prog. Ser. 261: 21-39.

Garibotti, I. A., Vernet, M. \& Ferrario, M. E. 2005. Annually recurrent phytoplanktonic assemblages during summer in the seasonal ice zone west of the Antarctic Peninsula (Southern Ocean). Deep-Sea Res. I 52:1823-1841.

Gaudichaud, C. 1826. Botanique. En: L. de Freycinet (ed.) Voyage autour du monde, entrepons par ordre du ROi, ... exécuté sur les corvettes de S. M., "I'Uranie" et "la Physicienne", pendant les années 1817, 1818, 1819 et 1820. Pillet Aîné, París. 522 pp.

Gilbert, N. S. 1991a. Primary production by benthic microalgae in nearshore marine sediments of Signy Island, Antarctica. Polar Biol. 11: 339-346.

Gilbert, N. S. 1991b. Microphytobenthic seasonality in near-shore marine sediments at Signy Island, South Orkney Islands, Antarctica. Est. Coast. Shelf Sci. 33: 89-104.

Gómez, I., Wulff, A., Dunton, K., Karsten, U., Roleda, M. \& Wiencke, C. 2011. Light and temperature demands of benthic microalgae and seaweeds in polar regions. En: $\mathrm{C}$. Wiencke (ed.) Biology of Polar Benthic Algae. (Cap. 10, pp. 195-220). Walter de Gruyter GmbH \& Co. K.G., Berlin/New York. 337 pp. 
González, P. M., Deregibus, D., Malanga, G., Campana, G. L., Quartino, M. L. \& Puntarulo, S. 2017. Oxidative balance in macroalgae from Antarctic waters. Possible role of $\mathrm{Fe}$. J. Exp. Mar. Biol. Ecol. 486: 379-386.

Gregory, W. 1855. On the post-Tertiary lacustrine sand containing diatomaceous exuviae from Glenshire near Inverary. Q. J. Microsc. Sci. 3: 30-43.

Grunow, A. 1862. Die Österreichischen Diatomaceen nebst Anschluss einiger neuen Arten von andern Lokalitäten und einer kritischen Uebersicht der bisher bekannten Gattungen und Arten. Verhandlungen der kaiserlich-königlichen zoologischbotanischen Gesellschaft in Wien 12: 315-472 [Abt 1], 545-588 [Abt. 2].

Grunow, A. 1867. Diatomeen auf Sargassum von Honduras, gesammelt von Linding. Hedwigia 3: 33-37.

Guiry, M. D. \& Guiry, G. M. 2018. AlgaeBase. World-wide electronic publication, National University of Ireland, Galway. http://www.algaebase.org.

Gutt, J. 2001. On the direct impact of ice on marine benthic communities, a review. Polar Biol. 24: 553-564.

Gutt, J., Barratt, I., Domack, E., d'Udekem d'Acoz, C., Dimmler, W., Grémare, A., Heilmayer, O., Isla, E., Janussen, D., Jorgensen, E., Kock, K.-H., Lehnert, L.S., López Gonzáles, P. Langner, S., Linsem, K., Manjón Cabeza, M. E., Meißner, M., Montiel, A., Raes, M., Robert, H., Rose, A., Sañé Schepisi, E., Saucede, T., Scheidat, M., Schenke, H.W., Seiler, J. \& Smith, C. 2011. Biodiversity change after climate-induced ice-shelf collapse in the Antarctic. Deep Sea Res. II 58: 74-83.

Häder, D.-P., Kumar, H. D., Smith, R. C. \& Worrest, R. C. 2003. Aquatic ecosystems: effects of solar ultraviolet radiation and interactions with other climatic change factors. Photochem. Photobiol. Sci. 2: 39-50.

Häder, D.-P, Helbling, E. W., Williamson, C. E. \& Worrest, R. C. 2011. Effects of UV radiation on aquatic ecosystems and interactions with climate change. Photochem. Photobiol. Sci. 10: 242-260.

Hanelt, D., Melchersmann, B., Wiencke, C. \& Nultsch, W. 1997. Effects of high light stress on photosynthesis of polar macroalgae in relation to depth distribution. Mar. Ecol. Prog. Ser. 149: 255-266.

Hargreaves, B. R. 2003. Water column optics and penetration of UVR. En: E. W. Helbling \& H. Zagarese (eds.) UV effects in aquatic organisms and ecosystems. (Cap. 3, pp. 61105). The Royal Society of Chemistry, Cambridge. 575 pp.

Hasle, G. R. 1965. Nitzschia and Fragilariopsis species studied in the light and electron microscopes. Part III. The genus Fragilariopsis. Skr. Norske Vidensk-Akad. I Mat.-Nat. KI NS 21:1-49.

Hasle, G. R. 1973. Some marine plankton genera of the diatom family Thalassiosiraceae. Beiheft zur Nova Hedwigia 45:1-49.

Hasle, G. R. 1978. Some freshwater and brackish water species of the diatom genus Thalassiosira Cleve. Phycologia 17: 263-292.

Hasle G. R. \& Heimdal, B. R. 1968. Morphology and distribution of the marine centric diatom Thalassiosira antarctica Comber. Journal of the Royal Microscopical Society 88: 357369.

Hasle, G. R. \& Syvertsen, E. E. 1981. The marine diatoms Fragilaria striatula and F. hyalina. Striae 14: 110-118.

Hasle, G. R. \& Syvertsen, E. E. 1997. Marine Diatoms. En: C. R. Tomas (ed.) Identifying Marine Phytoplankton (Cap. 2, pp. 5-385). Academic Press, California.

Hasle, G. R., Medlin, L. K. \& Syvertsen, E. E. 1994. Synedropsis gen. nov., a genus of araphid diatoms associated with sea ice. Phycologia 33: 248-270.

Hegglin, M. I., Fahey, D. W., McFarland, M., Montzka, S. A. \& Nash, E. R. 2015. Twenty questions and answers about the ozone layer: 2014 Update, Scientific Assessment of Ozone Depletion: 2014, 84 pp., World Meteorological Organization, Ginebra, Suiza.

Heiden, H. \& Kolbe, R.W. 1928. Die marinen Diatomeen der Deutschen Südpolar-Expedition 1901-1903. Deutsche Südpolar-Expedition, Botanik 450-715. Berlin-Leipiz.

Helbling, E. W. \& Zagarese, H. 2003. UV effects in aquatic organisms and ecosystems. The Royal Society of Chemistry, Cambridge. 575 pp. 
Helbling, E. W., Villafañe, V. \& Holm-Hansen, O. 1994. Effects of ultraviolet radiation on Antarctic marine phytoplankton photosynthesis with particular attention to the influence of mixing. En: C. S. Weiler \& P. A. Penhale (eds.) Ultraviolet radiation in Antarctica: Measurements and biological effects (pp. 207-227). Antarctic Research Series 62. 257 pp.

Helbling, E. W., Chalker, B.E., Dunlap, W.C., Holm-Hansen, O. \& Villafañe, V. E. 1996. Photoacclimation of Antarctic marine diatoms to solar ultraviolet radiation. J. Exp. Mar. Biol. Ecol. 204: 85-101.

Hernández, E. 2016. Efecto de la radiación ultravioleta sobre bacterias marinas antárticas. Facultad de Ciencias Exactas y Naturales. Universidad de Buenos Aires. 149 pp.

Hernando, M. \& Ferreyra, G. 2005. The effects of UV radiation on photosynthesis in an Antarctic diatom (Thalassiosira sp.): Does vertical mixing matter? J. Exp. Mar. Biol. Ecol. 325: 35-45.

Hernando, M., Carreto, J., Carignan, M., Ferreyra, G. A. \& Gross, C. 2002. Effects of solar radiation on growth and mycosporine-like amino acids content in Thalassiosira sp., an Antarctic diatom. Polar Biol. 25: 12-20.

Hill, W. R., Dimick, S. M., McNamara, A. E. \& Branson, C. A. 1997. No effects of ambient UV radiation detected in periphyton and grazers. Limnol. Oceanog. 42: 769-774.

Hillebrand, H., Worm, B. \& Lotze, H. K. 2000. Marine microbenthic community structure regulated by nitrogen loading and grazing pressure. Mar. Ecol. Prog. Ser. 204: 27-38.

Hoban, M. A. 1983. Biddulphioid Diatoms. II: The morphology and systematics of the pseudocellate species, Biddulphia biddulphiana (Smith) Boyer, B. alternans (Bailey) Van Heurck, and Trigonium arcticum (Brightwell) Cleve. Bot. Mar. 26: 271-284.

Holland, R., Dugdale, T.M., Wetherbee, R., Brennan, A. B., Finlay, J.A., Callow, J. A. \& Callow, M. E. 2004. Adhesion and motility of fouling diatoms on a silicone elastomer. Biofouling 20: 323-329.

Hommersand, M. H., Moe, R. L., Amsler, C. D. \& Fredericq, S. 2009. Notes on the systematics and biogeographical relationships of Antarctic and sub-Antarctic Rhodophyta with descriptions of four new genera and five new species. Bot. Mar. 52: 509-534.

Honeywill, C. 1998. A study of British Licmophora species and a discussion of its morphological features. Diatom Res. 13: 221-271.

Hooker, J. D. 1847. Diatomaceae. The Botany of the Antarctic Voyage of H.M. discovery ships "Erebus" and "Terror", years 1839-1843, Vol. LVI. Londres.

Horner, R. 1984 Do ice algae produce the spring phytoplankton bloom in seasonally icecovered waters? A review of recent literature. Proceedings of the Seventh Diatom Symposium, 1982. Koenigstein, Koeltz. 541 pp.

Hoyer, K., Karsten, U., Sawall, T. \& Wiencke, C. 2001. Photoprotective substances in Antarctic macroalgae and their variation with respect to depth distribution, different tissues and developmental stages. Mar. Ecol. Prog. Ser. 211: 117-129.

Hoyer, K., Karsten, U. \& Wiencke, C. 2002. Induction of sunscreen compounds in Antarctic macroalgae by different radiation conditions. Mar. Biol. 141: 619-627.

Huang, R. \& Boney, A. D. 1985. Individual and combined interactions between littoral diatoms and sporelings of red algae. J. Exp. Mar. Biol. Ecol. 85: 101-111.

Huang, Y., McClintock, J. B., Amsler, C. D., Peters, K. J. \& Baker, B. J. 2006. Feeding rates of common Antarctic gammarid amphipods on ecologically important sympatric macroalgae. J. Exp. Mar. Biol. Ecol. 329: 55-65.

Huang, Y., Amsler, M. O., McClintock, J., Amsler, C. D. \& Baker, B. J. 2007. Patterns of gammaridean amphipod abundance and species composition associated with dominant subtidal macroalgae from the western Antarctic Peninsula. Polar Biol. 30:1417-1430.

Huovinen, P. \& Gómez, I. 2013. Photosyntetic caracteristics and UV stress tolerance of Antarctic seaweeds along the depth gradient. Polar Biol. 36: 1319-1332.

Hurd, C. L., Harrison, P. J., Bischof, K. \& Lobban, C. S. 2014. Seaweed ecology and physiology. Second edition. Cambridge University Press, Cambridge. 551 pp.

Hustedt, F. 1930. Die Kieselalgen Deutschlands, Österreichs und der Schweiz mit Berücksichtigung der übrigen Länder Europas sowie der angrenzenden 
Meeresgebiete. Pages 785-920 en L. Rabenhorsts, editor. Kryptogamen Flora von deutschland, Österreich und der Schweiz. Akademische Verlagsgesellschaft m. b. H., Leipzig.

Hustedt, F. 1952. Diatomeen aus der Lebensgemeinschaft der Buckelwals (Megaptera nodosa Bonn.). Arch. Hydrobiol 462: 286-298.

Hustedt, F. 1958. Diatomeen aus der Antarktis und dem Südatlantik. Deutsche Antarktische Expedition 1938/39, 2: 103-191.

Iken, K. 1999. Feeding ecology of the Antarctic herbivorous gastropod Laevilacunaria antarctica Martens. J. Exp. Mar. Biol. Ecol. 236: 133-148.

Iken, K. 2012. Grazers on benthic seaweeds. En: C. Wiencke \& K. Bischof (eds.) Seaweed Biology, Ecological Studies 219 (Cap. VV, pp. 157-175). Springer-Verlag Berlin Heidelberg. 510 pp.

Iken, K., Barrera Oro E. R., Quartino, M.L., Casaux, R. J. \& Brey, T. 1997. Grazing by the Antarctic fish Notothenia coriiceps: evidence for selective feeding on macroalgae. Antarct. Sci. 9: 386-391.

Iken, K., Quartino, M. L., Barrera Oro, E., Palermo, J., Wiencke, C. \& Brey, T. 1998. Trophic relations between macroalgae and herbivores. En: C. Wiencke, G. A. Ferreyra, W. Arntz \& C. Rinaldi (eds.) The Potter Cove coastal ecosystem, Antarctica. Reports on Polar Research (Ber. Polarforsch.) 299: 258-262.

Irving, A. D., Connell, S. D., Johnston, E. L., Pile, A. J. \& Gillanders, B. M. 2005. The response of encrusting coralline algae to canopy loss: an independent test of predictions on an Antarctic coast. Mar. Biol. 147: 1075-1083.

Janech, M., Krell, A., Mock, T., Kang, J.-S. \& Raymond, J. A. 2006. Ice-binding proteins from sea ice diatoms (Bacillariophyceae). J. Phycol. 42: 410-416.

Jenkins, S. R., Marshall, D. \& Fraschetti, S. 2009. Settlement and recruitment. En: M. Wahl (ed.) Marine hard bottom communities Ecological Studies 206 (Cap. 12, 177-190). Springer-Verlag Berlin Heidelberg. 445 pp.

Johansen, J. R. \& Fryxell, G. A. 1985. The genus Thalassiosira (Bacillariophyceae): Studies on species occurring south of the Antarctic Convergence Zone. Phycologia 24: 155179.

Johnston, E. L., Connell, S. D., Irving, A. D., Pile, A. J. \& Gillanders, B. M. 2007. Antarctic patterns of shallow subtidal habitat and inhabitants in Wilke's Land. Polar Biol. 30: 781788.

Kain, J. M. 1989. The seasons in the subtidal. Br. Phycol. J. 24: 203-215.

Kang, J.-S, Kang, S.-O. \& Lee, J. H. 1999. Cryophilic diatoms Navicula glaciei and N. perminuta in Antarctic coastal environment I. Morphology and ecology. Algae 14: 169179.

Kang, J.-S., Kang, S.-H., Kim, D. \& Kim, D.-Y. 2003. Planktonic centric diatom Minidiscus chilensis dominated sediment trap material in eastern Bransfield Strait, Antarctica. Bot. Mar. 255: 93-99.

Karentz, D. \& Bosch, I. 2001. Influence of ozone-related increases in ultraviolet radiation on Antarctic marine organisms. Amer. Zool. 41: 3-16.

Karsten, U., Wulff, A., Roleda, M. Y., Müller, R., Steinhoff, F. S., Fredersdorf, J. \& Wiencke, C. 2011. Physiological responses of polar benthic algae to ultraviolet radiation. En: C. Wiencke (ed.) Biology of Polar Benthic Algae. (Cap. 10, pp. 195-220). Walter de Gruyter GmbH \& Co. K.G., Berlin/New York. 337 pp.

Kellogg, T. B. \& Kellogg, D. E. 2002. Non-marine diatoms from Antarctic and Subantarctic Regions. Distribution and updated taxonomy. En: A. Witkowski (ed.). Diatom Monographs Vol. 1. A.R.G. Gantner Verlag, K.G. 795 pp.

Kim, D. 2001. Seasonality of marine algae and grazers of an Antarctic rocky intertidal, with emphasis on the role of the limpet Nacella concinna Strebel (Gastropoda: Patellidae). Reports on Polar and Marine Research (Ber. Polarforsch. Meeresforsch.) 397. 136 pp.

Kim, J. H., Chung, H., Oh, Y. S \& Lee, I. K. 2001. Macroalgal flora of Maxwell Bay, King George Island, Antarctica: II. Rhodophyta. Ocean Polar Res. 23: 347-360.

Kirk, J. T. O. 2011. Light and photosynthesis in aquatic ecosystems. Third edition. Cambridge Univ. Press, Cambridge. 662 pp. 
Kirst, G. O. \& Wiencke, C. 1995. Ecophysiology of Polar algae. J. Phycol. 31: 181-199.

Klöser, H., 1998. Habitats and distribution patterns of benthic diatoms in Potter Cove (King George Island) and its vecinity. En: C. Wiencke, G. A. Ferreyra, W. Arntz \& C. Rinaldi (eds.) The Potter Cove coastal ecosystem, Antarctica. Reports on Polar Research (Ber. Polarforsch.) 299: 95-105.

Klöser, H., Mercuri, G., Laturnus, F., Quartino, M. L. \& Wiencke, C. 1994a. On the competitive balance of macroalgae at Potter Cover (King George Island, South Shetlands). Polar Biol. 14: 11-16.

Klöser, H., Ferreyra, G. A., Schloss, I. R., Mercuri, G., Laturnus, F. \& Curtosi, A. 1994b. Hydrography of Potter Cove, a small fjordlike inlet on King George Island, South Shetlands. Estuar. Coast. Shelf Sci. 38: 523-537.

Klöser, H., Quartino, M. L. \& Wiencke, C. 1996. Distribution of macroalgae and macroalgal communities in gradients of physical conditions in Potter Cove, King George Island, Antarctica. Hydrobiologia, 333: 1-17.

Knight, M. \& Parke, M. W. 1931. Manx algae: an algal survey of the south end of the Isle of Man (30). Univ. Press of Liverpool, Liverpool. 155 pp.

Knox, G. A. 1994. Benthic communities. En: Studies in Polar Research. The biology of the Southern Ocean (Cap. 11, pp. 193-220). Cambridge Univ. Press, New York. 444 pp.

Kohler, K. E. \& Gill, S. M. 2006. Coral Point Count with Excel extensions (CPCe): A Visual Basic program for the determination of coral and substrate coverage using random point count methodology. Comput. Geosci. 32: 1259-1269.

Krebs, W. N. 1983. Ecology of neritic marine diatoms, Arthur Harbour, Antarctica. Micropaleontology 29: 267-297.

Kuylenstierna, M. 1989-1990. Benthic algal vegetation in the Nordre Älv Estuary (Swedish West Coast). University of Gotebörg. 244 pp.

Lagger, C., Servetto, N., Torre, L. \& Sahade, R. 2017. Benthic colonization in newly ice-free soft-bottom areas in an Antarctic fjord. PlosOne 12: e0186756.

Lagger, C., Nime, M., Torre, L., Servetto, N., Tatián, M. \& Sahade, R. 2018. Climate change, glacier retreat and a new ice-free island offer new insights on Antarctic benthic responses. Ecography 40: 1-12.

Lamb, I. \& Zimmermann, M. H. 1977. Benthic marine algae of the Antarctic Peninsula. A preliminary guide to the commoner benthic marine algae of the antarctic Peninsula and adjacent Islands. Biology of the Antarctic Seas 5. Antarctic Res. Ser. 23: 129-229.

Lange-Bertalot, H. 2001. Diatoms of Europe. Diatoms of the European Inland Waters A.R.G. Gantner Verlag K.G.

Lavigne, A. S., Sunesen, I. \& Sar, E. A. 2015. Morphological, taxonomic and nomenclatural analysis of species of Odontella, Trieres and Zygoceros (Triceratiaceae, Bacillariophyta) from Anegada Bay (Province of Buenos Aires, Argentina). Diatom Res. 30: 307-331.

Le Jolis, A. 1863. Liste des algues marines de Cherbourg. Mémoires de la Société Impériale des Sciences Naturelles de Cherbourg 10: 5-168, pls I-IV.

Levkov, Z. 2009. Amphora sensu lato. En: H. Lange Bertalot (ed.) Diatoms of Europe, Vol. 5. A.R.G. Gantner Verlag K.G., Ruggel, Liechtenstein.

Littler, M. M. \& Littler, D. S. 1980. The evolution of thallus form and survival strategies in benthic marine macroalgae: Field and laboratory tests of a functional form model. Am. Nat. 116: 25-44.

Lobban, C. S. 2015. Grammatophora ornata (Fragilariophyceae: Grammatophoraceae), a new species with areolate valvocopulae, from a coral reef. Diatom 31: 12-17.

Lokhorst, G. M. 1978. Taxonomic studies of the marine and brackish-water species of Ulothrix (Ulotricales, Chlorophyceae) in Western Europe. Blumea 24: 191-299.

Lokhorst, G. M. \& Trask, B. J. 1981. Taxonomic studies on Urospora (Acrosiphonales, Chlorophyceae) in Western Europe. Acta Bot, Neerl. 30 (5/6): 353-431.

Longhi, M. L., Schloss, I. R. \& Wiencke, C. 2003. Effect of irradiance and temperature on photosynthesis and growth of two Antarctic benthic diatoms, Gyrosigma subsalinum and Odontella litigiosa. Bot. Mar. 46: 276-284. 
Lotze, H. K., Worm, B. \& Sommer, U. 2001. Strong bottom-up and top-down control of early life stages of macroalgae. Limnol. Oceanogr. 46: 749-757.

Lotze, H. K. \& Worm, B. 2002. Complex interactions of climatic and ecological controls on macroalgal recruitment. Limnol. Oceanogr. 47: 1734-1741.

Lotze, H. K., Worm, B., Molis, M. \& Wahl, M. 2002. Effects of UV radiation and consumers on recruitment and succession of a marine macrobenthic community. Mar. Ecol. Prog. Ser. 243: 57-66.

Lubchenco J. 1983. Littorina and Fucus: Effects of herbivores, substratum heterogeinity, and plant escapes during succession. Ecology 64: 1116-1123.

Lüning, K. \& tom Dieck, I. 1989. Environmental triggers in algal seasonality. Bot. Mar. 32: 389397.

Lyngbye, H. C. 1819. Tentamen hydrophytologiae danicae continens omnia hydrophyta cryptogama Daniae, Holsatiae, Faeroae, Islandiae, Groenlandiae hucusque cognita, systematice disposita, descripta et iconibus illustrata, adjectis simul speciebus norvegicis. pp. [i]-xxxii, [1]-248, 70 pls. Hafniae [Copenhagen]: typis Schultzianis, in commissis Librariae Gyldendaliae.

Llabrés, M., Agustí, S., Fernández, M., Canepa, A., Maurin, F., Vidal, F. \& Duarte, C.M. 2013. Impact of elevated UVB radiation on marine biota: a meta-analysis. Global Ecol. Biogeogr. 22: 131-144.

Macaya, E. C., Rothausler, E., Thiel, M., Molis, M. \& Wahl, M. 2005. Induction of defenses and within-alga variation of palatability in two brown algae from the northern-central coast of Chile: Effects of mesograzers and UV radiation. J. Exp. Mar. Biol. Ecol. 325: 214-227.

Maggi, E., Bertocci, I., Vaselli, S. \& Benedetti-Cecchi L. 2011. Connell and Slayter`s models of succession in the biodiversity era. Ecology 92: 1399-1406.

Magurran, A. E. 2004. Measuring Biological Diversity. Blackwell Publishing. 256 pp.

Majewska, R. \& De Stefano, M. 2015. Epiphytic diatom communities on Phyllophora antarctica from the Ross Sea. Antarct. Sci. 27:44-56.

Majewska, R., Gambi, M. C., Totti, C. M. \& De Stefano, M. 2013a. Epiphytic diatom communities of Terra Nova Bay, Ross Sea, Antarctica: structural analysis and relations to algal host. Antarct. Sci. 25: 501-513.

Majewska, R., Gambi, M. C., Totti, C. M., Pennesi, C. \& De Stefano, M. 2013b. Growth form analysis of epiphitic diatom communities of Terra Nova bay (Ross Sea, Antarctica). Polar Biol. 36: 73-86.

Majewska, R., Kuklinski, P., Balazy, P., Yokoya, N. S., Paternostro Martins, A. \& De Stefano, M. 2015. A comparison of epiphytic diatom communities on Plocamium cartilagineum (Plocamiales, Florideophyceae) from two Antarctic areas. Polar Biol. 38: 189-205.

Majewska, R., Convey, P. \& De Stefano, M. 2016. Summer epiphytic diatoms from Terra Nova Bay and Cape Evans (Ross Sea, Antarctica) - A synthesis and final conclusions. PlosOne 11: e0153254.

Manguin, E. 1957. Premier inventaire des diatomées de la Terre Adélie Antarctique. Espèces nouvelles. Revue Algologique, Nouvelle Série 3:111-134.

Manguin, E. 1960. Les diatomées de la Terre Adélie campagne du "Commandant Charcot" 1949-1950. En: L. Emberger \& R. Heim (eds.), Annales des Sciences Naturelles. Botanique et Biologie Végétale (pp. 223-363). Masson \& Cie, París. 339 pp.

Mann, K. H. \& Lazier, J.R.N. 1991. Dynamics of marine ecosystems. Biological-physical interactions in the Oceans. Blackwell Scientific Publications. $466 \mathrm{pp}$.

Marcías, M. L., Deregibus, D., Saravia, L. A., Campana, G. L. \& Quartino, M. L. 2017. Life between tides: Spatial and temporal variations of an intertidal macroalgal community at Potter Peninsula, South Shetland Islands, Antarctica. Est. Coast. Shelf Sci. 187: 193203.

Margalef, R. 1981. Ecología. Omega, Barcelona. 968 pp.

Margalef, R. 1991. Teoría de los sistemas ecológicos. Universitat de Barcelona, Barcelona. $291 \mathrm{pp}$.

Marina T. I., Salinas V., Cordone G., Campana G. L., Moreira E., Deregibus D., Torre L., Sahade R., Tatián M., Barrera Oro E., De Troch M., Doyle S., Quartino M.L., Saravia 
L.A. \& Momo F.R. 2018. The food web of Potter Cove (Antarctica): complexity, structure and function. Est. Coast. Shelf Sci. 200: 141-151.

Mc Clintock, J. B. \& Baker, B. J. 1997. A review of the chemical ecology of Antarctic marine invertebrates. Amer. Zool. 37: 329-342.

Mc Clintock, J. B., Ducklow, H. \& Fraser, W. 2008. Ecological responses to climate change on the Antarctic Peninsula. Am. Sci. 96: 302-310.

Mc Cook, L. J. 1994. Understanding ecological community succession: causal models and theories, a review. Vegetatio 110: 115-147.

Mc Minn, A., Runcie, M \& Riddle, M. 2004. Effect of seasonal sea ice breakout on the photosynthesis of benthic diatom mats at Casey, Antarctica. J. Phycol. 40: 62-69.

Mc Minn, A., Pankowskii, A., Ashworth, C., Bhagooli, R., Ralph, P. \& Ryan, K. 2010. In situ net primary productivity and photosynthesis of Antarctic sea ice algal, fitoplancton and benthic algal communities. Mar. Biol. 157: 1345-1356.

Medlin, L. K. \& Fryxell, G. A. 1984. Structure, life history and systematics of Rhoicosphenia (Bacillariophyta). IV. Correlation of size reduction with changes in valve morphology of Rh. genuflexa. J. Phycol. 20: 101-108.

Medlin, L. K. \& Round, F. E. 1986. Taxonomic studies of marine gomphonemoid diatoms. Diatom Res. 1: 205-225.

Medlin, L. K. \& Kaczmarska, I. 2004. Evolution of the diatoms: V. Morphological and cytological support for the major clades and a taxonomic revision. Phycologia 43: 245270.

Meiners, S. J., Cadotte, M. W., Fridley, J. D., Pickett, S. T. A. \& Walker, L. R. 2015. Is successional research nearing its climax? New approaches for understanding dynamic communities. Funct. Ecol. 29: 154-164.

Miller, K. A. \& Pearse, J. S. 1991. Ecological studies of seaweeds in McMurdo Sound, Antarctica. Am. Zool. 31: 35-48.

Moe, R. L. \& Silva, P. C. 1977. Antarctic marine flora: uniquely devoid of kelps. Science 196:1206-1208.

Molina, M.J., \& Rowland, F. S. 1974. Stratospheric sink for chlorofluoromethanes: Chlorine atom-catalysed destruction of ozone. Nature 249: 810-812.

Molis, M. \& Wahl, M. 2004. Transient effects of solar ultraviolet radiation on the diversity and structure of a field-grown epibenthic community at Lüderitz, Namibia. J. Exp. Mar. Biol. Ecol. 302:51-62.

Molis, M. \& Wahl, M. 2009. Comparison of the impacts of consumers, ambient UV, and future UVB irradiance on mid-latitudinal macroepibenthic assemblages. Global Change Biol. 15: $1833-1845$.

Momo, F. R., Bogazzi, E. \& Duttweiler, F. 1998. Amphipods of Potter Cove: community composition, biology and growth. En: C. Wiencke, G. A. Ferreyra, W. Arntz \& C. Rinaldi (eds.) The Potter Cove coastal ecosystem, Antarctica. Reports on Polar Research (Ber. Polarforsch.) 299: 144-149.

Moon, H.-W., Hussin, W. M. R. W., Kim H. -C. \& Ahn, I.-Y. 2015. The impacts of climate change on Antarctic nearshore mega-epifaunal benthic assemblages in a glacial fjord on King George Island: Responses and implications. Ecol. Indic. 57: 280-292.

Müller, D. G. 1984. Culture studies on the life history of Adenocystis utricularis (Phaeophyceae, Dictyosiphonales). Phycologia 23: 87-94.

Mystikou, A., Peters, A. F., Asensi, A. O., Fletcher, K. L., Brickle, P., van West, P., Convey, P. \& Küpper, F. 2014. Seaweed biodiversity in the south-western Antarctic Peninsula: surveying macroalgal community composition in the Adelaide Island/Marguerite Bay region over a 35-year time span. Polar Biol. 37: 1607-1619.

Nagumo, T. 2003. Taxonomic studies of the subgenus Amphora Cleve of the genus Amphora (Bacillariophyceae) in Japan. Bibliotheca Diatomologica 49, J. Kramer, BerlinStuttgart, Alemania. $265 \mathrm{pp}$.

Nair, A. Mohan, R., Shetye, S., Gazi, S. \& Jafar, S. A. 2015. Trigonium curvatus sp. nov. and Trigonium arcticum (Bacillariophyceae) from the surface sediments of Prydz Bay, East Antarctica. Micropaleontology 61: 185-192. 
Nash, E. R., Strahan, S. E., Kramarova, N., Long, C. S., Pitts, M. C., Newman, P. A., Johnson, B., Santee, M. L., Petropavlovskikh, I. \& Braathen G. O. 2016. Antarctic ozone hole. En: J. Blunden. \& D. S. Arndt (eds.) State of the Climate in 2015. Bull. Amer. Meteor. Soc. 97, S168-S172.

Navarro, N. P., Huovinen, P. \& Gómez, I. 2016. Stress tolerance of Antarctic macroalgae in the early life stages. Rev. Chil. Hist. Nat. 89:5

Neale, P. J., Helbling, E. W. \& Zagarese, H. E. 2003. Modulation of UVR exposure and effects by vertical mixing and advection. En: E. W. Helbling \& $\mathrm{H}$. Zagarese (eds.) UV effects in aquatic organisms and ecosystems. (Cap. 4, 107-134). The Royal Society of Chemistry, Cambridge. 575 pp.

Newman, P. A., Nash, E. R., Strahan, S. E., Kramarova, N., Long, C. S., Pitts, M. C., Johnson, B., Santee, M. L., Petropavlovskikh, I. \& Braathen G. O. 2017. 2016 Antarctic ozone hole. En: J. Blunden \& D. S. Arndt. State of the Climate in 2016. Bull. Amer. Meteor. Soc. 98 (8), S169-S72.

Nicotri, M. E. 1977. Grazing effects of four marine intertidal herbivores on the microflora. Ecology 58: 1020-1032.

Niell, F. X. 1979. Structure and succession in rocky algal communities of a temperate intertidal system. J. Exp. Mar. Biol. Ecol. 36: 185-200.

Noël, L. M.-L. J., Griffin, J. N., Moschella, P. S., Jenkins, S. R., Thompson, R. C. \& Hawkins, S. J. 2009. Changes in diversity and ecosystem functioning during succession. En: M. Wahl (ed.) Marine hard bottom communities. Ecological Studies 206 (Cap. 15, 213223). Springer-Verlag Berlin Heidelberg. 445 pp.

Obermüller, B., Puntarulo, S. \& Abele, D. 2007. UV-tolerance and instantaneous physiological stress responses of two Antarctic amphipod species Gondogeneia antarctica and Djerboa furcipes during exposure to UV radiation. Mar. Environ. Res. 64: 267-285.

Odum, E. P. 1969. The strategy of ecosystem development. Science 164: 262-270.

Olguín, H. F. \& Alder, V. A. 2011. Species composition and biogeography of diatoms in antarctic and subantarctic (Argentine shelf) waters $\left(37-76^{\circ} \mathrm{S}\right)$. Deep Sea Res. II 58: 139-152.

Orsi, A. H., Whitworth, T. \& Nowlin Jr., W. D. 1995. On the meridional extent and fronts of the Antarctic Circumpolar Current. 1995. Deep-Sea Res. I 42: 64-673.

Paar, M., Voronkov, A., Hop, H., Brey, T., Bartsch, I., Schwanitz, M., Wiencke, C., Lebreton, B., Asmus, R. \& Asmus, H. 2016. Temporal shift in biomass and production of macrozoobenthos in the macroalgal belt at Hansneset, Kongsfjorden, after 15 years. Polar Biol. 39: 2065-2076.

Pacheco, A. S., Laudien, J., Thiel, M, Heilmayer, O. \& Oliva, M. 2010. Hard-bottom succession of subtidal epibenthic communities colonizing hidden and exposed surfaces off northern Chile. Sci. Mar. 74: 147-154.

Pacheco, A. S., Laudien, J., Thiel, M., Oliva, M. \& Heilmayer, O. 2011. Succession and seasonal onset of colonization in subtidal hard-bottom communities off northern Chile. Mar. Ecol. 32: 75-87.

Palmisano, A. C. \& Sullivan, C. W. 1983. Sea Ice Microbial Communities (SIMCO) 1. Distribution, abundance, and primary production of ice microalgae in McMurdo Sound, Antarctica in 1980. Polar Biol. 2: 171-177.

Pasotti, F., Manini, E., Giovannelli, D., Wölfl, A.-C., Monien, D., Verleyen, E., Braeckman, U., Abele, D. \& Vanreusel, A. 2015. Antarctic shallow water benthos in an area of recent rapid glacier retreat. Mar. Ecol. 36: 716-733.

Patrick, R. \& Reimer, C.W. 1975. The diatoms of the United States exclusive of Alaska and Hawaii. Vol. 2, Part 1. Entomoneidaceae, Cymbellaceae, Gomphonemaceae, Epithemiaceae, The Academy of Natural Sciences of Philadelphia, Philadelphia. 213 pp.

Pavia, H., Cervin, G., Lindgren, A. \& Åberg, P. 1997. Effects of UV-B radiation and simulated herbivory on phlorotannins in the brown alga Ascophyllum nodosum. Mar. Ecol. Prog. Ser. 157: 139-146.

Peck, L. S. \& Veal, R. 2001. Feeding, metabolism and growth in the Antarctic limpet, Nacella concinna (Strebel 1908). Mar. Biol. 138: 553-560. 
Peletier, H., Gieskes, W. W. C. \& Buma, A. G. J. 1996. Ultraviolet-B radiation resistance of benthic diatoms isolated from tidal flats in the Dutch Wadden Sea Mar. Ecol. Prog. Ser. 135: 163-168.

Pellizzari, F., Silva, M. C., Silva, E. M., Medeiros A., Oliveira M. C., Yokoya N. S., Pupo D., Rosa L. H. \& Colepicolo P. 2017. Diversity and spatial distribution of seaweeds in the South Shetland Islands, Antarctica: an updated database for environmental monitoring under climate change scenarios. Polar Biol. 40: 1671-1685.

Peragallo, H. 1921. Diatomées d'eau douce et Diatomées d'eau salée. Deuxième Expédition Antarctique Francaise 1908-1910. Botanique: 1-103.

Peters, A. F. 2003. Molecular identification, distribution and taxonomy of brown algal endophytes, with emphasis on species from Antarctica. Proc. Int. Seaweed Symp. (pp. 293-302).

Picken, G. B. 1979. Growth, production and biomass of the antarctic gastropod Laevilacunaria antarctica Martens 1885. J. Exp. Mar. Biol. Ecol. 40: 71-79

Pickett, T. A. \& White, P. S. 1985. The ecology of natural disturbance and patch dynamics. Academic Press, Orlando. 472 pp.

Piepenburg, D. 2005. Recent research on Arctic benthos: common notions need to be revised. Polar Biol. 28:733-755.

Poulin, M. 1990. Family Naviculaceae: Arctic species. En: L. K. Medlin \& J. Priddle (eds.), Polar Marine Diatoms (Cap. 18, pp. 137-149). British Antarctic Survey, Natural Environment Research Council. 214 pp.

Poulin, M. \& Cardinal, A. 1982. Sea ice diatoms from Manitounuk Sound, southeastern Hudson Bay (Quebec, Canada). II. Naviculaceae, genus Navicula. Can. J. Bot. 60: 2825-2845.

Poulin, M., Bérard-Therriaullt \& Cardinal, A. 1984a. Les diatomées benthiques de substrats durs des eaux marines et saumâtres du Québec. 3. Fragilarioideae (Fragilariales, Fragilariaceae). Nat. Can. (Rev. Ecol. Syst.) 111: 349-367.

Poulin, M., Bérard-Therriault, L. \& Cardinal, A. 1984b. Les diatomées benthiques de substrats durs des eaux marines et saumâtres du Québec. 2. Tabellarioideae et Diatomoideae (Fragilariales, Fragilariaceae). Nat. Can. (Rev. Ecol. Syst.) 111: 275-295.

Platt, W. \& Connell, J. H. 2003. Natural disturbances and directional replacement of species. Ecol. Monogr. 73: 507-522.

Priddle, J. 1990. The Antarctic planktonic ecosystem. En: L. Medlin \& J. Priddle (eds.) Polar Marine Diatoms. (Cap. 5, pp. 25-34). British Antarctic Survey, Natural Environment Research Council, Cambridge. 214 pp.

Pritchard, A. 1861. A history of Infusoria, including the Desmidiaceae and Diatomaceae, British and foreign. 4th edition Whittaker and Co, Londres.

Prygiel, J. \& Coste, M. 2000. Guide Méthodologique pour la mise en ouvre de l'Indice Biologique Diatomées. Agence de l'Eau, Ministiére de l'Ammagement du Territoire et de l'Environment. Direction de l'Eau \& CEMAGREF, France. 134 pp.

Quartino, M. L. 2003. Aspectos ecológicos de macroalgas marinas de Caleta Potter, Shetland del Sur, Antártida. Facultad de Ciencias Exactas y Naturales. Universidad de Buenos Aires. $251 \mathrm{pp}$.

Quartino, M. L. \& Boraso de Zaixso, A. 2008. Summer macroalgal biomass in Potter Cove, South Shetland Islands, Antarctica: its production and flux to the ecosystem. Polar Biol. 31: 281-294.

Quartino, M. L., Klöser, H., Schloss, I. R. \& Wiencke, C. 2001. Biomass and associations of benthic marine macroalgae from the inner Potter Cove (King George Island, Antarctica) related to depth and substrate. Polar Biol. 24: 349-355.

Quartino, M. L., Zaixso, H. \& Boraso de Zaixso, A. 2005. Biological and environmental characterization of marine macroalgal assemblages in Potter Cove, South Shetland Islands, Antarctica. Bot. Mar. 48: 187-197.

Quartino, M. L., Boraso de Zaixso, A. \& Momo, F. R. 2008. Macroalgal production and the energy cycle of Potter Cove. En: C. Wiencke, G. A. Ferreyra, D. Abele \& S. Marenssi (eds.) The Antarctic ecosystem of Potter Cove, King George Island (Isla 25 de Mayo). Reports on Polar and Marine Research (Ber. Polarforsch. Meeresforsch.) 571: 68-74. 
Quartino, M. L., Deregibus, D., Campana, G.L., Latorre, G. E. J. \& Momo, F. R. 2013. Evidence of macroalgal colonization on newly ice-free areas following glacial retreat in Potter Cove (South Shetland Islands), Antarctica. PlosOne 8:e58223.

Quinn, G. P. \& Keough, M. J. 2002. Experimental design and data analysis for biologists. Cambridge University Press. Cambridge. 537 pp.

Quiroga, I. \& Chrétiennot-Dinet, M.-J. 2004. A new species of Minidiscus (Diatomophyceae, Thalassiosiraceae) from the eastern English Channel, France. Bot. Mar. 47: 341-348.

Raes, M., Rose, A. \& Vanreusel, A. 2010. Response of nematode communities after largescale ice-shelf collapse events in the Antarctic Larsen area. Global Change Biol. 16: 1618-1631.

Rautenberger, R. \& Bischof, K. 2008. UV-susceptibility of photosynthesis of adult sporophytes of four brown Antarctic macroalgae (Phaeophyceae). En: C. Wiencke, G. A. Ferreyra, D. Abele \& S. Marenssi (eds.) The Antarctic ecosystem of Potter Cove, King George Island (Isla 25 de Mayo). Reports on Polar and Marine Research (Ber. Polarforsch. Meeresforsch.) 571: 263-269.

Rautenberguer, R. \& Bischof, K. 2016. Dynamic summer solar radiation on Antarctic coastal ecosystems and its effects on photosynthesis of the endemic Antarctic brown macroalga Desmarestia menziesii (Phaeophyceae). Algol. Stud. 151/152: 123-150.

Reichardt, W. \& Dieckmann, G. 1985. Kinetics trophic role of bacterial degradation of macroalgae in Antarctic coastal waters. En: W.R. Siegfried, P.R. Condy \& R.M. Laws (eds.) Antarctic nutrient cycles and food webs. (pp. 115-122). Springer, Heidelberg. 702 pp.

Reizopoulou, S., Santas, P., Danielidis, D., Häder, D.-P. \& Santas, R. 2000. UV effects on invertebrate and diatom assemblages of Greece. J. Photochem. Photobiol. 56:172-180.

Riaux-Gobin, C. \& Romero, O. E. 2003. Marine Cocconeis Ehrenberg (Bacillariophyceae) species and related taxa from Kerguelen's Land (Austral Ocean, Indian Sector). Bibliotheca Diatomologica, Band 47. J. Cramer, Berlin-Stuttgart. 373 pp.

Riaux-Gobin, C., Compère, P., Romero, O. E., Williams, D. 2014. Cocconeis pinnata W. Gregory ex Greville (Bacillariophyta): Lectotypification and an emended description after examination of type material and South Pacific specimens. Phytotaxa 156: 81-99.

Richter, A., Wuttke, S. \& Zacher, K. 2008. Two years of in situ UV measurements at Dallmann Laboratory/Jubany Station. En: C. Wiencke, G. A. Ferreyra, D. Abele \& S. Marenssi (eds.) The Antarctic ecosystem of Potter Cove, King George Island (Isla 25 de Mayo). Reports on Polar and Marine Research (Ber. Polarforsch. Meeresforsch.) 571: 12-19.

Ricker, R. W. 1987. Taxonomy and biogegraphy of Macquarie Island Seaweeds. British Museum (Natural History), Londres.

Rivera, P. \& P. Koch, P. 1984. Contributions to the diatom flora of Chile II. En: D.G. Mann (ed.) Proceedings of the Seventh International Diatom Symposium, Philadelphia, 1982 (pp. 279-298). Koeltz Science Publishers. Koenigstein.

Rivera, P. \& Cruces, F. 2002. Fragilara striatula Lyngbye: Una diatomea marina muy poco conocida para Chile. Gayana Bot. 59: 35-41.

Roese, M. \& Drabble, M. 1998. Wind-driven circulation in Potter cove. En: C. Wiencke, G. A. Ferreyra, W. Arntz \& C. Rinaldi (eds.) The Potter Cove coastal ecosystem, Antarctica. Reports on Polar Research (Ber. Polarforsch.) 299: 40-46.

Roleda, M. Y., Zacher, K., Wulff, A., Hanelt, D. \& Wiencke, C. 2007. Photosynthetic performance, DNA damage and repair in gametes of the endemic Antarctic brown alga Ascoseira mirabilis exposed to ultraviolet radiation. Austral Ecol. 32: 917-926.

Roleda, M. Y., Zacher, K., Campana, G. L., Wulff, A., Hanelt, D., Quartino, M. L. \& Wiencke, C. 2008a. Photosynthetic performance and impact of ultraviolet radiation on the reproductive cells of Antarctic macroalgae. En: C. Wiencke, G. A. Ferreyra, D. Abele \& S. Marenssi (eds.) The Antarctic ecosystem of Potter Cove, King George Island (Isla 25 de Mayo). Reports on Polar and Marine Research (Ber. Polarforsch. Meeresforsch.) 571: 254-262.

Roleda, M. Y., Zacher, K., Wulff, A., Hanelt, D. \& Wiencke, C. 2008b. Susceptibility of spores of different ploidy levels from Antarctic Gigartina skottsbergii (Gigartinales, Rhodophyta) to ultraviolet radiation. Phycologia 47:361-370. 
Roleda, M. Y., Campana, G. L., Wiencke, C., Hanelt, D., Quartino, M. L. \& Wulff, A. 2009. Sensitivity of Antarctic Urospora penicilliformis (Ulotrichales, Chlorophyta) to ultraviolet radiation is life-stage dependent. J. Phycol. 45:600-609.

Roleda, M. Y., Lütz-Meindl, U., Wiencke, C. \& Lütz, C. 2010. Physiological, biochemical, and ultrastructural responses of the green macroalga Urospora penicilliformis from Arctic Spitsbergen to UV radiation. Protoplasma 243: 105-116.

Romero, O. E. 1995. Morfología, taxonomía y distribución de Cocconeis Ehrenberg (Bacillariophyceae) en Chile. Universidad de Concepción, Concepción, Chile. Tesis de Master. 325 pp.

Romero, O. E. 2011. Morphological study of the genus Cocconeis Ehrenberg (Bacillariophyceae) collected during the 1897-1899 Belgian Antarctic Expedition. Bot. Mar. 54: 179-188.

Romero, O. E. \& Rivera, P. 1996. Morphology and taxonomy of three varieties of Cocconeis costata and C. pinnata (Bacillariophyceae) with considerations of Pleuroneis. Diatom Res. 11: 317-343.

Rosenvinge, L. K. 1900. Note sur une Floridée aérienne (Rhodochorton islandicum nov. sp.). Botanisk Tidsskrift 23: 61-81.

Round, F. E., Crawford, R. M. \& Mann, D. G. 1990. The Diatoms: Biology and morphology of the genera. Cambridge University Press, Cambridge. $747 \mathrm{pp}$.

Roux, R., Gosselin, M., Desrosiers, G. \& Nozais, C. 2002. Effects of reduced UV radiation on a microbenthic community during a microcosm experiment. Mar. Ecol. Prog. Ser. 225: 29-43.

Rückamp, M., Braun, M., Suckro, S. \& Blindow, N. 2011. Observed glacial changes on the King George Island ice cap, Antarctica, in the last decade. Glob. Planet. Change 79:99109.

Runcie, J. W. \& Riddle, M. J. 2006. Photosynthesis of marine macroalgae in ice-covered and ice-free environments in East Antarctica. Eur. J. Phycol. 41: 223-233.

Ruocco, N., Costantini, S., Zupo, V., Lauritano, C. Caramiello, D., lanora, A., Budillon, A. Romano, G., Nuzzo, G., D'Ippolito, G., Fontana, A. \& Costantini, M. 2018. Toxigenic effects of two benthic diatoms upon grazing activity of the sea urchin: morphological, metabolomic and de novo transcriptomic analysis. Sci. Rep. 8: 5622.

Ryan, K. G., McMinn, A. Hegseth, E. N. \& Davy, S. K. 2012. The effects of ultraviolet-B radiation on Antarctic sea-ice algae. J. Phycol. 48: 74-84.

Sahade, R., Tatián, M. \& Esnal, G. B. 1998. Benthic faunal associations on soft substrates at Potter Cove, King George Island, Antarctica. Polar Biol. 19: 85-91.

Sahade, R., Tatián, M. \& Esnal, G. B. 2004. Reproductive ecology of the ascidian Cnemidocarpa verrucosa at Potter Cove, South Shetland Islands, Antarctica. Mar. Ecol. Prog. Ser. 272: 131-140.

Sahade, R, Lagger, C., Torre, L., Momo, F., Monien, P., Schloss, I. R., Barnes, D. K. A., Servetto, N. Tarantelli, S., Tatián, M., Zamboni, N. \& Abele, D. 2015. Climate change and glacier retreat drive shifts in an Antarctic benthic ecosystem. Sci. Adv. 1: e1500050.

Santas, R., Korda, A., Lianou, C. \& Santas, P. 1998. Community responses to UV radiation I. Enhanced UVB effects on biomass and community structure of filamentous algal assemblages growing in a coral reef mesocosm. Mar. Biol. 131:153-162.

Santelices, B. 1990. Patterns of reproduction, dispersal and recruitment in seaweeds. Oceanogr. Mar. Biol. Ann. Rev. 28: 177-76.

Sar, E. 1985. Contribución al conocimiento de Ulothrix flacca (Dillwyn) Thuret (Ulotrichales, Clorophyta). Lilloa 36: 215-219.

Sar, E. A. \& Ferrario, M. E. 1990. Licmophora flabellata (Carmichael ex Greville) C. Agardh (Bacillariophyceae), ultrastructure and taxonomy implications. Diatom Res.5: 403-408.

Schiel, D. R. \& Foster, M. S. 2006. The population biology of large brown seaweeds: Ecological consequences of multiphase life histories in dynamic coastal environments. Annu. Rev. Ecol. Evol. Syst. 37: 343-72.

Schloss, I. R. \& Ferreyra, G. A. 2002. Primary production, light and vertical mixing in Potter Cove, a shallow bay in the maritime Antarctic. Polar Biol. 25:41-48. 
Schloss, I. R., Ferreyra, G. A. \& Ruiz-Pino, D. 2002. Phytoplankton biomass in Antarctic shelf zones: a conceptual model based on Potter Cove, King George Island. J. Mar. Syst. 36: 129-143.

Schloss, I. R., Ferreyra, G. A., González, O., Atencio, A., Fuentes, V., Tosonotto, G., Mercuri, G., Sahade, R., Tatián, M. \& Abele, D. 2008. Long-term hydrographic conditions and climate trends in Potter Cove. En: C. Wiencke, G. A. Ferreyra, D. Abele \& S. Marenssi (eds.) The Antarctic ecosystem of Potter Cove, King George Island (Isla 25 de Mayo). Reports on Polar and Marine Research (Ber. Polarforsch. Meeresforsch.) 571: 382389.

Schloss, I. R., Abele, D., Moreau, S., Demers, S., Bers, V., González, O. \& Ferreyra, G. A. 2012. Response of phytoplankton dynamics to 19-year (1991-2009) climate trends in Potter Cove (Antarctica). J. Mar. Syst. 92:53-66.

Schloss, I. R., Wasilowska, A., Dumont, D., Almandoz, G. O., Hernando, M. P., MichaudTremblay, C. A., Saravia, L. A., Rzepecki, M., Monien, P., Monien, D., Kopczyńska, E. E., Bers, A. V. \& Ferreyra, G. A. 2014. On the phytoplankton bloom in coastal waters of southern King George Island (Antarctica) in January 2010: An exceptional feature? Limnol. Oceanogr. 59: 195-210.

Schoenrock, K. M., Schram. J. B., Amsler, C. D., McClintock, J. B. \& Angus, R. A. 2015. Climate change impacts on overstory Desmarestia spp. from the western Antarctic Peninsula. Mar. Biol. 162: 377-389.

Scott, F. J. \& Thomas, D. P. 2005. Diatoms. En: F. J. Scott \& H. J. Marchant (eds.) Antarctic Marine Protists (Cap. 2, pp. 13-201). Australian Biological Resources Study, Canberra \& Australian Antarctic Division, Hobart. 563 pp.

Seefeldt, M. A., Campana, G. L., Deregibus, D., Quartino, M. L., Abele, D., Tollrian, R. \& Held, C. 2017. Different feeding strategies in Antarctic scavenging amphipods and their implications for colonisation success in times of retreating glaciers. Front. Zool. 14: 59. doi: 10.1186/s12983-017-0248-3.

Segovia-Rivera, V. \& Valdivia, N. 2016. Independent effects of grazing and tide pool habitats on the early colonisation of an intertidal community on western Antarctic Peninsula. Rev. Chil. Hist. Nat. 89: 3.

Setchell, W. A. \& Gardner, N. L. 1936. Iridophycus gen. nov. and its representation in South America. Proceedings of the National Academy of Sciences of the United States of America 22: 469-473.

Shabica, S. V. 1976. The natural history of the Antarctic limpet Patinigera polaris (Hombron \& Jaquinot). University of Oregon, Corvallis. 294 pp.

Silberfeld, T., Racault, M.-F.L.P., Fletcher, R. L., Couloux, A., Rousseau, F. \& De Reviers, B. 2011. Systematics and evolutionary history of pyrenoid-bearing taxa in brown algae (Phaeophyceae). Eur. J. Phycol. 46: 361-377.

Simonsen, R. 1974. The diatom plankton of the Indian Ocean Expedition of RV "Meteor" 19641965. Meteor Forschungsergebnisse, Reihe D 19. 66 pp.

Simonsen, R. 1992. The diatom types of Heinrich Heiden in Heiden \& Kolbe 1928. Bibliotheca Diatomologica 24 (H. Lange-Bertalot, ed.). J. Cramer, Berlin-Stuttgart.

Skottsberg, C. 1907. Zur Kenntnis der subantarktischen und antarktischen Meeresalgen. I. Phaeophyceen. En: Wissenschaftliche Ergebnisse der Schwedischen SüdpolarExpedition 1901-1903 unter Leitung von Dr. Otto Nordenskjöld. 4 (1): 1-172. Stockholm: Lithographisches Institut des Generalstabs.

Skottsberg, C. 1921. Botanische ergebnisse der schwedischen expedition nach Patagonien und dem Feuerlande 1907-1909. VIII. Marine algae I. Phaeophyceae. Almqvist \& Wiksells Boktrycheri a.b. Stochholm.

Skottsberg, C. 1953. On two collections of Antarctic marine algae. Arkiv för Botanik Ser. 2 (7): 531-566.

Smale, D. A. \& Barnes, D. K. A. 2008. Likely responses of the Antarctic benthos to climaterelated changes in physical disturbance during the 21st century, based primarily on evidence from the West Antarctic Peninsula region. Ecography 31: 289-305.

Smith, W. 1856. Synopsis of British Diatomaceae. John Van Voorst, Londres. 
Smith, W. 1857. Notes of an excursion to the Pyrenees in search of Diatomaceae. Annals and Magazine of Natural History, Series 2, 19: 1-13.

Smith, R. C., Prézelin, B. B., Baker, K. S., Bidigare, R. R., Boucher, N. P., Coley, T., Karentz, D., Maclntyre, S., Matlick, H. A., Menzies, D., D. Menzies, Ondrusek, M., Wan, Z. \& Waters, K. J. 1992. Ozone depletion: Ultraviolet radiation and phytoplankton biology in Antarctic waters. Science 255: 952-959.

Sommaruga, R. 2003. UVR and its effects on species interactions. En: E. W. Helbling \& H. Zagarese (eds.) UV effects in aquatic organisms and ecosystems. (Cap. 15, pp. 487508). The Royal Society of Chemistry, Cambridge. 575 pp.

Sommer, U. 1999a. The impact of herbivore type and grazing pressure on benthic microalgal diversity. Ecol. Lett. 2: 65-69.5.

Sommer, U. 1999b. Periphyton architecture and susceptibility to grazing by periwinkles (Littorina littorea, Gastropoda). Internat. Rev. Hydrobiol. 84: 197-204.

Sommer, U. 2000. Benthic microalgal diversity enhanced by spatial heterogeinity of grazing. Oecologia 122: 284-287.

Sousa, W. P. 1979. Experimental investigations of disturbance and ecological succession in a rocky intertidal algal community. Ecol. Monogr. 49: 227-254.

Sousa, W. P. 1984. Intertidal mosaics: Patch size, propagule availability, and spatially variable patterns of succession. Ecology 65: 1918-1935.

Sousa, W. P. 2001. Natural disturbance and the dynamics of marine benthic communities. En: M. D. Bertness, S. D. Gaines, \& M. E. Hay (eds.). Marine community ecology. (Cap. 4, pp. 85-130). Sinauer Associates, Inc., Sunderland, Massachusetts. 550 pp.

Sousa, W. P. \& Connell, J. H. 1992. Grazing and succession in marine algae. En: D. M. John, S. J. Hawkins \& J. H. Price (eds.). Plant-animal interactions in the marine benthos (pp. 425-441). Clarendon Press, Oxford.

Stammerjohn, S. 2016. Antarctica. En: J. Blunden. \& D. S. Arndt (eds.) State of the Climate in 2015. Bull. Amer. Meteor. Soc., 97: S155-S156.

Stanwell-Smith, D. \& Barnes, D. K. A. 1997. Benthic community development in Antarctica: recruitment and growth on settlement panels at Signy Island. J. Exp. Mar. Biol. Ecol. 212: 61-79.

Steinman, A. D. 1996. Effects of grazers on freshwater benthic algae. En: R. J. Stevenson, M. L. Bothwell, \& R. L. Lowe (eds.) Algal ecology - freshwater benthic ecosystems. (Cap. 12, pp. 341-373). Academic Press, San Diego. 753 pp.

Stepanek, J. G. \& Kociolek J. P. 2014. Molecular phylogeny of Amphora sensu lato (Bacillariophyta): An investigation into the monophyly and classification of the amphoroid diatoms. Protist 165:177-195.

Strahan, S. E. \& Douglass, A. R. 2018. Decline in Antarctic ozone depletion and lower stratospheric chlorine determined from aura microwave limb sounder observations. Geophys. Res. Lett. 45: 382-390.

Suda, C. N. K., Vani, G. S., Feijó de Oliveira, M. Rodrigues Jr., E., Rodriguez, E. \& Lavrado, H. P. 2015. The biology and ecology of the Antarctic limpet Nacella concinna. Polar Biol. 38: 1949-1969.

Sundbäck, K., Nilsson, C., Odmark, S. \& Wulff, A. 1996. Does ambient UV-B radiation influence marine diatom-dominated microbial mats? A case study. Aquat. Microb. Ecol. 11:151-159.

Sundbäck, K., Odmark, S., Wulff, A., Nilsson, C. \& Wängberg, S. A. 1997. Effects of enhanced UVB radiation on a marine benthic diatom mat. Mar. Biol. 128: 171-179.

Takeuchi, I. \& Watanabe, K. 2002. Mobile epiphytic invertebrates inhabiting the brown macroalga Desmarestia chordalis, under the coastal fast ice of Lützow-Holm Bay, East Antarctica. Polar Biol., 25: 624-628.

Tatián, M., Sahade, R., Kowalke, J., Kivatinitz, S. C. \& Esnal, G. B. 2002. Food availability and gut contents in the ascidian Cnemidocarpa verrucosa at Potter Cove, Antarctica. Polar Biol. 25: 58-64.

Tatián, M, Sahade, R \& Esnal, G. B. 2004. Diet components in the food of Antarctic ascidians living at low levels of primary production. Antarct Sci 16: 123-128. 
Tatián, M., Sahade, R., Mercuri, G., Fuentes, V. L., Antacli, J., Stellfeldt, A. \& Esnal, G. B. 2008. Feeding ecology of benthic filter-feeders at Potter Cove, an Antarctic coastal ecosystem. Polar Biol. 31: 509-517.

Taylor F. J. R. 1967. Phytoplankton of the south western Indian Ocean. Nova Hedwigia 12: 433-476.

Taylor, R. L., Caldwell, G. S., Dunstan, H. J. \& Bentley, M. G. 2007. Short-term impacts of polyunsaturated aldehyde-producing diatoms on the harpacticoid copepod, Tisbe holothuriae. J. Exp. Mar. Bol. Ecol. 341: 60-69.

Tedetti, M. \& Sempéré, R. 2006. Penetration of ultraviolet radiation in the marine environment. A review. Photochem. Photobiol. 82: 389-397.

Teixidó, N., Garrabou, J., Gutt, J. \& Arntz, W. E. 2007. Iceberg disturbance and successional spatial patterns: the case of the shelf Antarctic benthic communities. Ecosystems 10: 142-157.

Terradas, J. 2001. Ecología de la Vegetación. Omega. 760 pp.

Thomas, D. \& Jiang, J. 1986. Epiphytic diatoms of the inshore marine area near Davis Station. Hydrobiologia 140:193.

Torre, L., Abele, D., Lagger, C., Momo, F. R. \& Sahade, R. 2014. When shape matters: strategies of different Antarctic ascidians morphotypes to deal with sedimentation. Mar. Environ. Res. 99: 179-187.

Torre, L., Carmona Tabares, P. C., Momo, F. R., Meyer, J. F. C. A. \& Sahade, R. 2017. Climate change effects on Antarctic benthos: a spatially explicit model approach. Clim. Change 141: 733-746.

Toyoda, K., Cox, E. J., Sims, P. A. \& Williams, D. M. 2005. The typification of Achnanthes Bory based on Echinella stipitata Lyngbye, with an account of the morphology and fine structure of the Lyngbye's species. Diatom Res. 20: 375-386.

Toyoda, K., Cox, E. J., Sims, P. A. \& Williams, D. M. 2006. (1718) Proposal to conserve Achnanthes brevipes (Bacillariophyceae) against $A$. adnata, $A$. baccillarioides, and $A$. dubia, and with a conserved type. Taxon 55: 527-528.

Turner, J., Bindschadler, R., Convey, P., di Prisco, G., Fahrbach, E., Gutt, J., Hodgson, D., Mayewski, P. \& Summerhayes, C. 2009. Antarctic climate change and the environment. Scientific Committee on Antarctic Research, Cambridge. 526 pp.

Underwood, G. J. C., Nilsson, C., Sundbäck, K. \& Wulff, A. 1999. Short-term effects of UVB radiation on chlorophyll fluorescence, biomass, pigments, and carbohydrate fractions in a benthic diatom mat. J. Phycol. 35: 656-666.

Uribe, R. A., Ortiz, M., Macaya, E. C. \& Pacheco, A. S. 2015. Successional patterns of hardbottom macrobenthic communities at kelp bed (Lessonia trabeculata) and barren ground sublittoral systems. J. Exp. Mar. Biol. Ecol. 472: 180-188.

Valdivia, N., Díaz, M. J., Holtheuer, J., Garrido, I., Huovinen, P. \& Gómez, I. 2014. Up, down, and all around: Scale-dependent spatial variation in rocky-shore communities of Fildes Peninsula, King George Island, Antarctica. PlosOne 9: e100714.

Valdivia, N., Pardo, L. M., Macaya, E. C., Huovinen, P. \& Gómez, I. 2018. Different ecological mechanisms lead to similar grazer controls on the functioning of periphyton Antarctic and sub-Antarctic communities. Prog. Oceanogr. doi: 0.1016/j.pocean.2018.01.008.

Van de Vijver, B., Zidarova, R., Sterken, M., Verleyen, E., de Haan, M., Vyverman, W., Hinz, F. \& Sabbe, K. 2011. Revision of the genus Navicula s.s. (Bacillariophyceae) in inland waters of the Sub-Antarctic and Antarctic with the description of five new species. Phycologia 50: 281-297.

Van Heurck, H. 1880. Synopsis des Diatomées de Belgique Atlas, pls. 1-30, Anvers: Ducaju et Cie.

Van Heurck, H. 1909. Diatomées. Resultats du voyage du S.Y. "Belgica" en 1897-1899 sous le commandentement de A. de Gerlache du Gomery. Rapports Scientifi ques: Botaniques. Expedition Antarctique "Belgica", v.5, p. 1-129.

Van Landingham, S. L. 1971. Catalogue of the fossil and recent genera and species of diatoms and their synonym. Pages 1757-2385 Lehre: J. Cramer, part. 4.

Vargas Abarzúa, E. \& Zúñiga Molinier, L. 2010. Tiempo y sucesión ecológica en Ramón Margalef. ARBOR 741: 163-171. 
Vernet, M., Sines, K., Chakos, D., Cefarelli, A. O. \& Ekern, L. 2011. Impacts on phytoplankton dynamics by free-drifting icebergs in the NW Weddell Sea. Deep-Sea Res. II 58:14221435.

Villafañe, V. E. \& Reid, F. M. H. 1995. Métodos de microscopía para la cuantificación del fitoplancton. En: K. Alveal, M. E. Ferrario, E. C. Oliveira \& E. Sar (eds.) Manual de Métodos Ficológicos (pp. 170-185). Universidad de Concepción, Concepción. 863 pp.

Villafañe. V. E., Sundbäck, K., L. Figueroa, F. \& Helbling, E. W. 2003. Photosynthesis in the aquatic environment as affected by UVR. En: E. W. Helbling \& H. Zagarese (eds.) UV effects in aquatic organisms and ecosystems. (Cap. 11, pp. 357-397). The Royal Society of Chemistry, Cambridge. 575 pp.

Vinebrooke, R. D. \& Leavitt, P. R. 1999. Differential responses of littoral communities to ultraviolet radiation on an Alpine lake. Ecology 80: 223-237.

von Quillfeldt, C. H., Ambrose, W. G. \& Clough, L. M. 2003. High number of diatom species in first-year ice from the Chukchi Sea. Polar Biol. 26: 806-818.

Wahl, M. 1989. Marine epibiosis. I. Fouling and antifouling: some basic aspects. Mar. Ecol. Prog. Ser. 58: 175-189.

Wahl, M. 2008. Ecological modulation of environmental stress: interactions between ultraviolet radiation, epibiotic snail embryos, plants and herbivores. J. Animal Ecol. 77: 549-557.

Wahl, M. 2009. Epibiosis: Ecology, effects and defences. En: M. Wahl (ed.) Marine Hard Bottom Communities. Ecological Studies 206. (Cap. 4, pp. 61-72). Springer-Verlag Berlin Heidelberg. 445 pp.

Wahl, M., Molis, M., Davis, A., Dobretsov, S., Dürr, S., Johansson, J., Kinley, J., Kirugara, D., Langer, M., Lotze, H. K., Thiel, M., Thomason, J. C., Worm, B. \& Zeevi Ben-Yosef, D. 2004. UV effects that come and go: a global comparison of marine benthic community level impacts. Global Change Biol. 10: 1962-1972.

Walker, A. J. M. 1972. Introduction to the ecology of the Antarctic limpet, Patinigera polaris (Hombron \& Jaquinot) at Signy Island, south Orkney Islands. Brit. Antarct. Surv. B 28: 49-69.

Waring, J., Baker, Underwood, G. J. C. \& Baker, N. R. 2006. Impact of elevated UV-B radiation on photosynthetic electron transport, primary productivity and carbon allocation in estuarine epipelic diatoms. Plant Cell Environ. 29: 521-534.

Waring, J., Baker, N. R. \& Underwood, G. J. C. 2007. Responses of estuarine intertidal microphytobenthic algal assemblages to enhanced ultraviolet B radiation. Global Change Biol. 13:1398-1413.

Weber, M., Steinbrecht, W., Frith, S. M., Tweedy, O., Coldewey-Egbers, M., Davis, S., Degenstein, D., Fioletov, Y. E., Froidevaux, L. , de Laat, J., Long, C. S., Loyola, D., Roth, C. \& Wild, J. D. 2017. Stratospheric ozone. En: J. Blunden \& D. S. Arndt (eds.) State of the Climate in 2016. Bull. Amer. Meteor. Soc. 98, S49-S51.

Whitaker, T. M. \& Richardson, M. G. 1980. Morphology and chemical composition of a natural population of and ice-associated Antarctic diatom Navicula glaciei. J. Phycol. 16: 250257.

Whitehead, R. F., de Mora, S. J. \& Demers, S. 2000. Enhanced UV radiation - a new problem for the marine environment. En: S. de Mora, S. Demers \& M. Vernet (eds.) The effects of UV radiation in the marine environment. (Cap. 1, pp. 1-34). Cambridge University Press, Cambridge. 324 pp.

Wiencke, C. 1990. Seasonality of brown macroalgae from Antarctica-a long-term culture study under fluctuating Antarctic daylengths. Polar Biol. 10: 589-600.

Wiencke, C. \& M. N. Clayton. 2002. Antarctic Seaweeds. Synopses of the Antarctic Benthos, 9. A.R.G. Gantner Verlag KG, Ruggell, Lichtenstein. 239 pp.

Wiencke, C. \& Amsler, C. D. 2012. Seaweeds and their communities in polar regions. En: C. Wiencke \& K. Bischof (eds.) Seaweed Biology, Ecological Studies 219 (Cap. 13, pp. 265-291). Springer-Verlag Berlin Heidelberg. 510 pp.

Wiencke, C, Gómez, I., Pakker, H., Flores-Moya, A., Altamirano, M., Hanelt, D., Bischof, K. \& L. Figueroa, F. 2000. Impact of UV-radiation on viability photosynthetic characteristics and DNA of brown algal zoospores: implications for depth zonation. Mar. Ecol. Prog. Ser. 197: 217-229. 
Wiencke, C. Clayton, M. N., Gómez, I. Iken, K. , Lüder, U. H., Amsler, C. D., Karsten, U. Hanelt, D., Bischof, K. \& Dunton, K. 2007. Life strategy, ecophysiology and ecology of seaweeds in polar waters. Rev. Environ. Sci. Biotechnol. 6:95-126.

Wiencke, C., Amsler, C. D. \& Clayton, M. N. 2014. Macroalgae. En: C. De Broyer, P. Koubbi, H. J. Griffiths, R. B., C. Udekem d'Acoz, A. Van de Putte, B. Danis, B. David, S. Grant, J. Gutt, C. Held, G. Hosie, F. Huettmann, A. Post, \& Y. Ropert-Coudert (eds.) Biogeographic Atlas of the Southern Ocean (Cap. 5.1, pp. 66-73). Scientific Committee on Antarctic Research, Cambridge. 475 pp.

Witkowski, A., Lange-Bertalot, H. \& Metzeltin, D. 2000. Diatom flora of marine coasts I. A.R.G. Gantner Verlag K.G., Ruggel, Liechtenstein. 925 pp.

Witman, J. D. \& Dayton, P. K. 2001. Rocky subtidal communities. En: M. D. Bertness, S. D. Gaines, \& M. E. Hay (eds.) Marine community ecology. (Cap. 13, pp. 339-366). Sinauer Associates, Inc., Sunderland, Massachusetts. 550 pp.

WMO. 2014. Scientific Assessment of Ozone Depletion: 2014, Global Ozone Research and Monitoring Project. Report No. 55, World Meteorological Organization, Ginebra, Suiza, 2014.

Worm, B., Lotze, H. K. \& Sommer, U. 2000. Coastal food web structure, carbon storage, and nitrogen retention regulated by consumer pressure and nutrient loading. Limnol. Oceanogr., 45: 339-349.

Wulff, A., Nilsson, C., Sundbäck, K., Wängberg, S. Å. \& Odmark, S. 1999. UV radiation effects on microbenthos - a four month field experiment. Aquat. Microb. Ecol. 19: 269-278.

Wulff, A., Wängberg, S. A., Sundbäck, K., Nilsson, C. \& Underwood, G. J. C. 2000. Effects of UVB radiation on a marine microphytobenthic community growing on a sandsubstratum under different nutrient conditions. Limnol. Oceanogr. 45: 1144-1152.

Wulff, A., Roleda, M. Y., Zacher, K. \& Wiencke, C. 2008a. UV radiation effects on pigments, photosynthetic efficiency and DNA of an Antarctic marine benthic diatom community. Aquat. Biol. 3: 167-177.

Wulff, A., Zacher, K., Hanelt, D., Al-Handal, A. Y. \& Wiencke, C. 2008b. UV radiation - a threat to Antarctic benthic marine diatoms? Antarct. Sci. 20:13-20.

Wulff, A., Roleda, M. Y., Zacher, K. \& Wiencke, C. 2008c. Exposure to sudden light burst after prolonged darkness - a case study on benthic diatoms in Antarctica. Diatom Res. 23: 519-532.

Wulff, A., Iken, K., Quartino, M. L., Al-Handal, A. Y., Wiencke, C. \& Clayton, M. N. 2011. Biodiversity, biogeography and zonation of benthic micro- and macroalgae in the Arctic and Antarctic. En: C. Wiencke (ed.) Biology of Polar Benthic Algae. (Cap. 3, pp. 23-52). Walter de Gruyter GmbH \& Co. K.G., Berlin/New York. 337 pp.

Zacher, K. 2014. The susceptibility of spores and propagules of Antarctic seaweeds to UV and photosynthetically active radiation - Field versus laboratory experiments. J. Exp. Mar. Biol. Ecol. 458: 57-63.

Zacher, K., Wulff, A., Molis, M., Hanelt, D. \& Wiencke, C. 2007a. Ultraviolet radiation and consumer effects on a field-grown intertidal macroalgal assemblage in Antarctica. Global Change Biol. 13:1201-1215.

Zacher, K., Hanelt, D., Wiencke, C. \& Wulff, A. 2007b. Grazing and UV radiation effects on an Antarctic intertidal microalgal assemblage: a long-term field study. Polar Biol. 30:12031212.

Zacher, K., Roleda, M. Y., Hanelt, D. \& Wiencke, C. 2007c. UV effects on photosynthesis and DNA in propagules of three Antarctic seaweeds (Adenocystis utricularis, Monostroma hariotii and Porphyra endiviifolium). Planta 225:1505-1516.

Zacher, K. \& Campana, G. L. 2008. UV and grazing effects on an intertidal and subtidal algal assemblage: a comparative study. En: C. Wiencke, G. A. Ferreyra, D. Abele \& S. Marenssi (eds.) The Antarctic ecosystem of Potter Cove, King George Island (Isla 25 de Mayo). Reports on Polar and Marine Research (Ber. Polarforsch. Meeresforsch.) 571: 287-294.

Zacher, K., Rautenberger, R., Wulff, A. Hanelt, D. \& Wiencke, C. 2011. The abiotic environment of polar benthic algae. En: C. Wiencke (ed.) Biology of Polar Benthic 
Algae. (Cap. 2, pp. 9-21). Walter de Gruyter GmbH \& Co. K.G., Berlin/New York. 337 pp.

Zacher, K., Bernard, M., Bartsch, I. \& Wiencke, C. 2016a. Survival of early life history stages of Arctic kelps (Kongsfjorden, Svalbard) under multifactorial global change scenarios. Polar Biol. 39: 2009-2020.

Zacher, K., Savaglia, V. \& Bartsch, I. 2016b. Effects of temperature and interspecific competition on growth and photosynthesis of two endemic Antarctic Desmarestia species. Algol. Stud. 151(152): 103-122.

Zar, J. H. 1996. Biostatistical analysis 3rd edition. Prentise Hall, New Jersey. 850 pp.

Zar, J. H. 2010. Biostatistical analysis 5th edition. Prentise Hall, New Jersey. 944 pp. 
Apéndices 
Apéndice 3.1. Densidad (nro. de células $\mathrm{cm}^{2}$ ) y abundancia relativa porcentual de los taxa de diatomeas hallados entre abril 2004 y enero 2005.

\begin{tabular}{|c|c|c|c|c|c|c|c|c|c|c|c|c|c|c|c|c|c|c|c|c|}
\hline & \multicolumn{2}{|c|}{ Abril } & \multicolumn{2}{|c|}{ Mayo } & \multicolumn{2}{|c|}{ Junio } & \multicolumn{2}{|c|}{ Julio } & \multicolumn{2}{|c|}{ Agosto } & \multicolumn{2}{|c|}{ Septiembre } & \multicolumn{2}{|c|}{ Octubre } & \multicolumn{2}{|c|}{ Noviembre } & \multicolumn{2}{|c|}{ Diciembre } & \multicolumn{2}{|c|}{ Enero } \\
\hline & d & $\%$ & d & $\%$ & $d$ & $\%$ & d & $\%$ & d & $\%$ & d & $\%$ & d & $\%$ & $d$ & $\%$ & d & $\%$ & d & $\%$ \\
\hline A. brevipes & 27,5 & 0,09 & 0,0 & 0,00 & 0,8 & 0,00 & 7,6 & 0,01 & 0,0 & 0,00 & 0,0 & 0,00 & 2,3 & 0,00 & 0,0 & 0,00 & 1,9 & 0,01 & 0,0 & 0,00 \\
\hline Amphora sp. & 1,9 & 0,00 & 24,3 & 0,11 & 0,0 & 0,00 & 74,8 & 0,11 & 6,9 & 0,01 & 8,4 & 0,02 & 6,6 & 0,01 & 22,9 & 0,02 & 23,7 & 0,05 & 0,0 & 0,00 \\
\hline B. mosimanniae & 0,0 & 0,00 & 0,0 & 0,00 & 2,1 & 0,01 & 0,0 & 0,00 & 0,0 & 0,00 & 0,0 & 0,00 & 8,7 & 0,01 & 0,0 & 0,00 & 16,8 & 0,04 & 0,0 & 0,00 \\
\hline C. antiqua & 198,7 & 0,55 & 546,4 & 1,79 & 364,0 & 1,37 & 367,4 & 0,76 & 315,6 & 0,32 & 4,9 & 0,01 & 105,4 & 0,12 & 14,4 & 0,01 & 16,3 & 0,04 & 25,5 & 0,19 \\
\hline C. fasciolata/costata & 220,7 & 0,55 & 589,1 & 2,34 & 1781,5 & 7,36 & 4969,3 & 8,32 & 14444,7 & 16,39 & 2986,0 & 5,79 & 2502,8 & 2,93 & 589,8 & 0,52 & 299,1 & 0,71 & 92,3 & 0,70 \\
\hline C. melchiori/dall/mel & 56,2 & 0,11 & 0,0 & 0,00 & 280,6 & 1,05 & 31,0 & 0,06 & 622,5 & 0,56 & 576,3 & 1,02 & 361,8 & 0,42 & 307,7 & 0,22 & 45,2 & 0,10 & 20,6 & 0,17 \\
\hline Cocconeis sp. & 0,0 & 0,00 & 103,0 & 0,12 & 38,3 & 0,19 & 227,1 & 0,25 & 1127,0 & 1,05 & 26,1 & 0,11 & 184,1 & 0,23 & 0,0 & 0,00 & 32,4 & 0,07 & 0,0 & 0,00 \\
\hline Entomoneis sp. & 2,9 & 0,01 & 103,0 & 0,12 & 4,8 & 0,02 & 15,2 & 0,02 & 37,5 & 0,03 & 106,1 & 0,22 & 0,0 & 0,00 & 7,3 & 0,00 & 16,8 & 0,04 & 0,0 & 0,00 \\
\hline E. ocellata & 0,0 & 0,00 & 0,0 & 0,00 & 0,0 & 0,00 & 0,0 & 0,00 & 0,0 & 0,00 & 1,4 & 0,01 & 0,0 & 0,00 & 0,0 & 0,00 & 0,0 & 0,00 & 0,0 & 0,00 \\
\hline F. islandica/striatula & 448,1 & 1,19 & 141,8 & 0,55 & 278,6 & 1,28 & 3529,4 & 5,77 & 2154,2 & 2,44 & 368,0 & 1,05 & 1234,1 & 1,42 & 256,4 & 0,17 & 660,5 & 1,40 & 97,2 & 0,72 \\
\hline F. kergelensis & 0,0 & 0,00 & 0,0 & 0,00 & 0,0 & 0,00 & 0,0 & 0,00 & 0,0 & 0,00 & 1,4 & 0,01 & 0,0 & 0,00 & 1,1 & 0,00 & 0,0 & 0,00 & 0,0 & 0,00 \\
\hline F. rombica/separanda & 0,0 & 0,00 & 0,0 & 0,00 & 0,0 & 0,00 & 0,0 & 0,00 & 0,0 & 0,00 & 4,1 & 0,02 & 0,0 & 0,00 & 0,0 & 0,00 & 0,0 & 0,00 & 0,0 & 0,00 \\
\hline G. arctica & 0,0 & 0,00 & 0,0 & 0,00 & 0,0 & 0,00 & 0,0 & 0,00 & 0,0 & 0,00 & 4,1 & 0,02 & 0,0 & 0,00 & 0,0 & 0,00 & 0,0 & 0,00 & 0,0 & 0,00 \\
\hline L. gracilis & 19,8 & 0,05 & 103,0 & 0,12 & 15,0 & 0,07 & 10,0 & 0,02 & 6,6 & 0,01 & 12,8 & 0,04 & 0,0 & 0,00 & 2,2 & 0,00 & 0,0 & 0,00 & 25,5 & 0,19 \\
\hline Navicula sp. & 0,0 & 0,00 & 0,0 & 0,00 & 0,0 & 0,00 & 0,0 & 0,00 & 0,0 & 0,00 & 1,4 & 0,01 & 0,0 & 0,00 & 0,0 & 0,00 & 0,0 & 0,00 & 0,0 & 0,00 \\
\hline N. directa & 47,7 & 0,13 & 0,0 & 0,00 & 0,4 & 0,00 & 416,6 & 0,54 & 352,6 & 0,32 & 99,1 & 0,09 & 46,1 & 0,05 & 63,9 & 0,04 & 40,7 & 0,10 & 0,0 & 0,00 \\
\hline N. glaciei & 0,0 & 0,00 & 206,1 & 0,23 & 0,0 & 0,00 & 0,0 & 0,00 & 0,0 & 0,00 & 0,0 & 0,00 & 0,0 & 0,00 & 0,0 & 0,00 & 0,0 & 0,00 & 0,0 & 0,00 \\
\hline N. perminuta & 38949,1 & 85,27 & 43769,6 & 83,70 & 19090,7 & 83,92 & 50377,5 & 74,17 & 66260,9 & 67,12 & 62402,7 & 89,90 & 81519,6 & 92,05 & 137970,0 & 98,04 & 38889,8 & 91,16 & 7623,3 & 58,09 \\
\hline O. aurita & 0,0 & 0,00 & 0,0 & 0,00 & 0,4 & 0,00 & 17,6 & 0,02 & 0,0 & 0,00 & 0,0 & 0,00 & 0,0 & 0,00 & 0,0 & 0,00 & 0,0 & 0,00 & 0,0 & 0,00 \\
\hline P. delognei & 0,0 & 0,00 & 0,0 & 0,00 & 0,0 & 0,00 & 30,0 & 0,05 & 16,1 & 0,01 & 0,0 & 0,00 & 0,0 & 0,00 & 0,0 & 0,00 & 0,0 & 0,00 & 0,0 & 0,00 \\
\hline Pleurosigma sp. & 0,0 & 0,00 & 0,0 & 0,00 & 0,0 & 0,00 & 7,6 & 0,01 & 3,6 & 0,01 & 0,0 & 0,00 & 0,0 & 0,00 & 0,6 & 0,00 & 0,0 & 0,00 & 0,0 & 0,00 \\
\hline P. kamtschaticum & 5052,0 & 12,00 & 5467,5 & 10,92 & 1057,2 & 4,43 & 6979,8 & 9,88 & 11634,6 & 11,51 & 695,4 & 1,67 & 2390,1 & 2,75 & 1399,1 & 0,95 & 2676,6 & 6,27 & 5230,2 & 39,95 \\
\hline R. genuflexa & 0,0 & 0,00 & 0,0 & 0,00 & 31,0 & 0,16 & 0,0 & 0,00 & 0,0 & 0,00 & 0,0 & 0,00 & 0,0 & 0,00 & 6,8 & 0,00 & 0,0 & 0,00 & 0,0 & 0,00 \\
\hline T. antarctica & 4,8 & 0,01 & 0,0 & 0,00 & 0,0 & 0,00 & 0,0 & 0,00 & 3,6 & 0,01 & 0,0 & 0,00 & 0,0 & 0,00 & 0,0 & 0,00 & 0,0 & 0,00 & 0,0 & 0,00 \\
\hline T. aspera & 0,0 & 0,00 & 0,0 & 0,00 & 0,0 & 0,00 & 0,0 & 0,00 & 0,0 & 0,00 & 0,0 & 0,00 & 0,0 & 0,00 & 13,9 & 0,01 & 8,4 & 0,02 & 0,0 & 0,00 \\
\hline
\end{tabular}


Apéndice 4.1. Toma de variables ambientales en Peñón de Pesca (Tabla A. 4.1) y fechas de realización de muestreos de los sustratos artificiales para el estudio de la colonización y sucesión de macroalgas bentónicas (Tabla A. 4.2).

Tabla A4.1. Fechas de realización de mediciones de variables ambientales en el sitio de emplazamiento de los sustratos.

\begin{tabular}{|c|c|c|c|c|c|c|c|c|c|}
\hline Fecha & $\frac{\alpha}{\alpha}$ & $\stackrel{4}{3}$ & \ُ & 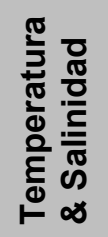 & Fecha & $\frac{\alpha}{\alpha}$ & $\stackrel{4}{3}$ & $\stackrel{m}{3}$ & 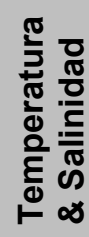 \\
\hline $02 / 01 / 2009$ & + & + & + & + & 02/10/2010 & + & + & & + \\
\hline $07 / 02 / 2009$ & + & + & + & + & $22 / 11 / 2010$ & + & & & + \\
\hline $18 / 03 / 2009$ & + & + & + & + & $24 / 11 / 2010$ & + & + & + & + \\
\hline $13 / 04 / 2009$ & + & + & + & + & $10 / 12 / 2010$ & + & & & + \\
\hline $11 / 05 / 2009$ & + & + & + & + & $23 / 12 / 2010$ & + & & & \\
\hline $22 / 06 / 2009$ & + & + & + & & $24 / 12 / 2010$ & + & & & \\
\hline $12 / 10 / 2009$ & + & + & + & & $28 / 12 / 2010$ & + & & & \\
\hline $13 / 11 / 2009$ & + & + & + & & $15 / 01 / 2011$ & + & & & \\
\hline 24/12/2009 & + & + & + & & $22 / 02 / 2011$ & + & & & + \\
\hline $30 / 12 / 2009$ & + & & & & $28 / 02 / 2011$ & + & + & + & + \\
\hline $07 / 01 / 2010$ & + & + & + & + & $20 / 04 / 2011$ & + & + & + & + \\
\hline $19 / 01 / 2010$ & + & & & & $11 / 05 / 2011$ & + & + & + & + \\
\hline $26 / 01 / 2010$ & + & & & & $17 / 11 / 2011$ & + & + & + & \\
\hline $12 / 02 / 2010$ & + & + & + & + & $24 / 11 / 2011$ & + & & & + \\
\hline $19 / 02 / 2010$ & + & & & & $07 / 12 / 2011$ & + & & & \\
\hline $02 / 03 / 2010$ & + & & & & $20 / 12 / 2011$ & + & + & + & + \\
\hline $18 / 03 / 2010$ & + & + & + & & $04 / 01 / 2012$ & + & & & \\
\hline 09/04/2010 & + & + & + & + & $10 / 01 / 2012$ & + & & & \\
\hline $20 / 04 / 2010$ & + & & & & $12 / 01 / 2012$ & + & & & \\
\hline 05/05/2010 & + & & & + & $19 / 01 / 2012$ & + & + & & + \\
\hline $07 / 05 / 2010$ & + & + & + & + & $30 / 01 / 2012$ & + & & & \\
\hline $06 / 08 / 2010^{+}$ & + & + & + & + & $06 / 02 / 2012$ & + & + & + & + \\
\hline
\end{tabular}

${ }^{*}$ Mediciones realizadas bajo hielo marino ( $30 \mathrm{~cm}$ de espesor). 
Tabla A 4.2. Instalación y fechas de muestreo de sustratos artificiales para el estudio de la colonización y sucesión de macroalgas durante un período de cuatro años. Se resaltan los muestreos realizados adicionalmente en condiciones de laboratorio se sombrean.

\begin{tabular}{|c|c|c|}
\hline & $\begin{array}{c}\text { Tiempo de } \\
\text { colonización } \\
\text { (meses) }\end{array}$ & Fecha \\
\hline \multirow{2}{*}{ 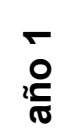 } & Instalación & 17 al 26/02/2008 \\
\hline & 12 & $26 / 02 / 2009$ \\
\hline \multirow{7}{*}{$\begin{array}{l}N \\
\substack{c \\
\tilde{N}}\end{array}$} & 15 & $20 / 05 / 2009$ \\
\hline & 18 & $18 / 08 / 2009^{*}$ \\
\hline & 20 & $20 / 10 / 2009$ \\
\hline & 21 & $05 / 11 / 2009$ \\
\hline & 22 & $19 / 12 / 2009$ \\
\hline & 23 & $18 / 01 / 2010$ \\
\hline & 24 & $15 / 02 / 2010$ \\
\hline \multirow{11}{*}{ 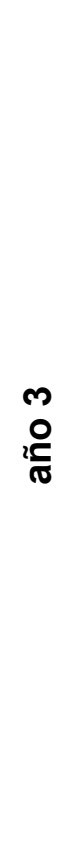 } & 25 & $18 / 03 / 2010$ \\
\hline & 26 & 04/09/2010 \\
\hline & 27 & $11 / 05 / 2010$ \\
\hline & 28 & $23 / 06 / 2010$ \\
\hline & 29 & $13 / 07 / 2010$ \\
\hline & 30 & 07/08/2010 \\
\hline & 31 & $17 / 09 / 2010$ \\
\hline & 32 & 05/10/2010 \\
\hline & 33 & $29 / 11 / 2010$ \\
\hline & 35 & $24 / 01 / 2010$ \\
\hline & 36 & $12 / 02 / 2011$ \\
\hline \multirow{5}{*}{ 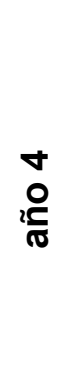 } & 38 & $14 / 04 / 2011$ \\
\hline & 39 & $11 / 05 / 2011$ \\
\hline & 45 & $16 / 11 / 2011$ \\
\hline & 47 & $20 / 01 / 2012$ \\
\hline & 48 & 08/02/2012 \\
\hline
\end{tabular}


Apéndice 5.1. Resultados de los análisis de covarianza (ANCOVA) realizados para evaluar los efectos del pastoreo (sin clausura vs. con clausura) y la irradiancia (PAB, PA y $P)$ sobre las variables analizadas (A5.1.1-A5.1.16). En negrita se indican los resultados significativos $(p<0,05)$.

\begin{tabular}{|c|c|c|c|c|c|}
\hline \multicolumn{6}{|c|}{ A5.1.1. Biomasa $\left(\mathrm{mg} \mathrm{cm}^{-2}\right)$} \\
\hline & SS & gl & MS & $\mathbf{F}$ & $\mathbf{p}$ \\
\hline Intersección & 92.781 & 1 & 92.781 & 0.80019 & 0.373789 \\
\hline Tiempo & 579.501 & 1 & 579.501 & 4.99791 & 0.028237 \\
\hline Pastoreo & 1307.621 & 1 & 1307.621 & 11.27759 & 0.001215 \\
\hline Irradiancia & 272.824 & 2 & 136.412 & 1.17649 & 0.313772 \\
\hline Pastoreo x Irradiancia & 184.865 & 2 & 92.433 & 0.79719 & 0.454232 \\
\hline Error & 9043.999 & 78 & 115,949 & & \\
\hline \multicolumn{6}{|c|}{ A5.1.2. Cobertura Total Macroscópica (\%) } \\
\hline & SS & gl & MS & $\mathbf{F}$ & $p$ \\
\hline Intersección & 15704,58 & 1 & 15704,58 & 15,21753 & 0,000204 \\
\hline Tiempo & 291,14 & 1 & 291,14 & 0,28211 & 0,596853 \\
\hline Pastoreo & 10292,72 & 1 & 10292,72 & 9,97351 & 0,002269 \\
\hline Irradiancia & 2888,07 & 2 & 1444,04 & 1,39925 & 0,252985 \\
\hline Pastoreo x Irradiancia & 533,55 & 2 & 266,77 & 0,2585 & 0,772876 \\
\hline Error & 79464,43 & 77 & 1032,01 & & \\
\hline
\end{tabular}

A5.1.3. Cobertura Macroscópica de Diatomeas (\%)

\begin{tabular}{lrrrrr}
\hline & SS & gl & \multicolumn{1}{c}{ MS } & \multicolumn{1}{c}{ F } & p \\
\hline Intersección & 14022,40 & 1 & 14022,40 & 20,89871 & 0,000018 \\
\hline Tiempo & 1863,93 & 1 & 1863,93 & 2,77796 & 0,099633 \\
\hline Pastoreo & 13552,86 & 1 & 13552,86 & 20,19893 & $\mathbf{0 , 0 0 0 0 2 4}$ \\
\hline Irradiancia & 1790,76 & 2 & 895,38 & 1,33446 & 0,269321 \\
\hline Pastoreo x Irradiancia & 217,18 & 2 & 108,59 & 0,16184 & 0,850864 \\
\hline Error & 51664,65 & 77 & 670,97 & &
\end{tabular}

\section{A5.1.4. Cobertura Macroscópica de Clorofitas (\%)}

\begin{tabular}{|c|c|c|c|c|c|}
\hline & SS & gl & MS & $\mathbf{F}$ & $\mathbf{p}$ \\
\hline Intersección & 44,44 & 1 & 44,4433 & 0,191324 & 0,663026 \\
\hline Tiempo & 721,94 & 1 & 721,9447 & 3,107897 & 0,081830 \\
\hline Pastoreo & 218,30 & 1 & 218,3037 & 0,939775 & 0,335332 \\
\hline Irradiancia & 175,83 & 2 & 87,9153 & 0,378466 & 0,686162 \\
\hline Pastoreo x Irradiancia & 1418,78 & 2 & 709,3917 & 3,053857 & 0,052856 \\
\hline Error & 18118,91 & 78 & 232,2937 & & \\
\hline
\end{tabular}

A5.1.5. Cobertura Microscópica de Diatomeas (\%)

\begin{tabular}{lrrrrr}
\hline & \multicolumn{1}{c}{ SS } & gl & \multicolumn{1}{c}{ MS } & \multicolumn{1}{c}{ F } & \multicolumn{1}{c}{$\mathbf{p}$} \\
\hline Intersección & 7191,89 & 1 & 7191,89 & 16,76510 & 0,000104 \\
\hline Tiempo & 371,29 & 1 & 371,29 & 0,86552 & 0,355105 \\
\hline Pastoreo & 11504,27 & 1 & 11504,27 & 26,81771 & $\mathbf{0 , 0 0 0 0 0 2}$ \\
\hline Irradiancia & 16,74 & 2 & 8,37 & 0,01951 & 0,980688 \\
\hline Pastoreo x Irradiancia & 1122,09 & 2 & 561,04 & 1,30786 & 0,276337 \\
\hline Error & 33031,47 & 77 & 428,98 & & \\
\hline
\end{tabular}


Apéndice 5.1. Continuación. Resultados de los análisis de covarianza (ANCOVA) realizados para evaluar los efectos del pastoreo (sin clausura vs. con clausura) y la irradiancia (PAB, PA y $\mathrm{P}$ ) sobre las variables analizadas (A5.1.1-A5.1.16). En negrita se indican los resultados significativos $(p<0,05)$.

\begin{tabular}{|c|c|c|c|c|c|}
\hline \multicolumn{6}{|c|}{ A5.1.6. Cobertura Microscópica de Clorofitas (\%) } \\
\hline & SS & gl & MS & $\mathbf{F}$ & p \\
\hline Intersección & 6,1993 & 1 & 6,19928 & 0,509897 & 0,477315 \\
\hline Tiempo & 26,4297 & 1 & 26,42968 & $2,173,869$ & 0,144398 \\
\hline Pastoreo & 0,9005 & 1 & 0,90052 & 0,074069 & 0,786221 \\
\hline Irradiancia & 3,4460 & 2 & 1,72298 & 0,141717 & 0,868090 \\
\hline Pastoreo x Irradiancia & 35,5557 & 2 & 17,77787 & 1,462248 & 0,237996 \\
\hline Error & 94,83163 & 78 & 12,15790 & & \\
\hline \multicolumn{6}{|c|}{ A5.1.7. Cobertura Microscópica de Rodofitas (\%) } \\
\hline & SS & gl & MS & $\mathbf{F}$ & $\mathbf{p}$ \\
\hline Intersección & 0,035527 & 1 & 0,035527 & 4,855499 & 0,030508 \\
\hline Tiempo & 0,003000 & 1 & 0,003000 & 0,410006 & 0,523843 \\
\hline Pastoreo & 0,029941 & 1 & 0,029941 & 4,092020 & 0,046513 \\
\hline Irradiancia & 0,066771 & 2 & 0,033385 & 4,562814 & 0,013366 \\
\hline Pastoreo x Irradiancia & 0,008421 & 2 & 0,004211 & 0,575471 & 0,564810 \\
\hline Error & 0,570713 & 78 & 0,007317 & & \\
\hline \multicolumn{6}{|c|}{ A5.1.8. Riqueza de la comunidad a nivel microscópico (S) } \\
\hline & SS & gl & MS & $\mathbf{F}$ & p \\
\hline Intersección & 90,53375 & 1 & 90,53375 & 126,1447 & 0,000000 \\
\hline Tiempo & 0,10252 & 1 & 0,10252 & 0,1428 & 0,706498 \\
\hline Pastoreo & 1,11268 & 1 & 1,11268 & 1,5503 & 0,216813 \\
\hline Irradiancia & 2,97548 & 2 & 1,48774 & 2,0729 & 0,132693 \\
\hline Pastoreo x Irradiancia & 1,10393 & 2 & 0,55197 & 0,7691 & 0,466922 \\
\hline Error & 55,98040 & 78 & 0,71770 & & \\
\hline
\end{tabular}

A5.1.9. Equitatividad de la comunidad a nivel microscópico (J)

\begin{tabular}{lcrrrr}
\hline & SS & gl & MS & F & p \\
\hline Intersección & 0,872235 & 1 & 0,872235 & 16,99233 & 0,000095 \\
\hline Tiempo & 0,105358 & 1 & 0,105358 & 2,05252 & 0,156055 \\
\hline Pastoreo & 1,274822 & 1 & 1,274822 & 24,83527 & $\mathbf{0 , 0 0 0 0 0 4}$ \\
\hline Irradiancia & 0,016962 & 2 & 0,008481 & 0,16522 & 0,848009 \\
\hline Pastoreo x Irradiancia & 0,060166 & 2 & 0,030083 & 0,58606 & 0,559012 \\
\hline Error & 3,901165 & 76 & 0,051331 & &
\end{tabular}

A5.1.10. Diversidad de la comunidad a nivel microscópico (H)

\begin{tabular}{|c|c|c|c|c|c|}
\hline & SS & gl & MS & $\mathbf{F}$ & $\mathbf{p}$ \\
\hline Intersección & 0,828246 & 1 & 0,828246 & 14,30170 & 0,000303 \\
\hline Tiempo & 0,121240 & 1 & 0,121240 & 2,09350 & 0,151934 \\
\hline Pastoreo & 0,915363 & 1 & 0,915363 & 15,80599 & 0,000156 \\
\hline Irradiancia & 0,082517 & 2 & 0,041258 & 0,71243 & 0,493616 \\
\hline Pastoreo x Irradiancia & 0,140882 & 2 & 0,070441 & 1,21634 & 0,301872 \\
\hline Error & 4,517171 & 78 & 0,057912 & & \\
\hline
\end{tabular}


Apéndice 5.1. Continuación. Resultados de los análisis de covarianza (ANCOVA) realizados para evaluar los efectos del pastoreo (sin clausura vs. con clausura) y la irradiancia (PAB, PA y $P$ ) sobre las variables analizadas (A5.1.1-A5.1.16). En negrita se indican los resultados significativos $(p<0,05)$.

\begin{tabular}{lcrccc}
\hline A5.1.11. & Densidad Total de diatomeas (células $\mathbf{~ c m}^{-\mathbf{2}}$ ) & & \\
\hline & SS & gl & MS & F & p \\
\hline Intersección & $1,49 \mathrm{E}+12$ & 1 & $1,49 \mathrm{E}+12$ & $8,248,792$ & 0,005234 \\
\hline Tiempo & $1,45 \mathrm{E}+11$ & 1 & $1,45 \mathrm{E}+11$ & 0,802042 & 0,373204 \\
\hline Pastoreo & $7,38 \mathrm{E}+11$ & 1 & $7,38 \mathrm{E}+11$ & 4,087001 & $\mathbf{0 , 0 4 6 6 0 0}$ \\
\hline Irradiancia & $1,74 \mathrm{E}+11$ & 2 & $8,71 \mathrm{E}+10$ & 0,482602 & 0,618983 \\
\hline Pastoreo x Irradiancia & $7,41 \mathrm{E}+11$ & 2 & $3,70 \mathrm{E}+11$ & 2,052125 & 0,135255 \\
\hline Error & $1,43 \mathrm{E}+13$ & 79 & $1,80 \mathrm{E}+11$ & &
\end{tabular}

A5.1.12. Densidad de Células Vivas de diatomeas (células $\mathrm{cm}-2$ )

\begin{tabular}{lccccc}
\hline & SS & gl & MS & F & p \\
\hline Intersección & $1,39 \mathrm{E}+12$ & 1 & $1,39 \mathrm{E}+12$ & 8,118287 & 0,005586 \\
\hline Tiempo & $1,25 \mathrm{E}+11$ & 1 & $1,25 \mathrm{E}+11$ & 0,730382 & 0,395344 \\
\hline Pastoreo & $6,07 \mathrm{E}+11$ & 1 & $6,07 \mathrm{E}+11$ & 3,543476 & 0,063462 \\
\hline Irradiancia & $1,54 \mathrm{E}+11$ & 2 & $7,71 \mathrm{E}+10$ & 0,449992 & 0,639258 \\
\hline Pastoreo x Irradiancia & $7,25 \mathrm{E}+11$ & 2 & $3,62 \mathrm{E}+11$ & 2,114110 & 0,127521 \\
\hline Error & $1,35 \mathrm{E}+13$ & 79 & $1,71 \mathrm{E}+11$ & &
\end{tabular}

A5.1.13. Densidad de Células Muertas de diatomeas (células $\mathrm{cm}^{-2}$ )

\begin{tabular}{lcrrrr}
\hline & SS & gl & MS & F & p \\
\hline Intersección & $1,67 \mathrm{E}+09$ & 1 & $1,67 \mathrm{E}+09$ & 4,35070 & 0,040221 \\
\hline Tiempo & $7,15 \mathrm{E}+08$ & 1 & $7,15 \mathrm{E}+08$ & 1,86546 & 0,175872 \\
\hline Pastoreo & $6,36 \mathrm{E}+09$ & 1 & $6,36 \mathrm{E}+09$ & $\mathbf{1 6 , 5 8 7 0 6}$ & $\mathbf{0 , 0 0 0 1 1 0}$ \\
\hline Irradiancia & $6,24 \mathrm{E}+08$ & 2 & $3,12 \mathrm{E}+08$ & 0,81444 & 0,446570 \\
\hline Pastoreo x Irradiancia & $1,23 \mathrm{E}+08$ & 2 & $6,17 \mathrm{E}+07$ & 0,16090 & 0,851658 \\
\hline Error & $3,03 \mathrm{E}+10$ & 79 & $3,83 \mathrm{E}+08$ & 4,35070 &
\end{tabular}

A5.1.14. Riqueza de diatomeas (S)

\begin{tabular}{|c|c|c|c|c|c|}
\hline & SS & gl & MS & $\mathbf{F}$ & $\mathbf{p}$ \\
\hline Intersección & 425,8967 & 1 & 425,8967 & 134,8912 & 0,000000 \\
\hline Tiempo & 47,0418 & 1 & 47,0418 & 14,8992 & 0,000231 \\
\hline Pastoreo & 16,2531 & 1 & 16,2531 & 5,1477 & 0,026005 \\
\hline Irradiancia & 13,1492 & 2 & 6,5746 & 2,0823 & 0,131428 \\
\hline Pastoreo x Irradiancia & 0,6307 & 2 & 0,3154 & 0,0999 & 0,905060 \\
\hline Error & 249,4294 & 79 & 3,1573 & & \\
\hline
\end{tabular}

A5.1.15. Equitatividad de diatomeas (J)

\begin{tabular}{llrrrr}
\hline & SS & gl & MS & F & p \\
\hline Intersección & 1,564786 & 1 & 1,564786 & 127,6938 & 0,000000 \\
\hline Tiempo & 0,241401 & 1 & 0,241401 & 19,6995 & 0,000029 \\
\hline Pastoreo & 0,022247 & 1 & 0,022247 & 1,8155 & 0,181705 \\
\hline Irradiancia & 0,048892 & 2 & 0,024446 & 1,9949 & 0,142819 \\
\hline Pastoreo x Irradiancia & 0,024991 & 2 & 0,012495 & 1,0197 & 0,365408 \\
\hline Error & 0,968082 & 79 & 0,012254 & & \\
\hline
\end{tabular}


Apéndice 5.1. Continuación. Resultados de los análisis de covarianza (ANCOVA) realizados para evaluar los efectos del pastoreo (sin clausura vs. con clausura) y la irradiancia (PAB, PA y $\mathrm{P}$ ) sobre las variables analizadas (A5.1.1-A5.1.16). En negrita se indican los resultados significativos $(p<0,05)$.

A5.1.16. Diversidad de diatomeas $(\mathrm{H})$

\begin{tabular}{|c|c|c|c|c|c|}
\hline & SS & gl & MS & $\mathbf{F}$ & p \\
\hline Intersección & 4,585780 & 1 & 4,585780 & 61,23921 & 0,000000 \\
\hline Tiempo & 2,293126 & 1 & 2,293126 & 30,62276 & 0,000000 \\
\hline Pastoreo & 0,291033 & 1 & 0,291033 & 3,88650 & 0,052177 \\
\hline Irradiancia & 0,453822 & 2 & 0,226911 & 3,03020 & 0,053956 \\
\hline Pastoreo $\mathrm{x}$ Irradiancia & 0,132659 & 2 & 0,066329 & 0,88577 & 0,416450 \\
\hline Error & 5,915762 & 79 & 0,074883 & & \\
\hline
\end{tabular}


Apéndice 5.2. Densidad (nro. de células $\mathrm{cm}^{2}$ ) y abundancia relativa porcentual de los taxa de diatomeas hallados luego de $23,40,59$ y 73 días de colonización (a-d, respectivamente), para los tratamientos de pastoreo (sin clausura y con clausura) e irradiancia (PAB, PA y P), y para ambos tratamientos control. PAB: PAR + UV-A + UV-B, PA: PAR + UV-A, P: sólo PAR, mc: media clausura, rd: radiación solar directa.

\begin{tabular}{|c|c|c|c|c|c|c|}
\hline \multirow[t]{3}{*}{ a) 23 días } & \multicolumn{6}{|c|}{ Sin clausura } \\
\hline & \multicolumn{2}{|l|}{ PAB } & \multicolumn{2}{|l|}{ PA } & \multicolumn{2}{|l|}{$\mathrm{P}$} \\
\hline & densidad & $\%$ & densidad & $\%$ & densidad & $\%$ \\
\hline Achnanthes brevipes & 65,9 & 0,07 & 288,3 & 0,15 & 236,2 & 0,35 \\
\hline Amphora marina & 272,3 & 0,28 & 464,8 & 0,24 & 27,3 & 0,04 \\
\hline Brandinia mosimanniae & 0,0 & 0,00 & 0,0 & 0,00 & 0,0 & 0,00 \\
\hline Cocconeis antiqua & 0,0 & 0,00 & 0,0 & 0,00 & 0,0 & 0,00 \\
\hline C. fasciolata/costata & 180,3 & 0,18 & 0,0 & 0,00 & 88,1 & 0,13 \\
\hline C. melchiori/dallmanni/melchior & 92,0 & 0,09 & 0,0 & 0,00 & 60,8 & 0,09 \\
\hline Diploneis smithii & 0,0 & 0,00 & 0,0 & 0,00 & 0,0 & 0,00 \\
\hline Entomoneis sp. & 92,0 & 0,09 & 0,0 & 0,00 & 0,0 & 0,00 \\
\hline Entopyla ocellata & 0,0 & 0,00 & 0,0 & 0,00 & 0,0 & 0,00 \\
\hline Fragilaria islandica/striatula & 1930,8 & 1,96 & 3716,3 & 1,91 & 3787,7 & 5,57 \\
\hline Grammatophora arctica & 0,0 & 0,00 & 0,0 & 0,00 & 0,0 & 0,00 \\
\hline Licmophora antarctica & 65,9 & 0,07 & 165,4 & 0,08 & 27,3 & 0,04 \\
\hline L. decora & 88,3 & 0,09 & 243,5 & 0,13 & 0,0 & 0,00 \\
\hline L. gracilis & 686,6 & 0,70 & 464,8 & 0,24 & 292,5 & 0,43 \\
\hline Navicula directa & 0,0 & 0,00 & 0,0 & 0,00 & 148,2 & 0,22 \\
\hline N. glaciei & 978,0 & 0,99 & 3021,7 & 1,55 & 170,1 & 0,25 \\
\hline N. perminuta & 81843,5 & 82,96 & 165738,7 & 85,13 & 49552,3 & 72,86 \\
\hline Nitzschia pellucida & 0,0 & 0,00 & 0,0 & 0,00 & 0,0 & 0,00 \\
\hline Pleurosigma sp. & 0,0 & 0,00 & 0,0 & 0,00 & 27,3 & 0,04 \\
\hline Pseudogomphonema kamtschaticum & 12353,0 & 12,52 & 20576,0 & 10,57 & 13594,4 & 19,99 \\
\hline Trachyneis aspera & 0,0 & 0,00 & 0,0 & 0,00 & 0,0 & 0,00 \\
\hline
\end{tabular}

\begin{tabular}{rrrrrr}
\hline \multicolumn{5}{c}{ Con clausura } \\
\hline PAB & \multicolumn{1}{c}{ PA } & P \\
\hline densidad & $\%$ & densidad & $\%$ & densidad & $\%$ \\
\hline 1832,5 & 0,41 & 1113,7 & 0,21 & 2101,9 & 0,38 \\
589,6 & 0,13 & 727,7 & 0,13 & 0,0 & 0,00 \\
726,5 & 0,16 & 0,0 & 0,00 & 612,1 & 0,11 \\
0,0 & 0,00 & 727,7 & 0,13 & 0,0 & 0,00 \\
1461,7 & 0,33 & 4548,2 & 0,84 & 3245,2 & 0,58 \\
0,0 & 0,00 & 3024,9 & 0,56 & 1727,7 & 0,31 \\
0,0 & 0,00 & 1455,4 & 0,27 & 0,0 & 0,00 \\
0,0 & 0,00 & 0,0 & 0,00 & 0,0 & 0,00 \\
0,0 & 0,00 & 0,0 & 0,00 & 1081,7 & 0,19 \\
92692,0 & 20,70 & 73512,1 & 13,61 & 136364,7 & 24,45 \\
0,0 & 0,00 & 659,7 & 0,12 & 0,0 & 0,00 \\
2374,2 & 0,53 & 4889,9 & 0,91 & 9454,8 & 1,70 \\
1947,1 & 0,43 & 3341,1 & 0,62 & 7986,4 & 1,43 \\
653,4 & 0,15 & 3659,1 & 0,68 & 2577,8 & 0,46 \\
549,2 & 0,12 & 0,0 & 0,00 & 0,0 & 0,00 \\
2560,2 & 0,57 & 1885,7 & 0,35 & 1081,7 & 0,19 \\
262036,6 & 58,52 & 354765,6 & 65,69 & 307210,9 & 55,08 \\
0,0 & 0,00 & 0,0 & 0,00 & 1292,0 & 0,23 \\
0,0 & 0,00 & 0,0 & 0,00 & 0,0 & 0,00 \\
80366,6 & 17,95 & 85708,9 & 15,87 & 82818,7 & 14,85 \\
0,0 & 0,00 & 0,0 & 0,00 & 204,0 & 0,04 \\
& & & & & \\
\hline
\end{tabular}

\begin{tabular}{rcrr}
\hline \multicolumn{4}{c}{ Controles } \\
$\mathrm{mc}$ & \multicolumn{3}{c}{$\mathrm{rd}$} \\
\hline densidad & $\%$ & densidad & $\%$ \\
\hline 227,3 & 0,13 & 1333,1 & 0,86 \\
0,0 & 0,00 & 129,4 & 0,08 \\
0,0 & 0,00 & 0,0 & 0,00 \\
209,9 & 0,12 & 0,0 & 0,00 \\
140,4 & 0,08 & 642,9 & 0,41 \\
0,0 & 0,00 & 425,3 & 0,27 \\
0,0 & 0,00 & 0,0 & 0,00 \\
0,0 & 0,00 & 0,0 & 0,00 \\
0,0 & 0,00 & 0,0 & 0,00 \\
13738,3 & 7,96 & 6483,5 & 4,17 \\
0,0 & 0,00 & 0,0 & 0,00 \\
0,0 & 0,00 & 0,0 & 0,00 \\
75,8 & 0,04 & 687,3 & 0,44 \\
1576,6 & 0,91 & 639,6 & 0,41 \\
140,4 & 0,08 & 166,6 & 0,11 \\
650,6 & 0,38 & 2310,2 & 1,49 \\
124859,8 & 72,35 & 113012,7 & 72,64 \\
0,0 & 0,00 & 0,0 & 0,00 \\
0,0 & 0,00 & 0,0 & 0,00 \\
30961,9 & 17,94 & 29737,9 & 19,12 \\
0,0 & 0,00 & 0,0 & 0,00 \\
& & &
\end{tabular}




\begin{tabular}{|c|c|c|c|c|c|c|c|c|c|c|c|c|c|c|c|c|}
\hline \multirow[t]{3}{*}{ b) 40 días } & \multicolumn{6}{|c|}{ Sin clausura } & \multicolumn{6}{|c|}{ Con clausura } & \multicolumn{4}{|c|}{ Controles } \\
\hline & \multicolumn{2}{|l|}{$\mathrm{PAB}$} & \multicolumn{2}{|l|}{$\mathrm{PA}$} & \multicolumn{2}{|l|}{$\mathrm{P}$} & \multicolumn{2}{|l|}{$\mathrm{PAB}$} & \multicolumn{2}{|l|}{$\mathrm{PA}$} & \multicolumn{2}{|l|}{$\mathrm{P}$} & \multicolumn{2}{|l|}{$\mathrm{mc}$} & \multicolumn{2}{|l|}{$\mathrm{rd}$} \\
\hline & densidad & $\%$ & densidad & $\%$ & densidad & $\%$ & densidad & $\%$ & densidad & $\%$ & densidad & $\%$ & densidad & $\%$ & densidad & $\%$ \\
\hline Achnanthes brevipes & 14110,5 & 2,19 & 43871,2 & 7,54 & 29866,8 & 17,21 & 3428,5 & 0,64 & 0,0 & 0,00 & 10890,9 & 1,13 & 7193,8 & 1,00 & 20464,1 & 3,28 \\
\hline Amphora marina & 0,0 & 0,00 & 0,0 & 0,00 & 15,7 & 0,01 & 0,0 & 0,00 & 0,0 & 0,00 & 0,0 & 0,00 & 0,0 & 0,00 & 0,0 & 0,00 \\
\hline Cocconeis antiqua & 0,0 & 0,00 & 11,7 & 0,00 & 524,8 & 0,30 & 701,5 & 0,13 & 773,7 & 0,10 & 0,0 & 0,00 & 9,9 & 0,00 & 0,0 & 0,00 \\
\hline C. fasciolata/costata & 1406,1 & 0,22 & 35,2 & 0,01 & 758,3 & 0,44 & 654,4 & 0,12 & 6040,4 & 0,78 & 674,5 & 0,07 & 6,6 & 0,00 & 294,3 & 0,05 \\
\hline C. melchiori/dallmanni/melchior & 0,0 & 0,00 & 516,6 & 0,09 & 0,0 & 0,00 & 723,7 & 0,14 & 0,0 & 0,00 & 1465,8 & 0,15 & 792,6 & 0,11 & 132,6 & 0,02 \\
\hline Entomoneis sp. & 0,0 & 0,00 & 0,0 & 0,00 & 0,0 & 0,00 & 0,0 & 0,00 & 0,0 & 0,00 & 0,0 & 0,00 & 1133,0 & 0,16 & 0,0 & 0,00 \\
\hline Fragilaria islandica/striatula & 241045,2 & 37,37 & 73989,1 & 12,71 & 22077,2 & 12,72 & 312148,1 & 58,65 & 487827,7 & 63,39 & 564697,5 & 58,48 & 442234,7 & 61,27 & 174821,6 & 28,03 \\
\hline Licmophora antarctica & 8539,6 & 1,32 & 18562,9 & 3,19 & 2704,7 & 1,56 & 4605,3 & 0,87 & 15552,1 & 2,02 & 11707,6 & 1,21 & 8442,9 & 1,17 & 4744,4 & 0,76 \\
\hline L. decora & 1667,8 & 0,26 & 4854,4 & 0,83 & 1574,3 & 0,91 & 4020,5 & 0,76 & 7051,0 & 0,92 & 13912,4 & 1,44 & 12934,3 & 1,79 & 1678,2 & 0,27 \\
\hline L. gracilis & 4635,8 & 0,72 & 1138,8 & 0,20 & 537,2 & 0,31 & 2181,2 & 0,41 & 3162,3 & 0,41 & 4916,0 & 0,51 & 1152,9 & 0,16 & 2837,9 & 0,45 \\
\hline Navicula directa & 1667,8 & 0,26 & 23,5 & 0,00 & 200,8 & 0,12 & 2639,7 & 0,50 & 0,0 & 0,00 & 0,0 & 0,00 & 1151,8 & 0,16 & 155,7 & 0,02 \\
\hline N. glaciei & 494,3 & 0,08 & 6199,2 & 1,07 & 0,0 & 0,00 & 2228,4 & 0,42 & 0,0 & 0,00 & 87014,7 & 9,01 & 1133,0 & 0,16 & 0,0 & 0,00 \\
\hline N. perminuta & 287172,6 & 44,52 & 386074,7 & 66,34 & 86282,7 & 49,72 & 125426,2 & 23,57 & 172299,6 & 22,39 & 194550,7 & 20,15 & 179385,9 & 24,85 & 362255,6 & 58,08 \\
\hline Pseudogomphonema kamtschaticum & 84233,4 & 13,06 & 46708,2 & 8,03 & 28985,6 & 16,70 & 73432,5 & 13,80 & 76853,7 & 9,99 & 75818,9 & 7,85 & 66191,5 & 9,17 & 56357,4 & 9,04 \\
\hline Rhoicosphenia genuflexa & 0,0 & 0,00 & 0,0 & 0,00 & 23,5 & 0,01 & 0,0 & 0,00 & 0,0 & 0,00 & 0,0 & 0,00 & 0,0 & 0,00 & 0,0 & 0,00 \\
\hline
\end{tabular}




\begin{tabular}{|c|c|c|c|c|c|c|c|c|c|c|c|c|c|c|c|c|}
\hline \multirow[t]{3}{*}{ c) 59 días } & \multicolumn{6}{|c|}{ Sin clausura } & \multicolumn{6}{|c|}{ Con clausura } & \multicolumn{4}{|c|}{ Controles } \\
\hline & \multicolumn{2}{|l|}{ PAB } & \multicolumn{2}{|l|}{ PA } & \multicolumn{2}{|l|}{$\mathrm{P}$} & \multicolumn{2}{|l|}{ PAB } & \multicolumn{2}{|l|}{ PA } & \multicolumn{2}{|l|}{$\mathrm{P}$} & \multicolumn{2}{|l|}{$\mathrm{mc}$} & \multicolumn{2}{|l|}{ rd } \\
\hline & densidad & $\%$ & densidad & $\%$ & densidad & $\%$ & densidad & $\%$ & densidad & $\%$ & densidad & $\%$ & densidad & $\%$ & densidad & $\%$ \\
\hline Achnanthes brevipes & 72785,6 & 9,84 & 799,0 & 0,34 & 1195,0 & 3,06 & 6017,4 & 1,85 & 4057,1 & 1,77 & 3683,1 & 0,93 & 19101,0 & 3,89 & 6406,0 & 4,40 \\
\hline Amphora marina & 0,0 & 0,00 & 0,0 & 0,00 & 39,8 & 0,10 & 0,0 & 0,00 & 0,0 & 0,00 & 0,0 & 0,00 & 0,0 & 0,00 & 0,0 & 0,00 \\
\hline Brandinia mosimanniae & 0,0 & 0,00 & 0,0 & 0,00 & 0,0 & 0,00 & 296,3 & 0,09 & 0,0 & 0,00 & 0,0 & 0,00 & 940,2 & 0,19 & 0,0 & 0,00 \\
\hline Cocconeis antiqua & 1488,1 & 0,20 & 8,2 & 0,00 & 91,7 & 0,23 & 962,5 & 0,30 & 66,1 & 0,03 & 311,1 & 0,08 & 974,0 & 0,20 & 21,4 & 0,01 \\
\hline C. fasciolata/costata & 2167,2 & 0,29 & 1414,5 & 0,60 & 500,5 & 1,28 & 2626,1 & 0,81 & 389,2 & 0,17 & 814,6 & 0,21 & 101,6 & 0,02 & 233,7 & 0,16 \\
\hline C. melchiori/dallmanni/melchior & 231,1 & 0,03 & 106,8 & 0,05 & 0,0 & 0,00 & 0,0 & 0,00 & 0,0 & 0,00 & 0,0 & 0,00 & 0,0 & 0,00 & 0,0 & 0,00 \\
\hline Entomoneis sp. & 462,3 & 0,06 & 0,0 & 0,00 & 0,0 & 0,00 & 0,0 & 0,00 & 310,5 & 0,14 & 0,0 & 0,00 & 0,0 & 0,00 & 0,0 & 0,00 \\
\hline Entopyla ocellata & 0,0 & 0,00 & 618,0 & 0,26 & 197,8 & 0,51 & 701,1 & 0,22 & 66,1 & 0,03 & 0,0 & 0,00 & 33,9 & 0,01 & 0,0 & 0,00 \\
\hline Fragilaria islandica/striatula & 172501,5 & 23,33 & 5518,4 & 2,35 & 2035,2 & 5,21 & 148902,9 & 45,69 & 50356,2 & 21,99 & 56790,2 & 14,37 & 172243,2 & 35,07 & 926,7 & 0,64 \\
\hline Licmophora antarctica & 14968,2 & 2,02 & 6032,1 & 2,57 & 114,3 & 0,29 & 3544,2 & 1,09 & 1410,9 & 0,62 & 7498,3 & 1,90 & 13800,8 & 2,81 & 675,8 & 0,46 \\
\hline L. decora & 1343,8 & 0,18 & 1203,1 & 0,51 & 0,0 & 0,00 & 1628,7 & 0,50 & 157,3 & 0,07 & 2823,4 & 0,71 & 628,4 & 0,13 & 0,0 & 0,00 \\
\hline L. gracilis & 15909,6 & 2,15 & 5112,2 & 2,18 & 221,8 & 0,57 & 1475,8 & 0,45 & 785,9 & 0,34 & 4758,6 & 1,20 & 3867,3 & 0,79 & 2259,6 & 1,55 \\
\hline Navicula directa & 9911,2 & 1,34 & 2270,7 & 0,97 & 152,6 & 0,39 & 883,2 & 0,27 & 1887,3 & 0,82 & 3944,0 & 1,00 & 5397,0 & 1,10 & 959,0 & 0,66 \\
\hline N. glaciei & 462,3 & 0,06 & 0,0 & 0,00 & 0,0 & 0,00 & 0,0 & 0,00 & 372,5 & 0,16 & 1001,9 & 0,25 & 0,0 & 0,00 & 379,8 & 0,26 \\
\hline N. perminuta & 342270,0 & 46,28 & 185885,2 & 79,23 & 21256,2 & 54,43 & 64569,3 & 19,81 & 122963,7 & 53,70 & 180085,5 & 45,56 & 145406,7 & 29,61 & 108877,0 & 74,70 \\
\hline Pleurosigma sp. & 0,0 & 0,00 & 0,0 & 0,00 & 62,4 & 0,16 & 0,0 & 0,00 & 0,0 & 0,00 & 0,0 & 0,00 & 33,9 & 0,01 & 126,6 & 0,09 \\
\hline Pseudogomphonema kamtschaticum & 105012,4 & 14,20 & 25656,2 & 10,94 & 13182,3 & 33,76 & 93648,6 & 28,73 & 45869,8 & 20,03 & 133277,7 & 33,72 & 128514,8 & 26,17 & 24756,9 & 16,99 \\
\hline Rhoicosphenia genuflexa & 0,0 & 0,00 & 0,0 & 0,00 & 0,0 & 0,00 & 0,0 & 0,00 & 0,0 & 0,00 & 311,1 & 0,08 & 33,9 & 0,01 & 126,6 & 0,09 \\
\hline Thalassiosira antarctica & 0,0 & 0,00 & 0,0 & 0,00 & 0,0 & 0,00 & 666,2 & 0,20 & 310,5 & 0,14 & 0,0 & 0,00 & 0,0 & 0,00 & 0,0 & 0,00 \\
\hline
\end{tabular}




\begin{tabular}{|c|c|c|c|c|c|c|c|c|c|c|c|c|c|c|c|c|}
\hline \multirow[t]{3}{*}{ d) 73 días } & \multicolumn{6}{|c|}{ Sin clausura } & \multicolumn{6}{|c|}{ Con clausura } & \multicolumn{4}{|c|}{ Controles } \\
\hline & \multirow{2}{*}{$\frac{\text { PAB }}{\text { densidad }}$} & \multicolumn{3}{|c|}{ PA } & \multicolumn{2}{|l|}{$\mathrm{P}$} & \multicolumn{2}{|l|}{ PAB } & \multicolumn{2}{|l|}{ PA } & \multicolumn{2}{|l|}{$\mathrm{P}$} & \multicolumn{2}{|l|}{$\mathrm{mc}$} & \multicolumn{2}{|l|}{ rd } \\
\hline & & $\%$ & densidad & $\%$ & densidad & $\%$ & densidad & $\%$ & densidad & $\%$ & densidad & $\%$ & densidad & $\%$ & densidad & $\%$ \\
\hline Achnanthes brevipes & 163616,1 & 24,54 & 8682,8 & 1,82 & 179302,0 & 33,38 & 2482,3 & 0,48 & 2296,0 & 0,34 & 8200,0 & 2,62 & 9079,4 & 1,65 & 18489,0 & 9,31 \\
\hline Amphora marina & 0,0 & 0,00 & 0,0 & 0,00 & 0,0 & 0,00 & 0,0 & 0,00 & 0,0 & 0,00 & 0,0 & 0,00 & 601,0 & 0,11 & 0,0 & 0,00 \\
\hline Brandinia mosimanniae & 0,0 & 0,00 & 0,0 & 0,00 & 1346,8 & 0,25 & 0,0 & 0,00 & 0,0 & 0,00 & 0,0 & 0,00 & 0,0 & 0,00 & 0,0 & 0,00 \\
\hline Cocconeis antiqua & 40,3 & 0,01 & 0,0 & 0,00 & 29,0 & 0,01 & 2482,3 & 0,48 & 896,1 & 0,13 & 816,7 & 0,26 & 621,7 & 0,11 & 113,8 & 0,06 \\
\hline C. fasciolata/costata & 1549,9 & 0,23 & 1601,6 & 0,34 & 3375,9 & 0,63 & 9711,3 & 1,89 & 1890,9 & 0,28 & 1951,6 & 0,62 & 3918,9 & 0,71 & 1858,7 & 0,94 \\
\hline C. melchiori/dallmanni/melchior & 0,0 & 0,00 & 572,4 & 0,12 & 0,0 & 0,00 & 0,0 & 0,00 & 0,0 & 0,00 & 357,4 & 0,11 & 0,0 & 0,00 & 0,0 & 0,00 \\
\hline C. orbicularis & 0,0 & 0,00 & 0,0 & 0,00 & 0,0 & 0,00 & 0,0 & 0,00 & 982,9 & 0,14 & 0,0 & 0,00 & 0,0 & 0,00 & 0,0 & 0,00 \\
\hline Corethron sp & 0,0 & 0,00 & 159,2 & 0,03 & 0,0 & 0,00 & 0,0 & 0,00 & 0,0 & 0,00 & 0,0 & 0,00 & 20,8 & 0,00 & 0,0 & 0,00 \\
\hline Entomoneis sp. & 1746,0 & 0,26 & 572,4 & 0,12 & 57,9 & 0,01 & 0,0 & 0,00 & 1891,3 & 0,28 & 408,3 & 0,13 & 954,5 & 0,17 & 68,6 & 0,03 \\
\hline Entopyla ocellata & 0,0 & 0,00 & 0,0 & 0,00 & 0,0 & 0,00 & 0,0 & 0,00 & 404,7 & 0,06 & 0,0 & 0,00 & 0,0 & 0,00 & 34,3 & 0,02 \\
\hline Fragilaria islandica/striatula & 116033,2 & 17,40 & 65839,2 & 13,81 & 138112,9 & 25,71 & 256174,6 & 49,77 & 314461,9 & 46,35 & 53994,9 & 17,28 & 188118,7 & 34,26 & 31615,3 & 15,91 \\
\hline Licmophora antarctica & 10570,3 & 1,59 & 11259,3 & 2,36 & 4510,9 & 0,84 & 8470,2 & 1,65 & 15217,8 & 2,24 & 4359,5 & 1,40 & 11304,4 & 2,06 & 5234,4 & 2,63 \\
\hline L. decora & 1772,9 & 0,27 & 0,0 & 0,00 & 1375,8 & 0,26 & 1752,8 & 0,34 & 404,7 & 0,06 & 954,7 & 0,31 & 20,8 & 0,00 & 2580,2 & 1,30 \\
\hline L. gracilis & 2190,6 & 0,33 & 6476,0 & 1,36 & 356,6 & 0,07 & 1023,4 & 0,20 & 7482,2 & 1,10 & 2717,4 & 0,87 & 14663,1 & 2,67 & 705,1 & 0,35 \\
\hline Navicula directa & 23048,9 & 3,46 & 11099,5 & 2,33 & 2930,3 & 0,55 & 1752,8 & 0,34 & 11625,1 & 1,71 & 4996,0 & 1,60 & 19369,6 & 3,53 & 5303,0 & 2,67 \\
\hline N. glaciei & 0,0 & 0,00 & 617,3 & 0,13 & 0,0 & 0,00 & 2482,3 & 0,48 & 0,0 & 0,00 & 993,9 & 0,32 & 601,0 & 0,11 & 1273,0 & 0,64 \\
\hline N. perminuta & 251250,7 & 37,69 & 263251,8 & 55,21 & 88092,2 & 16,40 & 145659,1 & 28,30 & 174935,5 & 25,79 & 119457,7 & 38,23 & 156084,0 & 28,43 & 71808,5 & 36,15 \\
\hline Pleurosigma sp. & 13,4 & 0,00 & 0,0 & 0,00 & 0,0 & 0,00 & 0,0 & 0,00 & 0,0 & 0,00 & 0,0 & 0,00 & 0,0 & 0,00 & 0,0 & 0,00 \\
\hline Pseudogomphonema kamtschaticum & 93106,6 & 13,97 & 106698,5 & 22,38 & 117630,1 & 21,90 & 82687,9 & 16,07 & 145921,7 & 21,51 & 112847,8 & 36,12 & 143687,5 & 26,17 & 59583,4 & 29,99 \\
\hline Rhoicosphenia genuflexa & 1746,0 & 0,26 & 0,0 & 0,00 & 0,0 & 0,00 & 0,0 & 0,00 & 0,0 & 0,00 & 0,0 & 0,00 & 0,0 & 0,00 & 0,0 & 0,00 \\
\hline Thalassiosira antarctica & 0,0 & 0,00 & 0,0 & 0,00 & 0,0 & 0,00 & 0,0 & 0,00 & 0,0 & 0,00 & 408,3 & 0,13 & 0,0 & 0,00 & 0,0 & 0,00 \\
\hline
\end{tabular}

